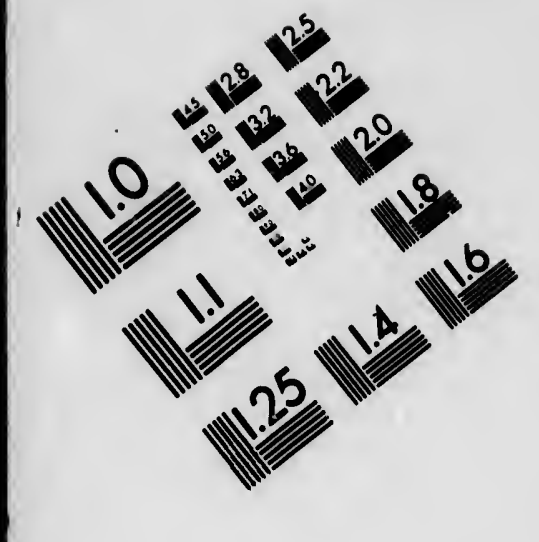

IMAGE EVALUATION

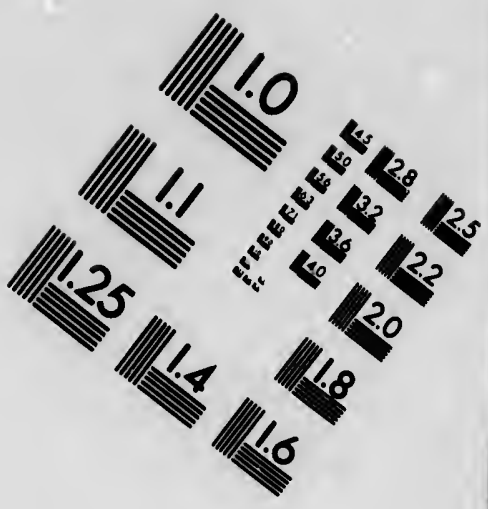

TEST TARGET (MT-3)
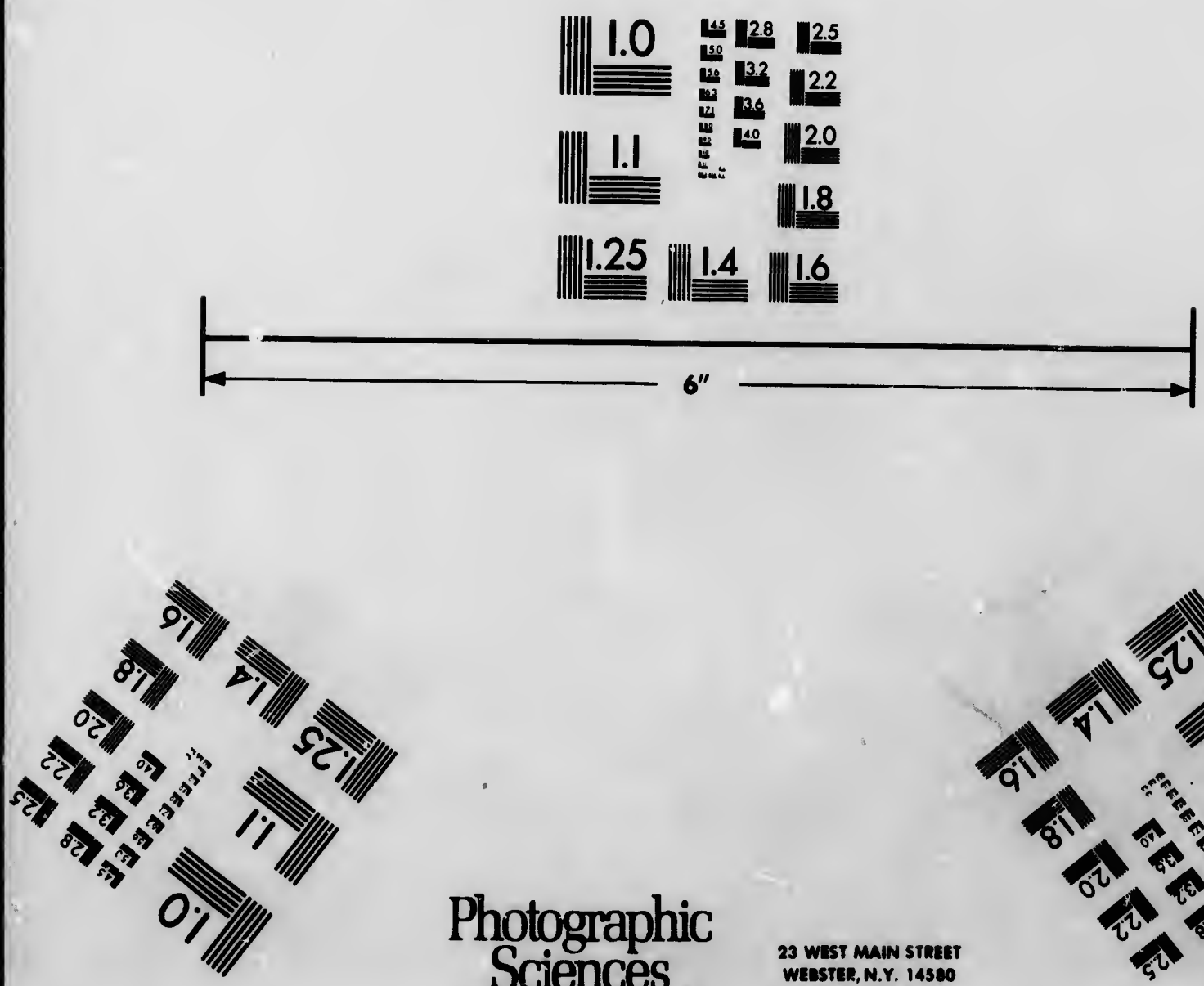

Photographic Sciences Corporation

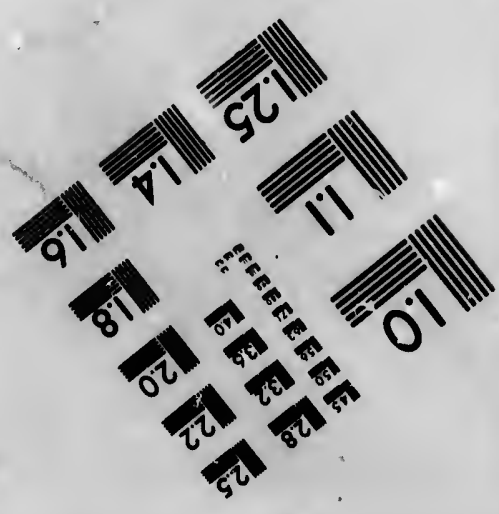




\section{CIHM/ICMH Microfiche Series.}

\section{CIHM/ICMH Collection de microfiches.}
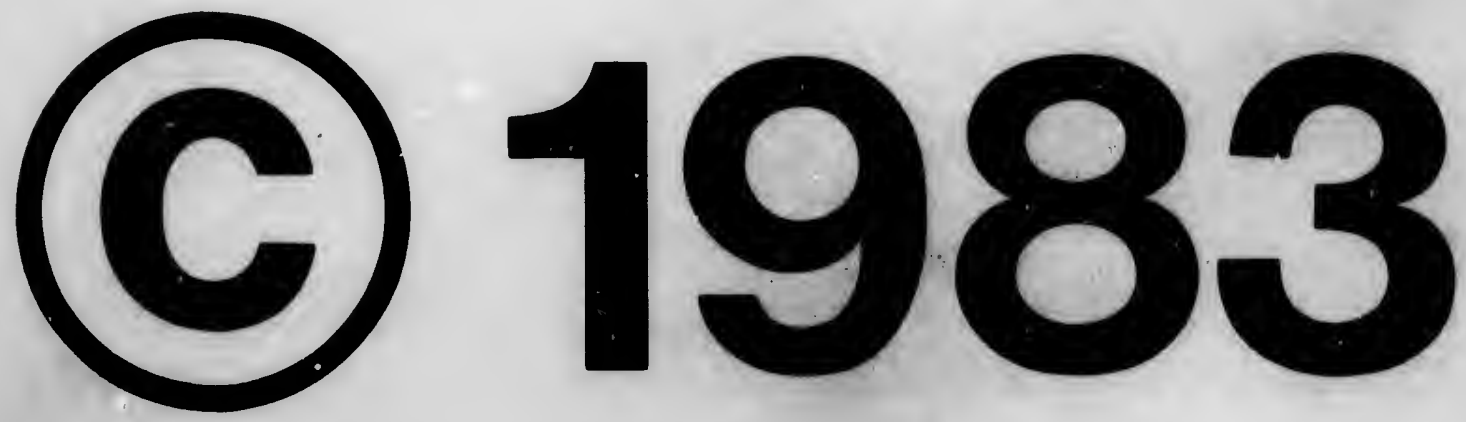
The Institute has attempted to obtain the best original copy avaliable for fllming. Features of thls copy which may be bibllographically unique, which may alter any of the Images in the reproduction, or which may significantly change the usual mothod of filming, are checked below.

Coloured covers/

Couverture de couleur

Covers damaged/

Couverture endommagée

Covers restored and/or laminated/

Couverture restaurbe et/ou pelliculce

Cover title missing/

Le titre de couverture manque

Coloured maps/

Cartes géographiques en couleur

Coloured ink (i.e. other than blue or black)/

Encre de couleur (i.e. autre que bleue ou noire)

Coloured plates and/or illustrations/

Planches et/ou illuatrations en couleur

Bound with other material/

Relie avec d'autres documents

Tight binding may cause shadows or distortion along intericr margin/

La re llure serrée peut causer de l'ombre ou de la distortion le long de la marge intérloure

Blank leaves added during restoration may appear within the text. Whenever possible, these trave been omitted from filming/

II se peut que certaines pages blanches ajoutées lors d'une restauration apparalssent dans le texte, mais, lorsque cela btait possible, ces pages n'ont pas dtó filmbes.

Additional comments:/

Commentairea supplémentaires:
L'Institut a microflimo le melliour exemplaire qu'il lul a sté posalble de se procurer. Les dotalls de cet exemplaire qui sont peut-etre uniques du polnt de vue bibllographique, qui peuvent modifler une imuge reproduite, ou qui peuvent exiger une modiflcation dans la móthode normale de filmage s int Indiqués ci-dessous.

Coloured pagea/

Pages de coulour

Pages damaged/

Pages endommagées

Pages restored and/or laminated/

Pages restaurbes et/ou pelliculbes

Pages dlscoloured, stained or foxed/

Pages décolorbes, tachet6es ou piqubes

Pages datached/

Pages dótach6es

Showthrough/

Transparence

Quality of print variea/

Qualité inćgaie de l'Impression

Includes supplementary materlal/

Comprend du matóriel supplómentaire

Only edition available/

Soule éditlon disponible

Pages wholly or partially obscured by errate slips, tiasues, otc., have been roillimed to ensure the beat possible image/

Les pages totalement ou partiellement obscurcies par un feulllet d'errata, une pelure, otc., ont etć filmbes a nouveau de façon à obtenir la meilleure Image possible.
The co to the

\section{Es}

The im possib of the filmins:

Origin: beginn the las sion, other first $p$. sion, a or illus

The las shall c TINUE whiche

Maps, differe entirels beginn right al require mothor

This irem is filmed at the reduction ratio checked below/ Ce document eat filmb au taux de réduction indlque ci-dessous.

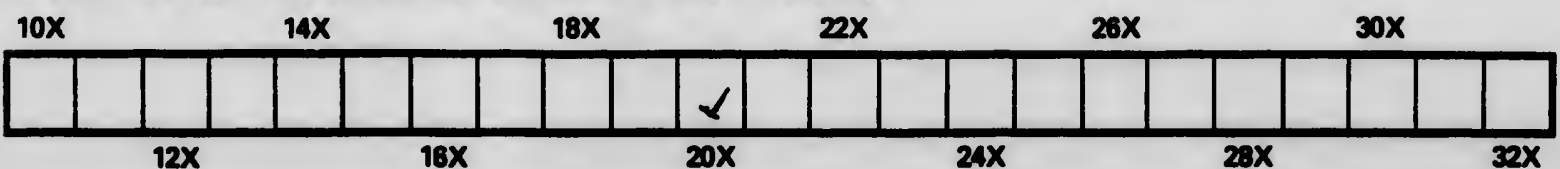


The copy filmed hare has been reproduced thanks to the generosity of:

\section{Entomology Research Llbrery}

Ayrleulture Caneda

The Images appearing here are the best quality posalble consldering the condition and legibility of the original copy and in keaping with the filming contract specifications.

Original coples in printed paper covers are filmed beginning with the front cover and ending on the last page with a printed or Illustrated Impression, or the back cover when appropriate. All other original copies are filmed beginning on the first page with a printed or lllustrated Impression, and ending on the last page with a printed or lllustrated impression.

The last recorded frame on each microfiche shall contain the symbol $\longrightarrow$ (meaning "CONTINUED"), or the symbol $\nabla$ (meaning "END"). whichever applies.

Maps, plates, charts, etc., may be fllmed at different reduction ratios. Those too large to be entirely included in one exposure are fllmed beginning in the upper loft hand corner, loft to right and top to bottom, as many frames as required. The following diagrams illustrate the mathod:
L'exemplaire fllmb fut reproduit grtse la gónóroslté do:

\section{Bibliothique de recherche entomologique} Agriculture Canada

Les Images sulvantes ont bté reproduites avec lo plus grand soln, compte tenu de la coridition ot de la netteté de l'exemplaire filmo, ot on conformité avec les conditions du contrat de flimage.

Les exemplaires originaux dont la couverture on papier eat Imprimbe sont fllmbe on commençant par le premliar plat et on terminant soit par la derniere page qul comporte une empreinte d'impression ou d'illustration, solt par lo second plat, selon le ces. Tous les autres exemplaires orlginaux sont filmós en commencant par la premibre page qul comporte une empreinte d'impression ou d'illuatration et en terminant par la derniere page qui comporte une teile empreinte.

Un des symboles sulvants apparaitra sur le dernilere image de chaque microfiche, selon le cas: lo symbole $\rightarrow$ signifle "A SUIVRE", lo symbole $\nabla$ signifle "FIN".

Les cartes, planches, tableaux, etc., peuvent etre flimbs des teux de róduction différents. Lorsque lo document est trop grand pour etre reprodult on un seul cllchs, il est filme partir de l'angle superiour gauche, de gauche te droite, ot de haut on bas, en prenant lo nombre d'images necessaire. Les diagrammes auivants illustrent la mothodo. by errata

ned to

ent

une pelure, façon a
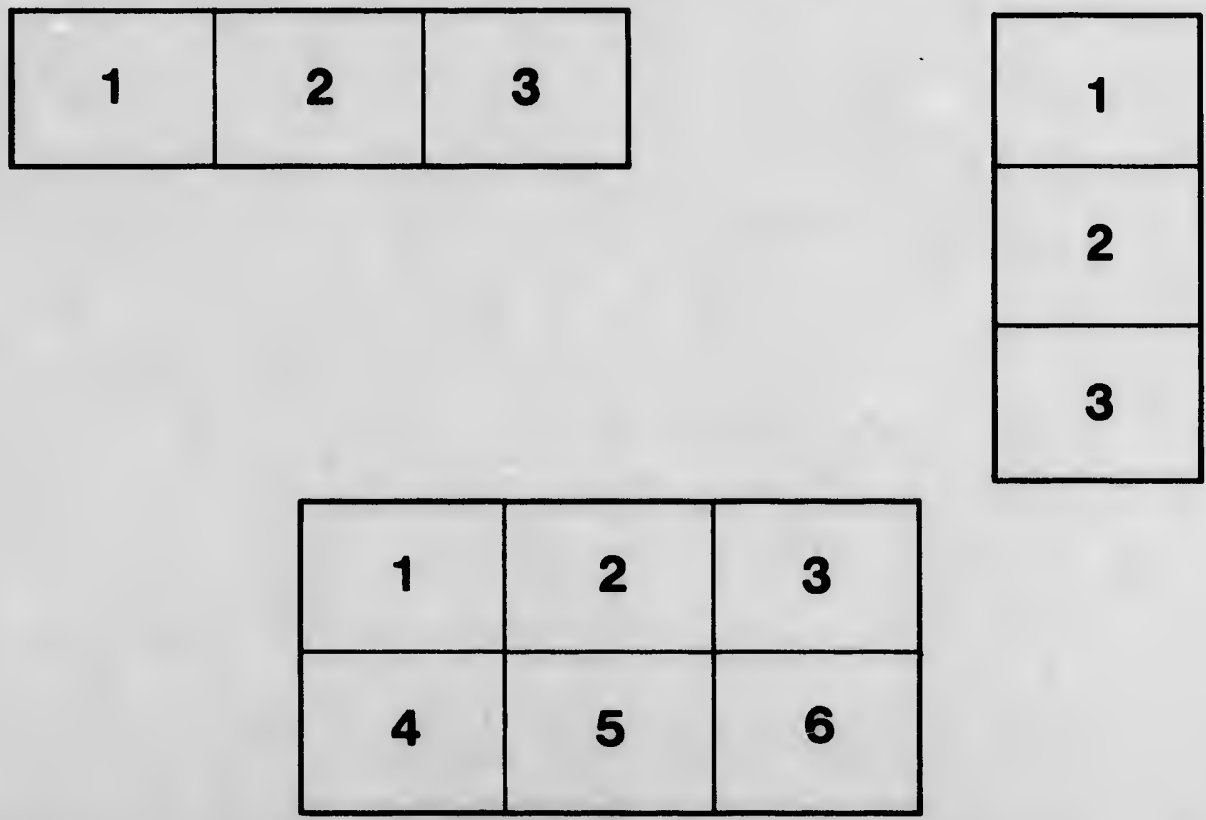



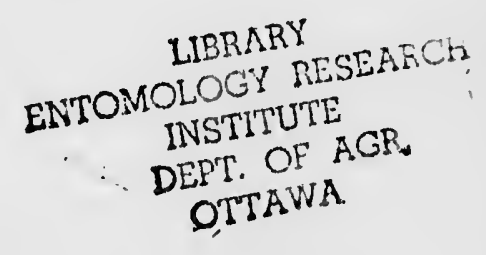

\section{F A U N E \\ HYMÉNOPTÈR0LOGIQUE \\ DE LA PROVINCE DE QUÉBEC.}




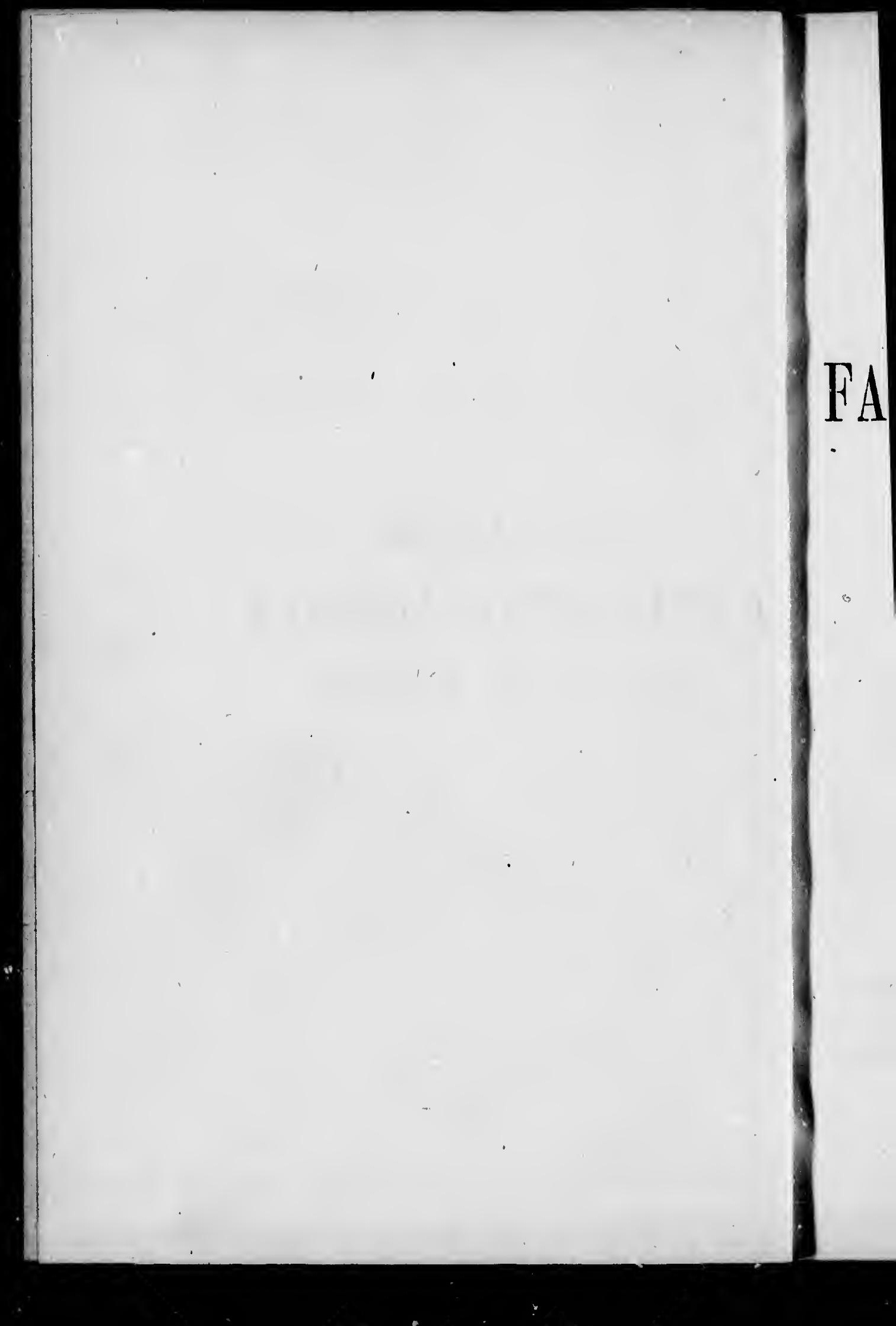




\title{
ADDITIONS ET CORRECTIONS
}

\author{
$\Delta \boldsymbol{U}$ \\ VOLUME II \\ DE LA
}

\section{FAUNE ENTOMOLOGIQUE \\ DU CANADA}

TRAITANT DES HYMÉNOPTÈRES

PAR

I'ABBE I. PBOVATCEER.

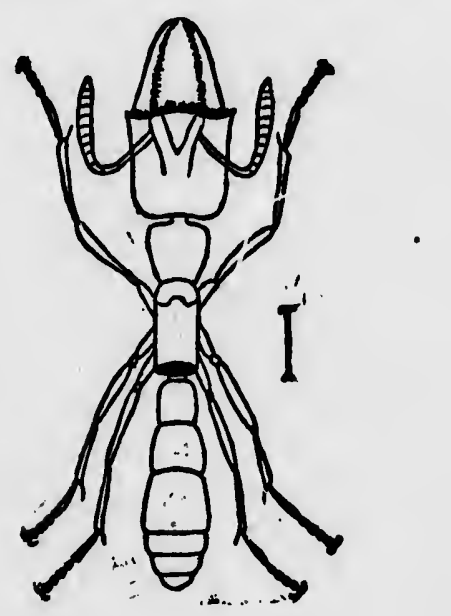

QUEBC

TYPOGRAPHIE DE O. DARVEAU

8\%, rue de la Montagne.

$\overline{1889}$ 


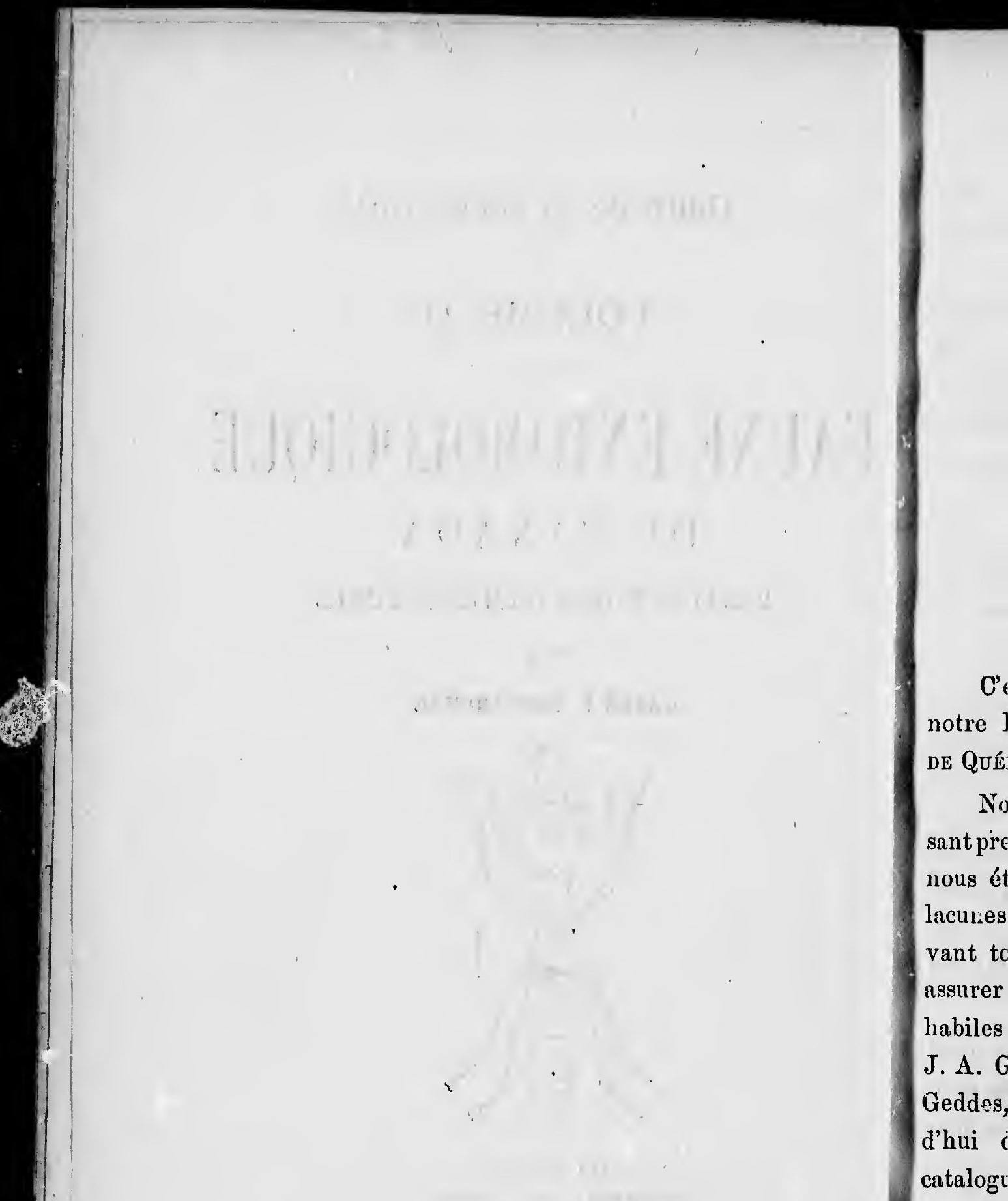


C'est en février 1883 que nous avons terminé notre Faune Hyménoptírologique de la Province DE QUÉBEC.

Nos captures, à bien pell de chose près, se réduisant presque exclusivement à nos seules observations, nous étions convaincu dès lors, que de nombreuses lacules restaient encore à combler. Aussi, poursuivant toujours nos chasses, et ayant pu surtont nous assurer le concours de quelques amateurs zélés et habiles chasseurs, tels que MM. W. H. Harrington, J. A. Guignard, d'Ottawa, et du Capitaine Gamble Geddes, de Toronto, sommes-nous en mesure aujourd'hui d'ajouter plus de 200 espèces nouvelles au catalogue de nos Hyménoptères, dont la plupart sont, 
non seulement nouvelles pour notre Province, mais même jusqu'ì ce jour incommes ì la sieience, et ronstituent de véritables conquêtes sur l'inconnu.

Comme la diffusion de chaque espèce d'insecte, surtout de ceux à vol facile, n'est jamnis restreinte à des bornes particulières et précises, nons n'avons pas hésité à attribuer à notre faune tons les IIyménoptères dont la présence a pu être constatée dans Onturio, bien que quelques esperes peuvent se rencontrer lì qui ne se trouvent pas ici. D'un aure côté, MM. Inarrington et Guiguard, quoique habitant Ottawa, ont presque toujours dirigé leurs chasses du côté de Hull, par conséquent sur notre territoire.

Notre faune entomologique est une mine encore toute nouvelle, et offrira pendant de longues années l'occasion de nombreuses découvertes, surtout, si les observateurs se funt plus nombreux et plus disséminés. Consignons chaque année les progrès obtenus, les conquêtes rempurtées, et plıs tard, quelque patient travailleur pourra refonảre ces matériaux en un tout plus homogène et constituer une monugraphie de l'ensemble.

Comme il sera facile de le voir, nous avons aussi donné la description de quelques. Hyménoptères nouveaux étrangers à notre faune, ils sont notés en leur. lieu propre. 


\title{
ADDITIONS RT CORRECTIONS
}

\author{
A I.A
}

\section{FAUNE HYMÉNOP'TEROLOGIQUE}

\author{
DE LA PROVINCE DE QUÉBEC
}

\section{5}

Fam. 1. Tenthrédinides, Faune, Yol. II, p. 170.

9. Gen. Nematus, Jurine, p. 183 et 740.

Aux 16 espèces décrites, ajoutez la suivante.

17. Némate d'Erichson. Nematus Evichsonii, Hartig.

q-Long. .33 pee. Noir avee une bande rouge a l'abdomen. Tête et thorax d'un beau noir brillant ; lo labre, les palpes aveo les jaunbes, exeepté a l'uxtrémité, blane ; les angles postériour's du pronotum près des ailes, íachés de blanc: Antennes noires, brunâtres en dessous. Ailes hyalines avec les nervures et le stigma, noir. Patces rousses, arec les jambes blanehes, noires à l'extrérnité, les hanches avec les tar'ses postérieur's noirs. Abdomen noir avec un large anneau rouge, comprenant les segments 2,3 , 4 et 5. 
Iarve cendrie avec courts poils épars noirs et des taches noires à la base des pattes écuilleuses. T'ête noire.

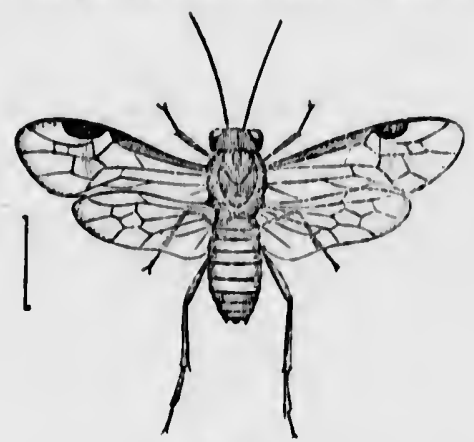

Fig. 1.

Vit sur le mélèse, Larix Americana, qu'ello díponille complètement de ses feuilles; se transforme en septembre sous l'herbe ou la mousse et éclôt au commencement de juin. Voir Le Naturaliste Canadien, Vol. XV, page 45.

Après le gen. Nematus, ajoutez le suivant:

Gen. Mrsse, Messa, Leach.

Antennคs grêles et assez longures. Ailes comme dans les, Némates, mais la $2 \theta$ cellule cubitale avec les 2 récurrentes, recevant la $2 \mathrm{e}$ à sa nervure de division d'avec le $3 \mathrm{e}$ cubitale; cellule lancéolée pétiolée. Corps court et robuste.

Une seule espèce rencontrée.

Messe hyaline. Messa hyalina, Nort. Proc. Ent. Soc. Phil. IV, 8.

-Long. .16 pce. D'un noir brillant. Le labre, les mandibules, les écailles alaires, blunc. Antennes filiforınes, grêles, assez longues. Ailes hyalines, lo stigma blunchâtre, la $3 e$ cubitale en carré; ailes inférieures avec 2 cellules médianes. Pattes blanches aveo les hanches noires, excepté a l'extrémité, les cuisses postérieures avec teinte roussâtre, l'extrémité de leur's jambes noirâtre. - Ottawa (Harrington).

Fig. 1.-Le Nematus Erichsonii à l'ètat parfuit, grossi, 
11. Gen. Dolerus, Lench, p. 197.

Al1x 9 espèces décrites, njouter la suivante.

10. Dolère front-blano. Dolerus albifrons, Nort.-Bost. Nat. Hist. Prov. VIII, 152.

o-Iong. 19 pee. Noir avee pubescence blanche particulidrement abondunte sur la fuce ot les flunes. Los bords du chaperon, le lubre, les écuilles aluires, les 6 segments basilaires do l'ubdomen, roux. L'extrémitó des cuissos postérioures, des 4 jumbes antérioures ot plus ou moine des postérienros, et tous les tur'ses, uoir on noiratre; les trochanter's aveo uno bando d la bnso des jumbes postérioures, blanchatres. Ailos hyalines, les norvures noiros.

$\sigma^{2}-\Lambda$ rec les articles basilalres des antennes roussatros on do.sous; uno tache ontre les autennes; la fuco an-dessous ot les écailles alıires, blane.

Cnpturé un $\sigma^{7}$ all CapRoupe; se distingue surtout de l'apricus par sa face blanche, sa plus petite taille et ses trochanters blancs.

Dans la clef systémastique, page 196, au No. 13 (12), après : Fice blanche, il futut lire: albifrons. C'est cette omission qui nous a fait oublicr d'en donner la desoription.

13. Gen. Selandria, Leach, p. 199 et 742.

Aux 13 espèces sécrites, ajoutez la suivante.

14. Sélandrie du Canada. Selandria Canadensis, n. sp.

क-Long. .pee. Noiro avec les pattes en partie blanches. Lo chaperon, lo lubre, les écailles alaires uvec les bords latéraux du prothorax, blanc. Lobo médian du mésothorux sillonné au milicu, Ailes hyulinos, avec lę nervures of le stigmn, noir; la collulo lancéolśo fer'méo au milicu; uiles inféricures avec uno rellule discoüdale. Pattes blanches, les hanches noires ondessus, a la base, les cuisses noireses, les 4 antérieures blanches aux extrémités, les postéricures avec un petit anneau blanc à la base: les jambes blanches arec l'extrémité noire; les postéricures noircs avec un large anneau blanc; les tarses blanes avoc le dernicr articlo noir. Abdomen entièrement noir. 
Capturée au CapRonge. Sa cellule lancéolée fermée la distingue de toutes les autres.

\section{EXTRA LIMINA.}

M. J. Fletcher, d'Ottawa, notre Entomologiste d'Etat, nous ayant transmis tout dernièrement un lot d'Hyménoptères, reçus du Rév. G. W. Taylor, de Victoria, Colonbie Britunuiłue, dans lequel nous avons trouvé un bon nombre de nouveautés non encore sigualées à la science, nous les décrirous à la suite de leur genres respectifs, sous l'en-tête ci-dessus, étınt effectivement en dehors des lirites embrassćes dans notre Faunk.

Sélandrie marginée. Selandria marginata, n. sp.

ㅇ-Long. .30 pee. Noire; le chaperon, le labre, les écailles alaires avec les bords latéraux du prothorax, blane. Antennes assez courtes, le $3 \mathrm{e}$ article a peine plus long que te 4e. Ailes hyalines, 'es nervures brunes, blanches à lia base, le stigma noir, épatis et faisant saillie, la cellule lancéoléo avec sa nervure transverse presque droite, les ailes inféricures avee 2 cellules mélianes. Pattes noires avec les genoux blancs, co blanc s'étendaus plus ou moins sur la balso des jaumbes et l'extrémité des cuisses. Abdomen noir, liseré de jaune tout autour, les segments dorsanx aree uno petite ligne blanche aux sutures.-Vancunver (Fletcher).

Son abdomen marginé de jaune la fuit distinguer à prepremière vue.

17. Gen. Allanius, Panz. j. 210.

Allantus cogitans, Prov. p. 211, est plutôt une Teu hrède qu'un Allante, car ses antemues, quoi! ue plus courtes que d'ordinaire dans les Tenthrèdes, sont filiformes, à articles assez allongés, et ne sont pas épaissies en allant vers l'extrémité, il faut donc lire: Tenthredo cogituns, Prov, puis ajouter l'espèce suivante.

4. Allante robuste. Allantus robustus, nov. sp.

o-Long. .41 pec. Noir avec les antennes et les pattes rousses. Fort robuste. Antennes courtes et forten, entierrement rousses, à article 3 plus long que 4. Le chaperon, le labre, les man. 
dibules, uno tacho en trianglo entro les antennes, uno tacho sur les bords laléraix du protho:ax, une tache sur les côtés des plaques basilaires, uno autre au dessus de hanches postérieures, blanc. Les joues rousses aree une tache blanche à l'extrémité remontant on avant en ligno orbitalo jusqu'tu milieu des yeux; les écailles alaires, le costa, lo stigma avec les pattes, roux, les tarses blanejaunâtre. L'ćcusson obsculément taché do roux. Ailes hyalines aves les nervures jaunes. Les hanches anterieu:es rousses, les 4 postérieures noires arec teinte de roux plus su moins prononcéo. Liextrémité des énisses et des janbes postérioures noiro. A $\mathbf{A b}$. domen déprimé, élurrigi avant l'extrémité, noir avec les sogrmonts $1,2,3$ et + roux plus ou moins obscur. - Ottawa (Hurrington).

Espèce bien reconnaissable par sa coloration.

\section{- EXIRA LIMINA.}

Allante rouge. Allantus rubricus, n. sp.

ㅇ-Long. .38 pec. D'un rougo forrugineux dans toutes ses parties; lo chaperon, lo labro et les maudibules, blanc-jaunâtre. Antennes eourtes, entierement rouges, lo 30 article, beaucoup plus long quo le te. Tête grosse, en carré, épaisse en arriere des yeux. Les sutures des flancs noirâtres, la poitrino woec courto pubescenco gritiâtro. Ailes hyalines-juunâtres, los nervures brunes, le stigma pâle à la base. Pattes sans aucuno tache, les 4 antéricures arec los jambes et los tarses plus pâles. Abdomen peu allongé, cléprimé, plus large avant l'extrémité, les 2 premiers segnionts arec bandes transversales noirâtres peu apparentes.-Vancouver (Fletchor).

Sa coloration pourrait le faire prendre pour la Tenthredo mellinus, Harr., mais il est plus trapu, a l'abdomen plus court et plus large, et ses antennes sont bien celles des Allantes.

\section{Gen. Taxonus, Meg. p. 213 et 743.}

EXTRA LIMINA.

Taxon parent. Taxonus parens, nov. sp.

men's

†-Long. 32 pec. Noir avoc les pattes rousses. Tête médiocre; lo chaporon noir, échancré en demi corcle; lo labre, los mandibules, les écailles alaires, les bords latéraux du prothorax 
avec l'extrémité des hanches, blanc. Ailes hyalines, les nervures et lo stigma, noir, le dornier nvec uno grando tacho blancho a la base; cellule lancéolée avec une nervule trunsverse obliq̨ue, ailes inférieures snns cellules médiancs. Pattos rousses, los postérieures avec les tarses, brunâtres; toutes les han hes noires avece le sommet blanchâtre. Abdomon ullongé, cylindrique, al cưtés: pa:- llèles, noir, les 2 derniors segments étroitement marginés do blauc,-Vancouver (Fletcher).

18. Gen. Strongylogaster, Dahlb. p. 215 et 743.

Aux 12 espèces décrites, ajoutez les 4 suivantes.

11. Strongylogastre ceint-de-roux, p. 714 , au lieu de rubrocinctus, Nort., lisez : rufocinctus, Nort., et les trois premières lignes de la description doivent se lire comme suit :

o-Long. 28 pce. Noir, le chaperon, le labro, les éctilles alaires, les bords supérieurs du prothorax, blancs, les hanches et les trochantins noirs.

13. Strongylogastre anormal. Strongylogaster abnormis, n. sp.

o-Long. .28 pee. Noir avec les pattes rousses, A part la bouche qui est brunâtre, la tête, le thorax et l'ibdomon sont entierement noirs. sans ancuno tache. Los pattes rousses, les hanches noires à l'extrême basc. Ailes hyalines avec les nervures noires, les supérieures avec une norvule transver'se oblique, les inférieures sans ancune cellule médinne, la cellulo lancéolée de celles-ci courte, n'atteignant la nervulo transver'so qui partagro la collule brnchiule au dessus d'ollo, que sur l'appendico qu'ollo porte à son extrémité; point de ncrvure au bord extériour furmant les collules. - Voir fig. 5.

$\delta^{7}$-Semblable à la $\&$, à l'exception des tarses postérieur's qui sont tout noirs, tandis que chez la o les 2 articles termintur, ollument sont noirs.

Espèce bien distincte par la nervation insolite de ses ailes.

Capturé au CapRouge. 
14. Strongylogastre hanches-pâles. Strongylogaster pallicoxus, nov. sp.

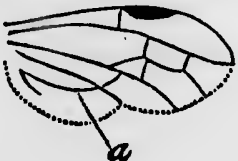

Fig. 2.

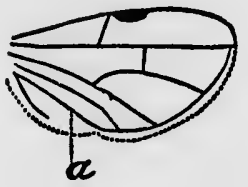

Fig. 4.

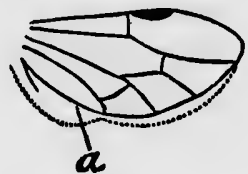

Fig. 3.

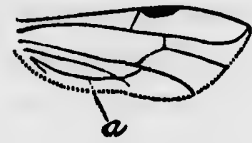

Fig. 5.

ㅇ-Long. . 30 per. Noir arec les pattes et uno bande à l'abdomen, jaune-miel. Le chaperon, le labro, les mandibules, los palpes, les écailles alniros, les bords superieurs du prothorax, toutes les ha:aches avec les trochanters, blanc. Chaperon forteinent échancré; têto très grosso en arrière des yeux. Ailes hyalines, lo costa avec ln baso du stigma pâles. Pattes d'un beau jaune miel avec un petit anneau au *ominet des cuisses, noir, les 1:ures pustérieurs bruns à l'extrémité; les hanches et les trochanter's blancs. A udomen noir : ćlargi vers l'uxtrémité, avec uno largo tacho roussâtre couvrant les segments 2,3 et 4 , une somblable tache lui correspondant sous lo ventro.

Fig. 2-Type des niles infirielles dיs A'lantus, Strongylogaster et Tenthredo; in cellule lunceinlée a uintteint piss le hord de l'aile, ut les cellules exterieures ne sont pas fermies pur une nervire.

Fıg. 3-Aile infërieure des Strongylog'ster mellosus, apicalis, epicera, ct de Perineura, Harlig.

Fig. 4-Aile intörieure du Slrongylogaster pinguis $\sigma^{\lambda}$; la cellule Inncéolée $a$ atteint le burd de l'ule, les cellules catérieuıes sout fẹruées pur une nervure un peu en dedans du bord de l'ilile.

Fig. i. Aile infirieure dı Strongylngaster abnormis + , Pıv, ; In cellule Iancéolie a n'atteint pus le burd de lailu, et porto la nervu'e qui sipare la cellulo immódinteurent au dessus, sur uu appendice ì son textrémitó. 
$\sigma^{7}$-Semblable à la $ᄋ$, à l'execption des hanches postéricures qui n'ont que l'extrémité de blanche, le reste étunt jauno-miol.

Capturé au CapRouge et à Ottawa.

15. Strongylogastre en-deuil. Strongylogaster luctuosus, n. sp.

\%-Long. 31 pec. Noir avec les pattes rousses. Toute la boucho noire. Une largero tacho sur les bords latéraux du prothorax, les écailles alaires avec les pattes, roux. Ailes hyaliues, lo costa roussâtre, lo stigma et les norvures, noir ; la collulo lanréoléc sans nervulo trausrer'se, les ailes inféricures avee 2 cellules médianes. Tontes les lianch noires, les postéricures plus ou moins rousses a l'extrémité, les tarses postériours bruns i l'oxtrémité. Abdomen noir avec uno lau'go tacho rousso couviant les segments $1,2,3$ et 4 , une semblablo tacho lui correspondant sous lo ventre-Ottiwa (Harringtou).

Très rapproché du rufocinctus, Nort.; mais s'en séparant distinctement par l'absence de nervule transverse à sa cellule lancéolée.

16. Stróngylozastre très-proche. Strongylogaster proximus, n. sp.

o-Long. .32 pee. Très rapproché du pallicoxus, Prov., en différant senlement par les earactères snivants : écusson blane, Éailles alaires blanc-rutsiâtıe; abdomen un pen plıs fort avec la base ot l'extrémité, noir, cette dernidre avec lo segment terminal blanc.-Ottawa (Harrington).

19. Gen. Tirnthrevo, Leach, p. 219 et 745.

Aux 25 espèces dícrites, ajoutez les 4 suivantes.

26. Tenthrède sérieuse. Tentluredo cogitans, Prov.

Allantus cogitans, Prov.-Faune, Hym. p. 211.

27. Tenthrède des-montagnes. Tenthredo montana, n. $\mathrm{sp}$.

o -Longr. . 40 pec. Noire; le chaperon, le labre, les mandibules excepté d l'extrémité, uno tache smo los joues, les bords latéraux du prothorax, avec une tache au haut des hanches poitélicures et une autre sur les côtés des plaques basilaires, blanc. Lo chaperon 
avo: uno éhnneruro profoude et étroite. Antemnes assez courtes, entidremont noires. Mandibules forlugineuses a l'extrémité. Énilles ahnires roussatres. Ailes hyalines-jaunatres. Pattes rousses, les antélieures arec une ligno noile en dessus; les hanches noires, les 2 premicres patires blagnchâtres ì l'extrémitó co nvant. Alidomen déprimé, lirgho, pen allougé, roux avec les 4 premiers segments noils. Valves de la talrière rousson.-Capt. Geddes (Montagnes-Ruchonses).

Voisiue de la semirubra, Nort., mais s'en distinguant par l'échancrure de son chaperon, sa trille plus : etite et plus ramassée, ses 4 pattes postérieures entièrument rousses, etc.

28. Tenthrède noire-bleuâtre. Tenthredo atrocœrulea, n. sp.

q-Longr. .50 pece. D'un brun noir-bleuatre, surtout a l'abdomen. Le chaperon, lo labre et les mandibules excepté à l'extrémitó, blanc. Pattes rousses, arec les hanches, les trochanter's et la base des cuirses, noir, les cuisses antéricures avec une ligno noire en dessus. A bơomen allong̨é, robuste, brillant, noir-blelâttro sans aucune tache. Ailes legèrement obscures-Ontanio (Geddes).

Bicu distincte par sa colorition.

29. Tenthrèłe à-ventre-pâle Tenthreclo ventralis, Say.-Allantus ventrulis, Say, Proc. Am. Ent. Soc. II, 2:31).

- -Long. .45 pre.- Noire tachéc do blanc; la finco au dessous des antennes, le chaperon, le labre, les mandibules, les joues, de larges lignes orbitales pé élrant jusque sur le vertex, los écailles alaires, les bords laltéranx et les angles infólieurs du prothorax, une tacho sur les flatce, une allto all-dessus des 4 hanches postérieures, l'extlémité de la poitrine, les 4 pattes anté rieures avee leur's hanches excepté on dessus, blatuc. Les pattes postéricures noires arec l'extrémité des hanches, la base des cuisses, un large annean i la base des jambes, blanc. Ablomen d'un noir brillant en dessus, avec lo ventro d'un blane salo. Ailes hyalines, les, nervures noiros.-Ottawa (Harrington).

EXTRA LIMINA.

Tenthrède cuisses-rouges. Tenthredo erythromera n. $\mathrm{sp}$. 
o-Long. .42 pce. Noire avec lo chaperon, le lnbre et les mandibules, blanc; les pattes rousses, moins les tarses postéricurs avec l'extrémité do leurs jamber qui sont noir's de mâmo que lo:s hanches. Têtu grosse, en carré, tì̀s épaisse en alrière des yeux. Ailes hyalines, légèrement obscurcies, les nervures et lo stigma, noir', celni-ci jannâtro à la baso. Abdomen déprimé, élnu'gi postéricurement, entièrenent noir. - Vancouver (Flotchor).

Voisine de la rufipes, Say, mais s'en distinguant par ses hanches et ses ćcailles alaires noireis.

Tenthrède à costa-noir. Tenthredo nigricostata, n. sp.

o-Long. . +2 pec. Noire avec les pattes rousses; labdomen d'un noir blenâtre. Lo chapjeron et lo labre noirs, les mandibules blanches. Ailes avec le costa noir, les hanches aussi noires; pour le resto semblable a la précédente.-Vincouver (Fletcher).

Tenthrède à couleurs-variées - Tenthredo varipictus, Nort. Trans. Am. Iint. Soc. II, 231. - Vancouver.

Tenthrède hanches-rousses. Tenthredo ruficoxa, n. sp.

o-Long. 40 pee. Noiro avec l'abdomen roux, le chaperon, le labre, les mandibules, uno tacho sur les juues remontant en avant en formant uné lignno orbitale jusqu uur. antennes, une à lá base de celles-ci avee une petite tache au-l lessus des hanchos postéricures et les bords latéraux du prothorax, blanc-jaunâtre Les écailles alaires, les pattes, y compris les hanches et les taries, avec l'abdomen excepté lo premier segment, d'un roux foncé. Ailes hyalines avec lo stigma roussâtre do même quo la nervuro sous-costalo.-Vanconver (Fletcher).

Tenthrède aux.extrémités-noires. Tenthredo terminalis, n. sp.

б-Long. 40 pee. Noire avec l'abdomen roux. Le chaperon, le labre, les inandibules, uno tache all-dessus des hanches postéricuies, une autro au-clessus des intermédiaires, blane. Pattes rousses, les hanches noires a la base, les ti reses postericurs noirs avec l'articlo terminal ponx Ailes hyalines avec les nervures et le stigma noirs. Abuomen roux, noir a la baso et à l'ox-. trémité.-Vancouver (Fletcher). 
Peut-être le $\sigma^{\pi}$ de la précédente ou de la nigricostata, quoique différant assez grandement en coloration.

Après le genre Texturido, Leach, p. 219, ajoutez le suivant.

\section{Gen. Szxalnixle Synaivema, Hartig.}

Ce sont des Tenthrèdes avec cette seule différence que la cellule lanccólée des ailes supérieures est contractée an milieu, au lieu d'être fermće par une nervule trausverse droite.

Deux espèces rencontrées.

1. Synairème d'Amŕrique. Synairema Americana, Prov. Cunadian Entomologist, XVII p. 50.

O-Long. .46 pes. Noire, la face all-dessous des antennes, le chaperon, los mandibules, les palpes, les joues, le scape en dessous, des lignes orbitales se courbant en dedans, sur lo ver tex, une tache de chạıue côté du lobe médian du mésotho:ax, une tache sur les écailles alairos, l'écusson, un point on avant et un autre en arrière, le sommet des plaques basilaires, le; flanes et la poitrine en partio, blanc. Antennes longnes et grếe.s. Ailes hyalines, les nervures et le stigma, brun. Piltes blanches y compris les hanches et les trochanters, les 4 cuisses antérieures avec une ligne noire exté:ieurement se pua:suivant sur les jambes et los tarse., les postríieures noires avec los hanclies excep.é uno tacho noire en clessus, les trochanter's et lo tiers basilaire des cuisses, blanc. Abdomen allongé, noir, les côtés du ventre blanchâtres.

Capturée an Cap-Ronge.

EXTRA IIMINA.

Le chahanches blanc. téricurs les nert ì l'ex-.

2. Synairème du-Pacifique. Synairema Pucifica, n. sp.

q-Long. .35 pee. Noire avec l'abdomen roux. La tête, le thorax, les pattes, noir sans aucuno tache. Ailes, passiblement enfuméos, à cellulo lancéolée ferméo an milien, les nervures y compris le costa avec le stigma, noir. Abdomen cglindrique, 
robuste, roux avee lo premier segment noir, et uno tache noire mal définie sur les segments ierminnux-Vancouver (Fletcher).

Ce genre qui ne compte encore qu'une seule espèce en Furope, se trouve actuel'ement en posséder deux en Ainérique.

Gen. Lyda, Fabr. p. 228 et 749.

Aux 11 espèces décrites, ajoutez les 5 suivantes :

12. Lyde cornes-jaunes. Lyda ochrocera, Harris-Harr. Cat.

+ -Noiro avec la tête, les pattes et le thorax en partie, jaune-ocre. Antennes juune-ocre, brunatres il l'extrémité. Dos du mésonotụm jaune avec une tache noire de chuque côté en avant; l'écusson et le. inétathorax, noir. Ailes hyalines, les nervures brun-jaunâtre. Tar'ses postérieur's brunâtres. Abdomen fort large et déprimé, noir.

Ontario, bien reconnaissable par sa coloration.

13. Lyde tachée-de-jaune. Lydla luteomaculata, Cress. Trans. Am. Ent. Soc. VIII, 28.

ㅇ-Long. .50 pce. Noire; le bord dn chaperon remontant on triangle au miliou, une large tache en dedans des yeux, deux autres plus petites all-dessus des antennes, 2 autres transversales au dessus des yeux, 2 petites bandes longitudinales sur le vertex, les mandibules, les jones avee une ligne bordant l'ocriput, le collier, les écailles alaires, les scapulaires, une tache en $\mathrm{V}$ an milien du mésothorax en avant, une autre tache sur' chacun des lobes, l'écusson, le post-écusson, les flunes, des taches au dessus des hanches, blanc-jiunâtre. Antennes jaune-pâle, le scupe arec l'ẹtrémité du pavillon, noir. Ailes hyalines-jaunâtres, les nervures brunes, la $3 e$ enbitale plus grande que la 20 ; la 20 cellule brachiale sans nervures transverses. Pattes roux-pâle, avec les hanches noires, blanches en dessous et a l'extrémité. Abdomen large, déprimé, jaune varié de brun, les plaques basilaires, le premier segment plus ou moins avee une ligne a la base de chacun des autres, noir. Jambes antéricules aveo une épine latéralo.Ottawa (Harringtron). 
che noire 'letchori. spèce en mérique.

is-Harr.

n partie, ité. Dos côté en , les norAbdomen

ta, Cress.

omontant ux, deux sversales e vortex, it, le colnu milieu es lobes, ssus des srec l'exnervures lule biaavec les bdomen s, le prechacun térale.-
14. Lyde p^rplexe. Lyda perplexa, Cress.-Trans-Am. Ent. Soe. VIII, 31.

Q-Tong. .35 prec. Noire; la tête grossiè:ement ponetıce, les lignes enfoncies sur lo vertex très protondes; lo chiperon, une potite ligne légèrement conbe s'étendant des yeux à l'occiput, les mandibules, les palpos, les angles postérieur's du prothorax, une tache au dessons, une marque en forme de lune sur le dos du mésothorax en avant, les écussons, les écailles ulairev, les pattes excepté la base des hanches, st la plus grande partio du ventio, jaune-pâle. lics antennes courtes, noiros, de 22 mrticles, le 30 trois fois la longuen' dı 4e. Ailes hyalines, les nervures brunes, la $2 e$ cellule brachiale avec une nervure transverso incomplete, la 30 cubitale plus longue que la 2e. Jambes antérieuressans épreron latéral. Abdomen teint de violei, une tahe junne-orange, oblongue, recupant to milieu des segments 2 a 4 ; la base et lo sommet du ventre, noir.-Ottawa (Harrington).

Très rapproché de la Canarlensis, Nort. et de la Burquei, Prov. mais en différant surtout par la forme de ses antenues.

15. Lyde de-Harrington. Ly:la Harringtonii, nov. sp.

.f-Thong. .35 pee. Fivire avee l'abdomen roux, le bord antérieur du chaperon, les mandibules, les joues, 2 petites lignes courbes sur le vertex, 2 autres en dehors plus lariges, irrégillières, se répandant jusqu'en dehor's dos yeux où olles forment une espèce de crochet, le tier's apical des antennes, les écailler alaires, une double tache sur le nilieu du mésothorax en avant, l'écusson at le post-écusson avee les pattes, blanc-jaunâtre. Antennes médiocres, le 30 article i peine plus long que le 4e. Ailes hyalines, los nervures noires, la 30 subitale beanconp plus grande que la 20, la $2 \mathrm{e} \mathrm{brachiale} \mathrm{avec} \mathrm{une} \mathrm{norvure} \mathrm{transverse} \mathrm{incomplete.} \mathrm{Pattes}$ d'un jaune roussâtre, les jambes antérieures suns éperon latéral, les hanches noires. A.b.tomen d'un betu jaune micl, les plaques busilaires avee la basedu premier segment, noir, le reste sans taches. -Ottawa (H:urington).

Nous dédions avec plaisir ce bel insecte à $\mathbf{M}$. W. Hague Harrington. M. Hirrington, président actuel du Field Entomologist Club d'Ottawa, est un entomologiste fort distingué. 


\section{Lyde ooracée. Iydar "ata, Say.}

\&-Iong. .36 pee. D'un juune ve. ree, brillante ; tête plus large quo le thorux. Yeux petits et largement séparés. Antennes de 28 articles, noirâtren, la moitié busilnire di premier article pâle, ce premier micicle 3 fois aussi long que le second, to 30 pas si long que le 1er, a peine plus long que le 49. Une tiche sur lo vertex renfernant les ocelles et 2 lignes dans les sutures do la base des antennes al l'occiput, noir. Tête transparento avec 3 on 4 croissants bruns, s'étendant des orbites extérieurs an derrière do la tête. Tabre large, noirître; une ligne noirâtre transversale sur lo con, une tuche sur lo collier de chaque côté près des scapuluires, unie par los sutures au lobe antérieur, une tuche plus grande de chaque côté de l'écusson uvee d'autres taches sur le métathorax, noir. Quatre taches brunes sur le mésothorax, 2 sur le lobe antérieur, et une sur ehacun des lobes latéraux. Abdomon noirûtre aux côtés, plus pâlo au miliou. Pattes jaunâtres; sommet des cuisses, les jambes et les tarses, brun. Ailes hyalines, grandes, les nervures brunes; le stigma pâle; la nervure séparant les 2 rudiales coïncidant avec la soconde nervure truns. verse; 3e cellule brachiale a norvures transver'ses incompletes.Otiawa (Harrington .

Après le genre $L y d a$, p. 228, ajoutez le suivant.

\section{Gen. Lophyre, Lophyrus, Latr.}

Tête transverse, grosse dans les $\delta$, petite dans les $\zeta$, chaperon petit, à hords ondulés; labre petit, arrondi. Antennes de 17-23 axticles, dentées en scie dans les o, bipectinées duns les $\sigma^{2}$, l'article terminal simple. Ailes avee une cellule marginale et quatre cubitales, la nervule divisant les 2 premières incomplète, la $2 \mathrm{e}$ et la $3 \mathrm{e}$ chacune avec une nervure récurrente; ailes inférieures avee 2 cellules disoüdales. Abdomen large et déprimé

Larves non-poilues, sociétaires, sur le pin et le sapin.

Trois espèces rencontrées. 
Lophyre du-sapin. Lophyrles abietis, Harr. Inj. Ins. p. 411.

o-Iong. .28 pee. D'un juune brunatre; les yeux, les antenues, une tache sur les lobes latérunx du mésothorux, noir. Antennes courtes, i clents longues et serrées, plus lurges au milieu. Ailes hyalines, le stigmu blanchatte, les nerviures brunatres. Pattes et tout fo dessous plus pâle que le dessus et sans aucune tache. Dauns les $\delta$ les antennes sont poilues et bipectinées, la tête, lo thorax, lo dos de l'abdomen, noir, les pattes et le ventre jaune-roussâtre.-Hull (Harrington).

Il ne serait fas surprenant qu'on pût rencontrer cet insecte à Québec même. Nous avons trouvé à Danville, en 1880, un jeune pin ravagé sériensement par des lurves de Lopihyres, c'étaient probnblement celles de cette espèce.

2. Lophyre d'Abbett. Lophyrus Abbottii, LeachZool. Miso. III, 1819 ; Trans. Am. Ent. Soc. II, 324.

६-Tıng. 32 pee. D’un testacé brunâtre; les antennes noires, de 17 articles, chaque article, excepté les $3 \mathrm{~d}$ a a base et le terminnl, avee un appendice mousse on dedans. Les trois articles terminaux des palpes maxillaires courts, le 3e aussi long que le 4e et le 5e. La tête, le thorax et les flanes couverts de grosses ponctuations peu denses. Eperons des jaunbes postérieures longa et mousses, les ongles avec une forte dent en cledans peu éloignée de l'extrémité. L'extrémité des mandibules, les côtés du métsthorax et les ongles, noir; les palpes, les écuilles aluires, les fluncs avee les côtés de l'nbdomen et les jambes, d'un blane de cire. Ailes légèrement obseurcies, la cellule laneśolée fermée par une nervure légèrement oblique.

$\sigma^{3}-$ Antennes de 18 urticles dont 15 portent un ramean do chaque côté, le dernier en massue, noires de même que le corps; le labre, les' pattes, les écailles alaires et le eollier, blane; le reste du corps ot les pattes jaune-brunâtro. La moitié basilaire des ailes obseurcie ; cellule lancéolée avec une nervure droite.Huli (Harrington).

Capturé sur des pins à Hull. 
3. Lophyre futuve. Lophyrus fulvus, Nort. Trans. Am. Eut. Suc. 1V, 86.

o Iong. .30 pre. Trupu, d'un fiuse pale; les antennu, une tache a l'endroit des ocelles, une bande longitudinale sur chincun clos lobes Intérnux du mésothorinx, tout lo métathorıx, les plugues lasiluires nvec le promier segment nbabminal, une tuche a lu poitrine, nvec moe nutre a lu base du rentre et les vinlves de In turière, noir. Antennes do 13 articles, combtes, plus épmisses nu milieu et dentées en dednns. Ailes hyulines, les nervi: es

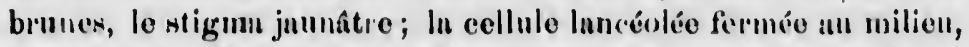
suopétiolíc. Puttes de la couleur du corps, les turses brunâties. - IInll (Harrington.

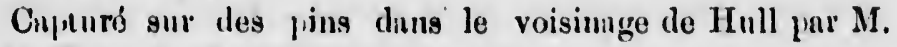
Hurrington ; $\sigma^{2}$ ericore inconnu.

\section{Autres Additions}

2. Gen. Trichosoma, Lench, p. 176.

Aux 2 espèces amćricaines encore connues, ajoutez la snivante.

Trichiosome de-Taylor. Trichiosoma Taylori, n. sp.

o-Iong. .60 pce. Niril nvec pubescence blinchâtle, cette

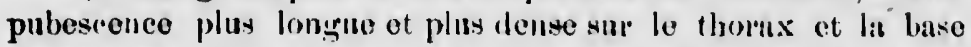
delablomen. Le chaperon avec une petite échanerure an milieu, lo lablre allongé et augruleux en avant. Antennes in funicule

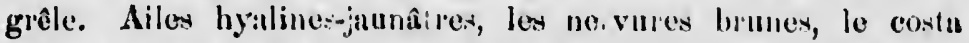
jaune aved une tarbe mire au sligma qui s'ullonge en pointe jusque prebs de la moitié de la 20 radiale. Palles noires avec les jumbes et les tarkes jamnes; les cuisses postérieures avec une petite-dent vers l'extrémité. Abdomen noir avee les trois do:niers segments bordés de jaune, les plaques terminales jiannes on dessous.

$\sigma^{x}-$ Long. . 80 pre. Mandibules allongées, avee 2 fortus dents au-dessous de lenr printe. Les 4 cuisses postérienres renflées avec une dent de chaque cốóvers l'extrémité; leurs hanches très allongées et portant 3 fo:tes ilents sur lenr trinche extérieure. Ihordure jatuse de l'ahulomen commengint vers le milieu et conviant entidement les 2 rerments terminaux taut en dessus qu'en dessous.-Vancouver (F'letcher'). 
Nons dédions avee plaisir ce bel insecte au Rév. G. W. Tuylor, de Cedar Hill, près Victoria, tle Vuncouver, zéllé entomologiste qui on a fuit la capture.

ntenncen, min, les 10 tilchio ulver do épuisses ervinies milion, unatres.

la' sni-

n. sp. cetto il batso aII IIInicule costn jus:ec les

Après lo genre Acordulecera, Suy p. 758, , joutez lo suivant.

\section{Gen. Lanidre. Labidia, nov. gen.}

(De labis, lubidos, nince; uliusion à l'armuture de l'extrémité de l'abdomen).

Tête grosse, transversale, aussi large que le thorax. Antennes de 8 articles, les 2 premiers renflés et poilus, lo $3 e$ le plus long, plus épais à l'extrémité, fig.6, les 4 derniers rentlés en massue. Thorn $x$ court et robuste. Ailes in 2 cellules rndiales et 4 cubitales, les lère et 3e chacune avec une nervure récurrente; la celiule lancéolée avec une nervule transverse droite. Pattes fortes, les postérieures surtout. Abdomen allongé, défrimé, ì 8 segments dont le dernier porte une fossulette an milieu et abrite la base de deux écailles se rejoignant à l'extrémité en forme de pince fig. 7.

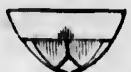

Fig, 7.

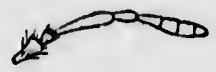

Fig. .6

Sanf les antennes en massue, et la pince de l'extrémité de l'abdomen, ces insectes ont toute l'apparence de tenthrèdes avec les pattes un peu plus fortes. C'est le seul genre, parmi les Cimbicides, portant 4 cellules cubitales, avec une double cellule radiale.

Labidie de-la-Colombie. Labidia Columbiana, n. sp.

$0^{x}-$ Long. .33 pce. Noire avec l'abdomen blanc-jaunâtre. Lo chaperon, le labre, les pulpes, les joues, les bords latéraux du prothor'ux, l'éeusson avec les pattes, blane. Têto excavée entre les yeux, rugneuse; les 2 articles basilaires des antennes poilus, la massue finement pubescente. Ailes hyalines, légèrement obscurcies, le stigma allongé, jaune. La poitrine, le dessus des hanchgs 
postérieures, une ligno sur les cuisses en dehor's, l'extrémité des jambes, avec les tarses postérieurs, noir. Les plaque basilaires avec lo premier segment abdominal, noir avec les rôtés blanc, tous les autres segments blanes avee une ligne noire a la base, cette ligne plus ou moins dilatéc au milieu. Ises écailles terminales on forme de pince, ciliées sur leur's bords.-Vancouver (Fletcher).

o-lincore inconnue.

Gen. Pristirirorı, Latr. p. 181.

Anx 3 espèces décrites, njontez la suivante.

Pristiphore sycophante. Pristipllora sycopleanta, Walsh, Proc. Ent. Soc. 'sil. VI, 263.

o-liong. .16 pee. Noire; la bouche noire, le chaperon coupé caruément, la fuce avec une espèce de petite carène au milieu. Antennes longues, légèrement ponssâtre: en dessous. Les écaillettes pâles. Ailes hyalines, les nervures noires. Paltes blanchâtres, les hanches excepté ì lenr extıémité, les auines, l'article terminal des tarses, l'extrémité des jambes postérieures avec leurs tarses entierement, noir. Abdomen noir, poli, brillant, à ponctuations per prononcées.-Ottawa (II:rrington).

Sa larve vit dans les galles du saule.

Gen. Nematus, Jurine, pp. 183,740 et ci-dessns 5.

Anx 17 espèces décrites, ajontez les 6 qui suivent :

18 Némate concolcre. Nemutus concolor, Nort. Trans. Am. Ent. Suc. I, 196.

ㅇ-Tong. .2.4 pce. Noir ; antennes un pen fortes; tête grossierement ponctuée; thorax ì ponctuations peu profoncles et confluentes; chaperon lisse, avec une échancrure arrondie en avant, ses bosds et le labre blanchongatre. Ablomen orale, count; pattes noires, les jumbes antérienres d'un brun de poix, l'ongle interne gros. Ailes i teiute violette, les nervures brunes, 20 cubitale bi-angulense en dersons, plus large p.èr de lit premiè e, une bulle transparente couvint en patie la neivure tambrerse 
de la 1dre cubitale et une antre da la réception de la lère réeur. rente.

ठ઼-Antennes longnes et giêles. - Ottarva (Harrington).

19. Némate à-abdomen-rouge Nematus erythrogaster, Nort. 'Trans. Am. Ent. Soc. I, 205.

ㅇ-Tong. .28 pee. Noir; antennes médiocrement longues, brunâtres en dessons, à articles non ienflés à l'extrémité. 'Tête yug'uense sur le vertex, avec les ocelles dans des petites fosses, le chaperon échancré, son bord antérienr avec le labre, jaune-pâle. Les écaillettes avee les angles antérienris, jaune-ronsinatre. Ailes hyalines, le stigma brun, pâle a la base, le costa anssi pâle. Pattes variées, les hanches, les trochanters avec une bande a la base des jambes, blane; les 4 cuisses postérieures avec l'extrémité des jambes intermédiaires, roux-pâle; le sommet des cuisses et des jam bes postérieures avec lenr's tarses, noir. Abdomen ronx clair, avec les 2 segments basilaires noirs. Les segments ronx avec une petite bande brune de chaque côté du milieu.--Ottawa (Harrington :

Espèce bien reconnaissable par sa coloration.

20. Nématc militaire. Nematus milituris. Cres. Trans Am. Ent. Soc. VIII, 7.

ㅇ-Long. $.26 \mathrm{pce}$. Noir, antennes plus de la moitié du corps en longueur, grrêles, particulièrement a l'extrémité. La bouche noiro, les palpes, les côtés du prothorax, les lobes latéraux du, mésothorax, les écaillettes, les flanc's excepté une étroite bande alt-clessous des niles, la poitrine, les pattes excepté la moitié apieale des jambes postérieures avec leurs tarses, roux-pâle. Ailes hyalines, le stigma noir, la 3e cubitale peu plus grande que la lère, la 2 e recevant chacune des 2 récurrentes à même distance de chacme de ses extrémités. Abdomen allongé, brillant, le ventre roux-testacé, plus ou moins varié de brun-Ottawa (ILarrington).

S.s ćnales romsses le remlent bien recomaissable. 
21. Némate persuasif Nematus suadus. Cress. Trans. Am. Ent. Soc. VIII, 10.

q-Tung. .15 pce. Janne-miel varié de noir. Une tache entre les ocelles, une bande sur lo lobe médian du mésothorax, une autre plus petite sur chacun des lobes latéraux, une ligno audessous des ailes, une tache au devant des hanches intermédiaires, la base des hanches postérieures, l'extrémité des jambes postérieures avec leurs tarses, le dos de l'abdomen excepté une lande apicale à chaque segment, noir. Antennes longues, noires, avec les 3 articles basilaires du funicule, à peu près d'égale longueur. Ailes liyulines, les nervures brunes, le stigma pâle. Abdomen largement ovale, les valves de la tariere noires.Ottawa (Harrington'.

Bien remarquable par sa coloration.

23. Némate à-large-bande. Nematus latifusciatus, Cress. Trans. Am. Ent. Soc. VIII, T.

९- Long. .30 pee. Noir, brillant; le bord antérieur du chaperon avec le labre et la base des mandibules, blanchâtre.. Antennes des trois-quarts de la longneur du corps, les 3 articles basilaires du pavillon à peu près d'égale longueur. Les angles postérieur's du prothorax avec les écaillettes, jaune-roussâtre. Ailes hyalines, les nervures et le stigma, noir ; la 20 cubitale recevant la lère récurrente à environ le tiers de sa base et la 20 récurrente ì environ le sixième de son sommet, la $3 \mathrm{e}$ cubitale d'environ la moitié de la longuenr de la $2 \mathrm{e}$, de largeur à peu près égule. Pattes jaune-roussâtre, la base des hanches postérieures en clessus, l'extrémité de leur's cuisses, la moitié apicale de leur's jambes, leurs tarses entièrement, noir. Abdomen ovale-oblong, subléprimé, ridé en traver's, avec les 4 segments basilaires jauneroussâtre.-Ottawa (Harrington).

24. Némate similaire. Nemutus similaris, Nort. Report Depart. Agricult. Washington, 1879.

ㅇ-Jung. .25 pce. Janne-roussâtre. Antennes noires, les trois articles basilaires du funicule à peu près égaux. Face blanchâtre, une tache sur l'occiput s'étendant jusqu'en arrière de la tête, les pro et mésothorax excepté les sutures, noir. L'écusson pâle. Ailes hyalines, les nervures noires. Pattes jaunes, les tarses antéricur's noirâtres; les jambes postérieures avec lour's 
tarses, noil. Tes plaques basilaires avec une bande sar chaque segment ablominal et les valves do la tarière, noir.-Ottawa (Harrington).

Gen. Emphytus, Leach, p. 191.

Aux 10 espèces décrites, ajoutez les 2 suivantes :

11. Emphyte pieds-jaun-paille Emphytus stromineipes, Cress. Tians. Am. Ent. Soc. VIII, 52.

ㅇ-Long. 26 pee. Noir, grêle; le chaperon is labre, les mandibules excepté à l'extrémité, les palpes, le collier, les angles supérieurs du prothorax, la poitrine, les écuillettes, les nervures de la base des ailes, les pattes y compris les hanches, avec le ventre, jaune-pâle. Antennes pâles en dessous ì l'extrémité, les articles 3 à 5 allongés, le 30 le pliss long. Ailes hyalines, iridiscentes, les nervures et le stigina, brun; la cellule lancéolée arec une nervule transverse oblique; les ailes inférieures sans cellules médianes. Tu bord apical des eogments abdominatux plus ou moins pâle, leur's côtés aussi pâles.-Ontario (Harrington,.

12. Emphyte de-Hull. Emphytus IIullensis, nov. sp.

$\sigma^{x}$-Tong. 25 pece. Noir varié de jaune; la face all-clessous des antennes, excepté une petite taehe enfoncée de chaque côté à la base du chaperon, les palpes, les joutes, les orbites antérieur's et postérieurs, les bords supér eurs du prothorax, les écaillettes, les flancs arec les hanches et les trochanters, jaunc-pâle. Les pattes jaune-roussâtre, tous les tarses arec les jambes postérieures larés de byun; la poitrine noire. Antennes assez courtes, les 3 articles basilaires du pavillon al'ongés, le 1er des trois le plus long. Le chaperon échancré. Ailes hyalines, les nervares et lo stigma, noir, le dernier pâle à la base; cellule lanééléc avec une nervure transverse oblique; ailes inférieures sans cellules discoïdales. Abdomen allongé, jaune-soussâtle avec une bande noise sur le dos interrompue di chaque segment.- Hull (Harrington).

O - Encore incommue. I.es 2 petites lignes enfoncées, transversales, noires, à la base du chapreron, rendent cette espèce bien reconnaissable. 
Gen. Selandria, Leach, pp. 199, 742 et ci-dessus 7.

Aux 15 espèces décrites, ajoutez les 2 suivantes :

16. Sélandrie montivague. Selandria montivaga, Cress. Truns. Ain. Ent. Soc. VIII, 13.

o-Tong. .25 pce. Noire, brillante: le labre d'un blancsale. Antennes à peu près de la longneur de la tête et du thorax réunis, gr sles, les articles 3 et 4 égaux en longueur. Les pro et mésothorax, l'écusson excepté au sominet, les écaillettes, les flancs excepté 2 taches en dessous plus ou moins confluentes, finve-ferrugineux. Ailes fuligineuses-pâles, les nervures et le stigma brun, cellule lancéolée pétiolée; ailes inférieures avec une cellule médiane. Les genoux et les jambes antérieures obscurément pâles.

Var. Ecusson tout noir, flancs sans les deux taches noires an bas.-Ottawa (Harrington).

17. Sélandrie inhabile. Selandria inhabilis, Harr. Trans. Am. Ent. Soc. I, 246.

o-Long. 16 pce. Noire; antennes courtes, filiformes, le second article de la moitié du premier, le terminal court; la face au dessous des ocelles rugueuse et foncée; la labre brunhlanchâtre au sommet; les écailles alaires, le prothorax, le mésothorax et la moitié antérienre des flanes, roux. Abdomen court, presque aussi large que long; le sommet des cuisses et les jambes, pâle, arec plus ou moins de noir au sommet des dernières. Ailes amples, fuligineuses; nervure marginale courbe et reçue près du tiers de la nervure cubitale.

$\sigma^{n}-A$ rec les jambes intermédiaires et postérieures noires.-Ottawa ! Harrington!.

Fam. II UROCÉRIDES, p. 235.

1. Gen. Oryssus, Fabr. p. 237.

A l'espèce décrite, ajoutez les 3 suivantes, qu'on pourra distinguer comme suit les unes des autres. 
Abdomen plus ou moins rouge;

Abdomen avec seulement l'extrémité rolsse ......................... 1. hæmorrhoidalis.

Abdomen entièrement roux excepté le premier segment ............... 2. occidentalis.

Abdomen entièrement noir ;

Face avee 2 taches blanches, moitié basilaire des ailes avec le sommet et une tache a l'extrémité du stigrma, blanc hyalin .................... 3. Sayi.

Face sans taches blanches; ailes obscurcies dans tonte leur moitié apicale, point de tache an stigma ....... 4. affinis.

2. Orisse du-nord. Oryssus occidentalss, Cress. Trans. Am. Ent. Soc. VIII, 48.

$0^{7} q$-Long. .40 pee. Noir avee l'abdomen-roux. La tête, le thorax avec le premier segment abdominal fortement rugueux. Une petite tache de chaque côté de la face en dedans des yeux, l'extrémité du labre, les articles 3-6 des antennes en dessus plus ou moins, les genoux avee une ligue en dehors des jambes, blane. Vertex avec 3 paires de pointes entourant les ocelles. Ailes hyalines dans leur moitié basilaire, au sommet, et à l'extrémité du stigina, obcurcies dans le reste, les nervures brunes, blanches dans la partie hyaline. Les tarses brun plus ou moins ronssâtre. Abdomen brillant, poli, le premier segment seul seabre et noir, le reste roux; $\delta^{\top}$ avee une tache blanche a l'extrémité.-Ottawa (Harrington).

On reconnaîtra peut-être par l'examen d'un grand nombre de spécimens que cette espèce se confond avee l'hcemorrhoiclchlis, Harris

3. Orysse de-Say. Oryssus Sayi, Westw.-Trans, Am. Ent. Soc. VIII, 49.

q-Long. .55 pee. Noir; le thorax, la tête et le premier segment abdominal scabres, le reste poli, lisse. Une petite ligne transversale de chaque côté de la face en dedans des yenx, l'extrémité du labre, les articles 3 et 4 des autennes en dessus, les 
genoux avee une ligne en dehor's des jambes, hlanc. Iue vertex avec 6 petites pointes entourant les ocelles. Ailes obscurcios dans lent moitié apicale, hyalines dans leur moitić basilaiı'e ot au som.. met, le stigma avee uno thehe blanche a son sommet qu'entourro aussi une tache hyaline de l'aile. Abdomen entièrement noir.

万-Avec une tache blanche à l'extrémité de l'abdomen et les ailes moins foncées.-Ottawa (Harrington).

Capturés ơ et of par M. Harrington à Ottawa sur un potean de télégrapho en cèdre.

4. Orysse allié, Oryssus affinis, Harr. Harr. Cat. \& Inj. Ins. $18: 35$.

- - Long. .48 pee. Noir, scabre on avant et lisse en arriere. La face sans taches, le vertex avec 3 paires de pointes. Les articles 3,4 et 5 des antennes en dessus, les genoux, avec une ligno sur les jambes en dehor's, blanc; les tarses brull-rolissâtre. Ailes hyalines dans leur moitié basilaire et ohscurcies dans le reste, le stigma sans tache apicale. Abdomen sans tache, brillant, finement ponctué, scabre senlement sur lo premier segment.IIull (IItrrington).

Capturée une seule q. Peut-être simple variétó du précédent.

Gen. Xiphidri, Latr. p. 242 et 750.

Aux 3 espèces décrites, ajoutez la suivante.

4. Xinhidrie atténuée. Xiplliảia attenuata, Nort. Proc. Eint. Soc. Phil. I, 144.

ठ-Tung. .26 pee. D'un jaune roussître plus on moins teint de brun. Antennes de 16 articles, brunes, juunes-ronssâtres à la bare. L'extrémité des mandibules, une tache sur le vertex, les côtés du cou, le dos du tholax en girande partie, des taches sur les flancs et en desson-, noir; lo milien dn mésotho:ax, l'écnsson, des taches sur le métathomx, le dessons, arec los hanches, jaune-pâlo. Les pattes jaune-ronssâtre. Ailes hyalines, les nerrures pâles, les ailes intéricures avec 2 cellules médianes. Abdomen allongé, cylindrique, resserré anx sutures, jamo-rousiâtre, chaquo segrment plus ou moins teint de brun aumileu.-Hull (IImrington). 
Ise vertex urcies dans ot an som. ביוי ont noir. bdomen et inr un po1. Cat. \& "n arridre. Les an'tiune ligne re. Ailes reste, lo int, fineiment. du pré-

Nort.

is teint es ì la ox, les fill les on, des e-pâle. *s, les ongé, serston).

\section{Fam. IV. ICHN EUMONIDES. Vol. 11, p. 249.}

Il n'est pas de famille, dans tout l'ordre des Hyménopitères, offrant une aussi grande différence de coloration dans les deux sexes de la même espèce, que celle des Ichnenmonides. La preuve en est daus ces espèces, souvent fort communes, dont on ne connait encore qu'un seule sexe; nul donte que l'autre sexe ne se trouve aussi dans les collections, mais affublé d'un nom différent. Comment pourrait-il se faire, par exemple, que des espèces aussi communes que Ichneumon comes, latus, trizonatus, etc., n'auraient encore jamais laissé capturer leurs femelles? Celles-ci, très probablement, sont unicolores et connues sous d'autres noms. Malheureusement ces insectes, Ichneumons, Amblytèles, Phygadeuons, Hémitèles, Cryptes etc., sont de ceux qu'ou ne surprend jamais dans l'accouplement. Des observations plus suivies sur leur habitat, l'analogie des formes, la texture des téguments etc, ont déjà permis de réunir les sexes de quelques espèees, comme l'Ichneurnon flavicornis qui n'est que le $\sigma^{7} \mathrm{du}$ centrator, le galenus, $\sigma^{7}$ du cincticornis etc., espérons que de nouvelles études et observations nous permettront de réunir aussi les sexes desautres, mais en attendant, il nous faut encore compter avec les sexes séparés et les noms propres qui les distinguent.

\section{Gen. Ichnrumos, Linné, p. 257 et 752.}

Aux 81 espèces décrites, ajoutez les 8 qui suivent.

8.2. Ichneumon rapproché. Ichneumon adjunctus. nov. sp.

q-long. 45 pee. Noir arec les pattes rousses. Face toute noire. Antennes courtes, atténuées à l'extrémité, non enroulées, toutes noires. Ailes légèrement enfumées. Aréole eentrale dı métathorax en carré, ses angles supérieur's arrondis. Post-pétiole aciculé. Les hanches, les trochauters, les jaunbes et les tarses postérieur's, noir, les premières ronssâtres près de la base; les cuisses postérieures tachées de noir au sommet.-Hull (Guignard). 
Très rapproché du similaris, Prov., en différant par les carnctères suivants: fuce sans lignes orbitales roussîtres; anteunes plus courtes, plus grêles, non enroulées; aréole du métathorox en. carré, celle du similaris étant benueonp plus largo que hante; pattes postérieures en partie noires; trille pilus petite.

83. Ichneumon très-noir. Ichneumon aterrimus, 11. sp-

으-Tong. 45 pee. Entièremont noir, avec: un large anneall jauno aux antennes. Les pattes do devant blanchatles en uvant. Antennes grenues, i articles coults. Thorax finement ponctué. Aréole centralo dn métathorax en carré, bien distincte. Corpys court et robuste. Abdomen à post-pétiole finement ponctué et non aciculé, les gastrocelles peu prononcés.-Toronto (Geddes).

Se distingue de l'uter par ces gastrocelles peu distiucts et de l'upertus par sou absence do taches et son pust-prétiole non aciculí.

\section{Ichneumon d'Ontario.-Ichneumon Onturiensis,} n. sp.

₹-Tong. 52. pee. Noir et janne; la face, les mandibries, les orbites antérienr's et postérieurs, lo scupe des antennes en dessous, le collier, les écailles alaires, une petito ligne en avant et une autre en dessous, l'écusson, 2 tacches sur la fitce postériouro du inétathorax, les pattes en partio avee un anneau à tons les segrments abdomin:ux, jaune. Thorax finement ponctué; aréolo eentrale du métathol"ax en earré. Ailes hyalines-jaunâtres, lo stigma fuure. Pattes jauness, les 4 hanches antérieures en dessus, les postérieures a ièrement, leurs cuisses avec l'extrémité de leurs jambes, une ligne en dehor's sur les $\dot{4}$ cuisses antérieures, noir, tarses postérieurs, irrun plus on moins foncé. Abdomen allongé, noir, tous les segments, exeepté le Be, avee une ligne jauno au sommet, le 3e jaune avec une ligne noire a la base, le segment terminal rou-sâtre, ou noi:" marrginé de roussâtre. Lo post-pétiole très finement aciculé.-Toronto (Geddes:

3ien distinet de tous ses voisins par sa coloration qui, quoi gue vartable, eonserve tonjours le $3 e$ segment abdominal janue avec une ligne noire it ta base, et le 2e noir avec une ligne janne au sommet. 
frunt par les inssittres; anréole du méup plus large leplus petite. vimus, n. sp. argo annoan res en avant. ent ponctuś. incte. Corpss ponctué et to (Geddes). istincts et do pítiole non

Onturiensis, mandibnies, unternes en ne en avant postérieure i it tous les tué; aréole I11nâtres, lo i en dessus, trémité do intérieures, Abdomen une ligne la base, le sâtre. Le

ration qui, abdominal avec une

\section{Ichneumon jaune-oitron. Ichneumon citrinus} n. $\mathrm{sp}$.

$\sigma^{7}-$ Tong. .70 pee. Jaune-citron, un point de chaque côté de la fice ant-dessus du chaperon, tout lo clerrière de ln tête aveo une grinde tache sur le vertex deseendant jusqu'aux antennes, une bande longitudinale sur chacun des lobes du mésothorax, les sutures du métathorax, une double tache surr les flanes, une doublo tache aussi sur la poitrine, une tache in l'extrénité des cuisses postéricures avec lo sommet do leurs jambes et l'extrémité do l'abdomen, blane. Antennes noires, avee le scape jaune-pâle en dessous. Ailes possablenrent enfumées arec les nervures brunes ot le stigma fiuve. Métathorax densément ponetué, ses lignes sonlevées pen prononcées formant une arćole centrale on carré. Post-pétiole ponetué, brusquement élargi un sommet avec une tacho noiro aviunt l'extrémité, le reste de l'ubdomen allongé, déprimé, jaune-citron avec les 3 dernicrs segments noirs.Ottawa (Harrington).

lispèce tout-à-fait remarquable par sa couleur jaune- pâle qu'on croirait décolorée.

\section{Ichneumon caché. Iclınєumon absconditus, n. sp.}

ర-long. 35 pee. Noir, grềle; les côtés do la face, les orbites antérieurs et postérieur's interrompus sur le vertex, une tache de chaque côté da chaperon, les palpes, une ligno sur les bords latór:uux du prothorax, une autre aur dessons de l'insertion des ailes antérieures, avec l'écusson, blanc. Tête en carré transversil ; antennes sétacées, conrtes, grenues, brunes, roussâtres en dessons avee un petit anneau blane en dessins an cleli du milieu. Ecusson plan, blane aree une échancrure en avant; le métathorax à lignes soulevées distinetes formant une aréole centrale en carré aree sa partio antérieure arrondie. Ailes subhyalines, les nervures brunes, lo stigma brun-roussâtre. Pattes noires, les antérienres avec les gonoux, uno ligne sur lo devant de la jambe et les tarses, blanchâtre; les postérieures sans ancune tacho. Abdomen allongé, linéaire, les segments 2,3 et 4 fortement ponctués, avec les sutures et une étroite ligne an sommet roussâtres; les gastrocelles petits, ronssâtres, lo post-pétiole peu 3-Fúvrier $1880^{\circ}$ 
slargi, poli, ponctuó. Tes benilles ulnires blanches avec uno tucho roussatro.-Ottuwa (Flotchor).

Pent-être certains iudividus dis cette espèce se trouveraient-ils i avoir les seginents 2 et 3 de l'abdomen plus ou moins roux.

86. Ichneumon voisin. Ichneumon vicinus, Cress. I'roc. Ent. Soc. Phil. III, 169.

o - Iong. .45 peo. Roux, robusto; antennes il axticles assez courta, rousses in la base et noiratres à l'extrémité nvec un anneau pâlo an milien. Les côtés du prothornx, les environs de l'écusson, les sutures du métuthorux, le dessous avec les hauches postérieures, noir. Ailes subhyalines, les nervures hrunes, lo stigma fiuve. L'écusson jaune plus ou moins roux. Métathơax finement ponctrié, los lignes saillantes pell soulevées et formant une aréolo en carré longitudinnl. Tues enisses postérieures, excepté à ln base, avec lo sommot do leurs jumbes, uoir. Abdomen finernent ponctué, le post-pétiole finement acienlé, les guastrocelles ob iques et peu enfoncés; les segments 3 et + avec une ceinturo noile a la base; l'extrémité rousse, sans tache.-Ottawa Har. rington!.

Tiupproché du seminiger, mais moins robuste, son postpétiole plus étroit et sans taches, ete. ; dans le seminiger le post-pétiole es; distinctemeut aciculé avec une tache pâle de chaque côté au soinmet.

87. Ichneumon approcha.1t. Icluéumon apploximans n. $\mathbf{s p}$.

8 -long. .55 pee. Noir avec les segments 2 et 3 de l'abdomon jaune-romssâtre, de même que les pattes en partio. Têto ot thol"'x moir sans aucune tache. Ailes hyalines-jaunatres. Aréole centrale du métathorax en carré tranversal. Pattes rousses, toutes les jambes avec l'extrémité des enisies et ley tarse.; jauno roussâtre, les jumbes postérieures noires il l'extrémité. Abdomen allongé, as:ez robuste, noir avee les segrnents 2 et 3 jame roussatre, le 2e avec une ligne noire au sommet et le $3 e$ arec une semblable au sommet, une plus petite a la base et souvent une 
longitudinule au milien; lo dernier segmont entierement noir; le post-pétiole tinement aciculé-Tononto (Godeles).

Voisin de l'Amblyteles rufizonalus, mais en diffitant par sa face noire et sa bunde rousse de l'ubdomen, qui est toujours plus ou moins tachíe de noir.

88 Ichnoumon à-4-points. Ichneumon quadri-punctatus, n. sp.

$\sigma^{2}$ - Tong. .30 pec. Noir avec l'ublomen roux; la face, los mandibules, les joue.s, lo scapo en dessous, les orbites interrompus sur lo vertex, le collier, les écuilles ulaires, une ligne nu dessous, les bords latélaux du prothorax, los écussons avec les 4 hanches antélieures et leurs trochantius, jaune-pâle. Antennes sétacées, grenues, roussâtres en dessous. Ailes hyalines, les nervures ot le stigma, noir. Pattes rousses, les postérieures avec la moitió apicale des cuissos, lo sommet des jambes et les tauses entieremont, nour, les 4 hanches antéricures jaune-pâle avee un point nois en dehors. Métathoras a lignes soulevées distinctes, formant uno aréole en carré sur le dos, la face postérieure avec une tache jaune-pâle mar ginée de roux sur chuenn des côtés. Abdomen allongé, cylinclrique, d'un beuu roux à l'cxception du ler segment qui n'a do ronx que lo sommet, les gistrocelles profonds.-Ottawa (Harrington).

Ressemblant beancoup par sa coloration au W-album, mais de bieu plus petite taille. Notre spécimen portuit un point noir sur chacune cies hanches pâles, en dehors.

\section{Ichneumon de-Vancouver. Ichneumon Vancou-} veriensis, Prov. Cau. Ent. XVII, 114.

$\sigma-$ Tong. .62 pee. Noir; la fitco avee 4 points blanes, un do chaque côté du chaperon et un an clessous de chaque antenne. Celles-ci entièrement noires et submoniliformes. Une tache sur les écalles alaires, une ligne en avant et une autre au dessous, lo collier et l'écusson, blanc. Ailes légèrement enfumées; l'uréolo pentagonale, les nervures noires. Métathorax avee les angles subépineux, l'aréole centrale transverse, ar’ondie antérieurenent. Pattes noires, les 4 jambes antérieurcs avee une ligne blanche en 
dehors, les postérieures urec une antro plus petite près do la buso. Abdomon ullongé, avec lo pédicule grêle et ponctuó, ontièrement noir.-Vunconver (Broclio).

Voisin du sulcyuneus, mais de plus forte trille, uvec les cuisses entierement noires, et des milques blinches nussi differentes.

\section{Gen. Horlismr.sus, Grav. p, 291.}

Aux 3 espèces décrites, ajoutez la suivante :

4. Hoplismène noir - IIoplismenus stygicus, nov. sp.

o'-Tong. .68 pee. Entièrement noir dans tontes ses partios, a l'exception d'un muenu blanc nux antennes. 'lête on carré trunsversil, non rétrécio en uridie des yeux. 'Thorax den: sément ponctué; écusson convexe, ponctué; métuthorax granuléruguenx, pubescent. ses angles latéraux mucronés, avec uno aróole centrale triangulatre, mais ì peine fermée en arric̀re, les cardnes lutérales s'écultant pour so rent!le nux nngles mucronés. Ailes fortement obscures, l'al'éole grande, en carré. Pattos postérioures beancoup plus griandes quo les antres. Ablomen allongé, ponctuć a la base et lisso au sommet, lo premier segment ponctué et bicaréné postrírenrement.-Ontario (Gedues).

3. Gen. Amblyteles, Westm: p. 292 et 766.

Aux 23 espèces décrites, ajoutez les 2 suivantes:

Amblytèle macrocéphale. - Anblyteles macrocephalus, nov. sp.

ठ-Long. .3S pec. Noir avec teinte bleuâtre. Ia face et les flunes avec une comrte pubescence grisâtre. Tête grosse, transversale, renfléc en ariò le clus yeux; les antennes médiocres, entièrement noires, thoriax wans aucune tache, les écailles alaires noires; métathorax excuvé postélieurement, luguonx avee uno aréole centrale en car'ré striće longitudinalement. Ailes hyalines, les nervurus et lo stigma, noir. Pattes jousses, les antérieures plus ou moins jaunâtres eu avant. Abclomen linćuire, sans aucuno tache, le post-pétiolo avec quelques grosses aciculations, les outures des segments médians fortement prononcées. 
Un seul spécimen capturé an Cnp-Rouge; especeo bien remarquable par sa grosse tête qui rappelle celle des Pyraemons.

25. Amblytèle superbe. Amblyteles superbus, n. sp.

f-long. .52 pree. D'un beun roux; les yeux, la moitió upicule des untennes, los sutures du thorax uvec une ligne a la base des segments 2 et 3 do l'ubdomen, noir. Antennes usse\% courtes, noueuses, non onroutéos, ì urticle 3 à peino plus long quo

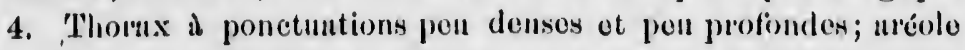
contrale du métathorax obsolète, les lignes sonlevées indistinctes. Ailes fuligineuses, les nervures noires, lo stigmu fiune. Puttes saths ancune tuche, post-pétiole lange, finement aciculé, les gintrocelles petits, fovéiformes; tarièro noire, ì poino sortunte. - Vimconver' (Fletehor').

Sn conleur plus cluire, sa trille plus élancée, les lignes noires de son ubdomen avee sa tête plus petite lo distingnent de la viniété ronge de l'Hudronicus.

Gen. l'latylabus, Wesm. pp. $304 \& 76 \%$.

Aux 7 espèces décrites, njontez les 6 qui suivent. On pourra modilier comme ci-dessous la clef pour les distinguer les unes des autres.

1 (2) Coulour, vert-blentitro, brillant; écusson bl:mc.................... 8. magnificus, $n . s p$.

2(1) Conlour, noir et roux;

3(4) Abdomen entiòrement noir avee les pattes rousses.............. 7. Rubricapensis, 769

4(7) Abdomen noir avec seulement le 20 segment roux ;

$5(6)$ Abdomen taché de blanc al l'extrémité; écusson blanc.............. 1. scutellatus, 303.

6(5) Abdomen salns taches a l'extrémité; écusson noir................ 9. mitralis, $n . s p$.

7(16) Ablomen roux, avec l'extrémité noiro;

8(9) Eeusson blanc; thorax plus on moins roux ..................... 2. signatus, 305 .

$9(8)$ Ecusson uoir ou ferrugineux;

10(15) 'Tête et thornx, noir'; 
11(12) Antennos courtes et fortes, rousses à la base, sans anneau pâle.. .... 10. craśsicornis, $n . s p$.

12(10, Anteunes asse\% grêles, noiros avee un anneaı jâle;

13(14) Segments ablominaux 1 et 2 aciculés; taille, .32 pee .......... 11. aciculatus, $n . s p$.

14(13) Sagment 1 seulement aciculé; taillo .26 pee ................... cincticornis $n . s p$.

15(10) Tête noire, thorax plus ou moins loux; 4. thoracicus, 306.

16(7 Abdomen roux avec l'extrémité rousse;

17 (18) Thisax noir; métathorax fortement mucroné; hanches postérienres noires. 5. 4-carinatus, 306.

18(19) Thorax noir, métathorax à peine nucroné; toutes les hanches rousses, antennes rousses............

13. ruficornis, $n . s p$.

19(15) Thö:ax roux;

20(21) La face, les sutures din thorax, les troehanters avee la ba se du pédicule, noir. 3. ornatus, 305.

21(20) Lar face et tout le reste, roux, antennes rousses à la base, noires daus le reste avec un anneau blance au delà du mi-

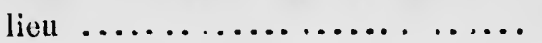

6. lineolatus, 307 .

8. Platylabe maznifique. Plutylubus magnificus, n. sp.

\&-Long. .50 pee. D'un bean vert métallic bleuâtre. Les o:bites antérieurs, une petite ligne en arrière des youx, un anneall aux antennes, une ligneswe les bords latéraux du prothorax, l'écllsson avec une ligne sut' lo dovant des jambos antélieures, blanc. Antennes fort longues, noires avec in anneau blanc au milieu. 'Tête courte, rétiécie en arrière des yeux. Eeailles alaires vertes. Métatho:ax clensément ponctuć, subépinenx aux angles, l'aréole centrale en calré, polie, brillante, ponctnée. Ailes hya. lines, lo stigma et les nervures, noir. Pattes bleuâtres. Abdomen court, large, d'un vert bleuâtre, le post-pétiole indistinctement aciculé, les gastrocelles très profonds, obliques; tarièro sortante. -Bécancour.

Espèce bien remarquable par sa coloration; sa plus petite taille, sa couleur plus claire etc. la disting “ent du montunus. Une seule of capturée à Bécancuur. 
ornis, $n . s p$.

latus, n. sp.

cornis $n . s p$. acicus, 306.

inatus, 306.

ornis, $n . s p$.

natus, 305.

latus, 307.

ficus, n. sp. aitre. Les ux, un anplothorax, ntérienres, a blanc au les alail'es ux angles, Ailes liy: Abdomen inctement sortante.

lus petite ontunus.
9. Platylabe à-mitre. Platylabus mitrulis, n. sp,

of-Long. ,20 pee. Noir avec une bande rousse à l'abdomen. La face finement ponctúe, tuberenlense an milion. Antennes ansez longues, filiformes, rousses a la base et noires a l'extrémité. Thorax poli, brillant, tronqué carrément ì l'extrémité, ses angles postérieurs fortement mucronés, le métanotum avec une aréole centrale en forme de mitre; écusson assez convexe, non earéné surr les côtés. Ailes enfunćes avec les nervures et le stigna, noir, une tache hyaline al la base de ce dernier. Pattes ronssos, les hanches postérieures plus ou moins obseures à la base. Abdomen en ovale, poli, brillant, noir avec lo 2 e segment roux, le premior segment très large au sommet, fortement aciculé; tarière un peu plus corte que l'abdomen.-Bécancour.

Cette jolie petite espèce est bien rernarquable par le pédicule de son abilomen fort ćlnrgi et aciculé.

10. Platylabe cornes-épaisses. Platylabus crassicornis, n. sp.

q-Long. .20 pee. Noir avec l'abdomen ronx. Tête large, en carrés vue en dessus, la face finement ponctuée. Antennes assez longues, ronssâtres à la base, noires ì l'extrémité, les articles de la base allongés, les terminaux plus conrts et plus épais, le scape roux. Corps court, robuste, d'un noir brillant, le métathorax a angles so terminant en pointes monsses. Les écailles alaires blanches. Ailes légèrement obsenres, le stigma aree une tache blanche à la basse, l'aréole pentagonale. Pattes rousses y compris les hanches, les postérieures nvee la base des hanches, l'extrémité des cuisses et des jambes, et les tarses, noir. Abciomen en ovale, déprimé, poli, brillant, les segments 2 et 3 roux, le reste noir, le post-pétiole finement acieulé, lat tarière à peine sortante. - Hull (Guignard).

11. Platylabe aciculé. Platylabus acilatus, n. sp.

q-Tong. 31 pce. Noir avec l'abdomen roux. Tête en carré iransversal, médiociement épaisse, la fice finement ponctuée. Antenne longues, filiformes, noires avec un anneau blane au milien, le scape noir. Thornx court et robuste, entièrement noir, le métathorax rugueux, ses angles se terminant 
en épines mousses. Ailes légèrement enfumées, le stigma noir avec une tache blancho à la base, les écaillettes blanches. Pattes ronsses, l'extrénité des cuisses et des jambes postérieures avec les tarses, brun-foncé. Abdomen oblong, déprimé, le premier segment noir $\boldsymbol{a}$ ln base, pertant 2 petites carènes vers son milieu et fortement aciculé au sommet. Lue $2 \mathrm{e}$ portant aussi des aciculations a la base, les terminaux noirs avec une tache blanche a l'extrémité; tarière à peine visible.-Hull (Gruiguard).

Bien distinct par son post-pétiole.

12 -Platylabe à-cornes-annelées, Platylabus cincticornis, n. sp.

९-Long. .19 pee. Noir avec l'abdomen en partie roux. Tête plus large que le prothorax, assez épaisse. Antennes filiformes, noires avec un anneau blanc au milieu, le scape noir, mais les articles qui le suivent quelque peu roussâtres en dessous. Thorax court et assez robuste, les angles du métathorax arrondis. Ailes légèrement enfumées, le stigma noir avec une tache pâle à la base; les écaillettes blanches. Pattes ronsses y compris les hanches, les postérieures avec l'extrémité cles cuisses, des jambos, et les tarses, brun-foncé. Abdomen oblong, noir avec les segments 2 et 3 ronx, le premier finement aciculé au sommet; tarièro légèrement sortante.-Hull (Guignard .

Sa plus petite taille et la forme de son abdomen le distinguent surtout du crassicornis.

13. Platylabe ruficorne. Platylabus ruficornis, n. sp.

$o^{7} f$-Long. .21 pee. Thorax noir avec l'abdomon et les pattes, roux. Tête en carré transversal, la face finement ponctuéc, à pubesence grisâtre, plus abondante dans le $\delta$. Antennes grenucs, rousses dans le $\delta$, dans la o rousses a la base seulement, noires dans reste, plus épaisses ì l'extrémité, non enronlées. Métathorax a lignes soulcrées distinctes, ses angles postérieures sub-épincux; écusson caréné sur les côtés. Ailes hyalines, les nervures et le stigrma brun foncé, les écaillettes roussiltres. Pattes sans aucune tache. Abdomen en ovalo, poli, brillant, le premier segment tris large au sommet, finement aciculé et plus ou moins obscur sur les côtés; taric̀e a peine sortante.-Ottawa (Harrington). 


$$
\text { IV.-ICHNEUMONIDES }
$$

stigma noir ches. Pattes tricures aveo le premier s son milieu si des acicu. e blanche d ).

abus cinc-

artie roux. tennes filisciape noir, en dessous $\mathbf{x}$ alrondis. ache pâle à ompris les les jambos, ye les seget ; tarièro

en le dis-

iis, 11. sp.

len et les ent poncAntennes ase seulenon enis angles s. Ailes caillettes ale, poli, nent aciine sor-
Gen. Phalogenes, Wesmael, pp. 307 et 769.

Aux 12 espèces décrites, ajontez les 6 suivantes: On pourra les distinguer les unes des autres par la clef ci-dessous.

\section{Femelles}

1(8) Thorax et abdomen, noir ;

2 (3) Pattes noires, antennes avec un anneau blanc .................. 6. aterrimus, 769: 3(2) Pattes rousses;

4(5) Jambes postérieures noires avec une anneau pâle, antennes fortes, ì articles courts, enroulées............ 8. Gaspesianus.

5(4) Jambes postérieures rousses; antennes grêles ;

6(7) Tarière à valves très larges, tête fortement renflée on arrière des yeux. 13. crassitelus $n$.sp.

7(6) Tarière ordinaire; tête ordinaire; trochanters blanes........... 14. recticaudax, n.

8(17) Thorax noir, abdomen plus ou moins roux ;

9(10) Pattes noires, écussons blanes...... 9. tuberculifor, 7n0. 10(9) Pattes rousses, ćcussons noirs;

11(12) Tarière de la moitié de l'abdomen environ;

12(13) Stigma noir avec une tache blanche d la base................ 15. recticomin; n. sp.

13(12) Stigma brun-pâle, sans tache...... 15, pinguis, n. sp. 14(11) Tarière à peine sortante; stigma jaune;

15 18) Antennes avec un an neau pâle au milieu;

16(17) Les 4 premiers segments abdominaux roux, le reste noir .............. 1. hebruk, 307.

17(16) Lo 1er avec les 2 derniers segments abdominaux noirs, les autres roux plus au moins teints de noir........ 10. Falardeaui, 7.t1.

18(15) Antennes sans anneau pâle; l'ousses a la base ................... 11. arbus, t7.

19( 8 ) Thorax plus au moins roux; abdomen roux;

20:21) Abdomen avec les derniers segments noirs.

2. tuberculifrons, 308 . 4-Février 1886. 
21(20) Abdomen roux a l'extrémité;

22(23) Abdomen grêle, ses deux derniers segmente séparés du reste par un étranglement............... 5. pyriformis, 309 .

23(22) Abdomen assez large, de forme ordinaire;

24,25) Pattes rousses, trochanters pâles. 3. mellinus, 308 . 24,25) Pattes variées de noir et de jaune-roussâtre, toutes les jambes avec un anneau pâle au milieu.

17. annulatipes, $n . s p$.

\section{MaLfs.}

1(4) Thorax et abdomen, noir;

2(3) Face noire, sans taches 6. aterrimus, 769 .

3(2) Face noire avec taches orbitales blanches............... 7. nigricornis, 770.

4(13) Thorax noir; abdomen plus on moins roux;

5(6) Les 4 premiers segments abdominaux roux; antennes avec un anneau pâle... 1. hebrus, 307.

6(5) Le premier segment avec les derniers, noirs;

7(10) Face jaune ou blanche, les 4 hanches antérieures blanches;

8(9) Face blanche; antennes courtes; hanches postérieures noires; stigma brun. 10. Falardeaui,' 71.

9(8) Face jaune; antennes furt longues; hanches postérieures rousses; stigma jaune.. 11. orbus, 771 .

10(7) Face noire; hanches rousses ou noires; stigma noir;

11(12) Toutes les hanches noires....... 18. recticomis, n. $s p$.

12(11) Toutes les hanches rousses, les 4 antérieures plus elaires ......... 19. indistinctus, $n . s p$.

13(4) Thorax plus au moins roux;

14(17) Abdomen avec l'extrémité noire;

15(16) Tête courte, transversale, ronsse. 2. tuberculifrons, 308.

16( 15) Tête longue, prolongée on arrièro des yeux, noire ............. 12. quadriceps, 771 .

17(14) Abdomen avec l'extrémité rousse; 
18(19) Face noire au dessus des antennes, jauno

au dessous; lo collier, l'écusson, jaune ................. 5. pyriformis, 309 .

iformis, 309 .

19(18) Face entièrement ronsse, lo collier et

l'écusson roux ............... 4. helvus, 308 .

aellinus, 308.

6. Phœogènes aterrimus, Prov. p. 769, $\sigma^{7}$.

q-Long. .40 pee. Entièrement noire; antennes fortes, enroulées, avec un anneau blane au milieu. Tariere a peine sortante. Pour lo reste semblable au $\sigma^{\pi}$.

Capturée à Bécancour.

11. Phæogenes orbus, Prov. p. 771.

q-Long. .25 pce. Même coloration que dans le $\sigma^{x}$ avec les exceptions qui suivent: Antennes "ousses, a peine obscurcies a l'extrémité, longues, faiblement noueuses, non enroulées. Les pattes et l'abdlomen d'un roux ferruginenx, plus foncé que dans le $\sigma^{\top}$. L'abdornen roux à l'extrémité, le 1er segment secilement noir à la base, le $2 \theta$ avee une impression transversale pres de la base.--Vancouver (Fletcher).

Bien que cette $q$ ait été capturée à Vancouver et notre $\sigma^{2}$ au CapRouge, la forme et la coloration ne permettent pas de douter que ce ne soient les deux sexes de la même espèce.

13. Phéozène queue-épaisse. Phoogenes crassitelus, n. $\mathrm{sp}$.

q-Long. 31 pce. Noir avec les pattes rousses. Tête on carré, très finement ponetuée, la bonche et le bas des antennes en dessoue, brunâtre. Thorax court, trapu, lo métathorax épineux aux angles et portant une aréole centrale arrondie en avant. Ailes subhyalines, à aréole grande, pentagonale, le stigma brunfoncé, taché de blane à la base. Pattes d'un rou" clair, y compris les hanches, !es postérieures avec l'extrémité des jambes ot les tarses, brun plus ou moins foncé. Abdomen en ovale allongé, lo premier segment finement aciculé au sommet, le 2e et partio du 3e ponctués, les autres polis, brillants. Tarière moins du quart de l'abdomen, à valves liurges, noires, brusquement tronquées a l'extrénité, le dernier segment prolongé et rétréci comme pour servir de base a la tarière.-Hull (Guignard). 
Bien reconnaissable par la forme insolite de l'extrémité de son abdomell.

\section{Phéogène queue-drolte. Phaogenes recticaudus,} n. sp.

ç-Long. .30 pce. Noir avec les pattes roneses; les mandibules excepté a l'extrémité, les palpes, les écailles alaires, les bords latéraux du prothorax avec les 4 trochantors antéricurs, blanc. Tête on carré, plus large que le thorax, épaissie en arriere des yeux. Antennes longues, un pen plus épaisses vers l'cxtrémité. Le métathorax arec lignes suulevées distinctes. Ailes hyalines, lés nervures brunes, le stigma jaunatre; aréole pentagonale. Pattes d'un beru roux, les postérieures plus ou moins obscurcies sur les jambes et les tarses, leurs trochanters roux en dessus et blancs eis dessous. Abdomen allongé, linénire, atténué en pointe a l'extrémité ; tarière saillante, droite. Ottawa (Guignard).

15 Phéogène cornes-droites. Phceogenes recticornis, n. sp.

†- Long. .28 pce. Noir avec l'abdomen roux. Tête et thorax d'un noir foncé, poli, brillant; tête grosse, transversale; la face sans ancune tashe. Antennes filiformes, droites, plus épaisses a l'extrémité, roussâtres a la base, surtout on dessous. Métathorax sub-épineux aux angles, al lignes soulevées distinctes, formant une aréole allongée an milien. Ecailles alaires blanches. Ailes subhyalines, le stigma noir avec une grande tache blanche. à la base ; les nervures brunes, pâles à la base. Pattes roux-foncé, les postéricures arec l'extrémité des enisses, des jambes et les tarses, brun-foncé. Abdomón en ovale, déprimé, le premier segment excepté au sommet avec les deux ou trois derniers, noir; tarière de la moitié de l'abdomen environ.-Bécancour.

$\sigma^{7}$-Même coloration que dans la $\subsetneq$ avec les exceptions qui suivent: toutes les hauches et le trochanters, noir; le scape en dessous jinunâtre.

Sa tarière plus longue que d'ordinaire, distingue cette єspèce de toutes ses voisines. 
16. Phéogène gras Phwogenes pinguis, n. sp.

o-1ong. .22 pee. Noire avec l'abitomen roux. La face finement ponctuée. Antennes brun-roussâtre ì la base. Thorax cou't et trapu, lo métatho:"ix inerme, densément ponctué. Ailes hyalines, les nervures et le stigma pâles, les écuillettes blanches. Pattes roneses, les postéricures avec les trochanters, l'extrémité des cuisses, des jambes et les tarses, noir ou brun foncé. Abdomen en ovale allongé, obtus ì l'extrémité, roux avoc les segmeuts te:minaux noirs, le premier segment peu ćlurgi, sans taches et poli à l'extrémité; tarridre de la moitić de l'abdomen environ.Ottawa (Harrington).

17. Phéogène pieds-annelés. Pluengenes annulatipes, n. sp.

O-Long. .24 pce. Vurié de noir et do roux avec l'abdomen roux. Ita fitce rousse, renflée pour l'insertion des antennes; cellesci courtes, ì articles courts, plus épaissses ia l'extrúmité, enroulées avec un anneau blane au milieu. Thorax allongé, d'un brun roussâtre, lo mésothorax avee la ficce postérieure dn métathorax roux brunâtre, le dernier inerme, densément ponctué, sans lignes soulevées distinctes; l'écusson jauno. Ailes sublyyalines, les nervures brunes, les écaillettes junnes. Pattes jaunos, toutes les jambes avec un anneau pâle au milien, les hanches postérieures, leurs cuisses et la moitić apicale de leur's jambes, noir. Abdomen entièrement roux, assez long, atténué ì l'extrémité; tarrière a peine so:tante.-Ottawa (Harrington).

Très distinct du mellinus par ses pattes à couleurs variées et le roux sale de son abdomen.

\section{Phéogène indistinct. Pluceogenes indistinstus,} n.. sp.

$\delta^{7}$-Long. .36 pee. Noir avec les pattes ot les segments doux et trois de l'abdomen roux. 'Tête transversale, plus large que le thorax, les mandibules, les palpes, les ćcuilles alaires, blane; la face finement ponctuée, tuber'ulense au inilieu et avec des orbites roux indistincts. Antennes filiformes, noires, roussâtres en dessous, le sceupe plus ou moins roussiutlee et taché de 
jaune en dessous. Thorax poli, brillant, a lignes sonlevées distinctes. Ailes hyalines, les norvures et le stigma, bran. Le: 4 trochantins antélieurs blancs, l'extrómité des cuissos ot des jamhes postérienres avec lenrs tal'ses, noir. Aldomen en ovalo, déprimé, le ler segment all sommet avec les 2 suivants roux, le resto noir. - Ottuwa (Harrington).

Voisin du subspinosus mais avec le mótathorax plus latge, inermes et une taille plus robuste.

Gen. S̈trupus, Grav. p. 310 et 772.

Aux 3 espèces décrites, ajoutez la suivaute.

Stilpne appendiculé. Stilpnus ceppendiculutus, n. $\mathrm{sp}$.

o-Long. 17 pce. Nc:?: la fare, particulièrement sur lo chaperon et les jones, avec une forte pubexcence blanchâtre. 'Têto transversale, peu épaisse. Antennes à articles pen distincts, plus cuurtes que le corps, fi'iformes, lo sciıpe obscurément roussâtre en dessous. Thorax court, assez éjais, le mésothorax a lobes distincts, le métathorax a lignes soulevées distinctes, ses angles a peine tuberculenx. Ailes hyalines, iridescentes, a stigma grand, brun, presque triangulaire; aréole pentagonale avec sa nervuro extérieure pen clistiucte, la nervure cubito-discoüdale portant un appendice en forme d'éperon bien remarquable. Pattes jauneroussâtre, les hanches plus ou moins obscures, les postélieures avec leurs cuisses, lenr's jambes et leurs tarses, excepté un anneau pâle à la base des deux prenières, brun plus ou moins foncé. Abdomen noir, poli, brillant, le 1er segment rug'ueux, i peine élargi au sommet, les 20 et 30 obcurẹ́ment loussîtres à la base. Ottawa (Guignard).

Gen. Phygadeuon, Grav. p. 311 et 772 .

Aux $46^{\circ}$ espèces décrites, ajoutez les 15 gini suivent; ce qui porte a modifier comme ci-dessous la clef pour la distinction des espèces.

\section{Femelles}

1(14) Thorax et abdomen, noir;

2(7) Pattes noires;

$3(6)$ Eeusson noir, orbites noirs; 
4'5 Jumbes postérienres entièrement noires. 1. Blakei, p. 313.

$5: 4)$ Jambes postérienres tachées de blanc on dehor' .................. 2. maculatus, 317. Frilosy.

6(3) Gensson et orlites, blanc........47. Guignardi, n. sp. Fteroormis s

$712)$ Pattes lousses;

8(13) Ecusson noil;

9(12) Antenues suns anneau pâle;

10,11) 'Toutes les lianches rousses......... 4. maturus, 314.

11(10) Ties 4 hanches antéricures et leur's tro-

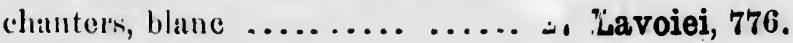

12(9) Antennes avee un anneau blane; tarièro longue................ 3. sigwatus, 314 .

$13(8)$ Eeussont taché de blanc; tarière à peino sortante............... 48. electus, $n$. $s p$.

14(1) Tiırax noir ou loux, abdomen plus ou nooins joux;

15 66) Fensson noir ;

16(39) Antennes noires à la base avec un annean blanc au milien.

17(32) Abdomen noir à l'extrémité ;

18(23) Manches postérieures noires;

19(20) Abclomen avec l'uxtı́mité noire tachée de blanc........... 7. rubrocintus, 315 .

20(19) Abdomen sams taches de blanc à l'extrémité;

21(22) Jambes postérieures sans anneau pâle à la base; écailles alaires noires. .49. fusiformis, $n$. $s p$.

22 21) Jambes postérieures avec un anneau pî̀le à la base; écailles alaires blanches .................. 34. 3-annulatus, 777

23(18) Hanches postérieures rous 'es;

24(29) Ablomen avec l'extrémité noire saus taches de blanc;

25(28) 'Tarière aussi longue que l'abdomen ou peu s'en faut:

26 27) E(aillettes noires; antennes grêles et longues.............. 50. longicornis, n. sp. 27(26) Eicaillettes blanches; antennes médiocres, plus épaisses à l'extrémité. 9. occidentalis, 316.

28(25) Turière à peine de la moitié de l'abdomen .............. 51. nigriceps, $n$. $s p$ 
29(24) Abdomen avec l'extrémitú noire tuchée de blane;

30(31) Cuisses noires; scupe noil. ........ 6. inhabilis, 315. 31(30) Cuiswes rousises; scupe roux.......... 8. alacris, 116. 32. 17) Abdomen i l'extrémité rousse, quelquefois tachée de jaune; 33 38) Toutes les hanchess noìes; métuthoiax fortement rugneux, mucroné aux angles, son uléole centrale transver'sile;

34(35) Pattes noires, les 4 jambes antérieures avec une lị;ne pîle en dehors. 20. mucronatus, 319.

35(34) Pattes rousses, les 4 jambes antérieures rousies ;

36,37) Fluncs du métuthorax totalemeut r'ugueux; jambes postérieures rousses uvee un anneau noir a l'extrézi.ic ................... . abdominalis, 319. 37(36) Flanes du métathorax avec une plaque lisse; jambes postérieures noiros. 30. vulgaris, 776.

38(33) Toutes les hanches rousses ; métathorax uniformément ponctué, avec une aréole conique bien distincte. 37. Lechevalieri, 778 .

39(16) Antennes noires a la baso et sans anneau blane, ou bien l'onsses ou pâles a la baso;

40(47) Antennes noires i la basie;

41(46) Abdomen noir à l'extrémité;

42(45) Hanches noires, du moins les postérieures;

43.44) Tarière moins de la moitié de l'abdomen en longueur'; aréole du métathorax transversale................ 12, ovalis, 317. $V$

44(43) Tarière presque aussi longue que l'abdomen; aréole du métathorax de forme eonique..............

45,42) Toutes les hanches rousses; abdomen avec les segments 2 et 3 plus ou moins ronx............... 38. cornutis, 758 .

46(41) Abdomen roux à l'extrémité, ovale, déprimé; tarière courte........ 35. Mignaulti, 777. 
47(40) Antennes rousses ou pâles $\lambda$ la base, uvec ou suns unneu pâle;

48(a9) Abdomen noir a l'extrémité uvec ou sans taches blanches; $49(50)$ lice jume ................. 13. segnis, 317 . 50 (4) lince noiro;

$51(54)$ Tarière mussi longno que l'abdomon ou it pell pios;

52 .53) Hanshos noires; aréolo du métathornx transvorwile .............. 18. caudatus, 319 .

53(52) Hanches rousses; métuthorax a aréolo triangulairo, ses mucrons aux $u n-$ grles élurgris, sillonnés et coujués curr'́ment............... 52. truncatus, $n . s p$.

54(51) Turier'o courte, ì peine sortunte;

55(58) Articles 3, 4 et 5 des untennes à pou press égaux;

56 57) Métathorax inerme, ressorréa la baso. 41. constrictus, 779. 57(56) Métathorax oxcavé en arrière, mucroné aux angles.............. 10. subfuscus, 316 .

58(55) Articles des antennes 4 et 5 pius courts que 3; métathorax à areole conịuo. 45. acaudus, 780.

59(48) Abdomen à extrémité rousso ou jaunâtro;

60(65) Tarière de la moitié de l'abdomen environ;

61(62) 1er segment ubdominal noir, poli, brillant, lisse .................... 24. inflatus, 321.

62(61) lor segment abdominal roux, ou noir seulement à la baso du pédicule;

63(64) Métathorux fort et court, iner'me aux angles ................ 22. crassipes, 230 .

64.63) Métathorax allongé, fortemont mucroné aux angles............. 23. rotundiceps, 320.

65,60) Tariere a peine sortante; abdomen fortement atténué ì l'extıémité.... 46. attenuatus, 781.

66(15) Ecusson blane, juune ou roux ;

67(79) Abdomen ichneumonaire p..r scn extrémité, e'est-ì-dire à segments terminaux rétrectés do marière a rondre l'extremité aigruë ;

68(74) Ecusson blanc ou jaune pâle ;

69,70) Abuomen à extrémité rousse, sans tache.. 53. potens, n. sp. 
70(71) Abdomen i extrénité rousse tuchéo do jaune-pâle, lignes jaunes sur lo vertex. .................. 54. jocosus, $n .8 p$.

71(70) Abilomen à extrémitó noiro;

$72(73)$ 'lete ot thormx, noir ; tariere tres coute.............. 5.). brevicaudus, n. $s p$.

73 72, Tête et thorux, roux ...........56. Geddesii, n. sp. 74(68) Heusson roux;

75) 7i) Aklomen roux, sans tuches de noir.. 43. rubricus, 780 . 76 75) Abolomen plus ou moins tuché de noir ;

77(78) Abelomen noir a l'extrémité seulement. 57. fasciatus, $n . s p$. 78(77) ibdomen a bande noire a la base de tous les segments. ........ 44. alternans, 780 .

79(67) Abdomen amblytélaire par son oxtrémité, c'est-it-diro nvec los seginonts terminaux peu ou point rétractés do manière d laisser l'extrémité obtuse;

80(87) Abdomen noir a l'extrúnité;

81(84) Eerıssor blıne ou jumne-pále;

82(83) Antennes a articles renflés ì l'extrémité; hanches rousses. 28. planus, 322.

83(82) Antennes ì iuticles non renflés ì l'extrémité; les 4 hanches antérioures blanches............. 58. fraterculus, $n$. $s p$.

$8+(81)$ Keusson roux ;

85(86) Antenues grenues, fice entieroment noire................... 42. terminatus, 780

86 85) Antennes unies, fuco rousse sur. les côtés .............. 59. gracilicornis, $n$. $s p$.

$8780)$ Abdomen à extrémité rousse;

88,89) Thorax noil, écusson roux ......... 21. major, 320 89(88) Thorax voux, écusson blanc....... 27. robustus, 322 Males

1(4) Thorax et abdomen, noir;

2(3) Antennes avec un unneau blane........ 1. Blakei, 313. 3(2) Antennes sans anneau blanc.... 20. mucronatus, 319. 4(1) Thorax noir; abdomen plus ou moins roux; 5.37) Abdomen noir a l'extrémité; 
6(30) Fince noire muns mucune tuche;

7 (10) Abolomen portunt du noir a tons les segments;

8(9) Abrlomen noir uvec les kegments 2, 3 et 4 marginéx de poux nu sommet; a1temnes donsses en dessons.... (60. marginatus, $n, s p$.

udus, $n$. $s p$. desii, $n$. sp.

bricus, 780.

iatus, $n . s p$.

rnans, 780.

lanus, 322.

ulus, $n . s p$.

natus, 780

rnis, n. sp.

major, 320

ustus, 322 .

lakei, 313. hatus, 319 .
9(8) Ablomen i bundes ulternes noires et romsien .... .......... (61. similaris, $n . s p$.

10,7) Abrlomen roux ou nvec quelques segments entièrement roux, quoiqüo l'fièrement obscurein quelquetiois;

11(20) Lontes les latinches noires, les 4 premières quelquefois pûles ì l'extrémite;

12(13) Le + jambes untérieures pâles extérienroment; métuthorax mucronc. 20. mucronatus, 319.

1312 ) Les 4 jumbes antérienres ronsses;

14(17) Abdomen ì extrémité noire tachée de blane;

15 16) Euusson noir ; tête en cur'ć...... 32. cephalicas, 777.

16(15) Eeusson taché de blanc; têto détıécie en arrière des yeux............ 5. rectus, 305.

17 (14) Ablomen dextrénité noire sans tache de blanc;

18(19) Abilomen linéuire, ì côtés parallèles. 33. parallelus, 777.

19(18) Abtomen en ovalo; antennes longues....12. ovalis, 317.

$\mathbf{2 0}(25)$ Les 4 hanches antéricures ronsses, los postérieures noires ou rousses;

21(24) Hanches postéricures noires;

22(23) Hanches postérieures entièrement noires, leur's cuisses rousses uvee un unnenu noir ì l'oxtrémité........... 36. aciculatus, 778 .

23(22) Hanches postérieures noires on dessus. seulement, leurs cuisses plus ou moins obseures au milien..... 39. autumnalis, 779.

24(21) Hanches postérieures rousses; uréole dı métatholàx en carré..... 40. subspinosus, 779.

25(20) Les 4 hanches antérieures blanches, lcs postérieures noires plus on moins rousses all sommet;

26(29) Segments ablominaux 1 et 2 noir's;

27(28) Autennes filiformes, à articles allongés; 
gustrocelles distincis....... 41. constrictus, 779 . 2S(27) Antennes sétacées, légd̀rement grenues

gastrocelles indisiinets....... 62. capitalis, n. sp. 29(26) Segments abdominaux 2,3 et 4 roux, le pé-

dicule noir avec le sommet roux. 16. pubescens, 318 .

30(6) Face plus ou moins tachée de blan.; de jaune ou de roux,

31(36) Face blanche au dessous des antennes; 32(33) Hanches postérieures noires, les 4 antérieures pâles on dessous noires à la base .................. 14. impressus, 327.

33 32) Hanches postérieures rousies ;

34(35) Jones 1. ires, les 4 hanches antérieures rousses ................. 11. nitidulus, 317 . 35(34) Jures blanches, les 4 hanches antérieures blanches............. 17. albicornis, 318 . 36(31) Face noire avec des lignes orbitales blanches plus ou moins dilatées près du chaperon.............. 31. orbitalis, 776 . 37 (5) A!domen avec l'extrémité rousse; lo dernier sogment quelquefois plus on moins obseur ;

38(41) Toutes les hanches rousses ou jaunes; 39(40) Stigma noir, 1er segment abdominal noir................... 24. inflatus, 32 . 40 (39) Stigna fauve, 1or segment abdominal roux, la base du pédicule seulement noile................. 25. ruficornis, 321 . 41(38) Tontes les hanches pâles en dessous, plus ou moins noires en dessus; stigma noil ou brun foncé..... 26. pallicoxus, 321. 47. Phygadeuon de Guignard. Phygudeuon Guignardi, n. sp.

ㅇ-lıong. .36 pee. D'un bean noir foncé brillant; les orbites anıérieurs se prolongeant jusque sur le vertex, un anneau aux antennes, l'écusson, une ligne sur les bords latéraux du prothorax avec une autre au-dessous de l'insertion des ailes antéricures, blane; les mandibules avec le devant des jambes et des tarses an- 
terrieurs, roussâtres. I a ficce finement ponctuce. Antennes onroulées, à articles allongés, avec un anneau blanc au milien. Ailes hyalines, les nervures et le stigma brun-foncé. Métathorax pont:tué, légèrement pubescent, ses angles arrondis. Pattes noires, les épines de l'extı émité des jambes d'un testacé r'oussâtre. Abdomen linéaire, atténuć aux cleux extrémités, poli brillant, les sutures après les segments 1,2 et 3 enfoncées; tarière sortante, noire. - Ottawa (Guignard).

Nons dédions avec plaisir cette belle espèce à M. J. A. Guignard, zélé entomologiste d'Ottawa, qui en a fait la capture.

48. Phygadeuon choisi. Phygadeuon electus, n. sp.

q-Tiong. .31 pee. Noir, poli, brillant, avec les pattes rousses. Un anneau aux antennes, une ligne orbitale sur le vertex de chaque côté, une ligne sur les bords latéraux dı prothorax, une antre au dessous des ailes antélieures, une tache échancréo sur l'écussion avec les deux derniers segments de l'abdomen, blánc. Antennes enroulées, d'un brun roussâtre, avec un anneau pâle au milien et noires à l'extrémité. La tête, le thorax et l'abdomën finement et denéement ponctués. L'écusson aplati, poli, blanc, cette couleur blanche échanerée en avant: le métathorx avec ure aréole en carré arrondi en avant, la partie postérieure de ses flanes ruguense. Ailes légèrement enfumées, le stigma noir. Pattes rousses avec les hanches noires; cuisses postérieures ronflées, leur extrémité noire ainsi que celle de leurs jambes et leur's tarses. Abdomen assez court, poli, brillant, fort, ì pédicule court, les 2 dernier's segments blancs avec la tarière noire, celle-ci d peine sortante.-Ottawa.

Très rapproché de l'Ichneumon helvipes, Cress., mais s'en distinguent par sa taille trapue, son écusson blanc et les côtés des flanes de son métathorax qui sont ruguenx.

49. Phygadeuon fusiforme. Phygudeuon fusiformis, n. sp.

ㅇ-Tong. .26 pee. Noir avec l'abdomen roux; toute lá fáce y compris la bouche et le scape, noir. Tête transversale, plus large que le thorax; antennes longues, filiformes, unies, à aiticles o-Mars 188 s.

coxus, 321. euon Gui-

les orbites inneau aux protholax intérieures, s tarses an-

$$
\text { - Mars 188. }
$$


allongés, noires avec un annenu blane au deld du milieu. Thorax court, trapu, le métathorux à ponctuations confluentes, sans aréole au centre, mais a angles tuberculeux. Ailes subhyalines, le stigma brun, l'aréole grande, presque carrée, les écailles ulaires noires, un petit anneau roux à la base des 4 cuisses postérienres. Abdomen roux, poli, brillant, avec l'extrémité noire, le pédicule allongé, élargi et lisse a l'extrémité, le reste fusiforme daus son ensemble, le deruier segment tronqué; tarière de la moitié de l'abdomen environ. - Ottawa (Harrington).

Voisin du vulgaris, mais s'en séparant surtout par ses antonnes grềles et non enroulées.

50. Phygadeuon à-longues-zornes. Phygadeuon longicornis, n. sp.

- - Long. .25 pee. Noire avec l'abdomen roux. Ia fare sans aucune tache. Antennes fort longues, filiformes, non enroulées, noires avec un petit anneau blanc en dessus an delà du milieu. Thorax noir, sans aucune tache, le métathorax a lignes soulevées peu distinctes, ses angles postérieur's inermes. Ecailles alaires noires. Ailes hyalines, l'aréole fort grande, er. carré avec la nervure inféricure anguleuse, le stigma jaunâtre. Pattes d'un roux foncé, l'extrémité les cuisses, des jambes at des tarses des postérieures, noire. Abdomen court, déprimé, ovale, poli, brillant, à pédicule long et courbé, les segrments terminaux noirs, sans aucune tache; tarière forte, plus courte que l'abdomen.Ottawa (Harrington).

Espèce bien remaryuable par ses lóngues antennes, sa grande aréole et sa forte tarière.

51. Phygadeuon tête-no're. Phygadeuon nigriceps, n. sp.

q-Long. .22 pce. Noir, avec les trois premiers segments de l'abdomen roux. 'Tête en carré transversal, non très grossc, ontièrement noire, les palpes teints do roussâlre, ln face finement ponctuée. Antenues filiformes, assez longues, à peine enroulées, noires avec un anneau blane vers le milien. Thorax subcylindriqu, poli, brillant, a métathorax excavé postéricurement, la 
face postérieure rugueuse et bordée d'une carène, le métanotum poli, brillant, sans aréole distincte.. Ailes subhyalines, les nelvures brunes, les écaillettes blanches. Pattes noircs, les 4 antérieures avec les jambes et les tarses, roux, les postérieures ronsses avec l'extrémité des cuisses, des jambes et les tarses, noir. Abulomen en ovale allongé, déprimé, finement ponctué, les 3 prenier's segments roux, le reste noir, sans tache blanche a l'extrémité, le premier segment élargi au sommet, entièrement roux; tarière un peu plus courte que l'abdomen.-CapRouge.

Voisin de l'annulatus et du cincticornis mais se distinguant de l'un et de l'autre par la structure de son métathorix.

52. Phygadeuon ironqué. Phygadeuon truncatus, n. sp.

q-Long. .25 pee. Noir arec l'abdomen roux; tête large, transversale. Antennes longues, légèrement enroulées, rousses i la base avec les articles 3,4 et 5 allongés. Thorax poli, brillant le métathorax coupé carrément en arrière, mais excavé an milien et avec les angles mucroniformes, les lignes soulevées sur le dos très distinctes et formant un triangle an milien. Ecailles alaires jaune-pâle. Ailes sub-hyalines, le stigma brun-roussâtre. Pattes d'un beau roux c'air, sans aucune tache. Abdomen en ovale, déprimé, poli, brillant, le premier segment noir, fort élargi au sommet et régulièrement aciculé, les segments 2,3 et partic de 4 roux, lo reste noir, les derniers tachés de blanc. Tarière aussi longue que l'abdomen.-Ottawa (Harrington).

Espèce bien remarquable par la longueur de sa tarière et son métathorax tronqué carrément.

41. Phygadeuon constrictus, Prov. p. 779.

nigriceps,

ㅇ-Même coloration que dans le $\delta$; tarid̀e d peine sortante. Tandis que dans le $\delta$ les antennes sont rousses a la basc, elles sont a peine teintes de roussâtres dans la $q$ et quelquefois portent un anneau blanc au milieu. Les ailes sont plus foncés et le stigma porte une tache pâle à la base. Liabdomen est ovale, déprimé et à peine rétréci à l'extrémité-CapRouge.

53. Phygadeuon gai. Phygudeuon jocosus, n. sp.

q-Long. .43 pee. Roux et noir. Tête noire, avec la face, 
les jones, des lignes orbitules interrompnes en arriere des yeux, jaune; la fuce roussâtre au milien, de même que le scaje des antemnes en dessons. Antennes longutes, noires, avec un anneau jaune au milien. Thorax robuste, noir en avant et roux on ar. rièe, lo dos du mésothorax noir avee une tache rousse; l'écur. son et le post-écusson jaune. Ailes hyalines-jaunâtres, leurs écailles ronsses avec une potite ligne au dessous et les bords du prothorax, jaune-pâle. Pattes entièrement rousses, 'ins aucune tache. Abdomen allongé, roux, sans aucune tac'y:; finement ponctué; tarière moins du quart de l'abdomen, noire.-Ontario (Guignard).

Bien distincte par sa forte taille et ses couleurs gaies.

54. Phygadeuon queue-courte. Ply adeuon brevicaudus, n. sp.

q-Tung. .30 pce. Noir avec les pattes et les 3 premiers segments abdominaux roux. Ia face densément ponctuée, les mandibules avec les écailles alaires roussâtres. Antennes fortes, enroulies, brun teint de roux daris le bas avec un anneau blane au milieu. Métathorax densément et uniformément ponctué avec une uréole subpyranidale au centre, trouqué carrément en arrière, avec les angles submucronés ; écusson jaune-pâle, le postécusson roux. Ailes hyalines, iridescentes, les nervures et le stigma, brun. Pattes postérieures avec les cuisses et les jambes excepté à la bise et les tar'ses, noir ou brun-foncé. Abdomen en ovale-illongé, rétréci à l'extrémité, déprimé, les 3 premiers segments roux, le reste noir avec une grande tache blanche à l'extrémité, le premier segment élargi et lisse au sommet; tarière a peine sortante.-CapRouge.

Voisin de l'anmulutus, mais s'en distinguant surtout par sf. tarière beaucoap plus courte et la structure de son métathorax.

55. Phygadeuon de-Geddes. Phygadeuon Geddessii, n. sp.

f-Long. 38 pce. Roux varié de noir. Tête rousse; antennes longues, enroulées à l'extrémité, rousses à la base, jaunes au miliou et brunes a l'extrémité. 'Thorax finement ponctué, roux 
avec les sutures noires; l'écusson taché de jaune. Ailes hyalinesjaunâtres, le stigma roux. Pattes rousses, les postérieures avec les cuisses, excepté a la base, ot l'extrémité des jambes, noir. Abdomen roux avec les segments terminaux noirs, lo dernier taché de blanc en dessus ; pétiole lisse, sans carènes a son oxtrémité. Tarière noire, de moins du quart de l'abdomen.-Ontario (Geddes).

Voisin du rubricus, Prov., mais s'on distinguant par sa plus forte taille, ses antonnes rousses a la base et son abdomen terminé de noir.

Nous dédions avec plaisir cette belle espèce au Capitaine Geddes, de Toronto, qui en a fait la capture.

56. Phyga. uoin à-ailes-fasciées. Phygadeuon fasciatus, n. sp.

q-Long. 25 pce. Roux; l'extrémité des antennes, les environs de l'écusson, le thorax en dessous, les pattes en partie, avec l'extrémité de l'abdomen, noir. Fac: finement porctuée; antennes assez courtes, rousses a la base, et noires a l'extrémité. Thorax allongé, subcylindrique; le métathorax inerme, finement ponctué, avec une aréole conique au centre. Ailes passablement enfumées, avec une bande transversale claire a l'endroit de l'aréole; le stigma noir avec une tache pâle à la base; les écaillettes jaunâtres. Pattes rousses, les cuisses postérieures en dessus avec l'extrémité de leur's jambes et leurs tarses, noir plus ou moins foncé. Abdomen allongé, atténué a l'extrémité, les 3 premiers segments roux avec le reste noir; tariere a peine sortante; le premier seginent lisse et médiocrement élargi au sommet.-CapRouge.

Voisin du rubricus, mais s'en distinguant par l'aréole de son métathorax, ses ailes à bande hyaline etc.

57. Phygadeuon potit-frère. Phygadeuon fraterculus. n. sp.

९-Long. .20 pce. Roux pâle arec la têto ot le thorax on partie, noir. Lo chaperon, les mandibules, les palpes, les écailles alaires avec une ligno en avant, un anneau aux antenues, les 4 hanches antérieures avec leur's trochanters, blanc. Antennes 7 - $\therefore$ vril 1885. 
noires, à artioles allongés of unis à la base, plus épatisses a l'extrénité, avec un petit anneau blanc an milieu, lo scape avec la base plus on moins ronx en desions. Thorax tinement pouetue, les lobes latéranx du mésothoirax, les environs de l'écusson, avec les sntures des flances, blanc. Jiécusson et le post-écusson, blane. Ailes hyalines, iridescentes, le stigma brun-jamâtre. Los pattes postérjeures avec le sommet des hanches, des cuisses, des jambes et les tarses, brun plus on moins foncé. Abdomen en ovale allongé, déprimé, le premier segrment pen élargi an sommet, les segments terminalux noirs marqués de bianchâtre an sommet; tarière de la moitié do l'abdomen environ.-Ottawa (Harrington).

Voisin lu planus par sal coloration, mais s'en distinguant par sa plus petite taille et ses hanches antípieures blanches.

58. Phygadeuon gracilicorne. Phygadeuon gracilicornis, n. sp.

૧-Tong .20 pee. D'un roux sale plus ou moins brunâue. La tête noire, transversile, plus large que le thorax, des lignes orbitales ronsies on avant jusque sur le vertex. Antennes longues, grêles, à articles allongés, avec ni? petit anneau blane au milieu

en dessus. Tholax trapu, roux sale, avca les environs de l'écusson et les sutures des flunes, noir ; écusson très convexe, métathorax finement ponctué, à aréole centrale peu distinete, ses angles subGpineux. Ailes hÿalines, lo stigna brun-junnâtre, les écaillettes roussâtres. Pattes comme le eorps d'un romx aalo plus ou moins teint de brun, les trochanter's noirs. Abdomen eourt, épais, en ovale, le post-pétiole finement ponetué on aciculé, les gastrocelles distincts, l'extrémité br'un-foncé obsurément tachée de blanchâtr'e ; tarière à peino sortante.-Ottawa I Harrington.

Voisin du terminulus, mais s'en sćlarant par ses antennes grêles, à articles allongés.

59. Fhygadeuo: marriné-de-rcux Pliygadeuon marginatus, 11. sp).

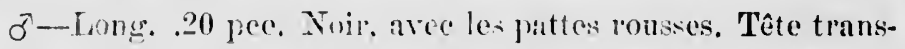
versale, phis lirge que le thoris, la tiree tinement ponctuée, le labre, les mamlibules, los jalyes aroe les antennes. jamue-poussâtre, les desnières bimatres en dessins, filitormes. Thorax tinement ponctié, lo métathorax avec une aréole centrale de forme 
conique, inerme anx angles. Ailes hyalines, lo stigma brun, les nervures a la base avec les écaillettes, blanc. Pattes roux-jaunâtre, les 4 trochanters antérienes blanes, l'extrémité des cuisses, des jambes et des turses pontérieur's, noire. Abrlomen allongé, linéaire, noir, les segraents 2-4 marginés de ronx all sommet, lo 2e longr, ponctué-lugueux à la base, à gastrocelles roux bien distincts ot portant un pli transversal à son milien, l'extrémité noire, sans au-: eune tache.-Ottawa (Marrington'.

Fispece bien remnirquable par la forme de son seeond segment abdominal.

60. Phygadeuon similaire. Phygudeuon similaris, $\mathrm{n}$. sp.

万ৈ-Long. 20 pee. Noir avee les pattes rousses. Tête transversale, plus large que le thoma, la fice noire sans ancine tache. Antennes à articles allonğés, unis. Thorax assez court, épais, gibbeux en avant, le métathorax à lignes sonlevées distinctes, mais sans former une aréole au centre, les angles inermos. . Ailes hyalines, le stigma brun, l'aréole grande, les écaillettes blane pur. Pattes rousses, les 4 trochanters antérieurs blancs, les postérieurs noirs, les henches postérienres a la base, le sommet des cuisses, leurs jambes et leur's tarses, noire. Abromen allongé, linéaire, noir avec une bande rousse an sommet des 4 premier's segments, le terminal avec mo tache blanche-Ottawa (Harrington).

Voisin par sa coloration dı marginutus, mais s'eu séparant distinctement par la forme de son thorix.

61. Phy gad auon ca pital. Plygudeuón capitalis, n. sp.

б-Tong. .20 pee. Noir brillant, avee l'abdomen taché de jaune-roussâtre. Tête ğrosse, renfléo en arrière des yenx. Les mandibules, les palpos; le scape en dessons, les éciilles alaires, les 4 hanches antérieures arec lenrs trochanters, blanc. Antennes moyennes, sétacées, gr anulenses a l'extrémité. Thoìa finement ponctuc, le métathn'ax à lighnes soulevées distinctes, sos angles inermes. Ailes hyalines, les nervures trunes, pâles à la base, le stigma brun. Pattes romx-jaunâtre, les pestérienres plus ou moins obscures sur les chisises, l'oxtrénité des jambes, les talrses ef la baso des hanches. Abelomen noil a la base et à l' xtrémité, les

Tête transprictuée, le anne-joushorax finede forme 
segments 3 ot 4 avec le sommet du 2 e d'un roux-jaunâtre sule, le 2 e segment uvec les gratrocelles distincts et faisant suite au postpétiole pour s'élargir continument jusqu'd son sommet.-Ottawa (Harrington).

Ses joues renflées en arrière des yeux le distinguent des espèces voisines.

Phygadeuon nitidulus, Prov. p. 317, $\sigma^{7}$.

c-Long. 20 pce. Noir, poli, brillant; le chaperon, les mandibules, les antennes, les écailles alaires avec les pattes, d'un roux forrugineux. Antennes épaissies ot légèrement obscurcies a l'extrémité, à articles courts, grenues, le $3 e$ article pas plus long que le 4e. Thorax allongé, paralldle, lo métathorax à aréole centrale de forme conique. Les cuisses légèrement obscurcies au milieu. Abdomen cylindrique, convexe, atténué a l'extrémité, le segment terminal obscurément roussâtre; tarière d peine sortante.-Vancouver (Fletcher).

Nous ne pensons pas faire erreur en rapportant cette $f$ a notre $\sigma^{7}$ nitidulus, bien qu'elle vienne de Vancouver et que le nôtre ait été capturé au CapRouge; la coloration, la forme, la la taille etc., sont à peu près identiques dans les deux individus.

Gen. Hemiteles, Grav. p. 323 et 781.

Aux 16 espèces décrites, ajoutez les 5 suivantes.

17. Hémitèle mucroné. Hemiteles mucronatus, n. sp.

ठ-Long. .23 pce. Noir, poli, brillant. avec les pattes rousses; les palpes avec les mandibules roussâtres, les écuilles alaires blanches; la face finement pubescente. Tête grosse, épaisse en arrière des yeux. Antennes filiformes, de longueur moyonne. Métathorax à lignes soulevées très saillantes, ses ingles postérieurs mucronés. Ailes légèrement obscures, plus claires a la base, le stigma noir avec une tache pâle à la base; aréole incomplete, la nervure extérieure manquant. Pattes d'un beau jaune miel y compris les hanches et les trochanters, les postérieures avec l'extrémité des cuisses, les jambes et les tarses, brun-foncé, Abdomen entiệrẹment noir, linéaire, finement 
e sale, le o au post-Ottawa zuent des

les manl'un roux ies a l'exlong que intrale de lieu. Abment terte.-Vansette ㅇa a et que le forme, la ux indi-

นs, n. sp.

$s$ puttes écuilles grosse, longueur es angles claires a réole inun beau les pos: 8 tarses, finement

pontué à la base et poli au sommet; le post-pétiole élargi et avec un profond sillon de chaque côté, formant une petite carène en dehors.-Ottawa (Guignard).

Espèce bien remarquable par son métathorax mucroné et la structure de son abdomen; le $2 \theta$ segment est ponctué-rugueux, comme chagriné.

\section{Hémitèle faible. Hemiteles debilis, n. sp.}

ठ-Long. .13 pce. Noir avec les pattes roux-jaunâtre; les mandibules, le scape en dessous et la base des antennes a la suite du scane, roux plus ou moins prononcé. Antennes filiformes, de longueur moyenne. Thorax finement ponctué, les écailles alaires noires, le métathorax rétréci, avec lignes soulevées distinctes. Ailes hyalines, le stigma brun avec une tache pâle d la base, l'aréole incomplète, les nervures brunes, blanches a la base. Les hanches postérieures plus ou moins obscures a la base. Abdomen linéaire, poli, brillant, noir sans aucune tache avec les 2 premiers segments finement aciculés, le premier passablement élargi au sommet, ses tubercules latéraux distincts. - Ottawa (Harrington).

Se distingue du parvus par la stucture de son abdomen et la forme de son thorax.

\section{Hémitèle géant. Hemiteles gigas, n. sp.}

$\sigma-$ Long. .30 pce. Noir avec l'abdomen plus ou moins roux. La face noire suns aucune tache, finement ponctuée, le chaperon soulevé en tubercule. Antennes assez longues, sétacées. T'horax densément ponetué, le métathorax ponctué-rugueux portant une carène transversale ì son sommet et une autre vers le milieu qui se courbe en avant à la ligne médiane. Ailes hyalines, le stigma noir, l'aréole incomplète, les nervures brunes, blanches à la base, avec les écaillettes noires. Pattes rousses, toutes les hanches, les postérieures avec leur's trochanters, l'extrémité des cuisses, la base et le sommet des jambes et les tarses, noir. Abdomen en ovạle allongé, déprimé, densément ponctué, le 1er segment noir, sțrié-r'ugueux avec 2 petites carènes peu prononcées, les segments 2 , 3 et 4 d'un roux sale, avec la marge apicale soulevée et lisse, les segments terminaux noirs.-Ottawa (Harrington). 
Fspèce bien remarquable par sa tailip et ln structure de ses segments abdoniuaux.

20. Hémitèle déolive. Herniteles declieus, n. sp.

q-Long. .20 pee. Noir; tête en earré truasversal, aussi large que le thorux. Antennes longuen, plus épuisses a l'extré. mité, noir on brun-foncé; la finco finement ponctuéc, le chuperon soulevé en tubercule. Thorux gibbeux on avint, déclive pos. térieuroment, lo métuthorux à lignes soulevées distinctes; les écailles ulaires blanc-jamatre. Ailes hyalines, lo stigma brun, grand; uréolo incomplète, la nervure extérieure supérieure munquant. Pattes rousses y compris les hanches, les postérieures avec les genoux, l'extrémité des jambes et les tarses, brun plıs on moins foncé. Abdomen allongé, poli, brillant, noir avec les seginents 2 et 3 roux, le premier ullongé, assez fuibloment élurgi all sommet où il est poli et ponctué, l'extrémité de l'abelomen sub-comprimée et tronquée; tarière à peine sortunte. - Ottuwa (IIarrington).

б-Avec los hanches postérieures, leur's cuisses et lours tarses, noir plus ou moins foncé, leur's jambes obsc'ures plus on moins roussûtres uu milieu. Abdomen ullongé, poli, brillant, plus épais à l'extrémité, les segmonts 2 et 3 d'un roux sale, lo 20 avec uno bande noịe au sommet.

Voisin du longicornis, mais s'en distinguant à première vue par la brièveté de sa tarière.

Capturé par nous à Bécansour; la forme et la texture des téguments ne permettent pas de douter que ce ne soient là les deux sexes de la même espèce.

21. Hémitèle aciculé. Hemiteles aciculatus, _. sp.

$\delta^{x}$-Long. .22 pec. Noir avec les pattes et l'abdomen plus ou moins roux. Tête en carré, renflée en urièro des yeux. I Ies ma1dibules, le scape en dessous avee les pattes, roux jaunâtre. Thorax robuste, le métathorax à lignes soulevées distinctes. Ailes hyalines, les nervures noires, le stigma noir avee une tuche pâle a la baso; aréole incomplate. Iues hanches postérieures avec l'extrénité de leurs euisses, noir, leurs tarses bru- 
nât:es. Ablomen noir avec les negments 3,4 ot partie de 5, roux, 1 ot 2 noirs et finoment nciculés, le promior largo nu sommot. Ottuwa (Hurriugton).

Bien remurquable par les aciculations de son abdomen.

Vur. Hanches nostérieures rousses, noires à ln base seulement, le 2e segment anssi roux.

\section{Gen. Cryp'rus, Fabr. pp. 329 et 783.}

Aux 32 espèces décrites, ajoutez les 23 qui suivent. Ia clef ci-dessous, en séparant les mâles des femelles, permettra do distinguer plus facilement ces especes les unes des autres.

\section{Finelues.}

1(10) Thorax ot abdomen, noir;

2(5) Pattes ronsses avec les hunches noires;

3(4) Tarses antérienr's nllongứs; turiero aussi longue quel'abdomen, colui-ci allongé et atténué à l'extrémité ............. 1. proximus, p. 330.

4(3) Turses antérieur's à artieles 2,3 et 4 courts, cordiformes ot épineux; abdomen plus court, plus renflé a l'extıémité.... 30. robustus, 783 .

5(2) Pattes rousses nvec les hanches ruusses, clu moins les postérioures;

6(7) Antennes noires, sans annenu pâle; facco a puboscence argentéo ........ 3. sericeifrons, 331.

7(6) Antennes noires avee un annenu pâle;

8(9) Aréole des ailes en carré, ses côtés parallìles............................ 2. velox, 330.

9 (8) Ar'úole pentagonale, ses côté rapprochés supéricurement .......... 33. pentagonalis, n. $s p$.

10(41) Thorax noir, abdomen plus ou moins roux;

11(32) Abdomen roux avec l'extrémité noirc ;

12(21) IIanches postérioures noires;

13(16 Antennes sans annean pâle; les 3 delniers segments abdominaux noirs;

14(15) Talres postérieur's blanes au milicu; pattes noires. ............. 13. 'rufoannulatus, 335. 
15(14) Tarses postérieurs brun-roussâtre; pattes rousses..................... 16. apicatus, 336.

16(13) Antennes aveo un anneau pâle;

17(20) Taridre du quurt de l'abdomen environ; pattes postérieures brunes ;

18(19) Mótathornx légèremont excavó en arridre, ses angles sub-épineux; trille plus forte; tarses postérieurs blancs....... 22. nontivagus, 338.

19(18) Métathorax non excavé, inerme; taillo plus petite ; tarses postérieurs bruns, 23. annulatus, 339.

20(17) Taridro aussi longue que l'abiomen; pattes postérioures rousses, leurs tarses blancs au miliou;

21(12) Hanches postérieures rousses ;

22(23) Antennes sans anneau pâlo: taridro aussi longue que l'abdomen ......... 34. brevicornis, n. $s p$.

23.22) Antennes avec un anneau pâle;

24(29) Aréole des ailes en curré, a cótés paralldes;

25(26) Ecusson taché de blanc; métanotum ponctué entre les 2 carènes transversales ................. 27. extrematis, 340 .

26(25) Ecusson sans tache, noir :

27(28) Sommet du pédicule avec une petite fossette; 2 e segment aciculé longitudinalement au milieu................. 35. sordidus, $n$. $s p$.

28(27) Sommet du pédicule lisse, 2 e segment non acicule..................... 26. nuncius, 240 .

29 ,24) Aréole pentagonale, ses côtés rapprochés supérieurement;

30 (31) Pattes variées de roux et de noir; antennes épaissies d l'extrémité... 36. spissicornis, $n$. sp.

31(30) Pattes entièrement d'un roux pâle, y compris les hanches et les trochanters. 37. mellipes, n. sp.

32(11) Abdomen roux avec l'extrémité rousse;

33(34) Antennes avec un anneau pâle; tarière grêle, plus longue que l'abdomen. 38. longicaudus, n. sp.

34(35) Antennes sans anneau pâle;

35(36) Aréole grande, d côtés parallèles; méta- 
notum fortement rugueux.... 13. rnfosnnulatus, 338.

36(35) Aréolo pentugonale, ses côtés rapprochés supórieurement ;

37(40) Pattos noires;

38(39) Fuce avoc un tubercule au milieu; taricre unssi longue que l'ablomen. 11. Americanus, 333

39(38) Faco sans tubercule médian, fortement ponctuéo; taridro courte......... 12. limstus, 334.

40(37) Pattes rousses avoc los hanches noiles. 14. persimilis, 395.

41(10) 'Thorax plus ou moins roux; ubdomen roux;

42(49) Aréolo pentigonulo;

4:(44) Métuthor'ux roir avec taches blanches. 28. atricollarig, 341

44(43) Métathorax roux, sans taches blauches;

45(49) Abelomen taché de blanc à l'extémité ;

46 47) Hunches untérioures, collior, écusson, tachés de blunc ................ 39. ormatus, $n$. sp,

47(46) Hanches antérioures, collior, écusscn noir................ 40. erythropygus, $n$. $8 p$.

48(45) Abdomen sans tacho do blanc d l'extrémité ou n'en por'tant qu'uno fort petite, son extı émité obtuso........ 41. amblytelarius, $n$. sp. 49(42) Arćolo on curr'é ;

51(50) Abdomon amblytélaire ; écusson roux. 29. affabilis, 341. 50(51) Abdomon ichuoumonaire; écusson blanc. 30. rufus, 349. Males

1(20) Thorax ot abdomen, noir;

219 , Ecusson noir ;

3(4) Pattes noires, la fuco et los 4 banches antérieures tachées do blanc...... 42. incognitus, n. sp. 4( 3 ) Pattes rousses;

5 ( 8 ) Hanches noires, les 4 antérioures tachées do blanc;

6( 7 ) La fuce ot le collior, blanc...........43. collaris, $n$. sp. 7 (6) Isa face ot lo collier, noir..........44. dubius, $n$. sp. 8(5) Hanches rousses;

9(12) Aréole des ailos on carré, grande;

10(11) La bouche seule blanche; orbites noirs. 4. osculatus, 331. $11(10)$ Ja bouche nvec de larges or:bites antérieur's, blanc............. 5. circumcinctus, 331 
12(9) Aréole des ailes pentagonale, petite;

13(16) Toutes les hanches rousses ;

14(15) La face blanche inférieurement; jambes postérieures rousses... ...... 33. pentagonalis, $n . s p$.

15(14) De petites lignes orbitales seulement blanches; jambes et tarses postérieur's noirs; taille plus forte ............45. luctuosus, Cress.

16(13) Les 4 hanches antérieures blanches;

17(18) Collier noir, face noire, à puboscence argentée ................... 3. sericeifrons, 331 .

18(17) Collier blanc, face blanche...... 6. eburneifrons, 332.

19(2) E'usson blanc; les hanches postérieures noires................... 7. scut 3llatus, 332.

20(23) Thorax noir, taché de blanc su.r le métathorax, abdomen noir, varié de roux;

21(22) Tarses postérieurs blanẹ au milieu; extrémité do l'abdomen noire.......... 8. exilis, 332.

22(21) Tarses postérieurs jaunes; abdomen rouxjaunâtre à l'extrémité .......... 9. contiguus, 333.

23(67; Thorax noir, sans taches de blane au métathorax; abdomen plus ou moins roux;

24(25) Abdomen noir avec une bande rousse au sommet de tous les segments.... 31. soriculatus, 784 .

25(58) Abdomen roux avec l'extrémité noire;

26:53) Hanches postérieures noires ;

27(50) Face noire;

28(45) Antennes sans anneau pâle;

29(38) Aréole des uiles en carré, ses cồtés parulieles;

30(35) Ecailles alaires noires;

31(34) Pattes noires, du moins les p̣ostérieures, . leurs tarses blancs au milieu;

32(33) Ecusson noir; métathorax fortement rugueux ........ $\quad . . . .1$ 13. rufoannulatus, 335.

33(32) Ecussor: blanc; métathorax non rugucux.................. 46. pubescens, $n . s p$.

34(31) Pattes rousses; métathorax à peine ruguenx .................. 18 Canadensis, 337. 35,30) Ecailles alaires blanches; 
36(37) Thorax grêle, fort allongé, taillo plus grande .................... 16. apicatus, 336 .

44(43) Métathorax court et large, point de lignes chaperon.................... 49. ignotus, $n . s p$.

37 36) Thorax court, trapu, taille plus petite.. 17. cinctus, 336 . 38(29) Aréole des ailes pentaģonsle, ses côtés rapprochés supérieurement;

39,40 , Les écaillettes et les hanches postérieures, noir ................... 47. linearis, $n . s p$. 40(39) Les écaillettes blanches, les hanches postérieures rousses;

41(42, Scape sans tache, nervures des ailes blanehes a la base................ 48. perditus, $n . s p$.

42(41) Scape roux en dessous;

43(44) Métathorax allongé, subcylindrique, avec une petite aréole étroite au eentre, orbites antérieur's blancs, dilatés ver's le orbitales blanches........... 50. segregatus, $n . s p$.

45. 28) Antennes avec un anneau pâle;

46(49) Ecusson noir, sans tache;

47(48) Jambes postérieures sans anneau blane à la base................... 24. imitator, 319 . 48(47) Jambes postérieures avec un anneau blanc; ì la base.... ............ 51. 3-annulatus, $n$. $s p$.

49(46) Ecusson blanc; hanches postérieures noires.................... 25. notatus, 340 .

50,27) Face blanche;

51,52) Scape noir, les 3 derniers segments abdominaux tachés de blane.......... 52. gracilis, n. $s p$. 52(51) Scape blanc en dessous, le pénultième segment à peine taché de blanc ...... 53. rectus, $n . s p$.

53(26) Hanches postéricures rousses;

54(55) Face noire; écusson blanc; les mandibules seulement blanches.. .... 54. albonotatus, n. $s p$. $55(54)$ Fuce blanche, ou notrblement tachée de blanc; 56 57) Tarses postérieur's blancs......... 32. elongatus, 784. $5756)$ Tur'ses postérieurs brun-roussâtre. 55. mellicoxus, $n . s p$. 50(25) Abdomen roux avec l'extémité r'ousse; 
59(60) Aréole des ailes en carré....... 11. Americanus, 333. 60(59) Aréole des ailles pentagonale;

61(64) Antennes rousses;

62.63) Abdomen linéaire; tête fortement renflée en arrière des yeux........... 20. ruficornis, 338 .

63(62) Abdomen élargi à la suite du pédicule; tête ordìnaire $\ldots \ldots \ldots \ldots \ldots \ldots \ldots . .19$. fungor, 337 .

64'61) Antennes noires;

65,66) Ecusson noir; jambes postérieures rousses...................... 15. mundus, 336 .

66(65) Ecussson blanc; jambes postérieures noires.................. 21. nigricornis, 338.

67(23) Thorax plus ou moins roux, abdomen roux;

68(69) Les 'í hanches antérieures blanches; métathorax roux avec taches jaunes, ou noir avec taches rousses ....... 28. atricollaris, 341. 69(68) Toutes les hanches rousses; métathorax roux, sans taches; abdomen taché de blanc à l'extrémité............... 30. rufus, 342 .

33. Crypte à-aréole-pentagonale. Cryptus pentagonalis, n. sp.

우 Long. pee. Thorax et abdomen, noir; pattes rousses y compris les hanches et les trochanters. La face finement ponctuée, le labre et les mannibules roux-blanchâtre. Antennes longues, filiformes, à articles allongés, noires avec un petit anneau blane au dela du milieu. Thorax allonge, peu robuste, le métathorax à aréole centrale peu distincte. Ecailles alaires blanches. Ailes hyalines, avec les nervures et le stigma, noir, l'aréole pentagonale, ses côtés rapprochés supérieujement. Pattes rousses, les cuisses avec les jambes et les tar'ses postérieur's plus on moins obscurs. Abdomen allongé, poli, brillant, le premier segment dilaté a l'extrémité avec un petit sillon, les segments terminaux avec une petito taehe blanche en dessus. Tarière aussi longue que l'abdomen.-CapRouge.

$0^{7}$-Avec la face, excepté une grande tache au dessous des antennes, le scape en dessous et les trochanters antérieurs, blanc.

Voisin du velox et s'en distinguant surtout par la forme de son arćole. 
44. Crypte cornes-oourtes. Cryptus brevicornis. n. sp.

o-Long. .40 pce. Noir avec l'abdomen roux. Tête en carré, épaisse en arrierre des yeux, la face entièrement noire. Antennes plus courtes que d'crdinaire, plus épaisses a l'extrémité, noires, obscurément roussâtres dans le bas. Thorax noir, sans auciune tache, le métathorax finement rugueux. Ailes subhyalines avec les nervures et lo stigma, noir, l'aréole assez petite, pentagonale, beaucoup plus étroite supérieurement, la nervure cubito-discoïdale sans appendice. Pattes d'un roux obscur, les antérieures aveo les hanches et les cuisses, noir, les 4 cuisses antérieures excepté a la base, l'extrémité des postérieures, avec leurs jambes et leurs tarses, d'un noir roussâtre. A.bdomen fort, avec les 3 premiers segments roux, le reste noir avec une tache blanche à l'extrémité, le premier segment élargi au sommet avec un sillon de chaque côté; tarière de la longueur do l'abdomen.Bécancour.

L'abdomen vu de côté forme une massue à son extrémité; bien remarquable par le roux sombre de sa coloration et la forme de ses anteunea.

35. Crypte sale. Cryptus sordidus, n. sp.

\$-Lيng. .45 pce. Noir avec les pattes et l'abdomen roux. Tête en carré transversal, la face finement ponctuée, ontièrement noire. Antennes a articles allongés, avec un large anneau blanc au milieu. Thorax finement popctué, le métathorax strié longitudinalement entre ses 2 carènes transversales, les écailles alaines noịres. Ailes hyạlines, l'ạcéole grạnde, en carré, les nervures noiles. Pattes rousses, les hąnches antérieures avec l'extrémité des cuisses posterieures, le tiers apical de leur's jambes ot lenrs tarses, noir, les derniers blancs au milieu. Abdomen fusitorme, a pédicule grêle, dilaté ạu sommet et portant une petite fossette; le 20 segment s'élargissant de la base au sommet, aciculé au milieu, les segments 1 excepté a la base, 2 et 3, d'un roux sale, le reste noil avec une tache blanche ver's l'extrémité; tarière un peu plus courte que l'abdomen.-Ottawa (Harrington).

Bien distinct de l'extrematis, par la forme de son abdomen, se coloration etc. 
30. Crypte à-cornes-épaissts. Coyptus spissicornis, n. sp.

\&-Long. .28 pce. Noir avec les pattes et l'abdomen roux. Tête en carr'é transversul, la ficce finement ponetuée. Antennes longues, à artieles épaissis au sommet, portant un anneau blanc au milieu et distinetement plus épaisses, au delà de cet anneau. Thorax grêle, allongé, le métathorax avec une carène au sommet et 2 autres longitudinales se rapprochunt a la base. Ailes hyalines, l'aréole pentagonale, les nẹrvures brunes. Pattes rousses, les hanches antérueures, toutes les cuisses au milieu, l'extrémité des jambes postérieures, noir plus ou moins foncé; tarses postérieur's roux, bruns aux extrémités. Abdomèn en massue, les 3 preniers segments d'un roux pâle, le reste noir avec une tache blanche sur le dernier ; tarière presque ausọi longue que l'abdomen.

б-Avec le labre, les orbites antérieurs, les palpes, iєs joues, l'écusson, les 4 hanches antérieures et leurs trochanters et les tar'ses postérieurs au milieu, blanc. Äbdomen grêle, les segments 2,3 et 4 roux, le reste noir.-Bécancour.

Bien distinct par ses antenues épaissies à l'extrémité et sa forme grêle.

37. Crypte à-pattes-jaunes. Cryptus mellipes, n. sp.

o-Long. .25 pce. Noir avec les pattes d'un beau jauncmiel; le labre avec la base des antennes en dossous, roussâtres. Antennes à articles allongés avec un anneau blane vers le miliou. Thorax allongé, les écailles alaires blanches. Ailes hyalines, l'aréole pentagonale, les nervires brunes. Abdomen fusiforme, épaissi à l'extrémité, les 3 premiers segments roux, le reste noir avec, une tache blanche sur les deux derniers; tarière aussi longue l'abdomen.-Ottawa (Harrington).

Bien distinct par ses pattes rousses et ses écailles alaires blanches.

38. Crypts à-longue-queue. Cryptus longicaudus; n. sp.

o - Ionng. .45 pce. Noil avec l'abdomen roux. Tête on carré, épaissio en arrid̀e des yeux ; la fuce tiıement ponctuée et légèrement pulescente. Antenucs longues et fortes, noires avec un an- 
neau blane vers le milieu. Thorax allongé, le métathorax plus fortement ponctuć que le reste, sans lignes soulovées bien distinctes. Ailes hyalines, a aréole en carré, les nervures noires, les écaillettes blanches. Pattes rousses, les hanches noires, les cuisses plus ou moins obscures au milieu. Abdomen entierement roux, épaissi, a l'extrémité, le premier seğment très finement ponctué; tarière beaucoup plus longue que l'abdomen.-Ottawa (Harrington).

Espèce bien remarquble par sa longue tarière et l'anneau blanc de ses antennes.

39. Crypte à-écusson-blanc. Cryptus scutellatus, n. $s p$.

o Long. .30 pce. Roux avac la tête et partie du thorax, noir. Face roussâtre, finement ponctuće. Les orbites antérieurs, les joues, un anneau aux antennes, le collier, les écailles alaires, un point en avant; une ligne au dessous, l'ćcusson avec le devant des hanches antérieures, blanc. Thor'ax presque lisse, le métathorax à lignes soulevécs peu distinctis, le prothorax avec le dos du mésothor'ax, noir, lo reste "'un roux pâle. Ailes hyalines, les nervures jaunâtres, l'aréole grande, en carré. Pattes rousses, les postérieures plus ou moins obscures à l'extrémité des cuisses, cies jambes et sur les tarses, ceux-ci blanes au miliell. Abdomen roux, fusiforme, a pédicule lisse, les 3 dernier's segments noirs, le ter. minal avec une grande tache blanche en dessus. Tariere plus courte que l'abdomen. - Ottawa (Guignard:.

Espèce bien distincte par sa coloration.

40. Crypte àcroupion roux Cryptus erythropygu', n. sp.

o -Long. .23 pce. Roux avec la tête ot lo thorax en partie, noir. Tête transversale, la face trè̀ finement ponctuée. Les mandibulos avec le scape en dessous d'un roux obscur. Antennes filiformes, noires avec un anneau blanc au dela du milieu. Los pro et mésothorax noirs avec le métathorax roux. Euailles alaires blanches. Ailss hyalines, iridescentes, avec lo stigma et les nervures jaune-brunâtre, l'aréole pentagonile. Pattes rousses, $\boldsymbol{y}$ cumpris les hapaches et les trochanter's, les postérieures avec les 
cnisses et les jambes plus ou moins obscurcies. Abdomen en ovale, le premier segment dilaté au sommet, le 2 e crmpanuliforme, les 3 premiers roux avec lo reste noir, le dernier tachó de blanc en dessus. Tariè'e aussi longue qu'de l'abdomen.Ottawa (Gnignard).

Bien distinct du précédent par sá forme plus grêle et s\& coloration.

41. Crypte amblytélaire. Cryptus ambiytelarius; n. sp.

으-Long. .28 pce. Roux avec la têto et pairtie dü thorax, noir. Tête noire, transveirsale, les orbitess antérieurs, dilatés sur lo vertex, un anneau aux antennes, une tache sur le collier, les bords latéraux du prothorax, les écailles alaires, le post-écusson, les 4 trochanter's antérieurs, avec un anneaú aux tarses postérieurs, blanc. Antennes filiformes, noires, avec un anneau blanc en dessus au delà du milieu. Dos du thorax noir, avec l'écusson et le métathorax roux. Ailes hyalines, iridescentes, les nervures brunâtr'es, l'aréole pentagonale. Pattes rousses, les 4 hanches antérieures plus ou moins blanchâtres, les genoux des puttes postérieures avec leurs jambes et leurs tarses, plus ou moins obscur, les jambes avec un petit anneau pâle près de la base. Abdomen déprimé, ovale, large, roux avec l'extrémité noire, sans tuches ou n'en portant qu'une fort petite; tarière à peine de la moitié de l'abdomen en longueur.-Bécancour.

Var, Antennes roussâtrés lá bäsè.

Espèce bien distincte par sa coloration. La forme de l'aréole des ailes empêche surtout de la confondre avec l'affabilis, Cress.

\section{Crypte inconnu. Cryptus incognitus, n. sp.}

ఠ̆-Liong. .30 pce. Noir avec courte pubescence blantlihtro; la face, les mandibules, les palpés, le scape en dessous, les écail: les alaires, une petite tache en avant, les 4 trochanter's antérieurs avec leurs hanches en partie, blanc. Antennes assez courtes, fortes, sétacées. Métathorax à lignes' soulevées distinctes formant une aréole centrale au milieu. Ailes hyalines avec les nervures noires, l'aréole pentagonale, Puttes noires, les 4 jambess ạtu. 
rieures plus ou moins jaunâtres en avant. Abdomen allongé, grêle, l'avant dernier segment étroitement marginé de blane au sommet.

\section{Capturé un spécimen à Ste-Angèle de Laval.}

43. Crypte a-collier-blanc. Cryptus collaris, n. sp.

$\sigma^{7}-$ Lóng. 35 pce. Noir avec les pattes rousses. La face excepté une tache médiane au dessous des ante: $\mathrm{n}$ s, les mandibules, le scape en dessous, le collier, lès écuilles alaires, un point en avant, une petite tache au dessous, d'un blane d'ivoire. Antennes courtes et fortes, sétacées. Thorax robuste, lo métathorax avec une aréole allongée au centre. Ailes hyalines, à nervures noires, l'aréole pentagonale. Pattes rousses, les hanchos noires, les 4 antérieures plus ou moins tachées de blane en dessous. Ábdomen allongé, le post-pétiole avec une petite fossette au sommet; le segment pénultième marginé de blanc.

Capturé un spécimen à Ste-Gertrude. Bien distinct par sa coloration.

\section{Crypte douteux: Cryptus dubius, n. sp.}

$\sigma^{3}$-Long. .60 pue. Noir, poli, brillant, avec les pattès jaunemiel. Face fortement ponctuée, toute noire. Deux petites lignes orbitales páles au dessus des antennes, celles-ci noires avec un anneau jaune oh dessous seulement. Ecailles alaires roussâtres. Aréole centrale du métathorax ên cairé, àrondie supérieurement. Ailes hyalines-jaunâtres, le stigmu jaune, les nelvures brunes. Puttes jaune-miel, toutes les hanches noires, les 4 antérieures tachées de jaune al l'extrémité ; les jambes postérieures noires a l'extrethiţ: Abdomen très allonigé; linéaire, allant en se rétrécissant du 20 segment jusqu'd l'extrémité, lo piemier avec 2 petites carènes et ponctue au sommet. - Ontário (Gleddes).

Nous rangeons avec hésitation cet insecte parmi les Cryptus, il pourrait tout anssi bien appartenii u derniers sègments de son abdonen sont séparés du reste par un étranglement plus prononcé et prennent réunis le forme d'un petit cône.

45. Crypte en deuil. Cryptus luctuosus, Cress.-Proc. Ent. Soc. Phil. III, 290. 
$0^{7}-$-Long. .58 pee. Noir avec les pattes rousses. Tête en carré transversul; la fuce finement ponctuée uvec 2 lignes o1bitales blanches au dessous des antennes. Métathornx rugueux, a lignes soulevées proéminentes maiy ne formant pas une aréole centrale. Ailes hyalines, à nervures noires, l'aréole pentugonale. Les jambes avec les tarses postérieur's, noir, le reste des pattes y compris les hanches, d'un benu roux clitir. Abdomen allongé, linéaire, noir sans uucune tache -Ottawa (Guignard .

Nous ne pen o décrite par.M. L. (Mon

\section{Crypte pubescent, Cryptus pubescens, n. sp.}

$\delta^{7}-$ Long. .24 pee. Noir avec une bande rousse a l'abdomen. Face noire, sans taches, avec une courte pubescence grisâtre de même que sur le thorax. Antennes fortes et courtes, sétacées. L'écoison blanc. Métathorax avec une aréole étroite sur le dos. Ailes hyalines avec les norvures brunâtres, à aréole pentagonale bien que ses côtés soient presque parallèles. Toutes les hanches noires, les 4 pattẹs antérieures jaune-roussâtre, les cuisses plus ou moins obscures a la base, les pattes postérieures noires avec la base des cuisses et des jambes rousse et les articles 2 et 3 des tarses blancs. Abdomen en ovile, at ténué aux 2 extrémités, le $2 \theta$ segment avec partie du premier et du $3 e$ roux, le reste noir avec une tache blanche a l'extrémité.-Ottawa (Harrington).

Cette petite espèce est bien caractérisée par sa coloration.

47. Crypte lineaire. Cryptus 'inearis, n. sp.

8--Long. 30 pce. Noir avec les pattes et l'abdomen roux; les mandibules blanches, le labre avec le scape en dessous, roux. Antennes courtes et fortes, roussâtres à l'extrémité; la tête plus large que le thorax. Le métathorax avec une aréole pyramidalo sur lo dos. Ailes enfumées-jaunâtres, à aréole pentagonale, le stigma brun avec une petite tache blanche a la base. Pattes ronsses, les postérieures avec les hanches noires, le soinmet des jambes et les tarses brưn-1'oussâtre. Abdomen allongé, linéaire, droit, le premier segment noir excepté au sommet, le risste roụx avec les.segments terminaux blun plus ou moins foncé.Bécancour. 


\section{Peut-être le $\sigma^{\top}$ du persimilis, Cress. ?}

\section{Crypte ferdu. Cryptus perditus, n. sp.}

$0^{x}$-Long. .27 pce. Noir avec les pattes et l'abdomon ronx. Tête petite, entièrement noire. Thorax finement ponctué, le métathorax avec une aréole en carré sur le dos. Ailes hyalines, les nervures brunes, l'uréole pentagonule, les écuilles alaires blanches. Pattes rousses y compris les hanches et les trochanterw, les postérieures avec les genoux, le sommet des jambess et les tarses, brun plus ou moins foncé. Abdomen en ovale allongé, noir à la base et a l'extrémité, les segments 2 et 3 et partie du 40 roux. Ottuwa (Harrington).

Ses hanches postérieures rousses et la forme de son ibde men le distinguent surtout du précédent.

\section{Crypte ignoré. Cryptus ignotus, n. sp.}

$\sigma^{x}$ - Long. . 26 pec. Noir avec les pattes et partie de l'abdomen roux. Tête plus large que le thorax, la face a: ac deux tnches orbitales blanches dilatíes ver's le chaperon et portant chacune une schancrure au bas, les mandibules, les palpes, une tache sur le sçape en dessous, les écailles alaires, blanc. Métathorax a lignes soulevées bion distinctes formant une aréole en carré au centre. Ailes hyalines, a nervures brunes, blanches a la base, aréoló pentagonale. Pattes d'un roux clair y compris les hanches, les postérieures avec les genoux, l'extrémité des jambes et les tarses plus ou moins brunâtres. Abdomen allongé, élargi au dela du milieu, le pédicule assez grêle et portant une petite fossette au sommet, les segments 2 et 3 avec le sommet du premier roux, le reste noir.-- Ottawa (Harirington).

Ses taches orbitales blanches le séparent surtout du suivant dont il est très rapl roché.

\section{Cry pte séparé. Cryptus segregatus, n." sp.}

$\sigma^{\pi}$ Long. .28 pce. Noir. Tête aussi large que le thorax, a face noire sans aucune tache; les palpes; le schápe en dessons; les écailles alaires avec les 4 trochanter's antérièure, blanc. Métathorax fortement ponctué avec une, aréole centrale en carié: Ailes hyalines, les nervures et le stigma jaune-pâle, l'areole pentagonale. Pattes rousses y compris les hanches, les postérieures 
avec l'extrémité des cuisses, des jambes et les tarses, noir. Abdomen assez fort, on ovale allongé d paitir du $2 \theta$ segnent, les segments 2 et 3 roux, le reste noir. -Ottawa (Hupipington).

Celui-ci avec le précédent pourraient être pris à première vue pour des o' Phygadeuons, mais les scupltures de leur métathorax les rapportent sans enonteste aux Cryptes,

51. Crypte tri-snnol6. Cryptus 3-annulatus, n. sp.

$\sigma^{\lambda}$-Long. .27 pce. Noir varié de roux et de blanc. La fuce finement ponctuée, les palper avec une petite ligne sur le labre, blanc. Antennes longues ot fortes, noiros avec un petit anneau blunc au delà du milieu. Ecailles alaires blanches; métathorax à pubescence blanchâtre, avec les 2 carènes trunsversales noires, sans aréole centrale. Ailes hyalines, a nervures brunes, l'aréole pentagonale, la nervure moyenne appendiculéo. Pattes rousses avec les hanches noires, los 4 trochanter's antérieurs aveo un petit anneau a base des jumbes et des tarses intermédiaires, blanc, les pattes postérieures avec l'extrémité des cuisses, noir, leurs jambes aussi noires avec un anneau blanc i la base, leurs tarses blancs avec la moitié apicule du ler article et l'extıémité, noir ; les éperons des 4 jambes postérieures, blancs. Abdonıen à pédicule long, en ovale allongé d partir du 2 e segment, les 3 premier's roux, le reste noir.-Ottawa (Guigṇard).

Cette jolie esṇèce est bien caractérisée par ses anneaux blancs.

52. Crypte délicat. Cryptus gracilis, n. sp.

ه Long. .35 pce. Noir avec l'abdomen on partio roux. Toute la fuce au dessous des antennes, les mandibules, les palpes, les joues, les écailles alaires, un point on avant, une pètite ligne au dessous, l'écussón et le post-écusson, les 4 hanches antérieur'es avec leurs trochanters, d'un blanc d'ivoire. Antennes longues, sćtacées. Thorax subcylindrique, le métathorax sans aréle distincte. Ailes hyalines, les nervures brunes, le stigma avec une petite tache blanche a la base, l'arécle pentagonale. Pattes d'un roux brunâtre, les hanches antérieures noires. Abdomen étroit, allongé, linéuire, les 4 premier's segments proux, le reste noir avec une tacbe blanche sur les deux derniers. - Ottawa (Guiguard).... 
Abdoles seg.

remière ur mé-

n. sp.

La fuco

e labre, anneau athorax noires, l'aréolo rousses ivec un , blanc, i, leurs 8 tarses e, noir; pédicule romiers nneaux

roux. palpes, e ligne rieures ngues, le disec une is d'un etroit, - noir (Gui- 


\section{LEGENDE DE LA PLANCHE II.}

1.-Acanthosoma cruciatu, vue en lessous.

2.-Chelinidea viltiger, Uhl.

3.-Alychus entrymus, très grossi.

4.-Corisus luteralis, Say.

5. - Elytre et anteunes d'un Iayganus.

6.-Antennes de Cymus.

7.-Plociomemus nodosus, Say.

8.-Ischuorynchus didymeus, Zett.

9. - Eilineala crassimana, Fubr.

10.-Blissus leucopterns, Sny

11.-Anthocoris musmelus, Sny.

12.-Geocoris bullatus, Say.

13.-Elytre d'Anthocoris.

14.-Elytre de Triphleps.

15.-Colluria Mei'leurii, Prov.

16.-Leptoterna dolabrata, Lin.

17.-Tête de Miris.

18.-Tête de Culocoris. 
Plinche IT.

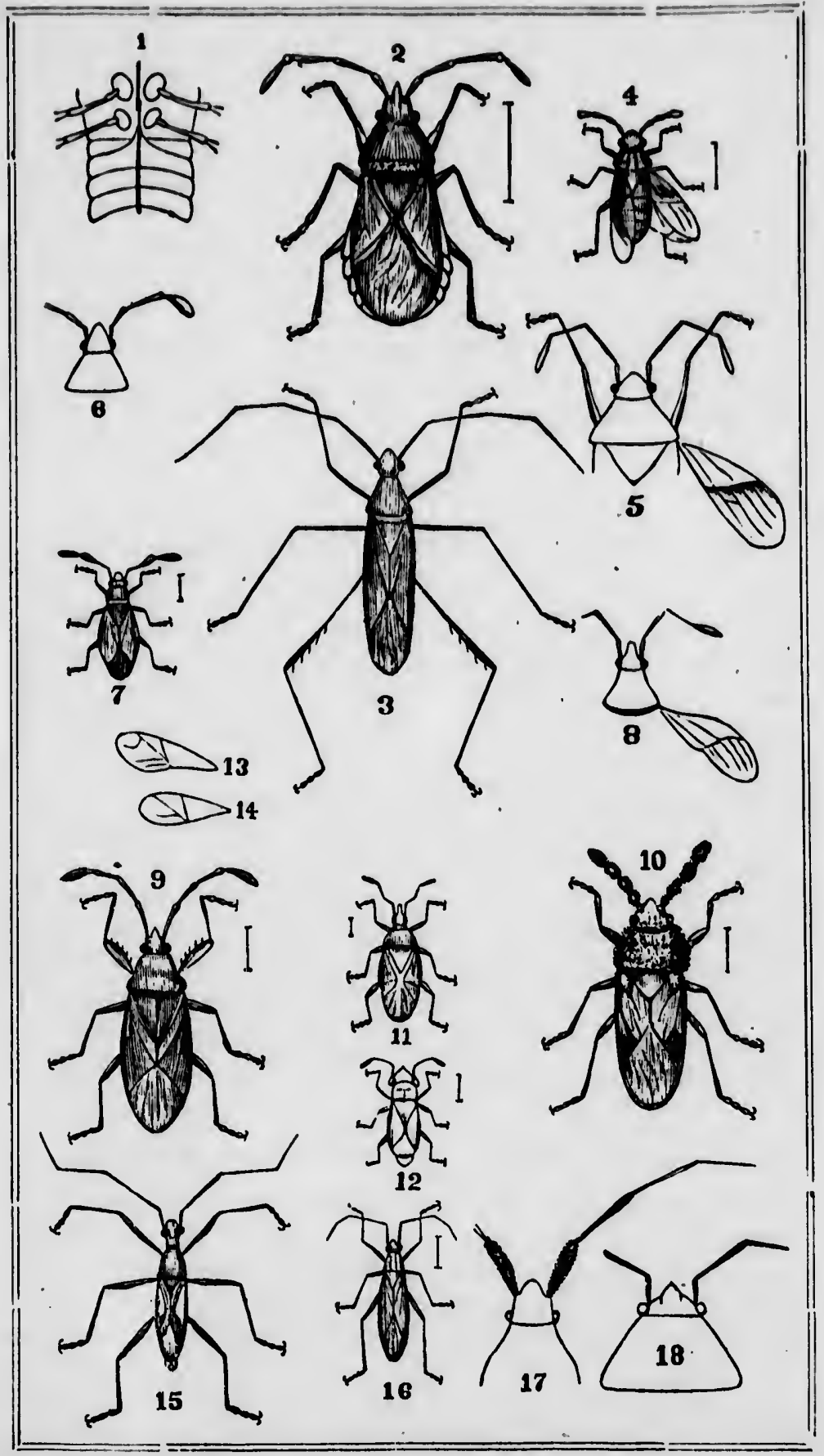

10-Mai 1886. 


\section{IV. -ICHNEUMONIDES.}

53. Crypte droit. Cryptus rectus, n. sp.

en arriele des yeux pce. Noir avec l'abdomen roux. Tête épaisse bules, les palpes, l'ext'émite au dessous des antennes, les mandiécailles alaires avec un é des joues, le scape en dessous, les sommet, les 4 hanches point en avant, l'écusson échancré au Thọrax robuste, le métathorax avee leurs trochanters, blanc. centre. Ailes hyalines, les avec une petite aréole conique au l'aréole pentagonale. Pattes d'vures noires, blanchâtr'es à la base, postérieures, noires. Abdom d'un roux brunâtre avec les hanches la base dn pédicule et l'exen allongé, linéaire, droit, roux avec fivement marginés de blatrémité, noir, les 2 derniers segments

-CapRouge.

Espece bien remarquable par sa taille et sa coloration, n. $\mathrm{sp}$.

54. Crypte marqué-de-blanc. Cryptus albonotatus,

$\sigma^{x}$-Long. 26 pee. Noir avec les pattes et l'abdomen roux. écailles alonsétıent ponctuée. Ises mandibules, les palpes, les les 4 hanches antécicison le post-écusson, le scape en dessous peu roussâtre. Thorax court ot leurs trochanters, blane quelque lignes soulevées distinetés. et trapu, le métathorax arrondi, sans pâles a la base, aréole subpent hyalines, les.nervures brunes, droits. Pattes rousnes, les postérienale, ses côtés étant presque les jambes excepté un petit anneau'es aree l'extrémité descuisses, brun plus on moins foncé. Abdom blanc à la base et les tarses, élargi postérieurement, roux avoc lox assez long, grêle a la base, terminal avec une grande tavec l'extrémité noire, lo segment

L'aréole des ailes de tache blanche. - Ottawa (Guignara). à-dire que ses côtés sont preste espèce est presque carrér c'estest fortement anguleuse.

hes-jaunes. Cryptus mellicoxus, n. sp. beau jaune-miel. Lu face finement les hanches et les pattes d'un che de chaque côté on dedans des jenctuée avec une tache blanque sur le labre et portant une bules, les palpes, les écailles alaires, échancrure au bas; les mandi-

$$
10 \text { - Mai } 1886 .
$$


dessous. Le métathorax a lignes soulevées distinctes formant une aréole conique au milieu. Ailes hyalines, les nervures brunes, pâles à la base, l'aréole pentagonale. L'extrémité des jambes postérieuras avec leurs tarses, obscur plus ou moins foncé. Abdomen assez fort, en ovale allongé, noir avec une bande rousse couvrant lo 20 segment entierement et partio du premier et du 3e, sans tache blanche à l'extrémité. - CapRouge.

Bien distinct du précédent par sa forme et sa coloration.

\section{Gen, Mesostenus, pp. 314 et 785 .}

Aux 7 espèces décrites, ajoutez les 3 qui suivent.

8. IMésostène à-plusieurs-ceintures. Mesostenus pluricinctus, n. sp.

क-Long. .24 pce. Noir; les mandibules, le seape, un petit anneau aux antennes, les écailles alaires, l'écusson et le post-écusson, blanc. Métathorax finement ponctué, inerme aux angles, et portant 2 petites carènes longitudinales sur le dos. Ailes hyalines, iridescentes, avec les nervures noires, l'aréole pentagonale, pętite, oblique. Pattes d'un beau roux pâle, les 4 antérieures avec les hanchess ot les trochanters blane, les jambes postérieures avec leurs tarses plus ou moins sombres. Abdomen en ovale allongé à partir dı 20 segment, à pédicule assez grêle, finement ponéué, tous, les segments marginés de blane au sommet, le dernier cotalement blanc; tarière un peu plus courte que l'abdomen.--Ottara (Harrington).

Voisin du sericeus mais s'en distinguant surtout par son manque de pubescence à la face et la forme de son abdomen, dont les premiors segments sont distinctement marginés ảe blanc.

\section{Mésostène armé. Mesostenus arrinatus, n. sp.}

+ -Long, .40 pee. Trapu, robuste, noir avee taches blan. ches. Le chaperon, une tacho sur les mandibules, les palpes, un anneau aux antennes, une tache sur les angles antérieurs du prothorax, les écailles alaires avec une petite ligne au dessous, un point au dessus des hanches intermédiaires, l'écusson, le post- 
écusson, une tache de chaque

une semblable tach sur. coté en arrière des ailes inférieures, mucron sur les angles do les flanes du métathorax avec un fort avee un large anneau belui-ci, blanc. Antennes fortes, noires gueux avec ses mucrons blancs, ela du miliou. Métathorax runes, les nervures brunes, l'aréole petite, en arrière. Ailes hyaliobsolete. Pattes d'un beau roux clate, sa nervure postérieure les trochanters. Abdomen largo clair y compris les hanches et cule dilaté au sommet, tous les segmet assez court, en ovale, à pédi: au sommet, le 1er presque entièments noirs marginés de blanc rousse précédant la marge blancement roux, le 20 avec un ligne domen.-Ottawa (Harrington).

Espèce bien remarqubl

voisin du dejectus, Con métathorax, domen noir et le reste de. nais s'en distinguant par son ab.

coloration.

sp.

10. Mésostène latigastre. Mesostenus latigaster, n.

\%-long. .30 pce. Noir avec l'abdomen roux. Tête grosse, transversale, finement ponctuée. Le labre, les mandibules, un anneau aux antennes, les écailles alaires avec une tache en avant, tacées, avec un anters antérieurs, blanc. Antenues très longues, sémarginés de blanc en desso au dela du milieu, les articles 1 et 2 aréole petite, en parallélogramme obl hyalines, à nervures brunes, térieures avec un petit anneau noir a l'e Pattes rousses, les posdes jambes, leurs tarses annelés de blan l'extrémité des cuisses et l'extrémité noire, large, déprimé, assenc. Abdomen roux avec

quart de l'abdomen.-Ottawa (Harrington).
Bien distinct dariè moins du

A l'espèce décrite, ajoutez la suivante.

Gen. Pezunachus, Grav. p. 347.

2. Pézomaque sillonné la suivante.

\&-Long. .15 pce. Tête Pezomachus sulcatus, n. sp. sâtre, colle-ci renfléc longitudin noir-poix avec la face rous- 
bulcs brines. Artennes plus longues que la tête et le thorar, d'un ferrugineux pâle, plưs épaisses et plus brunes à l'extrémité. Thorax partagé en denx nouds préque égaux, le premier arec un petit sillon au milieu et une bande rousse de chaque côté, le second noir, gibbeux. Point d'ailes. Pattes d'un brun de poix, lextrémité les hanches en dessous, roussâtre. Abdomen en ovalo a partir du 2 e segrment, noir, le premier légèremeat dilaté en ar-. rière des tubercules et avec lo sommet jaune. Tarière égalant a. peine le quart de l'abdomen.-Ottawa (Harington).

Très rapproché du Pettitii, Cress. pa: sa coloritıon, mini.3 s'en distingnant surtout par le sillon de son mésothorax jui est fortement prononcé.

Gen. Exochilum, Wesm. p. 353.

Aux 2 espèces décrites, ajoutez la suivante.

3. Exochilum nigrum. Anomalon nigrum, Prov. Faune p. 356.

Son chaperon tronqué et la nervure cubito-discuïlale de ses ailes presque droite, ne permettent pas de le coufondre avic les Anomalons.

Gen. Anomalon, Jurine, p. 355 .

Aux 5 espèces décrites, ajoutez les 8 ;ui suivent.

Les Ancmalons sont très variables dists leur coloration, aussi la détermination des espèces en est-elle difficile. La forne, la structure des téguments, la taille, la longuenr relative des antennes, la contraction de la cellule discoïdıle extérieure, sont les caracteres sur les'puels on pent se reposer davantage.

I(6) Antennes courtes atteignant à peine la moitié du corps;

2(5) Couleur rousse, face rousse;

34) Taille .72 pce., abdomen passablement élargi ¿-l'extrémité ............ 1. semi-rufum.

4( 3 ) Taille .48 pce., abdomen peu élargi a l'extrémité .............. 7. rufulum, n. sp.

5 (2) Couleur ncire, face blanche........... nigritum. 
rax,

iité.

ivee le

oix,

vale

al-

int à.

an:i.3

i est

?rov.

le de avec

ition,

La ative eure, ge.

fum.

n. sp.

tum.
6(1) Antennes de plus de la moitié du eorps, souvent l'égalant ì peu prè̀s en longueur';

7(10) Cellule discoïlalo extérieure n'n contractée à la base;

8 9$)$ Ailes notablement enfumées; taille forte. 8. nigro-rufum.

9( 8 ) Ailes hyalines, taille moyenne........ 2. hyaline, 357.

10,7) Cellule discoïdale extérieurs contractéé à la base;

11(14) Métuthorax avee un sillon longitudinal au milieu ;

12 (13) Hinches postérieures o noires, $\delta$ rousses. 4. anale, 357.

13(12) Hanches postérieures rousses........... 9. laterale.

14(11) Métathorax sans sillon longitudinal distinct;

15 16) Coulenr rousse; abdomen à peine obseurei à

l'extrémité .................. 10. unicolor, n. sp.

16(15) Couleur noire, plus ou moins variée de roux;

17(20) Les 4 hanches antérieures jaune-pâle, $\sigma^{x}$ et $q$;

18 (19) Ecusson of roux, o jianne............ 3. relictum, 357.

$19,18)$ Ecusson $\delta^{7}$ ㅇ t noir, abdomen très grête et fort long............... 11. chlamidatnm, n. sp.

20(17) Lus 2 hanches antéricures seulement jaune-pâle, les autres rousses ;

21(22) Abdomen très grêle o ot $\sigma^{7}$, les segrments

1 et 2 très longss, le $3 e$ peu élargí... 12. filiforme, $n . s p$.

22.21) Abdomen moyen, les segments 1 et 2 non trìs longs, lo 3e élargi ;

23(24) 'Thorax noir' varié de roux, valves de la tarière jaunes............. 5. prismaticum, 358 .

24 23) Thorax noir, valves de la tarière brunes... 6. exile, 358.

1. Anomalon demi-roux. Anomalon semi-rufum, Nort. - Proc. Eut. Soc. Phil. I, 36:2, o.

o - Long. .72 pee. D'un roux ferruginenx valuié de noir. Antennes à peine plus longues que lo thomax, ferruginenses, bruncs à l'extánité. La tête ferrugineuse, grossièrement ponctuée sur le vertex, la face au dessons des antennes, l'écusson, les 4 jambess intéricures, avec les tarses, d'un jaune plus ou moins roussâtre. $11-む 111$ ls.86. 
Les environs de l'écusson, le prothorax avec uno tacho sur les flanes au dessous des ailes, noir, lo reste du thorax ferruginenx. - Ailes hyalines-jaunâtres, le stigna fanve, la cellale discoüclale non contractée à la base. Pattes de la conlent du corpes, les jambes postêrienres au sommet avec l'extrénité des tarser, noir. Abdomon forlugineux, lo 2e segment avec une ligne noire en dessus, les 5 segnents terminaux plus ou molius noirs sur les côtés; les valves de tarière jaunes. - Ottawa (Itamingtou).

6. Anomalon roussâtre. Anomulon infulum, n. sp.

9- Long. .48 pee. IHun roax fermginenx dans tontes ses parties, ot semblable au précúlent en coloration, moins los taches jaunes qui ne s'y tronvent pas. Antennes conrten, it articles coners. Tue meinthorax avec une petite ligne noire an milien, ses lobes pen distincts. Tue vertex arec une tache noire, les youx lap)prochés inférieurement. To juothorax, les flances en prutie, les environs de l'éensson, l'extrémité des jambes pontérieures, noir. Ailes hyalines-jaunâtres, la colhule discoüclale à peine plus étiobte a la base. Tes 4 janbes antérienres avec les tarres d'un ronx plas clair. Abdumen grêle, le 2e segment aves une ligne noire en dessus, Jes terminamx médiocrement élargeris, noirs sur les côtés infériemenont, couverts d'une forte pubescence jumntre; les valves de la tarière jaune ron--itte. - Ottawa (Hatrington).

Très rapproché dı précédent par sa coloration.

7. Anomalon noiràtre. Anomulon nigitum, Nort.Proc. Ent. Soc. Phil. I, $36 \%$, .

$\sigma^{x}$ - Lohg. .48 pee. Toir avec l'abdomen en partic ronx. Antenues ì peine plus longues que le thorax, roussâtres en dessons, les 4 jattes antérieures arec l'extrémité de leurs hanches, jamne. Tiéchison noir, quelquefois jamuatre. Une ligne orbitule rousse en aprien: des yeux. Tout lo thorax noir à l'exception de l'extrémís du métathorax qui est ronsse. Ailes hyalines, les nervures pâles, te stigma roussatre, la cellule discoïdale non contractée a la base. Tes pattes postériemes noires, avee les trochanters, la baso des jamber et loe. tarses, janne, les derniers plus plus on moins obseurs an inommet des articles. Abdomen roux 
avee la base du 1er segment, uno ligne sur le 2e, les côlís des 3 qui suivent of les terminaus, noir. - Othawa (ILurington).

8. Anomalon roux-noirâtre. Anomalon nigro-rufum, Nort-Proc. Ent. Soc. P'hil. I, 361, 우

९-Tong. .82 pee. Noil avee l'abromen ronx. Antennes

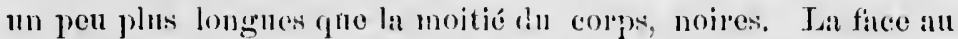
dessons des antennes, les jones, le scape en dessons, un point sur le vertex en dehors des ocellos, les valves de la tarière avec les tarses, jaune. Te thorax noir arec la partie inférienre du mé. tathorax rousse, celui-ci crensé an milien et strié transversalement, nue côte partant les éinilles alairos et se dirigeant sur less

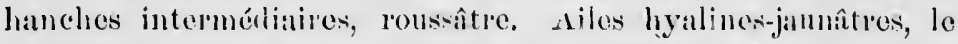
stigma jaune, la cellule discoülale non contractée. Pattes rousser, les 4 antérioures plus pâles, les postérieures ared les hanches en dessus et l'extrémité des jambes, noir. Abdomen ronx, lo premier segrment exeepté ì la base, arec le 20 noir on desisus, les segments terminamx noirâtres.

万’-Semblable ì la o avee les exceptions qui sulvent: $\Lambda_{n-}$ tennes entièrement jamnes; métuthorax sans tacho ronsse an sommet, les 4 pattes antérienres jannos, les postérienres arec les hanches, les enisses et l'extrémité des jambes passablement enfumées.-Capliongge.

\section{Norton n'a d'écrit que la o.}

10. Ancrnalon latéral. Anomalon laterale, Brullé.-Hyménoptères IV, 175.

o Long. .60 pece. Roux varié de noil et de jamne. Sa face au dessous des antennes aree les jones, jaune, le reste de la tête roux aree une tache noire sur le vertex. Antemes ronssitres, brunes a l'extrémité, noires ì la bise, le seape jamne en dessons. Thorax roux avec la partic antérienre et le pourtoar du mésothorax, noil ; la poitrine, los flancs en grande partie, lat région post-sentellare, le métathorax presque entidrement, noir. Ecusson jaune ou ronssâtre. Métathorax arec un sillon longitudinal bien dessimé, convert de rides tranurersales. Ailes légèrement enfumées, aree les norvmes noires et le stigma roux. P'attes 
rousses, lew hanches postérienres ronsses, les trochauters aveo l'uxtrémité de.j jambes postérieures, noir'; tarses jaunes, avec lo dernier article roux.-CapRouge.

Comme la plupart des autres, assez variable dans l'śtendue des taches diverses qu'il porte.

1.0. Anomalon unicolor. Anomalon unicolor, n. sp.

- - Isong. .52 pce. D'un roux presque entierement uniformo dans toutes ses parties. La fice avec les joues, les orbites autérieurs, et les tarses postérieur's excepté à la base du premicr article, janite. Le vertex avecune grande tache noire descenclant jusqu'aux antennes. Antenries dépassant a poino la moitié du corps, brunes à l'exilémité. Thorax sans taclıes, fillement ponctué; ésusson partagé en deux par un sillon. Métathorax grosièremont ridé au milion. Ailes, enfumées-jaunâtres, les nervures brunes, jaunes in la base, le stigma roux; la cellule discoïdale extérieure médiocrement contractée a la base. Pattes de la conleur du corps, les jambes postéricures a peino obscrurcies a l'extrémité. Abdomen à segrments: 1 et 2 très gréles et allongés, lo 20 avec une petite ligne noile en dessirs, les segmentis ventranx variés de jaune; valves de la tarière jaunes.-Bécancons.

Bien remarquable par sa conleur uniforms.

11. Anomalon à-manteau-noir. Anomalon chlamidatum, n. sp.

으 - Long. .50 pee. Thorax noir avee les pattes et l'ablomon, ronx. La fuce, les jones, une tache sur le vertex de cluaque côté, le scape on dessous, las 4 pattes antérieures avec les tarsos postéricurs, jaune. Antennes presque aussi longues que le corps, joussâtres, brunes à l'extrémité, le scape jaune. Thorax noil sans ancuno tashe, à l'exception clu pédicule du métathorax qui est roux à l'extrémité, l'écusson purait aussi obscurér ent lavé do roux; le métathorax avee uı sillon longitudiual bien distinet. Les paties jostérienres rousses, avec l'extrémité de leurs jambes noire, leurs tarses jaunes avec la base du premier article ronsse. Ailes hyalines, iridescentes, les nervures brunes, jannes ì la base, le stigrma roux, la cellule diseoüdale fortement contractéo à la 
aveo

vec lo

endue

sp.

forme

inté-

emicr

escen-

noitić

inent

horax

s nel-

iscoï-

do la

cies a

ngér,

tratix

mi

bdo-

:qü

11'sos

prips,

silns

est

de

inct. bes

isse. ase, i la

laso, laissant ì peine une nervule transverwe. Abromen roux, a segments 1 et 2 longrs et très grêles, to 20 avec une petite liğne noiro en dessus, les torminaux noirs on dessus et juunatles en dessous ; valves do la turièro jaunes.

$\sigma^{x}$ - Semblable a la $p$, avee une tache ronsise sur lo vertex en arrière des yeux; thotax noir sans aucuno tache.

Ottawn (Hanrington), CapRouge.

12. Anomalon filiforme. Anomalon filiforme, n. sp.

으- Long. .+2 pee. Fort grêle, roux varié de noir. Antennes plus de la moitié du colpes en longueur, rousisos, brunatres à l'extrémité. Ia fince an dessous des antennes, les mandibules, les joner, le scape en dessous, avec les valves do la tarière, jamne. Ite derriere de la tête roux avec une grande tache noiresur le vertex. Thorax roux; échsson roux, les slltures arec la poitrine, moir. Métuthorax uon excavé on arrière, fortement strié transversalement. Ailes hyalines, très fuiblement enfumées, les norvures noires, lo stigma bron, très étroit, la ecllulo discoïdale fortement contratéc al la base. Paltes poltson, les trochanter's postélicurs avec le sommet de leurs jambes, plus ou moins obseur. Abilomen a segments 1 et 2 tris longs et d'ígale grosseur, 2 avec mo petite ligne brino o's dossus, los terminamx ave une lache noire en dossus, lo 30 seggment court, et s'élargissant on triungle continn avee le $4 \mathrm{e}$.

$\sigma^{7}$ - Iree l'écusson, les 4 hauches antéricures et leurs troehanters, jaune. To scape roux avec los articles 2 et 3 des antemnes noirs en dessus. Le dos du thorax areo le métathorax en prutic, noir.-Béc:inco'ur.

Ia forme de l'abdomen de la o est tont à fait remarquable, les segments terminaux étant courts, forment une espèce de massue aplatie à l'extrémité.

Gen. Camporlex, Grav. pp. 361 et 786.

Aux 9 espèces décrites, ajoutez les 2 suivantes :

10. Campoplex argenté. Cumpoplex urgenteus, Nort. - P'roc. Ent. Soc. Plit. I, 365. 


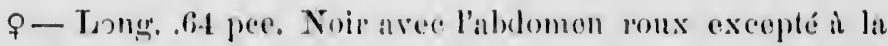

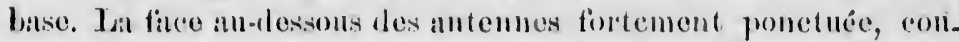
verte, do mêmeque lo thor:ax, de poils angentís. Antennes un pen

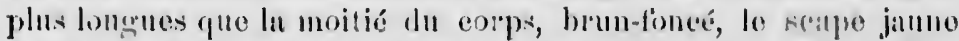
en destous. T.es mandilubles oxcepté à l'extrémité, less palpes,

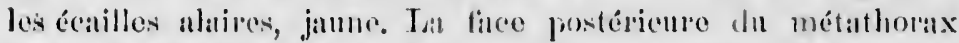
striée traturepialement an bas, brillante an sommet. Jo premier

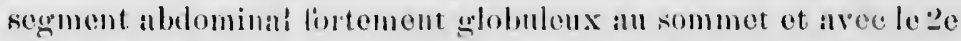

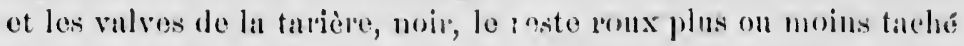
de noir; lo 20 segment jumne on jamberomx en lessons. Les jumber postéricures, les épines avee les 4 antérienres, jumbes exeepté une ligne sur Jes cuistes antérienres en avant, les luanches i.termélianos et les deux tiers de lenres cuisses aver les patfes postérieures, noir. Niles sub-hyalines. Toronto (Geddes).

9. Campoplex semi-rufrus, Prov. p. 7\&6, 우.

$0^{x}-$ Semblable it la of arec les exceptions qui suivent:

Lo scapo arec les écuilles alatires, blane; les 4 paltes antérienres entièrement blanches, les postérioures avec los jambes blanches, excepté à l'extrémité; l'abdomen roux n'ayant du noir qu'al premier et an 2e segment.-O(tawa (Hilrington).

11. Campoplex à-échelle. Cumpoplex scularius, n. sp.

q-Long. .35 pee. Noir aree l'alblomen roux; la fuee avee lo thorax it pubeseence blanche assez llense. Antennes forton, it peine plus longues que lo thorax, prespue anssi grosses ì lintlémitéqu'a la base. Jes mandibules, les palpes, les écriilles alatires avee les 4 trochanters antériours, jaune. Métathorax avee un sillon bien distinct an milicu, ce sillon portant des rides transversiles en forme déchelte. Ailes hyalines, fublement enfumćes, les nervures brumes, pâles à lia base, le stigma brun, la ceellule discoüdale médiocrement contractée a la base. Paltes jonsices, les 4 antélieures plus clares, los hanches anlérienres jamners en dessons, fontes les autres noires, les trochanters postérieurs anssi noirs. Abdomen roux aree le premier et te 20 segment noirs,

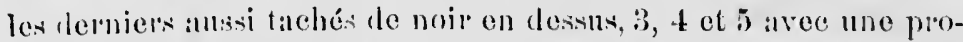
jection jumne on dessons en forme de dents amondis; valion de la turiere noires. 
J-Avec lo senpo jauno on dessous; les seuments nbdomimanx l ce z noirs avee le sommot roux. P'our tont lo reste semWhable it la o.

o Capturéc gar nous a" Caplionge, of pris par M. Hulringtion a Ottawi. Voisin de alius Nort., mis s'en distingruaut surtont par la structure de son mútathosiax.

\section{Gen. Imaneria, Holmgren, pp. 365 et 786}

A!ıx 23 espicees décrites, ajoutez $\operatorname{les} 5$ qui suivent.

\section{Clef pour la distinction des espéces.}

1(18) Aludomen entichement noir ;

a(1i) ILunches postérienres noires;

:(1+t) T'arière d'au moins le quart de l'aludomen;

If 7 ) Métathorax fortement oxcavé un arrière;

$5\left(6^{\circ}\right)$ Ailes avec une aréole ............. valida, p. :36i.

(i) (i) Ailes saus atrolo.................. mellipes, 368.

7 (4) Métathorax non exsave en arrière;

$8(11)$ Jambes postérieures avece in ammeau blanc;

$9(10)$ Toutes les hanches noires, du moins it

la baso.......................... plena, 67.

10 9 ) Les + hanches antérieures blanches ou rousses ................... 4. parva, 368 .

11( 8 ) Jamber postéricures sans anneau blane quoiquo sonvent plus pâles an milieu:

1:(13, Les 4 hanches antérieures rousser, aréole pérliculée, petite, oblique ..... . arg əntea, 369.

13,12, Toutes les hanches noires; anéole pé liculée, lroite ......... ......... s. hyalina, 369 .

1.4 3) Tarière à peine sortaute ;

$15(16)$ Jimbes postérieures arec un anne:n blanc ......................... annulipes, 3617.

16(15) Jambes postériemes salls amnoau blanc au milieu, métathorax exc:uvé....... 6. genuina, 36!)

17. (2) Hanches postériemes rousses, jaumbes postóriemes arec un anmma blanc «u milieu. ................. „1. Guignardi, n.p. 


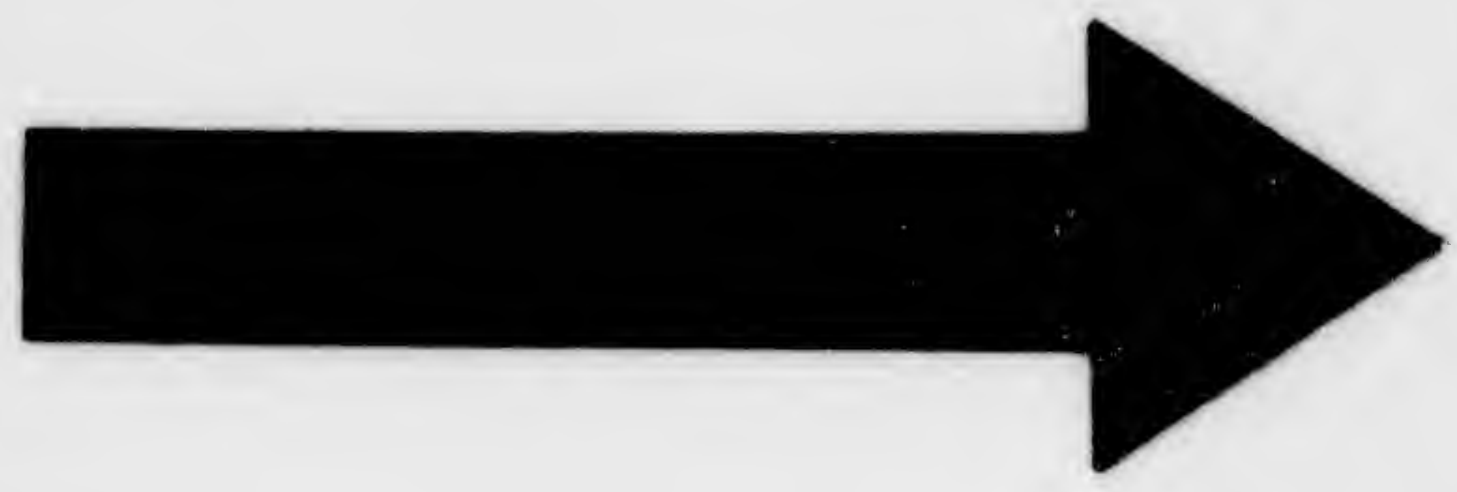




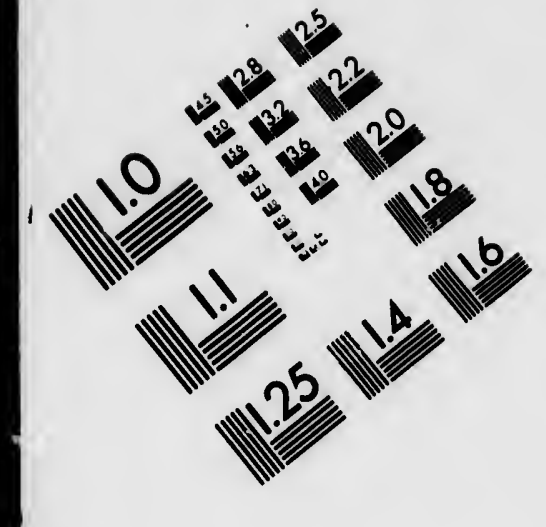

\section{IMAGE EVALUATION \\ TEST TARGET (MT-3)}


Photographic Sciences Corporation

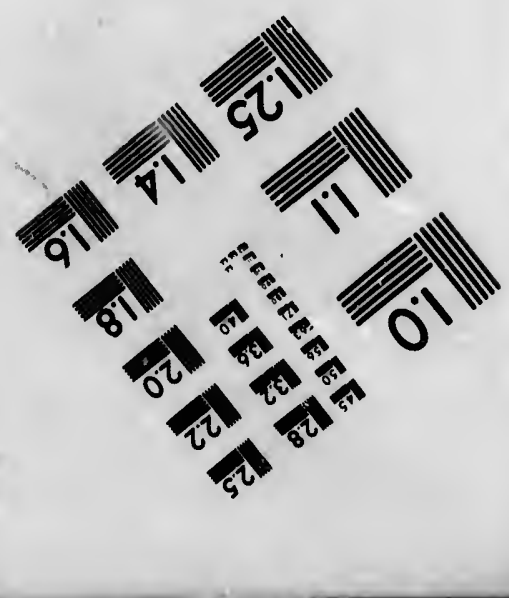


18( 1 ) Abdomo plus ou moins roux;

19(40) Hanches postérieures noires, du moins a la baso;

20(29) Abdomen noir, n'ayant de roux que la marge des segments;

21(24) Aréolo plus ou inoins péliculéo;

22(23) Face postérienre du métathorax striéo transversalement ..............11. infumata, 370 .

23(22) Faco du métathorax pleino ot sans stries transversales. ...........22. dubitata, 787.

24(21) Aréolo sessile;

25(26) Tarière presque aussi longue que l'abdoinen. ...................... 9. sessilis, 370 .

26 25) Tarière comrte, moins du quart de l'abdomen;

27(28) Thorax court et trapu, aréole triangulaire.................. 10. marginata, 370 .

28(27) Thorax allongé, linéaire; aréole pentagonale ............... 25. brevicauda, $n . p$.

29,20) Abiomen avec un ou plusieur's segments roux;

30(37) Jambes postérieures sans petit anneau blanc à la base;

31(32. Tontes les hanehes noires.......... 21. nigricoxa, 786. 32(33) Les 4 hanches antérioures rousses ou jaunes ; 33(34) Cuisses postérieures noires; métathorax excavé et strié transversalement en

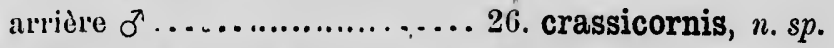

3.1(33) Cuisses postérieures rousses; métatho- • rax non excavé;

35 36) Aréole pédiculée ............. 15. fusiformis, 371.

36(35) Aréole sessile ...................27. compacta.

$37(30)$ Jambes postérieures avec un petit allnealu blane a la base;

38(39) Thur'ax allongé; métathorax sans aréole eentralo distincte..............16. flaviricta, 362 .

39(38) Thorax assez court et trapu; métathorax avec une aréole eonique; antenncs souveni loussîtres à l'extrémité 13. dentata, 373. 
40(19) Hanches postérieur's rousses;

41(5t) Face noile;

42(45, Jambes postérieures noires avec un annean blane an milien;

43(44) Le scape noir; toutes les hanches rousses .....................23. distinctz, 787

44(43) Le scape jauno en dessons: les $t$ hallches antérieures blanches ..........13. flavipes, 371 .

45(42) Jambes postérieures rousses, sans an. neau blinc ;

46 51.) Toutes les hauches rousses ;

47(50) Tarière du quart de l'abdomen environ; aréole petite, droite;

48(49) Abdomeu en milssue; aréole à peine pédiculéc.................. 12. clavata, 371 .

49(48) Abdomen allongé, linciare ; aréole très petite, très longuement pédiculéo....17. ruficoxa, 372.

50(47) Tarière à peine sortante; aréole petite, oblique ....................... pallipes, 372 .

51(46) Les 4 hanches antérieures juunes ou hlanches;

52(53) Abdomen noil à segrments margintés de ronx.......................... basilaris, 371 .

53(52) Abdonen roux, n'étant que peu ou point tacké de noir.................28. pilosula, n. sp. 54 41) Face blanche .................20. sericea, 373 .

24. Limnérie de Guigsard-Limneric Guignardi, n. sp:

q-Long. 32 pec. Noire avec les pattes rousses. Los mandibules, les palpes, les écailles alaires, les 2 hanches antérieures avec leurs trochanters, blanc. Antennes plus courtes que lo corps, lear scape roussîtıe en desisons. Thor:ux court, robuste, très finement ponctué, le métathorax à lignes soulevées distinctes, sa face postéricuro striće tranversalement. Ailes hyalines, iridescentes, les nervures ot le stigrma, noir, l'aréole petite, pédiculéo, en parallélogramme oblique. Patter d'un benu roux do même quo leurs hauchos excopté les antérioures; les 4 jambes antériemro blanches en avant, les postérieures noires avec fü large anneau blanc au milicu et un autro plus petit à? la $1 \%$-juin 1886. 
base, lemrs enisses terminées par un petit anneau noir, leurs turses noir avee le premier article blane i la base. Abdonen fort, mélioerement conprimé, entièrement noir, tarière à peiric sortinte.

$\sigma^{\nwarrow}-$ Arec les 4 hanches antérienres blanches, le scape des antennes ansisi blance en dessous. Ottawa.

Nons délions avec plaisir cette jolie espèce à MI. J. A. Guignard; zélé intomologiste d'Ottawa, qui l'a obtenue $\delta^{-1}$ et $q$ de chenilles de Notodonte concinna.

25. Limnérie à-queue-courte. Limneria brevicaucla, i. sp.

-Iong. .20 pece. Noire variée de roussâtre. Les mandibules, les palpes, les écailles alibires avec un point en avant, les 4 hanches antérieuress avec leurs trochanters, blanc. Antennes assey longues, filiformes. Métathorax a lignes sonlerées distinctes, eouvert infúrieurement, de même que la face, d'une pubescence blanche. Le thorax court, timpu. Ailes hyalines, les nervuress noires, l'aréole petite, sessile, pentagonale. Pattes d'un roux brunâtre sale, les hanches postérieures noires, leurs jambes et leurs tanses, plus ou moins obscur, les premières plus pâles an milieu. Abelomen en massue comprimée ì l'extrénité, les segments 2 et 3 margines de ronx ul sommet; tarière ì peine sortante.-Ottawa (Grignard).

Bien reconnaissable jar sa petite aréole pentagonale et sessile.

26. Limnérie à-cornes-épaisses. Limneric crassicornis, n. sp.

万-Tong. .35 pee. Noire avec l'abdomen plus ou moins. roux, la face avec le métathorax et le bas des flancs, avec pubescence blanche. Ises mandibnles, les palpes, avec les 4 hanches antériemes et leurs trochauters, jaune pâle. Métathoms excavé et strié transversalement. Ailes hyalines, les nerrures noires, le stigna très étroit, à peine distinct, l’aréole triangulare, grande, distinctement pédiculée, les écailles alaires noires. Pattes, d'un roux pâle, les postérieures noires. Abromen en massno compriméc à l'extrémité, à pédicule lonğ et grsêle, noir avoc les segments 3, 4 et 5 ronx. - CapRonge.

Espece d'un faciès tout particuliex; of encore incounue. 
lenrs domen peine

les an-

J. A. is et ?

vicau-

mandi$\therefore$ les 4 tennes inctes, scence irvures 1 ronx abes et ûles ant ex segpeine hale et ssicormoills pubesanches excavé noires, rande, es, d'un omprigments ue.

27. Limn rie compacte. Limneria compactu, l'rov. -Can. Fut. XVII, 116.

우 -- Long. .23 pee. Noire avee les pattes et l'abdomen roux. tes mandibules, les palpes, avec les éctailles ahaires, blanc. Antemnes tiliformes. Thorax court et than, le mésotimmax gribbeux en avant, le métatho:ax déclive. Ailes légè̀rement enfumées, à atréole trangnlairesensile. Pattes ronsses, les hanches postérieures noires à la base en dedaus. A jomen formant une petite massue allongréo avec un pédicule long et grêle, noir à la basse et à !'extrémité. Tin'ière du ynart de l'abdomen environ, recourbée supérieurement.- Vausouver (Tiılor).

Se distingue surtout de la ruficoxu par son aréole sessile.

28. Limnérie poilue. Limneric pilosula, nov. sp.

o-Long. .30 pce. Noire arec les pattes et l'abdomen ronx. Las mandibules, les paljes, les écailles alaires avec une donble tache en avant, et les 4 hanches antérieures arec leurs trodhautrirs, blance. Face a pulescence aryentée courte, la même pubes. rence, mais beanconp plus longue, se montlant anssi sur les flanes du métathorax. Antennes filiformes, de la longueur du corps, lo scape plus on moins blanc en clessous. Thomx robuste, le métathorax déclive, ponctué, ses côtés mmnis de poils blinces. Ailes hyalines, les nervures noires, aréole triangulaire, brièvement pédiculéo. Pattes roussos, y compris les hanches postéyienres, les jambes de cetto dernière paire brunâtres et lenr's tarses noirs. Ablomen roux, noir seulement ì la base du pédie'ule, les segments terninaux formant une massue fusiforme; tal'ière á peine du quart au !'abdoment, ses valves noires.

$0^{x}$ - Semblable à la of arec le scape blanc en dessous ef les pattes antérieures plus pâles. - Ottawal, Cap Ronge.

Se distingue de la ruficoxa par son abdomen emrièrement rọn, et du pallipes par ses tarses postérieurs noirs.

12. L,imneria clavata, Prov. p. 3 个1.

La description donnée est celle dn $\sigma^{\prime}$, ci-suit cello de la $\supsetneq$.

o - $\Lambda$ belomen on massie, le sommet des segments 2 et 3 et des autres plus ou moins, ronx. Tarière redressée, de la moitic de l'ablumen environ, - Calp !onge. 


\section{Gen. Pyracaron, Holing. pp. 373 et 787.}

Aux 3 espèces décrites, ajoutez la suivante :

Pyracmon incomplet. Pyraemon incompletum, n. sp.

f- Long. .41 pce. Noir avec l'abdomen roux. 'Tête grosse, en carré, très épaisse; les mandibul's, lo scape en dessons, les palpes, d'un roux blanchâtro sale. Antennes longgues, birunes. Thorax assez court, gibbeux on avaut, déclive postérieurement, le metathorax strié transversalement sur sa finco postélieure ; les écailles alaires noires. Ailes légérement enfumées, les nervures et lestigma, noir, l'aréole avec la nervure postéricure effacéo par das bulles d'ail. Pattes rousses, y compris les hanches et les trochanters, les tarses postéricur's lirunâtres. Abdomen roux, poli, brillant, étroit, allongé, sans aucune tache, à pélicule allongé ot grêle, comprimé seulement à l'extrémité; tariere à peine sor'tante, ses valves noires,-Ottawa (Guignard).

Espèce bien remarquable par son aréole incomplète.

Gen. Podociaster, Brull. p. 375.

A l'espèce décrite, ajoutez la suivante :

Podogastre sillonné. Pollogaster sulcutus, n. sp.

O-Long. .40 pee. Roux varié de noir; la tête très g!osse, rappelant celle des Pyracmons. La fice au dessous des antennes, les jones, les maudibules, lo scape en dessous, avec les 4 trochanter's antérieurs, jaune-pâle, lo resto de la tête roux avec une grande tache noire sur le vertex tonchant les yeux et les anteunes; vertex trìs finement ponetué, creusé postérieurement. Antennes longues, roussâtres, noires à la base et brunes ì l'uxtrémití. Lo dos du métathorax, lécusson avec le métathorax excepté à la base, roux, lo reste noir y compris la poitrine, les flanes avec une grande bande rousse partant des écuilles alaires et aboutis_ sant aux hanches intermédiaires. Lícusson of le métathorax avec un petit sillon an milieu, le rlernier tout eouvert de petites alvéoles formées par des rides irrégulières et prolongé en pédicule au dessus des han hes postérieures. Ailes hyalinos, légèrement enfimées, avec les nervtires noires, pâles à la base; point d'aréole; stigma rousiâtre, très étroit; cellule discoïlale contractéce à la base. Paltes rousses, grêles, les postérieures longues, le premier 
article de leurs tareses aussi long que les suivants rẻuriis; les hanches posterieures avec leurs trochantor's et l'extremité de'curs jaunbes, noil'; les tarses jaunes aveo l'oxtrẻmité noiro. Abdomen munquant, mais que nous atons tont lieu de croiro roux varié de noir et comprimé fortement a l'extrémité.-Ottawa (Gnignard).

Ce bel insecte, malheureusement privé de son abdomen, se zapproche des Pyracmons par sa grosse tête, mais ne porte pas d'aréole à ses ailes; son écusson sillonné le rapprocherait des Porizons, mais son métathorax pédiculé le range incontestaiblament parmi les l'odogastres.

\section{Gen. Porizon, Fallen, p. 377.}

Dans la description du genre, p. 377, ligne 2e, au lieu de: " les 2 nervures iuférieures," il faut lire: les 2 nexvur'es anterieures.

Aux 3 espèces décrites, : joutez la suivante:

\section{Porizon allongé. Porizon elongatum, n. sp.}

$\delta^{7}$ \% - Long. 29 pce. Noir avec los pattes et l'abdomen d'un roux sombre. Antennes allongées, filiformes, brunes, roussâtr'es à la base en y comprenant lo: scape. Thorax pou allougé, ussez robuste, le métathorax finement ponetué avec une petite aréole allongée sur lo dos. Ailes hyalines, les nelvures et le stigma, noir, la nervure eubito-discoïdale s'unissant au radius sans laisser place a une nervule transverse pour diriser les 2 cellules cubitalos. Hanches postérieures noires à la base. Abdomen grêle, allongé, à peine plus épais a l'extrémité, poli, brillant, d'un roux brunâtre, les 2 premier's segments noirs; tarière redressẻe, de la moitić de l'abdomen environ.-Běcancour, Cap Rouge.

Se distingue surtout du rugosum par son métathorax.

Gen. Thersilochus, Holmg. pp. 379 et 789 ..

Aux 2 espèces décrites, ajoutez les 2 suivantes :

Face postérieure du métathorax non entourée

d'une carène.................... 1, micans.

Face postérionre du métathorax entourée d'une carène; 
Putter et hauches jaune pâle uniforme...... 2. pallipes. Hanches postériecies noires;

Ecusson strié transversulement...... 3. maturus, $n$. sp. Ecusson non strié, in peine ponctué.. 4. errabundus, $n . s p$.

3. Thersiloque mûr. Thersilochus maturus, u. sp.

.9 - Long. 22 pece. Iroir foncé, nvec lus pattes ronssâtres. Tête on earré, plus largo que le prothorax, a fiuco trids finement ponctuée. Antemes moyennes, filisormes, lo scilpo en dessous avoc les mandibules, roussâtren. 'Tlorix gros ot court, lo métathorax ringuoux, arrondi. Ailn's hyalines, sans aréole, ou plutôt avec une aréole manquant do ses nervures extérienres. Pattes d'un roux brunâtro sale, les 4 hanches postérieu z'es noires. Abdomen ovale-oblong, poli, brillant, les segments 2 ot 3 ronx, le pédicule long; tarièro do la longrneur de l'abdomen, redressée.Hull (Guignard).

Jolie espèce bien remarquable par sa coloration.

4. Thersiloque errant. Thersilochus errabundus, n. sp.

f - Longr. 28 pee. Noir avee l'abdomen rour. Tête grosse, en carré, la fíce très tinement ponctuée. Antenues longues, noires. Thorax déclivo postérieurement, le métathor'ux à lignnes soulevées bien distinctes, dessinant un petit sillon su le dos, arćole manquant de ses nervures extèrieures; lo stigma granıl ot épais. Pattes ronsses avec les hanclies noires. Abdomen à pédicule grêle, assez large, comprimé à partir du 20 segment, roux avec les propremiers et les clernier's segments noir's.-Ottuwa (Ifarrigton).

Espèce bien distincte par sa coloration.

Gen. Exktastes, Giav. pp. 303 et. 794.

Anx 7 espèces décrites, ajoutez la suivante.

Exétaste à-ailes-fasciées. Exetastes fascipennis, Cress.-Proc. Ent. Soc. Phil. IV, 275.

o-Tong. 45 pee. D'un bean roux clair dans tontes ses parties. Mandibules brunes a l'extréinité. Antennes longues, brunes avec un anncau pâle an milieu, le scapo roux on dessous. Thorax tı’ès finiment porctué, le métatorax avec une ligne bruico au milieu; écusson soulevé, inerme, ses onviıons noirs. Ailes

hyı biut griat duc les tallie bren ailes $1(69$ $2(43$ $3(34$ $4(1:$ $5(9$ 612 $7(8$ $8(7$ 10 (11 11 (10

$12(6)$ $1: 3(4)$ 14. 23 15 (22) $16(21)$ 17 ( 20

$18(19)$ $19(18$ 
hyalines-jaunâtres avec l'extrémité enfumée et une autro bande

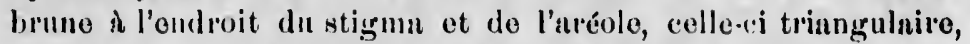
grande, la nervure cubjto-discoüdale arquéo. Pattes de la couleur du corps, sans aucune tache, les turses antéricurs plus longs que les jambes. Abdomen poli, brillant, contracté a l'extrénité, a tarière d'environ le quart de sa longnenr, les valves de celle-ci brenes et plus a largos l'extiénité.—Ottawa (Guigniard).

Cette belle espèce so distingue, de toutes les autres par ses ailes tachces et l'anmenu pâle de ses antemnes.

Gen. Mrsoleirus, Grav. pp. 394 et 704 .

Aux 28 espèces décrites, ajontez les 8 qui suivent:

1(69) Anter.nes grrêles, filiformes, plus minces à l'extrémité;

2(43) Thotax noir;

3(34) Eeusson noil';

4(13) Abdomen noir ;

5(9) Une aréole aux niles;

6 12) Antennes sans anneau pâle;

7(8) Aréole pentagonalo; taricie longue... 1. sericeus, 395.

8(7) Aréole triangulaire, tarière à peine sortante .................... 29. angustus, $n . s p$.

9(5) Point d'aréole anx ailes.

10(11) Hanches et enisses postérieures jaunes.. 2. decens, 396. 11(10) Tanches et cuisses postérieures noires.. ................ 30. cinctipas, $n_{.} s p$.

12(6) Antennes avec un anneaı pâle .... 31. perditus, $n$. $s p$. 1:3(4) Abdomen plus on moins jaune ou roux;

14. 23) Antennes avec un annean pâle;

15(22) P'oitrine uoire;

16(21) Faco noiro;

17(20) Jambes postérieures noires; stigma noir.

18(19) Hanches postérieures rousses ; abdomen cylindrique $\ldots \ldots \ldots \ldots \ldots . . . .32$. rufomixtus, n. sp.

19(18) Hanches postériemes noires ; abdomen filiformo............ 33. filiformis, $n, s p$. 
20(17) Jumbes postérienres rouswes, noires is L'extrémité soulement; lo stigma roussatre.................... 4. annulatus, 397.

2.1 (16.) Fuce jaune-pâle, toutes les hanches noires. 3. Moyeni, 396. 22(15) Poitrino juune-pâle; lo collier blunc. 2. albopleuralis, 39z 23(14) Antonnes suns unneul pâle;

24(33) Ailes avec une aréolo ;

25(26) Ablomen noir nvoc. une tuche triangulairo juuno sur chnque segment. . 6. triangularis, 398.

26(25) Abdomen roux, sans tuches noires sur les côtés ;

27(28) Lobes latéruux dn mésothorax tachés de jaune.................. 7.. interruptus, 398.

28(27) Lobes latéraux du unésothorax sans taches;

29(30) Fuce of ot $\delta$ blanche ............. 8 inceptus, 399 . 30.(29) Fince of noire;

31 (32) Arćole triasıgulaire, sessile; ehmperon a pubescence argentée .......... 34. barbatus, $n . s p$. 32(3i): Aréole très petite, pédiculéo; ehaperon nu ........................ 35. largus, $n_{n} s p$. 33(21) Ailes sans aréle .............. @ depressus, 39 y $3+(3)$ Eeusson jaune ou roux; abdomen ou rouge et noir, ou jaunâtre;

35(36) Antennes avec un anneau pâle; $९$ avec la fuce blanche...... ..... 27. variabilis, 795.

36(35) Antennes sans anneau pâle;

3i(38) Face noire; tariere presque aussi longue que l'abdomen............... 10. rufipes, 399.

38(37) Face blanche; twière a peine sortunte;

39:40) Antennes entièrement noires, hauches noires................ 36. nigricornis, $n . s p$.

40.39) Antennes plus ou moins jaunes on rousses;

41(42) Ecusson roux; aréole triangulaire, oblique, pédiculée............ 13. Laurentianus, 401 .

42(41) Exusson et post-écusson, jaune-pâle ; aréole subpédiculé .......... 15. flavicornis, 401 .

$43(2)$ Thorax plus on moins taché de jaune, de blane ou de roux; 
44(45) 'Thorax noir, tuchó do blune ou do jaune-pâle; ubdomen noil", unneló do blanc.................... 11. muliebris, 400 .

45(56) Thornx noir taché de roux;

46 (iis) filuncs noirs, saus tuches;

47(50) Uno aréolo aux uiles;

48(49) Aréolo pentugonale, los 4 pattes antériemes blunches........... 27. peregrinus, 794.

49(48) Aréole triungulairo; puttos rousses.... 14. lucens, 401. $50(47$, Ailes sans aréole;

$5152)$ Tête noire; métuthorax suns taches.... 22. lætus, 404. $52(51)$ 'Tète plus on moins jousse; métuthorax. souvent taché de roux........... 23. fucatus, 404.

$53(+6)$ Flames plus ou moins roux;

54(55) Stigma jaunâtre, sans tacho pâle ; abdomen plus ou moins obiscur a la baso et ¿ l'oxtrémitó ................ 16. rufulus, 402.

$55(54)$ Stigma brun, avec une tache pâle à la base; abdomen roux, sans taches:.. 17. discolor, 402.

56.45) Thor'ux joux, quelquefois taché de noir ;

57(53) Antennes uvee un unnenu pâlo..... 12. honestus, 400. 58,5i) Antennes sans anneau pâle;

59(62) Ailes sans aréole;

60(61) Métathol'ax d carènes distinctes; abdomen noir à l'extrémité .......... 24. erectus, 404.

61(60) Métathorax à carènes oblitérées; abdomen sans taches............ 25. uniformis, 405.

62(59) Ailos avec nue arcolo;

63(64) Sutures du thornx noiros........ 20. seminiger, 403 .

64,63) 'Thorax entièrement roux;

$6 \overline{5}(68)$ Aréole sessile, triangulaire;

66(67) Abdomen fusiforme, rétréci aux 2 extrémités................. 19. concolor, 403 .

67,66) Abdomen elavifurme, s'élargissant de la bạse à l'extrémité............. 18. unicolor, 402.

68(65) Aréole longuement pédiculée, triangulaire, oblique ............ 21. canaliculatus, 403. 
69( 1 ) Antennes renflées an dela du milien..................26, rhopalocerus, 405.

29. Mésolepte étroit. Mesoleptus “ngustus,. "sp.

8’-Tong. 30 pee. Noir avec les pattes rousses: la fince, los mandibules, les palpes, lo smupe en dessons, un point de chaque côté sur lo vertex, les joues mi-lossons des yeux, uno thehe en coiı sur les lobes litéraux du mésothornx, les écuilles nlaires, mo. potito ligno on avant avoc uno antio an-dessons, bine. La face avec uno bande médiano noiro dilatéo vers le chaporon. Antennes longues, brun-foncé. Métuthorax finement ponctué, uveo une aréole longitudinalo peu distincte sur lo dos. Thornx court et robuste. Ailes hyalinom, iridescentes, il norvures noires, stigma brun; aréole trèy petito, en trianglo avee la nervure exteriouro a peino visible. Patten rousses, les postévioures noires avec les hanches ot In moitió busilnire dos conissos, roux. Abdomen noir, allongé, peu élargi vor's lo milion;, les segments médinns avec la murge apicale obscurément roussâtre.

+ - $A$ aréole des ailes plus grande; la fuce, en outio des ligrnes orbitules, n'a que 2 points blances all-dessous des antennes. Turicre a peine sortunte.-Ottawa (Harrington).

30. Mésolepte à pieds-ceints de-blano. Mesoleptus annulatipes, n. sp.

ơ-Long. .28 pee. Noir; la face nu dessons des antennes, les mundibules, l’extrémité des joues, les palpos, le scape en dessous, les écuilles aluires, uno potite ligno en avant, une tache sur les lobes latéraux du ménothorax, les 4 hunches untérioures, tous les trochanters avec un large annean anx tarses postiricurs, jaune-pâle. Antennes presque aussi longues que lo corps, noires avee un anuenu blanc un dela du nilieu. Tôte assez grosso, large, tr'ansversale. Métathorax avec !ignes soulevées distinctes, formant une petite aréole en carré a la base. Ailes légèromont onfumées, les nervures noires, lo stigma noir avee un point blanc it In base; point d'aréole. Pattes noires, les jambes untérieures avec leurs tarses plus on moins jaune-pâle, les tal'ses postérieurs avec les articles 2, 3 et 4 blanes. Abdomen déprimé, finement ponetuć, le ler segrment rétréci a la base.-Shorbrooke. 
L'unneau de ses antennes avec ses pattes noires le distinguent a première vie du decens.

us, 405.

sp.

fince, les chinque nche on iles, 11110. Lin fitco AntenIvoc 11110 conrt et , stigma riollte a avec les en noir, uvec la

des liintennes. soleptus

ntemnes, en desache sur res, tous térienrs, *, noires o, larige, tes, forhent onblanc a élicures térieur's noment.
Mésolopte égaré. Mesoleptus perditus, n. sp.

8-long. 40 pece. Noir on brun foncé ; la fuce an-rlestous des antonnes, lo labre, les mundibules, los lignes orbilules lemontant jusque sur lo vertex, les érnilles alaires nvee les 4 jambes anté. rioures ot leurs tmisen, jumb-pâle. Antennes très longuen, areo un large annean pâlo un-dola du milien. Jes lobes latérunx dı mésothornx avec la pointe juno on avant, lo métathorux uvec 2 petites curènes un miliou bordant un canal longitudinul, tress distinct. Toutes les hanches, les cuisses excepté a l'extućmité, uvec les jumbes postérienres excepté i la base, noir ou brun foncé ; les cuisses aulérienros jaunes on avant, les tarses postériours noirs avec un petit anneru jaune a la base du premior articlo ot los articlos 3 ot 4 blanes. Abclomen a pédicule long et grêle, subeylindrique dans lo reste, noir, les serments terminanx i pubesconce jumuatro. Ailes hyulines, à aróole petite, en triangle irrégulier, sensilo.-Otıwa (Guignard).

32. Mésolepte mêlé-de-roux. Mesoleptus rufomixtus, n. sp.

o-long. 32 pae, Noir avec l'ublomen en partio roux. La face tres finement ponctuće avec le bord lı chaperon ronssîtpe. Antennes filiformes, noires, avec $u$ bel annean blanc an-dela du milieu. Thorax suns uncune tuche, écusson- proéminent, métathorax déclive, avec lignes sonlevés distinctes formant une aréojo étroite et allongée au milien. Ailes hyalines, d nervures noires, l'aréole sessile, triangulaire, lroite, Pattes brun-roussître, les deux antérieures plus pâles, tous les tunses blanes avec l'extrémité noire, les hanches postérioures noires avec taches roussos en dossus et en dessous, lours cuisses brunatres et leurs jambes noires. Abdomen allongé, étroit, pen élargi postérieusement, noir avec les sogments 3 ot 4 , la moitié aspicale da 2 e et le sommet du premier d'un roux sale.

$\delta^{7}$-Avec la fuce jaune, les mandibules blanches et les pattes d'un roux clair sans aucuno tache; pour le leste semblabled la $\supsetneq$. -Ottawa (Harrington), Cap-Ronge. 
33 Mésolepte filiforme. Mesoleptus filiformis, n. sp.

o-Long. 32 pee. Noir; la bouche jaunâtre; tête non épaissio en arviero des yeux. Antennes plus courtes que lo corps, avec un anneau blanc au dela du miliou. Thorax grê̂lo, sans aucune tache a l'exception de l'écusson et du post-écusson qui portent un point blanc all sommet. Ailes hyalinos, les nervures noires, le stigma brun-foncé, aréolo pentagonale; le métathorax a ligne's soulevées formant une aréole étroite et allongéo au milieu. Pattes noires avec les articulations plus on moins rousses, les turses postérienr's plus longs que leurs jambes, Abdomen très allongé, fliforme, grêle a la base, poli, brillant, lo segments médians plus ou moins roux au sommet.-Knowlton.

Espèce bien remarquable par son abdomen grêle et poli.

34 Mésolepte barbu. Mesoleptus barbatus, n. sp,

ㅇ-- Long. 30 pee. Noir avec l'ablomen roux. La fuce, les flanes, le métathorax avec une pubescence blanehe, plus longue et plis apparente sur la face. Les nandibules, le scape en dessous: les écailles alaires avec les 4 hanches antérientes et leurs trochanters, blanc. Antennes brunâtres, assez courtes. Thorix peu robuste, lo métathorax avec une petite aréole étroite au milieu. Ailes hyalines, les nervures brunes, le stigma fauve. L'aréole triangulaire, sessile, droite. Pattes roux-ciair, les postérieures arec les hanches et lo dessus des trochanters, noir. Abdomen étroit, légèrement en massue à l'extrémité, noir avec les segments 3 et 4 ot le sommet de 1 et 2 roux, les term: naux noil's avec pubescence blanchâtre--Bécancour.

\section{Mésolepte large Mesoleptus largus, n. sp.}

- $\quad$ - Long. 26 p. Noir avee l'abdomen roux. Ises mandibules, lo seape en dessous avec la base des antennes, et les écailles alaires d'un jaunes roussâtre. Antennes courtes, noires, roussîtres a la base, surtout en dessous: Thorax robuste, ses flanes polis, brillants, métathorax ì lignes soulevées formant un sillon longitudinal au milien. Ailes hyalines, a nervures brunes, le stigma graud, noir avec uno grande tache pậle a la base, l'aréole longruement pédiculée, très-petite, oblique, peu apparente. Piotto.s roux 
n. sp.

ête non \$ que lo x ğrêle, -écusson les nor'; le méallongéo o1 moins jes. Ahllant, les owlton.

t poli.

1. sp,

a face, les us longuo pe on desis et leums Thorax étuoite au ma fauve. - les posténoil: Ab1. avec los ax noil's p.

andibules, es écailles rousinatres inc's polis, lon lorigrile stigna le longrumitte.s roux

clair, toutes les hançhes noires en dessus, l'extrémité des cuisses, des jambes postérieures nvec leurs tarsos, brun plus ou moins foncé. Abdomén déprimé, court, arrondi à l'extrémité, roux, noir a la baso et à l'extrémité, le sommet du ler segment avee le 20 très finement aciculés; tarière à peine srtante-Bécancour.

La forme de l'ablomen rend cette espèce bion reconnaissable.

36. Mésolepte cornes-noirus. Mesoleptus nigricornis, n. sp.

ㅇ-Tong-45 jex. Noir, poli, brillant, avee L'abdomen d'un roux brunâtre. La face, les mandibules, les palpes, une petite ligne de chaque côté sur le vertex, les écailles alaires, une petite ligne en avant et une autre au-dessons, l'éeusson et le post-écus_ son, les 4 pattes antérieures excepté leurs cuisses plus ou moins tachées, blane-jaunâtre. Autennes presque aussi longures que le corps, filiformes, entierement noires, à articles peu allongés. Thorax robisste, poli, briliant, lo métathorax avec une aréole longitudinale peu distincte. Ailes hyalines, légèrement enfumées, à nervures, brunes, à stigrma jaune, l'aréole petite, triangulair'e, longuement pédiculée. Toutes les hanches noires, les 2 antérieures tachées de blanc en dessous, les cuisses plus on moins obscures, à la base, les postérieures avee leur's jambes et leur's tarses, br'un-roussâtre. Abdomen poli, brillant, 'on ovale-allongé, tronqué ì l'extrémité, roux avec lo premier seg'ment et partie du 2e noir-Ottawa (Harrington).

Espèsce bien remarquable par sa forte taille et ses antennes noires.

\section{EXTRA LIMINA}

Mesoleptus fasciatus, Prov._Can. Ent. XVII, 116.

Gen. Exyston, Schiodte. p. 406.

Aux 2 espèces décrites, ajoutez la suivante :

3. Exyston marginé. Exystón marginatum, n. sp.

$\uparrow$ - Long. 30 pee. Noir, poli, brillant; la fuce, les écaillos alaires, les écussons, une tiche sur le scipe an dessous, les pattes 14-Juiliet 1886 
on partie, aveo le bord marginal des arceanx dorsaux de l'abdozen; jaune. Ailes hyalines, les nervures brunes; mréle petite, zriangulairc, pediculéo. Métathorax à lignes soulevéêr distinctes. Pattes jaunes, los euissss rousses, les antérioures en dessus selllement, les postérieuress avec un anneau noir a chaque extrénité. Lues jambes postérieures jaunos, noires i shaque extrémité, dépourvues d'éperons. Abdomen en massie, grêlo à la base, noir, tous les segments avec une large margo jauno au somr et.-Captrué a Toronto. (Brodie.)

\section{Gen. Truphon, Grav. p. 410.}

Des 10 espèces décrites, retranchez la 1ère qui est un Polyblastus, et ajoutez les 6 suivantes :

1(9) Thorax noir; abdomen noir plus ou moins taché de jaune ou de roux;

2(6) Une aréole aux ailes, segments abdominaux 1, 2 et 3 plus ou moins roux au sommet;

3(4) Aréole droite; abdomen non taché de blanc à l'extrémité............. 2. Dufresnei, 411.

4(5) Aréole oblique; abdomen non taché de blane à l'extrémité............ 1. Fractus, $n . s p$.

5 (3) Aréole oblique; abdomen taché de blanc ¿ l'extrémité .............. 4. clypeatus, 412.

6(2) Ailes saus aréole;

7 ( 8 ) Face noile; seginents 2,3 et 4 avee une tache jaune cọnunune sur lo dos. 3. dorsalis, 411.

8(7) Face blanclie; segmonts 1 et 2 obseurément marginés de jaune........ 5. excavatus, 412.

9(1) Thorax noir; abdomen plus on moins roux :

10(25) Ecusson noir";

11(12) Métathorax très poli, avec 4 carènes longitudinales................ 11. Americanus .

12(11) Métathorax avec carènes longitulinales et transversales;

13(22) Ailes avec une aréole; 
l'abdopotite, inetes. us senémitó. té, dé, noir, -Cap-'
14(19) 1er segment avo uno carène do chaque côté du milicụ atteignant presque lo sommet;

15(18) Aréole triangulaire, brièvement pédiculée ;

16(17) Hanches postérieures rousses; extrémité de l'abdomon rousse ......... 8. communis, 413.

17(16) Hanches postérieures noires; extrémité do l'abdomen noire .................. 7. seminiger, 413.

18(15) Aréole trè petite, très longuement péliculée ......................12. pediculatus, $n . s p$.

19(14) ler segment avec une carène de chaque eôté du milieu seulement à la base ;

20(21) Hanches noires; stigma sans tacho pâlo...................... 6. Hervieuxii, 412.

21(20) Hanches ronssos; stigma avec une tache pâle $\therefore$................. 9. Dionnei, 414.

22(13) Ailes sans aréole;

23(24) Chaperon noir; 1er segment sans tubercules sur les côtés ................ 13 rufocinctus.

24(23) Chaperon roux; 1er segment avec tIIber'cules sur les côtés......... 14. tuberculifer, n. sp.

25 10) Ecusson janne on roux;

26(27) Ecusson pâlo; pattes noires............ 10 Clapini, 414.

27 (26) Eeusson et post-écusson, roux; pattés rousses; métathorax finement ponctué avee un petit sillon au miliẹv...15. rufigaster, $n . s p$.

1. Tryphon brisé. Trypleon fructus. $\mathbf{n}$. sp.

ס-Long. .35 pce. Noir avee les pattes rousses; la face excepté une ligne longitudinale au milieu, le chatperon, les mandibules, les joues, lo scapo en dessous, une tache en crochet sar les lobes latéraux du mésothorax, blanc. Tête large; antennes sétacées, noires, plus conrtos que le corps. Métathurax avec 2 petites carènes bordant un étroit sillon au milieu. Ailes hyalines, les nervures et lo stigma brun, aréole triangulaire, sessile, la 2 e récurrente angulense et comme brisée. Pattes rousses y conipris les hanches, les poslérieures avec les janbes, les tarses; les trochanter's et la moitié apicale des cuisses, noir. Abdomen allongé, 
Jétréci à la base, lo ler segment sans carènes distinctes, les segments 2,3 ot 4 obscur'ément inurginés de roux au sommet.Ottawa (Harringtion).

11. Tryphon d'Amérique. Tryphon Americanus, Cress. -Proc. Ent. Soc. Phil. III, 276.

$0^{x}$ - Long. 30 p. Noir avec l'abdomen roux. La face, lo chaperon, les mandibules excepté a l'extrémité, les palpes avec less 4 jambes antérioures, jaune-pâle. Un point noir au dessus du chaperon, de chaque côté. Antennes longues, roussâtres à la base et à l'extrémité, lo scapo jaune on dessons. Métathorax poli, brillant, assez étroit, avec 4 carènes longitudinales. Ailes hyalines, les nervures noires, le stigma noir, avec une tache pâle à la base; arcóole triangulaire, subpédiculéc. Pattes rousses y compris les hanches, les 4 jambes antéricures avec un large anneau anx postérieures près de la base, jaune-pâle, les cuisses postérieures avec la base ot l'extrémité de leur's jambes, jaune-pâle. Abdomen allongé, subsessile, roux, noir à la baso et a l'extrémité, le ler segment avec 2 cardues an piniliẹ n'atteignant pas lo sommet, noir arec l'extrémité rousse.-Caprouge, (Ottawa).

o - De taille un peu plus petite, la face noire avec le chaperon jaune; les laanches postérieures brunâtres à la base.

Espèce bien recounaissable par son métathorax. Noús pensons que l'affinis, Cress. n'est que la of de l'Americanus.

11. Tryphon à-aréole-pédiculée. Tryphon peuticulatus, .n sp.

$\delta^{7}$ - Long. 31 pee. Noir avec l'abdomen ronx. Le chaperon, les mandibules excepté a l'extrémité, avec les palpos, jaunopâle. Antennes médiocres, brunâtres, le scape d'un roux sale en dessous. Thorax finement ponctué, le métathorax à lignes soulevés formant une aréolo en carré au centre. Ailes hyalines, les nervures brunes, le stigma noir avec une grande tache pâle ì la base; aréole très longuement pédiculee, très petite, on ia diruit presque creusée daus l'épaisseur de la nervure, la 20 récur'rento anguleuse au milieu. Pattes rouses, les 4 antérieuros un peu plus pâles, la baso des hanches, les jambes et les tarses postérieurs avec l'extrémité de lcurs cuisses, brun plus ou moins fóncé. Ab- 
domen allongé, cylindriquo, les segments 2,3 et 4 aveç le sommet du 1er et la barse du 50 roux, le reste noir, le premier un pạ plus étroit a la base, avec deux cuènes n'atteignant pas le sommet.-Bécancour.

Espèce bien remarqualle par la forme de l'aréole de șeș ailes.

12. Tryphon ceint-de-roux. Tryphon rufocinctus; Cress.-Proc. Ent. Soc. Phil. III, 280.

$q$ - Long. 23 peo. Noir, subopaque, la tête et les antennes entierement noires, moins les mandibules qui sont rousses a la buse. Les écailles alaires d'une jaunâtre pâle. Métathol'ax à lignes sonlevés peu distinctes, avec uno aréole centrale étroite et allongée. Ailes hyalines, iridescentes, les nervures et le stigma, noir, le dernier pâle ì la base; point d'uréole. Pattes d'un roux foncé, les hanches avec l'extrémité des cuisses pastélienres, noir. Abdomen subsessile, les segments '2 et 3 et partie du 40 roux, le reste noir, le premier ponctué, avec 2 petitos carènes dépassant à peine lo milieu.-Ottawa (Harrington).

\section{Tryphon tuberculifère. Tryphon tuberculifer} n. sp.

ㅇ -28 pce. Noir avec l'abdomen ronx. Le chaperon, les mandibules, le scape en dessous, les pattes avec le milien de l'abdomen, d'un roux foncé ; les écuillettes jaune-pâle. Antennes moyennes, brun-roussître, surtout en dessouss. Lo métathorax à ligues soulevées peu distinctes formant unc aréole étroite et a]; longée au milieu. Ailes hyalines, les neıvures brunes, le stigmą noir avec une grạnde tache pâle à la bane; point d'aréole; la 20 récurrente anguleuso près do sa base. Pattes entièrement rousses avec les hauches noires, les 4 antérieures rousses au sommet. Abdomen avec les segments 2,3 , la moitié apicule du premier et la base du 4e roux, le leste noir, l'extrénité polic, briliante, les segments 1 et 2 avec uno dépression transverse au miliou, le premier avec quatre petites carènes atteignant à peine le milieu. -Bécancour.

Espèce voisine du minimus, Cress., mais s'en distinguant par sa plus forte taille, ses hanches noires, etc. 
14. Tryphon a-abdomen-roux. Tiyplion oufigaster, n. sp.

\$ -- Isong. 23 pee. Noir avec les pattes et l'abdomen roux. Lo chaperon, les mandibules excepté al'cxtrẻmité, avec lesécuilles alaires, jauno-pîle. Antennes longucs, noires, testacés en dessous a la base. Lus écussons roux, lo prenier proéminent; métathorax finemen ponctuć, avec un petit sillon au milieu. Ailes hyalines, irideseentes, les nervures et lo stigmu, brun; point d'areole. Pattes rousses sans aucune tache. Abdomen subsessile, fortement comprimé à l'extrémité a la manière des Banches, entierement roux il l'exception des dernier's segments qui sont plus ou moins obscurecis, le ler segment allongé, plus étroit ì la base avec un petit canal au milieu n'atteignant pas l'extrémité.Ottawa (Har'rington:.

\section{Gen. Exenterus, Hartig p. 796.}

A l'espèce décrite, ajoutez la suivante.

2. Exentère de Hull. Exenterus Hillensis, n. sp.

$0^{2} \%$-Long. .28 pce. Noir, le chaperon, la face, excepté une ligne longitudinale all milieu, les mandibules, le scape en dessous, le bord antérieur du prothorax, une tache en triungle sur les côtés du mésothúrax, une petite ligne an-dessous des ailes, une petite tache all-dessous, l'écusson et le post-écusson, une tacho do chaque côté sur les flancs du métathorax, les pattes avec uno ligne au sommet de tous les seginents abdominaux, jaune. Antennes assez courtes, brunes, passant au jaune ì l'extrémité. Thorax finement ponctué, le métathorax r'llgueux. 'Ailes légèrement enfumées, le stigma brun avec une tache pâlo à la base, l'aréole triangulaire, sessile. Les hanchus postérioures, leur's cuisses, l'extrémité de leur's jumbes et de leur's tar'ses, avec le milieu des cuisses intermédịires on dehors, noir. Ablomen sessile, poli, brillant, fortement ponctué, le 1ei segrment rétréci ì la base ct portant doux carènes bien distinctes n'atteignaint pas lo sommet

- et formant un canal au inilieu, de 20 avec un sillon obliquo de chaque côté près de la base en formo de gastrocelles, tous les segments ponctués et portant une ligne jaune all sommet, celle du 
1er segmont beaucoup plus large que les auties et échancrée en avant au milion - Hull (H:urrington).

Trìs rapproché du Cunculensis par sa coloration, mais s'en distinguant surtout par ses deux segments basilaires de l'abdomen qui sont simplement ponctués, et les sillons obliques de son second seginent; il est aussi moins robuste.

Gen. Mesoleius, Holmgren, p. 415 et 796.

Aux 8 espèces décrites, ajoutez les 3 qui suivent.

1(2) Thorax et abdomen, noir saus aucune tache. 7. niger, 796.

$2(3)$ Thorax et abdomen, noir plus ou moins taché do blane ou do jaune;

3(4) Thorax noir saus aucune tache, abdomen avec une bande transvorsale jauno. 4. Canadensis, 474.

4(15) Thorax noir avec taches blanches, abdomon noir;

5 8) Ailes avec un aréole;

6(7) Cuisses postérieures avec un petit anneau noir près du genou qui est blanc.. 9. annulatus, n. sp.

7 (6) Cuisses postérieures entièrement arousses. 10, telarius,n. $s p$.

8,5 ) Ailes sans aréole;

9(12) Poitrine noire;

10(11) Face blanche; jambes postérieures noires aves un largo anneau blanc al milieu... 1. fissus, 415.

11(10) Face noiro avec un tubercule blanc au milieu, jambes postérieures noires avec un petit anneau blanc à la base....... 8. junctus, 797.

12(9) Poitrine jaune miel ;

13 14) Jambes postérieures noires avec un largo anneau blanc............. 2. submarginatus, 416.

14(13) Jambes postérieures brunâtres....... 3. mellipes, 416. 15(4) Thorax noir avec l'abdomen ronx;

16(17) Antennes avec un anuenu.blanc au milieu ................... 6. antennatus, 418 .

17(16) Antennes sans anneau blanc;

18 (19) Hanches et cuisses postérieures noires.. 5. tardus, 474.

- 19(18) Hanches et cuisses postérieures rousses, renflées.............. 11. inflatifrons, $n . s p$. 


\section{Mésoló annelé. Mesoleius annulatus, n. sp.}

q-Iong. .31 pee. Noir, poli, trìs finement pouctué; les mandibules, los palpes. les écailles alaires, uno ligno sur los bords tatérniix des lobes du-mésothorax, nue ligno sur l'écusson et lo post-écusson, les hanches antérieures, excepté in la base, leuris trochanter's, la moitić apicale des 4 trochanters postérieurs, un petit annenu il l'extıême sommet do toutes les cuissen, avec la marge apicale des segments dorsanx de labdomen, blanc. Antennes longues, brunâtres vers l'extrémité, surtout en dessous. Le vertex avec une petite ligne orbiale blanche de chaque côté. Lie.métathorax uai, wans atreune carene saillante, so: flanes roux inferricurement. Ailes hyulincia, les nervures brt:nes, lo stigma jousentre, l'arcole sessile, triangulaire, oblique. Pattes d'un beau roux elair, $y$.con!nuris los 4 hanches postérieures; la moitié basilaipe des troclanter's postérieurs, un petit anneau i la base et ver's l'extrémité de leur's cuisses, leurs janmbes et leur's tarses, noir, les tarses antéricurs jaune-pâle avee ie sonmet des articlos noir, $\mathbf{y}$ compris les ongles. Ablomen on orale allongé, poli, tous les segments marginés do blanc, le lor rétréci a la base, sans aucane carène; tarière d'onviron ln moité de la longueur de l'abdomen,--Ottawa (Guignard).

Espèce bien remạ:quable par la colorition de ses pattes.

10. Mésoloi à-queue. Mesoleius telarius, n. sp.

ítong. 20 pee. Noir avec les pattes rousses; la bouche jaunâtre, face finement ponctuée, 2 potites lignes orbitales sur lo vortex. Antennes brunâtres, le senpe taché de blance en dessous. Los écailles alaires avec les écussons, blane; le métathorax sans carènes, d'un roux jaunâtre al sommet, ses flanes plus on moins tachés de roux. Ailes hyalines, les nervures brunes, le stigma jaunâtre, l'arcóole triangulaire, oblique, subpédiculée. Paites d'un beau roux clair y compris les hancties excepté a la base ile la lère paire, les jambes postérieures daus leur moitié apicale, lexirs tarses, excepté un anneau à la base des articles, broun pliss on moins foncé. Abdomen aillongré, poli, brillant, tous les sogments marginés de blane all sommet, le premicr rétréci à la baze, sans carènes; tarière do plus de la vioitié de l'abdomen.-Bécancour.

J'aréole des ailes sépare cetto esp.èce également di junctus et du mellipes. 
11. Mésoloi a-front-renflé. Mesoleius influtifrons, n. sp.

$\$$-Ling. .32 pes. Noir avec les pattes et l'abilomen roux. In fuce renflée uı deseous des antennes ot fortoment ponctuée. Antennos fortes, assoz courtes, noires. Thorax poli, brillunt, lo métuthorạx avee lignnes soulevées formant une aréole allongée. Ailos hyulinzs, les norvures et le stigma noirâtres, point d'aréule, ot la 20 jecurrento fortement anguleuso. Tontes les pattes, y compris les hanches, d'un roux $11 \cdot$ iforme, les cuisses fortement jenflées. Abdomen allongé, roux avec le premier segment noil a la base, poli, brillant et pretant uno petilo fossetto vers son sommot.-Ottawa (Harrington).

\section{Gen. Polyblastus, Holmg. p. 11 \%.}

Anx 4 especes décrites, ajoutez le 4 qui suivent:

1(8) Thorax et nbdomen, noil';

2(7) Ailes sans aréolo;

3(4) Abdomen noir, sans aucune tacho. 5. Gaspesianus, 410.

4(3) Abdomen noir, les segments marginés de jaune au aommot;

5(6) Poitrino et flancs, noir.........6. decoratus, $n . s p$.

6(5) Poit!ine et flanes d'un janno roux 3. Quebecensis, 420 .

7(2) Ailes avec une aréole; antennes annelées de blane............... 7. annulicornis, $n$. sp.

8(13) Tholax noil, abdomen rollx;

9(10) Ailes sans aréole, abdomen noir à l'extrémité ....................... dilatatus, 419. 10 (9.) Ailes avec une aréole ;

11(12) Jambes et tarses postérieurs, noir... 8. inornatus, n. sp. 12(11) Jambes et tarsos postérienrs, blanc, annelés de noir................. 1. annulipes, 419. 13(8) Thorax plus ou moins roux, abdomen roux.................. 4. subcrassus, 420 .

5 Polyblastus Gaspesianus, Prov. ; Tryphon Gaspesianus, Prov. Petite Faune, p. 410.

6. Folyblaste décorร. Polyblastus decoratus, n. sp. ㅇ-Llong...27 pce. Noir avec les pattes.rousses; la ficce ox- 
ceptá une ligne longitudinale an - lien, lo chaporon, los mandibules, les joues, les écuilles ulnire:' 'c une tucho on crochet sul' les lobes latéruux du m ssothorux, a...ne. Tôte ordinaire, trunsverwale; antonnes plus coiltes que lo eorps, lo scupe plus ou moins taché de blanc on dossous. Métnthorax sans lignes soule. vées bien distinctes, strié longitudinulement sur su faco postérieure. Ailos hyalines, suns méolo, lo stigmu jaunatro. Iranchos rousscs, los 4 puttes antérieures roussor, les postérioures noires avec l'articulation des cuissos ot des trochanter's rousse. Abdrimen noir, sessile, plus épais it l'extrémité, los seugments 2 ot 3 avec uno dépression transversale an milieu et marginés de ronssître un sommot, lo premier seginent plus largo alı sommet, eallaliculé au miliou, inais suns curènos sailluntos. - Ottawa (Hillrington).

7. Polyblaste à-entennes-annelées. Polyblastus an. nulicornis, n. sp.

†-Long. .25 peo. Noir, poli, brillant; le ehaperon, lès mandibules, les joues avec une tache de chaque côté do la fáce au bas des yeux et un annoau aux antennes, blanc, le reste noir sans aucuno tache. Antennes un peu plus courtes que lo corps avee un anneau blanc au delt du milięu. Eeusson proémiment ; métathor'ax court avoc lignes soulevées distinctes. Ailes légèr'ement enfumées, lo costa taché de blane à ln base, mais avoc los écuillettes noires, aréolo petite, triangulairo, pédiculéo, le stigma noir. Les 4 jambes antérieur'es plus ou moins juunâtres on avant. Abdomen sessile, large, déprimé, les segments 1 ot '2 rugueux, lo premier avec 2 caremes divergentes vor's lo sommet, les segments 2 et 3 impressionés trausversalement, los tormiṇaux polis, brillants.

Nons avone capturé cette jolie espèce d Knowlton, sur les bords du lac de Brome.

8. Polyblaste sans-ornements. Polyblastus inornatus, n. sp.

으-Long. 32 peo. Noir avec l'ablomen roux; la têto et lo thorax noir foncé, sans aucune tache, finement ponetués. Tête non épaissie en arrière des yenx. Antonnes longues, brunâtres en dessons. Ecailles alaires noires. Métuthorax arrondi, sans 
cureses distinctes. Ailes hyulines, a nervures noires, aréolo nossile, trianguluiro. Puttes noires, les jumbes do devant roussatres, les 4 hunches postérieures, avec un petit anneuu i la buso des cuisses, roux. Abdomen d'un roux sale, noil id l'extrémité ot sur ses marges latérules, lo lor segment assez long, sans conènes, plus large a l'extrémité, les segments 2 ot 3 avee une dépression trunsversalo an miliou; tarière comre, nuis sortante.-Ottuwa (Hurington).

Voisin du dilatatus, mais s'en distingrant par son abdomen plus allongé, ses janıbes noircs, sa tête plus courte, etc.

Gen. Cteniscus. Hal. p. 420.

Aux 5 espèces décrites, njoutez les 3 qui suivent.

6. Cténisque hanches-jaunes. Cteniscus flavicoxe, Cress.-1'roc. Int. Soc. 1'hil. III, 283.

-I. Iong. .28 preo. Noir avec l'abdomen roux; têto noire, polic, la fuce, les orbites fiontaux rétrécis de shuque côté des antennos, les joures, le chaperon, les mandibules et les pulpes, jauno pâle. Antonnes unssi longues quo le col'ps, to tior's appicul jaı ? tre, les 2 articles basilaires jaunes en dessous. Thorax noir; po'، ; les écnilles alaires, une petito ligno en avunt, une autro an dessous, lesécussons, jaune. Métathornx a lignes soulevéos distinctes, formant une aréole subarrondio au contre. Ailes hyulines, les norvures pâles a la buse; aréole petite, oblique, pédiculéo. Pattes fuuves, toutes les hanches jaunes, les jumbes postęrieures brunâtres. Abdomen subsessile, un peu court, subdépriné, poli, brillant, lo segment busilaire noir, les autres fuuves, les te et 30 plus ou moins tuchès do noir sur les côtés.-Ottuwı (Harrington).

7. Cténisque à-pieds-épais. Cteniscus crassipes, n. sp.

o-Long. :30 pco. Noir; les antennes, les bords du prothor'ux, les écussons, lo métathorux, les pattes avec l'abdomen en partic, jauno. Ia face a pubescence grisâtre. Antennes brunâtres à l'extrémité. Les écailles alaires uvec lo boid supérieur du prothornx, jaune. Les écussons jaunes, do même que le métathorax, ce dernier noir a la base, poli, brillant. Ailes hyalines, les nervures jaunâtres, point d'uréole. Puttes juunes, les postéricures avec les hanches noires on dessous, leur's jambes avec un

êto ct lo

s. Têto cunctros di, sans 
nnucun noir à l'extrénité; toutes les cuisses courtes ot ronfles, lon posterieuress noires. Abelomen on mussuo, lo lor sogmont entierement jume, lo 20 nvee uno bundo noire a la buse, les suivants noily uvoo uno bundo jaune nu sommot. - '́oronto (Brodio).

8. Cténisque a-orbites-blanes. Cleniscus orbitulis Cress. -l'roc. Kint. Soc. P'hil. III, 283.

o-Iong. .2t pee. Roux, varié do blanc ot de noir ; la fince, lo chuperon, les mundibules, les joues remontunt jusqu'uu huut des yeux, les orbites frontuux, blunc. Têto grosse, "ipnissio on แ1rièro des yeux, noiro sur lo vortex ot postérieuremont. Antennos presque anssi longues que lo corps, noiros, ln moitié apiculo juunâtre. 'l'hor'ux fiuve, poli, une tncho noire uu milleu en uvunt de l'écusson, les écrilles nlaires, une potite ligno on avant, une autro au bas dos côtés do la poitrine, blunchâtres; len écussons bluncs uvec lours environs noils. Sétathornx entièement fiuve, les lignes soulovées bien distiuctes, formunt wo mréolo eontrule allongée. Ailes hyulines, lo stigma grand, noir uvec une tucho pâle à la baso; l'aréole petite, obliquo, pétioléo. Pattes fuuvos, les 4 harichos untérioures blanchûtres. Abdomon subsessile, on mussue, poli, fiuve, légèrement obscurci a l'extrémitó.-Ottuwa (Hurrington).

Gen. Erronesus, Holmg., p. 423.

Aux 4 espèces décrites, ajoutez les 2 qui suivent:

\section{Erronème triste. Erronemus tristis, n. sp.}

o-Long. .23 peo. Noir ; têto on carré transversal, la fuce sans taches, à pubesconce juunâile. Antounes sétacées, noiles, plus longues que la tête ot lo thornx réunis. Thorax ép:tis, court, distinctement ponctué; l'écusson ploéminent, fortement excavé on avant, earélé au sommet, sn surfuco rugacuse; métuthornx très court, à lignes sonlevées très prononcées, formant une aréole presque carréce sur lo dos. Ailes légerement obscuros, les norvures et lo stigma, noir, l'aréole pédiculéo brièvon.ent, en parallélogranne oblique. Pattes noires, les 4 jambes antéricures avec lours turses d'un jauno sale, les jumbes postéricures trichées de jamue jâle al la buso en dehor's. Abdomon sessile, en ovale, épais, les 2 premiers segrnents subrugnenx, les antres polis quoique

ponc mutros

Cress

mon

inent

noire.

cont, ment

aréolo viures, lior, Is Pattes uno tu Abilon ou mo lo so: ringtor

bescon alui ios, peino $\mathrm{p}$ distinet miliou vures, 1 miol, le jainbes un anne lo somm 
ponetnés, lo 1er earéne sur los côtér et portant sulp non diaque 2

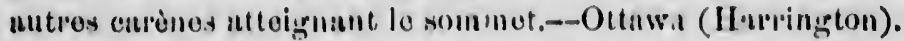

Fspèce bien remarquable par sa sombre colontion.

6. Erronème moitli-roux. Eironemus dimiliatus, Cress. - Timus. Am. Jint. Sor. II, 108.

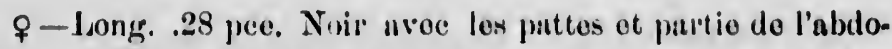

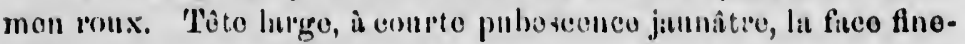
ment ponctuce, le chitparon ponssâtro. Antumuen moyonnes, noiles, roussîtros i l'extrémité. T'iorix contr et jobuste, pubes-

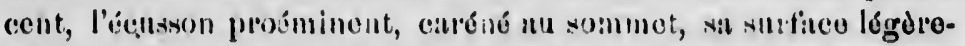
ment ponctuóo; métuthomx i lignos s'mlovios formunt une aréole allongée an inilion. Ailos hyalinos, lo stigrm t ot los norvures, biun-foncé, l'aréolo potito, subsossile, en trianglo irrégu-

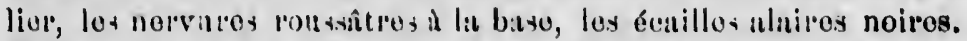
Pattes ronsises, les cuisses ronfléces, los jambor purtóricures aveo uno tuche pâle il la bave on dohors; trintes los hinnches noiros. Abifomen on ovilo allongé, noir avee les segiments 2,3 ot 4 plus ou moins boux, lo 101 avec sos 2 eardnos doisales ittoignant lo so:mmot, l'oxtrómité a pubosconco juunâtro. - Ottaw.ı (Harjington).

Espèç bien distincte par sa coloration.

Gen. Bassus; Fubr. pp. 427 et 798.

Aux 18 espèces décrites, ajoutez les 3 qui suivent:

la fuco noiles, $s$ collt't, excavé ithornx o ar'éolo les norpar'ales avec hées de , épais, quoique

19. Basse cylindrique. Bussus cylindricus, n. sp.

б-Long. .20 pco. Noir, grêle; la face sans tache, avec bubescence grisitro, los palpos, le scipo en dessous, los écailles alaices, uno potite ligno on uvant, blanc. Antennes filiformos, d peine plus longues que la têto et lo thorax. MEsothorax a lobes distincts ; écusson suns tache; métuthorux avec un petit sillon an miliou bordé par 2 carènes. Ailes hyalines, lo stigrina et los nervures, brun, uréole en triangle irrégulior, sessilc. Pattos jaune miol, los hancies antériouros avoc tous les trochanters, ot los 4 jambes antérienres, blanc, los jambes postérien'es blunches avec un anneau noir ì chaque extrémité, lours tarses alssi blancs aveo le sommet dos alticlos noir. Abdomen allongé, cylimbique, les 2 
premiers segnents rugueux, le 1er nvec 2 curènes dorsales. Ottawa (Guignard).

q-Le scapo et les écailles alaires ì peine tachés de blane; les pattes d'un jarune miel unifor'me avec les jambes postérienres et leurs tarses, noir, les prenières avee un large anneau blane au milieu.-CapRouge.

20. Basse dorsal. Bassus dorsalis, n. sp.

o-Long. . 16 pre. Noir avec les pattes jaunes; le chaperon, les mandibules, les palpes, le scape en dessons avec les écailles alaires, blanc. Antennes plus longues que la tête et le thorax, noirâtres. Métathorax avec une aréole dorkale. Ailes hyalines, sans arcóole, le stigma jaunatre. Pattes jaunes, lẹs postérieụres avec les jambes et les $t$, ses plus ou moins obscurs. Abdomen avee une tache jaune dorsule sur les segments 2 et 3 , le premicr allongé, à peine plus largo a l'extrémité, les autres fusiformes dans leur ensemble.-CapRonge, Ottawa (Guignard).

Voisin de l'agilis, mais s'en distinguant par son thorax, sa plus petite taille etc.

21. Basse à-écusson-blarc. Bussus scutellaris, Cress. -Trans. Am. Eıt. Soc. II, 112.

+-Long. .22 pec. Noir, la face, le chaperon, les mandibules, les joucs, les orbites antérieurs, le scape en dessous, les écailles.alaires, un point en avant, wre petite ligne an dessous, une ligno sur les lobes latéraux du mésothorax, l'écusson et lo post-écusson, la poitrine avec une strie sur les flancs, les 4 hanches antérieures avec tous les trochanter's, blanc. Antennes filiformes, plus courtes que lo corps, brunâtres en dessous. Thorax finement ponctué, le métathorax obliquement rugueux au milieu, ectto partie séparéo du reste par 2 carènes divergentes au sommet. Ailes hyalines, les nervures et le stiggma bruuâtres, point d'aréole. Pattes d'un betu jaune-miel, l'extiêne sommet les cuisses postérieures avec laur's jambes excepté un largo anneau blane au milieu, et leur's tarsce, noir. Abrimen subdéprimé, les trois promiers segments rugueux excepté sur leur marge apicale, le reste pọli, brilant; le premier segment avec un point blanc an sommet au milieu, 2 et 3 uvec leur marge apicale rousse portant uno petito tache blanche de chaque côté. Caplouge.

Bien distinct du sycophanta par sa coloration. 
Gen. Exochus, Grav. p. 436.

Aux 5 espèces rencontrées, ajoutez la suivąnte.

6. Exoque taché de-roux. Exochus "ufonzaculatus, n. sp.

f-Iong. 20 pee. Noir varié de rolix; la fice avee des lignes orbitales contịnuées jusque sur le vertex nù elles sont dilatées en petit triangle, le chaperon, les mandibnles, les palpes, lo scape en dessous, les écailles alsires avec un point on avant et une ligno sur les bords dı prothorax, les 4 hanches untérieures avec leurs trochanters, blanc. Antennes brunâtres a l'extrémité. Thorax ì pubescence grisâtre, lo métathorax poli, brillant, sans carènes distinetes; les écussons avec une tache sur les flanc's da méso et du métathorax, roux. Ailes hyalines, a nervares et stigma brun-foncé, sans aréole. Pattes rousses, à chisses renflées, l'extrémité des enisses, des jambes et des article's des tarses des postérieures, brun-foncé. Ablonen allongé, cylindrique, roux, noir a la base et à l'extrémité.-Ottawa (Harrington).

Assez semblable au lavis par sa forme, mais s'en distinguant par sa coloration.

\section{Gen. Coleocen'rus, Grav. p. 440.}

Aux 2 espèces décrites, ajoutez la suivante.

3. Coléocentre pieds-jaunes. Coleocentrus mellipes, n. sp.

万人-Long. .63 pec. Noir arec les pattes d'un beau jaune. miel; Tête on carpé transversal, sans allcune tache. Antennes longues, grêles à l'extrémité, avec un large anneau jaune ver's lo milieu. Thojax finement ponctué écusson convexe, le métathorax de forme cubique, granulé-ruguenx, sa fice dorsile avec un sillon an milieu bordé de chaque côté d'uno petite curène. Ailes notablement obscurcies, avec une aréole triangulaire très petite et longuement pédiculée. Pattes d'un bean janne micl avec les hanches et les trochanters d'un no $\mathrm{r}$ de poix. A bejomen allongé, lin are, les segments 1 et 2 rugueux ì la base, le reste poli, lisse, lo premier 2 fois anssi long que lo $2 \mathrm{c}$, portant une double carèno a son milicu.-iGeddes) Montagnes Rocheuses. 
La forme de son métathorax et son aréole des ailes nous inclinent à ranger ce bel individu dans le geure Coleocentrus, sans que la $o$ en soit counue.

Gen. Ephialess, Grav. p. 450.

Anx 6 espèces décrites, aj utez la suivante.

7. Ephialte à-pieds-varies-de-blanc. Ephiulles variatipes, n. sp.

$0^{x}$-Long. .50 pee. Noir; les palpes, les écailles alaires, avec une ligne en arant sur les bords du prothorax, les 4 hanches antérieures avec leur's jambes en avant, blauc. Antennes blanchâtres en dessous à la base. L'écusson avec une grande tache polie sur les flanes, ronx. Ailes hyalines, les nervures noires, l'aréole triangulaire, sessile. Pattes rousses variées do blanc, les postérienues avec les hanches et les cuisses rousses, colles-ci noires a l'extrémité en dessus de même que leurs jambes à l'extérieur et leurs tal'ses. Abdomen allongé, ponctué, avec protubérances sur les côtés de chaque segment et un anneau sonJevé, brillant, aux sutures, le 1er segment à peine plus court que le 2e, canaliculé au milieu à la base avec une carène de chaque coté.-Ottawa (Guignard).

Se distingue surtout du macer, Cress. par sa face noire, ses flancs tacliés de roux, sa plus forte taille etc.

Après le genre GLYPTA, p. 467, ajoutez le suivant.

Gen. ThEkonie. Theronia, Grav.

Tête courte, transversale. Antennes sétacées, un peu plus courtes que le corps. Thorax robuste, assez court; écusson proéminent, non caréné. Ailes avec une aréole triangulaire. Pattes assez courtes, les cuisses médiocrement renflées. Abdomen court, robuste, en ovale, à premier segment brièvement rétréci à la base, plus étroit que le $2 \mathrm{e}$; tarièreun peu plus courte que l'abdomen.

Une seule espèce rencontrée.

Théronie tête-noire. Theronia melunocephala, Cress. 
९-Long. .47 pce. D'un jaune miel nniforme avec la têto noire. Le chaperon, les mandibules, les palpes, avee une tache au dessous des antennes, l'oussâtres. Antennes brun-roussâtre, le scape roux-jnunatre en dessous. Thorax poli, brillant, très finemont ponetué, lo métathorax avec lignes soulevées formant uno aréole allongée sur lo dos. Ailes hyalines-jaunâtres, les nervures brunes, le stigma jaunâtie, l'aréole en triangle oblique. Pattes de la coulenr du corps, l'extrémité des tarees postérieur's plus ou moins obseurcie. Abdomen robuste, en ovale, subnirliculé, le premier segment avec un sillon longitudiual forcoment prononeé sur son disque, à tubercules saillants sur les côtés on uvant du milieu; tarière à valves brunâtres, un peu plus courte que l'abdomen.-_Ottawa (Harrington).

Gell. Epirhyssa, Cress. p. 449.

A l'espèce décrite, ajontez la suivante.

2. Epirhysse en massue. Epirhyssa clavata, n. sp.

q-Long. 38 pee. Noire; fuce noire avec des lignes orbitales blanches interrompues vis-ì-vis les antennes et sur le vertex; les palpes, les écailles alaires, une ligne au-llessous, une antre sur les bords supérieurs et inférieurs du prothorax, une ligne sur l'écusson, blane. Mésothorax fortement gibbeux en avant; métathorax finement ponctué nvec un petit sillon sur le dos. Ailes hyalines, le stigma brun-foncé avec une tache blanche à la base, poirit d'aréole. Pattes jaune-roussâtre, tous les trochanter's blanes, les jambes blanches, les 4 postérieures, noires à la base et à l'extrémité, leurs tar'ses blanchâtres avec l'extrénité des articles noire. Abdomen tout noir, près de trois fois la longueur du thorax et de la tête, renflé b.usquement en massue à l'extrémité; tarière aussi longue que l'abdomen. - C'apronge.

L'absence complète de taches abdominales ne permet pas de la confondre avec la Crevieri.

Gen. Euxoride. Eiıxorides, Cress.

Ce genre ne diffère du précédent que par les car.ıctères suivants: les ailes ont une aréole triangulaire, subqútiolée; la tête 
est p.lıs transverse, étant moins renflée en arric̀ré des yeux; la face est pliss large nu bas, et les pattes postérieures sont proportionnellement plus courtes te plus robustes.

Euxoride a'A mérique. Euxorides americanus, Cress.

-Trans. Am. Ent Snc. III, 167.

q-Long. .33 pec. Noir, opaqúe ; lo labre, les mandibules, les palpes, le scape en desisous, la marge inferrieure du prothorax, lesécaillos alrires, uno petite tache en avant, blane. Thorax allongé, déprimé, les trois lobos antérieur's du mésothorax bien distịncts, le médian dépassant les latéraux, le métathorax finemont rugueux, avec un petit canal an milicu ot une courte pubescence sur les côtés. Ailes hyalines, iridescentes, l'aréole triangulaire, oblique, subpétiolée. Les 4 han hes antérieures et leurs jambes, blanc', leurs cuissen jaunâtres en dehor , les cuisses postérieures y compris leurs lıanches, jaune-miel, leur's troihan. ters a la basc, un petit anncan ì la base et au sommet de leur's cuisses, leurs jamber excepté a la base avec leur's tarses et les tarses des pattes intermédiaires, noir. Abdomen allongé, grêle, légèrement brillant, noir ; tarière un peu plus courte que l'abdomen:-CapRougre.

Bien que notre spécimen diffère un peu de la description de M. Cresson, nous pensons toutefois que c'est bien là la même espèce. M. Cression note les segments abdominaux coinme marginés de blanchître, le nôtre les a tout noirs.

Gen. Pimpla, Fabr. p. 454.

Aux 17 espèces décrites; ajoutez la suivante :

18. Pimple queue-poilue. Pimpla hirticauda, n. sp.

\%-Lung. .20 pue. Variés de noir et de roux; tête noire, sans taches; palpes blancr; antennes brunes, plus pâles à l'extrémité. Tholax d'un roux sunguinuent, le prothorax avec lo dos du mésothorax, noir, eelni-ci avec un sillon médiın. Les, écailles alaires avec les pattes, llanc, los hanches postéricures avec la base de leurs cuisses, roux plus, ou moins foncé. Ailes hyalines, les nervures brunâtres, le stigma fauve, l'arcole subtriangulairc. Abdomen allongé, cylindrique, fortement ponctué, roux br'nâtre avec le piemiel segrment et la cointure apicule de 
tous los antres, noip; talièro un pon plus courte que l'abdómen, noire, poilue.-Ottawa , Guignard).

Se distingue de la rufavoriatre par la coloration de son thorax, ses pattes blanches \&c.

Gen. Grypta, Grav. p. 469

Extra t.LMINA

Giypte de.Californie. Glypta Californica, n. sp:

o -Long. .30 pcie. Noir avec l'abdomen plus ou moin roux. Le labro roussâtro, les palpes et les écailles ailaires, pâles. La face finement ponctuée avec un tubercule au milicu. Antenines entièrement noires. Thorax noil sans aucune tache. Ailes hyalines, le stigma jaune-brunâtre. Pattes d'un beau roux clair, less jambès postérieures noires avec un anneau blanchâtre a la bașo et une longue strie de la même couleur en dehors, lè taises aussi noirs avec ìa base des articlẹs roussâtre. Abdomen noir, avec le sommet de tous les eegments roux; taridre noire, plus longue que d'abdomen.-Californie (Coquillett).

Bien distinct par. sa coloration.

Gen. Lampron jta, Curtis, p. 473.

Aux 17 espèces décrités; ajoutez les 2 suivantes.

8. Lampronota nigricornis, Prov. p. 477.

$\sigma^{7}$-Long. .40 pce. Semblable à la o avec les exception qui suivent: face blanche, ainsi que le scape en dessous; les antennes avec un annea pâle plus ou moins distinct en dessus. Les pattes postérieures noirés ì l'exception de la base des jambes qui est jauno.

18 Lampronote lisse. Lampionota laviguta, CressTrans. Am. Ent. Soc. III, 162.

아-Long. 38 ṕce. Noire avec le labre, les écailles alaires, et les pattes, roux. Tête et thorax finement pouctús ; métathorix très finement ruguoux avec urr petit sillon dorsal. Ailes avec une aréole pédiculée. Pattes et hanches d'un jaџne-loux; les' jaïbes' postérienres à l'extrémité avec leur's tarses, noirâtress. Abdomen 
poli, brillant, lisse, sans taches; tariere plus longue que lo corps. - CapRouge.

Son nbdomen lisse permet toujonrs de ne as ia confondre avec la punctulatu.

19. Lamprouote pieds-noirs. Lampronota nigripes, n. sp.

o-Long. 35 pec. Noire, la face finement ponctuée; deux potites lignes orbitales blanches sur le vertex. Antennes entierement noires. Eeailles alaires noires, muis avec l'urticulation des ailes janne. Métathornx ponctué-r'ugueux, avec un sillon mal défini au milien. Ailes hyalines, le stigma brun, l'aréolo

brièvement pédiculée. Pattes noires, les jambes antéricures avec toutes les articulations plus on moins roussâtres, la base des hanches postérieures aussi roussâtre. Abdomen noir avec les sutures des trois premiers segments basilaires rousses; tarière de la longucur du colp's envi!on.--Ortawa (IJarington).

Bien reconnais:able par ses pattes noires.

Gen: Kchthrus, Grav. pp. 485 et 803.

Aux 7 espèces décrites, ajoutez la suivante.

8. Echthre de-Provancher. Echthrus Provancheri, Brodie.-Cunadian Eutomologist XVII, 118.

9- Lo"g. .48 pre. Noil avec l'abdomen en partic roux, la tête et le thorax entièrenıent noirs, très finement ponetués; la fuce.avec un petit tubereule an milieu; les mandibules, les jalpes, les antemuer, noir. Le mésothorax trilobé et lo métathorax rugueux sur les côtés et en arrière. Ailes lógèreǹent erfumées, les nervar y et le stigma, noir, l'aréole grande, presque carrée. Pattes roussen, les hauch.s altériures, les cuisses et les jambes postérieures à lewr sommet, noir, les tarses postérienrs aroc la base et l'extrémité noires, le milieu blanc. Abdomen pédiculé, co: pédicule poli, brillant, les autıes segments ponctués; segments 1, 2 et 3 a'un roux brillant, le reste noir avec l'avant dernier segment blanc. Tarière noire, épaisse, presque anssi longue que le corps.

ठ -Avec les palpes, les 4 hanches antérieures et leurs tro-

chan abdis

brillar ricurs postér neall : bane d eonitin: tué, sa foinleve térieur tache blances, scurein. niers is de l'abc

Le distingu

Tèt petits. formes, déprimé

(1) Déc Pletysoma lui substit 
chanterw, blanc; print de tache blunche su: le pénultième segment abdominal.-Muskokn, Ont.

Espèce bien remarquable par sa coloration.

Gen. Xrlonomus, Grav. p. 488.

Aux 4 espèces décrites, ajoutez la suivante.

5. Xylonome chaud. Xylonomus caliılus, n. sp.

q-Tonun. :36 pee. Noir varié de roux. Tête noire, polie brillante; to labre, 2 petites taches an dessus, les orbites antericur's interrompus au dessons do l'insortion des antennes, les postérienr's dilatés au milien et interrompus sur lo vertex, un anneau anx antennes, les écuilles alaires avec tous les genoux ot la base du ler alticle des tarses postérieu:s, blance. Antennes plus courti's que le corpss, g iêles, filiformes. Thorax densément ponctué, sany tubercules an prothorux, le métathorax ronx, a lignes foilevées distinctes et portunt 2 petites épines à 8 a fuco postérieurẹ au bas. Ailes hyalines, le stigma brun avec nno grande tache blanche a la base. Pattes d'un roux sale avec les genoux blancr, les jambes postérieures avec leurs tarses plus on moins obseurcin. Abdomon allongé, subpédiculé, roux sal avec les dernier's segments brun plins on moins funcé; tarière de la longueur de l'abdomen environ.-Ottawa (Harrington ?.

Les taches blanches de la tête avec le métathorax roux distinguent facilement cetite espèce de toutes les autres.

\section{Extra limina.}

\section{Gen. Aplomìne. Aplomerus, l'rov. (1)}

(De aplous, simple et meron, cuisse).

Tête grosse, piolonģée en arrière dès yeux, ceux •ci, un peu petits. Antennes sétacées, fortes, à articles courts, submoniliformes, de la moitié de la longueur du corps. Thorax long et déprimé, le prothorax prolongé antérieurement en forme de cou,

(1) Décrit dans le Canadian Entomologist, vol. XVII, p. 115, sous le nom de Platysona, mais comme ce nom a déjà été employé pour un autre insecte, il faut lui substituer celui de Aplomerus.

Ir: tro- 
plus étroit que la tête; le mésothorax avec son lobe médian nvancé é élevé sur le prothorax; écusson déprimé avec une fossette en avant; le métathorax allongé, portant 4 carènes longitudinales. Ailes courtes, sans arcole, la nervule divisant les 2 cubitales courte. Pattes avec les cuisses renflces, inermes, les jambes cylindriques à la base, s'élargissant ensuite et étunt légèrement conprimées, les intermédiaires très comprimées au milieu de leur partie élargie. Abdomen long, brièvement pédouculé, le premier segment déprimé, portant une carène sur ses bords latéraux, l'extrémité légèrement comprimée et fendue en dessoins pour la réception de la tarière, qui est aussi longue que le corps.

Allić anx Xylonomus et anx Odontomerus, mais différant des uns et des autres par des antennes plus courtes et plus fortẹs, par, les cuisses inermes, et par la forme des jambes.

Aplomère tibial. Aplomerus tibialis, Prov.

Pla'ysoma tibialis, Prov._Can. Eut. XVII, 115.

○-Long .45 pee, longueur de la tarière .45 pee. Noir, avec les jambes rousses et l'abdomen d'un roux brunâtre. La tête et le prothorax fuítement ponctués, la fossette en avant do l'écussón striée. Le métathorax strié transversalement à la bnse entre les earènes. Lo premier segment abdominal finement acieulé entro les carènes marginales. Vaalves de la tarière diun brun ferrugineux.-Vaneouver (Taylor".

Hétéropelme longs-pieds. Heteropelima longipes, n. sp.

$\sigma^{\lambda}$-Lóng. .85 pee. Nöir varié de roux. La face au dessous des antennes, les mandibules avec le scape en dessous, jaunepâle, le reste de la tête, excepté une grandu tache noire sur le vertex, jaune roussâtre. Antennes assez courtes, minces à l'extrémité, jaune-orange, le scape noir en dessus. Thorax roux, les sutures, le bord inférieur du prothorax, le lobe médian du mésothorax en avant de l'écussol, le sommet du métathorax, noir ; l'écus:ou.et les 
érnill's alnires, jaunes. Ménathorax à rougosi és transverses. Ailes subhyalines, jaunâtres d la baso et bruıatres a l'extrénite, lo stiguna jaune, les nervures bjunes. Pattes jaune-orange, les 4 antérieures plus claires, les postérienres nvec l'extrémité des han. ches, des cuisses ot les jumber, noir. Alidomen allongé, grêle, longuement pédiculé, janne-roussâtre, le 20 segrnont uvec uno tache noire sur le dos, les derniers brunâtres.-Californio (Coquillett).

Nous devons d̀ la bienveillance de M. D. W. Foquillett, d'Anaheim, Californie, de posséder 1 u lot d'Hy'néwoptères parmi lesquels se trouvait cette espèce nouvolle avec quelques autres que nous décrivous ci-dessous.

Banche à-queue. Bunchus caudutus, n. sp.

ㅇ - Tong. .40 pee. D'un roux orange; le chaperon, les maindibules, avec les orbites antìricurs, janne-pâle. Antennes avec une tache d l'endroit des ocelles, noir, le scape roux en dessous. Thorax ronx avec les sutures noires; écusson ponctué, inerme. Ailes hyalines, légè: ement obscurcies à l'extı'émité, les noivures noires, le st:gma jaune, l'aréole pédiculéo, triangulaire. Pattes de la coulcur du corps, l'extrémité des jambes postérieures avec lo premier article de leurs tarses, plus ou moins obscinr. Abdomen poli, brillant, sans ancuno tache; tariere noiro, du quart de l'abdomen environ. -Anaheim (Coquillett).

Bien remarquable par sa tarière distinctement sortante.

Fam. V. BRACONIDES. Vol. $I I, p .491$.

Gen. Bracon, Fab. p. 497.

Aux 17 espèces décrites, ajoutez la suivante.

18. Bracon pieds-noirs. Bracon nigripes, n. sp.

o-Long. .20 pee. Noir avec l'abdomen roux. Tête globuleuse, entièrement noire, bion remplie en arrière des yeux, la faco fiuenent ponctuée. Thorax allongé, déprimé, poli, brillant. Ailes plus ou moins enfumées, la récurronte reçue dans un angle de la 1ère cubitale. Pattes entièrement noires, les trochanter's postérieur's roux en dessus à l'extrémité. Abdomen ontièrementroux 
s'élargissunt considérublement jusqu'uแ sonmmot du 2o segrnent, to Jer uvec ln partio méliano soulevéo et accompangéo d'une potito carène de chaque côté, le 20 nvec une protubérunce triungulairo a lu buse, rugueux dans lo resto, les autres polis, brillants. 'lurière noire, plus longue que l'abiomen. - Cuj Rougo.

o-Mímo colorntion queduns la qurce l'abdomen moins élurgi nu sommet du 2e regmont.

Var. Les mandibules rouskos avec l'oxtrémité noire.

Voisin du r'ufovariegatus,muis s'eu distinguant surtont par ses pattes entièıment noiles.

Gen. Sypgaster, Brulle, p. 508.

Aux 4 espèces décrites, ajoutez les 2 qui suivent.

5. Syngastre pieds-noirs. Synyaster atripes, n. sp.

으-Long. .35 pce. Noir avee l'abdomen roux-jannâtre. Têto noiro sar.s aucuno tuche, subglobuleuso, bien remplio en arridre des yeux. Thorax noir, lo métathorax ponctué-1uguenx avee une liggne curénale au ınilieu. Ailes hya ines, légèrement obscures, le stigma brun. Pattes noires, les turse d brunâtres. Abdomon on orale allongé, lo premier segment seul rugueux et portant une putite carène de chaqun côté du milieu peu distincte, légèrement obscurri a la basc, le 20 sans protubérance au miliou, lisse de même que le reste; tarière de la longueur de l'abdomen environ.-CapRouge.

Son $2 \mathrm{e}$ segment abdominal lisse le distingue surtont du fartus.

6. Syngastre rư̧ueux. Syngaster rugosus, n. sp.

O-Iong. .3 pre. Noil avec l'abdomen roux. Tête on carré, entierement noire, la face arer: pubescence griłâtre. Thorax allongé, poli, brillant, uxcepté le lobe méllian du mésothorax qui est ponctué-puğneux on arrière, de même quo le métanotum. Ailes plus ou moins enfumées, la récurrente reçue dans un angle de la lère cubitale Pattes noires, les hanches postérieures avee 
leurs chisses excepté un somimet ot lo métulhorux, rrux. Alulomen en ovule i purtio" du 20 segment, to promier large, 1 et 2 ariculés, lo reste poli, brillant, les segments terminumx plus pôles ot fortensent rétrécis. 'Turicre forte, un pen plus longruo qua l'abdomen. CupRongo.

$\sigma^{7}-$ Avec len cuisses postériemres a'un roux brunatre, l'ubdomon ausvi d'un roux brunâtro, aciculé nenlement a la baso du ler sogrment.

La forme de con abdomen et son métunotum ruguenx le distinguent surtout du macilentus.

Gen. Opıus, Wesm. Ip. 511 et 804.

Aux 2 espèces décrites, ajoutez les :3 suivautes.

Abdomen avec l'extrémité rousse ;

Abdomen noir i la base ............ mellipes, (1) 511.

Abdomen enticrement ronx.........3. macrocephalus, n. $s p$. Abilomen noir a la base et i l'oxtrénité ;

Tête en nujeure partio rousse ............ ruflceps, $n$. sp.

Tête noire, lo scinpo dos antennes senlement roux;

Stigma fiuve; 2 e cubitule à nervuro supérieuro presque dioite; «bdomen obsciurément taché de roux ................. politus, 80 t.

Stigma noir ; 2e culitule à nervure supéricure fortement anguleuse vis-i-vis le stigna ; ubdomen avec le 20 segment jaune.5. cinctus, $n . s p$.

3 Opius macruoéphøle. Opius macrocephalus, n. sp.

\% Long. .17 pec. D'un bean roux clair, brillant, a l'exception de la tête qui est noire ot trè̀ gro ise ; mindibules roussâtres, la face swee un petit tuberenle au milien; antenues noires, le scupe anssi noir avec un petit cercle roux an sommet. Lo thorax, les pattes, l'abdomen, d'un beau roux clair; lo métathorax r'ugueux. Ailes légèrement obscurcies, le stigma très grınd, noir ; les tarses avec l'extrémité des jumbes postérıeures, brun plus ou

(1) Le nom spécifique pallipes employé à la proge îl1 étunt déjù sippliqué à un insecte de Belgique, doit fuire place à celui de mellipes. 
moins fonces. Alorlomin en ovule ullongé, non extrémité brunatre, non premier segrment rugueux, avoc un sillon de chnque côté do la partio médinno qui est noulevéo. Ottuwn (Hurrington).

Cetto bello espiece se distingue de toutes les autres par sn colorition.

\section{Opius tête-rousse. Opius ruficeps, n. sp.}

क-long. .1t pee. Noir, avec la têto, les pattes et une coin turo a l'ubdomon d'un roux plas ou moins palo. Une tache noiro silr lo vertex a l'undroit des acolles. Antennes avec lo scapo roux. Thorux poli, brillant, les lobes du mésethorax très dis.tincts, lo métathorax rugueux. Ailes hyalines, iridescontes, ia :-o cubitalo plus longuo que large recornot la récurrente a son anglo interne, lo ntigmu noir, grand. Puttes d'un roux pâle avec lo delnier article den tarkes noir. Abdomen a premior, seginont noir, portant 4 petices carenes, lo reste poli, brillant, les segments 2 et 3 roux, le reste noir; turjèro no dépassant pas to dernior nogment-Ottawa (Guignard).

La poitrine est aussi quelquefois tachée de roussâtre.

5. Opius à-ceinture-jaune. Opius cinctus, n. sp.

o-Long. .12 pee. Noir,poli, brillant; la bouche, lo seape en dessous, les écrilles alaires nvec les pattes, jauno-roussâtre; la fucco à pubescence grikâtro. Métnthornx ruguenx. Ailes hyalines, lo stigma noir, la 2e cubitale fortoment élargie vis-i-vis lo stigma. Les pattes y compris les hanches suns autre tache que lo dernicr articlo des turses qui est noir. Abdomen court, bridvement atténué a l'extrémité, noir avee le 20 segmont juune en dessus, lo promier ruguenx avec une fossette de chaque côté do la partio médiane, lo 20 avec un rudiment de protubéranco au milieu de sa base. CapRouge, Ottawa.

Daus le $\sigma^{x}$ le jaune de l'abdọmen s'étend souvent au 3 e segment. 
Gen. Prantitus, Fsenb. p. 511.

Aux 4 espèces décrites, njoutez les 4 suivuntes.

Têto et thom nx, noir ;

Alubmen noir a la base et a l'extrémitó;

Abromen tout noir, lo métınlıorux plus on

moins tuché do juune ....... 5. gracilis, $n . s p$.

Abdomen plus on moins tuché de junne an

20 segment, inétuthorix tout noir.(i) robustus, $n .: p$.

Abiomen plus on moins junnâtre a la baso;

go cubitulo ainssi large quo longue....7. politus, $n$. sp.

2 e cubitulo plus longuo gue largo.8. incompletus, n. sp.

'́êto juuı, du moins on purtie; thorax juแı (quel-

quefois tachó do noir);

ler nogrment ubdominal noil';

Antennes a urticles courts, les orbites ponté-

riour's juunes ............ dimidiatus, 512 .

Antennes is articlos plus allongés, têto noiro

on arridre des youx ............4. humilis, 513.

Antonnes a articles allongés, In tête et lo mé-

sothorux ontidremont junnes .....2. vulgaris, 512

1or segment abdominal plus ou moius jauno; têto ot thorax juunes.............. 3. communis, 512

apo on lin fuce $\theta$ nes, lo tigma. lornior ht attélo prejo mede $\mathrm{sa}$

5. Périlitè grêle. Perilitus gracilis, n. sp.

\&-Long. .13 pce. Grêle, noir avec les pattes janno-roussâtre. Ia bouche, les palpes, les écailles aluires, uvec los flanc's ot l'uxtrémité du métuthorax, d'un juuno ronssâtre sale. Ailes lígdrement enfumées, lo stigma grand, brun-loussâtre, la norvure récurrente fuisant suito is la norvme inter-enbitule. luos jambes postérieures avee leurs tursos, plus ou moins obscur. Abdomen tı'ès grêle a la base, ot en formo do losange a l'oxtrémité, tout noir (quelquefois le 1er segment junnatro); turide do la longueur do l'ubdomen.-CapRongo.

6 Périlite robuste. Perilitus robustus, n. sp.

q-Long. .22 pee. Noir, la bonche, to scape entièrement, les antennes en dessous à la base, le prothorax, les écuillesalaires, les pattes avec lo 20 segment abdominal, d'un beau roux ciair. Thorax nois, poli, bıillant, lo métathorax finement ponctué-ru- 
gueux. Ailex hyalines, les nervures pâles à la base, lo stigma griand, brun funcé, avec une tache pâle à la base, la nervaro inter-cubitale ne faisant point suito à lat récurrente. Liextrémité des. jambes et des cuisses postérieures aveo leurs tarser, brun plus ou moins foncé. Abdomen en ovale à partir du 20 segment, le premier rugneux, le reste poli, brillant; tarière plus longue que l'ablomen. Caplonge.

La plins furte taille de tontes les espèces par nous rencontrées.

7 Périlite poli. Perilitus politus, n. sp.

- Long. . 18 pee. Noir, poli, brillant, avec les pattes d'un roux jaunatre sule. La bouche, les antenues en dessous à la base avé les écailles alaires, roux-jaunâtre. Métathorax finement rugrueux, à linnes soulevées distinctes. Ailes byslines, lo stigma brun, pâle à la base, la lécurrente faisant suite à la nervure intercubitale. Le dernier article de tous les tarses noir. Abdomen a premier segment ruguenx, lo reste poli, brillant, médiocrement élargi postérieniement, d'un jaunâtre sale, noir à l'extrémité' seu-. lement; tarière un peu plus courte que l'abdomen. - CajiRonge.

¿Iême coloration dans le $\sigma^{\top}$, les tarses postérieur's seulement sont plus sombres.

\section{Pér:lite incomplet. Perilitus incompletus, n. sp.}

$5^{x}$-Lon!̣. 10 pee. Noir, arec los mandibules, les pillpes, les paltes et le lor sogment abilominal jauine-jále. Antennes avec le sciupe noir, les articles subclenté : en dessons. jaunâtres dans le bas. Métathor:ax lugueux. Ailes hyalines aveo lo stigma brunâtre, une grande radiale at eignant presque l'extrémité de l'aile, Ia 2e cubitale beanconp plus longue que large, la $30^{\circ}$ incomplete. Abdomen avec lo premior kegment jaune, acicule, lo reste en ovale allongé, poli, brillant.-Uttawa (Guig ıad .

Petite espẹce bien reccnnaissable par la disposition des nervures de ses ailes.

Gen. Gamosecus, Prov. p. 513.

Aux 2 espèces décrites, ajoutez la suivante.

3. Gamocelle têtr.-larğe. Gamosecus laticeps, n. sp. q-Long. .18 pec. Jaune-pâle varié do noir. T'ête traus- 
versale, très large et courte, non épaissie en arricie des yeux, jau $\tau$, noire sur le vertex entre les yeux Antennes brunes en dessun, le scape jaune en dessoun. Thorax janne avec le dos noir; ai es hyalines, les nervures pâles disposées comme dans le vigilu:x; lo stigma jaune, long et étroit, le radius se dirigeant én droite ligne au bord postérieur. Pattes jamess sans aucune tache. Abcomer janne, noir ì la buse et à l'extrémité; tarièro du quart de sa longuemr environ.-Ottawa (Harringrion .

Se distingue du vigilax par sa tête large mais non épaissie en arrière des yenx, son stigma plıs long et plus étroit etc. Bien remaiquable par sa tête large et courte.

Gen. Microcronus, Wesm. p. 804.

A l'espèce décrite, ajoutez les 2 suivantes.

2. Microctone céphalique. Microctoñ us cephalicus, n. sp

б-long. .25 pce. Jaune-pâle, avec les yellx, une tache sur lo vertex a l'entroit des ocelles, le dos du thorax et l'abdomon en partie, noir. Tête cubique, jenflée en arrière des yeux; antonnes de longnour moyenne, brunâtres à l'extrémité. 'Thorax avec le dos noirâtje et les flunes roussâtres. Ailes hyalines, iridescentes, le stigma trẻs grand, jaune de même que les nervures, Is. radiale courte se fermant au stigna sans conmuniquer à la cubitale, une scule cubitale et $\mathbf{2}$ discoüdales formées, la nervure parullèle non intersticiale. Pattes jaune-pâle. Abromen pédiculé, l'un noirâtre plus ou moins funcé sur le dos et en dessous.

Capturé à Ottawa. La grosseur de sa tête est particulièrement remaryuable.

3. Microctone linéaire. Microctonus linearis, n. sp.

†-Iıng- .13 pee. Noir, avec les pattes d'un roux brunâtı'e; le scape roussâtre en dessous. Antennes longues, filiformes. Thorax long, i $r$ étathorax rugueux, les écailles alaires noires. Ailes hyalines, le stigma brunatrc, la radiale grande quoiquo n'atteignant pas le sommet de l'aile. La base des hanches, l'extrémité des jambes et des cuisses postérieures arec leur's talses, brun plus ou moins foncé. Abdomen allongé, linénire, le pre. mier segment rugueux, les autres polis, brillauts, le 20 plus ou 
moins rousantre, l'extrémitó comme tronqué, tarière non sortante. -CupRouge:

Bien distinct du punctatus par sa forme plus grêle et plus allongée.

Gen. Rhopalophurus. Hal. p. 515.

A l'espèce décrite, ajoutez les 3 qui suiveñt.

Ailes hyalines, non fasciées;

lère cubitale pétiolée.

2. patiolatus, n. p.

1 èro cubitale non pétiolée ;

Abdomen plus ou moins jaune ..... 1. tauricornis, 515.

Abclomen intièrement noir ; antennes lon-

gues .................... 3. longicornis, n. §р.

Ailes légèremont enfumées avec une fascie hya-

line ................... 4. fasciatus, n. sp.

2. Rhopalophore pétiolé. Rhopalophorus petiolatus, 11. sp.

$\$$-Long. .10 pee. Noir, poli, brillant avec les pittes jamnemiel. Antennes plıs courtes quo le corps, grenues, plus grêles et

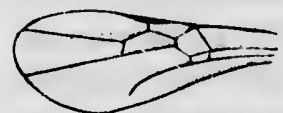

Fig. 7.

pâles à ia base. Tête transverse, non échancréc on arrière. Mésothor'ux sans sillons distincts; métathorax rugueux. Ailes hyalines, ciliéces do poils courts, la première cubitale longuement pédiculée, la 20 étroite, longue, subpentagonale; recevant la récurrente d̀. son angle interne, stigrma tr'ès étroit, presque nul. Pattes jauno-pâle, les tarses brunâtres. Abdomen à pédicule peu allongé, rugueux, le resto on ovale, poli, brillant; tarière dépassant peu l'abdomen.--Cap Ronge.

La sịngulière disposition de la lère cubitale distingue cette espèce de toutes les autres.

Fig. 7-Aile du Rhopalophorius petiolatus, Prov.

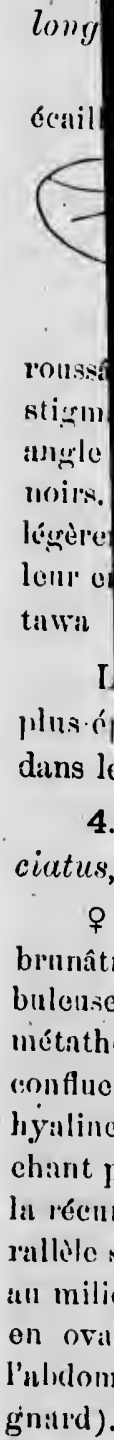

$$
\text { La }
$$

Fig. 8. 
3. Rhopalophore à lougues cornes. Rhopa'ophomes longicornis, "sp.-Fig. S.

p-Ismg. 12 pee. Noir, los mandibules, los pa!pes, les écailles alairas arec los patten, l'un jaunâtre sale: Tête en carré,

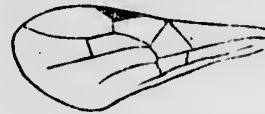

Fig 8. épaisi-e el mricie des yeux, le vertex non excavé, la face finement ponctuéc. Antemes lon șnes, légèrement coudées à la base, filifornes, à peines plus épaisres à l'extrémité, brunes, avec le scape ronssâtro en deso:ıs. Métathorax rugueux. Ailos hyalines, le stisma brunâtre. la 20 cubitale recevant la récurrente à son angle interne. Pattes postéricures avoc les cuisses et les iarses woirs. Abdomen noil, wans tache, lo premier segment rugueux, lémèrement élarıi :ı sommet, les autres formant:un ovale dans lour ensemble; tarière presque an-si longue que l'abdomen.-Ottawa Guignaml).

La forıne lle sa tête et ses s.ntennes, bien que faiblement pluscŕraissess à l'extrémité, rangent, sans conteste, cette espèce dans les Rhopalophores.

4. Rhopa ophors à-ailes-fasciées Rh̆opalophorus fas-. ciatus, n. sp.

9 - long. .Varié de roux-brunâtre et clo noir. Tête l'o:ıx. brunâtre, noiro sill le vertex, épaisse en atrière des yeux, subglobulense. Thiorix mux-brunâtre, lo dos dı mésothorax noir, 10 métathoma muncux avee une càne de chaque côté du miliere confluentes à la bave. Ailes légèrement enfumées, aveci une fascie hyaline en avait clu itigma, la lde cubitale pédiculée, ne touchant pais la discoüdale externe, la ze étroite et allongéo, recorant la récurrente a son angle interne. la 30 complete, la nervure parallile sub-intersticialo. Pattes brun-ronssâtrc, les cuisses noires all milien. Ahdomen à pédicule long, ruguenx, rons-âtro, lo restẹ en ovale, noir: poli, brillant; tariere forte, de la longuenr de l'uhdomen, loumâttre a la base, noired l'extrémité.-Ottawa (Guig'nard).

La furme le la têto et la.nervation des ailes nous'engagent Fig. 8.-. Lile du thopalophorus longicornis, Prov. 
a ranger cet insecte parmi les Rhopalophores, bien que notre gpécuimen soit privé de ses antemnes.

Gen, Phylax, Wesm. p. 521.

Aux 3 espèces décrites, ajoutez les 2 suivantes.

Dus de l'abdomen tout noir';

Pattes jaune-pâle; ailes fiangées...... 1. palliventris, 1 :1.

Pattes rousses; ailes non fiangées ...... 2. rufipes, 521.

Dos de l'abdomen plus au moins taché de jaune au 20 segment;

Thorax entièrement noir ;

Lo scrape et les écailles alaires $q$, noir.. 4. curtus, $n$. $s p$.

Lo supe et les écrailles alaires + , jaune-

roussâtre.................. 3. cinctus, $5: 2$.

Thorax noir avec la poitrine jaune........ 5. gracilis, $n . s p$.

4. H'hylax court.' Plıylax curtus, n. sp.

q-Long. .11 pce. Noir, poli, brillant, la face rétrécie ot allongéo inférieurement, la bouche jaunâtre. Antennes fortes, filiformes. Thor'ax court et robuste. Ailes passublement obscurcies, plus claires à l'extrénité, la première cubitale rec'evant la récurrentod son angle interne. Pattes d'un roux brunâtre avec les hanches noires, les jambes postérieures noiles avec un petit annę̧u pâlo a la base, lou's tarses aussi noirs, leurs cuisses plus on moins obscures à l'extrémité. Abdomen court et robuste, épris wu 20 segment, et en triangle i partir de cepoint, les segnents 2 vt 3 plins oil moins jaunes, le reste noir; tarière beaucoup plus longue que l'abdomen.-Ottawa (Guignard).

ơ-Avec la bouche, les palpes, la face an dessons des antennen, excepté une tache noire au milieu, les orbitos antérieurs et postérieurs, et les écailles alaires, jaune pâle. Les pattes jaunemussatre, los postérioures avec les hanches noires, leur's jambes ausssi njịres avec un petit anneau pấle à la base, les turses noirs et los cuisses légèrement obscurcies au sommet. Abdomen avec lo 2e segment, les côtés du ler et le ventre, jauno plus ou moins c|ạir.-Cap Rouge.

Malgré la différence de coloration, nous pensons que ce sont bien là les deux sexes de la mê.ue espèce.

res, l lant. ancul moins Roug

sans $t$

$$
\text { Ent. }
$$

int. $X$

117.

vent.

A

Tế

égales o lon $\mathrm{du}$ reçoit lo ailes inf coirit, ar moins

Ces

forme art de leurs

Deu

Premier: Sughents 
5. Phylax grêle. Phylax gracilis, n. sp.

$8^{7}$-Long. .16 pce. Noir, avee la bouche, les écailles alai : res, les pattes et le ventre, jaunc-pâle. Thorax allongé, poli; bril lant. Ailes hyalines, lc stigma assez grand, brun. Pattes san: aucuue tuche. Abdomen allongé, grêle, noir en dessus, plus ou moins distinctement jaunâtre sur le dos du $2 e$ segment.-Cap: Rouge.

Bien distinct du cinctus par sa forme grêle et ses ailes sans tache.

\section{Extra limina}

Fhylax du-Pacifique. Phylax pacificus, Prov.-Can. Ent. XVII, 117. - Vancouver. (Taylor.)

Phylax noir Phylax niger, Prov:-Can. Ent. XVII 117. - Vancouver. (Taylor.)

Aprés le genre Phylax, p. 521, placez les trois qui sui. vent.

Gen. Brachiste. Brachistes, Wesm.

(Dẹ brachiste, très courte).

Tête de ia longeur du thorax, à vertex convexe. Antennes égales ou plus conrtes que le corps. Fuce séparée par un petit sillon du chaperon. Ailes avec 2 cellules cubitales dont la 1èrẹ reçoit la récurreıte; la ¿e discoïdale fermée postérieurement; ailes infórieures éch.ıncrées inférieurement. Abdomen sessile; court, arrondi sur les côtés jusqu'à l'extrémité; tarière plus ou moins lougue.

Ces insectes se distinguent surtout des Eubadizons par la forme arrondie ou spatulaire de leur ablomen et par l'échancrura de leurs ailes inférieures.

Deux espèces rencontrées.

Premier segment stbdominal seul acicu'é. 1. submucronatus. Sügrments abdomiınux 1 et 2 aciculés... 2. crassigaster, n. sp. 
1 Brachiste submucroné. Brachistes subneucronatce, Prov. ; Eubudizon submucronatus, Prov. Fune p. 513.

2. Brachiste à-abclomen-épais. Brachisteg crussiguster, v. sp. - Fig. 9 .

8-Long. 19 pee. Noir, poli, brillant, avee les pattes d'un beau jaune-miel. Corjes robuste; abdomen conrt el épris. 'Tế:o ati:

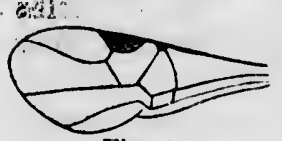

Fig. 9.

grosse, la firco finement ponetnée, à pubescence blanchâtre, séparcéc dı labre par uแ petit sillon. Antemues longnes, enroulées.à l'extuémité, lrunos, roussâtres à la basi.

Mésothorax à divirions distinctes, le love médian avancé; métathorax court, Jugueux. Ailes hyalines, le stignan noir, la radiale en ovale aigu, le cubitus à pen près d'égale grosseur dans tonte sa longueur, la -e disicoüdale fernéo postérienrenent. Pattes y conipris les hamchen, d'un bean janne-miel. Ablomen sessilo, court, large et épais, avec les 2 premiers segrments aciculés sur le dos. Tarière de la longraeur de l'abelomen environ.

ઠ๐-Même culoration que dans la $q$, mais avec l'abdotnen plus allongé et plus étroit.-Caplionge.

\section{Gen. Blaque. Blucus, Esenb.}

Tête transver'se, de la largeur du thorax ; le labre saillant. Antennes souvenc velues. Prothorax légirement jrolongé en avant. Ailes avec ane radiale dont la nervure inférienre est droite ou légèrement courbe, 2 cubitales, la lère recevant la récurrenté, le cubitus brusquement interrompu après avoir tracé lé comménsement de la $2 \mathrm{e}$; la 2e discoïdale ouverte postérieurément. Abdomen sessile. Tarière longue, droite.

\& Les insectes de ce genre sunt bien reconnaissables par la nervation de leurs ailes.

Deux espèces iencontrées.

Tarière plus longue que le corps; ler segment ab-

adominal simplement acieulé....... 1. longicaudus, $n s p$.

Tarière de la moitié de l'abdomen environ; ler seg-

ment abdominal arec un petit sillon de chaque côté du miiieu................. 2. defectuosus, $n . s p$, Fig. 9.m-Aile du Braehistes crassiyaster, P'rov. 
1. Baque àlongue queue. Blacus longicaudus, $\mathrm{n}$, sp. - Fig. 10.

o - Iong. 12 pce. Noir avec les pattos jaune-pâle ; les main-

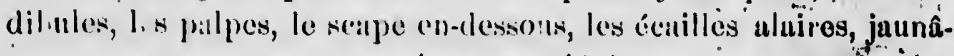

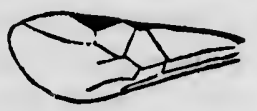

Figg. 10. tres. Antennes légèrement noucuses, plus oll moins $j$ ullâtrest it lia base on dessoun. Mélitthorax prnctuć, à lignes nonlevées distinc:es. Ailes hyalines, to stigma jaunobrunâtre, le rudins teìs légr remont courbe, la

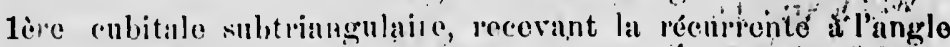
interive de sil bave, la 20 a peine commencée." Le. jumbes pósté riences plus ou moins obscules en dessous. Ähiomen sestilo, s'épaiswissant de la batse au soinmet, le prenier egrment acirulé, le reste en fintme de cylindre, proli, lrillint ; tariere du double do l'abdomen en longruenr. Óttilwal (Guignard).

\section{Blaque défectueux. Blecus defectuosus, n. sp.}

of Long. .13 pee. Noir avec les pattes jaune-roussâtre. Autennes brunce, le sceipe noir. Nésothorax avec 2 petits sillons obliques sur le dos, mítathorax rugrenc. Ailes hyalines, le stigma gr:and, allıngé, brunâtrọ, une. grande radiale en formo do fer de lanee, la lere enbitalo grantle, presque en carré, recovant lit récurrente, lit 2 e a poine commencée, la 1ere discoüdale tres. grinde, plus longue que la "e qui est ouverte postérieurement. Ablomen avec le lor segrnent rugueux, les antres polis, brillant; ; tariere un pou plus courto que l'abidomen:-Ottawa (Guignard).

\section{Gen. Orgree. Orgylus, Huliday.}

\section{Ischius, Wesmael.}

Tête tranşversale, anıssi iarge que lo thorax, yeux glabres. Antennes à anticles très noinbrenx. Ailes avec une cellule radiale ollongue-lancéol'e, cịnẻifurmé, conplète, $2 \%$ cellules cubitales dont la lère reçoit la récunente, là $2 \mathrm{e}$ incomplète, sóvivent à peine commencée. Abdomen sessile, de longueur moyeñne ; tariere longnie, filiforme.

$\cdots, b^{2}$

Ces insecte's se distingnent surtont des Blaques par la nervation de leurs ailss. Une seule espèce rencontrée.

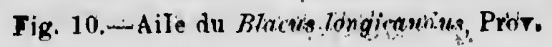


Orglle découvert. Oıgilus detectus, n. sr. -Fig. 11.

7-Long. .14 nce. Noir avec les patter rousses. Mandib. Lles rousses ; face finement ponctuée. Antennes longues, pu-

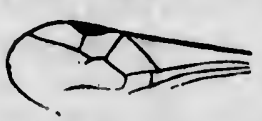

Fig. 11. bescentes, enroulées a l'extrémité, ronssâtres en dessons a la baso, le scape noir. Jos du mésothorax poli, buillant, ses lobes distincts ; métathorax scubre, wans carènes distinctes. Ailes hyalines, les nervures noires, la 20 cubitale onvorte en dehork. Pattes d'un roux brunâtre, les postérieures avec l'extrémité des.jambes et les tarses plus, ou moins obsenr. Ahdomen noir, le ler segment avec les deux tiel's du 20 finement rugnenx, lo reste poli, brillant, les segments terminaux, a partir du 4e, apparents, quoique plus courts. Tarière plus longue que l'abdomen.-Ottawa (Harrington.)

\section{Gen. Capiton. Capitonius, Brullé.}

Tête grosse, en car é, épaissie en arrière des yeux et à occiput excavé. Antennes ordinaires. Thorax assez conrt et robuste, le prothorax court, déprimé, formant une espèce de cou đominé par le mésothorax qui s'uvance au dessus, le métathorax en carré prolongé en un court pédicule sur lequel vient s'insérer l'abdomen. Ailes avec une grande cellule radiale et 3 cubitales complètes, dont la 1ère reçoit la récurrente, nervure parallèle non intersticiale. Pattes ordinaires. Abdomen brièvement pédiculé, inséré sur le bord supérieur din métathorax, le premier segment étant de forme conique et l'ensemble formant une massue ovale; tarière très longıe, 2 fois an moins la longueur de l'abdomen, ses valves plus épaisses à l'extrémité.

Brullé avait rangé ce genre parmi les Evaniides; ces insectes ont, de fait, quelque ressemblance avec avec les Aulacus, surtout quant à l'insertion de l'abdomen; mais comme la nervation des ailes joue le principal rôle dans la distribution des Hyménoptères, le manque de la 20 récurrente les range incontestablement parmi los Braconides, dans la sous-famille des polyunorphes. Tant qu'à l'insertion de l'abdomen à la partie su-

Fig. 11.-Une aile de Orgylus detectus, Pror. 
périeure dn métathorax, ce n'est pas dailleurs le seul exemple parmi les Briconides, puisque les Puxylomma de Bróbisson possèdent aussi ce caractère.

Une seule espèce rencontréc.

Capiton tête-rouge. Capitonius rubviceps, n. sp.-Fig. 12.

ㅇ-Long. 18 pce. Noir avec la tête rousse, une triché sur le vertex, avec la fice au dessous des antennes, noir plus ou moins

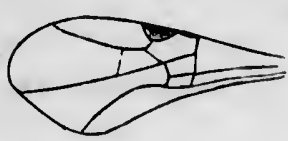

Fig. 12. ronssâtre. Tête plus large o to thorax, échancrée al l'occiput, portant sur le vortex une fossetto pour l'insertion des antennes et dans. laquelle se runge aussi. l'un des orelles. Antennes longues, filiformes. noires avec lo scape roux. Thorax et abdomen noirs, sans tacher, te premier forteinent rugueux, mais non strié transversalement, le prothorax rétréci en coul sur lequel s'avance le mérọthorax, dont les lobes sont te'ès distincts. Les flance, de même que la face, a pubescence blanchâtre. Métathorax rugueux, son bord postérieur relevé en un court pélicule sur lequel s'insère l'ubdomen. Ailes avec le stigma noir, triangulaire, la radiale en fer de lance, 3 cubitales dont la 1ère reçoit la récurrente. Pattes brun-foncé, l'extrémité des euisses brunâtre. Abdomen a premier segment s'élargissant de la base au sommet, rugueưx avec la partie mélliane soulevée et séparée du reste par un sillon de chaque côté, lo 20 segment très grand, lisse, et formunt avec lo reste un ovale, épaissi a l'extrémité ; tarière de la longueur du corps, ses valres épaissios al l'extrémité.-Ottawa (Guignard).

Les nouveanx genres introduits nous portent d modifier comme suit, la clef de la sous-famille desPolymorphes.

\section{POL YMORPHES.}

1(7) Abdomen pédiculé;

2(5) Trois cellules culitales;

31 4 ) Antennes filiformes ou sétacées........ Perrlrus, 511.

43 , Antennes épaissies a l'extrémité... Rhopalophorus, 515.

F'g. 12 -Une aile du Capitoni 's rubriceps, Prov. 
5(6) Denx cellules cubilales dintincter ... Mr voogroxus, 804.

6(2) Denx cellulen cubimles, mais la tèro mio

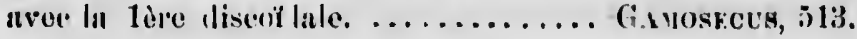

7(1) Abdomon sessile oll -ubsessile;

8(1ii) Trois collules cubitules;

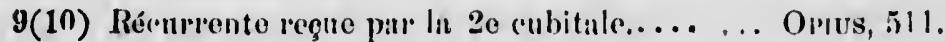

10(9) Récurrente régue pur la lèro cubitule;

11(1:) Le front arec uno fosisette entre les untonmes et les ocelles, et mo dent au haut de la fince a l'inse.tion dos antennes. . .... Hercos, 515.

12(11) Front anns fossotte, point de ilont ì l'insertion dos milennes;

13(14) Vortox mince, tête courte et hur.uge, com-

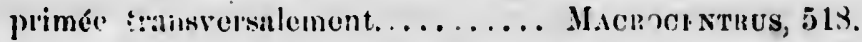

::14(13) Vortex plein, la tôte, le pluxsonvont épaissio en arricive des yeux; mésothorix non tuberenlet. . . .................. PuYıAx, 521.

15(8) Deux cellules culitules;

16(23) Abdomen insćré a la partio inférieure dn métuthorin ;

17,20) La 20 discoülalo (1) complitement forméc;

18(19) Abdomen long, a dos étroit, d'égale lallgenr d'un bont a l'autre; ailes inférienres sans échancıuro au côté interno........ JBADizos, 517.

19(19) Abdomen cont', larire, ariondi sur los côtés jusqu'd l'extrémité; ailes intérienres fortement échancrées au côté interno. Buscustriss, We m. 131.

20, 17) in 20 discoïdale entro curerte postévisurentent;

21(22) Radiale ovale-aiguë ............ BLArus, IVesm. 132.

22 21) Radiale cunćiformo.............. OrgYuls, Hatid. 133.

23,16) Abdomen inséré a la partio slupérieure du métuthorax qui s'allonge en pédiculo pour le receroir.................. Capritonits, Brul. 134.

(1) Voir la fig. 48, de la page 491, pour la distinction des cellules discoidables. 
Gen. Acatuis, Jatr. p. 522.

Aux 5 especes dícrites, ajoutez la suivante.

Agathis sorutatear. Agathis srutator; n. sp.

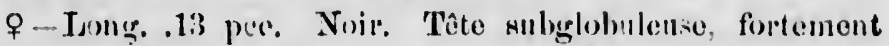
échancrée en arriere. Antennes longnes, filiformes, enroulées d lextrémilé. Thos:a g̣ibbenx on uvant, lo métathurax rugrnenx. Ailes paswablement enfunces, la ruliale tres petite, le stigma

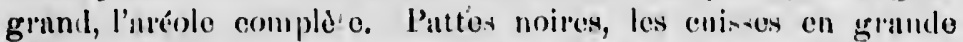
partio janne-miel, do mêne fro les junnbes postétionres excepté a l'extrúmité. Abdomen kessile, lo premier sogmont rugnenx, les autres polis, brillauts, les segrmenty 2 ot 3 jumnes, lo reste noir. Tariese vioire, plus longuge que le eorps.

ó-Même colosation que dinns la femelle a l'uxieption des pattos qui ont beancoup plus de jauno, los cuisises et les jambes postéricures étant entic:'oment de ectte coulen:. CaplR Myo.

Gen. Microdus, Esenb. p. 524.

Aux 5 espèces décrites, ajoutuz les 2 suivintes.

Abdomen entiòrement noir ;

Hanches jaune-miel.............. 1. Quebecensis, 52.

Hanches noires............... 7, nigricoxus, $n . s p$.

Abdomen plus oll moins roux on jauno-miel;

Thorax entidrement noir;

Toutes les hanches jaune-micl ;

Abdomen noir, taché de jaune-miel seule-

ment au 20 segment;

Chaperon noir ; jumbes portéricuies rouswes............. 2. laticinctus, $\mathbf{5} 25$.

Chaperon roux, jambes postéricures blanches............. 3. annulipes, 5.5.

Abdomen avec les 3 premiers segments

roux..................... 4. agilis .

ul. 134.

Toutes les hanches noires ...........6. dispar, n. sp.

Métathorax roux, ablomen roux avec seule-

ment le $\dot{1 e r}$ segment noir........... 5. bicolor, 526 
6. Mlorsda non-"varoll. Microrius dispar, n. sp.

f-Tong. .12 pere. Norir, la bonche noiro; tête on rarré tmunvirat, epainae. Thomx eutierement noir. Ailes subhyulinon, lo ntigma noir. Pattes roux.janmatre, nvec los bunches noirew, les pontérienren nvoe ln bino den cuinses, l'extrémité des jam-

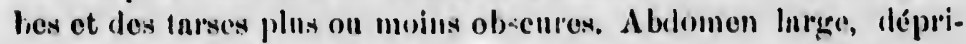
mé, nswez court, noil nrec lo ze nogment roux phusun muins clair, les 2 premiors serments aci-nlés; thriere nussi longue que lo thorux et l'ubdomen pris onsemble. Capplouge.

Differe surtout du luticinctus jur son 2e segmunt ub lominul aciculé et sa plus petite tuille.

7. Micro ?e hanches-noir.s. Microlus nigricomus, n. sp.

\&-Tong. .15 pee. Noir, len palpes uver les 4 paltes muterieures, jumne-ronseâtre. Antennos longues, sétucéces, moires, enroulées a l'uxtrémité. Métuthơnx rlugueux. Ailes hyalines, légèrement enfumées, lo stignın éroit, trids ullonge, novir. Toutes les

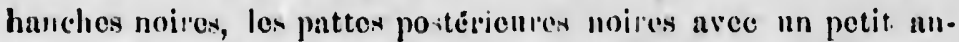
neal it la bne des jumbes et un bien plus latge an milien, roux, les épines de lenr extrémité pâlus. Ablımen entièrenn nt noir. les 2 p'eniors sogments ringunx, lo reste pori, brillant, lo 20 segrment avec une impression transverse au milich. 'Tarioro plus longue que l'ablomen, ses valves noires, plus épaisses a l'oxtlémité.-Ottawa (Harrington).

Bien distinct du Quebecensis, par ses hanches noires, et la structure de son abdomen.

Gen. Microgaster, Latr. p. 527.

A 1 x 7 espèces décritus, ajoutez les 10 qui suivent.

1(16) Qe Cullule cuivitulo complète; (1)

2(10, Suture des flanes du mésothorux créncléc, comme alvéoléo;

3.4) Ailes fusciées de biun.......... 1. callipterus, 527.

4,3, Ailos non fisciées d. bru');

(1) Cette cellule est dite complète lorsqu'elle possède an moins une par: ie de sa nervure extérieure, et incomplète lorsqu'elle en est totalement privée. 
5(6) 20 kegment sbilominul rugnumx.. 8. brov' caudu", n. sp.

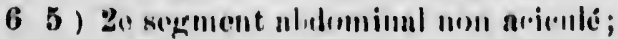

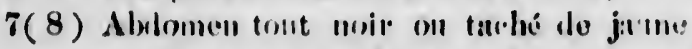
neulement : Inx rôtén a lı bu-c.. .... 2. xylnas, b28.

89 ) Abdonen nx. lo 20 segrment janne, noi Mlextrémite .............. . zonarius, Sin.

9 ( 7 ) Abdomen noir a la line, mon a lextré.

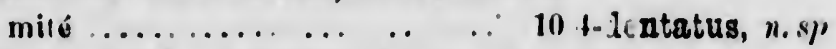

10(2) Suture des fluter du minn ho:

11(15, 2o segment ublumimal senble;

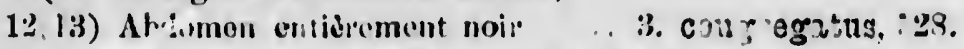

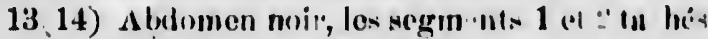
de jumue smr lex côtés ...... 11. Interalis, n. sp).

14(12) Alulomen roux, taché de mij \& la base .................... 12. auripes, $n . s n$.

15(11) 2escument abrlominal outierrment lisse. 4. carpatus, 528.

16i (1) 20 crilule rubitule in omp ete;

17(24) ze segment ubulominal jugueux ;

$18(23$ Tuntes les hinchos nuires;

19(22) 20 angrnent a! derminal nver nue potitı: forsotte brillante of ponctuéc nar le ilo:; antennes trìs fortes;

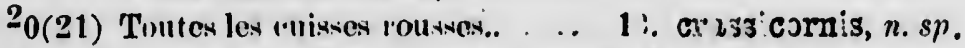
21(2 ) Tonton les ruisses noires. ... 14. fomur-nigrum, n. $s p$. 22(19) 20 segment "bduminal sans fossolte, muis portant avec lo 1or, mne potico cardios mélianc. .................. 15. acaudus, n. $s p$.

23(18) Toutes les hanches jaune-miol; intennc, longnes ot grêles.......... . 16. long: cornis, n. sp.

24(25) 20 segrment nbdominal rugnoux a la basc, lisso an rommet......... 17. melligaster, $n . s p$.

25 17) 2 e segment abdiminal non rugurux, quoique souvent avee une impressiou transvorse press lo la bane;

véoléo; s, 527 .

e par: ie vée.
$27(28$ Ifa ches rouswes ... . . . . . . . 5. ensiger, 529.

26 27) Alidomen toist uoir; 28.27) II:tnches nuires ou binn-foncé . . . 7. c'avatus, 129. 29(-6, Abdomen noir avec une bundo :ousse. 6. cinctus, 529 
8, Microgastre queue-courte. Microgaster brevicaudus, n. sp.

\$ - Iong. .15 pee. Noir arec les pattes yousses. Iues palpes avec lesécuilles alaires jatune-pâtc. Ailes sublryalinces, la 20 cellule.cubitale incomplete, sa norrure extérieure manquant, la la diale aree sa nervure inférieure incomplite, le stigrma brun. Low jat.es et les hanches ciun bean roux, les cuisses of les jambes pos. télicures avec un petit anneal noir an somnuch, lell's tarkes b: buatres. Abrlomen avec ie premiel kergment rugucux, le 2 caJécé an milieu, cette carène, fort élargie a la base, tarièrea peine sortante.

La petite carène de son 20 segment abilominal distingue partienlic̀rument cette espèce du cluvatus et du crassicornis, sus antenues sont aussi épaisses que ceiles du crussiconnis. -Cipturé au Ciplionge.

9. Microjastre à-bande-jauns. Microgaster zona. rius, Say-Say's Am. Eıt. II, 714.

o-Long. .11 pee. Noir, ponctue, avec les pattes et une bande à l'abdomen, jannâtres. Antennes brunes, roussâtres en dessons, le scippe jaunâtre en dessons; la boucho jaunâtre, les palpes blancs. Ailes hyalines, la maliale avee la nervure pen marquée, la 2e cubitale petite, mais complete. Pattes james, les tarses prostérienrs brums. Ablomen court, ses côtés avec uno bande transversale sur le dns, jannâtres; talrière de la longracur de l'abdomen environ.-CapR: nuge.

10. Microgastre à-quatre-dents. Microgaster 4-dentutus, n. sp.

J-Tung. .18 pee." Noir, rugueux, la face chagrinée arec lépixtome inlesé an miliru. Antennes fortes, le scapo roux en dessous. Thorax aree 2 lignes obliqu's convergeant vers uno fo.sette alvéoléc en avant de l'écusson; métathorax lugueux avec une forte carène an milien. 'Ailes hyalines, les rervure brunew, colle de la cellule radiale obsolete i la base, 2e cellule cubitale potite mais complète. Sligma grand, épaisis, blun-foncé avec uno tache pâle à la batie. Patte. ron nes areé les hanches nuires. Aldornen Inrge, court, aplati, les 2 premiers segments prigueux, 
le rese poli, les 2 prem ers segments ave lit bas. dn 3 e noir excepté un côtés, lo r ste roux avec une strie brume an milien plus on mon. ét ndue; les segments terminaux offant 2 lentelures de chaque ôté,-Ottawa (Guignard).

\section{Microgastrı à-côtés-jaunes. Microguster luterulis} n. sp.

q-Long. .13 pee. . Noir avec les pattes janne-miel; la bonche avec les écailles alaires, jaune roussâtre. Ailes lyyalines, le stigma gran !, brun-roussâtre, la 20 cubitale cumplete. Les 4 hanches antéricures arec leurs trochanters, blanc-jannâtre, les postérienres rousses, noires a la bave, lẹs jambes po térienres noires avec la ba-e rousse, leurs éperons blancon, lents tarses loi:s plus on moins distinctement annolés do ronx a la batse des articles. Abdomen noi:, l. 1er segment ruguenx, le 20 . nguenx it la base, lisse an somnet, cette parlie sépacée du rente pat:" une im-. pression transversale, tous demx boriés d'une bamle jame str. les eôtés, le reste pol', noir; tar ère noire, forte, aplatie, de a loirgueur de l'ablomen, les fances de l'ab.iomen roussâtres à lal base. -Canpronge.

\section{Microgastre pieds-çorés: Microguster auripes,} n. sp.

-Long. .17 pre. Noir, avec les pattes et l'abdomen d'un bean janne-poux, les mandibules. le scitpe en dessous alvec les éerailles alatires, brun-: olls:âtre. Antennes nétacéces, épaisser à la base. Thorax entièrement noir, fincinent ponctué, le métathorax scabre. Ailes hyalines, légerement enfumées al l'extrémité, le stignma brun, pấe à la base, la 20 cubitale complete. Pattes y compris les banches d'un beau jaune-roux, les pontériemres avee l'extrémité des jambes et los tarses plus on moins obselur. Abdomen roux, taché de noir sur. le milieu des 2 p:emiers seng rents qui sont rugueux, lo 20 avee un petit sillon de chaque côtú do la partie médiane, les segments terminaux quelquefois aussi tachés do noir an milieu; tarière courte, à peine sortante, noiro.Ottawa (IIarrington).

Voisin par sa colorition dı t-rlentatus, mais s'en distinguant surtont par la structure de son 2 e segment alulouinal ses hanclies rousses etc. 
13. Microgastro grosmes-ccrnes. Microgaster crassicornis, n. sp.

q-Long. . 18 pec. Noir avec les pattes d'un roux foncé. La fare allongée, rétrécio inférienrement et ponctuće, mandibules très allongées; les palpes pâles. Les écailles. alati es rousses. Le métathorax rugueux aver: uno petite fo-setto an milien. Ailes sub-hyalines, les nervures de la moitié apicale à peine distinctes, celle divisant la raliale de la lère eubitale tres forte, aréole incomplete. Toutes les hanches noires, les postérioures très grosses; l'extrémité des jambes postérieures avec leur's tarses légdrement obscurcis. Abdomen jout noir, les 2 premiers segments ruguons, en carré, le 20 arec une fossette au milieu, le $3 e$ rugueux ì la base et rétreci postérieurement, le 40 relevé et comprimé tranchant arece les suivants, l'extrémité tronquée; tarière plus longue que l'abdomen, sontenue par une forte gaîne en dessous, ses valves muires, aplatics, poilues.-Ste-Gertrude.

C'est ì Ste-Gertrude, eomté de Nicolet, que nous avons cilpturé ce remaruquable insecte. Les mandibıles allongées de cette espèce lui donnent quelque ressemblance avec les Agathis.

14. Microgastre cuisses-noires. Microgaster' femurnigrum, n. sp.

8-Long. . 1: pee. Noir, la face et le thorax avec une co'ute pubescente grirâtre, lo métathorax très scabre. Antennes conrtes, fortes, rétacies, suns taches. Ailes hyalines, le stigma b:un-foncé, la 20 cubitale incomplète. Pattes y compris les hanrhes, noir, les 4 antérieures avec les jambes et lo sommet des cuisses rous:âtrese, les postérienres avec les cuisses entièrement noires, leui's jambes roussâtres seulement à la base. Abulomon noir, sans.taches, les 2 premiers segments seabres, le 20 partagé en 3 lobes par 2 sillons longitudinaux; tarière à peine sortante.Ottawa (Hatrington).

Ses cuisses noires et sa plus petite taille, le distinguen $t$ surtout dı crassicornis.

15. Microzastre sans- queue Microgaster acaudus n. sp.

бo $q$-Long. . 10 pee. Noir arec les pattes jamies, palpes blancs. Ailes hyulines, le radius a peine distinct, la 20 collule 
cubitale incomplete. Pattes d'un bean jaune-miel avee les hauches noires, l'extrimité des jambes postérieures avec lenis tarses exeepté à la base du ler article, brun plus ou moins foncé. Aldomen noir, en massue, los flanes da ler segment tachés de jaune, les 2 premiers segments rugueux; tarière à peine sortanteOttawa , Guignard).

Se disting sue surtout de la crassicornis par sa tarière dípassant à peine l'extrémité de l'abdomen.

16. Miorogastre à-longues-cornes. Microgaster lengicornis, n. sp.

$\sigma^{7}$-Lnng. 10 pec. Nisir avec les pattes jaune-micl. Anten:ies longues et grêles, à articles allongén, le sciape jaunâtre an dessons. Mésolhorax rans sutures distinctes, le métathorax r'ugueux avo : une carène an milicu. Ailiss hyalinor, le stigm : brunjaunâtr., le radius à peine marqué, la 2 e cub tal incomplète, ses nervures extérieure: manquant. Abdomen avec les 2 premier's segments aciunlés-rugueux, lo reste poli, brillant, lo lor avec ses côtés jaunes.-CapRoùc.

17. Miorogasier veistre-jaune Microguster mellzgaster, n. $\mathrm{sp}$.

우-Long. . 18 pee. Noil avic les pattes et l'abdomen d'un buau jaune-miel ; les mandibules ronssâtıen, les palpes 1 âles. Antennes brun-roussâtre, le se:ıpe noir. Thorax densément ponetné, le métathorax rugueux. Ailes hyalines, lo stigma billl-roussâtro, la 20 distoödalo complète. Ise pattes postérieures avec l'ixtrémité des cuinses, le sommot des jan lies et les tares, noir. Ablomen assez large, épais, jaune-mel, avec une grande tache à la base sur lo dos et une antre sur les segnente terminaux, noilo le ler segment avec ln moitié du 2 e scabre, le reste poli, brillant; tarière nonro dépassant à puino i'extrénité le l'alụdomen.-SteGertrude.

Gen. Sigalphu:, p. 530.

A l'espièce décrite, ajoutez la suivante.

n. sp.

alpes cllule

2 Siga!phe divise en-tıois Sigulphus trisectus, n. sp.

$\delta^{7}-$ long .20 jice. Nuir avec les pattes rousses; les ma di

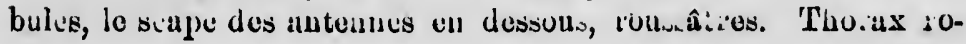


buste, les flaurs en partie aciculés, lo mét.uhnrax fortement rugueux. Ailes hyalines, le stigma grand, subtriangulaire, roussâtre, le cubitir atteignant lo sommet de l'ilile, la radialo grande' ovale-aigruë. Pattes d'un beau roux arec le dernior articlo dos tarses noir. Airlomen sessile, ovaleroblong, partagé on trois par les sutures au sommot des segments 1 et 2 qui sont tiès enfoncées, to premior seguent aciculé, les autres polis, brịilants-CapRoinge.

Bicn remarquable par son abdomen divisé en tro: parties. Gen. Chelonus, Jur. p. 530.

Aux 7 cspees dévites, ajoutez les 2 qui suivent. Aldomen taché à la base;

Seape des antenne entièrement noir.

Denx taches' i la base de l'abdomen. 1. insularis, 521.

Une tache ì la base de l'abilomen.... 2. basicinctus, 521. Sc:ipe des antennes roux, du moins en dessolls 8. rufiscapus, $n$. sp. Abilomen sams taches à la base;

Hanches noi:es;

Cuisses postérieures noiles ;

Métanotum avec 2 petites carènes longi-

tudinales ................. 3. sericeus, 522.

Métanotumu saṇs ('al'ènes;

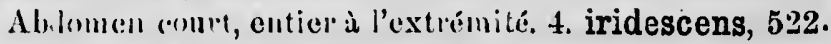

Aludomen allongé, fendu transvor-

saloment à l'extrémité ......... 5. fissus, 522 .

Cuinien protici ieures pousies, noires a l'ex-

trúnité reulement ;

Caisaces monse:; ventre raréné arce

la tarière sullinte $\ldots \ldots \ldots \ldots .6$. carinatus, 523.

Cuimes jaules, ventre sans caldre,

ta: :i..., erchét ............ 7. nanus, 52\%.

Il aches te:t:k cer, fice à pulescence argen-

tiv.................... argentifrons, n. sp.

8. Ch'lofia à scape-roux. Chelonus rufiscapus, n. sp.

9.1 ontr. .18 pre. Noir, scabre; In's mandibulos avec to scape do. anti anes d'un bua soux. Tcat to thoiax ponctué 
Plıgueux, le post écusson seul étant poli, lo métnthorax sans carènes lonyitudinales. Ailes hyalines, legèrement obscurcies vers l'extrémilí, le stigma.noir avec son bord inféricur roux. Toutés tes hanches noires, les $\dot{4}$ pattes antérieures rousses, les cuisses postérieures noires avec un petit anneau roux a la base, les 4 jambes postérieures noires avec un anneal roux all milieu, leurs turses plus on moins roux a la buso. Abdomen noir avec une tache pâle à la base de chaque côté, tous les segments a jugosités allongées, l'extrémité ınédiocrement plus lagrgo.-CapRouge.

Bien distinct de l'insuiaris 1 ar son scape roux, sa plus petite taille etc.

9. Chélone front-argenté. Chelonus argentifrons, n. sp.

бొLong. .17 p•e. Noir, rugneux-chagrins, les mandibules, le scape avec les pattes, jaune-roussatte. La face et les flancs avec une puluscence argentéc très appapnnte, surtout sur la face. Antennes brunâtres, jaunâtres à la base. Métathorax sans carènes. Ailos légèrement enfumées, plus fortement a l'ondroit du stigma, celıi-ci noir, de même quo les nervures. Toutes les hanches avec los 4 pattes antérieures, jaune-pâle, les tar'ses plus ou moins obscur's, les pattes postérieures avec l'extrémité des cuisses et des jambes noire. Abdomen noir, sans aucune tache, rhagriné-i ugueux, légè̀ement plus largè à l'extrémité, le ventio pâle.Ste-Gortinde.

Bien r'unarquable par sa face argentée.

Après le Gẹre Chelonus p. 530, insérez le suivant.

Gen. Ascogastre. Ascugaster, Wesm.

(De askos un sac, et gaster ventre).

De même que daus les C'hélones, la carapace de l'abdomen se compose d'une seule pièce. Les yenx sont glabres et non velus comme dans les Chélones. Ies ailes ont trois cellules cubitales dont la lère est séparée de la lère discoïdale; la is. 
currento est intersticinio on atteint l'origine de la 2e cubitale. Pour le jort et l'aplarence semblibles aux Chélones, Une seule espice rencontrie.

Ascogastre pattes-rousses. Ascogaster rufipes, n. sp. -Fig. 13.

q-Jong. .17 pee. Noir; la face rugnense et pubescento dans le bis. Tête en carré transressal, fortement épatissie en arrice des yenx. Antenness routses a la bise,

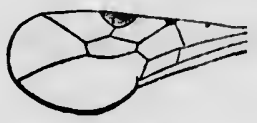

Fig. 13. noires a l'oxtrémité, se termiı ant en pointe tine. Tiécusison et lo métationax grossièrement ponctués. Ailes hyoiines avec un nuage plus ou moins obscur au milieu, lemrs écailluttes noires. T'attes rousses, les postérieures avec l'extrémité des cuisses, des jambes et les tarses, noir. Abdomen tont marqué de rugrosités Inngitudinales, noir, quelquefois obscurément taché de roux à la baso; le ventre roux à la base passo ensuite au testacé. CapRouge.

Les rugosités aliongées de son abdonın avec sa base tachée de roux distingueut surtout eette esprèce.

Gen. Rimtiniaster, Wesm. pp. 534 et 805.

Aux 2 espèces décrites, ajontez la suivante.

3 Rhitigastre ovale. Rhitigaster ovalis, n. sp.

o - Loner. 10 pee. Noir; les mandibules, les palpes, lo scape en dessous, les écailles alaires, blanc, les patter-janıe-pâle. Tête en carré, plus burge que le thorax. Antennes lesignes, filiformes. Thorax gribbenx, court, billart. Ailes hyalinew, iridescentes, le stigma étroit et très long, la radiale très grande, atteignant le hout de lanile, trois cubitales dont la lère est la plis petite, la 20 longue et étroite reegoit la récurrente a son origrine, la 3 e incomplète, la nervire parallèle non intersticiale. Abdomen avec le ler segment prugueux, allongé, formant un pridiculo étroit, noir, le reste formant un ovale, poli, brillant, jaun avec l'extrémité noire, tarière à peine saillante.-Caphouge.

Se clistingue fucilcment des deux antres par sit coloration.

Fig. 18.--Une aile de l'Ascogaster rufipes, I'rov.

tient :

5
sale,
l'extré
avec lo
hyalin

1ère di

pointe stigmil les hit ovale a -Ottin tale ply 1) sa plus 
Sous-fimnille V. EXODONTES p. 335.

Les 3 genres que nous ajoutous anx deux déji déerits, poum ront se distinguer les uns des antres comme suit.

Nervnre paralièle non intersticiale;

1ère cubitale sépartée de la lère discoülale;

Trois cellules cubitales............ 20. A I.ysta, 535.

Denx cellules cubitales, la 20 incemplète. Dacsusa, Hal.

dère eubitale confondue avec la lore dis-

coilale..................... Tringria, $n$. gen.

Norvure parallète intersticiale ;

lère cubitale séparcée de la lè̀e clis-

enilate ............ ............. Asynapies, n. gen.

1ère cubitale confonduc avec la lère dis-

coüdale.................... 21. Trichesia, 536

Gen. Alysia, Latr. pp. 535 et 805.

Des 5 espèces décrites, retrancliez la première qui appartient au genre Asynaphe, et ajoutez la snivante.

5. Alysie sornplète. Alysia completa, u. sp.

o.-Loug. .10 pee. Noire avec les puttes jaunc-roussâtre sale, quelque pen brunâtres. Les mitndibules rousses, noires à l'extrémité. Tête grosse, en carré, antemes longues, filiformes, avee le scupe roux ea dessons. Ise métathorax ruguenx. Ailes hyalines, avec 3 cubiales complètes, la lèro grande, dlivisće de la 1ère discoülale, recerant la récurrente, la 20 longne, retréeio en pointe antéricurement; la nervare parallèle non intersticialo; lo stigrma gr'und, b. un-jaunâtre. Paltes jaune-brunâtre y compris les hanches. Abdomen noir, poli, brillant, déprimé, court, en ovale allongé; tarière forte, noire, de la longueur de l'abdomen. -Ottawa, Guignatud).

$\delta^{x}-\Lambda$ stigma presque nul; de plus petite taillo; la' 2e cubitalo plus allongée en avant et recevant a sa pointe la récurrente.

Diffëre de la cuudutu par li forme des cellules des ailes et sa plus petite tailie. La 2 e cubitale est beancoup filus étroite 
et forme un triangle à partir do sa base, et la $2 \mathrm{e}$ discoïlale est égale à la première antírienrement, tundis que dans la coudata la 2e cubitale n'est triangulaire qu'ì $p$ artir du stigma et la 20 discoïdale est plus courte que la 1ère antérienrement.

Après le genre Alysia, ajoutez le suivant.

Gen. Dacnuse. Dacnusa, Huliday.

Tête transverse; occiput non excavé. Antennes longues, quelque peu enroulées à l'extrémité. Thorax subcylindrique. Ailes avec une radiule n'atteignant pas l'extrémité et deux cubitales, la 1ère recevant la récurrente et étant seule fermée. Nervure parallèle non intersticiale; stigma étroit et allongé. Abdomén subsessile, le 1 er segment se rétrécissant à la base, l'ensemble formant un ovale allongé; tarière sortante.

La nervation des ailes distingue surtout les Dacuuses des Alýsies. Deux espèces rencontrées.

ler segment abdominal seul aciculé........ crassitela, $n$. $s p$. Les 2 premier's segments abdóninaux aciculés.2. spatulata; $n$. $s p$.

1. Dacnuse à-queue-épaisse. Dacnusa crassitela, n. sp. -Fig. 14.

\%- Liong. .14 pec. Noire, avec les pattes jaune-miel ; les mun'dibûles jaúnatres excepti' a l'extrémité. Antennes brune , le scape

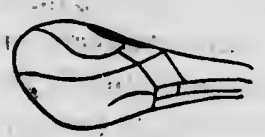

Fig. 14. en densolls avec la base des antennes, jallnâtres. Le métathorax tronqué à. l'extrémité, rugueux. Ailes hyalines, le stigma brunfoncé, long et étroit, radiale semi-cordiforme, natteignant pas le sommet; lère cubitale on carré oblique, la 20 plus étroite, nón fernée en dehors. Le dernier article des tar'ses noir, les postéricurs légèrémènt obscurcis. Abdomen poli, brillant, oxcepté le ler segmont qui est rugueux, on ovalo allongé; tarière moins du qualt do sa longueur, droite, épaisse.-Ottıwa (Guignard).

Fig. 14-Une aile de la Dacnusa crassitcla, Prov: 
2. Daonuse en-syatule. Ducnusic spatuleta, n. sp.

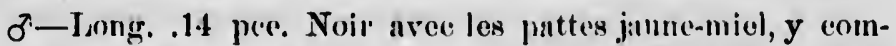
pris les hanch is; les mandibules avec uno tacho jaune, les émlles alaires noires; le métuthorax ponctué rugueux. Ailes hyalinos, les neivures briunes, le stigmu long et étroit, la imdiale grande, ovalaire, n'atteignant pas lo sommet, lo cubitus atteignant lo sominet, nuais ne consorvant sa grosseur que jusquia su moitié. Abdomen en spatule; élargi et arrondi ver's l'extrémité, los 2 premiers sogments uciculés, lo premior presquo enré, a suture le divisant du denxieme profunde.-Ottawa (II..mington,.

Gen. Trinalle. Trinaria, nov, gen.

(Trintrius, de trois; a.lusion aux trois masges presque igales que furment la tête, le thorax et l'ubdomen)

Tête très grosse, à vertex légèrement excıvé, à fice bornbée. Antennes très longues, filiforues, à ạıticles allongés, poilus. Thorax court, timpu, subglobuleux. Ailes velues, d stigma très étroit, avec une grande radiale atteignaut l'extréimité, 3 culitales dans la lère est confondue avec la discoüdale sinpérieure, la $2 e$ allongée, plus large en avant, la $3 e$ presque complète; la discoïdale inférieure plus courte que la supérieure en avant, la nervure parallèlé non iutersticiale. Pattes ordinairus. Abdomen court, en missue, à tarière médiocre.

La disposition des nervur's des ailes nous a engagé à séparer ce geure des Alysies.

Trina:re à-cornes-poilues. Trinaria piliconnis, n. sp.

\$-Long...12 peo. Noire aves les pattes jaunes. Les mandibules excepté a l'extrémité, lo scupe des anterines, le p:othorax avec les pattes y compris les hanches, jaune rousiatre. Ailes velues, hyalines, iridesentes, les nervmres brunes. Abdomen en massue, poli, bridlant, légèremént taché de jaunâtre à la baso ; la tarièrc du quart'de sa longueur environ, ses valves poilnes. Les pattes aussi avec poils pâlús.

Cap,turée an Caplionge. 


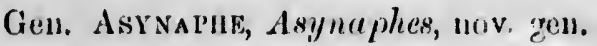

(De a privntif et Synuphe, unon; allusion ì la sépurution les leux c.llu'es discoüdaless).

Tête grosse, trausversule, anssi large ques le thurax; fice bombée pour lu réception des antennus. Antenues longues, filiformes, velues. Thurax court, fusiforme. diles avec une grande radiale ntteignant le sonnmet, trois enbitules innt lu preniière est séparée de la liscrïlale supérienre, la Je allongée, plus large en avant; la nervore parallèle intersticiale. l'attes grêles, les

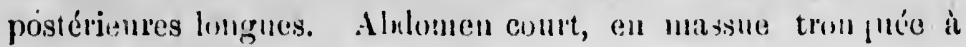
lextrémité. Turière de la lo igneur du l'ablumen.

La nervure intersticiale murait ces insectes anx Trichisies, mais la lère cubitale n'est gas unie avec la discoülale supérieure, c'est là ce qui nous a engingé à en formur 111 grenre distiuct.

Trois especes rencuntrées.

Tariere de la longuen de l'abdomen environ;

Lo prothorax aree lon écailles alaires,noir....... l. coudeta.

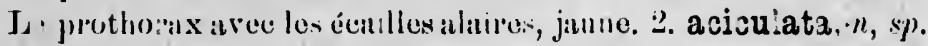
Tiuriere il peine du quart de l'abilomen ... 3. brevicauda, n. sp.

1. Asyna he à-forte-queue. Asyurephs cuculuta, l'rov.; Alysia cuudatu, Prov. Faune: p. 535.

2. Asyna tho acicuiée Asynrephes reciculctu, n. 'sl.' Fig. 15.

9 -I mg. .12 pee. Nuice polie, irillante; les mandilules excepté à l'extrémité, les jouses, le scipue des antenues, le proiho-

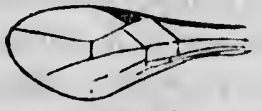

Fig. 15. max, les écuilles alaires, los pattes a" le ventre, jaunc-pâle. Los jambes pisstérienres b:unâtros anı som 'uet, le derricer article do leurs tarses, noir. Abdomen claviforme, a pédicnlo s'élarưissant de la base à l'extrémitǵ, finement aciculé sur sa face supérieure, le reste poli, brillant; tarièréćgale à l'abdomen, ses valves noires, légèrement poilues.-Otawa (Guignated).

Fig. 15-Une aile de 1 Asynaphes aciculatu, Prov. 
3. Asynaphe à queue-courte. Asy..ciples brevicauda, n. $s p$.

- - Iong. .14 pre. Noire, polie, brillunte, avee les puttes, les mandibulos, excepté a l'extrémité, les, ones, lo srape en des-

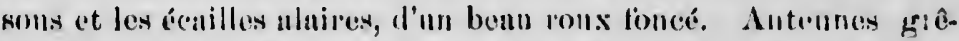

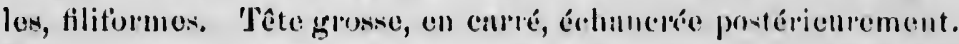

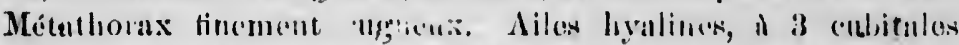

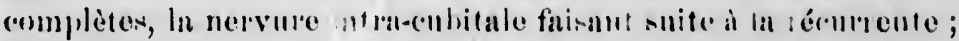

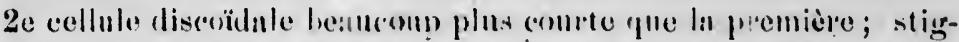

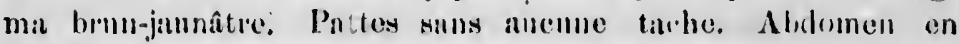
ovnle, à premiel regment rugneus, lo resto dépiné, poli, brilIant; tarjère dépassint a peinge lo dernier sogment ubdominal. -CiplRonge.

\section{Sons-fin. VI. FLEXILIVENTRES, 1. 537.}

Les insectes de cestte so:ss-famille ont, li plupurt, une forte ressemblauce entre eux. Il n'y a g'ière que la nervation des ailes qui serve à distinguer les genres les ins des antres. Comme ces iusectes, et surtout eeux de l'Amśrinure, n'out encore été que fort pen étudiés, le noubre de ceux ineutionnís par les auteurs est très restreint. Nous ajoutons ciny genres nouveaux anx trois précédenment donnés dans notre Guve. Nul donte que des recherches et des études plus suivies ne penvent ajouter encore considérahlenn'nt à ce nombre.

Comme les figures, en parlant anx yeux, sont très souvent plus promptement comprises que le texte, nous donnons des figures des ailes de tous les nouveanx. genres que nous avous formés.

\section{Clef pour la distinction des genves.}

Radiale ineomplete; is madius étant interrompu avant d'atteind:e lo bord de laile;

Cubitus présent ;

Une on 2 cellules cubitales.......2 2. Mpmorus, $5: 37$.

Ancune cellnle eubitale ferméo $: \ldots . \Delta$ phmara, $n$. gen.

Cubitus absent, point de cellules roubitilex.Nevineseses, n. gen. R.sliale complète, le radius atleignant le bord de l'aile; 
Doux cellules cubitules ;

Norvure parallele interaticinle (1)...24. Coprus, 539.

Norvuro purallelo non interstleinle;

Radiun ne dirigenut en ligne druite an

hord de l'aile; rmdiale étroite. Ropronsa, n. gen.

Rudius so dirigount eu ligne courbe un

bord de l'uile; rudiale grande. R.turos.ana, n. yen.

Trois cellulos cubitales;

Nerviro parallde intersticialo...... Kinenese, ILulid.

Norvure parallelo nou intersticialo;

Ablomen rylindrique, ótrungló entro les

segments 2 ot $3 . . . \ldots \ldots . . .23$. Aroveropus, 538.

Abdomen en ovale-nllongé, presque linéni-

jo, non étranglé à la 20 suture. Scotroneutus, $n$. gen.

Gen. Aphidius, lisenb. p. 537.

A l'espèce décrite, ajoutez la suivante.

2. Aphidius obsour Aplidius obscurus, n. sp.

o -long. .17 pce. Noir, poli, brillant, In ficce mu-lessous des antennes, jaume. Iues écuilles nlaires ot les hanches noires; métathorix avoe uno curène transversale au sommet. Ailes hyalines, volues, le stigma brun-pale, en trinnglo allongé, la radialo grando, ouverto en dehors, ln to cubitalo commencée. Pattes bru plus ou moins obscur, pâles aux urticulations. Abdomen d pédicule noir, lo resto brun plus an moins junnâtre, taridre noiro, courte, à peine sortunte.-Cip Rouge.

Bien distinct du Cunadensis par sa coloration.

Gen. Apindatre, Apliclaria, nov. gen.

(De Aphidius).

Tête transverse, anssi large que le thorax, pleine en arrière des yeux. Antennes filiformes, a articles assez allongés. Thorax court et robuste. Ailes avec une radiale incomplète et aucune cellule cubitale fermée, bien que le cubitus soit complet, nervure paralièle non intersticiale. Ablomen à premier segınent pen allongé et non très grêle, en ovale à l'extrémité, tarière à peine sortante.

(1) Voir Farse, page 496. 
Aphisairo simulante. Aphiduria simulans, n. sp. - Fig. 16.

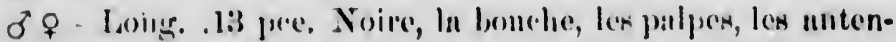

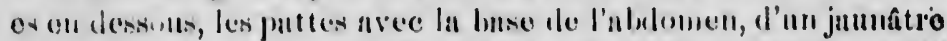

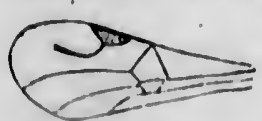

Fig. 1.i. ande. Mámbliorax ponctue; hrillant. Ailes veluen, hyalines, lo stigma grambl, jumne-palo, len nervires brences, la ranliale onverte, lo

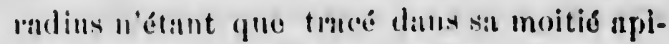

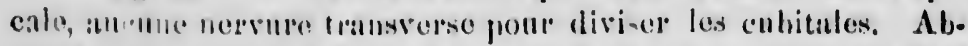

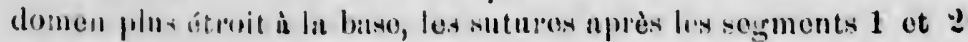

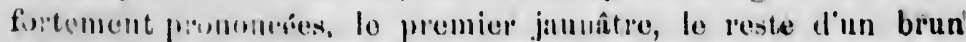
sale, poli, h illant, les dornies's sogments rétrecis pour porter la

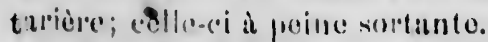

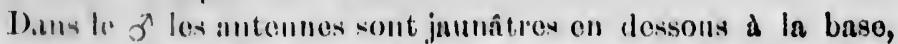

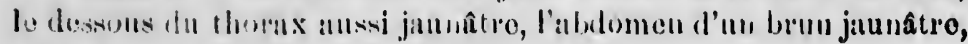
le veatre plus ratr.-O:Lawa (Gruignard).

Bien remanquble par l'absence de cellules cubitales.

Gen. Nivinetsf. Nevropenes, nov, gen,

(De Venion, nervile et penes, muvie).

Tète transverse, pleine en arrière des yeux, aussi large que le thorix. Thuriax asse\% robuste. Ailes avec une grunde radiale incomplete et le culitus manquant totalement, une grande cellule huméraie necompagaće de la 2 e discoüdale qui est fermée, et petite. Aludomen distinctement pédienlé, linćaire ớ, ovalaíré o ; tarièr à peine sortante.

La panvreté des nervures distingue surtout ces insectes des $A$ phidius. Une seule espice rencoutríe.

Névropène ovale. Nevropenes ovalis, n. sp. - Fig. 17.

$\delta^{x} \%$ - Tonu. . 08 pee. Noire uvec les pattes d'un jaune bru-

rrière horax cune rvire peu beine nât:e, ley cuisses surtout étant plus foncế('s. Abrlomen nuir ox. ecpté lo premior segrment qui est jaunâtro

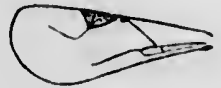

Fig. 17. et allongé, rugueux. Métahoux a ligries soulevées distinctes. Ailes velues, lo stigma graud, jaunatre, la radiale griande, incomplete, la 2 e cellule discoüdale seule fermóe, étroite, allongée. - Ottuwa (Guignard).

Fig. 16.-Wune aile de l'A plbiduriu simulans, Prot.

Fig. 17. - Une aile de la Nevropinos ovaliog Provi: 
Gen. Ropronie, Ropromia, nov. gen.

(De rop: on, mals:lle).

Tête grosse, transverse, plus large que le thorix. Antennes médiocres, filiformes. Thurax cunt et épais, le mésorhurax à lobes distinets, le nuétathorux arrondi. Ailes ì ceịlnle radiale en triangle aigir, le radius en ligne druite; deux enbitales, la première grande, reeevant la récurrente vers son milien, la 20 atteignant l'extrémitć de l'aile, en angle aign à son extrúmité antérieure, la nervure parallele prenant naissance an milien de la 1ère cellule discoïlale. Abdomen à prídicule tès allongé, plus épais in la base, le 2 e segment tribs grind, formint avec le reste une courtc m.ıssue ovoïle; tarière ne déprassant pas le dernier segment.

Bien remarquable parmi tous les flexiliveutr's par la nervation des ailes et la forme de son ablumen.

Ropronie pédiculee. Ropronia pérliculuta, n. sp.Fig. 18.

\&-Long. 27 pee. Nuire avec l'ablomen ronge. Là tête et tout le thorax fortement rugueux. La face ì pubsicence gri-

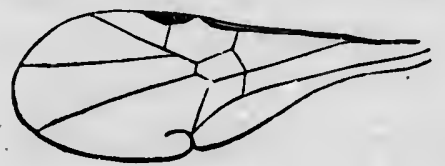

Fig. 18. râtre. Iess mandilunles, les an-

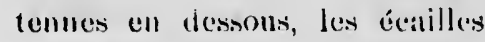
alaires arec les patter, d'un biun roussâtre. diles hy̆olines arece les nervised noires et mire talde obscure non très distincte an dessous du stigma. Toutes les hanches arec les pattes postérienres, noir. Ablomen à pédicule égalaut prenque le reste en longueur, noir, poli, briliant, ponctué en dessurn at la base et peu renflé an milien, plnt grêle an summet, le rête formant nue courte massne, polie, brillinte, longe; tarière à peine visible. Ottawa (Harrington).

\section{Gen. Ranomame. Radiolatia, nov. gen.}

(De ra lius l' une des nerrures de l'aile),

Tête transverse, pleine on arrière tes yeux, plus lurge que Fig. 18,- - Unẹ aile do la Ropronia pediculata, l'rov: 
le thorax. Antennes filiformes, à articles peu distincts. Thorax court et assez robuste. Ailes velues, à stigma étroit et allongé, une grande cellule radiale, avec le rarlins se dirigeant elt ligne courbe vers le bord de l'aile; denx cubitales, la $2 \mathrm{e}$ incomplète, nervure parallèle non iutersticiale. Abłomen pédienlé, le pélicule non très allongí, le reste en ovale élargi; tarière à peine sortante.

Une seule espèce rencontréo.

Radiolaire en-massue. Radiolaria clavatı, n. sp.Fig. 19.

\%-Long. .10 pee. Noire aree les pattex jaune-pâle. Antennes plas longues que lo corps, brunes, plus pâles à la batso en

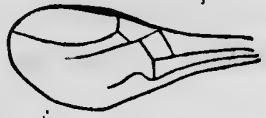

Fig. 19. dessous. Métahorax rugueux. Ailes relıes, les nervures brunes, le stirma étroit jaunâtre. Pélicule de l'abromon jannâire, le reste noir, brillant, en massue et subtronqué à l'extrémité; tarièe à peine surtanie. -Ottawa (Guignard).

Gen. EPHÈd.se. Ephedrus, Halliday.

$$
\text { (Etussus, We.m) }
$$

Tête ordinaire, à vertex plein. Mé-othurax à lobes distincts. Ailos avec une cellule raliale couplète, trois cubitales dont la 2e plus longue que large reçoit la récurrente camms dans les Opius; la nervure parallèle intersticiale. Abiluinen pédiculé, le premier segınent étant étroit et cylindrique. Tiurièro des $₹$ courte, moins du quart de l'abilomen. P'attes orlinaíres.

Ces insectes, tous de petite taille, se reucontrent souvent, sur les plantes en compagnie des Aphidins, ce qui porterait it croire qu'ils ont les mêmes habitudes, se nourrissant des larves de pucerons.

Deux espèces rencontrées.

Cubitus interrompu peu un dela de la 20 cu-

bitale .................. 1. incompletus, n. $s p$.

Cubitus atteignant le bord de l'ailo.. 2. completus, n. sp.

lig. 19--U.e aile de la liaaioiaria clacala, P'rov. 
1. Ephèdre incomplet: Ephedrus incompletus; n. sp.

-Long. .10 pcc. Noir, avec les pattes et les 2 premiers serments abdominnux d'un roux-j mnâtıe sale. Antennes noires, subdentées inférieu "oment. Thorax conre poli, brillant, le métathorax rugguenx ut reint de ronsiatro: Ailes hyalines, lo stigna brun-roussâtre, triangulaire; la 1ère, cubitale distincte do la ledediscoüdale, la nervule récurrente faisant suile à la nervure intracintale; la nervure parallele intersticiale; la 30 cenbitale incomplète. Tiextrímité des tarses postérionrs brun-foncé. Abdonien noir a l'cxteśmití, roussâtre a la base; lo premier - segment cvlindrique, rugruenx, non très allongé, les antres form int un ovale allongé; turiere peu sortante. CapRouge.

2. Ephèdre complet Epherlrus completus, n sp.-Fig. 20.

क-tong. .12 peè. Noir avec los piattes jaime-roussâtre.

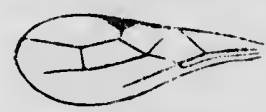

Fig. 20. Thorax atténué on un cou plus distinct quo dans le précédent. Métathorax fortement ruguenx. Ailes hyalines, le stigma triangulairc, jaunâtre, le cubitus atteignant le bord de l'aile, la 2e cubitale en oarré à la base. Abdomen à 2e secrment très grand, plus on moins jaunâtre; tarière à peine distincte. CapRougro.

Gen. Scotionevre. Scotioneurus, nov. gen.

(De Scotios, obscur et neuron, nervure).

Tête tranverse, pleine en arrière des yeux. Antennes à articles allongés, resserrés à la base. Thorax court et robuste. Ailes avec une radiale complète et 3 cubitales, la $2 \mathrm{e}$ très longue, plus large a la base, la récurrente faisant suite a la nervure intercubitale; nervure parallèle non intersticiale. Abdomen pédiculé, le reste en ovale allongé, linéaire dans le $\delta$; tarìre recourbée, plus courte que l'abdomen.

Insectes bien distincts des $A_{l}$ hidius par la nervation de leurs ailes.

Deux espèces rencontrées.

3e cubitale incomplete; stigma triangulai e... 1. dives, $n$. $s p$. 30 cubitale complète; stigma très long et très étroit .................. stenostigma, $n . s p$.

Fig. 20-U ne aids de l' Rgphedrus completus, Prov, 
1. Scotionèvre riche Scotioneurus dives, n. sp. Fig. 21. $\sigma^{7}$-Long. .10 pce. Noir avec les pattes d'un jaunâtre plus ou moins obscur. Lo premier articlo des antennes a la suite du

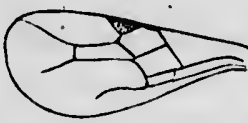

Fig. 21. scape pîle à la base. Métathorax rugueux. Ailes hyalines, la 20 cubitale plus longue que large, en triangle aigu à la brse: Abdomen pédieulé, le 1 er segment rugueux, jaunâtre, les autres en ovale allongé, noirs, polis.-Ottawa (Guigr.ard).

2. Scotionèvre à-stigma-étroit. Scotioneurus stenostigma, n. sp. Fì. 22.

o Loug. .12 peco. Noir, avce les pattes testacées. Méta thorax ponctué, finoment rugueux. Ailes poilues, iridesoente's,

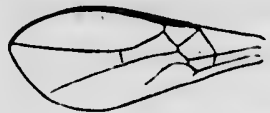

Fig. 22. hyalines, à stigma trè̀ long et très étroit, les norvures brun-foncé, la $2 e$ cubitale rècevant la récurrente d son angle interne. Abdomen avec lo ter segment scabre, lo reste en ovale-allonigé, la ta ière de la moitié de sa longueur enviror, légèrement courbée en dessus. - Ottawa (Guignard).

\section{Fam. VI. CYNIPIDES, p. 540.}

Cette fanille, quoique fort intéressante, a encore été si peu étıdiée, qu'on ne peut se fixer sûrement sur la détermination de ses genres et de ses espèces. Composée presque exclusivement d'insectes fort petits, et de structure différant peu dans les différents geures, elle a été une occasion, pour ceux qui s'en sant spécialement occupés jusqu’à ce jour, de pouvoir sigualer de nombreuses erreurs de la part de leurs dévanciers, mais aucun n'a pu encore réussir à jeter assez de lumière sur l'en̉semble, pour permettre de diviser avec certitude les groupes et les genres. Leurs écrits ne sont encore que des épis, des faisceaux éfar's, qui attendent un ou virier mieux renseiguć, possédant surtout des matériaux plus nombreux et de différentes régions,

Fig. 21-Une aile du Scotioneurus dives, Prov.

n. $s p$.

Fig. 22--Une aile du Scotioncurus stenositgma, Prov. 
pour en former. "n tout, une gurhe uni que, s'h:rmonisant dans ses différentes farties, suiviunt que lenrs caractères gánéraux leur désigneront la pluce yui leur est jíopre.

M. Miygr en Autriche et quelques autems américains, entre antres M. Bassett à Witterbury, Coun., M. Ashmead à Jucksonville en Floride, poursuivent actuellement des études sur cette famille, mais n'ont pu parvenir i y jeter assez de lumière pour asseoir ses divisions sur dess bases sûres et indiscutables, et nous demeurons 'neore dans le provisoire, pour la place que doivent occuper les nou veaux spéciñens que nons déconvrous ne correspondant pas aux descriptions déja données.

Les 18 genres dont nous avons trouvé des représentants peuvent se distung ler comme suit les uns des autres.

Clef pour la distinction des genves.

1,20) Ventro visible, pour le moins au dela de la moilic de sa longrneur; cellulo rabliale longue et étroite, portant l'arécle pu ès de sa base:

\section{GYMNOGASุTRES.}

2 15) Radiale ouverte on avant rurement fermée, 20 segment abdominal lo plus long. dépassant larement la moitié de la longuemr tolale; taujìre dressée :

\section{CTNIPIDES.}

3(1i) Radiale ouverte;

4.11) Sillons paurapsidaux distinets, s'étendant, rur toute la longuenr du mésonotum;

5(10) Fapdres nues ou nu,n très poiluen;

6(9) Espècess brillantes, po!ies, laisantes;

7(10) Ecusson avec 2 forécoles a la baso; radiIis presque droit ot n'ateeighant pas lo bord de l'ailo 3. Diastrophtes, 
8( 7 ) Esusson avec une nuturo transvorise d la base salss fuvéoles; abilemon treds comprimé, a segments tous découverts; valvo ventralo longrao.. .................. 6. Tribalia.

9(6, Espèces nom brillantes jar leur ponctua. tion ; écus on à 2 fovéolos ; radius n'atto:guimit pas le burd do l'aile................

\section{Andricus.}

10,5) Espèces forlemcrit.veluo ; écusson atrondi, bifoveolé à la basc; radius atteigruant le bord do l'aile; antennes courti's, le se article a peino pius long que lo 4e... 1: Cxnips:

11(4) Sillons parapsidaux nuls ou très peu dislincts, le s'étendant pas sur toute la longueur du mésonotum; radius atıeignant le bord custal; antennes ct pattes pubescontes; aréole oblitélée............... 10. Niurotraus.

12(3) Raulialo ferméo; élusison bifuvéoté ; valvo vontrale très longue, pointue et brillaute.

2. RHodites.

13(2) Radialo ferméo , rarement ouverte), 20 sogment ablomen occupant prosquo toute la fince dor alle, tariero toujours visiblo on dohors du deruier seiment :

\section{INQUILINIDES}

14(19) Le 2e ou 3e segment dorsal to plus long, abdumen inédioctrement comprimé;

1.5(16) Face non fortement sticiée; écusson bifovéolé; sillons parapsidaux déliés, convergents postérieurement; valve ventralo fortement allongéo......... Aulax). 4. Periclistus.

16(15) Face fortement striéc;

17(18) Sillons parapsiduux presque paralleles; tarière sélevant au dessus de la ligne du do ; auteunes o d 12 articles. .... ....... 11. Ceroptres.

18(17) Sillons parapsidaux convorgents on alridre; péclicule strié, tarière non saillante; antennes of a 14 articles............ 12. Synergus.

19(14) Le 5usegment doisal lo plus long; abdomen comprimé on lame de couteau.......... 7. Tbalia: 
20(1) Ventre nón appareut ou sculemerit à l'extrémité; cellule radialo en trinngrlo équiilatérul, nyant l'uréole à son inilieu :

\section{CRYPTOGASTRES.}

21(:2) Ecusson arrondi, séparé dı mésonotım par un sillon tranverso, saus fovcoles; têto plus large quo le thorax.

13. Allotria.

22(21) Eussson variable, avec 1 ou 2 fovéoles it $8 a$ base;

23(28) Eı.usson avec y fovéoles à la baso ;

24(23) Méronotum ca!éné et sti ié trunsversalcment; écusson bicanaliculé et striéc trans-

versalement......................... 14. Callaspidia.

25(24) Mésonotum uon caréné; écusson arrondi, irrégulièroment rugueux, biforéclé à la . base;

26(27) Sillons parapsidaux pou distincts, pédiculo plus ou moins long et lissc....... 15. Anacharis.

27(26) Sillons parapsidaux très distincts, pédicule généralement coùt et cannelé........ 9. Fiaites.

28(29) Ecusson non épineux, avec une sculo fovéole a la base; anteunes nou en massue à l'extrémité.................. 16. Lonchidia.

29(28) Ecusson terminé par une épine ou une pointe mousse; abdomen peu comprimẹ.. 17. OnYoura.

30(24) Ecusson cupuliforme ; baso do l'abdomen avec un collier tomenteux;

31(32) Antennes moniliformes, s'épaississant de la base a l'extrémité.. 5. Eucoila.

3:2(31) Antennes o a articles 4 et 5 très petits, courts, d'égale longueur, 2 et 7 plus gros, d'égalo longueur, les autres a la suite de 7 encore plus gros, moniliformes 18. Dimrcrostrophis. Gen. Rhodites, Hartig, p. 548.

A l'espèce décrite, ajoutez lı suivante :

2. Rhodite bicolore. Rhostites bicolor, Harris.-Proc. Ent. Soc. Phil. II, 48. 


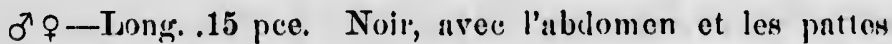
roux. Mandibnles roug(âtron. Thornx opaquo, ponctué-rngnenx, les sillons parupsidıux du mésonotu:n profonds, uvec des lignes intermélinires distinctos. Eucusson grossièremont jugueux. Flanes ontierement ruguenx, les plaques lisses étant a poine distincton. . A ilos hyalinos avec un liunge brun clans l'uréole et ses environs, ot 2 antres bandos moins apparentes dans la partio apicale. La ze norvulo transverso anguleuso avec une potite pro. jection en dedans de la madiale. Lu cubilus pou apparent. Los pattes sont rousses y compris les hanches, celles-ci pluvou noins obscures à la baso. - Hull ( Harrington).

Espèce bien remaryuable par sa culoration et sa forte taille.

3. Genre Diastiopius, Hart. p. 549 et 807.

Aux 2 espices décrites, ajontez la suivante.

8. Diastrophe noir. Diustiophus piceus, n. sp.

$\delta$ o -Long. .10 pee. D'un noir de poix; la fueo large, scabre, le chaporon p.li, brillant, lo vertex finement ponctué. Antennes ronssâtres à la base, lo 30 artic!e alısi long que 4 et 5 réunis, moniliformos ver's l'oxtrénité. Pronotum poli, médiocrement luisant, à sillons parapsidaux bien prononcés, le sillon módian pres de la vase, tres court. Esusson fortement rugueux, do mêmo que lo inétathorax, salis fuvéoles trè̀s distunctes a sa base,

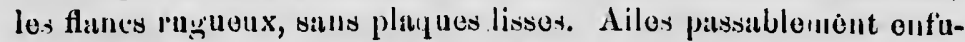
mées, les nervures noires, la indialo asserz courte, 3 cellules cubitales, mais le cubitus effacé en partio a sa base, l'aréole on 20 cubitale distincte, mais avec sa norvure antéricuro peu marquéo Patto; roussâtres, los hanches avec la balso des enisses brun-foll: Abdomon court, noir, poli, brillant, lesseginents ventraux légere. ment rous-âtıes; tarière d poine saillanto.-OLtawa (IIarrington).

\section{Gen. Tribalie. Tribalia, Walsh.}

Antennes o de 14 articles, article 3 une fuis et demi la longıeur de 4. Tête grosse, en carri, anssi large que le thorax, celui-ci médioctement robuste, moclérément poli, le mésonotum à sillons profondément maryués, muni d'un reboril et sans fo;settes à sa base; l'écusson hémisplhírique, ponctué avec une 
carìne longitulinale folie subobsolète au milien, et une suture tmunsverse enfoncée, mais sans ulvécles distinctes. Ailes à nervures bien prononcéts, la radiale courte, onverte en avant, le cubitus atteignant lo sommet de l'uile, la 20 cubitale très petite, mais complete. Pattes ordinnires, it cuisses nou renflées. Ab.lomen avec tous ses segmonts npparents, très co:npuimó à l'extrónité, la valve ventrale en forme d'épine aignë, égilant on dépassant le deruier segment; le deruier arceau dorsal tronqué à l'extıémité.

Rapproché des a no forme de son abdnuen, qui n'est cependant comprinis er. li.re qu'à son extrúmité, mais qui montre 7 segments dursaux bi a distinets. M. Walsh avait dícrit sun genre sur 11 senl spécimen pris mo:t, dont les ailes se trouvaient incilpables d'être pinfit tument distingucécs, le nôtre ayant été pris vivint et bien développé, nous domons liı description de ses ailes. 'Une seule espèce rencontríe.

Tribalie des-patates. Tribulia batatorum, Walsh.Proc. Ent. Soc. 1'hil. II, 471.

q-Longr. .19 pẹo. Noire ; touto liı tête finement rugurueure, opaque. Antennes fortes, les 2 premiers articles brillants, le reste opaque, noires, quelque pen roussat: es à la hase. Thorax avec trois sillons clorsuux larges et profonds, les deux latéraux se japprochant en arrière, lo médian n'at teignant pas le collier, do chaque côlé de eclui-ci se voit une petite strie, et unc autre, aux cô:és, au-dessus de l'insertion des niles ariérienres, l'écusson subhémisphúrique, ponctué avec nne car'ène obsolète surison milieu, porlant une sutitre enfoncée à sa base, mais sans fossettes distinctes. Iiles enfumées-jaunâtres, les nervures brun-roussâtre, la radiale peu allongée, ouverte en avant, sa nervure atteignant lo bord de l'aile et un peu épaissie a son extrémite. Paltes brunroussâtre, Abdomeı d'uı roux brunâtre, non très poli, àsutures distinctes, la valve ventrale brun-foneé ou noiro a l'extıćmité. Ottawa (Guignard).

Insecte bien remarquable par sa confurma:iun. 
8. Gen. Axdices, Hurt.p. 347.

Sous-Genre. Callivhitis, Forst.

Ongles avec une seule dent. Antennes avee le $3 \mathrm{e}$ article deux fois et un tiers plus long que le 4e, les autres allongés, subéganx, daus le $\sigma^{7}$ le 3 a article courbé on crensé en dessous.

Une seule espèce rencoutrée.

Andrique des-marais. Andricus palustris, 0 . Sarken.Proc. Kint. Soc. l'hil. I, 63.

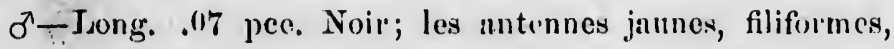
avee lo :o article 2 fois unssi long que lo 4e, combé ou échuncéé on dossous, le's 4 snivunts décroissint graducllement en longu " $r$, les autres de la même longueur. Thorax noir, brillaut, finement ponctuć, les deux sillows paupsidaux distincts, presque ? :alléles. Ecusson p'luguenx, bifovéolé a la busce. Ailes hyalinen, sans taches, les neivures brunos, l'aréole distincto mais tods petite, a peine éviclée, le eubitus distinct clans tonte sa longueur, mais n'attciguant pas le sommet.

- Après le genre Neurotelius, Hartig, p. 548, ajoutez les suivants.

\section{Gen. Péricliste. Periclistus, Först.}

Tôte en carré transversal, aussi liurge que le thorax. Antenues filiformes, à $3 e$ article non ou à peine plus loug que le $4 \mathrm{e}$. Thorax avec les sillons parapsidaux distincts mais délicats, convergents faiblement à là base, le médian ne dépassant pas le milieu du mésonotum. Ailes avec lu radiale fermće en avant, assez courte, le rudius légèrement courbe et atteiguant le bord costal. Abdomen avec le 2e segment occupant la surfice dorsille presque complètement; la valve ventrale allongée, saillante. Antenues de 12 articles $q$, et $14 . \sigma^{\top}$.

Une seule espèce rencontrée.

Péricliste mi-brun: Periclistus semipiceus, Harr.Injurious Ins. to vegetation, 11. 549.

$\sigma^{\lambda} q-$ Long. . 15 pee. Noir avec les pattes et l'abdomen rouxbrunâtre. Tête en curré transversal, vertex lisse, fitce arec ali- 
culations dirigres vers la bouche, le milien avee uno protuberance longitudinale, low mandibules rounsen, noires d l'oxtrémité. Antennes, noires a la baser, lo 2 a a ticlo lo plus potit, lo 30 a pen p:ès éral nux autros. Thoux finement ponctue, lo mésothorux uvec 3 liguos onfon'sen ni lumgon ni profonden, et dont la midiuno n'utleint pus lo devant. Jecusson hémispliériçue, finemont ponetué, sans fossettes distinctes a la base. Is métathorux po. tant sur ros carènes postérieures un mucron vers le milien. Ailes hyulinos, les norrures brun rousintre, la moliale ferméo en avant, portaut l'aréole vers sa baso; cubitus complet, formant liarólo. Paltes avee les hanches et l'abdomen d'un bean ronx elair, le dernior poli. brillant, lisse, plus ou moins noir sur le dos, avec un péliculo tiès court et sans stries a son sommet.CapRouge.

Eclos de galles sur la tige du laition cornmun, Sonchus oleraceus, près du sol. Ces galles pulymor] hes, d'environ un ponce le large sur de:ux à Irois ponces de longueur, contenant de 5 i 8 larves. Les galles rucueillies en mai sur des tiges de l'unnée précédente, ont douné leurs insectes en juin.

11. Gen. Cénoptis. Ceroptres, Hartig.

Tête transversale, à fuce gro:sièrement striée. Autennes de 12 articles dans les of et 15 dans les $\sigma^{7}$. Thorax a sillons parapsidaux presque parallèles. Ailes avec la radiale ferméo en avant. L'écusson avec deux fossettes à la base. Abulomen à 2 e segment occupant presque entièreinent la fuce dorsale, ce segınent paraissant divisé par une suture très déliçate. Valve ventrale s'élevant au-dessus de la surface dorsule. Pụttes ordinaires.

Une seule espèce rencontrée.

Céroptre pétiolicole. Ceroptres petiolicola, O. Sack. Amblynotus petiolicola, O. Sack. - Proc. Ent. Soc. Phil. I, 67.

o-Long. .07 peo. Noir, la tête et le thorax quelquo peu brillants. quoique líge, ement pubescents, le dernier a peiue pone- 
tué, a sillons parapsidaux distį̣ets quoique délicats; Geusson r"ngrueus. Isa fíco porte uno petite endedne entre les antennos; mandibulem brunes, pailpes jannes. Antennes de 13 articles, biunjaunâtro, los 4 ou 5 articles bu-ilatires allongés, les autres courts. Ailos ligalines, la radinle formée, la 20 nervure transvorse oblique, ungruleu-o, l'aréolo ì peu pròs an milieu do la indiale. Pattes biunen, plus claires unx jointures, les tarses pâles avoc l'extrémité noiro. Abdonnon bưun-foncé, brillant, brìvemont pídiculé; taridro s'élovant all-dossus de la ligne du dos, - Ottawa (1Larrington).

'Trouvé dans des galles de chêne.

12. Gen. Synercius, Hartig, p. 807,

1. Synerge lignicole. Synergus lignicola, O. Sack.Cynips (Synerges ?) lignicolı, O. Sac':. Proc. lint. Soc. P'hil. I, $252-S y n e r y u s$ rhorlitiformis, Walsh, Proc. Ent. Soc. I'hil. II, 499.-Faune Can. II, 807.

7. Gen. IbaLid, Latr. p. 553.

A l'espèce décritc, ajontez la suivante.

2. Ibalie 8-ailes-tachées, Ibulia maculipennis, Hald. -Proc. Acad. Nat. Sci. III, 127.

९-Isong. . 60 pec. Jauno avec taches brunes. Tête creuséo en arrioro, juuno avec uno tache brune au dessous des antennes et uno autro a l'endroit des occlles. Antennes jaune-loussâtre, noires il l'extrémité, plus ou moins obscures a la bisse. Prothorax jaune, ponetué, arqué et souleve en avunt, le mésonotum fortement strié 'n traver's avoc trois sillous longitudinuux, jaune avee une tache noiro en avant se répandant dans lo sillon médian ot sur les côtés on dehors des sillons latéraux, terminé en avant do l'écusson par uno bande noire. Ecusson rugueux, plan, mais rolevé à son extrémité en formant deux eornes par son échancrure médiane, le disque jainne avec lo métathorax noir. Ailes hyalines avec une tache birune a l'endroit du stigma et l'extrémité aussi b:une. Pattes jaunes avec la base des hanches et les cuinses rxeepté aux extrémitén, noires, les jambes postérieures aussi noires, excopté a la buse. Abdomen poli, brillant, com- 
primé en lame de couteau, juune avec toutes les sutures noires, cette coulour noiro so r'épandunt on taches plus ou moins piolongéos sur la ba.e du segment suivant; carène ventralo juuno; taridro dépussunt a poino l'ublomon.-IIIl (Hurrington).

\section{Gen. Allorrie. Allotria, Westwood.}

Tête pas plus large que le thorax. Antennes longues, sulflif, rmes, souvent poilues. Thorax ovoïde, robuste, sans sillons parapsidaux distincts ; écusson arrondi, lisse, convexe, sépnré du mésonotum par un sillon transverse sarı fovćoles. Abdomen d segruents 2 et 3 presque égaux.

Insectes petits, brillants, qu'on distingue surtout par la forme de leurs antennes et l'absence de fovéoles à la base de l'écusson. Deux espèces rencontrées.

Pattes et base des antennes birun-foncé......... 1. avenæ.

Pattes et base des antennes jaune-pâle......... 2. tritici.

1. Allotrie de l'avoine. Allotria avence, Fitch - Rep. VI on Noxious et Beneficial Insects, p. 100.

\&-Long. .06 pce. Noire, polie, brillante avec les pattes brunes. Tête courte, plus large que le thorax, avec quelques poils sur la face, plus denses sur la gorge. Antcnnes plus longues que le corps, pubescentes et avec der poils plus longs au sommet de chaque article, le premier article plus épais ot atténué en pódicelle la base, lo 2 e globuleux, le 30 et les suivants tronqués au sommet et atténués a la base, le terminal ovoïde. Ailes légèrement enfumées, frangées a leur bord, a collule radiale triangulaire fer'mée et portant l'aréole a son milieu; aréole incomplète, représentée par un point plus épais que forme la rencontre des nervures, aucune cellule cubitale. - Ottawa (Guignard).

Parasite des pucerons qui attaquent l'avoine.

2. Allotrie du blé. Allotria tritici, Fitch.-Rep. VI on Noxious et Ber Insects, p. 99.

- Long. 05 pio. Noire, polie, brillante, avec la tête et les pattes jaune-pâle (la tête quelquefois noire). Ia face et la bou. che jaunâtres. Antennes d 13 articles, aussi longues que le corps; insérées au miliou de la face, noires, pâles et plus grêles a la base, 
Io 1or article plus épris, lo 20 plus grele, on ovale, les autros courts et s'allongennt on se rupprochar.t de l'oxtrémite. Thorax plus large que la tete, noir, brillant. Aile hyulines, legerement onfumćes, bordéos d'une frnngo brune, lu rndialo on trianglo équilatérul, forméo on devant, ot portant l'uréolo d son angle infériour, aucuno eubitalo férméo. Pattes juune-pale, les tarses antérieur's nvec lo 1er articlo 2 fois plus long que lo douxidmo. Abdomen plus potit que lo thorux, presquo globuloux, legdrement compriné, tronqué on obtus ì son extrémité, avec une projoction epuisse au milieu.-Ottawa (Guignad).

Purasite des pucerons qui attaquent le blé.

14. Gen. Callaspidie, Callaspidia, Dahlbom.

Têto en curré transversal. Antennes filiformes, de 14 articles duns les $\sigma^{7}$ et 13 daus les $\%$, le 2 très petit, subglobuleux, lo 30 le plus long. Le thornx et l'écusson ridés transversalement, le dernier partagé en 2 alvéoles par une carème longitudinale, projeté au dessus du métuthorax. Ailes aveo une radiale triungulaire, ouverte en avant et ayant l'uréole \& son milieu. Le cubitus souvent oblitéré. Abdomen d 30 segment le plus grand, distinctement pédiculé. Pattes ordinaires.

Une seule espèce rencontrée jugée nouvelle.

Callaspidie de Provanoher. Callaspidia Provancheri. Ashm.(1)

o-Long. 18 pce. Noire avec l'écusson, le métnthorax ot les flanç roux. Têto transversale, de la largenr du thorax, finement rigueuse sur la fuce ot plus grossidriment sur le vertex. Antennes filiformes, de 13 articles, subınoniliformes, plus courtes que lo corps. Thorax court, gibboux, rugueux on dessus, poli sur les côtés, le mésonotum avec 4 côtes longitudinales ridées on traver's; l'écusson prolongé au-dessus du métnthor'ax et tronqué a

(1) M. W. H. Ashmead, de Jack sonville, Floride, nous a transmis, par anticipation, la de cription de cet insecte qu'il a bien voulu nous dédier, description ' u $^{\text {il }}$ publiera prochainement dans sa monographie de cette famille dans les Transactions of the American Entomological Society of Philadelphia. 
l'extrémité, portant 2 sillons longitudinanx séparés par une carène, lisse a la bure et ridé en traver's duns le reste. Ailen hyalines, $\dot{a}$ norvures jaunâtres, la radiạle on triangle, ouverte en avant et portant l'aréole représentée par un point épair, ver's sun inilien; aucune cellulo cubitale fermée. Puttes brun-joussâtre, les cuisses plus foncées. Abdomen pédiculé, poli, brillant, comprimé, to pédicule ronx, assez long, lẹ 3 e segment très grand et tris large ; vu de côté la forme de l'abdomen présente un ovule tronqué ubliquemont en dessous; tariere a veine sortante.-Caj)Rouge, Hull (Guignard).

15. Gen. Anucharis. Anacharis, Dalman.

Antennes de 14 articles $\sigma^{7}$ et 13 아. filifurmes dans les deux sexes. Aréole des ailes oblitérée. Thor:ı le plus comvent sans sillons parausidaux distincts. Ecusson avec deux fovéoles + la base. Abdomen à pédicule distinct, non strié.

L'abdomen pédiculé de çes insectas, surtont dius les ó, avec la forme de leurs antennes, les fait de suite reconmilitre. Truis espècus rencontrées, dout deux nouvelles.

Ecusson rugueux, avec un reboid tout autour. 1. marginata, n.sp. Ecusson lisse, non marginé ;

Pédicule de l'abrlomen court .... . ...... 2. subcomprissa.

Pédicule de l'abdomen aussi longr que lo thòrax

3. pediculata. n.sp.

1. Anacharis subcomprimée Anacharis subcompressa. Prov. -Eucoila subcompressa, Prov. Faune II, 252.

2. Anacharis marginée. Anucharis marginatu, n. sp.

$\sigma^{7}$-Long. 12 pce. Noire, polie, lisse, la face à pen près lisse avec poils blanchâtres dans le bats et sur les côtés. Antenucs brunes a la base et jaunes dans le reste, plus courtes que le corps, le $2 \mathrm{e}$ article très court, les autres a peu près égaax, allo. gér el rétuécis aux suturets. Ménono um poli, a sillons parapsidaux bien distincts les épaules et los flunces scribres ; écurson très rcabre, alvéolé, a 2 fossettes enfoncées brillantes a la base, marginé tuut autour. Ailes hyalinos, avec poils bruns, les nervures brun-roussátre, la radiale fernée, en triangle équilatérul. Paltes jaune-nicl, les hanches postéricures noires. Abdomen a pédiculo lisse, du 
quart de sa !nigurur onviron. grêle, le resto on massue fusifo:me, le 2e sigment plus long que le 3e.-CupRouge.

Bien distinet da prúlídent par son écusson scabre.

3. Anachar s pédiculée. Anachuris pediculatu. n. sp!

8-Long. .12 p.ce. Noire, polie, brillante area les pattes jaune-pâle. Tête un peu plus étroite que le thornx, la faı.e avec une protubérunce cal énale intre les antenne-, tinement ponetuéc ; vertex arrondi. Antennes filiformes, pubescentes, assiz enurtes, le 3e article un pe'u plus long quóle 40, toun les articlesdistinctement divisés bien que non pédiculés et non atiénués à la base, les 3 on 4 articles ba-ilatres jaunattes, less antres brun-lous-âtre. Thorax avec les sillous parapoidanx larges, comvergents pustérieurement, le méxonotum poli, brillant, lerminé par an a buid a sa haro ; lécenson proćminent, ponctuce, avee 2 fo. coless a na liase; le. fances aciculé-prugneux, le mélatborax ruguenx. A les hyalines, à cellule radiale fermée, en triangle équilatéral, arúnle oblitérée, représenté par un pront épair, le radius épais, brun. Pattes janne-pâle, les hanches légèrement obscurcies à la banc. Abdo. men fusifurme, à pélirule lisse, anssi long que la massue, légèement comprimé, entièrement noil:-Otawa (Gnigna:'(l).

Bien remar fuable par le long pédicule de son ahdumen.

\section{Gen. Figres. Latr. 1'. 655 .}

I.es 2 espèers dérites, appartenant an genre Eccolla, ajuntez les dei'x yui suivent:

1 Figite imp.tient Fugites imputiens, Say.

Figites im atiens Say. - Am. lint. II, 718.

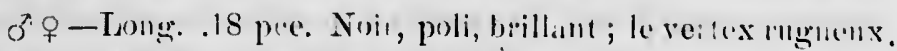

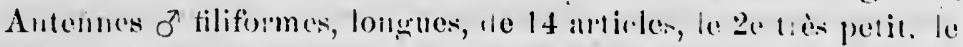

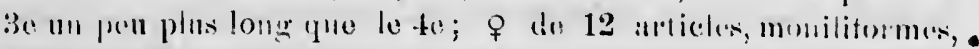

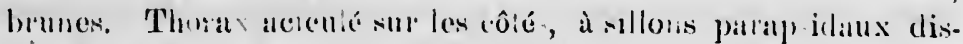

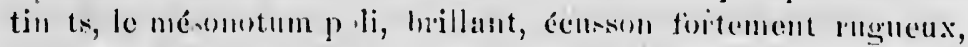

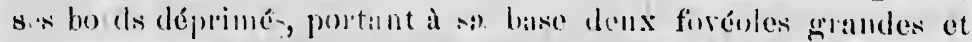

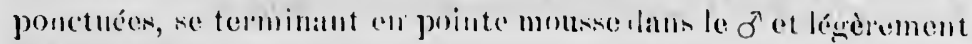

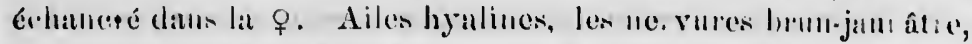

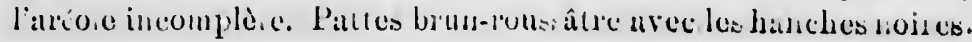


Abdomen comprimé, poli, brillant, a pédicule court et strié, lo ventre plus ou moins roussâtre a la base.-CapRouge, Ottawa.

La forme de son écusson empêche surtout de le confondre avec les Onychies.

2. Figite à-écusson-lisse. Figites laviscutum, n. sp.

$\sigma^{\top} \%$-Long. .12 pee. Noir poli, brillant, le vertex avec quelques petites stries. Antennes $\delta$ filiformes, +9 moniliformes, brun-foncé. Thorax à flancs presque lisses, lo mésonoturi poli, brillant. à sillons distincts ; écusson peu soulevé, poli, lisse, avec à peine quelques ponctuations au sommet, bifovéóé à la base. Ailes hyalines, chargés de poils bruns formant une frange au bord, les nelvures brunes, l'aréole incomplete. Pattes brun-roussâtre, les jambes plus claires. Abdomen allongé, noir, fortement comprimé, à pédicule strié.-CapRouge, Ottawa.

Bien reconnaissable par ses ailes ciliées et son écusson lisse.

16 Gen. Lonchidie. Lonchidia, Thomps.

Antennes de 14 articles. Abdomen à peine comprimé, subsessile, à 2 e segment plus court que le $3 \mathrm{e}$. Ecnsson avec une seule fovéole d la base.

Une seule espèce rencontrée.

\section{Lonchidie hérissée. Lonchidia hirta, $\mathbf{n}$ sp.}

q-Tong. 08 pec. Noire avec les pattes et l'abdomen d'un brun rous:âtre. Antennes forternent épaissies à l'extrémité relativement a leur grosseur a lu suite du 2e segment, brun-roussâtre dans cette partie déliée, et noires dans le réste. Thmrax trè-finemmint ponctué, les épaules et les flances scabres; l'écussca bémisphérique, scubre. Patten roux-brunatre, les hancher avec le milieu des cuisses et des jambes brun-iencé ou noir. Alles bya-

- lines, la radiale petite avec sa neivule transverse oblique mais non ondulée, l'aréole réduite à un point épaie, point d'autres nèrvures apparentes au-dela de l'aréole. Abdomon subsessile, brunfoncé, lougcâtro à sa partio infériuure.-CapRougre.

Espèce hien remarquable par ses antennes qui prósentent une massue très distincte. 
17 Gen. ONYchie. Onychia, Dalman.

Antennes filiformes ou moniliformes, à 14 articles $\sigma^{\top}$ pt 13 ㅇ. Thorax à sillons parapsidaux distincts; écusson armé d'une épine ou d'une pointe moussse. Abdumen comprimé, à 3e segment le plus long, à pédicule court, strié, mais non tomenteux.

L'épine ou pointe de l'écesson fait reconnaître ces insectes à première vue.

Trüis espèces rencontrées.

Ecusson à 5 côtes distinctes et armé et d'une pointe

terminale.................................... 1. 5-lineata. .

Ecusson rugueux et armé d'une épine, mais sans

côtes distinctes ..... ......................... 2. armata.

Ecusson en pointe obtuse, sans épine............. 3. inermis, $n . s p$.

1. Onyohia quinquelineata, Say, Figites quinquelineatus, Say-Am. Ent. II, 716-Faune 1I, 556.

2. Onychia armata, Say-Figites arniatus, Say-Am. Ent. II, 716-Faune II, 556.

3. Onychie inerme. Onychia inermis, n. sp.

$\sigma^{3} \nsucceq$-Long. 30 pce. Noire, la face finement ponctuéc avec une petite protubéranse au-dessus du chaperon bordée de chaque côté d'une fossette. Antennes $\sigma^{7}$ de 14 articles, filiformes, jaunâtres avec les 2 articles basilaires noirs, article 2 très petit, 3 a peine plus long que 4: : de 12 articles moniliformes, brunes, plus épainses a l'extrémité. Thorax à fianes rugueux, le dos poli; avec les sillons parapsidiux distincts ; l'écusson rugueux, bifovéolé a la ba-o et se tèrninant en pointe mousse. Ailes hyalini's, les nervures brun-jaunâtro; aréole incomplète. Pattes roussâtres avec les hanches noires. Abdomen médiocrement comprimé, poli, brillant, à pédicule court et strié, les plaques ventrales roussâtres inférieurement.-Cap.ouge.

Bien distinct des deux autres par son écnsson inerme.

5. Gen. Eucolla, Westwood, p. 551

Quatre espèces rencontrées, qu'on peut distinguer comme suit les uns des autres. 
Ailes tar.héns. 1. stignuhta

Ailes hyalines, srils taches ;

3e article des antenuen a peine phus long que lon antres;

Pattes bitult-rous:âtıe .................... 2. impatiens.

Pattes jaume-niel ..................... 3. mellip\&s.

3u article des antennes dintinctement plus long que lis antres ........................ 4. pedata.

1. Eucoila stigmata, Say-Diplolepis stigmatus, sìy, Am. Eıt. II, 718-Kleidotoma maculipennis, Prov. Faune II, 552 .

- 2. Eucoila impatiens, Sny, Diplolepis imputiens, Say, Amn. Ent. II, 717 - Kleidotoma cupulifera, Prov. Fuune, I I, 553 .

3. Euc ila mellioes S.ıy; Figites mrllipes,-Siry, Am. Ent. II,713-Kleirlotoma nivima, Prov. Fanne 11,708.

4. Eucoila péd culée. Eucoila pedatu, Say-Diplolepis pedutus, Say-Am. Ent II,717.

ㅇ-Lmg. 11 peo. Noire, polic, brillarite. Antennes brunjaunâtre, le ler arti.lo jeu•plus long que le 2e, lo 30 presque aussi lomg que 4 et 5 lémis et un peu arqué, les antres rylindriques-ovales à pen près égaux. La fuce avec une fossette longritudiuale de chaque côté au-dessins dı chıperon ; les mundibuless hrunes. Tholax saun sillons parapsidaux, mais avec une petite fossente an-dessus de l'insertion des ailes antérienres. Ailes très légèrement obscurcies, les nervures brutsus, l'arécle oblitélée, le cubitus presque complet.-Ottuwa (Guig:atai).

Se distingue surtont de sea voisines par le $3 e^{*}$ article des antennes.

18 Grn. Dinichostrophk. Dimicrosthophis, $\Lambda$ shm, n. gen.(1)

Antenues de 13 articles $q$ et $15 \sigma^{\pi}$; articles 3-7 dans la $q$ subitement rétıécis, 4 \& 5 comrts et égnux en longueur, les terminaux plus gros, moniliformes. Ecusson cupuliforne, comme

(1) Ir. $\Lambda$ ? mad nona a communiqué la description de ce nouveau genre or é pour l'espèce qui suit e qüil doit publier jrochainement. 
nitu.

iens.

sS.

ia.

Sily, aune

iens, tune,

Am.

plole-

brim-esquic

'yline lon:ibuless pelite ov très lée, le

e des

en.(1)

- la \&

s teromme buveau t. 
LÉGENDE DE LA PLANCHE III.

Fig. 1.-Phytoconis serupers, Say.

2.- " " aile.

3.-Aile de Neururolpus nubilus, Say.

4.-Antesne de Cumpsocerncoris.

5.-Jambe de Calocoris rapidus, Suy.

6.-Tête de Capsus ater, Lin.

7.-Calocoris bipunctatus, Fabr.

8.-Tête cue Resthenia insigmis, Say.

9.-Stiphrosoma stygicus, Say.

10.-Phymata erosa, H. Selıxf:

11._ " " thorax vu en disssous.

12.- " " patte antérieure.

13.-Corythuca juglındis, Fitch.

14.-Leptostyla nblonga, Say.

15.-Leptoypha mutica, Say.

16.-Aneur'es politu., Say.

17.-Aradns 4-lineutus, Say.

18.-Aradus robustus, Uhl.

19.-Sineu diadema, Fabr.

20.-Nabissubreoleoptrata, Kirb. 


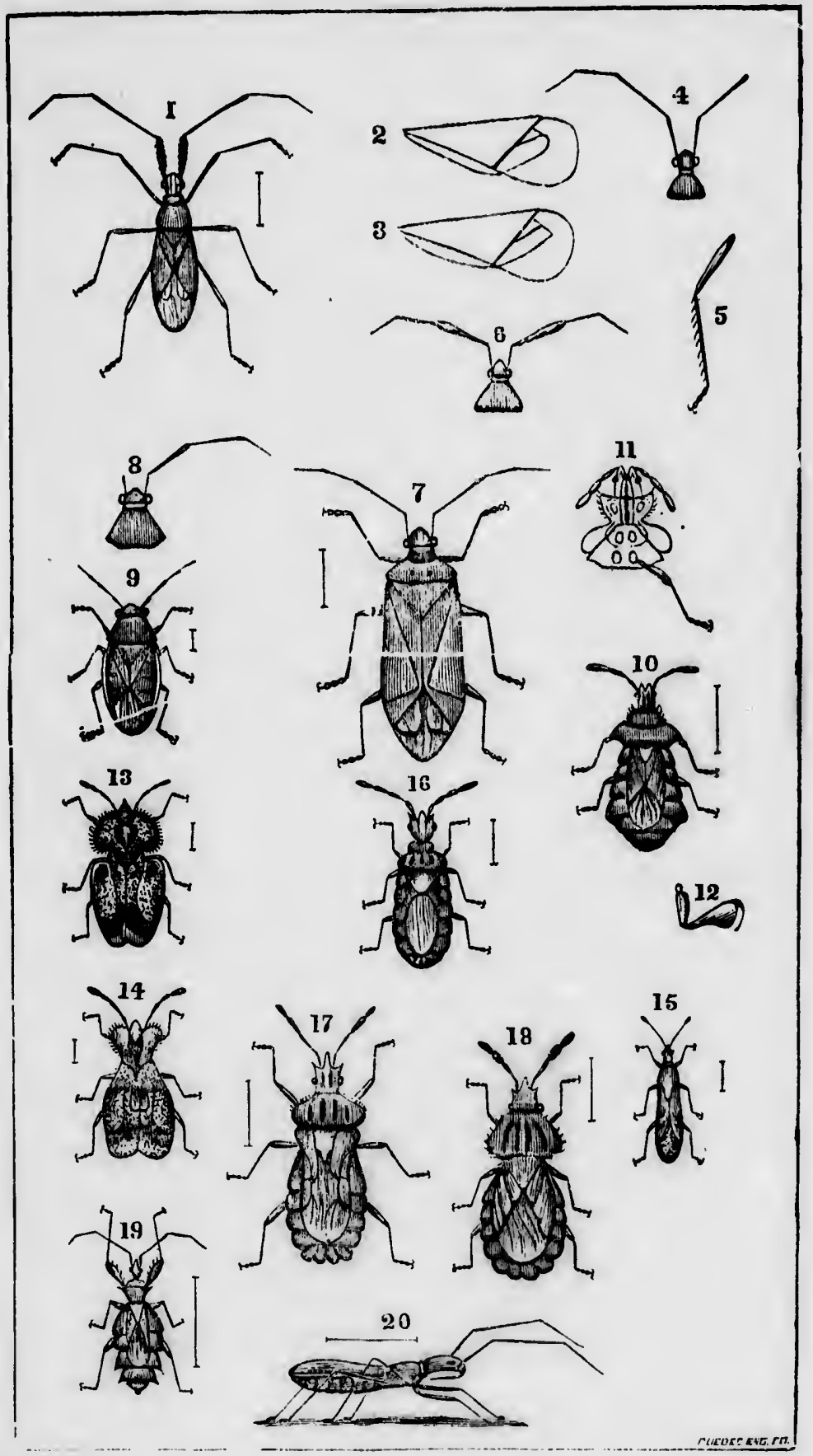

16-Fóvrier, 1887. 


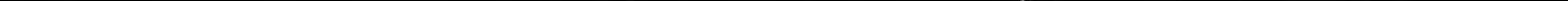


dans les Eucoillas, mais avec un sillon courbe da la base. Ailes ciliées.

Dimiorostrophe rufloorne. Dimicrostroplles ruficornis, Ashm.

\% -long. .09 pec. Noir avoc les pattes, y compris les hanches, d'un beau jauno d'ul. Face brillante, avec uno protubsiranco oblongue au milieu. Antennes très déliées d la basé, roussátres duns cotte partie et noires duns le reste, qui s'épaissit en massüe. Thorax lisse avec l'érusson soulevé et creusé en cupule à son sommet. Ailes hyalines, avec la radiale en triangle, formée en avant, sa nervule antérieure oblique nıais non ondulse, arécle réduite a un point épais; cubitus non apparent, lo bord postérienr des ailes frangé do cils brunatr'es.' Abdomen subsessile, d'un noir do poix, son oxtrémité ot son bord inférieur plus ou moins rou. geâlyes.-CapRouge.

Fam. VII.-PROCTOTRUPIDES, p. 557.

Aux 7 genres décrits, nous ajotitons les 5 qui suivent, réprésentant toutes les sections de la famille, a l'exception de la dernière, les Mymarieus.

Clef nour la distinction des sections et des genres.

1 12) Abơomon pédiculé, campanulé ; antenines do 12 a 15 articles, insérécs sur lo front :

I DIAPRIENS;

2(3) Fuce inférieuro; mandibules rostri:

formes ................. 1. Galessus, $\mu .5 j 9$.

3(2) I'aco antérieure, plus ou moins renfléo inférieluroment:

4(5) Têto subconiquo on arant, avoc los antennes o de 14 articles insérées au miliou du front............... 8. Diapria.

5(4) Tête en carré transversal, uvoc un turbercule frontal; 
6( 7 ) Ailes sans stigma distinct. ...... ..3. Aneuryncius, 560.

7(6) Ailes urec stigına distinct;

8(11) Antennes des $\$$ de 12 ou 13 articles;

9(10) Les 2 nervures sous-costales réuniesd leur extrémité pur la neivuro tranns. versale; radiale longue et étroite avec lo mains pou distinct..........2. Bas.sLs, 559.

10( $\theta$ ) Les 2 nervures sous-cost ules ti'es rapprochées, se ter'minunt sur le stigma qui est épais et courbo........... 4. SprLosricrus, 560.

11 (8) Antennes 9 de 15 articles, en massue a l'extrémité................... 9. Cinetus.

12(13) Abdomen subsessile et campanule; antennes droites, do 12 miticles, in. férées all-dessous du front : II PROCTOTRUPIENS.......... ProctotnuPEs, 561.

13.12) Abdomen variuble; untennes de 10 articles ou insérées près de la boucho;

14(17) Abdomen convexe, avec le dernier urceau ventrul caréné; ailes inférieures lobées; antennes de $10 \mathrm{al}$ ticles: III GONATOPIENS;

16(16) Ailes absentes, antenues do 10 arti. cles...................... 10. Gonatopus.

16(15) Ailes présentes; antennes filiformes, de 12 articles................6. Bethylus, 563.

17(14) Antennes insérées près do la bouche; ailes inférieures non lobées;

18(19) Abdomen subsessile, camprnulé, avec lo dernier arceau ventrul caréné ; ąiles piresquo entièrement dépourvues de cellules: IV CÉRA. PHRONTIENS; antennes de 11 articles, ailes avec un gland stigma semi-circulaire ............... 7. Megaspilus, 808.

19(18) Abdomen scssile, déprimé, le premier segment non campanulé; antennes coudées, de 12 à 10 articles, insérées près do la bouche: $V$ PlatyansteRINNs; 
20 (21) Nervure stigmatique des ailes longue ot oblique, le mésothorax occupaut presquo tout lo dessies du thorax... ... 11. Tezenonus. 21 (20) Ailcs sans neivules dintinctes...... 12. Platyanater. Après le gente Garesus, Curtin, p. 559, insérez lo suivant :

\section{Gen. Diaprie. Diupria, Latr.}

Tête allongée et renflée au dessous des antennes, celles.ci jnsérées vers le milieu de la face, sur son renflement inférieur, comme dans les Exoques, de 12 articles à peu jrès carrés, le premier plus long, le dernier un peu plus long que lo précédent. Dans les $\delta$, antennes de 14 articles, verticillées. Ailes sans autres cellules qu'une très petite radiale et une marginale, le stigma distinct.

Se distingue surtout des Proctotrupes par la tête allongée et subconique. Une seule espèce rencontrée.

Diàprie apicale. Diapria apicalis, Say.

Psilus apicalis, Say.-Am. Ent. II, 729.

\$-Long. .12 pec. Noire, polie, brillante. Tête conique en avant avec les antennes inséréos sur un renflemont do la face. Antennes assez courtes, de 12 articlon, brunes avec le premier article jaune, plus long que les autres qui sont a peu près carrés, volus, et comme fostonnés en dessous; métathorax poli aveo une petito ligne curénule do chaque côté du milieu. Ailes sans taches, avec frange et poils bruns, le stigma bien distinct, une cellulo marginalo étroite el uno très petito collule radiale. Puttes juunes, les cuisses renflées et quelque peu biunâtres au sommet, les hanches noires à la base. Abdomen campanulé, a pédicule court, mais distincı, abruptement rétréci à l'extrénité pour donner suito a la tarière $q$ i est forto et moins da la mọitió do sa longuour.-CapRougo.

Son abdomen brusquoment rétréci a l'extrémité empêche surtout do la confondre avec les Proctotrupes, ea tête est aussi plus allongée. 


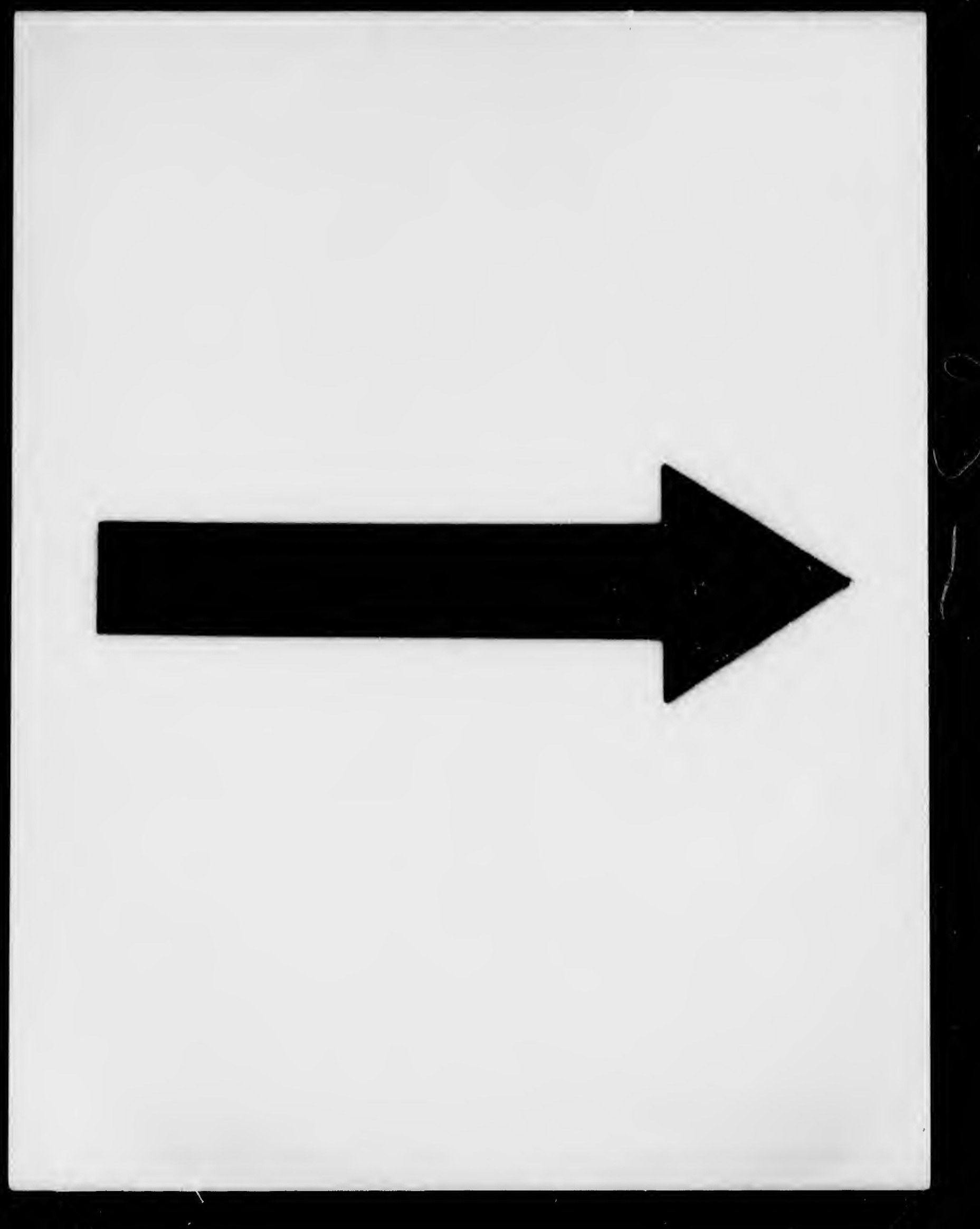




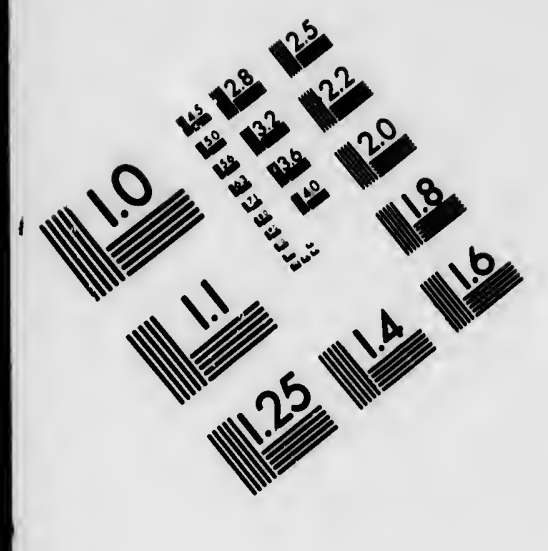

\section{IMAGE EVALUATION TEST TARGET (MT-3)}
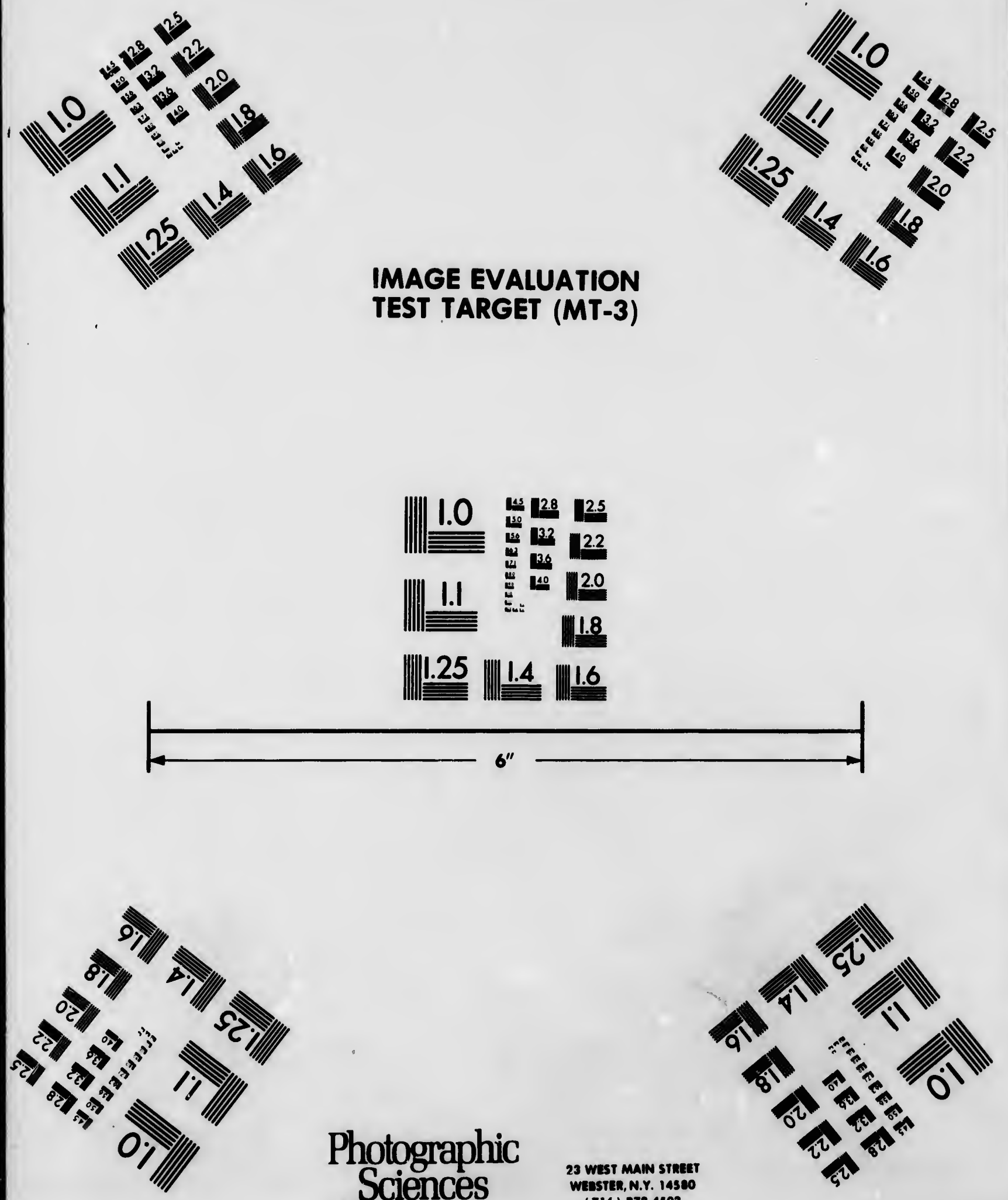

Photographic Sciences Corporation

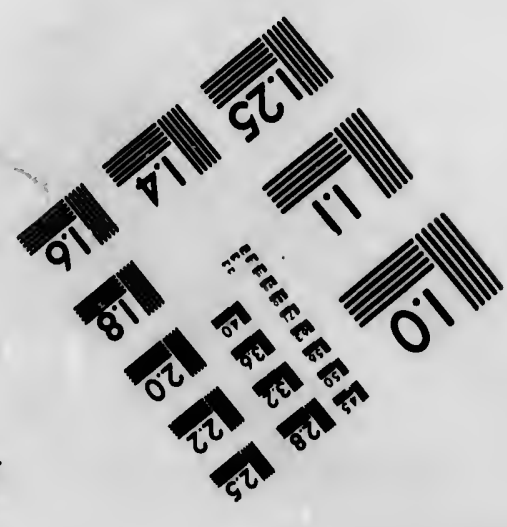


0 w 16

(1)

0

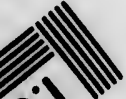


Gen. Aneurynches, Westwood, p. 560.

A l'espèce décrite, ajoutez les 2 qui suivent.

Er.usson armé d'une épine ............. 1. spinosus, 560.

Ecusison inerme;

Têto en enrić, fortument épaissie en arricre

des yeux..................... 2. inermis, $n . s p$.

Tête subglobuleuse ................ 3. aneurus, $n . s p$.

2. Aneurynque inerme. Aneurynchus inermis, n. sp.

\$-Lo1g. .15̃ pec. Noir, poli, brillant; les mandibules jaunátres. Antennes longues. jainne-bruıatro, le premier article lo plus long, avec longs poils pen denses, le te le plus court, les autres allongés. Tête grusse, en carré tr'ansversal, épaisse en arrière des yeux, a fuce renflée en tubercule pour l'insertion dess antennes. Thorax poli, brillant; l'écusson. soulevé mais inerme. Ailes hyalines, iridescentes, frangées, à stigma nul, la radiale en forme de trimuglo allongé, ouverte cn arrière, ni cubitales, ni discoïdales fermées. Pattes jaunt-pâle avec les hanches noires, los

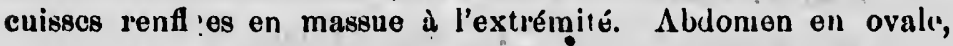
poli, brillant, a pédicule fort, poilu, du tier's de sa longueur environ, le $2 \mathrm{e}$ segment fusiforme, noir, le "wite d'un jaune plus ou moins noiı âtro. - CapRonge, Ottawa (Harrington).

3. Aneury aque sans-nervures. Aneurynchus aneurus, n. sp.

९-Long. .11 pee. Noir, puli; brillant, avoc les antennes et les pattes juunus. Têto sub-rglobulouse, avoc un renflemont transverse au mi.ieu sur lequel sont insírécs les antennes. Antennes do 13 articlos, le 1or tress long, les suivants tres courts, les 4 a 5 torusinaux épaissis graduellement en massuc, bruns, poilus. Thorux en losange, poli, brillant. Ailes sans nervures distinctes, frangéer, poilues, sans stigma. Pattes d'uu beau jaune-miel. Abdoinen subsossile, eampınulé, légèrement déptriné, rétréci à l'extrémité, à tarière à peine sortantẹ.-Stu Gurtrude.

Gen. Spllomicrus, Westw. p. 560.

A l'espéce décrite, ajoutez la suivante.

2. Sp:lomiore fovéolé. Spilomicrus toveatus, n. sp.

miel.

mant

Anter piemi termi lant; 1 potite taches tique une ce avec 1 Abulon trids igr très có pédicu

Antenn très co। poilus. sions 1 laire et mieau $v$ Abdoun meit tr sommet

De Cir Ent. 1I, $\sigma^{x}-$ jaunâtre 
\$-Long. .13 pce. Noir, les pattes et les antennes jauncmiel. La tềte en earré avè la face revflée jüsqu'au milieu, förmant uno protubérance sur laquellé sont inserées les anteniôs: Antennes de 13 articles, juunes, les articles terminaux bruns, le piremior article fort long, les silivarits treds courts, poilus, los 4 is terminaux ćpaissis gradicllemeńt en mássue: Thoráx poli; brillant, beincoup plus laige en avant, l'écus on brillanit avớc vile potite fovéole transverse on avant. Ailes velúcs, frangées, saris taches, n'ayant de bion apparente qu'uné petite iorvule stigrna. tíque un peu courbo, d'autres norvures moins distinctes formont une cellule brachiale triangulaire. Puttes d'un beau jaunc-miol, avec les ruissscs et les jambes renflées en massue a l'extrémité. Abdomen à pédicule conrt, mais distinct, déprimé, à 20 segrment trìs granḍ, rétréci on pointe et poilù a l'uxtrénité; tarièro droite, très coürte.-CapRouge.

Se listingne surtont du longicornis, par son abdomen a pédicule plus court et ses antennes jlus distinntement en massiue.

Après le Genre Spilomicrus, Westw., ajoutez lo suivant.

9. Gen. Ciñere. Cinetue, Jurine.

Tếte grosse, en carré transvi rsal, la face bombśe inférieurement pour la réception des antennes à la manière dès Exólues. Antennes $\sigma^{\prime}$ de 14 articles, le premier plus long et épaissi, le 2e très court, globuleux, les autres allongés, étranglés ì l'extrúnité, poilus. Prothorax très court, mésothorax grand, avec 2 inpressions longitudinales. Ailes avec une cellule rudiale triangulaire et une cellule brachiale, le radiüs à sa base envoie un raneau vers le centre de l'aile, le disique de l'aile sans cellules. Abdonnen en ovale, déprimé, à pédicule large, strié, le 2e segment très grand. Pattes avec les cuisses rentlées en massue au soinmet. Antennes + do 15 articles.

Deux espèces rencontrées, dont une nouveile.

Cinète pattes-jaunes. Cinetus mellipes, Say, - Am, Ent. 1I, 726.

$\sigma^{t}-$ Long. 13 pce. Noir, poli, brillant, pointu, la bouche jaunâtre. Antennes jaunes, brunâtres d̀ l'oxtrémité. Ailos saus 
taches, poilues, frungées; les nervures do la cellulo radialo s'étendant vors la base et lo contre de l'aile, les deux normures anales très distinctor, lo stigmu non apparent, n'étunt ropl'ésenté que par la nervulo lransvorse plus éprisse. A bdomen déprimé, ovule, a pédiculo avoe lignos longitudinales, lo 20 segment treds grind, composant a lui seul plus de lu moitié de l'abilomen. Puttes d'un beau jaune miol, los hanches noires, surtout a la base, les cuisses et les jambes renflées an sommet; les tarses antérieurs plus longs quo lour's jambes.-CapRougo.

\section{Cinetë à museau. Cinetus nasutus, nov, sp.}

†-Inng. .15 pen. Noir avec les pattos roux-jaunâtre. La face prolong:e en muscau dans sa partie inférieure. Tête subglobuleuse; les anténnes fortes, de $\mathbf{1 5}$ articles, le lor tres long, les derniers granulenx, s'épaississant insonsiblement on m:ssue, quelque peu brunâtres. Thorax rétréci oll avant, les sillons parapsidnux du mésonotum profonds, le divisant en 3 lobes. Ailes hyulines, velues, à radiale très potite, ln nervure stigmatique envoyait un rnyon ver's la base de l'aile. Pattes d'un beau jaunemiel, sans nucune tache. Abdomen à pédicule fc th et assez allongé, ncubre, lo reste en ovule, deprimé, puli, le 20 sogment tr'ès grand avec une petito fossette d la base.-Ottawa (Harringtou).

Se distingue ficilement du précédent par son thorax presque allongé en cou, la forıne de sa tête \&c.

A prìs le geure l'roctotrupes, Latr. p, 561, insérez le suivant :

10. Gen. Gonatope. Gonatopus, Klıg.

Dicondylus, Haliday.

Tête aplatin, large, avec les antennes insérées près de la bouche. Antenues presque filiformes, de dix articles. Thorax long, plus étroit que la tête, étranglé au inilieu. Point d'ailes. Abdomen ovale. Hanches antérieures très grandes, avec les cuisses renflées; tarses antérieurs à ongles très longs, en furne de pinces, dont l'insecte se sert a la manière des écrevisses pour saisil' sa proie. 
Ces insectes ont toute l'upparence des fourmis, n'en differant que par l'absence d'écaille au premier segment abdominal et par l'extrémité de celui-ci qui se retrécit en tarière fine et courte. Se trouvent sur les fleurs.

Une seule espèce rencontrée.

\section{Gonatope trompeur. Gonatopus decipiens, n. sp.}

ㅇ--Long. .11 pce. Noir avec les antennes or les pattos en partio testacées. Têto aplatio, largo, très fi. ement ponctuée, avoo un gros orello silr le vertex. Antennes insérées prèx do la bouche, do 10 aiticles, le 1 er p'us long et plus gron, lessuivants allongén; grêlẹs, les terminuux courts, moniliformes et un peu plus épuis, les torminaux plus ou moins obscurs. Thorax poli, brillant, étroit. allongé, étranglé à l'endroịt de l'écusson. Abulomen subsossile, on ovale. Cuisses antérieures fortement renflées, noiros, lour's jaunbes. testacées, lour's tarses brunâtres avec los ongles longs en forme de pinces; les 4 cuisses postérieures uvec leur'ṣ janbes, noires, leurs farses testacés.-CapRouge; rare.

Cet insecte à toute l'apprarence d'une fourmi.

Gen. Betrylus, Latr, p. 563.

A l'espèce décrite, ajoutez la suivante.

2. Réthyle fausse-fourmi. Bethylus formicoides, n. sp.

ㅇ-Noir, poli, blillant, arec les pattes et les antennes juunemiel. Tête allongée, aplatie, se rapprochant beaucoup do cello des fourmis. Antennes jaune-miel, insérées piès do la bouche, le premior article allongé, courbe et très jenflé, les autres épais, filiformes, les dorniers brunatres. Prothorhx aplati, tres long, d peine plus étroit on arant, brillant, d ponctuations fines ot peu denses; mésothorax court; métathorax plan, allongé, avec une fossette longitudinale ponctué sur lo disque, les côtés polis. Ailes hyalinoś, lo stigma donble, la radiale grande, ouvorto en arric̀re, aucune cellule discoïdale forméo. Pattes d'un juune-miel, les cuisses renflées, surtout les antérieures; les postéricures tachées de noir au sommet en dodans. A bdomen en ovulo allongr, poli brillant, quelque peu poilu au sommet; tariore a peine sortante. -Ottawa (Harrington). 
Se distingue surtont du prolongatus par son prothorax plus allongé, sa tête plins aplatie et la coloration de ses antennes. Le dernier aplartiendrait plutôt au genre $E$ piris de Wéstwood.

Après le genre Meraspu,us, West. p. 808, insérez les deux qui suivent.

\section{Gen. TEı.fмone. Telemonus, Haliday.}

Antennes de 10 articles $q$ et $12 \delta^{\circ}$, assez longues, terminées en massue teu sensible. Mésothorax occipant presque tout le dessus du thorax. Abdomen sessile, avec le 2 e segment allongé. Nervure stigmatique des ailes longue et oblique.

Une seule eslèce rencontrée.

Télémone noir. Telemonus ṡtygicus, n. sp.

q-Long. . 18 pce. D'un noir foncé brillant. La tête rugucuse à l'exception d'uné bande polic, brillante, sétendant au milen de la faco depuis les occlles jusqu'à l'épis'ome. Antennes insérées près de la bouche, longues, enroulées à l'extrémité, le scapo long et forrt, le 20 article très petit, lo $3 e$ le plus long, les autres plus longs que larges. Thorax trapu, rugueux, lo mésothorax purtagé en t:ois lobes dont lo médian est plus avancé; écusson en ovale, aplati, brillant; le métathorax court, rugueux, ses angles postérieur's sulbépineux. Ailes enfumées, le stigma noir, la nervuro stigmatique incomplète, n'atteignant pas la côte. Pattes noires, les genoux avec les tarses plus ou moins, jaunâtres. Alidomon sessile, court, robuste, en pointe a l'extrémité, le premier segment fortement acieulé à la base, le reste poli, brillant, le 2e segment lo plus grand; tarière uั̌n sortante.

Ce bel insecte a été capturé à Ottawa, par M. Harrington.

\section{Gen. Platygastre. Platygaster, Latr.}

Antennes de 10 articles, en massue dans les o. . Ailes sıns aucune nervure. 'Abdomen pédiculé avec le $2 e$ segment très grand et les suivants très courts.

Une seule espèce rencontrée.

tenn

près qui e potit sue a louse. proto lier ju longit profo stigm les ha oviale, tarièr'

étudia genres cette i

A vants.

$\mathrm{T}$ avant a niliforn lo pren vure di à l'endr très pet flées en

$\mathrm{Ce}$ mais ils en deux

Un 
Platygastre du Canada Platygaster Canculensis Prov.

$\sigma^{7}$ \& - Long. 14 pco. Noir a $3 c$ los pattos j:unno-nicl. Antennes jauncs, de 10 articles, légèroment puboscentes, in wérées près de la bouche, sans sillon pour loger leur premier article qui est très long, lérgèrement arqué, les articles 2,3 ot $\$$ plus petits, les auties a peu près d'égalo grossour, formant uno mas sue alllongée, plus ou moins brunâtre Iua face finement granulouse. Tête en carré transvereal. Thorax rotrẻei en aviunt, lo protorax très court antérieurement et c'étendant en forme de collier' jusqu'd̀ l'insertion des ailes, le mésothorax étroit, avec 2 sillons longitudinaux fortement prononcés. L'écusson moyen, sans sillon profond.d la base. Ailes subhyalines, finement pubescentes, sans stigma et sans nervures bien distinctes. Pattes jaune-miel avoo les hunches noircs, les cuisses légerement renflés. A bdomen on ovile, déprimé, à pédicule fort, volu, lo 20 scgment très grand; tarière non sortante-CapRouge.

Nous croyions avoir termivé les Proctotrupides, lorsqu'en étudiant les Chalcidides, nous trouvâmes des représentants des 3 genres qui suivent, qu'à première vue nons avions rangís dans cette dernière famille.

Après le genre Gílesus, Curt. p. 559, ajoutez les 4 suivants.

\section{Gen. Coptirre. Coptera, Say.}

Tête oblongue longitudịnalement, tronquée ou excavée eu avant au dessus de l'insertion des antennes. Antennes stibnoniliformes, s'élargissant graduellement en allant vers l'extrémité, le premier article très long et plus fort. Ailes sans aucune nervure distincte, se pliant en deux avec une fissure à l'extréctnité à l'endroit dı pli. Abdomen à $2 e$ segment très grand, les antres très petits. Pattes médiocres, avec les cuisses et les jambeṣ renflées en massue à l'extrémité.

Ce genre est très voisin, par la forme de sa tête, dos Galèses, mais ils s'en sépare par ses ailes fendues au sommet et se pliant en deux. Ne serait-ce pas le genre Entomacis, Förster ?

Une seule espice rencontrée. 
Coptère polie. Copterc polita, Say - A m. Eut. II, 728.

१-Long. .16 peẹ. Noire, polie, brilliunte. Tête allonğ̛́c, subeylindrique, portunt les antennes a son extrémité autérieuro; face inférieure. Antennes de 12 articles, pubescentes, noires, lo !er articlo fort, le plus long, un pen arqué, $2,3,4,5,6$ plus petits, le resto s'épnississant en mussue lâche. Prothorax trè̀s eourt en

- avant, le mésothorax avee 2 sillons longitudinaux fortement prij. noncés; l'écusson avee une double fussette à in base, Ailos hyalinos, iridescentes, rolnes, suns nervures distinctes, los supérieures Chancrées, commo fendues al leur extrémité. 'Puttes runsses, los cuisses plus ou moins brunes, en massue. Abdomen en ovile, déprimé, le pédicule du tiers do sa longueur environ.- Ottawa (Harrington).

Cet insecte se distingue à première vue par ses ailes fendues.

Gen. Platymisque. Plaiymischus, Westw.

Tête oblongue, non très allongée, un peu aplatie duns les $\%$. Antennes de. 12 artieles, filiformes dans les $\sigma^{\lambda}$, courtes et presque moniliformes dans les + . Dos du thorax trianguluire. Ailes avee une nervure sous-costale courte, terminée par un point calleux.

Ces insectes ont tonte la forme des Gìlèses, moins la tête qui n'est "une médiocrement allongée et les mandibules qui ue sont pas rostriformes. Une seule espèce rencoutrée.

Platymisque à-collier. Platymischus torquatus, n. sp.

q-long. .1t pee. Noir, poli, brillant, avec les pattes rousses plus ou moins brunes. Têto médiocrement allongée, a fico inférieuro. Antennes puhescentes, les articles 2, 3, 4 et 5 plus petits, 3 plus long que 2, les 6 derniers légèremont épaissis en massuc. Prothorax couvoit au collier d'uno pubescenco deneo et grisâtre. . Fcusson avec une seule fossetto à la base. Ailes volue, hyalines, sans autres norvures que le costa qui 'st court ot se termine en un point épais on formo de stigma. Pattes avoc los cuissos p!us ou mo' is brines ot renflées en inassue au sommẹt, 
les jumbes et les tursos ciliés-poilus. A.bdomen pédiculé, déprimé, en ovale, soll extrémité poinie.-Hall, CapRouge.

Bien distinct par le collier gris qu'il porte.

\section{Gen. Isosrase. Izostasis, Först.}

T'ête en carré transversal. Antenues insérées près de la bouche, de 10 articles, à scipe très long, arquué, ln massue assez grosse, furmée des 7 derniers articles, recourbée, attenucée à l'extrémité. Dos du prothorix très court, celui du mésothorax partagé en 4 lobes par 3 sillons longitıdinàux. Ecusson non séparé du mésonotum par un sillon profond. Ailes avec li nervure sous-margiıale terıninée par un point épais furmant un stigma donnant naissauce à un radius très distinct. Abdomen sessile, déprimé, droit. Pattes avęc les cuissus légèrement claviformes. Tarière nou sortante.

I.es nervures des ailes suffisent à première vue pour faire reconnaitre ces insectes. Une seule espèce rencontrée.

Isostase tête-ảe-bélier. Irostasis arietinus $\mathrm{n}$ : $\mathrm{sp}$.

- q-Long. .11 pec. Noir, avec la bouche, le scape des an te nnes, et les pattes, d'un benu jaunc-miel. Tête aussi large que lo thorax, a antennes fortes, le scape fort, arqua, jaune ainsi que l'article qui le suit, lo reste formant une forte massto brune recourbee en corne do bélier. Mésonotum avec 3 sillons bion distincts. Ailes hyalines, avec la sous-marginale brune se terminant dans un stigma grand et épaissi qui donne nuissance a un radius se dirigeant ver's le sommet de l'aile. Pattes jaunes, hanches noires. Abdomen sessile, poli, brillant, droit, tariere non sortaute. La lito et le thorax sont très finemen' ponctués, les 2 ocelles basilaires sont plus rupproch is de l'apical quo du coin interne des yeux. - CapRouge.

Gen. AcÉnote. Acerota, Först.

Tête grosse, à vertex plein, à occiput excıvé postérieurement. Autenues de 12 articles, insérées près de la bouche, lo seape assez court, les articles $2 \& 3$ cyathifurm3s, les autres for- 
mant une massue allongée. Les 2 ocelles basilaires plus rapprochés du coin interne des yeux que de l'ocelle apical. Thorax robuste; rugnelux, sans sillons parapsidaux distinets. Ailes avec la nervure sous-naryinale portant un point épais à son extrémité quoique de coloration ussez légère. Abdomen sessile, déprimé, druit, en ovale allongé, à bords trauchants ; tarière non sortante.

La disposition des ocelles distingue surtout ces inscetes dẹs Isostases. Une seule espice rencontrée.

Acérote opaque. Acerota opaca, n. sp.

.-.13 pee. Noir opaque avec les pattes rousses plus ou moins obscures. La têto ot lo thorax ponctués-rugueux, ot l'ab domen avee le doß des segments nciculìs longitudinulement. Ailes hyalines. L'ubdomen est sessile quoique son premior seyment soit plus étroit quo les autros.-CapRouge.

\section{Fam. VIII._CHALCIDIDES, p. 564}

La fauille des Chalcidides n'a été, comme les deux précódentes, que fort peu étudiée, et demeure encore, vu les nom. breuses découvertes qu'on fait tous les jours de nouvelles especces, dans une graude confusion.

Si les formes étringes, et parfois tout-à-fait singulières, ajouteut un iutérêt tout particulier à leur étude, il faut avouer que leur petite taille en général est un.obstacle sérieux à leur connaissance. Il u'est pas toujours facile de compter les articles de leurs antennes, encore moins ceux de leurs tarses, et dans plusieurs genres, on a établi des espéces sur des caractères si peu tranchés, qu'il pourrait se faire que mieux conuues on en réduirait notablement le nombre.

Comme les ailes des Chalcidides ont une nervation toute spéciale, Walker donne à ces nervures des noms particuliers qui sont d'un grand secours pour la distinction de certains genres. Liuile fignrative ci-jointe sirvira à les distinguer. 


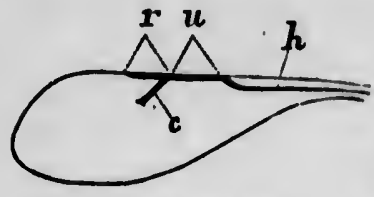

Fig. 23.

Fig. 23, $k$ est l'humérus on solus. costale, $u$ est l'ulna qui est quelquefois interrompue pour se joindre à l'humérus, et s'y unit a'autrefois, comme dans la prósente figure, par une courbe conltinue ; $r$ est le radius, et enfin $c$ est le cubitus qui se termine souvent par un point calleux. (1)

Les nouveaux genres que nous avons rencontrés nous permettent de modifier comme suit la clef systématiyue pour les distinguer les uns des antres.

Clef pour la distinction des tribus et des genres.

1(27) Prothorax très dévoloppé, généraloment en (anré transwersal ;

2(11) Cuisses postérieures très renflées, plus oú moins dentées on dessous avoc une ruinuro dens laquelle s'emboîte la jumbe qui est ưquée ;

3(4) Ailes pliées en deux dans lo repos, turièreo o rediessrío sur le dos: I. LEUCOSPIDIE NS. 1. Leucospis, 567.

4(3) Ailes étendues dans le repos; tarière cachce ou dioite; II. CHALCIDIENS;

j(10) Antennes insérées ver's lo nilieu du front ;

6(7) Pédicule do l'abuomon distinct; articles 2 ot 3 des antennes of très petits, 5-10 cour's, massue 3-articulćo ...................... 13. Sircra.

7(6) Pédicule de l'abdomen très court; articless des autennes o 2-10 très épais, presque égaux ;

$89)$ Abdonion court, subtriangulaire......... 14. Chalcis.

$9(8)$ Abdomen avee les dernier's segments rétrécis et allongés on une especte de queue pour. servir d'étui à la tirièro ......... 15. Phasgonophora.

toute rs qui enres.

10. 5 ) Antennes insérées près de la bouche; jumbes inermes, pointues à l'extrémité ...... 16. Haltichelea

(1) Dans la désignation ordinaire les nervures, $h$ serait la sous-costale, $u$ et $r$ la marginale, et $c$ la sous-marginale ou radius. 
11(2) Cuisses postéricures simples, jambes droitos ;

12.17) Cubitun nssez long ot no ne rocourbunt pus ell cirochot ver's la côto: III. EUURYTOMIENS ;

13 (16 Corps contractile, fortement ponctué, fl incs uvec un sillon pour la récoption des cuisses intormédinires;

14,15) Aintonnes of ot $q$ de 8 miticlos, les articles 3-7 duns lo o dilatés en dessins, longuement ciliés ot contructés on pédiculo au som. mot........................ 2. Eunrtóma, 568.

15 14) Antennos $\sigma^{7}$ de 7 articles, o de 8, dians le $\sigma^{7}$ non contructés on pédiculo au soinmet; stigmis souiont brun, épnissi et élargi... 3. Drearous, 56 భ.

16(13) Corps non contractile, ponctué sans ctre très rugicux, dépourvu do sillons pour la réception les cuisses; antennes do 9 articles, 3-9) ciliés longuernent dans los ơ, brievemont daus les . ........................ 17. Isosoma.

17(12) Cubitus tiess court, lo plus souvent recourbe en crochet rers la côte : IV. TORYMIENS;

$18(26$, $\Lambda$ bdomen plus ou moins comprimé duns lo

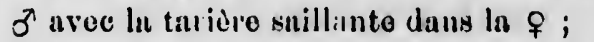

19(23) Cuissos postérieures avec épines; ou dentéos ell scio en dessous;

20 19) Cuisses postéricures avoc épines seulement ;

21(2:) Hanches postéricures dentées. 4. Monodontonerus, 569.

2:(21) Hanclies postéricures luermes, l'épine de la . cuisse nouvent obsoldte........... 18. ÓLigosthe.us.

23(19) Cuisses postérieures ni dentées ni cípineuses;

24(:5) Eeusson avec nne ligne tranversule bien distillcte près du sommet ........... 1\%. Srntomaspis.

25(24). Wusson sans ligno transversale; taridre généralement longue........... 5. Callmone, 570.

26(18) Abdomen cylindrique dans lo $\sigma^{\pi}$, conique dans la , mais sans tarièc saillante..... 20. OrMYrus.

2.7(1) Prothorax peu dévoloppó, génélaloment a dos trìs court; 
28(31) Thornx fortemont divolopprí, mqué, fortcment ponciné ; ecuskon prolongú un dexalls dı mútathornx; V. EUCHARIDIENS;

291301. Antonnes dontées ou fubollsar; cubitus a peine divelopé; tête trids courte ol laige. 6. livcuanis, 570.

30(29) Antennor ni dentíes ni flubellées, preequo on mussuo; cubitus asazz long ....... 7. Pemuampus, 571.

31(28) Thorax non tids dévoloppé, ni treds fortement pouctué, Éunson non piolongé sill le métstlornx ;

32.37) Antonnes inserries pris de ln bonche; taridre sortanto: VII. SPALANGIENS;

33(34) Prothorax rétréci on cou,niles incomplètes, 13. Tubocolax. 34(33) Prothorux non rétréci en eon, niles compldtes;

35(36, Ulin plis encirte quo lo radilis.......... 21. Mioromelus.

36(35) Ulnn plus longue quo lo radius; culitus tiès erollt........................ 22 Spatanata.

37(32) Antennes non insérécos près do la bouche; nbdomon plat on dessus; taridre rimemont saillante; lote courto, transversule, nouvent plus lurgo quo lo thorux : VIII. PTEROMALIENS;

38(50) Flames avec un sillon pour loger los cuissos interinédiniros ;

39.57) Thures do 5 articles ;

40(41) Ecusson on curré trarsversal... ..... 8. Papraaus, 572.

$41(40)$ Eiusson non transrersul, plus ou moins allongrée ;

42(43) Ulna épaissic, très longuc, occupant près do

la moitié de la longnour totalo do l'ailo, 23. Metacolus.

43(42) Ulna ordinaire, occupant ì peino lo quat do

la longueur totalo do l'aile, non rpaissio ;

44(45) Point calleux du cubitus trds largo.... 24. Dinotus.

45(44) Point calle'ux du cubiuls ordinairo;

$4(i$ 47) Tarièro do la moitie de l'abdomen. 25. Roptrocerus.

$4746)$ Tariero cachèo ou tris courte ;

48(49) Sillons purapsidaux bien distincts; anten-

nes do 9 articles ................ 9. Semioteldus, 
49(48) Sillons parapsidaux peu profonds, peu distincts ; antennes de 13 articles ........ 10 Preromalus.

$50,38)$ Flancs suns sillon pour loger les cuisses intormédiaires ;

51 56) Antennes a plus de 8 articles;

52(5:) Mésono: um rétréci en avant de l'écusson; jambus intormédiaires aveu une forte épine: IX EUPE LMIENS. . 26. Charitopus.

53(52) Mésonotum non rétréci on avant do l'écusson, son disque rebordé en arridre: $X . E N$ CYRTIENS ;

54(55) Ecusson avec une touffe de poils raides; ulna tres longue; cubitus et radius très courts.................... 27. Chiloneurus.

55. ja) Ecusson sans touffe de poils; pavillon des antennes très long ............... 28. Copidosoma.

56(51) Antennes d pas pitus de 8 articles.... 29. Coccophagus.

57(39) Tirses de 4 articles ;

5:-(62) Ulna non interrompue, passant dans l'himérus par une ceurbe : XI. EULOPHIENS;

59(6(1) Parapsides distinctement séparées; jambes postéricures avec 2 longs éperons ...... 30 Euplectrus.

60(59, Parapsides indistinctes, jalmbes postérieures à íperon court....................... 31: Mrotropis.

$6159)$ Parapsides pou distinctes; antennes on pectinées...................... 11. Euconhus, 5 76.

62(58) UIna interrompue pour passer dans l'humérus;

63(64) Ulaa très longuc, donnant naissance au cubitus au delà de la moitié do la longueur de l'uile ..................... 32. Chrysocharis.

64(63) Ulna ordinaire, so terminant en avant cle la moitié de la longueur do l'aile;

65! 66) Ecusson sans sillóns ; antennes en apparence do 3 articles............... 33. Trichasius.

66,6(i) Ecusson avec sillons; antennes do plus do 3 articles apparents;

67(68) Ecusson avec un seul sillon au milieu. 34. Hor.copei.te. 
68(67) Ecusson avoc un sillon de chaque côté du milieu ....................... 35. Tetragtichus.

A près le genre Lr.ucosprs, Fabr. J'. 567, insérez le suivant.

13. Gen. Surcue. Smicra, Spinola.

Tête courte, transversale. Antennes de 13 articles, ?e premier long, le $2 \mathrm{e}$ petit, le 3e à peine visible, le reste forts, pubescents, formant une massue allongée. Thorax gibbeux, le prothorax court, transvercal. Ailes à cubitus court, terminé par un point épais. Cuisses et hanclıss postérieures grandes, les premières ovalaires, renflées, armées de dents en dessous, la jainbe arquée.et terminée par une forte épine, canaliculée en dessous pour s'adapter à la courbure de la cuisse. Pédicule de l'abdomen très grand, le reste formant une masse sub-globuleuse.

Deux espèces rencontrées.

Noir, sans taches, les cuissos postérienres noires

ou brunes, plus on moins jaunâtres à la base. 1. microgaster

Noir, sans taches, cuisses postérienres ontiere-

ment woires; antonnes plus courtes.

2. Canadensis.

1. Smicre microgastre. Smicra microgaster, Say.

Chalcis microguster, Say -Am. Ent. I, 219.

o - Long. . 18 pce. Noire, le thorax et la tête ponctués-chagrinés, la ficco arec un sillon pour loger le scape des intennes, ot une petite carène an dessons les divisant a lour base. Métathorax fortemont rugneux. Ailes subhyalines, la nervuro costalo brunroussâtre, épaisse. Pattes noires, plus ou moins roussâtros aux articulations. Les cuisses po-térieures jaunes ou tostacées a la base, de même que tous los tnrses. Abulomen subghlobuleux, d pédicule un peu plus court quo les hanches, colles-ci avec doux petites dents on dessus vor's leur sonımet; la massue de l'abdomen un pou plus longuo quo lo pédicule.

Capturée à Hull, non encore rencontrée dans les enứrons de Québec.

2. Smiore du Canada. Sinicra Canadensis, Cress.

Sinicra Cunalensis, Cress. - Trans. Am. Eut. Soc. IV;39. 
९-Jung. .16 pee. Fntierement unire, ln face a rugosités transversales, le chaprion poli, liste. Antennes noires, robustes. Thorax ponctué-chagriné, lo métıthorax avec lignes sonlevies interrompues. Ailes liyalines, lésirement ob-enreies a l'uxtrismité. Pattes noires arec len tatro's jâles excepté a l'extrémité, les 4 preniè̀es plus on moins jatmûtues aux articnlations; les ruirses postérieures sans auchne tache, d dents fines et nombrenses. Pédicule de l'abdomen fort, un pen plus court que lo reste qui forme une maskue subglobulcuso. - Ottawa (Harrington).

Ses cuisses ; ostérieures sans taches la distinguent surtout de la précédente.

14 Gen. Chalcis. Chalcis, Fabr.

Tête courte et"triangulaire. Antennes de 13 articless, plus ou moins filifornes, insérées au milien du·front, leur premier article logé dans nu sillon. Thorıx robuste, écusson grand, hémisphériqıe. Abdomen sessile ou subsessile, oblong, subtriangulaire. Les chisses antérieures sulofusiformes, les jostérieures ovalaires, renflées, avec la marge inférieure fincment dentée, les jambes intermédiaires avec une épine au sonmet, les postérieures prołongées en éperon.

L'absence de pédicule à l'abdomen permet toujours de ne pas confondre les Chaluis avec les Smicres. Une seule espèce rencontrée.

Chalcis ovale. 'Chalcis ovata, Say.-Am. Ent. I, 219.

ㅇ - Long. .14 pee. Ponctrée-ringueuse, noire, le scapo des antennes en dessous avec l'extrémité de leur massine, plus on moins jaunâtı o; less écuilles alaires aussi jannâtren. Ailes hyalines, duervule costale brune. Pattes variées de jaune ot le noìr, les hanches noires, les quatre puttes aitéi ieures ronssâtres avec les genonx plus clairs, les cuisses postérjeures noires, testucées-blanchâtres au somnut de mème que lemrs jambes et lenrs tarsen. Abdomen poli, subtriangulaire, un peu comprimé-CapRouge.

15. Gen. I'H.s ganopirione. Phasgonophora, Westw.

Tête hémiṣ hérịue, à occiput légèrement creusé en arrière, face pleine, à sillow antr.nnaire profond. Antennes filiformes, 
à articles plus longs que larges, insérées vers le milieu de la face. Prothorux en carré transversal ; f́cusson renflé. Ailes à uervure stigmati ${ }_{\mid}$ue assez courte et envoyant à son extrémité un rumean éplais et court. Abdomen sessile, rétréci à lı base, avec les derniers segments formant une espièce de quene, le te arceau ventral formant une snillie comprimée ver's le nilieu de l'adomen. Cuisses postérieures renflées, épineuses en dessous.

Spinola dit que e'est le premier arceau ventral qui forme la saillie abdominale, mais en examinant attentivement on verra que ce n'est pas le $1 \mathrm{er}$, mais bien le $4 \mathrm{e}$, les à premiers étant courts et refoulés à la base du ventre. Une seule espèce rencontrée.

\section{Phasgonophore élézante. Phasgonophora elegans} n. sp.

O-Long. 18 pee. Noire, la tête ot le thorax fortement ponctués-ruguoux, te métathorix l'étant encore davantage par des petites lignes roulevées irrr gulières. Sillon antennaire large et profond, atteignaut les ocelles. Anteunes assez courtes, sans taches. Ailes hyalines avec la nervure sonscostale et le stigma br'un-ronssâ re, une petite tache do la même couleur a l'extrémité du stigma. Pattes noires avec les tarses pâles, les genoux plus ou moiıs jaunâtres, les euisses postérieures entièrement noires, renflées, et portant ô a 6 dents en dessous, leurs jambes aussi noires, arquées et so terminant palr un fort éperon. Abdomen sessile on à pédicule très court, resserré a la baso et en pointe efficée à l'extrémilé, poli, brillint, à l'exception des dernier's segments qui sont pouctués ot poilus, la saillie ventrale jaiunâtre d sal pointe.-Hull.

Nons avons capturé ce joli petit insecte sur le bord d'un marais à Hull, et nous en avous reçı un antre excmplaire de $\mathbf{M}$. Harrington capture anssi au même endroit.

\section{Gen. Haltichllde. Hiltichella, Spin.}

Tête triangulaire; yenx grands. Antennes de 13 articles, légèrement en mıssue, insérées près de la bonche. Ailes, avec une courte nervure maiginale, une trìs couite stigmatique, et 
une plus courte encore post-marginale. Abdomen ovale, subsessile, le 2e segment légèrement aplati en dessns. Cuisses postérieures renflées, inermes ou avec seulement quelques dents en dessors, leurs jambes terminées par 2 éperons, les interunédiaires avec un seul.

Une seule espècc rencontrée.

Haltichelle verte. Haltichclla vividis, n. sp.

- - long. .20 pce. D'un leau vert métallic, fortement chagrinée. Tête triangulaire, transver'so. Antennes insérées au dessous du milieu de la face, rapprochéus l'uno de l'autre, le scape roux, n'atteignant pas les ocelles, lo pavillon noir, en maskue. Prolhorax assez court. Ecusson petit, poli, brillant. Ailes hyalines, sans nutre nervure que la sous-costale qui se rapproche dı bord pour portei lo stigma et no s'étend pas all dela. Pattes d'un jaunâtio sale, les cuisses vertes, les postérieures dilatées, chagrinées, avec une dent ver's leur extıémité, leur's jambes pubuscentes, arquées, brunes avec un anneau pâle à la bitse; leur's tarses jâles. Abdomen sessile, en ovale, poli, brillant, les segments a partir du 40 très petits. Tarière noire, un peu plus longue que l'abdomen.-Hull (Guignard).

\section{Gen. Eunytome, Ill, p. 568.}

A l'espèce décrite, ajoutez les 3 qui suivent.

Abdomen brusquement racourci à l'extrémité ;

Scilpe des antenues entièrement noir, taille plus petite 1. studiosa.

Scape des antennes jaune, du moins ì la base; taille plus forte;

P.atter noires

2. diastrophi.

Pattes jaunes 3. nigricoxa, n. sp

Ablomen atténué à l'extrémité en uno longue pointe.

4. conica, $n . s p$.

2. Eurytome du diastrophe. Eurytoma diastrophi, Walsh.

- Eurytoma cliastrophi, Walsh-Am. Entom. II, 299. 
९-Long. 12 pece. Très rapprorhée de la studios", dier. différant guère que parr sa plus forte taille et le scupe de sce antennes qui est plus au moins jaune. Ser antennes sont aussi plus courter.-Ottuwal, CapRouge.

3. Eurytome hanches-noires. Eurytoma nigricoxa, n. sp.

Q - I Iong- . 09 pee. Noire, fortement ponetuéc-rnguenke kilr Ia tête et le thornx avec poils blanes. Antennes de 8 articles, mais avee les anticles do la massue bien distincts, to secape juune en dessous. Ailes hyalines, les norvures jannes, l'ulua et le c'11- . bitne forts. Pattes d'un beau janne-miel, y compris les 4 hanches antérioures, mais les hanches postérieures noiles. Abdomen poli, brillant, a pédicule assez court, les .5 premiers regments sans aucune trace de ponctuations ; la tariere jaune, a peine sortunte.--Ottawa (Harrington).

Très rapprochée de la plupart des espèces décrites par Wal.h, Riley, Ashmead ete., mais différant tonjours en quelques points de.leurs descriptions.

\section{Eurytome conique. Eurytoma conica, n. s!.}

†-Long. 16 pee. Noire, fortement ponctuée sur la tête et la thorax. Antennes de 8 articles, velues, lo scape entielement noir; la boncho rous: âtre. Ailes hyalines, les nervures pâles. Pattes noires, avec les genoux iaunes, los tal'ses blancs aroc l'extrémité noire. Abdomen a pédicule médiocié, plus fortement eomprimé que d'ordinaire, poli, brillant, se terminant parr une longne pointe conique fuisunt suite a la ligne dorsale. - Ottawa (IIarrington). .

Cet insecte n'a pas la forme contractile des deux précélents et son abdomen atténué en longue pointe sembléiait l'exclure de ce genre, cependant il $\llcorner\mathrm{n}$ a bien tous les autres earactèies.

3. Gen. Decatoma, S S $\mathbf{j}_{\text {in. }}$ p. 568.

Décatome à-ailes hyalines. Decutoma hyalipennis, Walsh.

Decatoma hyalipennis, Wulsh-Am. Ent. II, 299.

Decatoma basilaris, Prov._Faune p. 569. . 
Le prothorax prorte presque toujours wne tache jaune sur chaque épranle.

2. Déontome variant. Decatoma varians, Walsh.

Decutoma varians, Walsh-Am. Eutom. II, 300.

o-Long. .09 pee. Varié de noir et do jaune; la bousche, lo scape des mil cunes, lis orbites interrompus sur le vertex, lo pro. thorax; les flatice, les pattes avec la base c's l'abdomen en dossous, jatluc, to reste luir. Têto et thoris ponctués-gramulenx. Ail.s byalines avec le stigma cipalis, noir, filisant la base d'une bande étroite brance traversant l'aile entide. Pattor jalunes, los cuisses plus ou moins brumes. Abdomon pédienlé, puli, brillant,

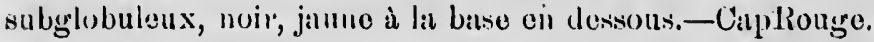

Nous en avons fait éclore un grind nombre de galles cueillies sur ie Vuccinium 1 ensylvanicum. 'Nous avous tont lieu de croire que l'insecte lui-même esı le producteur de la gille, cir nous u'avons trouvé autre chose dall, toutes les loges que nulls avolns oiveltes que lii peau jalune de sa larve.

17. Gen. Isosome. Isosoma, Walsh.

Ces insectes diffirent surtınt des Eurytomes par les carıctires suivants : corps finement ponctué, quelquefois presinas lisse ; n'étant pas contractiles, ils sont dépour'vus de ce sillon dans le flanc destiné à recevoir la cuisse intermédiaire; antenụes de 9 articles, brièvement ciliées dians les $q$ et longuenent dans les $\sigma^{\prime}$, muis ces articles non pédonculés conmue dans les $\sigma$ Enrytomes. L'abdemen subsessile se tient en ligne avec le thorax, ne se courbant fas en dessous comme chez les Eurytomes.

Deux espècès rencontiéés:

Corps ponitué-rgranuleux, pattes presque entidrement noires.......................... 1 hordei.

Corps très fincment ponctué, prisque lisse, pattes en partie jannes..................... . tritici.

1. Isosome de l'orge. Isosoma horlei, Harr. -Eurytoma hordei, Harr._-New Engl. Farm. IX, No. 1, p a. 


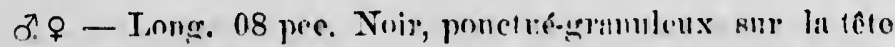

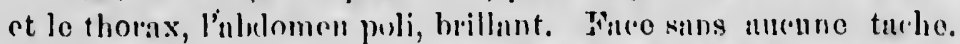
Antennes médincerement puleserentes dans les o, citiécestams

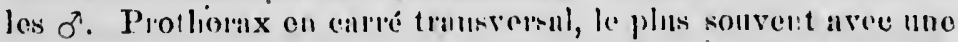
tache jaunatre a chaque cpunle. Ailes hyalines aree le stignma

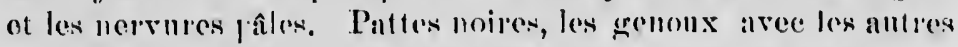
artionlations jam âtres, les habches noires, les talres pâles aveo l'extıémité noire.-Cil]:Ronure.

Ces insectes sont parasites de la Ć́cidomye qui juoduit des galles anx jointures des chammes de l'orge.

2. Isosome ciu blé. Isosoma tritici, Riley.

Isosoma tritici, liil.-Am. Nat. XVI, $2+7$.

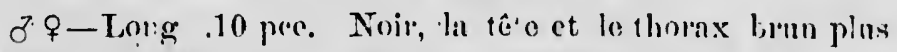

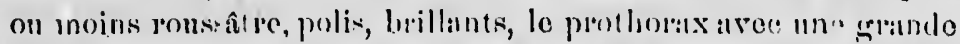

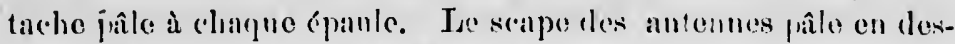

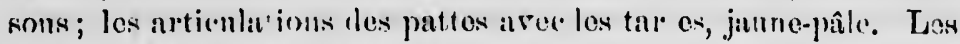
nervures dies ailes brunes.

On n'est pas encore fixé sur le mode de reproduction de cet insecte ; est-il comme le précédent le parisite d'un diptère on vit-il, à l'état de lurve, de la substance de la paille du lilé di us lequel on le trouve, la chose reste encore douteuse. La diffírenco qui paraît bien constatée entre les 2 inscetes, c'est que le premier se tronve dans des galles anx jointures des tiges d'orge, et le second dans le creıx même des entre-nœuds dı blé.

\section{Gen. Óligosthine. Oligosthenus, Walk.}

Tête transversale. Antenues presque en massue, plus longues et moins épaisses daus les $\delta$. Thorix robuste, le prothorax en carré transversal. La nervure stigmatique avec nu rameau simule se recombinut vers la côte. l'artes médiocres, les - cuisses postérieures renflées et s'ćlurginsant grrulıellenent de la base à l'extrimití, en avant de laquelle elles sont échlumerées et portent d'ordinaire me petite épine. Abdomen sessile, convexe triangulaire, à tariòre un peu plus longue que lıi.

Une seule espèce rencontrée. 


\section{Oligosthène à-2-tachıs Oligosthenus binucalatus,} II. $s p$.

ᄋ-Lomg. . 18 pee. Noir nvec les puttes on jartio jannes. Fuce sans nuruno tache; tête et thornx opaques, ponctués-uranulenx. Ailes hyalines, lígèrement obscurcios a l'extrémite, avoe 3 tncher bruncs sur lo limbe, l'une plus grando et plus fincéo touchant le rameala stigmatique, l'autro vers le milien da limbe. Les hanclies et les cuisses noires, los jamben, les talwes avoc l'ex trémite des colisses, janne. Les cuisses postérienres médiocrement renflées, échancrées a leur cxtrémité, mais saus dont laus notro individu. Abdomen eourt, robuste, thes fincment pouchne, poili a la base, poilu a l'oxtrémits; telridro forto ot un peu phlus longuto que l'abdomen,_Oltuwa (Hurri igton).

Les 2 taches des ailes rendent cet insecte très reconuaissable. C'est avee hésitation que nous l'uvoins rangé dans ce genre qui, d'a rès Walkë, devrait avoir les cuisses postérieures dentées en dessous; mais sa couleur l'excluant des Callimones, nous ne voyons aucun autre genre qui lui couvienne davantage.

19 Gell. Syrromaspe. Syntomuspie, Först.

Tôte transversale. Antennes presquẹ en massue et velues; leur premier article long, le $2 \mathrm{e}$ court, ' cyathiforme, le 3e très couri, le te et les suivants jusqu'au. $10 \mathrm{e}$ cie plus en plus longs, allongé ou presijue carré; l'ćcusson convexe, avec une imjression transversale au-delà de son milien. Pattes d'égalle grosseur entre elles. Abdomen allongé, convexe, pédiculé dans les "ơ", sessile dans les 우 ; tarière saillante.

Une seule espèce rencontrée.

Syntomaspe brillant Syntomuspis splendens, n., sp.

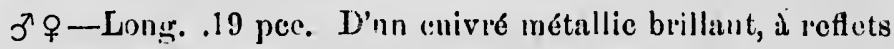
purpulins, la tête et lo thorax trids fincment ponctués, polis. Antennes noires, pubosenter, le seape jaune. Protiol'ax long, a poine rétréci on avant. Ailes hyalines, mais avec un grand nuaire brun occupant la plus ge:unle partic du limlic, ce nuage reufermant uno grando tache hyaline an dessons dil stigma, et laissant de même une maruge hyalino tout autour; ramean de la 
nervire stig.natique court ot recourbs. Pattes d'un beall jnune les hanches et les cuisses postérieures de la coulour du corps, los dernières jaunes a la baso.-Ottąwa (Harrington).

Bien remarquable pur ses ailes tachées de brun. Peut-âtre le maculipennis, Cameron, que nous n'avons point vu et qu'on a trouvé au Mexique ? La richesse de ses téguments porteruit croire y u'il appartient à des climats plus ensoleillés que le n3tre.

5 Gen. Callimone, Spin. p. 570 :

Aux 2 espèces décrites, ajontèz les 2 suivantes :

Cuirses vert métalliqao ou bleuâtre ;

Thorax fortement ponctué, tarière plus longue

que le corps.............. 1. longicauda, $p .808$.

Thorax finement ponctué ; tarière moins lon-

gue que le corps................ 3. tubicols:

Cuisses ontierement jaunes;

Abdomen vert métaliique à la base.... 3. fagopyrum, 573.

Abdomen avoc une bande jaune i la base.. 4. flavicoxa.

3. Callimone tubioole. Callimone tubicola, 0 . Sack.

Oallimone tubicola, 0. Sack. - Trans. Am. Ent. Soc: III, 60 .

O+ - Long. .08 pce. Vorte nvec réflexions bleuâtres, quelquefois plus ou moins cuivrées. La fuce cuivrée. Antennes noires, le scape janne. Thorax très finement ponctué. Ailes hyae lines, la nourvure pâle. Pattes jaunes arec les hanches ot les cuissos vertes, l'extrémité des unes et des autres, jaune, les jam bes et les tar'ses jaunes, les dernier's plus pâles. Abdomen à reflets

- blenâtres, taridre d poine plnse longue que l'abdomen, forte.CapRouge.

VAR.-Couleur générale brun-cuivré. Ta tạière est plus courte que dans celle mentionnée par 0 Sas un, nous pensons cependant que c'est bien la même espèce. Ses cuisses vertes la distinguent surtout de la fagopyrum.

4. Callimone hanches-jauniss. Callimone flavicoxa, Oे. Sack. 


\section{Callimone flavicoxa, O. Sack. - Tian̈s; Am. Eut. Soc. III, $f^{*}$}

c ong. 13 pee. Fuce d'un vert cuivreux a réflexion doré, finument porctuce ot puboscento. Antennes noires avec lo scape brun-cuivré. Couleur du thorax d'un vort métallique un peu sombre, la partio anter'icure de l'écusson plus ou moins cuivreuse. Ailes hyalines, avec poils biruns, et une grande tache ou ftrie au milieu du disque d'un brun pâle, non très distincte, la nervule brune. Pattes jauner, les hanches, surtout los posterieures, plus ou moins vertes a la base. Abdomen brun avec une bunde transversale janne pres de la base ot une tache verte en avant de cette bande, les segments terminaux, brun obscurément bleuâtr'更- Ottawn (Harrington), CapRouge.

Bieu que la coloration diffère quelque peu de la description de M. Osteu Sacken, cet insecte parait bien appartenir d̀ cette espèce. Nous n'avons encore pris que des $\sigma^{2}$.

\section{Gen. Ormyre. Ormyrus, Westw.}

Antennes de 13 articles, celles des o en massue, le premier article long, le 2e court, les 2 suivants très courts, 5-10 cyathi- . formes, 11-13 rapprochés et formant une massue tronquée obliquement. Dans les $\delta$, article 2 cyathiforme, 5-10 de plus en plus courts, 11-13 formant une massue ovale. Thorax renflé, avec le prothorax court et l'écusson renflé, ovale, son extrémité est pointue et prolongée sur la lère région du métathorax. Ailes velues, à cubitus très court.

Une seule espèce rencontrée.

Ormyre pieds-bruns._Ormyrus brunneipes, n. sp.

$\$$-Long. 11 pee. Vort, poli, brillant ; le thorax et l'abdlomen avec poils blunchâtres, la tête et le thorax à ponctuations peu distinctes. Antennes brunes, le scapo jaune. en dessous. Ailes hyalines, le cubitus très court, ne consistant qu'en un petit nœud à peine séparé du radius. Pattes d'un brun sale, avec les genoux et les tarses pâles, les cuisses postérieures de la couleur du corps. Abdomen conique, se rétıécissant de la base au sommet 
pour former un ótui i la tnrière qui n'est pas sortante. - Cup Rouge.

La forme conique de l'abdomen $q$ finit aisément distinguer ces insectes.

7. Gen. Perilampus, Latr, p. 571.

Aux 3 espièces décrites, ajoutez les 2 suivantes.

4. Pórilampe aoloulé. Perilampiıs aciculatus, n. sp.

f-Long. ·03 peo. D'un vert brunâtro foncé, avec l'abdomon d'un bleu violacé. Lo thornx et l'écusson fortement ponotué, la base aveo aciculations longitudinales et le vertex avec de semblables transverwalus. Ailes hyalines, les nervures jaunes: Patten vertes, brillantos, aveo los tarses roux.-Ottawa (Giii: gnard).

Se distingue surtont du plutygaster par les aciculations di sa face.

5. Pérịlampe lisse. Perilampus lıvvis; n. sp.

ᄋ-Long. '08 pce. Nril' d'airain violacé; la tête ot le thornx très finement ponctués, l'،odomen parfaitement lisse. Thornx avec les sillons parapsidaux bien distincts; prothorax légèrement rétréci en avant. Ailes hyalines, les nervures jaune-pále: Pattes noires, les turses avec l'extrémitó des jambes jnune-pâle. La fice très finement ponctuéc, sans nciculations, ni reflets métalliques. Abdomen a reflets bleuâtres, -Ottawa (Harrington).

Cette espèce, vu son manque de grosses ponctuations, sa face lisse, son prothorax $r$ ítréci légèrement, son sillon intennaire moins prononcé, pourrait peut-être former un genre particulier.

21. Gen. Micromitu. Micromelus, Westw.

'abilo. ations ssous. petit rec les ur du mmet

Tête transversale, plus large que le thorax. Antennes de 13 articles, simplement pubescentes. Prothorax arrondi en avant. Ailes avec l'ulna courte, plus courte que l'humórus. Pattes ordinaires. Abdomen pédiculé, déprimé, assez large, arrondi postérieurement avec la tarière passablement saillante.

Une seule espèce rencontrée. 
Mtoromole cotnos-noires. Micromelus nigivicornis, Prov.

Pteromalus nigricornis, Prov.-Fanne p. 576.

Cet insecte n'appartient pas au genre Ptóronıale, mais bien au genre Micromelus qui se range dans la tribu des Splígigastórides de Walker.

\section{Gen Spalanare. Spalangia; Latr.}

Tête en oviale, rétrécie un avänt. Antennes de 12 ärticles, insérées près de la bouche et ścartées entre elles, longies et filiformes dans les $\sigma$, avec le 3 e articlo long, de plus en plits épaissès dans les of avec les articles $3-9$ courts et les deruicrs plus longs et plus obtus. Ailes à ulnn longue et d̀ cubitus très court, ne formant qu'un point épais s'écaitant à peine de la côte. Abdomen pédiculé, en ovale, déprimé.

Une seule espèce rencontrée.

Spalangie bronzée. Spalangia anea, n. sp.

đo-Long: :08 pce. D'un noir plus ou moins bronzé, aveo la bouche rousse. Antennas tres longues, filiformes, pubescontes, a articlos distincts. Thorax polıctué-ingueux, a prothorax treds court. Ailes légèrement obscures, d nervures brunes. Pattes biun plus ou moins ronssâtro. Abdomen à pédicule court et fort, lo reste en ovale, déprimé, le 30 segment lo plus grand, poli, brillarit, arrondi d̀ l'extrémité. - Ottuwa (Haırington).

\section{Gën. Mfiacole. Metacolus, Först.}

Corps ponctué. Ailes avec l'ulna épaissio et occupant à peu jrès la moitié de la lóngneur de l'uile, lo cubitus aussi épaissi, mais court, terminé par un point -épais, le radius plıs long que le cubitus. Abdomen allongé, déprimé, conique. Pour le reste sembable aux Ptéromales.

Métacole conlqué. Metacolus conicus, n. sp.

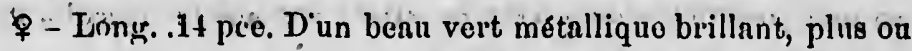
moius bleuâtro sur le vertex et los flancs. La face très finément 
ponetué, le thor'ux un peu plus fortomont. Lo seape des an. tennes bleu métullique lo reute br'un. Ailes hyulines nveo poils noirs, les nervures fortes et brun-fonce. l'attes j:tune-pale, les hunches ot les cuisses de In coulour du corps a l'exception des gononx qui sont nussi jaune.pale. Abrlomen déprimé, on cône très allongé; taridre non sortante.-CupRouge.

La nervation des. niles de cet insecte permet ì prémière vue de le distinguer des Ptéromales.

\section{Gen. Disol't. Dinotus, Först.}

Tête un peu plus large que le thorax; jones renflées; antemnes filiformes, assez longucs. Ailes id cubitus assez long portant à son extrémité une tache calleuse très grande. Cunisses postérieures renflées, leurs jaubes avee un seul éperon. Abdomen sessile, atténué en une longuв pointe, se rétrécissant de la base à l'extrémité.

Insectes bien reconnaissables par le large point callenx de leurs ailes. Une seule espèce rencontrée.

Dinote aigu. Dinotus acritus, n. sp.

\% - Long. . 99 pec. D'un vort mútullique plus ou moins blenâtre. Antennes brunes, le schpo jaunatie. Ailes hyalines, iridescentes, les nervures brunos. Pattes juinâtros, les hainches noires, les cuisses postérienres médiocrement renflées et du lu coulonr ducorps au milieu. Abilomon étroit, sos côtés relevés, atténuise en une longue pointe. - CapRounge.

\section{Gen. Roptrocirre. Roptrocerus, Ratz.}

Tête en carré transversal, aussi large que le thorax. Am tennes dans la $\&$ a funicule épais, le ler article brusquement rétréci. Thorax lisse, le métathorax très court. Ailes à cubitus assez long, terminé par un point calleux non très dilaté. Abdomen sessile, droit, épaissi en dessous, terminé par une tarière de la moitié de sa longueur environ. 
La tarière de ces insectes les distingue de tous les autres de cette tribu. Ụne seuı espèce rencontrée.

Roptrocère droit. Roptrocerus rectus, n. sp.

o - Long. .10 pce. D'un vert métallique plus ou moins cuivré. Antennes jaunes a la base, s'épaississant continuement jusqu'à l'extuémité pour se terminer par une massuo obtuse. Ailes hyalines, les nervures brunes. Pattes jaunes, les hanches et les cuisses plus on moins obscures. Abdomen droit en dessus, épaissi en deskous, à tarière forto, do plus de la moitié de sa longucur. CipRouge.

9. Gen. Semiotellus, Westw, p. 573.

Aux 7 espèces décrites, ajoutez la suivante.

8. Semiotelle chalcidifage. Semiotellus chalcidiphagus, Walsh.

Semiotellus chalcidiphagus, Wash.-Am. Entom. II, 368.

$\sigma^{\nwarrow}$-Long. .09 pce. D'un bleu indigo brillant avec reflets verdâtres en cortains endroits. La tête ot le thorax à ponctuations denses et fines. Antennes brunes, pubeseentes. Pattes rouxpâle, les cuisses et les jambes souvent obscurcies au milicu. Ailes hyulines, à cubitus très court, terminé par un point épais. Abdomen subpétiolé, aṛrondi à l'extrémité avec une petite pointe faisant saillie. Dans la $\%$ les ailes portent un nuage.brun s'étendant dans toute la longueur de l'ulna et occupant toute la largeur du limbe.-Oltawa (Harington).

Voisine de la fuscipes mais s'en distinguant par son abdomen plus allongé et son cubitus 3 fois plus court.

\section{, 26. Chanitope. Charitopus, Först.}

Tête courte et large. Antennes de 13 articles, en massue, les articles 3 et 4 très petits, la massue ovale, creuséc, en cuiller en dessous. Dos du prothorax petit, celui du mésothorax grand; écusson médiocre. Ailes manquant quelquefois. Pattes avec les jambes intermédiaires munies d'une forte épine à leur ex- 
trémité. Abdomen sessile, déprimé, atténué en une longue pointe ; tarière saillante.

Une seule espèce rencontrée.

Charitope a-face-pleine. Charitopus facialis, n. sp.

cuivié.

$\delta^{7}-$ Long. .18 pee. D'un bín foncé bleuâtre; la fáce pleine, large, finement ponctuée, avec poils écailleux épars bien apparents. Antennes filiformes, brunes, a premier article roux, très long, la massue à peino élargie, mais creusée en cuiller en dessous. Thorax robuste, large, le dos du prothorax très étroit, tout lo thorax comne la tête finement ponctué. Ailes hyalines, grandes, a nervures brunes, le cubitus terminé par un point épais, dépassé par le radius. Pattes de la coulour du corps, les hanches avec le métathorix, bleu d'azur, les jambes rousses, les tarses intermédiaires à peine dilatés a la base avec l'épine de la jambe médiocre. Abdomen vert à la baso, violeṭ brillant sur le dos, dépriıné, et atténué en longue pointe à l'extrémité.-Ottuwa (Harrington).

Cet insecte dont nous n'avons rencontré que le $\sigma^{\wedge}$ pourrait peut-être appartenir à quelqu'uutre genre voisin.

\section{Gen. Chilonure, Chiloneurus, Westwood.}

Tête coupée droit en arrière et arrondie en demi sphère en avant, avec les antennes insérées vers le inilieu de la face. Antennes de 11 articles, à scape fort long, le reste en for'me de massue allongée. Dans les $\delta^{\top}$ les articles sont allongés, rétrécis au milieu et portant deux verticilles de longs poils. Prothorax court, mésothorax grand, sans sillons parapsidaux et rebordé en arrière. Kcusson renflé et portant au sommet une touffe de poils raides. Ailes avec un stigma distinct et le cubitus égal au radius. Abdomen court et large, déprimé en dessus, subcordiforme; tarière à peine sortante.

Une seule espèce rencontrée.

Chilonure à-ailes-tachées. Chiloneurus maculatipennis, u. sp.

‡-Longr. .11 pce. La tête, les flancs, l'écusson, d'un jaunc- 
rouerâtre, lo reste nolr. La fạce finement ponctuéc, non rugueuse, brune sur le vertex. Scape des antennes jaune, le pavil: lon noir. Thorax très finement ponctule, avec poils g! isâtres sur. tout au bord postérieur du mésonotum. Ecussan jaune avec une touffe de poils rnides noir's. Ailes parfaitement hyalines dans leur moitié basilaire et brunes dans le reste, la partie hyaline por'tant unc bande foncéo ell avant du stigma, travor'sant presquo toute l'aile, do la cóte an bord inférieur. Pattes jaunes, les jambey et les tarses antérieur's presque blanes, les cuisses ot les jambes postéricures plus ou moins brunes, lonrs tarses blancs excepté à l'extrémité. Abdomen noir avec un lustro doré et une tache

- jaune à la basc,-Hull (Harrington).

\section{Gen. Copidosome. Copirlosoma, Ratzeburg.}

Tête arrondie en avant ; antennes insérées près de la bouche, à scal e fort long, les 6 articles du funicule allongés et grêles, la massue délicatement courbée à l'extrémité, on épaisse, et tronquée obliquement. Ia tête finement ponctuée. Le mésonotum et souvent aussi l'écusson à ponctuations sub-écailleuses. Ailes hyalines, avec l'ulna assez longue, le cubitus court et le radius indistinct. Abdomen sessile, à tarière très longue on a peine sortante.

Deux espèces rencontrées.

1. Copidosomęerrant, Huw.-C'halc. Départ. Agri. p. 11.

$\sigma^{x}$-Long. . 18 pee. Tête et pronotum, brun avec lustro légd. rement métallic; mésonotum d'un vert gai ; écusson brun cuiv'é. Antenne noires avec le seaped lustro métallique, la massue allongéo et délicatement courbéc. Ailes hyalines. Pattes avec les hanches et les cuisses, noir brillant, les cuisses antérioures jaunâtres au sommet; les jambes jaunes, les postérieures plus ou moins brunesa la base. Abulomen transversalement chagriné a la baso; dans la $f$ tarière du tiers de l'abulomen environ. - CapRouge.

Les antennes près de la bouche et la forme du mésonotum empê.hent de confondre ces petits inseçtes avẹc les Sémiotelles. 
2. Copidosome pieds-pâles. Copidosoma pallipés, n. sp.

\$-Iong. 12 pce. D'un vert métallique foncé, finement ponctuc. Ia face avec lo scapo des antennes, bleu; la massio des antennes noire, pubescente, trơnquée obliquenient à l'extrémité. Ailes hyalines; l'ulna a peu près d'égalo longụour: que le cubitus, le radius un peu plus court. Pattes jaunes, les hanches de la couleur du corps, los pattes postérieures noires avoe les: farses blanç, excepté l'extrémité qui est noil'e." Abdomen coniquo, brun cuivré, déprimé en dessus avec les côtés relevés, tarière forte, presque aussi longun an:e l'abdomen.-Ottawa (Harrington).

Bien remarquable rar ses tarses postérieurs blancs et sa forte tarière. Cette espèce appartiendrait peut-être plutôt au genre Homalotylus, Mayr, vu le sillon de sa fice peu prononcé.

\section{Gen. Coccophagus, Westw.}

Tête large, transversale, son bord occipital non tranchant. Antennes de 8 articles. Prothorax très court, rétréci en avant; mésothorax à sillons parapsidaux à peine distincts. Ailes à ulna un peu plus löngue que le cubitus, le radius aussi plus long, cubitus terminé pạr un point calleux. Pattes intermédiaires à éperons moyens à l'extrémité des jambes. Ablomen sessile, déprimé en dessus, droit, renflé en dessous, en ovįle élargi en une petite queue et atténué à l'extrémité servant d'étui à la tarière.

Trois espèces rencontrées.

Corps d'un brun enivié . ................ 1. brunneus, $n . . s p$. Corps bleu-métallique; antennes compri-

mées................... 2. compressicornis, $n . s p$. Corps vert-métalliquo avec les pattes blanches, 3. pallipes, $n_{0}, s p$.

1. Caccophage brun. Caccophagis brunneus, n. sp.

q-Long. 10 pco. 'D'un brun légèroment bionzé, la tête et lo thorax finement ponctués." Antennes courtes; noires, sans aucune tache. Pattes noires' les tarses d'un jaunatre salo. Abdomon presque orbiculaire avec sa pointo allongéo en queue.CápRougev: 
Var.-Lo scape des antennes jaune arec les pattes d'un jaune brunâtre sale.

2. Coocophage à-antennes-comprimées. Coccophagus compressicornis, $\mathbf{n}$. sp.

\$-Iong. .16 pce. D'un beau blen métallique; antennes brunes, fortement comprimées. Ailes hyalines avec l'uln longue ot lo cubitus conrt. Pattes brunes avec les tarses pâ es, excepté a l'extrémité. Abdomen en ovale allongé, atténué en pointe d l'extrénité, le dersous d'un brun violacé. - Ottawa (Harrington).

3. Cocoophage pieds-pâles. Caccophagus pallipes, n. sp.

\&-Long. .11 pce. D'un beau vert métallique avec les pattes blanches ou janne-pâle, les hanches de la couleur du corps. Antennes brunes." Thorax densément muis distinctement ponctué. Ailes avec lo cubitus ussez long et lo point calleux avec le rudimont d'un petit rameau. Abdomen ovale, atténué en pointo d l'extrémite, vert comme le thorax, brillant._Ottawa (Hurringt.).

Ses pattes blanches rendent cette espèce très reconnaissable.

30. Gen. Euplectre. Euplectrus, Westw.

Tête large et courte, transversale. Antennes insérées au dessons du milieu de la fuce, à scape long, funicule de 4 articles. Thorax fortement développé ; mésonotum avec une petite carène médiane. Abdomen à pédicule distinct quoịue court, cylindrique, le reste orbiculaire-ovale. Tête et thorax avec poils blancs épars. Téguments non métalliques. Jambes postérieures avec 2 lougs éperons, égalant souvent les 2 premiers articles du taitise.

Trois espèces rencontrées.

Abdomen sans tache, pattes jaunes;

Noir, les pattes y compris les hanches jaunemiel .................... 1. mellipes, $n$. $s p$.

Vert métallique, pattes jaune avec les hanches noires ................ 2. lucens, $n . s p$. Abdomen avec une grande tache pâle d la basi, pattes jaune-pâle, y compris les hanches. 3. viridæneus, n.sp 


\section{Eupleotre A-pattes-jaune-miel. Euplectrus mel-} lipes, $\mathrm{n}:$ sp.

\% -Long. .08 peo. Noir avee los pattes et les antennes jaunc-miol, La fuce noire suns uucuno tache. La massue dos antennes plus ou moins obscure a l'ext rémilé. Thorax finement ponctué, le mésonotum à carène médiane peu distincte, le pronotum non rugueux. Ailes hyulines-jaunâtres, les nervures jaunes. Pattes d'un beau jnuno miel sans aucune tacho, $\mathbf{y}$ compris les hanches. Eperons des jambes postérieuree egalant les 2 premieres articles des tarses. - CapRouge.

Voisin du Comstockii, How. mais de plus forte taille, a pronotum non rugueux, etc.

2. Euplectre brillant. Euplectrus lucens, n. sp.

o-Long. .08 pce. D'un beau vert métalliquo brillant, aveo les pattos jaunes. Thorax finement ponctué, le sj lubes du méso. notumı distinctement séparés. Ailes hyalines, iridescentes, a ulna courte, le radius plus long que le cubitus. Hanches de la couleur du eorps. Abdomen à pédicule court et fort, le reste de forme ovale, déprimé, poli, obtus à l'extrémité, avec la tarière saillante. CapRouge, Ottawa (Guignard).

Bien distincte de la précédente par sa taille et sa coloration.

3. Euplectre verdâtre. Euplectrus veridacneus, n. sp.

o-Long. .08 pce. Vert d'airain brunâtie, aveo les antennes et les pattes jaune-miel, le funicule et la massue des antennes plus ou moins obscurcis. Thorax treds finement poncturi. Ailes hyalines avec les nervures brunes, l'ulna longue. Abdomen pédiculé, en ovale atténué a chaque extrémité, noir avec une grande tache jaune-pâle à la base, laissant une bordure noire aux côtés.-Ottawa (guignard).

Voisin du Comstockii, Ashm., mais moins robuste, a thorax plus allongé, et à tache abdominale plus restreinte.

31. Gen. Mrol'iope. Miotropis, Thom.

Tête courte et large, a antennes insérées au dessous du milieu de la face. Thorax fort, à prothorax brusquement ré- 
tréci en avànt, le mésonotum avec les parapsides peu distinctes en:avant. Ailes avec l'humérus non interrompu, passant par nne courbe dans l'ulna, le cubitus assez loug. Abdomen subsessile, à pédicule très court. Tarses de quatre articles. Ecusson sans sillons. Corps non métallique.

- Les éperons courts des jambes postérieures distinguent surtout ces insectes des Euplectrès.

Miotrope nébuleuse. Miotropis nebulosa, 11. sp.

o-Lnng. 12 pcè. Brun foncé, la tète et surtout la fuco a reflets cuivreux. Antennes brunes, jannes a la base. Thorax finement ponctué. Ailes avec une grande tache peu fourée au milien du disque, touchant le cubitis mais ne touchant pas les bords:' Pattes brunes; les jambes avec les tarses ot l'extrémité des cuisses, juune-pâle. Abdomen subsessile, en ovule élargi, obtus à ll'extíémité, déprimé en dessus avec uno tacho pâ'e d la base:-Ottawa (H:urrington).

Les ailès nuagées de cette espèce la font facilement reconnaître.

11. Gen. Eulophus, Geoffroi, p. 576.

A l'espèce décrite, ajoutez la suivante.

2. Eulophe a-trois-branches. Eulophus tricladus, n. sp.

$\sigma^{2}$-Long. . 88 pee. D'un brun métallique plus ou moins cuivré, ponetué. Ariteunes plus éprisses au sommet, l'urticlo terminal bien plus fort que les précédents, les articles de la base émettent 3 rameaux poilus, aussi longs et anssi gros que l'antenne même. Mésonotum lurge et densément ponetué Ailes hyalines, avec l'ulna boauconp plus longue que lo cubitus. Pattes brunes, les jaınbes et les tarses jauno-pâle. : A.bdomen poli, britlaut, brun violacé, èlargi et arrondi a l'extrémité, avec une petito pointe all sommet:

Même coloration dıns la sans tache.-Ottawa (Harrington).

Voisin du dicladus, Say, mais ses antennes portant 3 branches an lieu de deux. 
32. Gen. Chuysooharis, Chrysocharis, Walk.

Antenues insérées vers le milien de la face, non en massue. Prothurax court, le mésothorax avec ses lobes distinctoment divisés. Ailes avec l'ulna fort longue, donnant naissance an cubitus au delà de la moitié de la longneur de l'aile, l'ulna étant interrompue pour passer dans l'huménus. Ablornen brièvement pédiculé.

Une seule espèce rencontrée.

Chrysocharis verte. Chrysocharis viridis, n. sp.

q-Long. .07 pce. D'un beau vert métalliquo brillunt avec les pattes blanchos. Antonnes brunes, filiformes, a articles distiucts. Ailes hyalines avoo poils biuns. Hanches do la couleur du corps. : Abdomén brièvemont pédiculé, subglobuleux, d'nn brun d'airain brillant, terminé par uno très petite pointe. - Ottawa (Harrington).

\section{Gen. Trichase. Trichasius, nov. gen.}

Tête cọurte et.large. Antenneg insérées aı bas de la fice, ne paraissant conposées que de 3 articles, le scape, le funicule et la massue qui sont à peu près id'égale longueur, le funicule est cependant composée de 4 à 5 articlea, la massue grosse et allongée en comprend anssi trois. Thorax sans sillons parapsidaux distincts ; écusson assez petit. Point d'ailes. Pattes ordinaires. Abdomen suborbiculaire, sessile, bọmbé en dessus.

Üne seule espèce rencontrée.

Trichase à massue. Trichasius clavatus, n. sp.

ᄋ-Long. .05 pco. , D'un brun roussâtro uniforme avec les pattes jaunes. La massue des antennes noire. Thorax densément ponctué, métathorax rugueux. Pattes juune-pâle, les tar'ses avec te dernier article brun. Abdomen plus brun quo le reste, poli, mais non métallique. - Ottawa (Harrington).

Cet insecte minuscule a ine apparence toute particulière arec la forte massue de ses antennes. 


\section{Gen. Holcopelte. Holcopelte, Först.}

Tête forto, transversale ; antennes de 7 articles, le 3 derniers formant une nassue allongée terminée en pointe. Prothorax court, beaucoup plusétroit que le mésothorax, celui-ci avec un sillon de chaque côté du milieu à la base; l'écusson grand, avec un sillon longitudinal an milieu; le métathorax petit, étroit. Aile : avec l'ulna interrompue et trés longue, le cubitus et le radius très courts. Tarses de 4 articles. Abdomen brièvement pédiculé, de forme ovalaire, pointu à l'extrémité, le 2e segment le plus grand ; tarière non sortante.

Ces insectes se distinguent surtout des Tútrastiques par leur abdomen pédiculé, la forme de le ir thorax et le sillon unique de leur écusson. Une seule espèce rencontrée.

Holoopelte pieds-blanos. Holcopeito albipes, n. sp.

万'--Long. .09 pee. D'un benu vert métallique avec tointe de bleu en cortaines partios. Lo vortex a pon près lisse, lo mésonotum et l'écusson fortement ponctués, celui-ci avec un sillon longitndinal an milieu; le protintrax beancoup plus étroit que lo mésothorax. Ailes hyalines avec poils noirs, l'ulna occupant plus do la moitió de la longueur do la côte, lo cubitus ot lo radius très courts. Antennes brun-funcé, pubescentês. terminées par une massue atténuée longu ument en pointe, le scape bleuât:e comme lo reste de la fuce non occupé par les youx qui sont gros et bruns. Pattes de la couleur du corps avec les tarses blancs terminés de noir. Abdomen distincternont púdiculé, de formo ovalairo, lo 20 sègment très grand, vert, les antres très courts, mais se rétrécissant en pointe.-Ottawa (Guignard).

35. Gen. Tetrastrque. Tetrastichus, Haliday.

Tête courte, transversale. Antennes de 9 articles dans les $\sigma^{7}$ et 10 dans les 9. " Thorax rútréci en avant, le prothorax très court; mésonotum sans sillons parapsidaux. Ecusson avec 2 sillons longitudinaux. Ailes a vec l'ulna interrompue en passant dans l'humérus. Tarses de 4 articles. Abdomen court, déprimé en dessus, à tarière cachée ou sortante.

Uue seule espèce rencontrée. 
Tétrastique a-3-sillons. Tetrasticus trisulcatus, n. sp.

$\delta^{2}$-Long. .09 pce. D'un beau vert foncé avee les pattes jaunes. Lo thorax et la têto tinement ponetués, l'abdomen lisse Antennos noires, lo scapo jauno en dessous. Prothorax tres court ; lo mésonotum ot l'écusson très finement ponctués, lo premier avec un petit sillon au milieu on alriere, et lo socond aveo un de chaque côté du milieu. Ailes hyalinos avec poils noir's, le costa frangé de poils, l'uina longue, interrompuo pour passer a l'humérus, le cubitus assez long ot le radius ti'es court, prosque nul. Pattes jaunes, les hanches et les cuisses, exoepté au som mot, de la couleur du corps. Abdomen court, sessile, arrondi ot terminé en pointe postérieusoment.

+ -D'un brun cuivr'é avec les antennes torminées par uno massuo bcaucoup plus épaisso quo les articlos qui la précèdent; les pattes aussi plus ou moins obscurcies de biunatres :-Cap. Rouge, Ottawa (Hurrington).

Bien remarquable par les sillons de l'écusson.

\section{Fam. IX-CHRYSIDES, p. 577.}

M. Frank Aaron a donné, dans le vol. XII des Transactions of the American Entomological Society, une monographie de cette famille qui a jeté un nouveau jour sur la distinction des genres et espèces qui lui appartiennent.

Aux 4 genres que nous avions mentionnés en premier lieu, il faut en ajourter 4 autres ayant aussi des représentants sur notre territoire. La clef qui suit pourra servir à les distinguer les uns des autres.

\section{Clef pour la distinction des genres.}

1(13) Face plus ou moins crousćo pour la réception du premier article des antennes. Prothoiax plus largo que long, plus court que lo mésothorax. Abdomen a 3 segments dorsaux, a ventre concuve;

2(5) 3 o segmont abdominal avec une série sousmarginale de trous ou fovéoles, contonue dans 
un sillon suivant lo bord marginal, co sillon preéedé d'uu bourrelot plıs ou moins renflé;

3(4) Face resserréo par lo rupprochomont drs youx; ocello inférieur renformé dans uno cavité bordéo par uno carèno. ler segmont abdo. minal élargi aux côtés, lo 20 trois fois plus long sur le dos quo sur les côtés, sa partio postéricuro fortomont concavo.......... 5. Stilbum.

4(3) Faco lurgo; ocolle inféricur nou séparé des autres par uno carene. $1 \mathrm{cl}$ segment abdominal non caréné sur les côtés, lo 2 e environ 2 fois plus long sur lo dos quo sirr les côtén, sa margo postérioure presque droite au milieu, convexe uıx ê̂tés............... 1. Chrysis.

5 (2) 3 e sogment abdominal sans sillon sous-malginal, étunt simplement déclivo ou portant une súvio do fovéoles à la surfaco;

6(7) Ongles des tarses bifiles au sommet, sans dents à l'extériour ou avec uno seule. ment ....................... 2. Hedychrum.

7(6) Ongles des tarses arec 2 a 6 dents d l'extremité ;

8 ( 9 ) Bord du 3e segment abdominal arrondi, simplement coché an milieu, non prolongé étant vu de côté.

6. Omalus.

9 (8) Bord du 30 segment abdominal allongé do chaque côté do la coche, paraissant, vu de côté, former uno espèce de bec pour poiter l'échancrure;

10(11 La coche ou échanerure da 3 e segment ouverte, non fermée par une mombrino... 3. Elampus.

11(12) La cocho close ou remplie par une membrane incisée triangulailumont en dessous... 7. Notozus

12(11) Bord apical du 30 segrment entier ou largement sinué .................. 8. Holopyga.

13(1) Face entièrement convexe. Prothornx anssi long ou plus long que large, p'us long que le mésothorax. Abdomen à 4 ou j̃ segments, a routro convexo ............. 4. Cleptes. 
5. Gen. Stulse. Stilbum, Spinola.

Tête beaucoup plus étroite que le post-écusson ; espace entre les youx étroit, la carènp qui est au dessus entourant un espace qui renferme l'ocelle inférieur. Post-écusson se projetant en une pièce subconique fortement excavée. 1er segment abdominal aplati aux côtés, formant en dessus une carène courte et oblique; $2 \mathrm{e}$ segment plus de 3 foị plus long sur le dos que sur les côtés, son bond postérieur fortement convexe; le 3e terminé par 4 dents dont les 2 du milieu sont plus avancées.

Une seu'e espèce renconțuée.

Stilbe améthisthe. Stilbum amethystinum, Fabr.

Chrysis amethystina, Fubr.-Syst. Ent. II, 359.

Stilbum splendidum, Brulle.-Hymon. IV, 15.

Stilbup calens, Spin.-Ins. Ligur. I, 19.

\%-Long. 42 pce. Bleu funcé avec teintes pourpres et vertes; les antennes et les tarses, brun, les cuisses ot les jambes de la couleur da corps. Cavile de la face étroite, a stries transversales. Prothprax a surfaco inégule, plus long aux côtés qu'au milieu, fortement ponctué. Mésonotum à ponctuations beaucoup rnoins prononcées excepté au sommet de sa portion médiane qui est, aver l'écusson, très fortoment ponctuée-rugueuse; projection du post-écusson fortement excavée en dessus en forme de cuillère. Ailes brunes, enfumées, a nervures violettes d la base. Abdomen a premier segment anguleux' en avau. sur ses côtés, d'ún blea verdâtre, lo 203 fois plus long sur lo dos qu'aux côtés, convexe a son sonmet, d'un bleu fonoé; le $3 e$ avec uno double déprossion ou sillon, la première pròs de la base, ot l'autpe près de son sommet, cette dernière portant do 18 a 20 . fovéoles, la marge postéricure avec 4 dents longues et aiguës, les 2 du milieu se projotant en arrière des autres, les côtés légèrement sinués on avant de la dent laterale, tout lo 30 segment d'un beau blo u purpurin.-Ontario.

Cleptes. 
Gen. Cukysis, Lin. p. 579.

Aux 2 especces décrites, ajoutez les 6.qui suivent.

- Clef pour la distinction des especes.

1(4) Marge npicale do l'obdomén entidro;

2(3) Coins postéricurs de la murgo apisale do l'abdomen non rillongés; cavitó fncialo stricie; eillon portunt les fovíolos attoigu:ant la luse du З० segment........... 3. verticalis.

3(2) Cuins postćrienr's dil 30 segmont légòrement avincér, lo bord torminal de celui-ci légèrement urrondi ; sillon portant los fovćoles non prolongé sul los cótćs du segment. 4. hilaris.

4(5) Margo apiculo do l'abdomon cochéo au miliou; cavité frucialo striéo transversalcmont, marges latérnles du 30 sogmont bisinuées....................... 5. perpulchra.

5 (6) Marge apicalo du 3o segmont 3.dentéo; post-écusson prolongé postérieuremont..... 6. parvala.

6( 7 ) Marge apicale du 3e segment 2-dentée; abdomen d'un rouge doré............ 2. aurichalcea.

7 (1) Jangu apicale du 3o sogmont abdominal ivoc + dents ;

8(11) Margo latérale du 3̀o segmont vue do côté; droite on ligèremont cumbice on dedans;

9(10) Deuls courtes, les 2 du milicu séparées par uno écharciruro zégulièro, les éloignant plus l'uno de l'uutro quo dos dêsts latérales..7. nitidula.

10(9) Dents toutes s̀ égale distance les unes des autres, ou les 2 du milicu plus rapprochécs J'une de l'uutro que des dents latérules..... 1. cærulans.

1'1( 8 ) Marge latésnlo du 3o segment vue de côté, sinuéco ou arquéo avant li dont latéraso, la marge antérioure du sillon sous-marginal portant les fuvéoles, peu soulovée.......

8. Nortoni. 


\section{Chryale aurloha:oea, Prov. p. 679.}

$0^{3}-$ Long. 25 pce. Abdomon d'un ronge dorr comme dus In \%. La cenvité de la fuce lisso au miliou et donsóment pónotuico sur les côtés. Lo premier artiolo dos 4 tarses postérieurs pale. Segment terminal do l'abdomen dents courtes ot sopares par. des sinus pou profonds, los doux du milieu peu prolongéos on. anvidro des latéralen,-Ottnwa.

Nous n'avions encore capturé que des $q$, nous devons a $\mathbf{M}$. Guignard le spécimen $\sigma^{7}$ décrit ci-dessus et capturé par lui a Ottawa.

\section{Ohrysis vertica:e. Chrysis verticalis, Patton.}

Chrysis verticalie, Pntt.-Can. Ent. XI, 67.

Chrysis striatellus, Nort.-Tinns. Am. Ent. Soc. VII, 239.

\&-Long. .22 pec. D'un vert violncé, ln coulour vorto étant plus prononcéo sur lo prothornx, l'écusson, lo sommet des sog. ments ubdominaux ot les pattes; les 3 premiors articlos des antennes avec l'neticlo basilairo des tar'ses, aussi vorts. La plus grando partio des segments abdominnux d'un violot bloûttro. Ailes a poine obscurcios an bord antérieur; nucuno collule cubitulo ferméo, 2 collulos discoïdales. Cnvité facinle striéo transversalement. In tôto ot lo thornx d ponctuntions serrés, presque égules; l'écusson nvee un petit ospaco poli en avant. Tout lo dos de l'ubclomen non poli, ponetué avec une courte pilosité grisâtre. Lo sillon autés-npicnl du 3e segmont prefond, a foveoles nombreuses; lu marge terminale arrondie avec uno légèré echancrure au milieu,-Ottnwa (Irarington).

4. Chrysis gaie. Chrysis hilaris, Dahlb.

-Hyin. Eui. II, 103.

Chrysis halictula, Gribodo.--Ann. Mus. Sonov. VI, 359.

q-Long. 19 pce. Vert blenâtec, la conlenr blone étunt plus upparente sur to vortox, lo mésonotum et l'itulonen. Cirvité ficiale mal détinie, ponctuéo at non striéce. I La tête el tô thorax densoment ponctués-rngneux. Ailes sub-liyalines, la scconde cellule discoüdalo seulo ferméo par der nervures disti.ctos., Abdomen en grundo partio ble:l, surtont lo 20 sugment, lo vert. no so montrant quo sur los côtés et all summct, los sagments 2 et

Nortoni. 


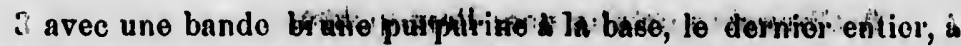
sillon sons-marginul conpe milten par une petite carène, et no s'étondant pas sur les côtés, los forroles súbolssolètes,-Oitawa (Harringtoii).

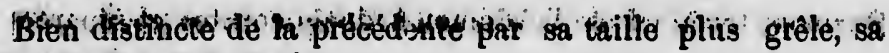
cavite ficiate portituce etc.

5. Chrysis très-belle. Chrÿis perpulchia, Cress. 二Proc. Ent. Soc. Phil. IV, 308 .

ㅇ .. Long. 35 pee. D'un beuu vert avec reflets bleuâtres on certaines pnrties. Cavité fuciale strićo ct séparéo du reste par une carène, de cette carène en part dérx altres moins apparentes qui vont renfermer l'scélle infériéri. Tête, thorax ot abdomen,

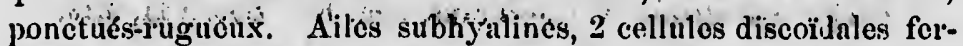
mées. A'bdomen a ponctuations donses et allongées, $1020 \mathrm{seg}$ nient a reflots bletâtrés sótrs un cortain joùr, lo 3o échancré au milieu, bisinné suit les côtés, quelqứefois peu distinctement, le sillón fovéifêté s'étendant sur les côtís jusqu'à la base, les fovéoles grosses et nombrouses-CapRonge, Ottawa (Guignard).

Variable daus sa coloration, mais en général avec lo vert dominaint de toutes paits.

6. Chrysis petite. Chrysis parvula, Fabr.

-Syst: Piez: 176.

Chrysis ctrinata, Say.-Ann. Macl. Iyc. I, 82.

" tridens, Lepell.-Binllé, Ins. Hym. IV, 46.

" virens, Cress.-Proc. Ent. Soc. Phil. IT, 309.

o-Long. .30 pce. Verte avec reflets blonâtres en certaines partics, particulièremont sur l'abdomen. Cavité faciale striée. La tête et le thorax fortement ponctués-rugucux; l'abuomen tout couvert aussi dé points enfoncés quioique moins pronóncés que sur le thorax. Ailes obscurcios prês de la côto; 2 cellulos discoïdales. Premier segment nbilominal vert, blonatre sur le dos, les 20 et 30 bleus avec une bando brune-purpurine a la base, et du vort au sommet et sur les côtés, le dernior coupé presque carrè au .sommet avoc sillon fovéifère non piécédé d'uno márge renflée, les côtés sinués avant la dent terminale.-- Ottawa (Harringtón). 
Especes bièn distincte par la marge termitiàle de sồ abdor

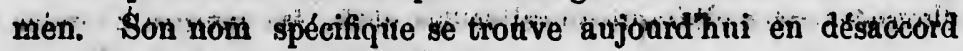
avec les espéces quii l'avoísinerit.

7. Chrysis nitidule. Chrysis nitidula, Fabr.

-Dint. Syst. 11, 243.

$\$-$-Lotig. .19 pce. Coulent verte avde blou en plus ou moins grande partièe. Cavité faciale ponctuée.' Ijà tête, le thorax avec lo premier segment abdominal, poncicties rugieux. Le prothorax vert sur ses marges antéricui:'e et postérieure et bleu au milieu. Le mésónotum blen, n'ayant du vert qu'nu sommet de sa partio médiane. Ailes légéremont onfumées, claires a la base. Abdomón bleu avoc du vert au sommet ct aux côtés des segments, le Be à 4 dents courtes an sommet dont les deux médianes sont plus distantes entre elles qué de celles dés côtés, séparés l'une de l'autie par une échincruro régulièro. Le sillon submarginal a fovéolos profondes et peu nombrouses. -CapRouge (Ottarra).

Très rapprochée de la coeru'ans, Fiabr., et comme ello variable dans sa coloration. Sa plus petite taille ot la disposition des dents abdominales suffisent pour les distinguer l'une de l'autre.

1. Chrysis cærulans, Fabr., p. 579.

Chrysis nitidula, Brulle - Ins. Hym. IV, 38. " bella, Cress.-Proc. Ent. Soc. Phil. IV, 312.

Très variable dans sa coloration et anssi dans la forme de son $3 e$ segment abdominal. La plus commune de toutes les especes de ce genire.

8. Chrysis de-Norton. Chrysis Nortoni, Aaron.

-Trans. Am. Ent. Soc. X'I, 237.

q-Long. .23 pcè. Du blou foncé avoc vert ot légers reflets pourpres ou vert émornude avee très peu de blen. Têto ot thorax densément et uniformément ponctués. Ailos légèremont enfumées, plus claires a la base. Abdomen densémont ponetué, mais à peino rugnoux, lo ler segment vort avec uno bando transversale bleito au milieu, le $2 \theta$ bleu foncé, quelqué peu purpurin a lâ base et vort sưr les côtés ét au sommet; le 3 e aussi bléit det quétque pêt pur- 
purin à la base, terminé par 4 dents dont les 2 médianes sont plus éloignées entro clles que de celles des côtés, los marges latérales sinuées on uvant de la dont apicale; fovéoles larges, lenr sillon se prolongeunt sur les cốtés jusqu'à la buse du segment. - CupRouge, Ottawa (Harrington).

Variable dans sa coloration ot très rapprochée de la cœerulans.

Il est une autre section des Chrysis présentant 6 dents a leur 3e segment abdominal, nous n'en avons encore rencoutré aucune avec ce caractère.

\section{Gen. Hedycrum, Latr, p. 580.}

L'insecte que nous avons décrit comme Hedychrum violaceum, p. 580 était Holopyga ventralis Say, mais nous avons capturé depuis le véritable Hedycrum violaceum, Lepell., il s'accorde avec la description que nuus avons dounée avec en sus les caractères suivants : ongles des tarses bifides au sommet, 3e segment abdominal entier, saus prolongement ni coche au sominet.

M. Aaron a formé le genre Hedycridium des espèces d'Hédychres qui portent une dent à l'intérieur des ongles de leurs tarses. Nous n'avons encore rencontré allcune espèce ainsi caractérisée.

\section{Gen. Omale. Omalus, Jurine.}

L'occiput, le disque du prothorax et du mésothorax lisses ou avec seulement des traces de ponctuations; le front, les côtés antérieurs du prothorax, les côté.3, et le mistathorax fortement ponctuís. Le post-écusson arrondi, non saillant. Ablomen lisse, avec quelques rares ponctuations très finss, le bord ipical du 3e segment arrondi et coché au milieu, non allongé vu de côté. Dents des ongles de 2 à 6 .

Les genres de cette section sont tous très rapprochés les uns des autres, et il n'est pas toujours fasile de compter les dents des tarses; si l'on ajoute que la forme du 3e seginent abdomiual 
varie assez souvent dans la même espèce, on en conclura que les méprises sont assez faciles dans la distinction de ces insectes.

4 Espèces rencontrées.

Deux dents aux ongles des tarses;

Margo torminalo du 3o segment somi-transpurento, jaunâtre, plus lurgo ău milieu.... 1. iridescens. Margo terminalo du 30 segment concoloro avec lo resto; angles terminaux du 20 segment prolongés en arrièro do la baso du 3e. 2. læviventris. Trois à six dents aux ongles des tarses;

Cocho du 30 segment aussi profondo que largo ......................... sinuosus.

Coche du 3 e segment beaucoup plus largo quie profonde.................. 4. corruscans.

Omale iridiscent. Omalus ividescens, Nort.

-Trans. Am. Ant. Soc. VII, 234.

Elampus marginatus, Prov.-Fauno p. 583.

2. Omale a-ventre-lisse. Omalus laviventris, Cress. -Proc. Ent. Soc. Phil. IV, 303.

Elampus lieviventris, Nort.-Trans. Am. Ent. Soc. VIII, 234. ": cyanescens, Prov.-Faune II, 582.

CapRougo.

3. Omale sinueux. Omalus sinuosus, Say.

Hedychrum sinuosum, Say.--Hit, T,ve. I, 32.

Elampus sinuosum, Nort.-Trans. A. Fnt. Soc. VII, 234. ". purpurascens, Piov.-Fuune II, i32.

CapRouge; Ottawa (Harrington).

\section{Oinale' brillant." Omalus corrvecans, Nort.}

Élanıpus corruscanș, Nort.-Trans. Am. Ent. Soc. VII, 234 f-long. 20 pce. D'un bleu verdâtre à réfloxions purpurines en dessus et verdâtres en dessons. L'occiput, les pro et mésothorax ot lo tiors upical de l'ścusson polis et couverts de larges ponctuations subobsoletes. Ailes hyalines, obscurcies dans leur tiors apical. Cavité faciale polie. Côtés dụ Zo segment abdominal bisinués. Ongles des tairsces a environ 5 dents distinctes.-CapRouge; Ottawa (Harringto.). 
L'esping que nous avops dócrite da la page 582 de notre Faupe sous le nom d'Elompus cormuscans, Norto appartient au genre Notozus.

\section{Gen. Elampus, Spip, p. 581.}

Des 6 espèces mentionnées, aucune n'appartient au genre Elampes, tel que donné dans la clef des genres ci-dessus, c'està-dire à 3e segment abdoninal prolongé en une espèce de bec à l'extrémité pour porter la coche, et ayant aux ongles des tarses de 2 à 6 dents.

$$
\begin{aligned}
& \text { Elampus spinosus, (Prov.) =Notozus viridicyaneus, Nort. } \\
& \text { "corruscans, Nort. (Prov.)= " " " " } \\
& \text { " viridis, Cress. }(\text { Prov.) }=\text { " marginatus, Patton. } \\
& \text { “ cyanescens, Prov. = Omalus læviventris, Nort. } \\
& \text { " purpurascens, Prov. }=\text { " sinuosus, Say. } \\
& \text { " marginatus, Prov.= " iridescens, Nort. }
\end{aligned}
$$

Deux espèces rencontrées.

Post-écusson non prolongé en arrière; 30 seg. ment aldominal à prolongation très courte.. 1. Cressoni. Post-écusson brièvemont prolongé en arrière; 30 segment abclominal a prolongation bion distincte

1. Elampe de-Cresson. Elampus Cressoni, Aaron. -'Trans. Ent. Soc. VII, 215.

f-Long. 19 poe. Bleu foncó: La têto et lọ thợax fortement ponctues, mais aveo vertaines parties lisses. L'occiput, la partio posterieure du prothorax avec la partio médiano du mésothorax, lisses, portant de peine des indications go ponctuatiops; l'écusson ot le post-écusson fortement ponctués et a réflexions vordâtres, le dérnier ariondi, non projeté en âvant. Ailess hyalines, assez fortement obscurcios dans laur moitié apicale. Abdomen bleu.foncé, de ponctuations obsolètes, le 30 segmont avec un seul sinus aux côtés, la partie médiane de l'extrémité pro. longéo en beo pour porter la coché, les lobes de celle-ci arrondis et nó tronqués; toute la partio apicale du 3 e segment avec une courte pilosilé grisatre assez dense. Lies ongles des tarsos pluridentés. - Ottawa. 
2. Elampe miroir. Elampus speculum, Say.

Hedychrum speculum, Suy-Bost. Jou'n. 1,285.

o-Long. 17 pce. $D$ un boau vert émeraude d réflexions légeremont bieuâtres sur lo thol'ux ot faiblemont cuivrées sur, lo vertex. Tout convert de ponctuations sans espaces lisses, l'abdomon les ayant boaucoup plus tinos que lo thorax. Postécusson prolongé en uno espèco do spatule d son sommet.so projet:ınt un pei en arriere, cetto spatule touto ponctuéc on dessus. Troisième segmont abdominal avec sẹs côtés bisinués et uno projection tronquée an sommet. Ailes hyalines, légerement obsculcies dans leur moitié apicalo. Ongles des tarses a 3 dents.CupRoug̨e; Ottrwa (Guignard).

\section{Gen. Notoze. Notozus, Först.}

Tête et thorax quelquefois également ponctués et d'autrefois avec quelques espacos lisses. Abdomen à ponctuations fines et denses; marge du $3 \mathrm{e}$ segment bisinuée. Post-écusson le plus souvent allongé en une espèce de spatule se projetant en arrière; projection apicale $d u 3 e$ segment abtominal remplie pur une membrane triangulairement incisée en dessous.

La membrane échancrée en dessous qui clot la projection abdominale de ces insectes est un caractére bien prononcé qui empêche de les confondre avec les genres voisins.

Trois espèces rencontrées,

\section{Abdomen d'un doré brillant aveo réflexions vertes}

ou cuivrees; thorax vert et bleu............ 1. nitidus.

Abdomen comme la têto ot le thorax, d'un bleu foncé avec réflexions purpurines ou un vertémeraude à réflexions cuivrées ;

Taille plus forte; projection abdominale large et courte, dépassant a peine la marge du 30 segment ..................... 2. viridicyaneus.

Tuille plus petite; projection abdominale plus longue et plus étro:te, se projetant di, tinetement en dchors do la marge du $30 \mathrm{seg}$ mont ...................... marginatus. 
1. Notoze net. Notozus nitidur, Aaron.-Trans. Am. lint. Soc. XII, 218.

Long. . 11 pce. Ża lêto et le thorax, vert, pourpre, ou hleu, plus foncé sur lo post-écusson ; l'occiput, les pro c't mésothorax at ponctuations peu denses, mais presque régulièrement distribuées. Abdomen fincment et peu densément ponctué, ćlégamment eolorié, d'un doré euivreux à réflexions verdâtres; le ventre vert; les cuisses ot les hanches, vert ot bleu, la membrane apicalo noire. Ailes enfumées-Ottawa.

2. Notoze vert-bleuâtre. Notozus viridicyaneus, Nort. Elampus viridicyaneus, Nort.-Trans Am. Ent. Soc. VII, 235.

" coruscans, Prov.-Faune II, 582.

“ spinosus, Prov.-Faune II, 531.

3. Notoze marginé. Notozus marginatus, Patton.

-Can. Eut. XI, 66.

Elampus viridis, Prov. - Faune II, $5 \nmid 2$.

8. Gen. Holopygr. Holopyga, Dalhb.

Ponctué de toutes parts, mais bien plus fortement sur la tête et le thorax que sur l'abdomen. Ongles des tarses avec 2 à 4 dents. Troisième segment abdominal sans projection médiane, généralement entier ou faiblement sinué au sommet.

Une seule espèce rencontrée.

Holopyge ventrale. Holopyga vertralis, Say.

Hedychrum ventrale, Say.-Long's sec. Exped. 330. “ violaceum, Prov. - Faune, II, 580.

Holopyga compacta, Cress.--Proe. Ent. Soc. Phil. IV, 304.

Insecte très variable dans sa coloration et sa forme. Les explications qui précèdent avec la description que nous en donnons à la page 580 suffiront pour le faire reconuaître.

8. Gen. Cleptes, Latr p. 583.

- La face convexe de ces insectes sufflit à première vue pour les faire distinguer des genres voisins.

Deux espèces rencontríes. 
Têto ot thorax vorts, ubdomon d'un biun métallique avec réflexions de vert, de pourpre ot de bleu......................... 1. Provancheri.

Coulour d'un bean rongo métalliquo doré avoo quelquo réflexions do vort, paraissant on général jougro....................... 2. speciosa.

1. Clepte de-Provanoher. Cleptes Provancheri, Aaron.

-Trans. Am. Ent. Soc. XII, 212.

Cleptes Americana, Prov.-Fuune II, 583.

Le nom spécifique Americana ayant été préalablement emplnyé par M. Cresson, M. Aaron lui a substitué celui de Provuncheri.

2. Clepte superbe. Cleptes speciosa, Aaron.

-Trans. Am. Ent. S')c. XII, 212.

ㅇ-Lung. .28 pee. Tête ot thorax ì reflets lorés, abclomon noir. Tête transver'sale, plus large que lo thorax, d'un boau violot métalliquo. Antonnes insérées près de la boucho, à funicalo légèrement entoulé et plus épais au milieu, lo scapo fort et un peu courbe, noir, lo 1er article du funicule petit, noir, lo 20 plus grand, jauno-roussâtre, les autres noirs, courts. Le métathorax avec les flancs et le collier du prothorax, vert, lo reste violet avec reflets mśtalliques, le dos du mésothorax à quatie sillons longitudinuux, lu surfuce portant de grosses ponctuations pon denses; lo métathorax très rugueux, ses angles subépineux. Ailes enfumées avec les nervures uoires, la rudiale incomplete, point de_cellules cubitales, doux discoïdales simplement indiquéos. Pattos d'ún testacó roussâtre, les cuisses d'un vert métalliquo plus ou moins brun. Abdoinen sub-sessilo, noir, on ovule, pointu a l'oxtrémité, lo bo segmont ot les suivants rétrécis on uno expeco do fourrean cylindrique logeant la tarièro, - Ottawa (Harrington). 
Fam. X.-LES FORMICIDES, p. 584.

De tont l'ordre des Hyméno ìres, la famille des Formicides est une de celles qui ont été le moins ítudiées, et cependant e'est bien l'une des plus intíressantes et anssi des plus difficiles. Les trois sexes qui distinguent cette famille, la vie sunterraine de la plupart des genres, le peu d'attrnits que ces insectes offrent d'ordinaire au coup d'œil, ont ćté autant de causes qui ont éloigné les amateury de leur étude.

Leurs mœurs sont cependant dles plūs intéressantes. Sous le rapport de l'intelligence, de l'instinct de consc rvation pour les soins à donner à la famille, et li protection silffisante à toute la communauté, les Foumis se rangent au premier rang dar.s toute la classe des insectes. Llles sont même supérieures aux abeilles sous ces différents raptorts. Seulès elles ont un ordre de guerriers pour repousser les attaques et aller faire des conquêtes sur les tribus voisines. Seules elles gardent dans un état de servitude les onnemis vaincus dans lenrs combats. Seules aussi elles savent se prévaloir de la possession, à part jeurs esolaves, d'sutres animaux domestiques, des pucerons, pout en tirer un miel qui, s'il ne leur est pns nbsolumẹt nécessaire, leur est du invins grandement utile pour les divers besoins de la fatnille.

Une autre considération encore très digne de remarque, c'est que, tandis que les abeilles dans leur mité de reine ou do chef de la communanté, figurent une monarchie, les Fournis nous représentent plutôt une véritable république duns la pluralité des mères, qui se partagent l'autorité.

Mais comme nous avous particulièrement en vue dans ces ADIITIONs d'ajouter anx genres et anx espèces les nouveanx individus tombés sous notre observation, nous renvoyons le lecteur aux considírations générales que nons avons donnérs a:x jages 584 et suivantes de notre Faune, et passons au détail de ee que nous avons à ajouter. 
Les récents travaux des MM. André, de France, dans leur Spéciès des Hyménoptères d'Europe, ont jeté un nouveau jour sur cette famille encore si pen connue; et comme, non seulement nos genres américains, mais ia plupart même de nos espèces se reucontrent dans les deux continents, nous nous sommes largement prévalu de cet ouvrage pour les observatious qui vont suivre. Ajoutons que nous leur avons emprunté lo plus grand nombre des gravures que nous joignons à notre texte.

\section{Classification des Formicides.}

1(4) Pótiole d'un seul article (fig. 25);

2(3) Abdomen proprement dit non étranglé eritro lo 1er et le 2e segrment; pétiole suz munté d'une écaille; abdomen non dentế à son extrémité (fig. 25) .......................... Sous-famille I.-Formicides.

3(2) Ábdomen étrangló intre lo 1er et le 2nd segment, + et $\&$ ar'mées d'un aiguillon (fig 26:.

ins un

mbats.

a part cerous, nt nédivers

harque, ou de ournis a plu-

Sous-Fam. I.-FORMICIDES, Formiciclos.

Clef pour la distinction des genves. OUVRIÈRES \&, ET FEMELLES $Q$.

1(6) Arêtes frortales prenant leur origine plus on moins près du bord prstérieur de l'épistome qui ne s'avance pas entre l'insertion des antennes (fig. 24); l's.bdomen vu en dessus montre 3 segments, dónt le deruior est conique ot terminal; orifico de l'anus petit, circulairo, cilié (fig. 25); o avec uno cellule cubitale complete; 
2(3) Antennes de 12 niticles insérées plus près du miliou des arètes frontales que do leur oxtrémité antérioure; épistomo trapéziforme, d sillons non connivents aveo les sillons frontuux; urêtos frontules sinuces en forme d'S; têto ni obtuso ni tronquéo on nvant (fig. 24); 6cuillo petito, ovalo, vorticale, fniblement convexe sur ses deux fucis (fig. 25). \& sans ocelles... . 1: Camponotus.

3(2) Antennes do 12 aríicles, insórées plus procho do liv base des arêtes frontales que do lour miliou, celles-oi divergentes des leur beso, non on forme d'S (fig. 27);

4(5) Articles basilaires du funicule dos antennes aussi longs ou plus longs que los autres (lo dernier except $\sigma$ ) ( fig. 28 ; ocolles très distincts ; écaille grande, verticalo; ailes $¥$ s'étendant au dela de l'abdomen, avoc une grande cellule discoïdalo. 2. Formica,

5(t) Articles bnsilaires du funiculo des antennes plus courts que les autros (excopté le premier) (fig. 29); ocelles 0 ou indistincts dans los o ; écaillo verticalo, quadınngulaire, droito; abdomen non prolongé antériourement.

3 Lasiug.

6(1) Arêtes frontales pronant leur origino aux angles latéranx do l'épis:omo qui est triangulaire, pı'ofondément échanclé en avant et s'avanģant on arridro entie l'insertion des antenues. Abdomen no montrant quo 4 segments en dessus, s'avanģunt en avant pour couvrir plus ou moins lo péticlo, colui-ci quadrangulaire, aplati, sans écaillo apparente (fig. 30 ); ailes $\&$ avec une soulo cellulo cubitalo completo 4 Tapinoma.

\section{MALES $\sigma$.}

1 (6) Epistome non prolongé entre l'insertion des ancennes; éperons des jambes simplos; ailes avece ou suns cellule discoïdale; 
2(3) Antennos insérées aussi près du miliou des arêtes froniales quo do lour extrémité antérioure, et distantes du bord postériour de l'épistome; foswottes cly;- illes séparces des fossettes untennales; écuillo épaisso; ailes sans cellulo dis. coïdule; cardnes frontales sinuées, a peiso divergontes................................... 1 Camponotus.

IPONOTUS.

Formioa.

3 Lasius.

3(2) Anteunes insérées près de l'extrémité antériouro des curènes frontales, do 13 articles; fossottes frontales unios aux fossottes untonuales;

4(5) Airo frontale nettement définio; organes génitnux extérieur's gr'ands; $10 r$ article du funiculo pas plus épais que lo second ; taillo grande, pou infórioure d collo do la $\$$, cellulo discoïdulo grende, mancuant raromont.

2. Formica.

5(4) Aire froutale indistincte; organcs gẹnitaux oxtérieurs petits; 1 er articlo du funiculo plus épais que lo second; tuillo petite, bien inferioure da colle de la o

3. Lasius.

6(1) Epistomo prolongé entro les antennon; éperons des jamber pectiriés; ailes avec une sculo cellule cubitule; scape presque aussi long quo les cinq premiers articles du funicule; pétiole de l'abdomon épais, obliquement comprimé, arrondi en dessus, saus écaille.................. 4. Tapinoma

1. Gen. Camponote. Camponotus, Mayr.

(De kampê courbure, et notos, dos).

Arrêtes frontales en forme d'S portant les antennes aussi près de leur milieu que de leur extrémité antérieure, fossettes clypéale:s séparées des fossettes antennaires. Mandibules triangulaires, dentées. Pétiole aves une écaille droite, ovale, plus ou moins épaisse. Abdomen à ler segment plus long quie le $2 \mathrm{e}$, o Avec une seule cellule cubitale aux ailes sans cellule discoïdale; taille plus grande que celle de l' \& . $\sigma^{7}$ A organes génitaux externes spiniformes. Ailes comme dans la $q$; taille à peu près aussi égale (Fig. 24 et 25). 
Les Camponotes sont les plus fortes trilles parmi nos fourmis. Ils creusent leurs nids dans lo tronc des arbrss on dans lo sol.

Quntre espéces rencontrées.

\section{Ouvrikres \& ET Femellis}

1(6) Profil du thornx sans anglo ni comrburo rontranto au point do jonction dı mésonotum ot du métanotum (fig. 25), mandibules armées do 4 i 2 donts, épistomo d partio médiano non sensiblement plus avancéo quo sos anglos latér'uux, non cohuncré au miliou; têto d'épnissour médiocro; métanotum visibloment toutiformo ; corps plus ou moins mat, du moins en partio;

2(5) Thor'ax pétiolo et pattes, au moins on partic, bruns ou rougeatron. Pubesconce courte, conlléo ; corps poll s'llgucux; points do l'abdomon méliocres ot pen sorrés;

3(4) La partio antériouro du thornx souvont prosquo noire. Abdomon mat, fortomont pubescolit, avec lo lor sogment completement noir ou tout all plus rouge brunâtro a sa baso; pilosité épnissc, un peu plus sorrée sur l'abdomen. Dans li $\&$ les segments abdominaux ont les deux tiers postériours pubescents, finoment ruguoux ot tornes; les ailes légèroment enfuméos do Joussâtre

.1. herculeanus.

4(3) Thorax d'un rougo assez vif ot peu foncé. Lo 1er kegmont abdominal ordinairement rouge sur sa moitió antér ieure. Pilosité rare, un pou plus abondanto sur l'ubdomen. Corps plus allonge ot têto relativement plus petite quo chez l'espèce précédonte (fig. 24). Dans la o la moitié antérieure du ler segment abdominal, souvent aussi du $2 \theta$, d'un r'ouge assez vif. Tout le corps, y compris l'abdomen, presque lisse, luisant, a peu près sans pubesconce. Ailes fortoment ulifumécs do roussâtro

2. ligniperdus. 
109 folltdans lo

B(2) D'un bran noiratre, quelquefois partio du thorax, lo devant de l'abdomen, les antennos et los pattos sont d'un feirraginenx mut. Tont 'o corps ot surtout l'abdomen usurerts d : abeocenco

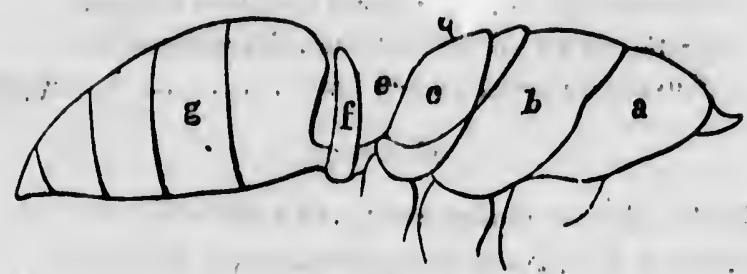

Itg, $2 \pi$.

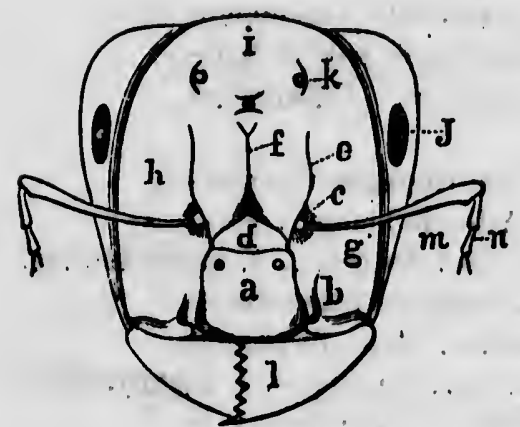

Fig. 24.

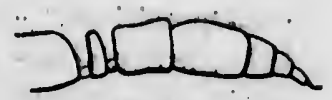

Fig 26.

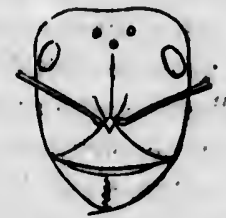

Fis. 27

rculeanus.

gniperdus.

très longne'ot abondante d'un jaund dor's. 'Abdomon avec de gros points onfóncés snir la partíe posterionre des segmento. 'f Avoc les áles légèremont enfumbes do jaunatre, ayant lo stigma et los nervìres d'un roussatie clair. 3. Pensylvanicus.

Fig. 24.-Tete du Camponotus ligniperdue, LaLc. 9.- $a$ ćplstomo ; $b$ ij8sette clypéale; $c$ fusactte antennitire; $d$ aire frontale ; o ardte fiontale if sillon

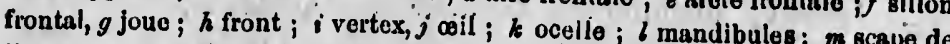
l'antenne ; $\boldsymbol{n}$ funicule de l'antenne.

Fig. 25.-Thorax et abdowen dn Camponotus ligniperdis, ; - a pronotum ; $b$ mésonotum ; $c$.métanotum ; $d$ face basale du métanotum ; e face déclive du métunotum ; $f$ icaille; $g$ ubdomen.

Fig. 26. - Pétiolo et aludomen di: Ponera contracta, Latr. \$

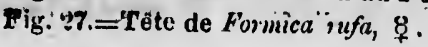


6(1) Fipistome échanc: ê an milien ; teto courte ot tridy épaisso; métauotum peu rétréci on ilessin:; corps entidrement livisant. Noir ou noir brun, les mandibules, lo thornx en partic, les an:ennos ot les p:tttes quelñ ar fois d'un rougr'âtre plus ou moins vif. Tuut lo corps finement ehagrines et parserrié de points enfoncér. Ailoy dans la enfiméces do jannatre à la baso.

4. marginatus.

\section{MALES $\sigma^{\top}$.}

I(B) Taille relativement grande (.40 a .50 pce);

2(j) Junes sans gros points enfonceis épars, épistomo ayant soulement 2 points foswottes prids do son bord postéricur. Noir, extrẹmitó des mandibules, articulations des pattes et parfois le filnicule des antennes rougeâtres: Pubescence presque nulle;

3(4) Abdomen mat, convert do ringosités transvorsalor, fincs et sorrés. Ailes, fuiblement onfumécs de roussâtı'e. Long. .40 d .j0 pco.... 1. herculeanus.

4(3) Abdomen assez luisunt, d rugosités tranversales moins fortes et moins sorréus. Ailes fortement enfumées de b!unâtre. Long. . 40 d .50 pec. 2 . ligniperdus.

5(2) Epistome ot joues marqués de quelques gros points enfuncés épar's. Noir, mat on peu luisant. Ailos un peụ enfumées de brnn. . Pubescenco longue et assez abondante; pilosité assez ferle. Long . 40 d .48 pet............. 3. Pensylvanicus.

6(1) Taillo relutivement petito (.25 .35 pce). Méso-

f.: notum sans gros points oiffọncés. Epistomo presque droit à son bord antérienr. Mandibules finement et longitudinalement ridées. Noir luisant; mandibules, funjeule des antennes, aiticulations des pattes et turses plus ou moins ronsaatres ou bı unâlres. Ailes enfumées de rolussâtre; stigma et nerviures d'un roussâtre très pâle. Pubesconce piesquo nulle. Lung. .25 a .32 pec........................... 4. marginatus. 
1. Camponote géant. Camponotus herculeanus, Lin. Formica herculeana, Lin. Faune, II p. 597.

2 Camponote ronge-bois. Camponotus ligniperdus, Latr,

Formica ligniperda, Latr. Faune, II p. 597.

Très rapproché du précédent comme on peut le voir par le détail de la clef dichotomi jue ci-dessus. Cette espèce se creuse aussi des galeries dans le tronc des arbres, mais niche aussi en terre avec dômes maçonnés ou sous les pierres. Elle hubite surtout la plaine et se rencontre aussi souvent dans les clairières des bois.

3. Camponote de Pensylvanie Camponotus Pensylvanicus, De Geer.

Formica Pensylvanica, De Geer. Faune, p. 598.

Nids sculptés dans le bois comme chez les 2 précédents.

culeanus.

4. Camponote marginé. Camponotus marginatus, Latr.

Formica marginxta, Latr.-St-Fargeau, I, 203.

Fait aussi son nid sous les écorces et dans le bois. Nous l'avons aussi rencontré daus le sol sous des pierres, dans des terrains secs et élevés.

2. Gen. Fourm. Formica, Lin:

Fossettes clypcales et antennaires confondues. Epistome trapéziforme, convexe, souvent caréné. Arètes frontales divergentes en arrière: non sinuées en forme d'S. "Aire frontale nettennent limites, triangulaire. Mandibules triangulaires, dentées. Antennes de' 12 articles (fig. 28), insérées anx angles postérieur's de l'épistome (fig. 27); funicule filiforme, avec les premiers articles plus longs que les. derniers. Trois ocelles sur

arginatus. 
le vertex. Thorax fortement étranglé entre le mésonotum et le métanotum, ce dénier gibbeux. Feaille dn pétiole droite, rarement épaissie. Ailes dans la $f$ avec une cellule cubitale et une discoïdnle grande. Taille surérieure à celle de l'ó. Dans le $\sigma^{\prime}$, mandibules à bords tranchants terminés par une grande dent (dans la sanguinex 4 à 5 dents). Antennes de 13 articles, à premier article du funicule plus court que le 2e. Ecaille épaisse, carrée, sou vent échancrée. Orgaines génitalix externes grands. Tuille à peu près celle de la o.

Cinq especces rencontríes.

\section{OUVVMRेRES १ ET FEMELLE $\%$}

1(2) Epistome échaneré d son bord antérieur, sans careno distincte. Airo frontale mate, finemont ridée. D'un rouge sang plus ou moins vif, quelquefois brunatre ou jaunatre; abdomen d'un noir brun; pilorité presque nulle. Long. 25 d .30. poe. (Fig. 31) ,........................... 1. sangrinea.

2(1) Epistome ans Gehancirure au milieu de san bord antérieur;

3(4 Aire frontale brillante, lisse ou: avee des rides t:ès fines; corps mat; thorax rungo arec ou salls tachos de brua. Addomon, vortex, funicule des antenaes, tarses of sonverit l'épistomo el les tibias d'un rouge brun. Long. .25 \& , 32 pce. (Fig. 28)

2. rufa.

4(7) Aire frontale mate, finement zidé; corpu médiocroment pubescent, non soyeux; pilosité épurse; tarses braus, a peine plus pâles quo les jambes; ailes $¥$ avec uno collule discrö̈dule;

5(6) D'un brun noir, axec leo mandibules, les aniennes, les pattes y coinpris les tarses, rougentres, Lo tbojax, lo dex:unt do la têto ot lo pétiolo sont souicent plus clakirs, juunâtres on rougeâtren, sarif toutefois une tache bruno qui se trouvo toujotits sur to pronotum. Long. .30 a .36 pec... 3 . fusca. 


$$
x \text { - PORMIC pes }
$$

(5) D'un forrugineux plus ou moins slair ; abdomen, souvent aussi lo ver'ex et lo front, d'un briun plus on moins noiratre. Parfuis tout to corps passo an brun, mais les jones of les bords du pronolum sont toujours rollgeâtres. - Long. $.30 \mathrm{a}: 38$ peo ............................... 4. ruflbarbis.

7(4) Tarses bouncoup plus jâles quo les jumbos, presque blancs. Ailes of sans cellule discoïdale. \& Long. .11 d. 13 pç. ; f . . $30 \mathrm{il} .40$ pc. (fig. 33 , 5. pallitarsis.

\section{MALES ठ゙.}

1.(2) Bord torminal des mandibulos armé do $q$ a 5 dents; épistome échancré au milieu de son bord antéricur. "D'un noil brun, pattos et parties génitales d'un rouge jaune............ 1. sanguinea.

2(1) Bord terninal des mandibules tranchant, noñ denté, termiue on pointo plus ou moins allong6o ;

3(4) Col'ps robuste, largo; tête. et thorax avec des poils dresses abondants : ab :omon a pubescenco non soycuso, Corpss noir, d̀ parties génitales avoe los pattos d'un jaune rouge. Youx ot abdomoil à poils diessés épars. Long. $.35 \mathrm{~d}$.40 pce... 2. rufọ.

4(7) Ailes avec une eellulo discoîdale;

5.6) Eeaille peu ou pas erhancté ; abdomen allong6, avec trn léger refiet métallique. Long: 35 a .45 peo.

3. fusca.

2. rula.

3. fusca.

6(5) Ecaillo largomont mais pen profondément échancréc. Abdumon sans reflo: métallique. Lnng. .40 d .45 pce. .................................. 4. rufbarbis.

7(4) Ailes sans collulo discoïdale, blanchatres, légèroment enfumés. "Jpistome convexo, tuberculoux; mandibules avec uno dent terminale lon. gue. . 15 pco. (Fig. 33) ....................... 8. pallitarsis.

1. Fourmi rouge-sang. Formiox sanguinea, Latr. Saint-Fargeau I, 203.

Cette fourmi habite surtout les clairières des bois, plus ra- 
rement les kords des routes où l'on voit ses dômes s'élever au dessus du sol. On trouve souveut dans ses nids des furmica fusca réduites en servitude.

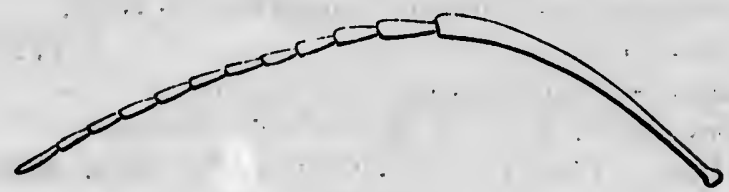

Fig. 28.

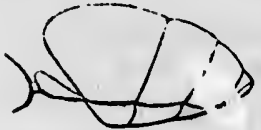

Fig. 30.

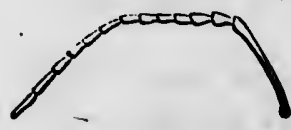

Fig. 29.

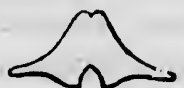

Fig. 3ı.

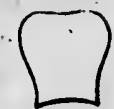

Fig. 3..

2. Fourmi rousse. Formica mufa, Lin.-Saint-Fargean, I, 201 ; Faune II, 600 .

Cette fourmi vit presque exclusivement dans les bois où elle entretient souvent des chemins bien battus de ses dômeș qu'elle élève au dessas du sol, aux arbres où elle ve rencontrer les pucerons.

3. Fourmi brune. Formica fusca, Lin.-Saint-Fargeau I, 205 ; Faune Can. II, 598.

La plus commane de toutes nos fourmis; timide de sa na-

Fig. 28.-Antennes de Formica rufa, \&

Fig. 29.-Auteune de Lavius niger, Lin. $\sigma^{\top}$.

Fig. 30.-Pétiole et abdomen de Tapinoma $\$$, vus de profil.

Fig. 31.-Epistome de la Formica sanguinea, Latr. $\$$.

Vig. 3\%,-Ecaille dn Lasius flavus, De Grer 8:

Fig. 33.-Aile de la Formica pallitarsis, Prcr $\cdot 0$ '. 
ture, elle fournit des esclaves à tontes les espèces plus puissantes. Ses nids simplement minés en terre, sont le plus souvent recou verts d'un dòme. Elle devient très importune dans les jardins, ell ereusant ses nids snus les racines des p'antes vivaces, On le rencontre partuut, dans les champs, les bois, les broussailles etc. Elle se loge aussi souvent sous les écorces des souches on des vieux arbres. Elle "st généraleinent plusrare dans les bois que duns les déserts.

4. Fourmi à-poils-roux. Formica rufibarbis, Fabr. Andre, II, 182.

Cette fourmi vit particulièrement dans les lieux secs, ne 'se rencontre jamais dans les bois; elle mine ses nids sons les pierres, rarement elle les creuse dans le sol pour les surmonter d'un dồme. Furel ne considère ces 3 dernières espèces que comme des variétés de la lère, herculeanus.

5. Fourm pieds-pâles. Formica paillitarsis, Prov. Faune, II, p. 5!8.

Cette espèce assez rare, creuse ses nids dans le sol ou se loge sous les écorces des vieux arbres.

-Fargean, ois où elle es qu'elle er les pu-

\section{Gen. Lasius. "Lasius, Fabr.} (De lasio velu).

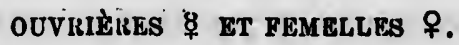

Fossettes elypéales et antennaires confondues ; épistome trapéziforme, convexe; arètes frontales assez courtes. Aire frontale large, mal définie. Mandibules triangulaires, dentées. Antennes de 12 articles, à funicule un peu plus épais à l'extrémité, les articleș de la base plur courts. Ocelles le plus soùvent indistincts ou nuls. Ecaille du pétiole droite ou peu in clinée. Abdomen non comprimé latéralement et ne 's'avançant pas au dessus de l'écaille. Ailes $?$ longues, avec une cellule cubitale et une discoïdale assez grande qui manque quelquefois. Corps gros et mou, de bien plus forte taille que chez 18. 


\section{MALES ơ.}

Mandibules avec une seule dent en avant ou dentelées dans toute leur étendue. Antennes de 13 articles; funicule à articles sub-éganx; le premier plus épais et le dernier plıs long que les autres. Orgnnes gúnitaux externes petits, à valvules externes aplaties, arrondies a leur extrémité. Ailes comme dans la o; taille de l'q.

Deux espèces rencontrées.

Couleur brun-noir plus ou moins foncé.................. 1, alienus. Couleur jaune-pâle ou légèrement roussâtrc............. 2. flavas.

1. Lásius étranger. Lusius alienus, Forst.-André, II, 198.

$8-$ Scape des antennes et jambes sans poils dressés. Colleur, brun plus ou moins fonce. Taille beaucoup plus petite que daus la f. Long. .06 a .08 pce.

8-Tête plus petite que le thorax, non échancrée postérieurement. Ailes hyalines, à peine obscurcies ; mandibules, untennes et pattes plus ou moins rougeâtres. Long: .20 à .25 lice.

$\sigma^{7}$-Bord terminal des mandibules tranchant, portant seulement une grosse dent eu avant. Sillon frontal bien marqué, front sans impression transversale, brillant. Long. .12 \& .15 pce.

Ce Lasius eat considén : par M. Forel comme une simple variété du $L$. niger, Lin., aussi le rencontre-t-on à couleur plus ou moins foncée. Il creused'ordinaire ses nids sous les pierrẹs et ses habitudes sont lucifuges et souterraines.

2 Lagius jaụne. Lasius fluvus, Fabr,-André II, 194. - Formica mellina, Prov, Faune II, 599.

D'un beau jauna pâle uniforme, le thorax et la tête sou. vept rongeâtres. Ecaille basse; un peu plus large au sommet. Eeaille f légèrement échancrée au sommet. (Fig. 32); sillon frontal nul. Dans lo $\sigma^{\top}$ lo front porte souvent une impression: transversale. 
Ailes enfunées de brun d la base. Scape et jambes avec poils dressés.

Taille très variáble : $\varangle .08$ \& .10 pce. $; \% .20$ d .25; $\sigma^{\wedge} .10$ d. .12 pce.

Ce Lasius a anssi des allures tout à fait lucifuges et sonterraines, on le trouve d'ordinnire sous les pierres où il entretient dans les galeries qu'il y creuse des pucernns qui se nourrissent des racines des plantes qui s'y rencontrent.

alienus. flavas.

- André,

s. Col:-

us petite

'ée postẹ́bules, an.25 p.ce. rtant selmarqué, $.12 \mathrm{~d} .15$ ne simple aleur plus les pierress

\& II, 194:

a.tête sou» u sommet. 2) it sillon impression:

\section{Gen. Tapinomr. Tapinoma, Latr.}

(De tapeinômu, abaissement; allusion d l'cecaille).

\&̛ $\$$-Tête elargie en arric̀re. Epistome convexe, profondément et étroitement entailié au bord antérieur et fortenient prolongé entre l'insertion dos antennes. Arètes frontales parallèles. Ocelles, silion frontal et aire frontale nuls. Mandibules larges; à bord terminal denié dang toute son étendue. Antennes de $\mathbf{1 2}$ articles, à funicule à peine épaissi a l'extrénité. Métanotım court, inerme, séparé du mésonotum par un étranglement. l'étiole paraissant sans écaille, celle-ci étant petite, couchée et soudée avec lui. Abdomen fortemeut prolongé en a vant et couvrant entièrement le pétiole. (Fig. 30) Dans lá o les ocelles sont présents, l'aire frontale avec lo sillon frontal sont aussi plus ou moins distincts. Ailes avec une collule cubitale et une cellule disooïdale manquant quélquefois. Taille un peu plus grande que celle de l' $\%$.

$0^{7}-$ Antennes de 13 articles, funioule $\mathrm{A}$ articles sub-égaux, excepté le dernier. Organes g'uitaux externes assez grands, les valvules externes en forme de cuillers, couvexes en dehors. De même taille que la ?.

Le manque d'écaille avec l'ablomen projeté en avant permettent de distinguer à première vư les Tapinones des véritables fourmis. Uns seule espèces reucoutrée que nous̉ croyons nouvelle. 
Tapinome boréal. Tapinoma boreale, nov. sp.

\$-Long. .10 pce. Noir ou birun-foncé ; les antennes of los pattes brun-juumatro. To funiculo des antennes a articles subégaux mais distinctemont plus épais a l'extrémilé. Los mandibulos roussatres. Abrlomen à pubosiconce peu aboulunto et courte, et a pilosité encore plus rare, paraissant comme ridé-ponctué. Les tarses plus pâles que les jambes.

Q-Long- .18 d .20 pec: Les mandibules, les pattes, le pótiole, d'un brun-jaunâtre. Abdomon très finement ponctué-rugueux, pubesconco presque nullo. Ailes hyalines-blanchâtros, avec uno denxiemo cubitale presque complete, la nervire inferieure ne fuisant défuut qu'au milien, uno troisième cubitule est mêmo commencée, mais uon complétéo. - CapRouge, Otlawa (Harrington).

Nids en terre, sous les pierres et sous les écorces des racines d'arbres morts, dıns les lieux dér ouverts. La nervure inférieure qui formerait la $2 e$ cubitale manque quelquefois, mais la nervule transverse qui la fermerait à son extrémité extérieure est toujours présente.

Aucun mâle rencontré.

\section{Sous-Fam. II.-PONGRIDES. Ponerida.}

P'étiole d'un seule article, cubique, nodiforıe, ou surmonté d'une écaille éjaisse. Abdomen rétréci entre sun premier et son denxieme segneat. Un aiguilon chez les ouvrières et les femelles. Nymijhes renfermées dans un cocon.

Delix genres. rencontrés.

\&q $\subsetneq$-Mandibules longnes et étroites, sans bord terminal, dentées dans tcute la longueur de leur bord intorne, lo chaporon denté d. son bord antérieur; pétiole épuis, sub-ejlindrique, tronqué obliçuement en dessus en avant et pro longé au-dessous dv métathorax au dell de son point d'atlache, tenant a l'abdomen par toutel'ćtoudue de sa fuco postérioure. Ailus $\sigma^{x}$ 
arec 2 collules cubitulo ila $3 e$ plus on moins conpldte) et 2 collules discoïlales completen......................... 5. Amblyopone.

\& \&-Mandibules triangnluires, aplatien, lour largo bord terminal simplo ou denté; ailos aveo 2 cellulos cubitales completes et une seulo collule discoïdulo; pétiole surmonté d'une écaille épais sc, toujours d'uno longueur plus grando que son spaisseur, non prolonge en avarit au dold de son point d'attache au métathorax et ne tenant $d$ l'ubdoinen que par' une etroito portion du diumetre de sa fuco postérieure

6. Ponera.

5. Gen. Amblyopone. Amblyopone, Erichs.

(Amblyopos, qui a la vue fable).

६̛ o Tête carrée, plus longue que large; arètes frontales courtes, légèrement arquées. Epistome étroit, denticulé sur son bord antérieur; unandibules longues, étroites, sans bord terminal, dentées irrégulièrement dans toute la longueur de leur bord interne. Antennes de 12 articles, insérées très près de l'extrémité antérieure de la tête, d funicule plus épais à l'extrémité. Yeux très petits, situés én arrière du milieu de la tête. Ocelles nuls daus les 8 . Thorax plus large en avant, legèrement comprimś à son milieu. Pétiole sub-cylindrique, un peu déprimé supérieurement, tenant à l'abdomen par toute sa face postérieure et prolongé en pointe au dessous du thorax au deld de son point d'attache all métathorax. Abdomen allongé, étranglé entre le premier et le second segment. Dans la o le mésonotum est divisé en 2 dans sa longueur par une ligne eufoncée et traver.é dans sa largeur par une petite carène, ce qui le partage en 4 parties subégales. $\sigma^{x}-$. A tête courte, triangulaire, plus étroite en avant; mandibules courtes ; yeux grands, sur les côtés de la tête. Ailes avec une cellule radiale complète et denx cellules cubitales, la $3 e$ même plus ou moins complète. Organes génitaux non apparents extérieurement.

Une seule espèce rencontrée que nous croyons nouvelle. 
Amblyci:one d-2-nouds Amblyopone binodosa, Prov. Arotromes binodosus, Prov. $\sigma^{x}$ - Faune II, 538.

8-Lnng. .20 pee. (Fig. 34.1 D'un rous-atre plins on moins obscur sur lo dos; les mandibulor. les antonnos ot los pattos do couleur plus colairo. Epistomo d dentioùlos inégnux en uvant, in murgo intériouro dos mundibules ninsai inśguloment donticulío, l'extrémitú tormince en pointo fine. La têo légdroment śchuncrés en alriere, plus largo en avant at portanit uno potite pointo do chaque côté al linsortion dos mr.ndibulos. Tôto mate, finement ruguleuse. Lo thorax et l'abdomon d pubesicence courto ot pen denke, lo promicr avec une lígère dépruesion entre lo mésonotum et lo métanotum, la fuco postérieuro du métuthorux déclive, lisso. Abdomon quolquo peu lnisant, a pilosité presquo nullo, lo pétiolo sub-cylindrique ot prolongé on pointo en avant un dela clo won point d'attucho an métathorax; un étrangloment ontro lo promior ot lo 20 segmont. - CupRougo, Ottawa.

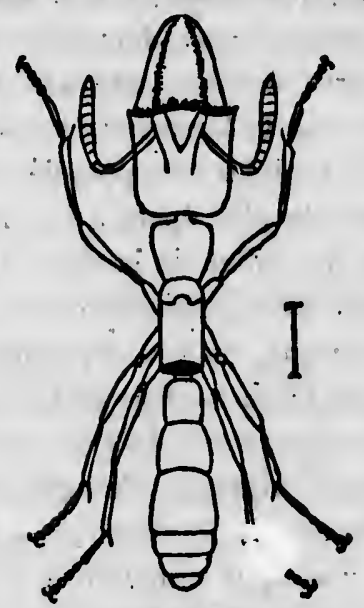

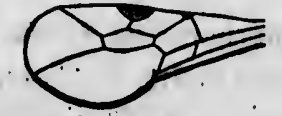

Nis, :5.

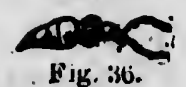

Fig. 36.

Fig. 34 .

$\sigma^{x}$-Long: 17 pce. (Fig. 3.j e: 36). Noir ou brun foncớ; têto assez courte, triangulairo; youx de grandeur ordinaire, sur les cốtés do lu têto. Mandibules polites, jaunaties, l'épistomo et los

Fig. 34.-Amblyopone binodosa, Prov. \&.

Fig. 3..-Aile de l'Amblyopone birodo:a $\delta$.

Fig. 36.- Ablomen de I'Amblyopone binodo a $\sigma^{7}$. 
manilibules unn out pen dentén. Antonnos d seapo conrt, to 20 articlo du furiculo plus long quo lo promicr. Thorax court ot

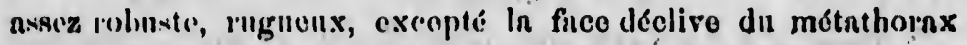
qui o.t liswo r.t luisanto. Ailos hyalines, los nervures brun-palo, une cellule rmilinlo e'mmpleto at trois collules cubitales, la 30 nonvont incomplite, doux ecllulex discoidnles dont l'inferionro ur

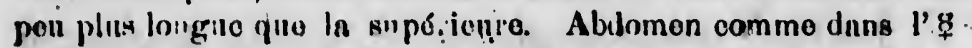
manis plins court ot plus robuste. Patles brunos, juunatios aux articulutions. - CapRongo.

L'absence d'uue deuxième rícurrente nous avait" porté a rangur ce mîle parmi les Bruconides, unnis la forme de sol abdomen ne permet pas de le síparer des Ponérices. L'insertion de l'abdomen avec le inétathorax (fig. 36) nous avait engags', vu sa reasemblance avec un soc de charrue. d former un nouvean genre sons le nom d'Arotropus, mais bion que Erichson, Roger; André etc., ne mentionné pas ce mode, uous avons constuté que c'était celui rles Amblyopones, et le pétiole tenant au premier segment par toute sa surfice ne permet pas de séparer ce mîle de cu genre, quelqüe disparitte qu'il paraisse comparé à l'ou"vrière.

Nons "i"urons encore rencontrí allcune femelle.

Cus insectes vivent sous les pierres, en familles peu nom: brenses. Ils sont sins aucun donte éminemment carnassiers; car les aiguillon parissant redoutable.

\section{Geu. Po.nkur. Ponera, Latr.}

(Pontroe, méchara)

Tête allongće, quadrangulaire; épistome nigu au sommet; mandibules à bord terminal denté et plus grand que le bord interne ; aire frontale indistincte. Antennẹg de 12 articles, robustes, scape assez grand, funicule en massue. Yeux très petits; placés à la partie antérieure des côtés de la tête. Thorax sans étranglement entre le mésonotum et le métanotum. Pétiole a écaille épaisse, droite, aussi large et aussi haute que le premier segment de l'ablomen, celui-ci allongé, cylindrique, étranglé en-

n foncé; lêto aire, sur les istomo ot los 
tre le premier et le second segment, (fig. 26). Pnttes courtes; ongles tes tarses simples.

Dans in of les yeux sont assez grands et les ocolles sont présents. Ailes nvec 2 celluler cubitales et une discoïdale; taille un peu plus grando que celle de l' $\%$.

Dans le ơ mandibules étroites, nen dentées. Autennes de 13 articles, i scrpe court, i funicule filiforme; yeux grands ; ocelles convexes. Ecaille nodiforme on subylobuleuse. Tnille de l'ouvridre.

Insectes vivant sous les pierres en sociétés pou noinbreuses.

Une seulẹ espèce rencoutrée.

Ponère oontractée. Ponera contracta, Lntr. - André, II, 240.

8-Long. .11 pce. Youx treds petits; mandibules a bord torminal donté; suture être lo mésonolum et le métanotum distincte; palpos maxillaires de doux articles dont le dornier est terminé pur uno soio. Tồio ot thornx dunsémont ot assez fortotement ponctués; l'abdomon flnemont pơnctué avec pube:cenco assez furte. D'un brun plus ou moins foncé avoc les mandibulos, lo dovant de l'śpistome, les antennos, les pattes, l'extrémité et la margo postérioure dn 20 segment abdominal, rougeâtrees.

\$-Long. .12 pce. Ailes a cellules cubitalos larges, non parallelos, la 1èro irreggulièro, la 20 trinngulairo. Curps assez puboscont, d'un brun noir foucé, un peu luisant. Los ailes légèroment enfiumées.

$\delta^{7}-$ Antennes a scapo treds petii, a peine plus long que lo promior article du funicule. Corps luisant, avec quelques points onfoncós épars, pilosité courte et abondante. D'un brun noir avec la boucho jaune et les pattes brunâtres. Epipyginm (1) prolongé en arrièro en une épine forte, recourbée en bas.

CapRouge, Ottawa ; nous n'avons capturé encore que des et nous avons reçu des $\sigma^{n}$ d'Ottawa.

(1) Epipy gium, arceau dors al du dernier segment de l'abdomen. 


\section{Sulıs-Fin!. III. Myrmtoiden Myrmicide.}

Ab lomen unu contractú entre le ler et lo 20 segment; péolles sont iscoïdale';

tennes de nds ; ocelTrille de

inbrouses.

- Andro,

los a bord notum disdornier est assez fortopube : cenco handibulos, sinité et la es.

es, non passez puberslégitromont ong que le ques points brun noir ygium (1) bas.

que des \& bodomen. tiole comprosu de 2 attieles lo jus souvent nodiformes; métuthorax sollvent $\dot{o}_{i}$ inenx.

Quitre genres dilis nutre fiume.

Pótiole ulfuchó a la finco antérosupéricuro de l'ub.

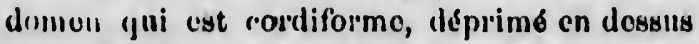
of convexe on dessons, a promior urticlo aplati, liupéziforıno. Métanotum urmó do deux dents oll épines ........................... 7. Cresastogaster.

Pétiolo nltuché a l'ox!rémité antériouro do l'ub. domen qui ost ovalo; métanotum armódo 2 dents, epines on tuborcules dentiformes;

Antennes do 11 artioles; éporons dis jambes sim. ples. Ailes $q$ ot $\sigma^{2}$ uvec une cellulle cubitalo non diviséo, la nervine transvorso s'unisknnt d la cubitulo d son point do partnge. Mandibulos triungulaires aplaties ............... 8. Lepsothonax.

Antonnos do 12 articlos; manndibules trianguInires, aplatios, eperons puctinés. Ailes of ot $\delta^{7}$ nvou uno collulo cubitalo a demi divisce; airu frontalo niguë on arrièso 9. Mrrmion.

Pétiolo attuché a l'extrémitó antérieur'e de l'ubdoinon; mútanotum mutiquo. .......... 10. Monomorium,

7. Gen. chemastogastrk. Crenastogaster, Lund.

(de kremastos, suspenilu et gaster, abdomen)

Tête arrondie, conrte ; épistome grand, arrondi en arrière, uon curénć. A rètes fort courtes, parallèles, éloignées l'une de l'autre; sillon frurital peu visible ou nul; mandibules do largeur moyeune, dentées. Antennes de 11 articles, terninćes par une massue plus ou moins distincte de 3 articles. Thorax, étranglé entre le mésonotum et le métanotum, ce dernier armé de 2 dents ou épines. Premier article du pétiole aplati, trapé- 
ziforme, non allonge en cylindre en .avant, le second nodiforme, sonvent divisé en deux par un sillon. Abdomen s'unissant au jétiole par sa face antero-supérieure, tiès convese en dessous, corpliforme et pointu à l'extrémité.

Ailes $\&$ et $\sigma^{\gamma}$ avéc une cellule cubitale et une cellule discoïdale, la nervule transverss s'unit au ramean cubital externe. Dans le $\sigma^{7}$ les nervures sont souvent plus ou moins oblitéréess. Les antennes dans ce dernier, souvent de 12 articles, ont le scape très court, peu plus long que le premier article du funicule.

Une seule expéce rencontrée.

Crémastogastre scutellaire. Cremastogaster scutellarie, Oliv. - André II, 392.

8-Long. .18 pee. Dun rouge plas ou moina vif, a l'oxcoption de l'abdomen qui est plus ou moins noirtre. Premier article dn pétiole plus large en avant, ses côtè presque droits, lo 2o partagé en deux lobos pax un sillon longitudinal. Fpinos du métanotum longues et aiguäs.

Dans la $q$ et le $\delta^{7}$ uiles avec une collule cnbitale ot uno cellulo discoïdate; taille un pee plü forte-Ottawa.

Ces insectes, d'orlinaire en farilles nombreuses, so trouvent sur les tronce des arbres, sous les écorces, et nichent aussi quelquefois en terre. Ils appartiennent particulièrement aux climats chäuds, aussi n'en avono-nous encore rencontré aucun dàns iè roísinage de Québéc.

\section{Gen. Leptothorax. Leptothorax, Mayr.}

(Do lepros, grefte, thorax, tho:ax):

Tête quadrangulaire, non échanerée en arrière, ses angles postérieurs arzondis. Epistome d bord antérieur un peu relevé près de l'articulation des mandibules, celles:oi plus ou moins distinetement dentées \& leur bond terminal. Arêtes froutales petites preaque droites et verticales. Antennes terminées par une massue de trois articles dont le dernier est plus long que les deux précédents rérnis.'Yeux de grandeur moyenne, situés 
vers le milien de la tête. Thorax à peine sillonné entre lé mésonotum et le métnnotum, ce dernier portant deux dents ou' deux épines. Premier article du pétiole cylindrịjue en avant, nodiforme en arrière, le second nodiforme. Làs 4 clisses postérieures fusifornies, avec leurs jambes dépo'itvues d'éperons. Tout le corpss parsemé de poils courts, barbelés on tron! ués à l'extrimité. Abilomen en ovale conrt, tronqué à la base.

o et $\sigma^{x}-A$ vec une cellule cubitale aux ailes et une cellule discoïdale; la nervule transverse s'unit à la nervure cubitale à son point de partage. Dins la o le métanotun est muni de deux tubercules plus ou moins dentiformes.

Ces insectes vivent en petites sociétés sous les pierres on les écorces des souches; ils ne paruissent pas rechercher les pucerrolis.

Une seulg espèce rencontrée.

Leptothorax du-Canada. Leptothorax Cunadensis, n. sp.

§ - Long. .12 à .15 prece. D'un brun plus ou moins foncé, les mandibules, les pattes, les antennes excepté la massue, le pétiole, plus ou moins rongeâttres. La tête et le thorax finenent ridés par des aciculations longitudinalus. Ls métano:um. al'mé do 2 épines; lo pétiolo a promior article gibbeux vors son miliou, 10 2o article noduleux, pius lingo que lo promior. Pattes avec los 4 cuisses postéricures isgèremont fusiformes. Abdomen en ovale, noir ou brun foncé, luisant aveé quelques poils épar's.

ㅇ-A taille un peu plus forte que chez l'ouvrière, l'abdomen un peu plus court et plus laurgo à l'extrémité; les ailes à norvonres pâles portant une cellulo cubitale ot uno discoïdale onvorte ì son extıémité, la nervule transverse joint le cubitus un peu on avant de son point de partinge.

"ठ-Lo dessuy brun noirâtre, to dessons avec lo pétiole ot les pattes rongeatres. Antennes filiformos, longnes, sinns massue, à peine plus épaisses à l'extrémité, do 12 articles dont lo :3e. est nresque aussi long que lo scapo. Métanotum sàns épinos, portunt ay-Octobre, 1887. 
seulement 2 paintes tuberculouses, Ailes comme dans la ஒ.Cap Rougo, Ottawa,

Assegz rare, sous lęs pierres.

9. Gen. Myrmique. Myrmica, Latr.

(De myrmêx, myrmêkos, fourmi).

\&-Tête en ovale avec les angle's postérieur's arrondis. Arètes frontales courtes, légerement sinuées; épistome convexe, arrendi en arrière. Aire frontale triangulaire, petite mais distincte, aiguë en arriere. Palpes maxillaires de 6 articles, les labiaux de 4. Antennes de 12 articles, d̀ scape arqué à la base, à funicule épaissi à l'extrémité en massue de 3 à 5 articles. Yeux ardinairs, situés pen en avant du milieu de la tête. Thorax à peine étranglé entre le inésonotum et le métanotum. Pronotum arrondi allx épaules, le métanotum armé de deux dents ou épines. Premier article du pétiole cylindrique en avant, gibboux en arriere, le $2 e$ nodiforme. Abdomen ovale, recouvert aux deux tiers par soll premier segment. Les 4 cưisses pastérieureses clạviformes, éperons pectinés.

Q-Ailes avec uno cellule cubitale d domi divisće ot nno caltule discoïdale. Tuille un peu plus forte que dans l' $\$$.

$\sigma^{2}$-Pête plus courte, sub-triangulairo; mandibules plus on moins largos, dentées, Antennes de 13 articles, a funiculo claviforme. Yeux groos, et convoxes, Mésonotum poitunt 2 sillons convergents; métanotum inerme, bidenté ou bituberculé. Eperons pectinés. Tuillo de l'ouvrière. Ailes commo dans la 우.

Les Myrmiques vivent en fimilles nombreuses sous les. pierres ; quoique armées d'aiguillons, uos espèces sont trup peu juissantes pour que, d'ordinaire, elles puissent les faire sentir lorsque nous les saisisssons.

Deux especes rencontrées.

Metanatum lisso ot luisant entro les épines... 1. lævinodis.

Mótmatum ridẹ ti'ansver'salement enitrelos

épines.

2. ruginodis. 


\section{X. - FORMIOIḊES}

1. Myrmiquie a.nouds-lisses. Myrmicá läviñodis, Nyl.-Annales des Sciences Nat. V, 50.

Myrmica incompleta, Prov. - Fiune iI, 602.

\&े-Mandibules a 7 ou 8 dents. Massie des anténnés de 4 articlos, ì scape arqué mais won brusquenent eoude pres do fit base. Mutanotum armé de denx épines ot à sillon peu distiñó to séparant du mésonotum; surfuco entre les epines lisse é luisante. Côtés de la tête grossièroment réticulés ; airo frontalo linse et luisanto. Pútiole presque lisse, portant des rides seulomont sur sos côtés. D'un rouge plus ou moins jaunâtro, àveo ì

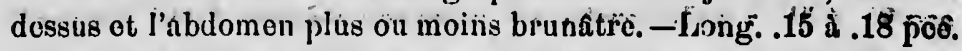

†-Taille un peu plus forte. Áles plus on moins fóncés

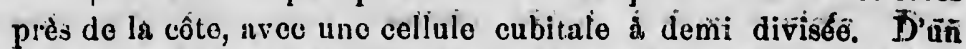
rouge brunâtre, une tacho à l'articulation des ailese, lá régiớr đơ l'óctisson, avec l'abdomen, noirâtroe.

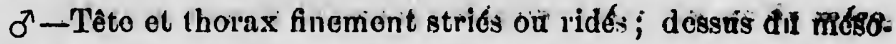
nutum, deraut de l'écusson, fure léclive du métanotum, nouds du pétiole avé l'abdomen, lisses è liuisants. Tête plus courte et plus rétrécio-du bas. D'un brun noirâtro ; mandibules, funiculo des antenness surtout a l'extrémité, les pattes avec. l'estrémité de l'abdomen, plus clairs.-CC.

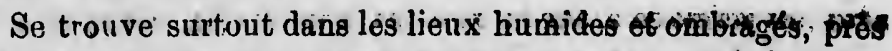
des ruisseaux, sonts les pierres on des tropceaux de bist. Ou dit qu'elle élève des pucerons qu'elle traite avec bết ucotip de

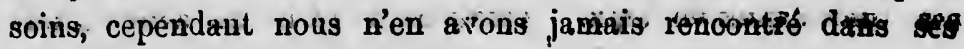
nids:

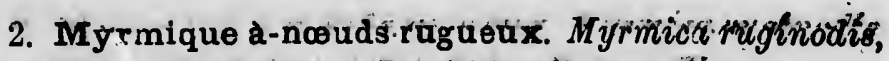
Nyl. - Anuales des Sciences Nat. Série I $\nabla$, tome $\nabla$.

8-Long. 15 peo. Semblable à la précédente avec les ox́coptions qui suivent: pétiole grossièrement ridé ét sillionné súr los cótés; métanotum ridé en travers éntré lés épinies.

Mênes differencess pour la o of le $\sigma^{\dagger}$ (1).

(1) C'est une + de catte espèce, dépourvie de ses ailes que nous avons capturéc au liac Sergent ế que nous avons donnée, sans la considérer assez a:tentivement, pour li Solenopsis fugax, Latr. ì la page I' Nuturaliste, Vol. XVIr. 
Cette es]'èce fait ses nids de la même manière que la Irrécédente, elle prarait seulement rechercher les fieux solitaires et noins fréquenités.

M. Forel a réuni sons le nom spécifique de rubra les 4 espèces qui suivent de Nylunder : $M$. scabrinodis, lavinodis, ruginodis et lobicornis, ne les considérant que coumo.des variétés de la même espéce. Et nous pensons qu'il avait rai'són, car nous tronvons des nuances sans fin diss la rugosité, la longneur des épines, la coloration de ces diverses espèces, etc. Ainsi pour la ruginodis, on la donne comme étant tonjours plus rugneuse que la lavinodis, et, à jart le pétiole, c'est tout le contraire que nous avons rencontré dans celle que nous avons attribuce à cette espèce en ruison de la surfacs entre le s épines du métanotum ridéc en traver's ; tête et thorax très finement ridés, le thorax surtont paraissant comme aciculé.

\section{Gen. Monomorium. Monomorium, Mayı.}

(De monos, un, morion, article).

\&-Tête ovale ou quadrilatérale, à épistome tron qué en $^{-}$ ạvant et s'avançant sur la base des inaudibules, ceiles-ci à bord terminal denté. Arètes froatiles pr:sque parallc̀les; aire frontale à côtés lćclives. Pailpes maxillaires d'un ou denx articles, les labiuux de deux. Antennes de 11 ou 12 articles, terninées jar une massue de 3 articles aussi longue que le reste du funicule, et dont le dernier est aussi long que les'2 précédent3 réunis. Yeux ovales, et souvent très petits. Thorax aux ćpaules artondies, plus ou moins étranglé entre le inésonotuin et le métanotım, ce dernier entièrement inerme. Pétiole à $\hat{1}_{\text {er }}^{*}$ article cylindri $u$ ue en avant, nodulerix en arrière, le 20 ' nodiforme et plus bas yue le ler; ablomen en ovale, tronqué en avaut, avec les angles antérieurs distincts.

9-Ailes avos uno seule cellule eubitale, sans cellulo discoüdale, la nervulo transver'se s'unit a la cubitule a son point de partage. 'Taille beaneoup plus forto quo ehoz $1^{\prime}$ \&

ovil 
$\delta^{\pi}$ - Epistomo quelquefois avec 2 carènes. Antennes a scapo co'urt, funieulo sans massue. Taillo entro la o ot l' $\%$.

Une senle espèce runcontrée et que nous devons ì l'importation.

Monomorium de Pharaon. Monomorium Plaraonis, lin.

Myrmica molesta, Lin. -Say II, 737 ; Faune II, 603.

Cette espece qui est devenue cosmopolite pour avoir été transportée dans toutes les parties du monde par le comincrce, devient parfois trés impoitune dans les maisons par ses dégats dans les provisions alimentaires.' Nous ne l'avons encore rencontré: ju’à $S$. Roch de Québec.

\section{Fiin. XI.-MUTILLIDES, p. 603.}

Cette petite famille se borne encore pour notre faune aux quatre genres̄ qui suivent:

Cullule radialu ơ ccurio, tronquéo d son sommet qui est éloigné de l'ixt:émité de l'aile: o (autant que connues) eans oicollon;

Youx ovales, plus ou inoins échanciés .......... 1. Mutillad.

Yeux ronds, polis, lisses.. ?. SPI ARophthalMa

Cellulo radialo $\delta$ longrue et en pointe da son soinmet qui atteint presque l'extıémité de l'ailo;

Trois cellules cubitales, la 20 ot la 3e recevant chacune une nervure récurrente; yeux petits; sommet de l'abdomen ơ inorme; thorax $q$ divisé par un sillon tra isverse ................... 3. Mrrmosa.

Deux cellules cubitales, recovant chacune une reécur'rente, sommet de l'abdomen or armé d'uno longue épine recourbée; thor:nx o d 3 nœends. 4. Metroca.

1. Gon. Mutilde. Mutilla, Lin.

$\delta^{x}$-Têto ordinairement transverse et comprimé; ycux oviles, do grandeur moyonuo, plus on moins échancrés ; ocolles 
en trianglo sar lo vertex. Antennes inróréos snj les côtés de la baso du chuperon, atténuécs a leur extrémité. Mandibules arquées, géuéralemont tuidentées. Prothorax s'étondant jusqu'a l'insortion des ailes. Ailes antérieures arec une cellulo radialo et trois cubitales, la radiale d'ordinairo a forme somi-circulnire, los 20 et 30 enbitales recevant chacnne urre norvaro récurrente, la 30 cubitale portunt d'ordinuro à son milion uno petite nervuro so dirigeant vers lo sommet de l'aile. Pattes de grandeur moyenne, puboreentes. Abulomen ovale, son premier segment subpyriforme, beaucoup plus putit que le $2 \theta$ qui est campauule, lo sommet de l'abdomen recourbé en dessous.

P-Aptères. Têto suborbiculairo ou en carré, quelquefois très grosse et portint on dessous do f.rmidables épines. Ocelles o; yeux ovales, entiors; manclibules urquées, unidentées. Thorax allonge, tronqué on avant et on arriere. Pattes plas foptes que dans lo $\sigma^{\lambda}$ ot armées d'épinos extérieurenont. Abdomen som. blable à celui du $\sigma^{\top}$.

Ces insectes appartionnent aux climats plus chauds que le nôtre, alıși ne les rencontre-t-on que rarement dıns nos r'égions tempérées. Nous n'en avons encore capturé qu'une seule espèce que nous croyons nouvelle, et dont nuus ne connaissons que le $\sigma$.

\section{Mutille du Canada. Mutilla Canadensis, nov. sp.}

$\sigma^{\pi}$ - Trong. 38 pee. In tête, le thorax avec lo premier scgment abdominal et les pattes, noir foned avec une pubescence blancho. Fixtrémité dos mandibules rousse. Sụapo dos antennes avec poils aigentés denses, surtout on dessous. La têto assez finemont ponctués lo thorax plus fortement, et le métathorax pugruenx avec une potịte aréole f́tuoite et allongéo, lisse et luisanto au miliou. Ailes presque noires, a reflots violets, la cellulo radiale arrondie an sommet, la. 2e cubitale triangulaire, rocovant la récurrente do mêmo que la 3a ver's son miliea. Ablomon, a part le premior segment, roux, finement ponctué, poli, brillant, nvec pubosconce de poils dressés noirs, lo ler segment à poils blanes.

Capturé un spécimen: au CupRouge et reçı un autre de 
St-Hyacinthe. Cette espèce appartient à ln première division do M. Blake par la nervation de ses ailes et sesait voisine de l'Oajaca, Blake, dont elle d'ffèrerait surtout par la pubescence de l'abdomen qui est noire et non d'un fauve brillant.

2. Gen. Sphfrophthalme. Spcerophthalma, Blake.

Male.-Tête transverse, arrondie ou presque en carré, avec les angles angles postérieurs arrondis, rarement aussi large que le thorax qui est généralement ovale. Yeux ronds, proéminents et polis. Ailes souvent inligineuses ou subhyalines avec nuages bruns. Abdomen ovale, subpétiolé.

Femolle.-Forme de la tête très variable; dans quelques espèces arrondie ou subcairée, quelquefois énormément déve. loppée, étant deux fois plus large que le thorax et armée de fories epines au dessons des joues. Thorax ovale. Jambes intermédia res et postérieures armées extérieurement d'épines. Abdomen ovale, à ler segment petit, campanulé et subsessile avec le second.

Ces insectes qui sont très nombreux én espèces ont été détachés des Mutilles en raison surtont de lenrs yeux ronds, entiers et polis. Ils sont aussi en général beaucoup plus poilns que les Mutilles.

Une seule espèce rencontrée.

1. Suhérophthalme à-une-seule-ceinture. Splccerophthalma unicincte, Prov.

Scolica unicincta, Prov.-Faune, 607.

Voisine de l'oceola, Blake, mais en différant par une pilosité beaucoup plus forte, sa cellule enbitale tronquée, et surtout ses segments abdominaux à partir du 3e qui sont polis, lisses, brillants, à l'exception de leur marge terminale chargée de poils longs et denses.

2. Sphérophthalme à poils-argentés. Sphaerophthatmo argentipilis. n. sp. 
ס'-Tong. 48 peo. D'un ronx uniformo, avee longs poils blancs. Têto nuesi large quo lo thornx, prolongréo er arridro des yellx; ceux-ci gris, les ocelles noirs. L'extrémiló des mandibulès avee lours marges supérieure ot inféricure', noir. Antenues bruncs a l'extrémité. Thorax plus fortoinent poncituś qu" la tête, a poils blance longs et pen denses, le métathorax aryondi, réticulé. Ailes eubhyalines, convertes de poils noirs, les nervures roussâtre's, lo stigma brun, la radiale ovale, n'atteignant pas l'extrénité do l'nile. Les écailles alnirns roux-jaunatre. Pattos aver poils blances, les enisses et les jambes, roux-brurâtro an milien. Ab comen en ovale, son premier segmentassez grîle a la base, dilaté an fommet et sessile sur le 2e, quoique portunt un sillon duns la suturc, lo 20 roux plus clair, les aut?es roux-bruratre, avec poils blunis longs et densor, lo dernier segment tronqué avee une petite ćpino de chaquo côté.-Florido (Ashmead).

\section{Gen. Mrrmosn. Myrmosa, Latr.}

Tête subglobulense; yeux pətits, ronds, latéranx; ocelles en triangle sır le vertex. Antennes subfiliformes, insérées près du chapeion, celui-ci plan et transverse $\sigma^{2}$, triangulaire et longitudinalement caréné dans la $\%$; mandibules larges et trideutécs dans le $\delta^{2}$, unidentéés et acuminées dans la o. Thorax eu carré allongé, ses angles antérieurs arrondis, le collier transverse se comrbant aux côtés, vers l'insertion les ailes, le métithorax tronqué po.stérieurement dans la 오. Ailes avec une cellule radiale et 4 cubitules, la 2 e triangulaire recevant la lère récurrente verc, son milieu, la $3 e$ en carré recevant la révurrente vers le tier's de sa longueur, la 4 e atteignant le sommet de l'aile. Abdomen o ovale-conique, le 1er segment un peu plus étroit que le $2 \mathrm{e}$; dans le $\sigma^{\star}$ abdomen oblong avce les marges des seyments crénelées, le dernièr concave et trideuté a son sommut.

Une seule espèse rencontrée.

Myrmose unicolore. Myrmosa unicolor, Say.

Myrmosa unicolor, Say. - Am. Ent. 1, 222.

Ischioceras rugosa, Prov. \&-Faunu 604.

yrenant ce $\delta$ pour une + , nous avions furmé pour lui le 
genre Ischioceras, que nous rangions dans les Scoliadides. Chose assez singulière, ni Say, ni M. Blake dans sa récente Monographio des Mutillides, ne mentio.auent lo munrnn que porte ce $\sigma^{7}$ sur ses hanches postéricures; ne strait-ce pas véollement une espèce distincte?

Gen. Methoca. Latr. p. 604.

A l'espèce décrite, ajoutez la suivante.

2. Méthoque noire. Methoca stygia, Say, 'o'.

Methoca Stygia, Say. - Boston Journal I, 299.

Ischioceras rugosa, Plov.-Faune p. 609.

Comme Latreille, nous avions rarigé cet insecte dans la famille des Scoliadides. Lea Mutillides, vu surtout la dissimilitude des sexes, ne sont ere qu'imparfaitement connues et ont donné lieu à plus l'une erreur. Latreille èt St-Fargeau avaient fait de cet insecte le $\delta$ du genre Tengyra, dans les Scoliadides.

\section{Gẹ . SAPYGA, Latr. p. 610.}

Sapyga maculata, Prov. + -Faune p. 610.

$\sigma^{7}$-Do taille un per moindre que collo de la + , semblable a cette dorniere avec les exceptions qui suivent: chaperon entièrement jaune, uno tache en forme du croix entro les antennes, celles-ci jaune-ronssâtro, le scape seulement noir avec l'extrémité du funicule. Pattes avec les cuisses noires, les jambes y compris les genoux, jaunes, les tarses jaunes plus ou moins obscurcis. Abdomen avec uno bando juuno sur le 20 segnent, une semblablo interrompue an milieu sur lo 30 , et uno tachọ do chaque côté sur lo 4 e.

La o est toujours de bion plus forto taille que lo ơ. Raro.

Eam. XII-SCDLIADIDES, p. 605.

Gen. Tiphia, Latr. p. 607.

A l'espèce décrite, ajoutez la suivante.

2. Tiphle tardive. Tiphia tarda, Say.-Am. Ent. II, 742 . 
$\sigma^{7}-\mathrm{T}_{\text {inng. } 22}$ pee. Noilo avec pubesconco grinatre. Iso frothorax avec ponctuations pou donaen; le métathorax aveo trois petites cardses all milien aboutissant a uno antre thansverse qui le couronno an sommet. Ailes légdroment onfumés, areo uno radialo courto et largo, lo stigma noir, donx cubitalos fermées, recerant chacuno nno récurrente, la 1 dro 2 foris plus Inngue quo la 20. Palles noirer avec poils blanchâtaes. A bdomen a premier segment beaneoup plus petit que lo suivant, gibbeux en dessis, plat en dessous, los sutures apres les 1er et 20 sogments étranglees distinctemen: ; arochot du fornior segmont vontmal petit, redressć- - Hull ((iuignnard).

Nous n'avons pas encore rencontré cette espice dans lo voisinatge de Québec.

\section{- EXTRA LIMINA.}

Tizhie plus petite. Tiphia minor, $n . s p$.

ó-Long. 28 pee. Noire sans aucune lache, a ponctuntions peu donsos et pen profondes, converte do poils hérissés, conrts ot pen clensos dans tontos ses parties, mais plus fortement sur les pattes. Ailes hyalines, a peine un peu juunâtres à l'endicit du stigma, la radialo tronquéo, avec un rudiment d'appondice au milien de sa nervuro postéricmo qui ost un péu angulouse on cet endroit. - Vanconver (Tiaylor).

Sa taille bien plus petite, la forme de sa cellule radiale et sa plus forte villosité la distingnınt de l'inornatı.

\section{Fam. XIII-SPHEGIDES, p. 611.}

Les changements gue l'on a apportés dans la distribution des geures de cette famille, avec les nouvelles captures que nous avous à ajouter, nons permettent de domer la elef suivante des geures que nois possédons.

\section{CLEF POUR LA DISTINCTION DES GENRES.}

1(i0) Prothorax ne firmant qu'un bourelet cous, nor. allongé en cou; mètalhoriux sans carc̀ues; 
2(3) Pétiold do l'abdomon do deux urticles.........1. Asmoprit.a.

3(2) Pétiolo do l'nbelomen d'un seul neticlo;

4(7) Douxidme collulo cubitale rocovant les 2 nolvures récuirrentes;

$5(6)$ Noir avec taches jaures; chaperon bilobé en avaut, mo:ns distinctentout dans los $5^{x}$; pétiolo anisi lougg quo tout lo thorax pris onsomblo..2. Peropaus.

6(5) Blou ou violet, sans tuches pâlos ; chaporon tridenté on nvant, dans la q quelquefois avee uno petito dent additionnelle do chaquo côté; pétiolo do l'abelomen plus conti quo lo métathorax ............................... 3. Chalymon.

$T(4)$ In 20 et la 30 cellnlo cubitale, chacenue avoc ime norvure récurrente;

8(9) Collulo radialo s'étondant au delà do la $3 r$ cubitale; chaperon of crénolé on avec des petites dents conites, dinns lo ó lo bord crénole; cerochots des tarses à 2 der ts en dessous........... 4. Spriex.

9 ( 8 ) Celiule radiale ne s'étendant pas'au clela de la 3o cubitule; chaperon of avec une coche profonde un milion, en arment, crochets des tarsos d 4 oll 5 dents .... ...................... 5. 1'riononxx.

10 (1) Prothorax allongé en forme do con antériontemont; métathorax presque carré, tronqué postérienrement, a surface dorsalo plane, carénó longitudinuloment et reticulós tran:sversalemont 6. RiInnopsis,

1. Gen. Amsophila, Kirby, p. 613.

Trois espèces renconirées.

Flanes avec plaques pubascentes argentées ;

Les tubereulex et 2 bandes sur los flanes, algentés ;

lur segmont abdominal (à part lo pétiolo) "

тoux.............................. 1. gryphus, 615.

Les tubercules avec mo seulo planuo sur les

flinc's, argentés;

ler segment abdominal noir......... gracilis, $61 \overline{7}$.

Flanes saus plaques argentées ; ler segment abdoniunl roux..........................3. conditor, 616 . 
2. Gen. Phiopeus, Latr. p. 612.

Deux espièces rencontrées. 1

Lo collier, l'écnsson, lo post-écusson, jauno. 1. cementarius.

Le Thorux entidremunt noir..................2. communis.

1. Pelopœus cementarius, Drury. - Faune p. 612.

2. Pelopøus communis, Cress.

A mmophila conmunis, Cress. - Proc. Ent. Soc. Phil. IV. 452.-Faune 11,614.

\section{EXTRA LIMINA.}

Pélope à-polls-argentés. Pelopceus argentipilis n. sp.

q-Long. 75 peo. Noir avec les pattes of l'abdomen roux. La tête, le thorax et les cuisses avec poils blancs; In fince a pubescence argentéc. Lo prothorax simple, lo mésothorax a ponctuations éparses, sillonné au milieu; lo métathorax avec un très fuible sillon au miliou do sa fico dorsalo ot do treds fines aciculations obliques do chaque côté, ses flanes densémont poilus, sa face postériouro aroc uno tache do poils argonlés au dessus des hanches postérieures. Ailes hyalines, légèrement obsenrecios a l'oxtrémité. Les pattes ot l'abdomon d'un beau roux chair, poli, brillant, les hanches noires. Le pétiolo noir, non' très grêlo, 2 fois onviron unssi long quo les banchos postérieures. - Vuncouver (Taylor).

Cette belle espèce nous a été transmise par M. Fletcher d'Ottawa qui l'avait reçue de M. Taylor de Vancouver.

\section{Gen. Chalybion. Chalybion, Dahlb.}

Pétiole de l'abdomen d'un seul article, pas plus long que les hanches postérieures. La deuxième cellule cubitale recevant les deux nervures récurrentes. Chaperon tridenté en avant, dans Ja o sourent avec une petite dent additionnelle de chaque côté, dans les espèces luctuosum et ccruleum, le chaperon manque des petites dents en avant, il est alors un peu dvaucé et très légèrement sinué au milieu).

Deux espèces rencontréos. 
Noil avec pulescence noire

1. luctuosum

Violet ou blen, avec pubescence noire

2. cæruleum

1. Chalybion luctuosum, Smith.

Ammophila luctuosa, Smith. - B. Mus. C'nt. IV. 224.Faune II, 614.

2. Chalybion cæruleum, Jin.

Pelopaus caruleus, Lin.-St-Furgeau, III, 320.-Fanne II, 613.

Bien différent dn précédent par sa enuleur bleue, et sa forme moings zimassée, le jétiole de son ubdomen plus long cte.

\section{Gen. Splutx. Splex, Lin.}

Pétiole de l'ubstomen d'un seul article, it peine plus long que les hanches postérieures. Cellules subitales 2 et 3 , hacune avec une nervure récurrente. Chaperon crinelé daus la of it son bord antérieur ou avee do petites desits conrtes, dins lo ô tronqué avec le bord créneló. Crochets des tnrses avec deux dents en desous.

Sphex ichneumonéen; Sphex ichneumonea, Lin.

Sphex ichneumonea, Liı._Systema Nat. I, 959; St-Furgeau III, 346.

O Long. 80 peo. Brun mais densémont convert d'une pulbesconce fauvo ou d'un 1 oux doré. Lat finco couverto, d'un durot doré. Les antennes noires. Prothurax court, entior, sa trancho dor'sale, ives uno ligne sur les cûtés du mérothornx, lo postécusson avec lo sommet du métnthorax, a duvet d'or, - lo rosto a pubosconce fauve. Ailes hyalinces jaunâtres, légèroment obscuncies à l'extrémité. Pattes nues, d'un ronx luisant, les hanchos avec une tacho a la baso des cuisses, noir. Abdomen en ovale, a pétiolo court, nu, ne portunt de poils fillives que surr le pútiole ot d l'axtrémité. - Ottuiva.

Nons n'avons encore jamais rencontré ce bel iusece dans les envirous de Québec, nous en avous ' $1 *$.u un spécimen ceptures à d'Ottawa. (Guignard), 


\section{Gen. Prionosyx. Prionoryx, Dahlb.}

'T'étiole de l'alıdomen à un seui article, à peine plus long que les hanches postérieures. Chaperon prolongé en avant duns tonte sa largenr, dans la o avec une forte coche au milieu au dessus de layuche se trouvo nu enfoncement allongé, dans le $\sigma^{7}$ Je clia eron n'est jas si avancé et est légèrement sinué en avant. Ailes avec la radialo ne s'étendint pas au delà de laß̉o cubitale, les cubiales 2 et 3 recevant chicune une nervure récurrente. Crochets des turses avec 4 ì 5 dents en dessous.

Ces insecte's ont toute l'apparence des Sphex, mais s'en distinguent facilement par les crochets de leurs tarses munis de 5 dents. Une seule espèce rencontrée que nous croyons nouvelle.

Priononyx du Canada. Priononyx Canadensis, n. sp.

o-Long. 45 pee. Noil avoc pubescence blanche, la fice à pubescence algentíe ed losigs poils blancs entremêlés. Anten. nes noires, le seape avec poils blances. Le prothorax et lo mésothorax chacun avee un petit sillon pen prononcé au milicu, to dernier finemont punctué, opaque, le métathorax aussi finement ponctué et opaque; tout le thorax avec poils blancs, Ailes hyalines, légèroment obscurcies à l'extrémité, la jadialo ne dépassant jas la 30 cubitale, arondie à l'extrémité, les nervures brun-funcé, les écaillettes noires. Pattes noires, épineuses, a reflets argentés, les crochets des tarses ferrugincux. Abdomen noir, poli, brillant, i péliolo dépassant a poine les hiunches postéricures, lo $1 \mathrm{er}$ segment at ra baso ot en dessous avoc piutio da 20 ans:i en dessous, roux, le reste noir, avec lat margo apicale des segments plus pâle et luisante. Lo $\delta^{\lambda}$ avec l'abdomen entiècoment noir, a l'exception des marges apicales plus clatres dos sergments. - Otlawa Guignard).

Diffère du Thomce, Fabr., par son absence de taches jaunes, de l'atrutu, St-Farg., par sa pubascence blanche, et du brunneipes, Cress, par son thorax entièrement noir et sa pubescence blauche. Nuus n'avons p.s cucore rencontre cut insecte dains le voisinage de Québec.

varia indiv distin 
6. Gen. Rinnorss. Rhinopsis, Westw.

Forme allongée et assez grêle. Proth'max prolongé en avant en forme de cou. Chaperon caréné au milien, l'́gèrement rostriforme. Antemes grêles. Métathorax en carré, tronılué postérieurement et caréné en dessus. Ailes étroites, un peu conrtes, les antérieures avec bimdes fuligineuses, 3 cellules cubitales, la 1ère et la że chacune avec une nervure récurrente (il arrive parfois que la nervule séparunt la lère cubitale de la 2 est obsolète, les cubitales se trouvent alor's réduites à deux seulement). I'attes longues et grêles, les cuisses renflées an milieu. Abdomen en ovale allongé, à pétiole plus conrt que les hanches postérieures.

Rhinopsis canaliculée. Rlinopsis canaliculala, Say. Ampulex canaliculata, Sny,-Am. Ent. I, 165.

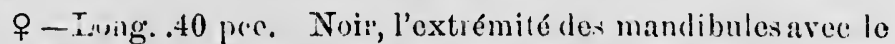
labre tenx; front avee ung arèno au dessis de rhaque antenne et une antre an milion qui doscend jusquau ehaperon. Prothorax denément ponetué et sillonué al milien; mésothorax at ponetuations grosses el claires aree un sillon de chaque côté du milien. Métathorax avec 8 sillons coupés par de nombreuses lignes trausverses. Ailes avee une bando noire. Abdomen poli, sans ancune tache.

M. Cresson doune cet insecte comme se trouvant en Canada, nous ne l'avons encore jamais runcoutrú.

\section{Fam. XIV.-POMPILIDEs, p. $61 \%$.}

Gen. Pompinus, Fabr. pp. 617 et 809.

Áux 13 espèces décrites, ajoutez celle dlomnée ci-dessous.

Bien que la nervation des ailes dans ces insectes soit assez variable, elle est cependant généralement constante dans les individus de la même espèce, et peut servir grandement à les distiuguer les unes des autres. Nous soumettous la elef sui- 
vante que uous avons trouvée très avantageuse pour leur distinction.

1 (22) Noir on bleuâtre, sans ancuı? tacho;

2 ( 7 ) Ailes noires ou brun foncé;

3 (6) 30 cubitalo non pétiolé;

4!5) Chaperon fortement échancré en avant..1. æethiops, p. 618

5 (4) Chaporon non échancré en avant....9. angustatus, 621. 6 (3) 3e cubitule pétiolée sur la radiale.... 11. tenebrosus, 622.

7 (2) Ailes hyalines, plus ou moins enfumécs alu som met;

8 (9) 3 o cubitale pétiolév..................12. cylindricus, 622.

9 (8) 30 cubitale non pútiolée sur la radialo;

10(11) 3e cubitale réduite à un seul point à la radiale 7. virginiensis, 620 .

11(16) Ze cubitale avec la norvule basilaire droite, rerticale on très peu inclinéc, la nervile extérieure se courbant intéricurement mais sans ferner la cellulo à la radialo;

12(13) Tu prothorax et la fice couverts d'une pubescenco grirâtıe sub-irgentéc................4. griseus, 619 .

13(12) Prothor:' $x$ et faco sans pubesconce grisâtro;

14(15, Abdomon $\delta^{\lambda}$ allongé, cylindiriue, jambes fortemont épincuses ...................13. argenteus, 622.

15(14) Mbdomen ovale, fusifo:mo, jambes médiocroment épincuses; t:ille plus petite..........5. parvus.

16(10) 3c cubitale avec ses 2 nervules transvorsos écartées du bas, lui clonuant nue fon!me triangulaito;

17(18) Bord postérieur du prothorax simplement आrqué......................... hyacinthinus, 620

18(17) Bord postérieur du prothorax anguleux..2. scelestus, 619

19(16) 30 cellule cubitale en carré irrégulies';

20 .21) Face ì pubciscenco algentée ...........3. Iuctuosus, 619 . 
21(20) Face sans pubescence argentée

8. apicatus, 621.

22(1) Plus ou moins taché de blane, de jaune ou de rouge;

23(24) Noir arec 2 taches blanches a l'abdomen ......................................13. biguttatus, 623.

24(23) Noir avec les segments basilaires de l'abdomen roux ............................ . 15. marginatus, 623.

s), p. 618 atus, 621 . osus, 622 . et ; icus, 622. ensis, 620 .

iseus, 619. nteus, 622 .

arvus.

thinus, 620 elestus, 619 tuosus, 619 .
2 Pompile petit. Pompilus parvus, Cress. - Proc. Ent. Soc. Phil. IV, 453.

†-Isong. .30 pco. Noir, immaculé, subopaquo, la tête et le thorax avec une obscure réflexion de verdâte; chaperon largoment arrondi en avant, poli, brillant an bord ; mandibules ferrugineuses à l'extrémité. Antennes noil foneé. Bord postérieur du prothorax anguleux. Métathorax abrupte en arriere avec une ligne longitudinale assez profonde. Ailes fuligineuses, légèremont violettes, à bord apical plus foncé, les inférieures subhyalines; la cellule radiale en pointe à l'extrémité, la 20 cubitale en carré, la $3 \mathrm{e}$ plus grande et rétrécio a la radiale, sa nervure basilaire droite quoique légèremont inclinéo. Pattes noires, épineuses, les cuisses teintes de bleuâtre et les tarses de brunâtre. Abdomen court, robuste, convexe, avec réflexion bleuâtre très prononcée.

万-A semblable coloration, avec les ailes plus claires, les pattes moins épineuses etc.-CapRouge, Ottawa (Guignard).

Jolie espèce bien distincte par sa forme, sa taille et sa coloration.

\section{EXTRA LIMINA.}

Pompile de Coquillett. Yompilus Coquilletti, n. sp.

đo-Long. .50 pco. Tricolore, noir, roux et jaune. Tôte courte, plus large que lo thorax, jauue, une tacho au dessus des antennes s'étendant jasqu'en arrièro des ocelles, noire, avec une potite tache rousse en avant do l'ọcelle inférieur; lo vertex avec une t $\quad \cdots$ da la base áu chaperon, roux plus ou moins foncé ; touto la têto avec pubescelice jauno; le chaperon prolongé on avant cn une largo pointe arrondie Antennes fortes, rousses, 31 -Decombre 1887 
les articles terminaux noirs on dessus, mos les articles festonnés. endessons. Prothorax noir an lord ancérieur, roux an milion avec la margo postéricure jaune, largement arqué postérieurement. Mésothorax noir avec une tacho roussâtre en avant do l'écusson, l'écusson ot lo post-écu-son jaunes; lo métathorax excepté nn point jauno au dessus des hanches postérieures, les flancs, excepté uné tache ronsse an dessus des hanches intermédiaires, toutos les hanchos ot les cuisses excepté a leur sommet, noir, les. jambes ot les tarses jaune roussâtre. Ailes grandos, dépassant l'abdomen, d'un brun roussâtre avec une grande tache hya'íno au dessous des cubitales et wne tacho plus foncéo do bíu au sommet; les cubitales 2 ot 3 a pou prés d'égalc lonirueur, rétrécies toutes deux à la radialo. Abdomen avec les segments 1 et 2 roux, marginés de noir an sommet, le premier de plus noir à la baso, les autres segments jaunes, marginés de roux au sommet, eetto marge s'avanģint on pointe jusque vers le milieu du seg. ment. Les jambes antérieures assez courtes, épinonses.-Californie (Coquillett).

M. D. W. Coquillett, d'Anuheim, Californie, qui s'occupe particulièrement de diptères, nous ayant fait un envoi d'hyménoptères de sa localité, nous y avons trouvé ce bel insecte, qui n'a pas encore été décrit, pensans-nous, et. que nolks sommes henreux de ponvoir lui dédier.

Gen. Agenra, Cress. p. 625.

Aux 5' espèces décrites, ajoutez les 3 qui suivent.

Clef.pour la distinction des espèces.

1. 2.) Ailes traversées par 2 bandes obscuress.... 1. pulchripennis, 626 .

2(1) Ailes sans bandes obscures;

3(14) A.bdomen noir:

4i5) Thorax bleu-foncé 4. architectus, 627.

5 (4) Thorax noir;

6(9) Pattes noires;

7. 8 ) A.bdomen distincternent pétiolé 
stonnés. miliet śrieurevant do excepté ; flincis, dianires, roir, les passant hy:'ino brili an i, rétrésnits 1 et noir à la sommet, d.u seg. A.-Calis'occupe d'hyméecte, qui sommes

anis, 626 .

ctus, 627. ata, 627 .
$8(7)$ Abdomen sessile 6. $\operatorname{arctath}, 1)$. ap.

9(6) Pattes rousses plus ou moins complete: ment;

11.13) Eperons des jambes aoirs ou bruns;

11(12, Corps robuto, 3 enbitales aux siles..... 2. mellijos, 626. 12 (11) Corps allengé, déprimé $\delta^{\lambda}, 4$ cubitales parfaites aux ailes

7. perfecta, 627.

13(10) Eperons des jambes blancs 7. calcarata. 14(3) Abdomen roux, corps noir. 8. rufigastra, n. sp.

6. Agénie noire. Agenia atrate, $\mathrm{n}$ : sp.

o - I Jng 28 pee. Noiro, presque totalument destituée de puhescence, noit pertant seuloment que sar. Io prothorax, lo metathorax et les hanchos, et eicore plas apparente a l'extrémité des antennes. Frace polie, britlanté, le chaper'on tronque en avant. Prothorax subrangtrleax son bord postérieur. Ailes passubloment enfumées, l'étant davantage à l'extrémité. Pattes tontes noires, les $t$ jambes antérieures seulement étant plus ou moins brunâtres en avant. Abùomen subpédicule, en ovaleallongé, poli, brillant, tout noir.

$0^{7}$ Semblable d la femette, mais plus grềle et avee une pubescence grisâtre plus distincto sur lo métathorax et les hanches. - Ilull (Guignard).

Le manque presque absolu de pubescence et sa petite taille distinguent particulièrement cette espèce de suts voisines.

6. Agénie a-éperon-blanes. Agenia calcarata, Cress. -Trans. Am. Kut. Soc. 1, 128 .

ర7-Luorg. 23 pee. Noire, grêle, cỷlindriquo, aveo pubesrence b'ancho plus arparento sur la face, io prothorax, le me. tathorax et les hareches. Chaperon tronqué on arant, blanc avec une tacho noire plus on moins grundo $a$ la base au miliou. Mandibules aveo ine tatcho blancho puess de l'extrémité. Antennes enurtes, éputisses, entidrement noires. Piothorax avec une ligno blanche intorrompuo an milieu an bord postérieur. Mérathorax arrondi et argenté an bas. Ailes hy:"ves, légerement iridescentes. Les cellules cubitales 2 et 3 is: caré, presquo 
égales. Pattes roussalres, les hanches, les trochanter's, la base des cuisses avec les 4 tarses postérieurs, noir'; l'extrémité dos hanches antérieures avec les éperons des jumbes, blnnc. Abdomen subcylindrique, subsessile, inmaculé.-Ottawa (Guignard).

Non encole rencontrée dans le voisinage de Québec.

8. Agénie à-abdomen roux. Agenia rufigastra, n. sp.

f-Long. .30 pce. Noire aves l'abdomen joux, lo bas de la face avec les flanes et les hanches a pubescence argentée. Antunnes assez longues, enroulées. Prothorax gr'and, arqué postérieuremont. Métalhorax arróndi, argenté sur les flancs. Ailes légèrement enfumées, a radialo lancéolée, In 1èro cubitule aussi large que la 2e. Abdomen ovale, subpétiolé, entièrement roux, fortement pubescent.-Hull (Guignard).

Cette sspèce répondrait assez exactẹment à la description de li congrua, Cress. mais la nervure de sa $2 \theta$ cubitale est privée de l'appendice que porte celle-ci.

Ger. Ceropales, Latr. pp. 628 et 810.

Aux trois espèces décrites, ajontez les 2 suivantes.

1(2) Abdomen entièrement noir ; cuisses postérieures lousses ... ......................... 4. bipunctata.

2(3) Abdomen entièrement roux.............. 3. superba, 810.

3(2) Abdomen noir, varié de blane ou do jaune pâle;

4(7) Abdomen avec ceintures blanches;

5(6) 1er segment aree une ceinture blanche on avant du sommet, les suivants avec la marge apicale blancho............................. 1. fraterna.

6(5) ler segment avec une tache blanche de chaque côtć, los autres avec la mar'ge apicale blanche .............................. 2. longipes, 810 .

7(4) Abdomen avec taches blanches séparées sur les côtés des segments 1,2 et 7 ; taille beaucoup plus petito ...................... 5. minima, n. sp. 
la base ité dos

Abdoignard).

i, n. $\mathrm{sp}$. as do la o. An16 posté8. Ailes ale atussi nt roux, scription itale est

unctata. ba, 810 .

raterna. pes, 810 . ma, n. sp.

4. Céropalo à 2 points. Ceropales bipunctata, Say. Am. Ent. I, 225.

†-Long. .60 pce. Noir opaque foncé, velouté, les orbitos antérieur's n'utteignant pas le sommet des youx, jaune-blanchâtre avec un point enfoncé à la base du chaperon de chaque côté; chaperon arrondi en avant. Article busilaire des antonnes taché de blanc on dessous. Bord postéricur du prothor'ux arqué. Lo métuthorax avec un sillon médian sur le dos, tronqué postériourcment̀. Ailes noir violet foncé, la 30 cubitale très élargio a la base. Pattes noires, les postérienres très longues, avec les cuisses d'un beau roux d l'exception d'un petit anneau noir à chaquo extrémité. Abdomen court, robusto, subsessile, sans aucenne tache.

Capturé à Ottawa par M. Guignard. Ce bel insecte n'a n'a pas cucore été rencontré dans les environs de Québec.

\section{Céropale minime. Ceropales minima, n. sp.}

$\delta^{7}-$ Long. 18 pce. Noire avec taches jaunc-pâle. La face au dessous des antennes, des lignes orbitales jusqu'au dessus des youx, le chaperon, lo labre, les 2 premiers articles des antennes on dessous, lo bord postérieur du prothorax, un point sur ses angles antéricurs, l'écusson et le post-écusson, avec une double tache sur les angles inférieur's du métathorax, une tache on avant sur les 4 hanches antérioures, l'extrémité des postérieures avec uno ligne on dihors, une grande takche sur les côtés des segments 1 et 2 do l'abdomen, avec 2 points sur l'extrémité diu bec, jaunepâle. Ailes légèrement obscures a l'extrémité, le stigrma furrugineux. P..utes jaune pâle, toutes les cuisses noires oxcepté aux extrémités, les pattes postéricures entièrenent noires, leurs jambes ot leurs tarses ferrugineux, brunâtres d l'extrémité. Abdomen ovalc-oblong, po!i, brillant.-Hull (Guignard).

\section{Fam. XVI. LARRIDES, p. 630 .}

Aux 3 genres décrits, ajoutez le suivant qui se distingue particulièment par sa deuxième cubitale qui est pétiolée.

Gen. Pison. Pison, Spinola.

Tête aussi large que le thorax; chaperon caréné, formant 
une petite pointe au bord antérieur. Prothorax très court; métathorax avec une petite carène sur lo dos et une fossette à sa face postérienre. Ailes avec la $2 \theta$ cubitale pétiolée, ses deux nervures se joignant inférieurement chacune à une récurrente, la radiale tronquéo et appendiculée. Abdomen en ovalo, les 3 premiers segments étranglés aux sutures.

Se distingue aisément par la nervatiou des ailes.

Une seule espèco rencontrée.

Pison lisse. Pison lovis, Smith.-Brit. Mus. Cat. IV, 317.

○-Iong. .22 pce. Noir arec pubescenco blanchâtre en certains endroits. In fuce an dessons des antennos pubeseonteargentéo. Antenros courtes, filiformos, légèromont onroulées. Lo prothorax arrondi postérieurement; lo métathorax opaquo avec un petit sillon an milieu et des stries fines rayonnant do la base à la circonférence, sa face postéricuro avec une fossette striéo transversalement; les côtés pubesconts argentês. Ailes subhyalines avee les norvures noires; la :o cellule cubitule pédiculée counmo dans les Nyssons. Puttes noires, presquio sans pubescence. Abdomen en ovalo allongé, noir, poli, brillant, les sutures apids les segments 1 et 2 gufoncées avec pubesconco blanche aux côtés, les segments terminaux noirs.-Ilull (Guiignard).

Cet insecte a les ailes des Nyssons avoo le métathorax des Lyrodes. Son abdomen étranglé aux sutures le fait distinguer à première vue.

Gen. Larra, Latr. p. 633.

Aux 2 espèces décrites, ajoutez les 3 qui suivent :

Abdomen plus ou moins roux a la baso;

Sugments 1 et 2 roux, corps plus trapu, métathorax aciculé.................... 1. abdominalis, 653.

Segmonts 1,2 et 3 roux, corps plus grêle, métrithorax très finemunt panctué................ 3. lævifrons. 
13 collrt; fossette \& ses denx currente, le, les $\mathbf{3}$

Cat. IV,

hâtro en besconte. inroulées. $\mathrm{x}$ opaquo unt do la fossetto 5s. Ailes itule pédiquo sians illant, les ibesconse Iull (Guihorax des listingırer

:

alis, 653 . evifrons.

Abdomen noir d la baso;

Jambes postériouros épinouses oxtériourement;

Stries dı métuthornx droites........... 2. terminata, 633.

Stries du métathorax arquées, recourbées en haut.

4. arcuata.

Jambes postérieures inermes extériouroment 5. minor, n. sp.

3. Larre front-lisse. Larra lovifrons, Sinith.-Brit. Mus. Cat. IV, 291.

$\sigma^{\lambda}-$ Irong. 30 pee. Noire; la fuce avee une donse pubeseence argentée, surtout au bas; lo vortex poli, krillant d l'ondroit des ocelles postérieur's. Antennes pubuscentes ot atténuées d l'oxtrénité. Thorax oprque, soyoux, n'uyant do pubosconce que sur les côtén, ceux dn métathorux argentés. Ailos hyulines, a nervures noiros; la cellule radiale tronquéo et continuéo jusqu'i la côto par un appendico. Patces plus on moins pubescontes, les 2 artinles terminaux des tarses roux ferruginoux. Abdomen allongé, les segmonts 2 ot 3 arec lo sommot du ler roux, lo resto noir, les 4 premiers segments avec une cointure pubesconte au sommet, les untres a ceinture testroée, lisso.-Ottawa (Guignard).

Smith u'a déorit que la $\&$ mais nous ne croyons pas faire orreur en rapportant ce $\delta$ a cette osprico.

4. Larre a-stries-arquées. Lar'a arcuata, Smith.Brit. Mus. Cat. IV, 293.

q-Long. 30. pce. Noire: l'extrémité des mandibules ferrllgineuse. Lo mésothorax' subopaque, l'ecusson brillant. Le métathorax nvee un sillon ềntral des deux côtés duquel partent des stries obliques so courbant en avant, la troncatnre postérieuro présontant une forme triangulaire sillonnéo en traver's ct partagée par un sillon qui est nuivi d'une carène s'éterdant jusqu'au bas, les côtés pubescents-argentés. Ailes subliya. linos, un peu plus foncées au sommet. Los 2 articlos te:minmux des tarses ferrngineux. Audomen lisse et brillant, lo segment terminal rugueux. - Ottawa (Guignard).

Bien distincte par la sculpture de son métathorax. 


\section{Larre mineure. Larra minor, n, sp.}

\&-Long. 21 pce. Noire avee pubescence blanchatte et l'extrémité ilo l'abdomen ronge. Ln face pubescente à reflots urguntés. Têto grosso, plus largo que lo thorax; untonnos gossez courtes. Thorax a pubescence plus apparente sur lo prothorax et les flanes; to métathorax ponctué rugueux. Ailès hyalines, les norrures bi unes; les 2 récurrentes rupprochées mais non contiguës a lour entrée dans lá 20 cubitule; point do vestige do norvure un dola do la 3o cubitale. Puttes roires avoe duvot blanchsíro, les jambes postérieures inermes sur leur trancho extériouro. Abdomon orale, les segments $1,2,3$ et 4 avec une bando d reflets argenites au sommet; les 2 terminaux ferruginenx.-Ottawa (G.)

$0^{7}-$ Semblable a la fomolle, mais avec l'abdomen tout noir ot lo pénultième urticle des tarses roux.

Très rapprochée de la terminata, Smith, mais en diffèrant surtout par sa plus petite taille, ses jambes postérieures inermes et l'absence de nervure au delà de la 3 e cubitale.

Fam. XVII. NYSSONIDES, p. 634.

Aux 3 genres mentionnés, ajoutez le genre Hoplisus, St-Farg. qui se répare des Gorytes par la nervation de ses ailes, comme nous le faisons connaitre plis loin.

Gen. Nysson, Lat. p. 635.

A l'espèce décrite, ajoutez les 2 qui suivent. Abromen noir avec des lignes jaunes interrompnos,

1. laterale, 635 .

Abdomen plus ou moins ferrugineux a la base ;

Le segment 1 avec la moitié du 2e ferruginenx, ce dernier avec un point jaune de chaque côté à la marge apicale.................................. 2. rusticus.

Lo seggment 1 ferrugineux sur les côtés, 2 et 3 avec une átroite ceinture rousse a ln base 3 . nigripes, n. sp. 
2. Nysson rustique. Nysson rusticus, Cress.-Trans. Am. Eut. Soc. IX, 282.

- Long. 21 peco. Noir, opaque, finenient ponetué, la têto et lo thorax avec poils blunces soyoux. Ecussón ponetne. Mérathorax uvec onviron 10 petites curènes sul lo dos. Allos hynlines, enfuméc au nommet et plus fortement a la eellulo rndiale. Pattes noires, kans aucuno tucho. Abdomon ovnle, at ténué d l'extrémité, épais, finement poneturs, lo lor sogment aveu partio du 20 forruginoux, co dernier avoe un point jauno do chnque côté a la margo upicale.-Ottuwn (Guigmurd).

\section{Nysson pleds-noirs. Nysson nigripes, n. sp.}

$\sigma^{x}$-Isong. .20 pee. Noir sans aucune tache, avec pubescence blanchâtre en certains ondroits; la faco aryentée au dossous des antemes. Lo prothora: prosquo earré en mriere, lo mesothorax finemorit ponctue, lo métathorax tres ruguoux avos un mucion aux angles. Ailes subhyalines, la radiale sans appendice, la 20 cubitule pédiculéo et lı 30 fortement rétrécio d la radialo. Pattes entierement noires, avec pubescenco blanchâtro sur les cuisses et

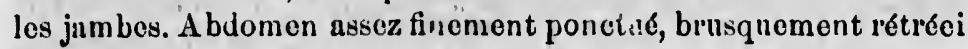
avant l'extrémité, lessutures a la base dos sognents 2 et 3 roussâtres ainsi qu'une tâche sur les côtés du premier, lo segrment terminal aveo 2 épines.-Hull (Guignard).

Voisin du pumilus, Cress. mais s'en distinguant par son absence de taches jaunes.

\section{Gen. Alyson, Latr. p. 635.}

A l'espèce décrite, ajoutez les 4 qui suivent:

\section{FEMELLFS.}

1(2) Thorax roux; abdomen noir et roux......... 2. melleus. 2(1) Thorax noir;

3 (4) Abdomen roux à la base............... 1. oppositus, 636.

4(3) Abdomen noir a la base;

5(6) Chaperon noir, mandibules jaunes.. 3. Guignardi, n. sp. .6(5) Chaperon jaune, inandibules jaunes..... 4. conicus, n. sp. 


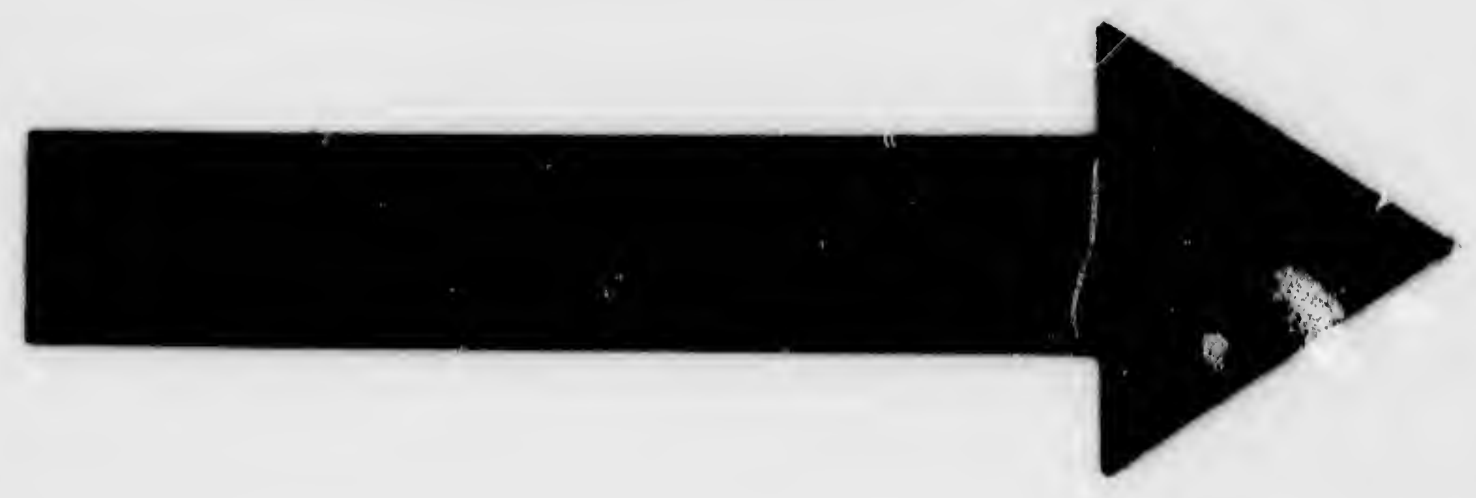




\section{IMAGE EVALUATION \\ TEST TARGET (MT-3)}
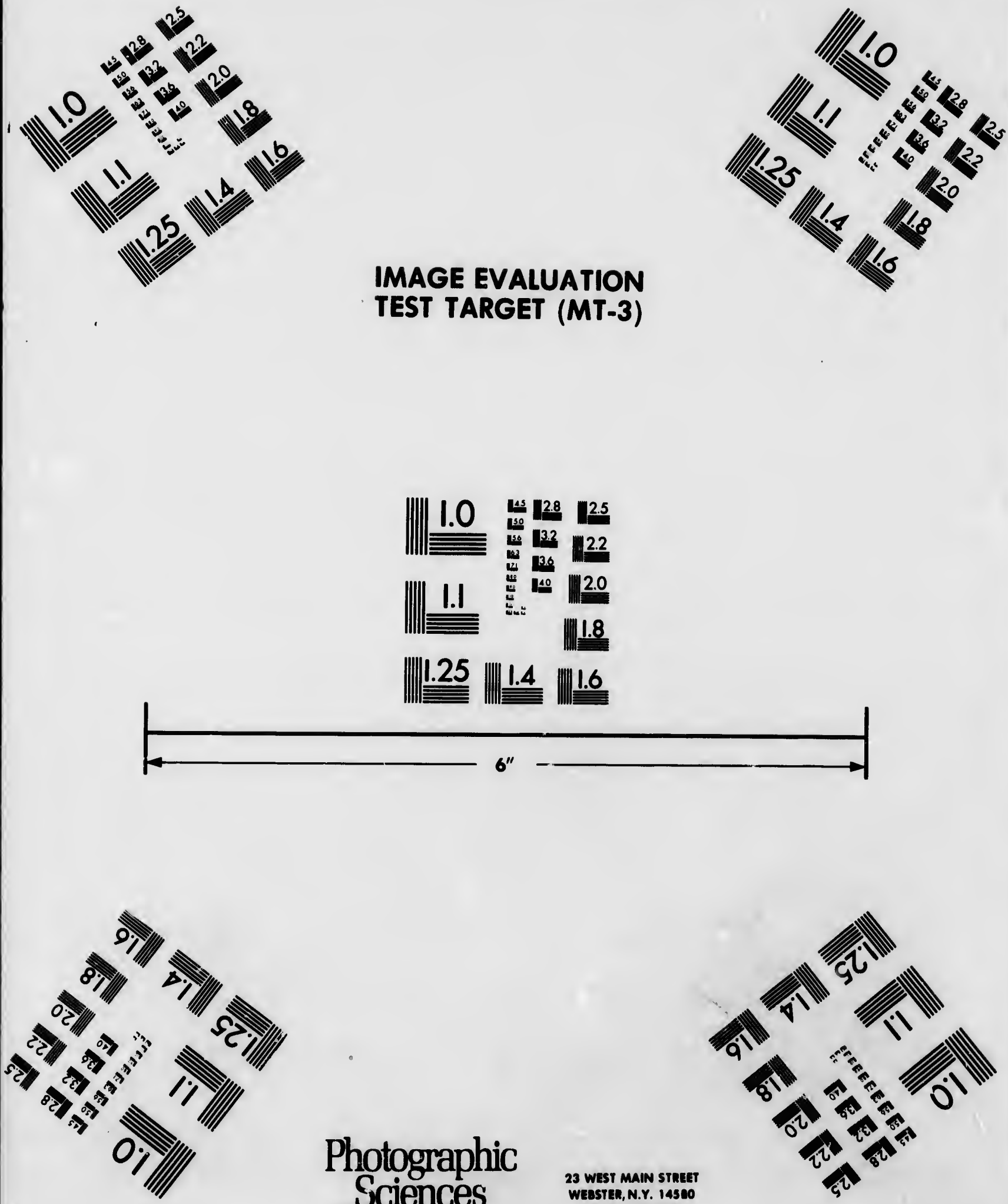

Photographic Sciences

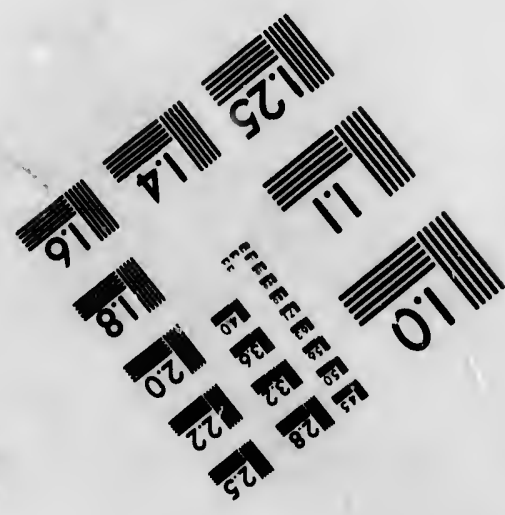

(714) 072.4503 
MALES.

1(2) Chaperon noir

1. oppositus.

2(1) Chaperon jaune;

3(4) Prothorax sans titches, métanotum non jugueux

2. melleus.

4(3) Prothorax avec taches jaunes; mélanotum ringueux ;

5 ( 6 ) Métanotum avec un espace renfermé on fol'ıne d'U

3. Guignardi.

6(5) Métanotum avec un espace ronfermé en iriangle aigu 5. triangulifer, n. sp.

2. Alyson jaune-miel. Alyson melleus, Say-Am. Ent: II, 762 .

\%-Long. .27 pce. Noir th roux; la tête noiro avec lo chaperon, les mundibules, lo scapo des antennes en dessous, jauneroussâtre, les mandibules jaune plus clair. Thorax jaunc-roux sans aucune tache, lo métathorax à :culptures assez fines, le mésothorax noir en dessus. Ailes hyalines avec une bande brune a l'endroit du stigma traver'sant l'aile presquo entièrement. Abdomen avec le premier segment et moitié du 2e, roux; lo reste noir, poli, brillant, le $2 e$ segment avec une tache ronde jaunepâle de chaque côté. Pattes rousses, l'extrémité des 4 cuisses posstérieures noire, los jumbes de la dernidre pairo noiros uvee un anneau blane d la base.

J-Tout noir, lo chupiron, les orbites antérieur's, le seapo des anteunes en dessuus, les hanchos antérienros avec la base des jambes et des tar'ses postérieurs, blane ou jauno pâle. Le prothorax quelquefois sans taches; et d'autrefois avec 2 ou 4 taches pâles. Lo métathorax comme dans la + . Abdomen noir avec l'extrémité rousse ot les deux taches pâles'sur le 20 segment.CapRougo, Otlawa.

Say ne mentionne pas la base blanshe des jambes postérieures qui, sans être quelyuefois très prononcée, est toujours distinguible, et ne doune pas non plus la description du $\sigma^{\prime}$; nous ne croyons pas faire erreur en lui rapportant celui que nous venons de décrire. 


\section{Alyson de Guignard. Alyson Guignardi, n. sp.}

oppositus.

2. melleus.

\section{Guignardi.}

alifer, n. sp. -Am. Ent:

avec lo chassous, jaune$x$ jaunc-roux tines, lo mébande brinne ement. Aboux; lo reste ronde jaune4 cuisses posbiree uvec un

urs, lo scape c la base des le. Le proou 4 taches on noir avec segment.-

mbes postéest toujours ption du on; it celui que

१-Long. .30 pce. Noir; les mandibules exceptó a l'extremité, jnune-miel, le chaperon noir, pouctué svec pubescence blunche, le scape des antennes junne avec une ligne noire on dessus, quelquofois une petite ligne jaune. orbitalo au bas des yeux. Thorax finenoinent ponctué, sans tachos; le prothorax uvec les anglos postéricurs et les flancs du mésothorax à pubescence' argentéc ; lo métathorax avec l'espace renformé sillonné de lignes' grosses et bien distinctes. Ailes hyalines avec une bande transversale brune on arrière du stigmu. Pattes noires arec los deux ar'ticles terminaux des tarses jaune-míel. Abdomen robuste, convexe, poli, brillant, les taches blanches du 20 segment grandes, l'extrémité pubescente, le dernier' segment brunatre.

$\sigma^{\prime}-$ Le chaperon, le labre, les mandibules éxcepté a l'extromité, le scape des antennes en dessous, les orbites antérieurs, 4 points sur lo bord du prothorax, l'extrémité des hanches anterieures, blanc on jaune pâle. Métathorax fortement rugueux. Pattes roux-brunâtre, les postérioures plus fóncées. - Bścancour, Otlawa (Guignard).

Nous dédions avec plaisir cette belle espèce à $\mathbf{M}$. Guignand le zélé entoniologiste d'Ottawa qui le premier nous en a trạnsmis un spécimen Nous en avons capturé plusieurs a Bécancour $\delta^{x}$ et + .

\section{Alyson oonique. Alyson conicus, n. sp.}

\&-Long. 22 pee. Noir ; le chaperon, les mandibules excepté a l'uxtrémité, les orbites antérieurs avec lo scapo des antenncs en dessous, jaune pâle. Vertex poli, brillant, sans ponctuations distinetes. Métathornx allongé, brillant, a stries fines et distantes. tant dans l'espuco r'elformo 'que sirr les flancs. Ailes hyalines, avec une bande transversale légerement obsouro a la radiale. Pattos brinli-roussâtrie, less antérioures avec los jambes et les tarses, jauno. Abdomen poli, brillant, noir; avec une taohe oirculairo blanche sur lo socond segrment, ayant sa plus grande largellr all sommot de ce second segment et s'amincissant de ce point ver's la base ot vers le sommet en forme de deux cônes opposés; la plaquo anale plane; assegez petite, al pubescence rous: sâtre- - Otlawa (Guign:urd). 
Son chaperon blanc et sa plus petite taille le distinguent surtout du précédent.

5. Alyson porte-triangle. Alyson triangulifer, n. sp.

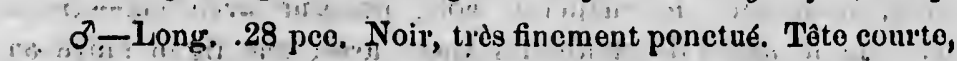
transversale. Le chaperon, les mandibules, les orbites avec lo scape des antonnes, blunc ou jauno pâle. Antonnes courtes, roussâtros en dessons, brunatyes on dessus, le dernier article en crois. sant, Les tuborculos avcc une petite tnche sur l'angle latérul du prothorax, blane; mésothorax donsément ponctué; métathorax peu allongé a carenes soulevées très distinctes renfermant l'uspace triangulaire do la base, ce triangle brillant, avoc 2 petitos carènes divergeant do la base ver's los côtés et d'autres strios moins apparentes, les côtés on dehors de l'espace ronformé a stries régulières, la face postérisure rugneuso: Ailes hyalines avoc uno bande légerement obscure a l'ondroit du stigma, la 1ère récurrente reque très près de la base de la 20 cubitule, la 20 récurrente intersticiale. Pattes rousses, les 4 hanches antérieures blanches en dessons, les postérieures avec la base de leur's cuisses et leur extrêmo sommet, noir. Abdomen allongé, poli, brillant, noir avec une tacho circulaire blanche sur lo 20 segment, te dernier segment joux et portant une longue épine de chaque côté. -Bécancour.

Espéce bien distincte par son métanotum plus court que lans les autres espèces, et le triangle qu'il porte ; pourrait pevitêtre former un genre nouveau. "Fetnelle inconnue.

\section{Gen. Gokytes, Latr. p. 636.}

Co genre, tel que restreint maintenaut, so rédnit pour nous a la seule espéce qui suit, que nous croyons nouvelle.

Gorytes arme: Gorytes armatus, n. sp.

\$ - Long. .30 pce. Noir, poli, brillant quoique fortement chargé de toutes parts de ponctuations grossos et peu denses. Teto transversale vue en dessus, a front large et fortement ponetué ; le chaperon, excepté a sa murge antériouro, lo seapo des antennes en dessijus, les orbitos antérieurs, lo bord du prothorux, les tubercules, une tache en arriere, une ligne transver'salo sur 
itinguent

er, n. sp.

te colurte, a avec lo tes, rousen croislatóinal du étathorax nant l'es2 petitos ires stries onforme a hyulines na, la 1ère 3 la 20 réintérieures u's cuisses i, brillant, ent, lo deruque côté. court que rrait pentpour nous e.

fortement peu denses. ment poneseape des prothorux, sversalo sur l'écrison; nvec une bande all sommot des segments nbdominaust, junne; les écrailles ulaires roussâtres, Métathorax avoc l'espatê trjangulairo renfermé sur lo dos slllonné de $12 \mathrm{~d} 14$ stries régtilieres, et la fico postérieuto parsemée de grosses ponetuations. Lon mandibulos noiros. portunt chacuno, près de la baste, aú bord superieur; uno longuo épino dressée, jaune; le chaperon a pubos cence blancho muis non ponetué. Ailes arec une tache brunviolet conviant la cellule radiale at partie do la 20 eubitalo. Pulter, noil ot jauno, toutes les cuises avec les hanches ot l'or. trémité des jambos surtout en dehors, noir, le resto jauna. Abdo. men court, en ovale, fortement ponctué, les 5 segments basiluitu avec la margo apicale jaune, cette murge plus large sur les scgments 1 et 2 et rétrécio au milieu; les segments 3 ot 4 avec uno bande lisse a la base, le segment terminal auteri forte. ment ponetué-sugacux. - Ottawn (Guignard).

Voisin du nebulosus, Packard, et peut-être lè or te cette espcce, les différences de coloration et les épines des nuantibules n'étant que des différences de sexe. Noús n'ávons poín vu a o décrite par M. Packard.

\section{EXTRA LIMINA.}

\section{Gorytes cornes-rousses.' Gorytes ruficornis, n. sp.}

o-Long. .50 pec. Noir, sub-opaque; la tête et lo thorax finement ponctués. Antemues entièrement d'un roux jaunstite, d l'exception du scape qui est plus on moins taché de brun en dessus. "To chaperon transver'sal, convexe, roux do mềne qüo les mandibules ot les or bite: all dossus des antennes jusque sur le vertex. Le bord du prothorax, les tubercules avec une täché en arrière, l'écurson et le post-écusson, une tache âllongée ét échancréo intéricurement sur les côtés du métathorax, jaùne. Dos du. métathorix avoe l'espice renferme finement strie, les côtés portant aussi des strios fines ot obliques, ces stries transversales au bas de la ficce dorsale. Ailes hyalines-jaunatres, l'extrúnité enfumée d partir du stigmu, mais sans descendre au deld du cubitus; lo stigna jauno. Paltes jaune-roussâtre, les 4 hanches postéricures avoc leur's cuisses excepté a l'exticénite, noir, sid-Janvio 1 
le dor nier articlo des tarses aussi noir. Abdomer: lisse, allongé, julune avec nino bundo noire d ln buso des 4 prenior's seginonts, cette bando treds étroite a la bisso du 3o, lo be ontidrenont jituno et lo terminal roux et ponctuć.

$\delta^{7}-$ Toute la fice uu-dessous des antennes, avec los orbites remontant jusque sur lo vertex, jaune; uno 1 gno sur le mésonotum au dessus des ailes, une grande thche nllongrio au dessousdoux grandes taches ovalos sur les côtés du métathorax so rejojgnint presque an milieu, juune. Abdomon juune aveo uno ligno ıoiro d ln base des 4 promiers segmonts; le terminul roussâtre.Californie (Coquillott).

Espèr: bien distincte par sa coloration.

\section{Gorytes recherché. Gorytes eximius, n. sp.}

o -Loug. .33 pce. Noir varié de blanc par, une pubescenco denso et argentée. Lo chaperon, les maudibules, les orbites antéricurs, les joues en arrière des youx, lo bord du prothorux, les

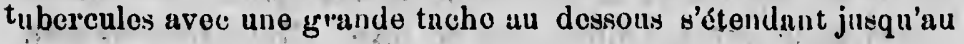
steruum, une tacho de chaque côté un dedans des ailos, l'écusson, les bords supérieu's des flancs du mésothorax avoe uno bande au sommet des segments abdominaux, blanc, a pubescorco argentée. Chaperon large, trunsversal, brillant. Anternes noires, soyeusos-blanchâtros a la base, roussâtres a l'extrémité. Esspaco renfermé dn dos du métathorax poli, avec un profond sillon au milieu, les flanes densément jubescents d'an beall roux uvec los boids supérienr's blancs, les flunes du mésothorax aussi toux d l'excoption des épaules qui sont blunches. Ailes hyalines, sans ancuno tuche, avec lo stigma brun et les norvures noires. Puttes noires mus couvertos d'uin efflorescenco blancho, los cuisses rousses de nême quo lo dedans dos jambes.-Califor ino (Cuquillett).

-1 La plus belle espèce que nnus ayions encore vie.

\section{Gorytes-à-larges ceintures. Gorytes laticinctus,} n. $\mathrm{sp}$.

o-Long. 42 pee. Noir, poli, brillant, la têto avec uno courto pubuscence grisatio. Lo chitporon, les mandibulos, la face, de petilce lignes orbitales n'atteignant pas le verlex, lo scape ex- 
, allongé, suginonts, sut j:tune

33 orbites e mésonio1 dossous: $x$ so rejoiune ligne ussâtro.-

uboscenco orbites anhorax, los ut juequ'au , l'écilsson, uno bande escolico arnes noires, 6. Espalco i sillon au ux avec les ussi roux d alines, sams 1'es. Puttes los cuisses io (Coquile.

\section{eticinctus,}

avec une los, la face, lo scape ex- copté uno tacho noiro d ln baso en dessus, los 4 i 5 articles basiluires des antennes en dessons, le bord du prothorax, une tacho sur los côtés du mésothorax près do l'insertion dos ailes, uno tache sur los écnilles ulaires, 3 ou 4 nutros au dessous sur les flunce, l'écusson, uno tacho sur lo post-écusson, une grando tacho ovale sur les ('ôtés du métathorax, les puttes on partio, avec une ceinturo uu sommot do chaque seginont ubdominal, jaune-citron. Les untennor roussâtros à l'extrémité on dessous. Ailos hyalinos', obscunrcies vor's l'ox́trémité, lo stigma jauno. Esppico triangulaire du métithorax avec un sillon an miliou et des rayons réguliors do chaque côtó. Pattes jauncs, une ligno en dehors des cuissos avec uno tacho à l'extrémité des jambes et la base des hanches, noir. Abdomen uvec une large cointure au. sommet do chaque segment, cellos des deux premier's échancrées au miliẹ, toutes dilatéos sur les côtés.-Vancouvor (Tuylor): :

\section{Gen. Hoplise. Hopli .८s, St-Fargeau.}

Tête comme dans les Gorytes, mais avec la face rétréciè vers le chaperon qui est généralement sub-triangulaire. Les

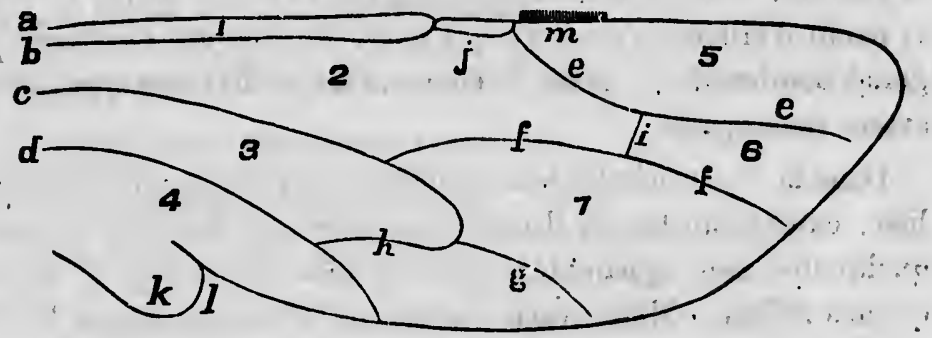

Fig. 37.

Fig. $37-1$, cellule costale; 2 , cellule médiane; 3 , cellule sous-médiane; 4 , cellule anale; 5 , cellule radiale on marginale; 6 , cellule cnbitale ou sous-marginale; 7 , cellule disıoïdale; $a$, nervure costale; $b$, nervure sous-cosiale; $c$, nervure exierno-médiane; $d$, nervure anale; $e$, nervure radiale ou marginale; $f$, nervure cubitale; $g$, nervure lis̄ōdale; $h$, nervure transverso-médiane; $i$, nervure transverso-cubitale j, stigma ; $k$, lobe basilaire; 1 , sinus ; $m$, spiuules. 
antennes sont ausai plus distantes du chnperon. Ailes antá. vioure commo dans les Gorytos; dans les postérieures la cellule sons-mddiane est toujours plus longue que la médiane sur la nervure externo-médiane (Fig. 37).

Ces insectes ont toute l'apparence des Gorytes et ne.s'en diatinguent gnere que par la nervation de lours ailes postérieuree

Trois tapioes rencontrées.

Espace renfermé du dos du métıthorex poli, sans

ponctuations ni stries.................... 3. phaleratus, 638 . Eopace renfermé poli, mais areo stries a la

base

1. ephippiatus, 637. Espace renferme strie longitndinalement...... 2. atricornis, 638.

1. Hoplise a-selle. Hoplısuis ephippiatus, Pack. Gorytes ephippiatus. Pack. Fanne p. 637.

M. Packard n'a pas donné une définition bien distinct: de epéce. Dans sa description il parle de deux grandes taches ovales sur las côtés, du métatinorax, et dans les explications quị la suivent, il dit qu'elle se distingue par l'absence de ces taches. Il parait d’ailleurs n'avoir va que lo $\sigma^{\lambda}$. Nous avons examiné un grand nombre de $\sigma^{\lambda}$ et de $\varsubsetneqq$ et voici les différences que uqus avans remarquées.

Days la ${ }_{2}$ neétathorax en dehors de l'espace renfermé est lisse, excepté au bas où il porte des stries; les deux taches sont quelquefois très apparentes, d'cutres fois très petites et q1:elquefois nulles. Même variété pour ces tacies aussi dans le $\sigma$.

2. Hoplise cornes-noires. Hoplisus atricornis, Pack. Gorytes atricornis, Pnck-Faune, p. 63 .

3. Hoplise caparaçonné. Hoplisüs phaleratus, Say. Garytes phaleratus, Suy-Funno p. 6.38.

Iam. XVIII-CRABRONIDES, p. 639.

Tête génáralement forte, à antennes insérées au deszi,us du milieu de la face. Yeux très souvent antérieurs plutôt que 
latéraux. Prothorax consistant en un simple rebord n'atteiguant pas l'insertion dos ailes autérieures. Abdomen sessile ou pédiculé. Ailes antérieures à une, deux ou trois cellules cubitales complètes.

On fait milintenant de vette famille, telle que carnctérisée ci-dessus, et avec raison, 5 fumilles différentes, qu'on peut distinger comine suit les unes des nutres. Nous ne les considererons ici qua comine des sous-fumilles.

1(4) Ailes antéricures a 3 çellules cubitales complètes;

2(3). Cubitales 2 et 3 rhacuno urec une nervure rícurrevite; abdomon sessile ou subsossile. 1. Philanthides.

3(2) ìre cubitale no recevant pas do norvure récurrente; abilomen pétiolé

2. Mimésides.

4(5) Ailes antéricures avec 2 cubitnles; chaperon ni caléné ni rost.ifor'mo................. 3. Pemphrédonides.

5(4) Ailes antérieures avec uno sculo cellulo cubitale complèto; ycux antéricur's...... 4. Crabronides vraies.

Nous no mutionnons pas les Mellinides qui ne se rencontrent pas duns notre fulune; ces insectes out 3 cubitales dont la lère reçoit une nervure récurrente.

\section{Sous-Fam. I.-PHILANTHIDES, Philanthida.}

Trois genres dans uotre faune.

Denxième collule cubitalo pétiolée;

Youx sub-échancrés; antennes insérées ver: lo miliou de lu ficce, non loin du chaperon, écurtées ontre elles; collulo sous-médiane des ailes postérieures égale on plus longue que la cellule médiane à la nervure extorwo-médiano, sogmont anal ơ non caréné sur les côtés...... ..... Phiranthus, $6+1$.

Yuux ontiers; antenucs insérées au dessus du nilicu de la face, rapprochéos entre cllos ot ristantes du chaperon; cellulo sous-médiane des ailos postérielu's bealucoup plus courte quo la médiano a la nervure externo-médiane; segment nnal ơ caréué sur les côtés..................... Aphilanthops. 
Deuxièmo cellule cubitulo pétioléc.. Cenceris, 643.

Gen. Phisanthus, Fubr. p. 641.

Al1x 3 es|cìces décrites, ajoutez la suivante:

4. Philanthe de Harrington. Philanthus Furvingtonii, n. sp.

Long. 30 pece. Noir arec tache's jaunes, fortement ponctué. Tête un peu plus étroito quo lo thorax; lo chaporon, les côtés do lit fice, lo scitpo des antennes en dessons, une ligno sur lo collier, les tuborcules une tacho on urrière, uno ligne sur l'écusson, los pattes en partio uvec 5 bandes a l'abdomon, jaune. Le front fortonont ponctué, lo thorax i ponctuntions plus fortes mais moins rupprọchées, lo métathorax à 7 ou 8 sillons longitudinanx. Ailos subhyalines avec uno tacho brune on arridre du stigmu couvrunt presque touto la radiale et la 20 cubitale; les nerrures bruiâtres, los stigma roux, los écuillettes testacées. Pattos avec les cuisses noires, plus ou moins rouseâtres en dedans, les jambes jaunes tuchées de noir en dehore, los turses jaunes, bruns d l'extrénité. Abdomon fusiformo, convexe, fortemont ponctus, los 5 promicrs segments uvec une bande juune d lent sommot; cetto bando dilatéc. aux côtés dans les deux premier's, ot plus large au milieu avee une échancrure duns le premier, l'extrémité noire ot fortement ponctuéc.-Otıawa.

Nous dédions avec plaisir cette nouvelle espèce a M. W. H. Harrington, d'Uttawa, qui en a fait la capture.

Gen. Aphilanthops. Aphilanthops, Patt.

Ce genre se sépare des Philantes par les caractères cidessus indiqués.

Une seule espèce runcontrée.

Aphilanthops froid. Aphilanthops frigidus, Sm.; Philanthus frigidus. Sm.-Faune 11, 642 .

Sous-Fam. II.-MIMÉsIDES. Mimeside.

Cette sous-famille ne comprend que les 2 geures $q u_{i}$ suivent. 
Douxièno collule cubitule recovant los 2 récurrentes; la collulo sous-médiano des ailes pos-

- téricures plus longue que la médiuno a la nopvuro sxtoluo-méliaue, stigma potit; époron iutérieur des jumbes postérieures aplnti...........Mrsssa, 647. unt ponctue. los côtés do III lo collier, 'écusson, los Lo front formnis moins inuix. Ailos mu couvinut: os bruiıatres, ac les cuisses ambes jaunos l'extrémité. o.s 5 promicus cotto bando go au miliou hoiro ot fortece d M. W. att aractères cis, Sm. ; Phi-

ida.

Douxidno et troi idme cubitules chacuno avec uno neivuro récurrente; cellule sons-inédiano dos ailes postérieures filus courte que ln médiuno a la norvuro extorno módiano; stigrnn grand, éporons des jambes postérioures semblubles.........Psen, 649.

Gen. Mimesa, Shuck, p. 647.

Aux Irois especes décrites, ajoutez les trois qui suivent :

Les espèces de ce genre sont très difficiles d distinguer les unes des autres; la coloration des autenues et de l'ubilomen n'est pas constante; nous peusous que les scul/itures du métathorux sont des carnctères beaucoup plus surs pour séjarer les espèces les unes des autres.

1(2). Hispace lenfermó du dos du métathoraxd strics tris filles, régulidres, so continuant sur les flunces et divorgeant on arrière du sillon médian qui ost tres profond.................... 4. proxima.

2(1) Espace renformó d stries sub-réguliores, assez fortes ;

3.4) Strios do l'ospaco renfurmó rérulieros a la buso du triangle ot transverses is sa pointo.... 1. paupera, $6 \pm 7$.

4.7) Strios do l'espnco renformé régulières a la baso et irrégulidies dans lo resto, les flancs on dohor's dn trianglo portant aussi des strios qui formont uno ospeco de résenu, surtout vors lo dos ;

5(6) Antennes noiros, pattes noires......... 2. argentifrons, 648.

6.5) Antcínes roussos, pattes roussos; dins los $\sigma^{2}$ anterinos denticulées en clessou4. ..... 3. denticulata, 648.

7(4) Stries do l'espace renfurmé irrégulieres, fortes, les fluncs rugueux, mais saus stries distinctes;

$8(9$, Triungle transvor'sul; très court, d stries régulidres. a la baso, sillon de la face dorsalo treds profond 5. unicincta. 
9;8) Trinnglo assez grand mais a poine distinct, fortoment ruguonx, kans stries ullongées, sillon do

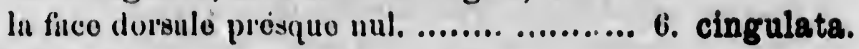

4. Mimèse très-proohe. Mimesa proxima, Cress.Proc. Ent. Soc. l'hil. 1V, 488.

-long. 32 pee. Nuir, avec une pubescenco blanche pou donso ost des ponctuations éparses, la fuco d pubord:oneo mgentíc. Antonios grêlos a la baso, ronfléos on maswio a l'extiómito, cotto mussue masaatio en deasous. Métathoinx a pubesoence blanche, appurente, l'espaco ronferiné du dos transvorso a stries fines ot nombreusos do chaquo côté du sillon médinn, ees stries so continuant sur los fianes on dehors do l'ospace renfurmé. Ailes hynlines, les nervures ot lo stigmn, noir, les nenilles olnires testncées. Pattos noires, pubescentes, los tarisos roussatice. Abdomon uliongé, étrolt, roux uvoc lo promior segment excepté a l'oxtrémitó ot los deux dorniors, noirs. - CupRougo.

Espèce bien distincte par les fines stries do son inćtathorax.

5. Mimèse d-une-seule-ceinture. Mimesa unicincta, Cress.-Proc. Ent. Soc. Phil. IV, 488.

$\sigma^{x}$-Long. 23 pre. Noiro avoc pubescenco blancho pen donse, la fuce ot lo chuporon à pubosconco urgentéo. Antennes noires, s'epnississant au sommet, joussos en dessous. Thorax d ponctuations tres fines et éparses, lo métathorax a espaco ronfermé avec stries régulièes d la baso, les côtés on dehor's étant trìs lugnoux mais sans stries distinctes, la fuce dorsule anssi rugucuse, d sillon médian profond. Ailes hyalines, lo stigmn ot les nervures, noir. Pattes noiren, los 4 jambes nostérioures avoc un unneau roussatro à a baso, les antéricures ontióremont roussâtres, les tarses brun-roussâtrc. Abdomen fusiforme, a pédiculo grêle, do la longueur du premier segment environ, d'un noir brillant avec lo 20 negmont roux oxcepté au sommot qui est brunâtro-CapRougo.

M. Cresson n'a donnó la description que de la $q$, nous croyons ponvoir lui rapporter le $\delta$ décrit ci-dessus qui se reconnait surtout à son unique ceinture de l'abilomen et à la sculpture de son mélathorax. 
6 Mimæse veinturé. Mimesa cingulata; Pack.Pros. Ent. Soc. Phil. VI, 410.

p-Long. .21 peo. Noire, a pnbescenco grivalro particuJièremont apparento sur los flances et lu buso du métathorax; la fice et lo chuperen \& pubencenco argentéo. Antennes noires, roussâtres d l'extrémité. Métathorax à o.pnco ronfurmể non très distinot contenant des stries irrégulidres, grosses et pou nonbreuses, les pritios on dohor's étnit tives ruguouses pa: des stries irrégulideros, In sillon mélian étant presque nul. Ailes hyalinos aroo los nervires noiren, los écaillos aluires testrcées. Puttos noires, les 4 po.tórioures avoc l'uxtrémitó des cuisses et la baso des junbos rotassatres, les jambes anterienres avoc tous les tarsos souseatros, les derniors plus ou moins lavés do brun. Abdomen court, fusiformo, ì pédiculo long ot grêlo, noir, poli, brillant avoo le sormmet du premier sugment et lo deruxièmo excoptó a l'oxt: 6 mite, roux.-CupRuuge.

Se distingue de la précédente et de la paupera par uue forme plus ramassée et particulièrement par la structure de son métathorax.

Sous-Fam. III. PEMPHREDONIDES. Pemphredonido.

Cette sous-fumille, duns notre faune, se borne nux 4 genres qui suivent, qu'on peut distinguer comme suit les uns des autres.

Ailes nntérienres anns 30 collule discoîdule ot n'uyant ainsi qu'une soule réchlurento; abdomen pétiolé .................................. 1. Stramus, 650.

Ailes autórioures a 3 collulos discoídales complètes et 2 récurrontes;

Abdomen distinctement pêtiolé; tête ot thorax plus ou moins poilus;

lère collule cubitalo recevant los 2 récurrentes, la 20 nécurrente quelquefois intersticiale.................... 2. Cemonus, 645.

lère ot 2e cubitalo chacụne avec uno récurrente

1. Pexphredon, 646. 33-Janvler 188. 
Abdomen subsessile ou avec un pedieulo tres court, tête et thorax sans poila, rère et $2 \theta$. oubitales cbacune avee une nervure récurrente....................... 4. Pasmalarous, 661.

\section{Sous-Fam.IV. CRABRORIDES VRAIES.}

\section{Crobronides veros.}

Cette sous-famille, pour notre faune, se renferme dans les six genres qui suivent.

1.2) Yeux échanerés ;abriomen allongé en massue ..... ............................. 1. TrYPoxyLon, 669.

2(1) Ycux entier's; cellulo radiale obtuse et tronquée au sommet ;:

3(10) Cellule cubitale non confluento arec la celInle diseoildale ;

4(5) Abdomen distinctenent pétiolé, co pétiolene lerminant par une esperso de nooud 2. Rhopalda, 668.

5(4) Abdomen sessile on subsossile, le ler segment ne se tor minant pas en noud;

G(9) Cellule radiale torminée par un appendice se convbant en dedans; ubdomin sessilo;

$7(8)$ : 9 arec lo dernier sogment abdominal terminé en mucron, $\sigma^{\lambda}$ aree les antennes et les jambes simples ...................... 3. Crasto, 65\%.

$8(7)$ o a dernier segment abdominal large, apluti, triangulaire, ses côtés droits, non relevés; ơ avce les articles du milieu des antennes dilatés ct les jambes antérieures armées d'un appendice dilaté en folme de coquille .................... 4. THYreopos, 662-

in

$$
\operatorname{ar}
$$

$$
\text { op }
$$

$$
\text { les }
$$

$$
\text { t1": }
$$

$$
\text { ba }
$$$$
\text { br }
$$

$$
\mathrm{mi}
$$

lig 
Gen. Trypoxylon, Latr. p. 669.

A l'espëce décrite, ajoutez la suivante.

Trypoxylon strié. Trypoxylon striatum, $\mathrm{n}$. sp.

\&-Long. .58 pce. Entidrement nos. a l'excepticn des tarses postéricur's qui sont blancs excepté a la baso du premior article. I a face d partir des antennes a pubescence argentée, opaque ot charrinéc au dessis avec puboscence pâle peu abondante, plus apparente sur le métathorax, lequel présente une légère dépression longitudinale str' son disque avec fines stries transversales. Ailes rasublement enfumées, plus clai:"es a la base et au sommet, les inféricures subhyalines. Abromen poli, brillant, à pédieule assez long, s'épuississant continuement du tiors de sa base au sommet, le 2 e segment plus étroit que lo premier a la baso, plus large au sommet, tous deux sans trace de ligne impressionnée sur le dos,-Ottawa (Guignard).

Diffère du politus, Say, par sa plus petite taille, sa face argentée, et l'absence de ligne impressionnée sur les'segments abdominaux 1 et 2 .

Gen, Crabio, Fabr. p. 652.

Aux 15 espèces décrites, ajoutez les 7 qui suivent. Clef pour la distinetion des espèces.

\section{FEMELLES.}

I(14) Abulomen resserré anx sutures, ponctué plus ou moins fortement;

213) 1er segment ubdominal avee taches plus ou moins grandos;

3(12) Stape des antennes jurne, du moins en dessous ;

4(11) Sregments 1 ot 5 avec taches tiansverses bien distinctes;

5(10) Abdomen ponctué rugueux;

6( 9 ) Thorax plus ou moins taché de jaune;

7 ( 8 ) Tontes les fascies interrompucs,droites 1. interruptus, li53

8(7) Fascies des seginonts + et 5 non intorrompuos, colles du lor segmont obliques.... 16. chrysargyrus. 
9(6) Thorax entièroment noir a part los tubercules...................... 17. producticollis.

10, 5 ) Abdomen a ponetuations très fines, lisse, . poli; thorax ì ponctuations allongées en stries

11(4) Segment 1 et 5 avee un point seulement do chaque côté; têto un peu rétrécie postérieurement ......................... 2. 4-punctatus, 654 .

12 ( 3 ) Scrape des antennes avec tout le thorax, nuir; Abdomen avec six paires do taches sur les côtés des segments ................. 19. atrifrons.

13(2) Segments 1 et 3 sans taches, 2, 4 et 5 evec fascies interrompues. 3. stirpicola, 655.

14(1) Abdomen non resserré aux sutures, si ponctué, très finement, non rngueux ;

15 (20) 1er seginent plus ou moins taché do jaune; 16(19) Uno on denx bandes contitiues aux segments postéricur's :

17 (18) Une tacho en arriere des tubereules. 6. villosifrons, 656. 18(17) Flanes sans autres taches quo los tubercules.

7. rufifemur, 657 .

19(16) Tontes les fuscies interrompuos au miliou, celles du segrment bsısila:re réduites a un point; une double tacho sur l'écusson. 9. singularis, 658.

20(15) 1er seymont sans taches;

21(28) Une ou deux bandes continues al l'extrémité do l'abdomon ;

22(27) Jumbes prostérieures juunes torminées de noir ;

23 (26) Thorax plus oı moins taché de jaune ;

24(25) Métanotum rugueux, a stries fortes, distinctes, à sillon médian bion distinct. 12. effossus, 660 .

25(24) Métanotum a strics fines, a poincs distinctes. ........................... 8. nigrifrons, 657.

26(23) Thorax sins altres tachos quo los tuborcules 13. aciculatus, 661 . 
cticollis.

bellus.

tus, 654 .

frons.

cola, 655 .

ifrons, 656 .

emur, 657.

alaris, 658.

fossus, 660 .

ifrons, 657.

ulatus, 661.

$2 i(22)$ Jambes postérieures rousses torminées de noir.; bande du 5e segment sub-interrompuo ..................................... 14. cubiceps, $6 \mathrm{hl}$

28(21) Abdomon avec toutes les tachos distinctes, bion quo parfois contiguës sur les segmonts terminaux ;

29 30) Troisieme segment sans taches... 4. 6-maculosus, 655

30(29) Troisième segment avec taches ;

31(34) Taches du 30 segment bien plus potites que les autres;

32(33) Taches allongées on bandes transversalea, mandibules tachées de jaine ..... 5. 3-fasciatus, 656

33(32) Taches réduites à des gros points sur los

- côtés des segments; mandibules noires. 10. pauper, 659

34(31) Taches du 30 segrment égales anx antres;

35(36) Chaporon doré, mótathorax pubescent 11. obscurus, 659.

36(35) Chàperon argonté, métathorax sans pubescence; : - "

37(38) Taches du 5e.segment contiguös

20. montanus.

38(37) Tachos du 5e segment séparées; abdomen plus court, plus ovalaire

15. denticulatus, 662.

\section{MALES.}

1(14) Abdomon resserré allx sutures ot plus ou moins fortement ponctué ;

2(13) ler segment plus ou moins taché de jaune;

3(10) Tuches du ler segment grandes, apparentes ;

$4(7)$ Thoi'ax plus ou moins tachó à part les tubercules;

5(6) Tête en carré vuo en dossus, thorax largo et court, prothòrax tache ............... 1. interruptus, 653.

6.5 ) Tête rétrécio en arrière des youx, thorax étroit et allongé ; taillo plus petite, prothorax non ou à peine taché aux angles. 19. atrifrons.

7 (4) Thorax suns autres tachos que les tubercules; tête fortoment rétrécio en aryièro des yeux;

8(9) Taches du lor segment sub-contiguës, fortement sinuées; abdomen allongé............ 18. bellus. 
9( 8 ) Tarhes du ler segment droites, d peine sisucen, abdomen court, largement ovalaire.

17. producticollis

10 (3) Taches du ler segmont trids petites, souvent réduites d un point;

11 (12) Segments 4 et 5 uvec uno bande continue............................... 16 chr ysErgyrus.

12(11) Segments 4 et 5 avec un point soulement, 4 arec taches séparécs............. 2, 4-punctatus, 654.

13(2) Sogments I ct 3 sans talches.......... 3. stirpicola, 655.

14(1) Abdomen non resserms aux sutures, lisso ou trids finement ponotur, non rugueux;

15.22) 1er segmont plus on moins tuché de juune;

16(19) Tête fortement rétrécie en arrière des yeux ;

17 (18) 1or' segment jesserj'é au sommot, à la suture............................. 6. villosifrons, 656 .

1S,17) 1 or segment non resserré au sommet. 7. ruffemur, 6577. 19(16) Tête non ou à peine rétrécie en arrièro;

(20(21) Tuches du ler segment rédnites à un point, celles du 5 e plus petites quo les autres. 14. cubiceps, 661 .

21 (20) Taches du ler segment de grandeur ordinaire; métanotum pubcscent, opaque, a striés peu distinctes ................ 8. nigrifrons, 657

22(15) lor segrnent sans taches;

23(2t) 30 segment suns taches. 4, 6-maculatus, 655 .

24(ะ3) 3e segment plus ou moins taché;

2i) 28 ,Tuchos du 3e segment plus potites que les aítres;

26(27) Tête fortement rétrécie en arrièré; prothorax tachs

20. montanus.

27(26) Tête à peiné rétrécie en aruière; prothorax sans taches. 3. fasciatus.

28(25) Taches du 3e segrmont égales aux autres;

$29(30$, Tête fortement rétrécie en arrière des

yeux.................................. 9. 9ingularis, 65 .

30, 29, Tête non ou d peino rútrécie en arrièro;

31.36) Thorax plus ou moins taché; 
32(333) Toutos les taches largement séparées au milieu ; métanolum à stries longitudinales irrégulièros 10. pauper, 659.

33(32) Taches contiguë.s à l'extriłmité de l'abelomen ;

34(35) Tubercules ocellés, les écussons tachés. 12. effossus, 660.

35(34) Tubercules non ucellés, lo post-écusson selllement.taché........................ 11. obscurus, 659.

36(31) Thorax sans taches a part les tubercules; 37(38) Antennes avec 4 dents on dessous, 15. denticulatus,662 38(37) Antennes simples, vans dents... ..... 13. aciculatus, 661 .

16. Crabron argenté-doré. Crạbio chrysargyrus, St. Farg. - Proc. Ent. Soc. Phil. VI, 82.

Crcebro arcuatus, 'Say.

$\sigma^{7}$-Lòng. .46 pce. 'Noir, finoment ponctué, lo chaperon avec les orbites antéricurs a pubescence argentée, le fiont au dessus des youx à pubescence durée sous un certain jour; la tête nne en dessus, presque on carré, tr'es pen rétrécie postérieure. ment. Antennes à seapo jauno avec une ligno noire en dessus, le 20 article du pavillon ties long et aplati en dessous, le 50 avec une dent ou renflement en dessors. Une bande interrompue sur le prothorax, les tubercules (quelquefois une tache en arrière de ceux-ci) uvec une ligne sur lo post-écusson, jaune. Métathorax à stries régulières et fortes dans l'espace ronformé, la faco postérieure à stries très fines et trarısverses de chaque côté du sillon médian. Ailes légc̀rement enfumées, le stigna jauno. lıes cuisses antérieures jaunes, noires à la biso aveo uno grosse. dent en dossous, les 4 postérieures noires avec le sommet jaune, toutes les jambes et les tarses jaunes, les derniers brunâtres à l'extrémité . Abdomen finement ponctué, mais à sutures distinctes, les sogmonts élant convexus, les 3 promiors segmenty avec une tache jaurie de chaque côté, 4 et 5 avec une bande continue, le Ge souvent aussi avec uno petito tache de chaque côté. Les tachos des 3 segments basilaires sont largement séparées, celles du $10 r^{\circ}$ souvent dilatéos on dedans.

q-Differe on ayant lo front plus distinctement doré, do même que le chaperon. Les antennes sont dentées vor's l'uxtré- 
mité. Los flancs portent une tache en arriere des tubercriles. Licxtrémité de l'abiomon est poiluo.-CapRougo.

Espèce bien distincte par les sutures des segments ubdominaux enfoncées quoique la surface soit finement ponctuée.

17. Crabron a-cou-allongé. Crabro producticollis, Pack._Proc. Ent. Soc. Phil: VI, 76.

$0^{x}$-I Iong. .32 pee. Tête passablement rétrécie postórieuroment; chaperon noir a pubescence argentée, front fortement ponetue. Antennes di seape juuno on riessous, avec une ligne noire en dessus, le pavillon brun, sub-fusiforme, darticles larges et aplatis en dessons où il est d'un testacé ronskâtre. Thor'ux fortement ponctué, sans autres taches que los tubercules, le metuhorax fortement rugueux, à fossulettes re so deśsinant pas en stries régulières, à sillon médian distinct, mais sans espace renfermé bien détermiré. Cuisses antérieures juunes avos uno tacho noire en dessus, renflées ot paraiszant comme sinuées, los postérieures noires terminées de jaune, les jambes jaunes, les 4 postérienres avec une ligne noire en dedans, les tarses bruıatres a l'extrémite. Abdomen court, ovalaire, convere, finemont et densément ponç tué, à sutures enfoncées, les 4 segments basilaires ivec chacun uno paire de taches allongés, droites, lés "5ê et ce avec une bande continuc, celle du 5e plus laige-Ste-Gertride.

Nous pensons bien que nos spécimens appartiennent a cette espèce, bien qu'ils diffèrent un peu de la description de M. Packard. Les nôtres rẹ'ont que 4 paires de taches à l'abdomen et M. Packard leur en donne 5, la taille des nôtres est aussi plus petite. Aucune femelle rencontrée. .

\section{Crabron gentil. Crabro bellus, Cress.}

-Proc. Ent. Soc. Phil, IV, 481.

o-Long. 40 pce: Tête en carré, vertex fortemont ponc. tué, lo chaperon à pubescunce argentée. Antennes noires, le scape jaune avec mue tacho noire en dessur, le pavillon noir, filiforme, non renflé en massue. Thorax noir, opaque a ponetnations tournant on stries longitudinales sur lo mésothorax et l'ecusson, lo métnthorax rug̃ueux êt coinme rélicialé, sanıs éspace renfur'né distinct. Une bando intorrompuo sur lo prothorux 
avec los tubcreules, jaune; l's écailles alaires roussâtreș. Ailes légdiemont obscurreies do jaunatre, lo stigina jauno. Pattos ncirč, l'extı êmo nommet des cuinsor, les jambes avoc la base des tarses, jnunc, juı bes aveé uno ligño' noiro on dedans, l'extrémité des tarses brune. Ablomon sub-sessilo, finoment ponctue, poli, billant, d sutures enfoncées quoique les segments so:ent pou convexes, les 5 promiors segments arec uno tacho inédiane de chique côté, ccilks du sogmont basilairo plus potites, lo segment teriniiial a poils jaunatros, son extrémité d bords relovés en gouttièro.-Car, Rrougo.'

$0^{x}-$ Encore inconn!.

19. Crabron front-noir. Crabro atrifrons, Cress. -Proc. Ent. Soc. Phil. IV, 484.

o-Long. 28 peo. Noir, opaque, à ponctuations profondes et denses. Tàto en carré, légèreniont rétrécio on arrièro, a peine plus large que le thorax, le chaporon à pubescence argontéo, les mandibulos noiros," "foruginéusos "à l'éxtrémité." Antennes simples, d'scapo jaine avec une ligne noiro' on dessus, le pavillon roussâtre on dessous. Thorax allonge, 'etroit, fortement ponctué, sans autres taches que les taberenles ocollés d'un point et une tache pen prononcéé suir lés angles du jirothornx (quelquefois une petite ligne sur' lo post-écusson); 'inśtuthorax grossidremont réticulk, avec stries longitudinales sur les flancs. Ailes subhyalines, dinorvures brunes." Pattes "noires, brillantes, le sommet des 4 culsegs antérieures, toutes los jambes excepté on désiono, ét les tairsos excepté a l'oxtrémité, jauno. A bdomen subsessile, on, ovale allongé, convexe, fortement ponctué, les sutures profondément enfoncées, chiquio segment avec une fascie médiane jaune interrompue air milieu excepté sur le $6 \theta$ où clle formo üne ligne continuo.-Cap Rouge.

Differe du producticollis par son 5 e segment dont les taches sont séparés et la convexité des segments moins prononcée, et de l'interruptis par une plus petite taille, son thorax plus court et plus large, etc.

20. Crabron des-montagnes. Crabro montanus, Cress.

-Proc. Ent. Soc. Phil.1V; 481.

emont ponees noires, le on noir, filia ponctuahor'ax et l'esains espaco o prothorux 
क-Long. .32 pre. Noil', epaque, finement et densément poncitué; tête en carré; lo chnpor on et les or'bites d pubescenco argonté, mandibules avec une tucho juune au milion. Senpe dos untennes jaune, lo pavillon noir, légèrement plus épois vors l'ex. trémité; les joues légèrement argentées. Thorux plus fortenert ponictué quo la tête, deux taches sur le prothorux, los tubercules, avec un point do chuque côté sul lo post-écusson, blanc; métathorax a stries grosses ot régulieres, la fuco postérieure présentant deux plaques polies, brillantes, séparéos pur an sillon profond. Ailes d peino obscurcies, a nervures brunes. Puttes nuires, los 4 jambes antérienres avec uno ligno jatne cxtérieure, les postérieures jaunes avec les extrémilés noires, tur'ses brurıs. Abdr,inen subso: sile, ovule, poli, brillant, lo $1 \mathrm{er}$ segment sars tarhes, quelquefois avoc un point Wlane de chaque côté, les segments 2 , 3,4 et 5 avec uno finscie transverse de chaque côté, lurgement séparées au milieu, dans lo be segment contig!ı̈̈s, celles du 20 plus larges et légèrement obliques.-CapRougo.

Diffère d" denticulatus par sun abdomen plus sessile, les taches de son 5e segment contiguẹs eț.

Gen, TuYreopus, St-Farg. p. 662.

Aux 5 espéces décrites, ajoutez les 4 qui suivent: '

\section{FEMELLES.}

1(8) Une ou 2 bandes continues à l'extrémité de l'abdomon;

2(3) Chaperon noir, tuillo forte 1. monticola, 663

2(2) Chuporon jaune;

4( 7 ) Chaperon entièroment juune;

5,6 Jarnbes tachées cle noir on dedans...... 5. pagasus, 665.

6(5) Jambos entièrement jaunos

6. advena.

7 (4) S'ape noir, jaune d l'extrémité... .......2. sinuatus, 664.

8 (1) Tuutes les taches do l'abdomen séparées;

9(10) Al dımen polletué-1ugucux... 3. rugoso-punctatus, 664. 10(9). Abdomen lisse, non rugueux............ 7 tenuiglossus.

MALES.

1) 8) Jambes antéricures avèe un appondico foliacé;

2(7) Thorax noir, sans aucune tuche; 
3.4) Srapo dos antonnes ortidremont juuno

8. argus.

4 (ii) Sunpo noir en dessun, juuno on dossous ;

6(6) ¿ibdomon a 6 "pai c." do tuchos tontes sé.

paréos

4. latipes, 665 .

6. 6) Abdomen a 3 paires de tachos sépuréos ot 3 bandes continues

9. elongatus, n. sp.

7 (2) Thorux taché do juuno ................ 5. pegasus, 66.

8( 1) Jambes untérioures simples, sans appendico. 6. advenus.

6. Thyréope étranger. Thyreopus advenus, Srnith.Crabro advena, Smi h. - Brit. Mus. Cut. IV, 421.

\$-Long. .40 pee. Noir, donsément ponetué, a puboscence blanchâtro; le chuporon, nno tacho a la bniso dos inandibules, lo scapo des antennes, uno bande sur le prothorax interrompue an milion, les tubercules, nvec une tache on demi lnuo sur l'écusson, jaune pâlo. 'Lo métathor'ax court, sans ospacts renformé bien distinct, fortement rugueux par les sț̣ies irrégulières et grossos, les flancs nus, brillant. Ecailles alaires ferrugineuses. Ailos légèrenont ot uniformément obscurcies, les nervures et le stigma brunatres. Pattes noires, los jumbes jaunes aveo une tnche noire en dedạıs vor's l'extıémité, tarses birunâtres, jaunes a la base. Ablomen avec uno bunde interrompue sur les 5 promiors segmonts ot uno cointuro continuo sur las 2 sinivants, janne, les taches du ler segginent plus rapplochéor que les autres et ondulées de chaque cô:é; le segment terminal en trianglo allongé, obtus a l'oxtrómité et longitudinaloment rugueux, à puboscenco roussâti'e.

$\sigma^{\pi}$ C'haporon noir, lo pavillon des antennes roux on dessous, avec les articlos $2,3,4$ ot 5 dentés on dessous, les pon :tuntion du métuthurax allongées on strios. Les pattes avec plus de jaune que dans la ; ; tous les segments abdominaux avee uno bande juune, intorrompue dans los 4 promiors. Los jambes antéricures sans. appendico foliacé.

Nous sommes surpris que M. Packard, après avoir donné la plaqué triangulaire plane de l'extrémité ile l'abdomen 우 coinme caractéristique du genre, ait encore rangé cette espèce de même que la tenuiglossus, parmi les Crabro. 


\section{Thyréope langue-grêle. Thyrcopus tenuiglossus, Pack. \\ Crabro tenuiglossa, Pack. - Pı'oc. En, · c. Phil. VI, 98.}

\%-Long. .32 pce. Noir, opnque, :. finoment ponctux. Têto ussez courto, on carré, lo chaperon nuir uvec pubeśconce urźontéo de mêmo que sur la baso des joilos et les corbites anté. jieurs. Stapo des antonies jaune, to pavillon no:s. Uno bando sur lo prothorax intorroin puo au miliou et échancere do chaquo côté, los tube:"cules avec uno ligno sur lo post-écusson, juuno; I es écrilles aluires furruginouses. Licep tco renformé du mésono. tum avec uno fossetto ovilo an milien, polie, brillunte, ot 3 grosses stries do chaquo côté, lo méiathornx en dehor's a stries treds fines ot obliques. Ailes légèremont obscureies, lo stigmin brunâtre. Toutes los enisses noires, jannes nu sommet, les antérionres plus que les antres, les jambes juunes avoe uno tacho noiro au sommot on dednus, los turses bruun̂ires Abdomon on oralo allonge, le premier soument ro-sorré a sa suture uvce lo 20 seginent, suns tachos, les 4 suivants uvec une tache do ehaque côté, lurgement séparćes au miliou, celles du 50 petitos ot obliques, co 5e sogment furtemont puboscent termine en triangle allongé, obcus a l'extrémits, a pubesconee doree et a ponctuations allongéos on stries. Langue a purtie médinne grêle ot fortemont prolongéo au dola des partios latérulos. Mâlo inconnu.-Ottuwa (Guignard).

Espice bien remarquable par son 5e segment plus fortement pubescent que d'ordinaire. Lè premier seguient porte quelquefois une petite tache en forme de gros point de 'chaque côté.

\section{Thyréope argus. Thyreopus ar:gus,-Harr.}

-Proc. Ent. Soc. Phil. VI, 359.

$0^{x}$-Long. .40 pce. Tête courto, se retrécissant immélintemont on arrietio des youx; lo chaporon, los mandibulos, nvec lo scape des antennes, jaune, lo chaporon ot los orbitos a jubesconco argontée. Antennes a scapo légèroment dilaté, lo pavillon fusiforme, a urticlos du milicu ronflés ot dilatés on dents en dossous, les 3 terminnux courts ot cylindriques. . Thorax noir; sans 
nucuno tache, finoment ponetué. Mésonotum derpace renformé distinct, brillant, portant quelques grosses stries d côte d'un willou médiun, la fuco postérioure juguouso ot commo alvéoléo. Ecraillos brun-fonce; ailos légdrement obscurcies, cluires a "la base, los nervures brunes. Pattes antérioures a trochantores ullongés, noirw, juunos un sommot, sans épine torminule; cuisses longuos, dilatées particulieroinent on arvidre on uno longue expunsinus so torminant par un long orochot grelo et uno epino qui lui est opposéo, juunes nvoc taches noires; los jambes avoe une expansion semi-cordifume et concavo-convexe, la moitiś extérieuro stant droito par co que son bord se replio on dodans, tandis que le côlé intériour est convoxo, suitout a la base et légeloment sinue, cet uppondice junue d la buse et noir dans le resto, parsomé de points transpments so rungéunt on lignes plus ou moins ré. gulières; turses d articles lurgos et courts. Pattes intormédiuiros juunes, los postéricures avóc los cuisses noires excopté d l'extrénité ot lours janbor junnes tachéos de noir on deduns ot on dehors, les turses noirs, jaines d la biso. Abdomon ullónge, cylindrique, avec uno bando jauno an sommet des 5 segmonts basiluires, cotte bando lurgo sur lo lor segment et interrompuo sur les 20 ot 30 ; lo 60 segrment.tres pubescont, le torminal noir, ponctú, suns épines: --CapRongo.

Fenelle inconnue. Espèce bien distincto par la coloration de son appendice tibial.

\section{Thyréope allongé. Thyreopus elongatus, n. sp.}

¿-Long. .45 pce. Noir, opaque, finement ponctus.' Tête on carré transvorkal, ti'es courto en arrière des youx et brusquemont rétrécie, avoc poils blanchâtıeis sur lo vertex; le chaporon; les mandibuiles oxcopté d l'éxtrémité, lo scupe des antenues, blaric ou juuno pâle. Scapo dos antentios fortoment dilaté au sommet, blanc uvec une bande noire en déssus, sinuée intérieure. ment près du sommet, le pavillon tout noir, fusiforme, les rirticles du milión courts, 'largos, aplatis on dossous, diminuant graduollement vers l'dxtrémité. "Thoráx sans aucune täho ; métáthorax rugucux pär des strics irrégulières. Ailos légèrement et uniforméinont obscurcies. Pattes antérieures avec les tiouhanter's blancs, noirs a lu baso et portant une épine au sommet, les

mméliate3s, invec lo s d jubeso pavillon its en dos. noir; sans 
cuirses dilatéon, blanchen, noires au sommot, les jumbes blanches on dossus, munies d'un grand appondice foliace on fistmo do bouclior, d bor'd postoriour simué et-8o torminant on pointo aignä, noir a la baso, blanchatro vers l'oxtrémité uvou 3 bancles longitudinales brunce, la bane au cóté extériour porto 3 fines lignes blunches travorsos. Les 4 pattes postérieures juuno-pale, lours cuissos aveo une ligne noire on dosens ot en dersolls; les postéricures avoe lours tarsen juunes, biunaties d l'oxtémitó. Abdoinon nllonge, poli, brillunt, noir avee une bunde jauno-palo sur ehmpue sogment, sur lo segment basiluiro cotto bundo est interrompuo et sinuéo de chnque cốté, plus large sur le 20 ot interrompue de meme quesur lo 3o; le segment torminal arrondi aveo uno longuo épine blanche de chuque côté et uno autre plus potite ontre colles-ci; la bunde dn 20 segrment s'inclino on avant sur los côtés et fait pluce duns l'angle dil sommet ane potito tacho triangulaire tout preds de la marge; lo 30 segment pinte on dessous un point de chaque côté press do son sominet.-CupRonge.

Femelle encore inconnue. Espece bien reconnaissable par sa coloration.

Gen. Bëpharipus, St-Fargeau, p. 666.

Aux 4 espèces décrites, njoutez la suivante.

Blépharipe cornes-noires. Blepharipus nigricornis, n. sp.

万-Long. .25 pce. Noir, poli, brillant, sans aucune tache. Tête on curré, épaisso on arrière des yeux, le chnperon d pubesconce argentéo. Lo mésothorax avec un potit sillon nu milivu on avant; to métathorax poli, brillunt, avec. un sillon módian, sans espace renfermé distinct. Ailes légèronout obscurcies, avec les nervures noires, los écrilies alaires noires. Pattes noires, les 4 chisses antéricures avec lours jambes, ronsses avec une ligno noire en dessus, les jumbes postérieures noires uvec un potit an. neau pâle prìs do la base et une tucho roussâtre en dedans, lours éporons roussatres. Aldomon fusiforme ot distinctument resserré aux sutures, quoique les segrments no soient que médiocremont convexes.- CapRougo.

Aucune + rencontrée. Se reconnait facilement par les sutures enfoncées de son abdomen. 
blanchos fin'me do nto aigü̈, - longituies lignes âle, loin's les posteAbuloinon ur ohim!to terrompiro rompue do unolongtuo stilo ontio ur los cótés 10 triangudessous un rable par sa igricornis, acune tache. pon d pubesn au miliuu llon mídian, curcies, avec s noires, les oc uno ligno un potit an. lodans, lours ctumont resue médiocieneut par les
Fam. XXXI - $\triangle$ NDR DNIDJS, p. 686.

Des 19 geures mentionnós, retranchez Gnatocerus qui n'est qu'une variétó de Mégachilo, et ajontez les 7 genres qui suivent.

\section{Clef pour la distinction des genres.}

1(34) Pourvus d'instruinonts pour la róolto du pollen ;

2(23) Brosec aix patten, lo lor aiticlo dos tarsos postorieurs souvent diluto en palette;

y 16) Trois collules cubitulos aux ailes antórioures;

4(5) 1ere cellule discoùtinlo beancoup plu, longue longuo que la radialo;

quo In radialo...................... 1. Antrophors, 869.

B 4 ) 1ero dincoidnlo plus contro ou d pcino plus longue quo la radialo;

6( 7 ) Stigma court, peu dóveloppó; palpes muxillaires a 4 articlos ................... 2. Melissodes, 691.

7(6) Stigma bion dóvoloppé, lancéole;

8 (9) 20 norviuro récuirento écartío du bas ver's l'oxtrémité do l'nile 11. Colnetes.

9 ; 8 ) 20 récurrento d peu près droito ou inclinéo veres la base de l'ailu;

10(11) Norvure basilaire do la lern discoülale droito ou légdrument oourbéo; côtés de la faco creusés on sillons piès des youx, fuce б" souvent d iongue pubescence....... 4. Andrina, 694.

$11(1 \theta)$ Nurvuru basiluire de la lère discoidalo obtu sémont courbée ou arrondie postérieurement;

12(13) Corps d̀ coulour's généralement non métalliques; chaperon $\delta^{x}$ allongé, jumais d longue pubescence, + avoo un espace nu linéaire d l'extrémité de l'abdoinen pour lo jeu do l'aiguillon ........................ 5. Hazrotus, 697.

13(12) Corps, du moiıs la tête ot le thorax, d oouleurs métulliques brillantes; youx échancrés;

1 (15) 1̇̀'o récurirente l'eq̣ite d l'oxtrême base de la 30 cubitule ou intersticiale avec la 20 nepvure transverse, corps entièrement métal-. lique, blcu ou vert ................. 8. Augoonlona, 705. 
15(14) 1dere récurrento requo par la 20 cubitale, au milieu ou peu au dela; chaperon " $\partial$ " allongé et proéminent; la tête et le thmax

$\therefore$ soulement à coulear métalliques.. 6. AgApostison, 703.

16(3) Doux cellules cubitules;

17(18) Antennes $\sigma^{7}$ bien plus longues que dans la o ; corps, du moins le thorax, a puboscence épaisse; "e cubitalo égale ou un pou plus longue que la 1ere; palpos máxillaire de 6 articles ................................. 3. Euonra, 693.

18(17) Antonnes a pey près égales dans les doux sexen, ou médiociemont plus longues dans les $\sigma^{x}$;

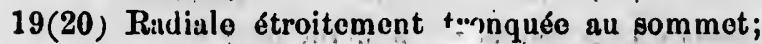
langue longue, gielc, plumeuse au sommot; lor article des palpes; labiaux plus long que les 3 suivants réunis. 20. Caturopsis.

20:19) Rindiale lancéolée;

21(24) Labie ordinaịre, non très allongé ;

22(23) Face finementt pubescente ; jambes postérieures o a biosse épaisse, cuisses postérieures $\sigma^{7}$ courtes et renflées, langue courte, triangulaiıcc, miticles des pailpes sub-égnux. 21. Macıoprs.

23(23) Face densément pubescento; jambess pustérieures $q$ \& brosse légère, cuisses postéricures ơ giêles, non renflées; lei áticiclo des palpes labiaux aussi long quẹ les 3 suivants réunis, languo longuo et grêle.. 7. Paxuraus, 704.

24(21) Chaperon très allongé; abdomen uon rétréci à la base. 22. Chelynia, n. gen.

25'2 ) Brosse sous lo ventre;

26.27) Stigma lancéolé, très dévoloppé; tête fortemont prólongée en arrière des yeux. 12. Heriades, 716.

27(26) Stigina couit, peu dévoloppé;

28(29) Crochuts des tarses sans pilotte, le 1er article des postéricurs plus ou moins dilaté et souvent appendiculé dans les $\delta$.'10. MEGachiLe, 709.

29(28) Crochets des tarses avec pelotte; 
30(31) Antennes somblables dans les 2 soxes, abdomen court, sub-ylobulenx............... 9. Osmi, 706.

iMON, 703.

OKRA, 693.

33(32) Pavilion des antennos ot a articles compitmés, sub-moniliformes, atténués d liextiémité et le dernier terminé par une épine courbe ............................... 24. A Á.

34 (1) Dépourvous d'instruments pour la jécoltó du poilón ;

35(38) 1ère cellule discoïdale beaucoup plys longue qưo la i adiale;

36(37) Ecusson arec une dent plus, on moins distincto de cbăquo côté; abdomen a pubes. cence écaillonse; palpes maxillaires d'un

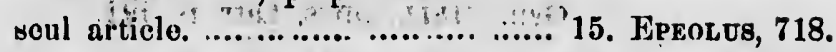

37(36) Ecusson inel'me, mais partagé en 2 lobes. 16. NoMada, 720.

38(35) 1ère cellule disccidale pas plus longue que la radiale ;

39(42) Stigma laneróolé, bien dévelopipé;

40(4l) Radiälo' lancéoléo, non séparéo de la côtẹ

Machopts.

17. SPHECodeg, 723.

41 (40) Radiale arrondie d l'extrémité, séparée de lu côte................................... 14. Ci.ratina, 717.

42(39) Stigma court, peu développé ;

43(44) Yeux poilis; abdomen o conique, or tpineux d l'extrémité .......................... 18. Cost Ioxxs, 724.

44(43) Yeux glabre.;

45(46) Radialo à pointéappendiculée et séparée de lil cơte ...................................... 25. - STELIs.

46(46) Radiale d pointe hon appendiculée ni sépuréo de la côto ........................ 19. Prosopis, 726.

Gen. Anthophora, Latr. p. 689.

Aux deux espèces: décrites, ajoutez la suivante.

31 Anthophore sub-globuleuse. Anthophora \&ubylobulosa, n."sp. 
8-Long. .35 pce. Noire avec pubescence blanche, entrcmêlée de poils noir's sur le vertex et sur le mésothorax. Chaperon et labre jaunes avec poils blancs, le premier bordé d'une ligne woire en avant; les mandibules entièrement noires: Antennes courtes, noires. Thorax tout couvert de poils blancs assez denses, plus longs sur les flance. Ailos súb-hysilines, les nervures brunes. Pattes noiles aveo longue pubesceince blanche, les articles terminaux des tarses roux-forrugineux: Abdomen court, convexe, sub-globuleux, très finement ponctué, le lel seg. ment avec longs poils épars, tous les autres avec une frange denso de poils blancs, lo 20 segment en portant un double rang, l'un a son sommet ot l'autre ver's son miliou, lo sogment unal avec uno échancrure anguleuse au sommet, formant une pointo de chaque côté. Fomelle inconnue.-CapRouge.

Bien distincte des 2 précédentes par sa plus petite taille, son abdomen couvexe, et surtout les franges de sou abdomen.

Gen. Melissodes, Latr. p. 591.

A l'espèce décrite, ajoutez les 8 qui suivent.

$1(4)$ Pubeseenco fuuvo;

2(3) Segmonts terminuux de l'ubdomen $\sigma^{x}$ épineux .................................. 2. dentiventris.

$3(2)$ Segments terminaux de l'abdomen $\sigma^{7}$ non épineux

3. obliqua.

4(9) Pubescence jaune-pâle, mais non blanche;

5; 8 ) Les 4 pattes antérieures noires;

6(7) Extrémilé de l'abdomen noire; taille plus forte......................................... 4. nigripes.

7 (6) Extrémité de l'abdomen à pjils brun-rous: sâtres, taille plus petite............... 1. desponsa, 692.

8(5) Les 4 pattes antérieures ì poils rouseâtres. ; abdomen $\&$ convexe, attenué brusquement 5. festonata, n. sp.

9(4) Pubescence blanche;

10(13) Les 4 pattes antérieures noires;

11(12) Abdomen atténué en pointe \l'extrémité...... 6. rustica. 12(11) Abdomen arrondi d l'oxtrémitś .................. 7. senilis. 


\section{2. íǴlissodo à ventre-denté. Melissodes dentiven-} tris, Smith:

-Brit. Mıs. Cat. Ir, 312.

$\sigma^{7}$-Long. .38 pce. Noire arec pubescence fauve, dense sur lo thornx, dense et longue sur la face muis de couleur blanchâtre. Le chaperon et le labre jaunes, les mandibules tachées de jaune rers l'extrémité: Antennes longues, plus longues que le thorax, lo pavillon roux on dessous a l'exception du ler article, noires en dessus. Ailes hyalines, les nervures brures. Pattes noires, a pubescence fuuve, plus longue et blanchâtre sur les trochanteris, lo dernier article des tarses roux-ferrugineux. Abdomon en ovale, as:ez couvexe, le premicr segment d poils faures épars, tor is antres avec une frange de poil fauves, le 20 en aynnt undouble l'nig, l'un à la base et l'autio vers le milicu, les segments 5 et 6 uvec une dent aux côtés à l'extrémité, le segnent anal ferrugineux.

Q-Differe par lo chaperon et lo labre noirs, touto la faco a pubescenco fuuve et peu dense, les antennes biunos en dessous, l'oxtrémité de l'abdomen noire et lo dornier articlo des tarses aussi noir.

CapRouge, Ottawa (Guignard).

3. Mélissode oblique. Melissodes obliqua, Say.

Macrocera obliqua, Sily-Am. Ent. II, 780.

$\sigma^{7}$-Long. . 38 pec. Noire avec pubcscence fauve, cette pubescence longue et blanchâtre sur la face, donse sur le thorax. Chaperon et labio jaunes, mandibules avec une tache jaune i la base et une autre rousse ver's le milien. Antennes roussâtres en dessous. Ailes sub-liyalines, à nervures brunes, Dernier, article des tarses postériours, roux-forrugineux. Abdomen a premier segment couvert de poils épars fuuves, te 20 avoc un double rang de frange fauve, lo piemier a la base et le second vors lo sommet se dirigeant obliquement on remontant vers le milieu, tous les autres avec une frange ver's le milieu et légdrement oblique de chaque côté; les segments terminaux sans dents,-CapRouge.

Très rapproché du précédent; $\$$ encore inconnue.

6. rustica.

.. 7. senilis. 
4. IÉlissode pieds-ńoirs. Melissocies nigripes, Stnith.

-Birit. Mus. Cat. II, 311.

Q-Long. .55 pee. Noire d pubescence ochracée, plins pâlo sur le thorax; chaperon densément ponctue; d murgo antérieure légdrement relevée. Ecrailles alaires testacé-brunâtre. . Ailes subhyalines, les nervures brunes. .Pattés noires, les : postéricures avec leur brosso extérieure roussátre. Ábdomén largo, obtus d l'oxtrémité, d pubesconce noir'e et très peu abondanto.

$\sigma^{7}$-Long. :45 pee. Semblabled la \%, mais le chnperon jaune, lo pavillón des antenines loux, pâle on dessous", a l'exception des deux articles basilaires, et les onglos des tares forrugineux."CupRougige."?

Bien reconnaissable par son abdomen et ses pattes noires.

5. Melissode festonnée. Mélissodes festonata, n. sp.

+ . Long. .47 pce. Noire, à pubescence jaune pâle, cette pubescence mêlée de poịls noirs sur le vertex et lo mésonoturn. Ecailles alaires noires. Ailes subhyalines, a norvures brunes. Puttes noires, a pubescence brun-roussâtre. Abdomen lạrge, déprimé, brusquement atténué an pointe d l'oxtrémits, le prenị̂r sogment d pubescence semblable d cello du thorax, les 20,30 et 40 aves une frange de poils biancs vers lemr milieu rolevée d la ligne médiane de l'abdomon, la faisant partuitre comme fustonnẹe, lo 20 avec une seconde frange moins abondante $d$ la base, les 50 et be d poils biuns rouseatros.

万’-Arec le chaperun jaune, une tache rousse sur les mandibules, le dessous des antennes testace, et les 2 dernier's segmonts sde l'abdomon denticulés.-CapRonge.

Diffère de la nigripes par sa taille plus petite et son abdomen moins allongé, et de la desponsa par son abdomen d franges blanches et à extrémité moins obtuse, atténuée en pointe.

6. Mélissode rustique. Melissodes rustica, Say.

Macrocera rustica, Say.-Am. Ent. II, 781.

f-Long. 40 pce. Noire avec pubescence blanchâtro. Faco courte et largo, chiperon avec une ligne médiane obsoletemont ponctuée. : Puboscenco du thorax entremêlée de poils noir's. 
Ecailles alaire noires. Ailes subhyalines, à nervures brunes. Pattes noires, les postériouros a pubescence jaunatre. Abdomon a promier segment a poils blanes epars, lo 2e avec une ligno do poils blance a la base et une autre ver's le milieu, les antres avoc uno senle baud', sub-interrompue au milieu. L'ablomon est déprime, ovalo all sommet.

$\delta^{7}$-Avec lo chaperon jamne, une tache reisso sur les mandibules, lo dessous des antennes roussâtre, l'article terminal des tarses ferringinenx, los bandes de l'ablomen comme dans la o -Otlawa (Guignard).

7. Mélissode vieille. Melissodes senilis, Smith. -Brit. Mus. Cat. II, 311.- $\sigma^{\pi}$ denticulata, Sm.

९-Lnng. 42 pec. Noire avec pubescenco cendrée; le chaperon fortement ponctué. Pubescence peu dense sur lo thoJux, plus longue et plus apparente sur les flancs. Firailles alaires noires. Ailes subhyalines, les nervures noires. Pattes à pubercence brune, plus pâle sur les tarses postéricurs, le dernier article de ccux-ci roux-ferrugineux. Abdomen ąssez convexe, large, oralc-obtus à l'extrémité, lo premier segment ì poils épars blanchâtres, le 20 avec une bande de poils blancy a la base et une autre vers le milieu, atténuće an milieu de l'abdomen, les 3 e et 4c avec aussi une bande blanche sub-interrompuo au milieu, les 50 ot 6e à pubescence brunc, le dessons à pubescence biune au sommet des segment ${ }^{2}$ blanchâtro sur les côtés.

${ }^{7}$-Avec le chaperon et lo labre jaunes, los mandibules ronksâtres vel's l'extrémité, les antennes rousses en dessons, les pattes a pubescence blanchatre, les tarses a articles terminaux ferrugincux. Abdomen a bandes blanches commo dans la o , les 5e et be kegments aussi avec bande blanche et une petite dent de chaque côté.-CaıpRouge, Ottawa (Guignard).

Smith a décrit ce $\sigma^{\top}$ sous le nom spécifique denticulata: mais la similitude de forme et de coloration ne permet guère de donter que ce ne soit le $\delta^{7}$ du senilis, no is les avons de plus capturés ensemble, dans le même endroit. 


\section{EXTRA LIMINA}

Mélissode large. . Melissodes lata, n. sp.

으-Long. .65 pco. Noire aree pubesconce griantro; lo rhaporon rolevé et tronqué antériouremont, lo labro à puboncenco. blanchâtre longne et dense, les inandibules obsentíment roussât.les. vors l'extrómité. E'unilles alaires brun-ronssâtre. Ailes suli-hyalines, les nervures nobes. Pattes a pubesconco brime, Wan hâlre sur les critses, les articles lerminaux des tarses rouxforrngineux. Tírensson à pubescence jaune-pâle denso (t comme partagie en 2 lober. Abdomon large, aplati, arrondi i l'oxtrémité, l'un noir foncé, pail'aissant comme velonté, lo prenier sersment à poils semblables à cenx du thorax, le to entierement moir, étroit, les 30 et te avec uno bando do poils blanes treds ap. jiarente an sommet, rello du 30 interrompue all nilicu, lo $50 \mathrm{a}$ jubescenre noiro avec wue tache blancho sur les côtén, lo 6e sans tarhe noire, le ciessons aree frange all sommet des segrmonts, brune au milieu et blanchâtu'esur les côtés. - Vancouver ('Taylor .

Espèce bien remar.juable par sa taille et sa color.ttion. Los bandes blanches de son ablomen sont tres aplarentes sur le fond noir velo'ité des sigurents.

Mélissode cornes-noires. Melissodes nigricornis, n. sp.

$0^{x}-$ Lungr. 5 pee. Noire avec pubesence blanchâlre; to (haperon janne aroe une étroite bande noire a la baso s'étendant NIIr les rôtes et clevenant une ligno brune en ayant, le labre anksi jailue avee une tarhe noire de chaque côté; les mandibules sans tarche. Antennes lonzlles, cépassant la base de l'abdonen, enticrement noires, les articlos termillaux comme festonnés en dessous. Jies écailles alaires brunâtre's ; ailes subhyalinos, à nervures noires. Pat ter a pubesence blanche, les articles terminax des tarses roux-ferrugincux. Ablomen court, thes convexe; sub-globulenx, las 2 segments basilaties à poils blanchítr sépar's, lo resto à poils moje, lo 60 a poils blanchatres an sommet, le terminal a poils

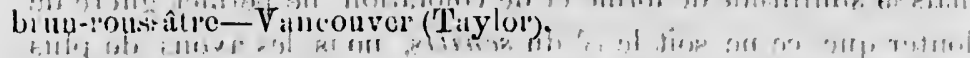
o Inconnue. Espèce bien remaruuable par ses antennes longn s it enticicuent noires. 
Après le genre Mecissodi;, p. 691, ajoutez le suivant:

$$
\text { Gen. Coluete. Colletpis, Latr. }
$$

Tête courte, jresque aussi larga que le thorax, sans sillons en deduns des yeux. An :enues filiformes, simplement ar.juces dans les 2 sexes. Thorax assez court, robuste. Ailes avec une radiale en pointe aux deux bouts, son extrémité apicale arrondie et portant un petit appendice ; 3 cubitales ferınées, la 1ère anssi longue que les 2 autres, la 2 e rétrécie cie chaque côté à la radiale, recevant la première récurrente vers son milien, la 3e fortement retrécie vers la rudiale, recevant la 2e réciriente an deli de son milieu; la $2 e$ récurrente à pirtie incérieure se courbant vers l'extrémité de l'aile. Premier article des tarses postérieurs assez long, n'ayant que peı de poils et impropre à la récolte du pollen, nuais le dessous des euisses, les hanches et l'extrémité du ućtathorax à longs poils pour cette fin, Extrémité de l'abdomen sans espace un pour le jen de l'aiguillon. Lingue courte, évasće, à 3 lobes; palpes labianx de 4 articles, les maxillaires de 6 , à peu près semblables, les articles placés bout à bout, les derniers très étroits.

Les 3 cubitales avec la marginale appendiculée rapprocheraient ces insectes des Anthophores, nais leur mantule de brosses aux jambes et tarses postérieurz en fout de véritables mérilégides, c'est-à-dire ne recueillant le pollen que par leurs cuisses, leurs hunches et l'extrémité dı tholax.

Une seule espèce rencontrée.

Collète hyaline. Colletes hyalina, nov. sp.

q-Long. 30 pee. Noire, polic, brillinte, avec pubeseence blanche ou grisatre, plus donse et plus longno sur la firce. Chatperon finement et densément ponctué. Antennes birunâtres en dessous a l'oxtrémilé. 'Thorax convert de poils blanchâtros pen denseses, lo métathorax sillonné-ruguenx an sommot. Les écaillettes testacéos-roussîtres. Ailos parfititement hyali+ies, los norvures et lestigma, brun. Pattes noires avec poils blanes pen 
denses, exceptés sur les cuissos et sur les banches ou les poils d'uil blanc do 1 eige sont longs et abondants. Abdomon en ovale, poli, brillant, convoxe, a pou près nu mais avec lo bord apjeral des segments déprinus et convert d'uno pubescence argentéo formant des ceintures completes; la frango analo blanche; lo dessous avec lignes argentées aux sutures.

$\sigma^{\top}-\mathbf{A}$ abdomen un pen plus allongé, lo promior segment avec uno excuvation largro et profondo d sa faco antérioure.

Capturé à Ottawa (Harrington) Hull, CappRouge etc. Une o captr.sée à Ottawa par M. Guignard ne portait que 2 cubitales à son aile droite, et à son aile gauche li nervure de division entre les cubitales 2 et 3 était encore incomplète, n'atteignant que le bord inférieur de la cellule.

Gen. Andrena, Fabr. p. 693.

Aux 11 espèces décrites, ajoutez les 16 qui suivent :

Clef pour la distinction des especes.

1(16) Thorax a pubesconco dense, cuchant les téguments;

2(5) Jambes \& tarses postérieurs roux-testacé;

3 ( 4 ) Pubescenen de la fuce ot de l'anus noile.. 1. bicolor, 694.

4 (3) Pubescence de la faco et de l'unus fuuve. 9. perplexa, 696.

5 (: ) Jambes postéricures noires ou bíunes;

6(11) Abdomen sans ceintures do poils au sommot

des segrinents, si non quelquefois sur les côtés;

7 (8) Pubescenco de la face et do l'anus noiro-... 5. vicina, 695.

8 (7) Pubescence do la fice et de l'anus fuuve, jaune ou blanche;

$9(10)$ Têto non épaissio en arrière des yeux, pu-.

bescence fuuve; abclomon déprimé.... 3. nivalis, 694.

10 (9) Tête épaissio en arrière des yeux; pubesconce grise................. 12, laticeps, n. sp

11(6) Abdomen à ceintures de poils au sommot des segments;

12(15) Pubescenco des ecintures blancho;

13(1i) Frange anale noiro; 20 cubitale en carré. 13. fimbriata.

14 (13) Frange anale griso; 20 cubitalo distinctement plus étroite on haut qu'on bas. 14. distans, n. sp. 
los poils lomon en c lo boi'd scence arnalo blan-

segmont ure.

Une 2 cubide divi, n'attei-

ent :

nts ;

:olor, 694 . lexa, 696 .

cina, 695 .

valis, 694 .

eps, n. sp

mbriata.

ans, n. sp.
15(12) Pubescence des ceintures juune, longue et dressée .......................... 15. hirticincta, n sp.

16(1) Thorax a pubescence ne cachant pas los tégumonts ;

17(-10) Abdomon sulis ceinlures pubescontes au sommet des segments, ou soulemunt sur les côtés ;

18(21) Abdomon a longo poils gris épar's ;

$19,20)$ Fiange anulo griso o 14. distans

20(19) Frango aunle brun-fuuve, taille plus forte + ? 4. frigida, 695

21(18) Abdomon sans longs poils giris épurs;

2む(20) Jambes et tarses postérieur's roux-testacé ;

23(24) Métanotum strié-rugnoux; jambes roux-clair.

2. hilaris, 695

24(23) Métanotum fiıement ponctué; jumbes roux-biun

16. desponsa

25(22) Jumbes postérieures noires ou blunes;

215,27) Jullos très épaisses on arrière des ycux, tar ses roux-forrugineux

17. fragilis.

27, 26) Joues ordinaires, tarses bruns, noir's ou forruginoux ;

28(29) Métanotum fortement rugaueax, stigma noir integra, 697.

29(32) Métunotum d stries régulières ; tarsos brunfunces, stigma juune; abdomen allorigé, atténué en pointo a l'extrémité ;

30(31) Espace irenfermé du mêtanotum strié, eri triangle à pointe perduo dans lo sillon do la faco postérieure.. ................... 18. lineata, n. sp

3! (30) Espace renformé du métanotum de formo semi-circulaire, strié, plan dans son pourtoul .............................. 9. victima, 696

32(29) Métanotam sans stries, très souvent couvcr't par la puboscence;

33(34) Chisperon $\delta^{\nearrow}$ jaune avoc 2 points noir's.... 19. clypeata. 
$34(35)$ Chnperon ơ noir, convort par uno longuio pubescenco blanchâtro

35(34) Chaperon noir, il puboscence courte olt nu;

36(37) Chaporon poli, brillunt, il ponctuntions obso. letes

37(36) Chuperon ponctuó de toute part;

38(39) Tarkes ferruginoux; chaporon a ponctuations finos, simulant des strios tinnsrores; abdomen $\sigma^{\pi}$ convexe................ 22. convexa, n. sp.

39.38) Tarsos bruns, forrugineux soulemont à l'oxtrémité, chiproron couvort par la pubescence................................... 6. hirticeps 695 .

40(17) Abdomen avec ceintures pubescentes au sommet des segrments;

4) (42, Chaperon poli, billnnt, a ponctuntions obsoletes; pubescence des ceintures jaune, interroinpue sur les 20 et 30 segments 23 . miserabilis.

42 4.5) Chaporon avoe uno ligno lisso an milieu;

43(44) Abdomen court, ovile, convexe, pubescenco les cointures courte.............. 8. algida, 696 .

44(45) Abdomen ovale, aplati, pubeseence des rcintures longue............... 7. placida, 696 .

45(41) Chaporon ponctué de tontes parts;

46(47) Abdornen fortement ponctué, ceintures peu pubescontes, cufuncécs, roussâtros ...... simpiex, 697.

47(46) Abdomen a puboseence des cointures dis. tincte; les ceintures non cufoncćes;

48(49) Sligma brun, ailes avec un nuage convrant

lextrémité et la cellule radialo...... 2t. nubecula.

49(48) Stigna jaune; ailes hyalines ou subhyulines;

50 5:) Thrax a pubescence fiuve;

51(52) Ailes teintes de fuuvo, tau'ses postérieurs ronx-clair.

25. fulvipennis,

52(51) Ailes hyalines, tarses postérieurs bruns; chaperon $\delta^{7}$ jaune .................. 26. simulata, n.sp.

53(50 Thorax a pubescunce blanche ou grise; stigma brun, frange anale blanche... 27. macilentus. n. sp. 
12. Andrèno tête-épaisse. Andrena laticeps, n. sp.

$c^{3}-$ Long. .25 pce. Noire a pulhoscenco blunchâtro longuถ

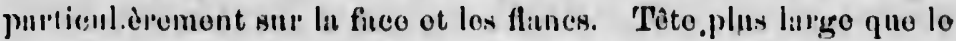
thorux, fortement épuissie oll arridre des youx; to chuporon trids finement ponotué et courert dans sat partio antéricure d'une Inngue of dinse pubesecuco blanche. Thoritx a ponctuntions peu distinctos, lo métanotum non rugnenx. Ailes hyaliner-junnatres, les nerrures et lo ntigma jaune-pâle, los écuillettes forruginensestestacées. Pittes do la coulonr du corpan, a pubescenco blanche, les tarses testaces-januatron. Aldomen assez convexe, ("ll ovalo allongé, pointu a l'extrénité, lu base ot l'extrémitó uvee poils blaucer, les segments inurqués all sominet duure bando testurée, lisse, mair sans pubescenco. In finngo mulo blancho.-Ottaw:L.

Espèce bien remarquable par la forme de ses jones qui frésentent à partir de l'coil, uno surfuco plane et dúclive très consillinable.

1.3. Audrène à-frange. Andrena fimbriata, S'nith. - Brit. M.us. Cat. I, 116.

9 - Long. .48 peo. Noire avoe pubescence janno jrâle, les rôtés de la fitce a pube cence jaune; le chaperon à ponctuations denses mais pell prononcées; lo pavillon des antennes furruginenx en desions. Thorax a pubessence junne abondante. Ailos subliynlincs, lo stigmn janne, les écrilluttes d'un tostacé-rous sâtro. Paltes noires, a pubescence noire, colles dos cuisses blanchûtre, derniors arijcles des tarses forrugineux. Abdomen ovale, la buso et lo sommet des segmonts avec longno fiangro do poils jaunesblanchâtres, la frange anale d'un br'un sale. - CupRouge.

Jjien distincte par la lougne frunge do ses segments abdisminaux.

14. Andrène ḋ-nervures-distantes. Andrena distans, n. sp).

q-Long. 36 pee. Noiro a pubeseence blanche ou jaunepâle. Fice ì pubescence grive et longne sur les rôtés, le cha-

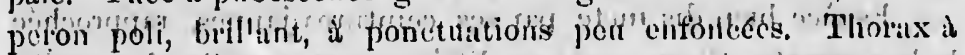

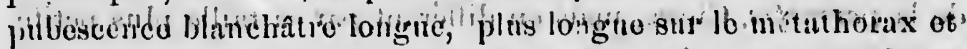

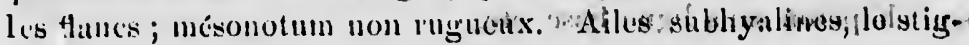

tus. n. sp. 
mu formginenx, les nervures brunes, les cenillettes testnce- brunâtre. Puttos nuires, a pubosconce grise. Abdomen on ovale, convoxe, poli, brillant, lı buve uveo poils blanes peu denser, les segments 2,3 et 4 uveo uno frungo do longs poils blanes au som. mot, collo du te segment plus ou moins interrompuo au milieu; firungo analo d'un blune sule.

o A pubesconce plus longno et benucoup plus donso sur in fuec. Iinbdomen a poils blunes si pen donses qu'ils so distinguent d peine on finuge ul sominet les segmonts. - CupRouge.

Une particularité bien remarquble do cette especce est la furme de su 2 cellule cubitale, dont la nervure basilaire est considérablament écarti'e du bas, ce qui donne à la cellulé une bien plus grande longueur en bas qu'en haut.

15. Andrène à-ceintures-poilues. Anärena hivticincta, n. $s p$.

o-Lrong. 45 per. Noire aree pubesconco jaune; la fucod pubesconce ussez dense, junne, lo clumperon a ponctuations peu densce. Antonnes noires. Thorux a pubescenco dense, d'un jauno citron, plus lunģuo sur les flunes. loes écaillos aluires noiros. Ailes hyuliner, légerement obycuros all sommet. Pattes noires, a pubescence junne sul les cuissor, bruno sur les jambes et les turses, les articles terminaux do ceux-ci tostacés. Abdomon ovale, convort do poíls jaunor, cetto pubesconce so rangenut on firnnge dense an knmmol des 4 premiers segments, lo basilaire avec sem. blubles poils jaunes sur son dinque, les segments torminaux avec longs poils noirs entromêlès do quelques poils pâles; lo volitro a pubescence noiro uvec uno frmuge de longs poils pûles ali sommet do chacun d'oux.

ठ̄-Avec pubescence plus palo sur le chinperon. Les pattes avec pubess:ence jaune pâle, tous les segincits abdominaıx à ceintures jannes, les terminaux avoe poils de la mêmo coulcur.Otluwa (Guignard.

Espèce bien dis incte par ses ceintıres jaunes, rapprochée de la permitis, Cıess., mais en différunt par sa taille plus petite, son chaperon sans ligne lisse etc. 
itnce- briluon ovile, lonses, les in all Homsu milieu;

inso Bitr. ln istinguẹt o. ce est la e est conune bien

rticincta, la finced tions pen d'un jaune es noiros. tes noires, bes et les non ovale, on fringe avee sem. naux avec o velitie d uii sommet

Les pattes minaux à coulcur:approchée lus petite,
16. Andrène engagée. Andrena desponsa, Suith. -Brit. Mus. Cat. I, 111.

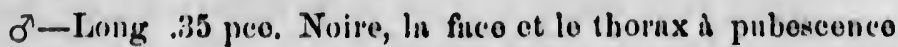
junne paile, de même que les puttes of le desnons du thorax. Ailes hyulinew-junthatres, les norvuros ot lo stigmu junues, les éconillettes testicées. Puttos d'un ronx brunâtro avee pubescenco junne, les turses plus pales ot il pubescence fiunve brillante. Abdomen en ovile allongé, en pointe a l'extrémitó. avee poils fiuves à lin base, les segments nvec une bando testucéo ronssâtro nu sommet, la finnzo unalo d'un janno celuir; en dessons les se'gmonts sont ciliós do poils blunchâtres, - CupRernge.

Pent-être le ơ des victima?

17. Audrène fragile. Andrena fragilis, Smith. -Bit. Mus. Cat. I, 115.

$0^{7}-$ Iong. .32 peo. Noiro, In fice presqu nue, n'uyant que quelques poils jaunes sur les côtés, lo chapporon a ponctuations peu densers et pen onfoncéce, joues renflúes et prolongées en urrièro des youx. Le thorax presinne nu, l'éc:usson poli, brill:mi, le múthinotum strié a ha buse et densúment ponctué on dehol's do l'espace renforme. Ailes hyalines, les nervires j:annes, lo, stigma jun nver; une tacho lis:éalire noiro au nilien. Puttes noires, a pubescenco finuvo pâle, les turses ronx-lormginoux. Abdomen

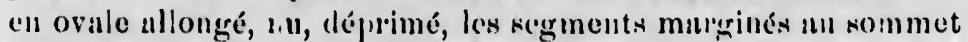
d'une bando conssâtre, dípriméce f'ango munle d'un gris salo avee lo dernier segmont fiture.-Cisponge.

Espece bien reconnuissible par ses joues renflíes.

18. Audrène à ligne noire. Andrenc lineata, n. spp.

f-Long. .35 pee. Notie, presquo sans pubescence, chuperon un, mais non brillint, a poactuntions pen distinctes. Thorax lisse, écusson brillant, métanonum a espalco renfermó strié, on formo do trianglo dont la pointe so perd dans lo sillon módian de la fitco postérieure, les côtés lonsémont ponctués. Ailes hy:lines, a nervares fauves, lo stigma allssi fatuve avec uno ligno noiro an milieu, les écuilles testatcées. Paltes à pubesconce ronx-

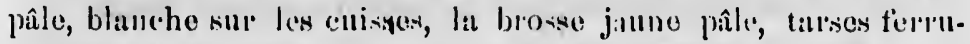
gineux. Abdo:non o:? ovilo allo:hgé, déprimé, nu, „ohi, brillant, 36 - Mars, 1888. 
les segments marginés au sommet par une ceinture large, enfoncéo, roukeâtre, brosso anale fiuve bauche.-Cap Rouge.

Espèce bien remarquable par la structure. de son métanotum et la coloration de son stigma.

19. Andrène à-chaperon-jaune. Andrená clypeatu, Sm. - Brit. Mus. Cat, 1,115.

б’-Long. .26 pec. Noire à pubescence fiuve, plus pâle 'sur la face et sur les joues. Chaperon jaune arec un point noir do claque côté; mandibules furrugineuses à l'extrémité. Ailes snbyalines, iridescentes, le stigma ot les nervures testacépâle. Pattes noires, a pubeseenco faure pâlo, peu dense, les articlestermianux des tarses ferrugineux. Abilomen ovale-oblong, à peu près nu, les côtés avec quelques poils farres-pâles de même que la franğe anale.

ㅇ--Le chaperon à ponctuations peu denses, nu, les côtés de la faco à pubescence pâlo. Ailes hyalines-jaunâtres, à nervures juines. Paltes brunes, les jambes ot les iárses brun-ferrugineux, à pubescence pâlo, la brosse jaune pâlo. Abdomen poli, brillant, finement ponctué, la brosse anale fauve-pâle.-CapRougro.

Ncris ne croyons pas faire erreur en rapportant cette 우 à cette espècc. M. Smith n'en décrit que le $\delta$.

20. Andrène vêtue. Andvena vestita, n. sp.

ర-Long. .23 pco. Noire, à puhescence grise ou blanche, longue et denso sur le chaperon, assez claire sur lo thorax. Ailes subhyalines, lo stigma janno entouré pal la nervuro brune, les écaillettes testacées-brunâues. Pattes noires avec les tarses roux-ferrugineux, a pubescence bianche, courte. Abdomon en ovale, attéuné ell pointe à l'uxtrémité, un, les seg'ments man'ginés all sommot par' une bande lisse à margo testacéo; la frange anale grise. Desious brun, les segnients a peino frangés de quelquess poils gris.-Ciphouge.

o-Fncore inconnue; la plus retite espèce que nous ayons rencontrée.

21. Andrène étrangère. Andrena aliena, Suiih. -Brit. Mus. Cat. I, 113. 
으-long. .35 pec. Noire a pubercence lianche on jamepâle, la face presque nue, n'ayant de pubescencęquo sur les côtés et le verlex, lo chaperon poli, brillant, a ponciliations obsolètes. Métathorax rugnenx à la base, finement ot densément ponetué sur les côtés. Ailes hyalines, légèreınent obseureies all sommel, lo stigrma janne, les cuenillettes lestarébs. Pattes a pubesconce d'un blanc sale, plus blanche et longue sur les cunisses, la brosse juune, les derniers articles des tarses ferrogineux. Ablomen ovale, quelque peu acumiié all sommet, lisse et brillant, les segments 2, 3 et + avec une petite frange de poils gris sur los côtés, fiango anale d'un blanc sale.

Ђ-La face toute couverte d'une pubescence jaunc-pâle, plus longue et plus pâle sur le eh:yjeron; lo thorax à puberconco jauno cachant presque les téguments. Abdomen ovale, poli. brillant, avec quelques poils jafines sur les côtés, mais sans ceintures distiuctes, frango anale jaune.-CapRouge.

Son chaperon poli, brillant et presyue totalement dénuć de ponctuations.rend cette espèce bien reconnaissable.

22. Andrène convexe. Andiena convexi, n. sp.

q--Loug. .36 pce. Noiro à pubescence jaumc-pâle, la fitco presque nue, le chaperon a ponctuatious nombreuses mais peu prononcées; lo thorax à ponctuitions u’ès fines, le métathorax finement ponctué, puboscent. Ailes hyalines-jaunâtres, à norvures brunces. Pattes noifics, il pubercerseo pâ!e. Abdomen ovale, convexe, avec quelques poils pî́les a la base et sur les côtés, mais sans ceintures distinctes, la frange amalo gris-foncé.

$\sigma^{x}$-Iong. .35 pee. Noirce, à pubrscence blancho peu dense, longuo sui lo thorax, la face presquo nuc, lo chaperon à ponctuations fines ot nombreuser, simulaut dos stries trausverses, lo métathorax non rugneux. Ailes subliyalines, à nervurus te-titcrés. Pattes à pubesconce blauchâtre, les tatrses brun-loussâtre. Abijomon très convexe, subglobuleux, nu, poli, b:illant, les segunonts 2,3 et 4 avec uno bancle lisso au sommet très étrontement marginée do testacé; la fiange anale d'un gris sale.-CapRunge.

23. Andrène misératle. Andrena miserabilis, Cress. -Proc. Ent. Soc. Phil. 1V, ¿59. 
9 Long. .32 pee. Noire avec pubesence jaune ochracéc, le chaporon a ponetuations pen denses, presque nulles an milien, lo pavillon des untennes roussâtre en dessons a l'extrémits. Thorax à pubescence janno assez longue, pou dense, no rachant pas los tŕgnments, lo métanolum tress finement ponctué. Pubescence des pattes jaunâtre, blanche ct plus longuo sur les cuisses, les tarises postérienr', brun-'errugineux. A belomen ovale-oblong, déprimé, brillant, tres fincment ponctué, les regments 2,3 ot 4 avec uno frango do poili janne-pâle denses all sommet, plus un moins interrompue sur les 2 e et le 30 ; frunge anale de la mêno conleur.

$\sigma^{\nearrow}$ - Plas petit et plus urêle, chaperorr avec une pubesceneo pâle longrue et dense; métunolum grossièrement róticulé; tarsos

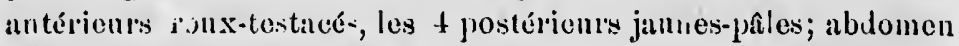
plus coinvexo que pains la 우.

Une o capturée à Ottawa. (Guignard).

24. Andrène nuage. Andrena nubecula, Smith.

-B it. Mus. Cat. I, 117.

ㅇ--Long. 38 peco. Noire, la faco au dessons des antennes finement striée, lisso aur lo rertex, lo chilporon finement ponctué, a poils blanchâtres, de mêmo que les rôtés de la fíce, les antgunes brunatres en dessous à l'extrémité. 'Thorax très firement ponctué, presquo nu, ex‘epté sur les côtés dn mélathorix qui sont chirrgés d'une pubescence longuo et dense. Aîles subhyalines avec un nuago foncé obsencissant le sommet et la radialo des untérienres, les postéricures avec la cellulo marginalo anssi olsourcio; les écuillettes testacées, des nerviu'es bilun-foncé. Pattes noires, laur pabescence brunâtre avec la brosso pâle, les tarsos postévietirs ferrliri:ienx. Abclomen ovale-oblong, trds fincment pone. tié, poli, brillant, les segrnents 2,3 ot 4 avec nno ceinturo do pubescenco blanche au sommet, la fiango analo d'un fiuvo jâle.-Cap Rouge.

Les pattes de nos spécimens ne sont pras d'un roux testacé tel que les dícrit M. Sinith, nous pensons cependant $c_{1}$ ne c'est bien la son insecte, le reste de sa description s'accrrde en tout joint avec.nos sjúcimens. 
25. Andrène à-ailes-fauves. Andrenct fulvipennis Smith,-Brit. Mus. Cat. I, 117.

f--Inng. 40 pce. Noire, la face a pubescence pâle, le oha: poron a ponctuations peu donses et pou prononcées, les mandibules ferruginéuses à l'extrémité. Thorax à pubescence fauve assez dense, mais ne eachant pas les téguments. Ailes hyalines-fauves, les nervures et les écaillettes testacé-fituve. Les jambes et les talses brun fuuve, pubescence des cuisses blanche. $\Lambda$ bdomen en ovilo allongé, poli, brillant, les segments 2,3 et 4 avec uno frange do poils blancs au sommet plus ou moins interrompue sur les deux premicrs; frange anale gris-ferrugineux.

$\sigma^{\gamma}$-Avoc les tarsos et partie des 4 jambes postérieures rouxfauve; l'abdomen nu, tr'ès convexe, a frange anale blanchâtre.CapRouge.

\section{Andrèné simulée. Andrena simulata, n. sp.}

+ -liong. .30 pce. Noire avec poils jaune-pâle. Le chaperon ì ponctuations pou densos, uu, avec poils pâlos sur les côtés. Le thorax très finement ponctué, à poils jaune-pâle, assez longę, mais no cachant point les téguments; le métathorax non rugueux, très finement ponctué. Ailos hyalines, les nervures brunes, le stigma pâle entouré d'une ligne brune. Pattes noires avec poils jaune-pâle, le floccus long et blanc. Abdomen ovale, déprimé, los segments 2,3 et 4 avec une ceinture blanche coinplete an sommet, la frange anale d poils blanchâtres biell fournis.

б-Avieo les antennes roussâtres a l'extrémité en dessous; chaperon jaurie-pâle avec un point noir de chaque côté: viel's le havi; abdomen plus convexe, la ceinture blanche des segments 2, 3 et 4 bien distinote, le stigma commo dans la f-Ottawa (Guignard).

Petite espèce bien distiucte par ses ceintures abrlominales.

27. Andrène maigre. Andrena macilentu, n. sp.

\&-long. .32 pce. Noire, à pubescence blanche, abonclante, longue et dense sur la face et lo thorax. Mandibules ferrugineuses à l'extrémité. Ailes hyalines, les nervures et le stigma. jaune-pâle, la radialo longue; les écuillettes testacé-brunâtre. Pattes a longue pubescence blanche, plus abondante que d'or- 
dinairc, les tarses fauves-ferrugineux. Abdomen en ovale allongé, poli, brillant, a longs poils blanes a la base, les seginents marginés all sommct d'une bando lisse, déprimée ct pâle, plus on moins frangée sur les $2 \theta$, 3e et $4 e$, frange anale d'un blanc sale; dessous noil, à frange blanche au sommet des segments.

б-A abdomen plus convexe, à frange des sogments abdominaux plus courte et moins dense, etc.-Cap-Rouge, Otlawa.

Gen. Halictus, Latr. p. 897.

Dès 11 espèces décrites, retranchez 6-cinctus, Prov. qui est le $ठ$ de coriaceus, Sm., et ajoutez les 3 qui suivent.

Clef pour la distinction des especes.

1(11) Couleur noire;

2 (3) Abdomen opaque, a 4 ceintures pubescentes complètes,"quelquofois 5 ot 6 dans lo $\sigma^{\top}$, métanotum finement ponctué..... 1. coriaceus, 699.

3(:) Abdomen poli, brillant, du moins à la base ;

4(7) Métanotum strié, rugueux; du moins ì la baso;

5(6) Métanotum finement strié à la base et lisse au sommet

8. distinctus, 700 .

6(5) Métanotum pubescent i la base ot fortement strie au sommet................... 4. discus, 700 .

7 (8) Métanotnm finement strié sur tonte sa surface; jambes et tarkes $\sigma^{7}$ jaune-pâle. 2. ligatus, 699.

8(7) Métatborax fortement rugueux, sans stries régulières, tant sur le dos que sur les eôtés;

9(10) Tarses $\delta$ noirs à la base, stigma noir, anton nes courtes, noires, in articles courts, renflés an milien, chaperon court et large, densément ponctué.. ......... 6. scabrosus, 700 .

10(9) Tarses of blancs d la base, stigma jaune, antennes. longues, chaperon allongé an bord antérieur

5. cinctipes, n. sp. 
11(1) Coulenr brun-cuivré on bronzé, vordâtro ou bleuâtre;

1:(13) Pattes ot abdomen testacés. 12. creberrimus

13(12) Pattes brunes, abdomen plus ou moins brilli ;

$1 \pm(1$ i) Vert cuivré, thornx a pabescence fuuve abondante, abdomen fortement poilupubescent, lo lor segmont et partio du Ze senlement étant nus.

7. pilosus, 701

15(14) Vert olive ou bronzé verdâtre on blenâtre ; abdomen plus ou moins pubescent, non poilu ;

16(19) Tarses postérieurs, blanc; ou jaune-pâle;

17 (18) Abdonıen o étianglé aux sutures... 10. constrictus, 702

18(17) Abdomen + ion ou à peine étrunglé alux sutures, atténué a la base; mśtanctian fortement strić..................... 9. albitarsis, 701

19(16) Tarses postérieurs bruns oụ bruns. ferrugineux;

20(21) Abdomen o a 4 ceiutures complètes $1^{\prime}$ pubescence argentéo..

10. constrictus

21(3i) Abajomon of sans ceintures completes de pubescence argentée, les seginonts terminaux nus ou plus on moius couvarts par la pubessence;

22(23) Thor'ux ì ponctuations éparses ; métanotum fortoment strié, flancs du thor'ux rugueux

11. confusus, 702

23(22) Thorax tres finement ponctué, flancs non rugueux ;

24(25) Abdomon court, tids poli, convexe, a puoussenco sutilemont d l'extl'émitć. 8. lævissimus, 701

25(24) Abdomen ovale, a segments plus ou moins testacés all sommet, la base, lus côtés et le sommet avec poils blancs épar's sur los segments, d l'exception dos 2 promiers qui sont nus.

13. disparilis. 
1. Haliotus coriaceus, Smitlı, p. 699.

Il arrive souvent que l'abdomen dans le or présente six ceintures complètes an sommet ile ses segment.s. L'espèce par nous décrite sous le nom de 6-cinctus, p. 700, n'est que le $\sigma^{7}$ de cutte espèce.

5. Halicte pieds-ceinturés-de-blanc. Halictus cinctipes, n. sp.

б-Long. .32 pee. Noir avec pubesconce grisâtue très clairo; In face à puberence algentée, lo chaperon avancé ot jaune an sommet. Antennes noires, sulb.dentées et testucées en dessous. Thorax finement ponetué, le inétathorax fortomont ringueux. Ailes hyalines, les uervures brunes, lo stigma jannâtre, les écaillettes brmnes. Patlos noires, les tarses aves lo promier articlo jaune-pâle, lo resto brunâtre. Abchmen allong̣é, très légèrennent rétréci à la base, très finemont ponctué les sulure: resserréces entro les segments 1 et 2,2 et 3 , l'extrémité avec quelques poils blanchâtı'es.-Ottawa.

Très rapproché du scabrosus Prov. mais s'en distinguant surtout par ses tarses blanes à la base, son chaperon beaucoup plus étroit et plus avancé, ses antennes plus longues etc.

10. Halictus consistrictus, Prov. p. 702.

Par erreur typographique le signe $q$ a été mis à la piace de $\sigma^{\lambda}$ : nous domnons ci-dessous la description de la o.

F-Long. .25 pce. 'Tête et thorix d'un vert d'airain, treds fine.nent ponctués, le chuperou bordé do longs poilis en avant, le métanotum ponotué à la base et lisse au sommot. Ailes trids légèrement enfumées, les nervures brunes, Pattes noires, à pubescence jaune-pâle, de même que celle qui recouvre les flancs ot la face; l'extrénnité des tarses d'un testiucé roussâtre. Abdomeı ovale, noir, portant a chinque suture une forte ligne ou ceinture d'uno pubescence jaunâtre très distincte, les derniers segments a semblable pubescence mais moins dense. - Ottawa (Gnignard), CapRouge.

Très distinct par les ceintures jaunâtres de son abdomen. La structure de son métanotum ne permet pas de douter de son idenitité avec le $\sigma^{\top}$. 
12. Halictus à-ponctuations-très-denses. Haliọtus creberrimus, Smith. - Brit. Mus. I, 72.

q-Long. .22 pce. Tête ot thornx d'un vert bronzé, a poncluations extrêmoment fines et tr'ès denses; chaperon avalicé, poli, brillant; untenues tostacées on dessons. Métnnotum strié i la base ot lisse au sommet, les flancs scabres ; los ćcailles alair'es uvec les nervures, testacé-pâle. Ailes hyalines, iridescentes. Pattos testacées, nvec les grenoux et les tal'ses plus pâles. Abdomen testacé, a l'eflets bronzés, a pubescence blancho au sommet, le sillon pour la tairière roussâtre.-CapRouge.

Se distingue surtout du lavissimus par ses pattes testacées.

13. Halictus dissemblable. Halictus disparilis, Cress.

-Trans. Am. Ent. Soc. IV, 253.

q-Long. .26 pec. Tête et thorax d'un ver't cuivr'é, à pubescence pâle, chaperon à ponctuations éparses, frangé de poils ocracés; mandibules plus ou moins teintos de forrugineux. Antennes ferruginouses en dessous à l'extrémité. Mésuthorax a ponctuations éparses avec une ligne enfoncée au milieu. Ecusson a ponctuations fines et denses. Métanotum à stries rayonnantes a la base, lisse au sommet. Ailes hyalines, les nervures et les écuillettes testucé-pâle. Puttos noir-brunâtre, à pubescence pâle, les trisea plus ou moins pâlos. Abdomon court, ovale, lisso et brillant, noir a reflots bronzés. les côtés, la base et l'extrémité a pubescence hlanchatre, cette pubescence éparse sur les autrés segments a l'exception des 2 premiers, la marge apicalo des segments subtestacée.-CapRougo.

Se distingue surtout du lavissimus, par son thorax plus distinctement ponctué, son abdomen moins nı et plus allongé etc.

Gen. Augochlora, Smith p. 705.

Aux 2 espèces décrites, ajoutez les suivantes.

3. Augochlore striée. Augochlora striata, n. sp.

' -Long. .27 pce. D'un bẹu vert métallique à refletṣ dorés en contains endroits, la fice fortement ponctuée, plus finemunt sur le vertex et plus grossièrement sur le chaperon qui est brunpurpurin. Antonnes noires, le pirvillon légèrement testacié. a 
l'extrémité en deskous. Thorux a ponctuations très denses, plus éparses sur l'écusson, lo métathoirix sans espace renformé par une curène, tout lo disque finement strić, ser côtés avoc lo reste der flanes cid thornx scabris par do fortes ponctuations. Les écailles alaires brunes a margo testacée. Ailes sublyyalines, à neivures brunes. Patter biunes, à pubosoneo jaunnâtro, les hunches ot los cuisses à reflots verts, les postéricures à pubescenco plus claire. Abdomon poli, brillant, a ponctuations peu distinetes, lo segment basilaire déprimé uu sommet, le thorax et l'abdomen ì pubescence testacée pou aboudante.

$\delta^{2}$-Semblablo d la $f$ avec los execptions suigantes: lo thorax d reflets bleuâtres; chaperon fortement avancé et convexe ; pavillon des antennes testacé on dossous. Puttes vert-bi'unâtre, les cuissos intermédiaires remarquablement courtos, toưtes les urticulations dos pattes avec los iaises testacé-pâlo ou jaunâtre, lés tarses postérieurs avos les articles torminaux brunâtres el dessus.

Examiné 2 ot 4 $\sigma^{3}$. Malgré la grande similitude entre elles des espèces décrites par Smith, nous n'avons pu identifier notre insecte avec aucune d'elles. Il se rapprocherait de la cuprea, mais le dos de son métathornx est entièrement strié et non lisse au sommet. Il se distingue de la purc, Say, par sa taille plus faible, sa pubescence jaunâtre, les stries de son métathorax beaucoup plus fortes, etc.

\section{EXTRA LIMINA.}

Augochlore à-ceintures-obliques. Augochlora obliqua, n. sp.

\$-Long. .40 pce. D'un vort légè 'ement cuiviré, à pubesconce grisatre dense, ne cachant copendant pas les téguments. La face fortement ponctuée-grinuleuse; le chaperon en avant avec le labre, les mandibules et les antennes, noir. Thorix densément ponctué, le métathorax à espace renfermé distinct, fortement granuleux, sans strios distinctes, la façe postérioure entouréo pal une carène aiguë, a stries rayonnantes, les côtés du métathorax ì fines stries obliques, to reste des flances fortement granuleux. Ailes légèrement enfumées, lo stigma jauno, les nervures brunos, 
la radiale a appendice distinct, la 20 cubitale recevant la 1ere réourrente prr do son sommet; les écaillettes testacées. Pattes brun-foncé à pubescence juunâtre. Abdopien a refiets cuivrér, resserre aux sutures, chuque segment portant vers lo milieu une ceinture transverse inclinéc de chaque côté, d'un brun purpurin, l'extrémité noire avec poils de lą mômo couleur.-Vancouver.

Espèce bien distincte par les ceincures brunes de son abdomen.

\section{Gen. Calliopsis. Calliopsis, Smith.}

Tète aussi large que le thorax; ocelles en triangle su. vertex. Langue longue et grêle, plumeuse d' l'extrémité, les palpes labiaux de 4 articles dont le 1er f́gale les 3 autres réunis, les maxillaires de 5 articles; le chitperon large et arrondi en avant. Ailes à cellule radiale étroitement tronquée au sommet, 2 cubitales dont li 1 ère est un peu plus. longue que la $2 e$ qui est rétrécie à la radiale. Abdomen terminé comme dans les Andrènes par un espace nu triaugulaire. Pattes postérieures avec longs poils en forme de brosse.

Une seule espèce rencontrée.

Calliopsis d'été. Calliopsis cestivalis, Prov. Panur: gus cestivalis, Prov. Faune II, 705.

La forme des palpes labiaux dont le ler article égale les 3 autres réunis range cet insecte parmi les Calliopsis au lieu des Panurgus.

ra obliqua,

"pubescence nts. La face int avec le : densèmentl $t$, fortẹment on tour'é pal' nétathorax à ; granuleux. rures brunies,

\section{EX'TRA LIMINA.}

Calliopsis à-4-lignes. Calliopsis 4-lineata, n. sp.

\&-Long. 28 pce. Noire, avec pubescence grisâtre plus abondante sir la face ot les flancs. Antennes noires. Thorax à ponctuations grosicieres et peu denses. Ailes hyalines, los nervires brunes, la cellule radiale en fur de lance. Paltes noires; sans aucune túche. Abdonen déprimé, large, plat er dessous; les segments $2,3,4$ ẹt 5 avec uno ligne transversale blanche, échanerée on dessons ver's le milieu de chaque côté, cette ligne 
interrompue au milicu sir lo $2 \mathrm{e}$, le promier segment uvec seulement un point blane de chaque côte; les segments 3 ot 4 avec une bande lisso roussatre a la bisce.

Capturée à Toronto.

Calliopsis interrompue. Calliopsis intermupta, n. sp.

o-liong. .27 pce. Noiro nrec une pubescence blanche plus abouduntes sur ln ficce et les flunces, plus longue ot plus fournio quo dıns la précéclente. Ailes légèrement obscures, les norvures noires. Abrlomen avoc cing lignes blanches interrompues an milion vor's le milien do chryue segment, celle du promier elargio auxx côtés et rétrécio on pointe sur le dos.

Captiriée d Toronto.

Après le genre Callliopsis, ajoutez le suivant.

Gen. Macrope. Macropis, Panz.

Tête transversale, à peı près de la largeur du thorax; chaperon- large, arrondi aitérieurement. Langıe triangulaire, plumeuse à l'extrémité, les palpes labiaux de 4 articles, non très allongés, les maxillaires de 6 . Thorax court et robuste. Ailes à cellule radiale lancéolée, non. tronquée ni appendiculée à l'extrémité ; 2 cubitales dont la $2 \mathrm{e}$ reçoit les 2 récurrẹtes. Pattes à cuisses courtes et renflées, les postéricures avec les jạmbes et le ler article du tarse dilatés et chargés d'une brosse épaisse dans les $\subsetneq$, avec les cuisses renflées.

Une seule espèce rencontrée.

Macrope ciliée. Macropis cilicita, Patton,-Ent. Month. Mag. X.V.II, 31

Eucera nuda, Prov. o - Faune II, 692.

\%-lung. 28 pco. Noire avec les pattes et l'abdomen polis, brillants, lo thorax i pubescence brun-sale. Lo chaperon jaune apoc uno impression noile cle chaque cité a la base; le labre et des mandibules, noir ; la face polie, brillante, tinement ponctuéo sur. le vertex, à pubcscence blanchatre peu abondante. Antennes testacées en dessous, métathorax pubescent a la base, poli, lissa 
nu sommot. Ailes légèremont enfumécs-loussât res, lo stigmajaune, les nervures brunes. Pattes a pubescence blanchâtro, los articles mélliuns des tarses testacé-roussâtro, les terminaux noirs. Abdomon poli, brillant, atténné i la base et fortement recourbé, les sogmonts avec une impression trunsversule an sommet, lo 30 et los suivunts frangés do poils blaiıes, surtout sur los côté,--CiıpRougo.

\section{Gen. Panurgus, Latr. p. 704.}

Les 2 espèces décrites appartiennent toutes deux au genre Culliopsis, Smith. Ies Calliopsis' se distinguent surtont des Panurgus par leur cellule radiale, qui est toujours plus ou moins tronquée au sommet.

Panurgus vernalis, Prov, p. 70 $:=$ Calliopsis andrenoldes, Smith, Brit. Mus I, 128.

Panurgus cestivalis, Prov. p. $705=$ Calliopsis æstivalis, Prov.

\section{Gen. Perdite. Perdita, Smith.}

Les Perdita se distinguent surtont des Panurgus par leur cellule radiale qui est tronquée comme dáns les Ĉalliopsis, mais plits large et beaucoup plus courte.

Perdite à-8-taches. Perdita 8-maculata, Say.-Am Ent. I, 237.

o-Long. .28 pee. Noir avec lo thornx lavé de vert cuivré et diverses taches juunes sul la fice et l'abdomen. Le chaperon avec 3 taches jaunes dont la médiane est plus allongéo, les orbites avec uno tache jaune triangulairo près du chaperon; le vertox densémont ponetué. Tout le thor'ix très finemeni et densément ponctué, le inétathorax de mêno, lo prothorax avec les angles lateraux et les tubercules jaunes. Ailes hyalines, avee los nervures testacées, la cellule radiale angulouse au sommet et portnnt un petit appendice. Pattes noires, les genoux avec les jumbes antérieures on avant, jaune, tarses tọstacé-bi'unâtre. Abdomon noir, en ovale allongé, les 4 segrments basilaires avec chacun une tache jaune transvorsalo de chaque côté, l'extrénité avec pubescence blanche, et l'article terminal rougo.

ס-Aroe le chaperon, u labre, lia base dos mardibules, le scape des antonncs en avant, juune, les pattes presque entierement jaunes, et les taches abdominales plus grandes-CapRouge. 


\section{Gen. Chelynie. Chelynia, nov. gen.}

(De chelynd lovre).

Tête aussi large quo lo thorux, a labre très développé, s'avangaut en carré fort on avant dos inunilibulos, son oxtrómité tronquéo ot légèroment rabuttue sur los côtés. Palpes labiaux do 4 articlos ciont lo 3e est inwérés all dossous do l'extrómitó du 2o, la langue longue et grêle. Antennes do longuour moyenne, a article terminal comprime. Thorix court, ectusson en dumi corcle; métnthorax très court, ne dúpussant pas l'écusson. Ailes aveo la collulo radialo lancóolóo, sa pointo so dótnohant lógóro. ment do la côte et portant un petit appondic ${ }^{2} 2$ cubitales, la 20 recevant los 2 ricurrentes. Pattes assoz courtes, loy crochets des tarses aveo uno dent, les pattes postériour'os munies d'une brosse a la jambe et au premier article du taree. Abilomen fort, subsessile, droit, non rétréci ì la base, arrondi of plus étroit d l'uxtrémité.

Le labre avancé de ces insectos los rond tout id fait remar. quables.

Une seule espèce rencontrée.

Chélynie a-grar de-lèvre. Chelynia labiata, n. sp.

\%-Long. 37 pce. Noire avoc poils cendrés peu abondants ; la frice a poils assez denses, blanchatres, lo labre nu, se projetant considérublement en avant, coupé carr'é à son extrémité où il s'élurgit en s'abaissant un peu de ehnque côté, sa surfuco chagrinéo a l'exception d'un espace triangrulaire a la base qui est poli et brillant. Antennes assez courtes, noires. Thorax densément ponctué, l'écusson à ponctuntions plus fortes; les flancs a poils cendrés, peu abondants, les tubercules et les écuillettes, noir. Ailes sub-hyalines, un peu plus obscures a l'oxtrémité, les nervures et le stigma, noir. Pattes noires, les tarses avoc poils jaunâtres en dessous. Abdomen fortement ponctué, à poils noir's épar's vers son extrémité, les sogments étranglés aux sutures, 1 et 2 portant une ligne blanc-jaunâtte au miliou, 3 et + uvec une même ligne interrompue au milieu, 5 aveo une tache transversalo de chaque côté, le reste noir.-Ottawa.

$\sigma^{7}$-Même coloration que dans la \&, le 5 e segment poitte une bande étroitement iutorrom pue au miliou; puboscence de la fuce plus longue et plus donso. Abdomon rocourbs on dessous a l'extrémité.-Ottawa. 
Gen. H\&mines, Latr. p. 716.

\section{FXTRA TITMINA}

Hóriado taobóe. Heriules maculatum, n. sp.

\%-Iong. .20 pce. Noire avec pubescence blanche, lo thorax et la teto fortement pouctuís. Métunotum nul. Ailes assez forte. mont enfumées, surtout a ln indinle, is nervures noires. Pnttes sans uncune tache. Abdomen conlt ot lurge, finement et donse. ment ponctuó, saus cnrène au sogınent basilnire, les 3 segments basiluires of nveo une tache blunche de chilquo côté un forme de gros points, d:r... lo $\sigma^{7}$ lo segment 4 porto do plus 2 tiches sem. blables de chaque cóté et le segment $\mathfrak{3}$ une, dessous a poils blanchatres.-Vincouver (Taylor).

Jolie petite espèce bien remarquable par ses taches abdominales,

Gen. Mrgiachile, Latr. p. 709.

n. sp.

bondants ; projetant inité où il finco chae qui est orax denlos flanes cuillettes, émité, les avoc poils poils noirs sutures, 1 uvec une transver-

poite une de la fuce lossous a

Des 13 espúces décrites, retranchez oblonga, Prov. qui appartient aux Osmies, changez le nom,spécifique simplex qui a été préalablement employé par Śnith pour un insecte de la Nouvelle-Hollande, en celui de inermis.

5. Megaohile pugnata, Say, p. 712.

Nous avpons décrit. In $p$ do cetto espèce sous lo nom do Gnathocerus: cephalicus, p. 716. Cet insecte joue do matheur, car M. Cresson avait avaut nous décrit la même o sous le nom de lucrosa, Trans. Am. Ent, Soc. IV, 267. Il est tont de meme assez singulier que:M. Croșson n'nit pas remarqué los fortes épines que cotta famello porte on arrière on dossous de la tête.

\section{Mogachlle inermis. Prov.}

\section{Megachile simplex, Prov.-Faune II, 712.}

Ce ơ par sa: taille et sa forme se rapproche beaucoup de la centuncularis, St. Farg., unais ses hanches antérieures ne sont pas armées d'une épine et son segment anal est simplement échancré et non tridenté. 
9. Mégachile larges-mains. Megachile latimanus, Say-Am. Ent. I, 168 ; Megächile acuta, Smith.-Brit. Mus. Cat. I, 492. Faune, p. 710 .

o-Long .58 pce. Noire, à pubescence blunche ou jauncpâle. Chaperon a ponctuations grusses, profondes et peu dẹnses. Thorax à ponctuations peu denses, irrégulièrement distribuées. Ailes hyaines, légèrement vibscurcies vers l'extrémité. Pattes a pubescence blanchâtre, des crochets tes tarses roux à la base, noir's à l'extrémité. Abdomen à śegment basilaire échancié ạ la base, les $2 \theta, 3 e$ et $4 \theta$ avec une dépression arquée sur le dos, dans sa forme générale il va se rétrécissant. graduellement de la base au sommet; brosse ventrale d'un jaune pâle brillant.-CapRouge.

Bien reconnaissable par la stucture de son abdomen.

: 'Gen. Csmia, Latr., pp. 706 et 811.

Aux 7 espèces dècrites, ajoutez les 9 qui suivent. Séparant les $\sigma^{7}$ des $q$, la clef ci-dessous pourra servir à distinguer les espèces.

\section{FEMELLES.}

1(16) Brosse ventrale noire;

2.9) Pubescence de la face noire, surtout au dessous des antennes;

3(8) Chaperon tronqué on :tvunt ou faibleinent échancre;

4(7) Téguments à reflets n!śtalliques, bleuâtres on verdâtres;

5(6) Thorax à pubescence ocracée; chaperon crónelé en avant; abdomen noir.bleuâtre. 3. lignicola,708.

6(5) Thorax à pubescence blanche; ehaperon sịm. plement tronqué en avant; abdomen bleufoncé, brillant ................................ 8. brevis.

7(4) Tégumerts noir's, brillants, sans reflets métalliques ...................................... 9. oblonga.

8(3) Chaperon profondément échancré en avant. 1. lignaria,70

9(2) Pubescence de la face blanche, ocracée ou jaune pâle, quelquefois entremêlée de poils noir's;

10(15) Chaperon tronqué en avąnt;

11(12) Couleur noire, pubescence ocracée, abdomen à segments frangés de poils jaunâtres... 6. frigida، 811. 
12(11) Couleur, vert, bleu ou pourpre ;

$\operatorname{manus,}$ t. Mus.

u jauncdenses. tribuées. Pattes d la base, ncré ḍ la dos, dans o la base apRouge. วn.

Séparant iguer les

leré ; ridâtres;

icola, 708 .

brevis.

oblonga. paria,707

igida, 811 .
13(14) Abdomen d ceintures pâles. 6. atriventris, 812 .

14(13) Abdómen sans ceintures, vert blouatre. 6. simill.ma, 708.

15(10) Chaperon ciénelé en avant et plus ou moins échancré; couleur blen-foncé; abdomeis marque de poils blancs...... ........... 10. faceta.

16(1) Bro:se ventrale blanc ou jaune-pâle;

17(18) Téguments d reflets bleuâtres on verdâtres ; chaperon tronqué en avant; abdomen sans ceintures.......................... 11. albiventris.

18(17) Téguments noirs, sans reflets métalliques;

19(20) Chaperon profondément échanré en avant ; abdomen d ceintures blanches........... bucconis, 708.

20(19) Chaperon allongé, rétréci et légèrement échancré en avant; abdomen sans cointures bien distinctes. 12. spoliata, n. sp.

\section{MALES.}

1 (14) Fuce à pubesconce blanche ou grise;

2 (9) 6 o segment abdominal arrondi, entier ou très faiblement coché;

3 i6 ) Articles 2, 3 et 4 des tar'ses intermédiaires très dilatés, cordiformes;

4 ( 5 ) 7 e segment très légérement échancré.... 13. latitarsis.

5 (4) 70 segment abdominal distinctement bildenté................................ 14. tarsata, n. sp.

6 (3) Airticles 2, 3 at 4 des tarses interméciaires ordinaires;

7. (8) 7e segment tr’ès faiblement coché ....... 11. albiventris.

8 (7) 70 segment bidenté, segments ventraux plats et teints de bleu.. 15. vicina.

9 (2) be segment distinctement coché ou échancré au milieu, plus ou moins réfléchi;

10(11) 6 esegment avec un petit sillon au milieu. 5. frigida, 811. 11(10) 6e segment avec un petit sillon sur le disque;

.12(13) 7e segment bidenté; ventre noir...........7. parva, 812. 13(12) 7 e segment profondément échancré; ventre

blouâtrê. 16. proxima. 29-Mai 1888 . 
14(1) Face d pubescence ocracée ;

15(16) 6e segment sillonné en dessus; abdomen à ceintures jaunes

5. frigida, 811.

16(15) 6 e segment avancé et réfléchi ; pattes vertes. 17. exigua.

8. Osmie courte. Osmia brevis, Cress.-Proc. Ent. Soc. Phil. III, 36.

9-Long. .34 pce. Bleu foncé; la face, le vertex, le dos du thorax avec le premier segment abdominal, a pubescence jaunepâle, longue et dense, sur le chaperon entremêlée de poils noirs. Chaperon tronqué en aviant. Vertex bleu, très finement ponctué. Ailes hyalines avec le sommet légèrement obscurci. Les flancs du thorax avec les pattes à pubesence noire, jaunâtre en dessous des tarses. Abdomen court, globuleux, bleu fonce, a pubescence noire d partir du 20 segment ; la brosse ventrale noire et dense.CapRouge.

9. Osmie oblongue. Osmia oblonga, Prov.

Megachile oblonga, Prov.-Faune II, 714.

L'absence de pelotte aux crochets des tarses ne permet pas de douter que cet insecte r'appartienne aux Osmies plutôt qu'aux Mégachiles.

10. Osmie gaie. Csmia faceta, Cress.-Trans. Am. Ent. Soc. VII, 103.

9-Long. .45 pce. D'un beau bleu d'acicr à pubescence pâle peu fournic, plus denso sur la face et les flancs. Tête très grosse; chapcron crénelé en avant avec 2 petites dents obtuses au milieu. Mandibules très fortes, canaliculèes sur leur marge inférienre, leur face interne avec pubescence jaunâtre. Mésothorax avec une fine ligne longitudinale sur le dos; les écailles alaires noires. Ailes subhyalines, obscurcies a leur sommet et a leur bord antérieur. Pattes noires, à pubescence pâle. Abdomen convexe, brillant, à ponctuations peu denses, les segments basilaires plus ou moins frangés de blanc aux côtés, tout l'abdomen marginé de poils blancs sur les côtés bien que la brosse ventrale soit noire.

$\delta^{\nearrow}$-La face, le thorax et la base de l'abdomen à pubescence pâle, longue et dense. Le chaperon erénelé au milieu; ailes plus 
pâles que dans la ㅇ. 6e segment r'éfléchi, coché au milieu et subsinué nux côtés; le 7e segment bidenté.

Capturé une o au CapRouge. La forte tête de cette espèce avec sa couleur blene la rend tout d fait remarquable.

11. Osmie ventre-blanc. Osmia albiventris, Cress. -Proc. Ent. Soc. Phil. III, 31.

ㅇ-Long. .2 pce. D'un vert bleuâtre, à pubescence pâle. La tête aussi large que le thorax. La face d pubostenco peu dense, le chaperon tronqué, sa tranche antéricure brillante. Thorax d'un'vert bleuâtre sombre; les écailles alaires noires. Ailes subhyalines, les nervures noires. Pattes noires, a pubescence blanche. Abdomen ovale, d'un vert bleuâtre, densément ponctué, le seg. ment basilaire a pubescence blanche, longue et peu dense, cette pubescence sur les autres segments très courte, plus donse et plus longue sur les segments terminaux. Brosse ventrale blanche et dense.

$\sigma^{\nearrow}-A$ pubescence longue et dense sur la face. Les antennes aussi longues que le thorax. Le 6 e segment entier et le $7 \theta$ coché au miliou.

Capturé au CapRouge et à Ottawa (Guignard).

12. Osmie dépouillée. Osmia spoliata, n. sp.

१-Long. .40 pce. Noire, sans reflots métalliques, avec pu. bescence blanche peu abondanto. Lo chaperon chagriné, tronqué en avant. La tête et le thorax densément ponctués, presque nus. Ailes légerement obscurcies, les nervures noires, les écaillettes noires. Pattes à pubescence blanchâtre, cette pubescence d'un jaune brillant en dessous des tar'ses postérieur's. Abdomen oblong, plus large ver's l'extrémitś, densément et finement ponctué, à sutures enfoncées, les segments portant a peine un commencement de frunge au sommet sur les côtés, l'extrémité aveo une courte pubescence blanche ; brosse ventiale blanche ou jaunepâle._CapRouge.

Un spécimen imparfaitement mûr, avait les pattes brunferrugineux, ainsi que le pavillon des antennes en dessous.

13. Osmie d-larges-tarses. Osmia latitarsis, Cress-l'roc. Ent. Soc. Phil. III, 20. 
Ђో-Long. .45 pce. Vert bleuâtre, la tête finement et densément ponctuée, avec pubescénco blanche longue sur le vertex ut les joues et plús dense sur la face. Chaperon tronqué en avant. Antennes noires, ansai longues que la tête et le thor'ax. Thorax vert blenâtre foncé, finement ponetué avee longue pubescence blanchâtre. Ailes subhyalines, les nervures noirâtres. Pattes noires, à longne pubescence blanche, cello sur les tarses rouskâtre en dessous. Les articles 2,3 et 4 des tarses intermédiaires fortement ólargis et triangulaires; l'épine interno des jambes postérieures près du double plus lungue quo l'antre et courbée en dedans, l'article basilaire des tarses $p$-stérieur's allongé, épais : en massue au sommet. Abdomen plus large en arriere, les 2. segments basilaires a longue pubescence blanche, les autres avec poils noirs, tous les segments avec une bande nue et lisse au sommet; le 5e largement arrondi, à peine coché ... milieu, frangé de poils blancs, le te très légèrement échancré.

Capturé un ơ au CapRouge; bieu remarquable par ses tarses dilatés.

\section{Osmie à-tarses-cordés. Osmia tarsata, n. sp.}

ठొ-Long. .35 pce. Tête et thorax noir's très finement ponctués, couverts d'une longue pubescence pâle, très loirgue sur lo chaperon, les flancs et le vẹrtex. Chaperon tronqué en avant; mandibules fortes, canaliculées sur leur margo inférieure, la deıt extérieure très aiguë. Ailes hyalines, très faiblement obscurcies au sommet. Puttes noirâtres, à pubescence blanchn, les tarses à articles intermédiaires dilaté, cordiformus, l'article basilaire dilaté en massue au sommet, a pubescence testacée en dessous. L'épine tibiale interne grande et courbe. Abdomen convexe, vert bleuâtre foncé, fortement ponctué, le bord apical dés segments uni, poli, !nillant, pubescence longue et blanche a la base, noire dans le reste, l'extrémité avec poils pâles, longs, entremêlés aux noir's; le be segment prolongé et obsolètement coché au inilieu, subsinué aux côtés, le $7 \mathrm{e}$ avec 2 dents aiguës.

Capturé au CapRouge. Diffère de la latitarsis et de l'integra par son 7 e segment bidenté, de la bella par son ventre noir, et de la vicina par sou abdomęn à pubescence noire. 
15: Osmie voisine. Osmia vicina, Cress.,-Proc. Ent. Soc. Phil., III, 38.

$\delta^{7}$-Long. .28 pee. Vert bleuâtre, plus clair sur l'abdomen. Tête avec longne pubescence jaune-pâle, dense sur la face. Chaperon tronqué en avant. Thorax d'un bronzé verdâtre, densémont ponctú, à pubescence longuo et pâle. Ailes subhyalines, légèrement obscurcies au sommet. Pattes vertes, a pubescence pâle, celle de dessous des tarses jaunâtre. Abdomen allongé, à pubescence pâle, longue à la baso et courte sur les autres segments, plus dense sur les terminaux; 6e segment réfléchi et coché au milieu, non sinué sur lẹs côtés, le 7e bidenté; les segments ventraux teints de bleu.

M. J. A. Guignard, d'Ottawa, à qui nous devons la découverte de plus d'un insectr a trouvé ce $\sigma^{7}$ dans une fleur de Cypripède, c'était là l'agent nécessaire à la fécondation de cette fleur. Il a pu aussi capturer la + , nous en donnons ci-dessous la description; M. Cresson n'a décrit que le o'.

†-Long. .30 pce. D'un vert plus clair et à pubescence pâle plus courte et moins dense. Chaperon prolor gé en avant et. légèrement échancré au milieu. Ailes subbyalines, obscurcies au sommet et au bord antériour. Abdomen plus court que dans le $\sigma^{7}$ a brosse vontrale blancho.-Ottawa (Guignard).

16. Osmie proche. Osmia proxima, Cress.

-Froc. Ent. Soc. Phil. III, 32.

$\mathrm{o}^{x}$-Long. .40 pce. Tête verte, densément ponctuée, couverte d'une pubescence dense, plus longue et plus pâle sur la face. Antennes noires. Thorax vort foncé, couvert aussi d'uue pubescance blanche dense. Ailes hyalines, les nervures noires, écaillettes noires, légèroment teintées de verdâtre, polies, brillantes. Pattes vertes avec une courte pubescence blanche. Abdomen vert ou vert.bleuâtre, densément ponctué, la marge apicale des segments polie, lisse, les côtés avec à puine quelques poils blınchâtres, le 60 segment est prolongé au sommet, rediesșé ęt échancré an milien, le segment terminal très profondément échancré au milieu.-Ottawa (Guignard). 
Bien remarq uable par la forme de son sixième segment abdominal qui la distingue surtout de l'albiventris, chez laquelle ce segment est entier, sans échancrure.

17. Osmie très-petite. Osmia exigua, Cress.-Trans. Am. Ent. Soc. Phil. VII, 107.

б-Long. .20 pce. La plus petite especee encore mentionzièe. Ver't teint de bleu ; tête et thor'ux à pubescence scracée lon igue et dense, laquelle est pale sur le chaperon et blanchâtre en dessous du thorax. Tête très grosse. Ecailles alaires d'un virt doré. Ailes a peine obscurcies au sommet. Pattes vortes, a pubescence pâle, brun-lestacé sous les tarses. Abdomeal court, globuleux, vert-bleuâtre, à pubescence ocracéce-pâle, longue d la base et sur les côtés des segments tcrminaux; 1.e segment prolongé, reffléchi et a'rondi a l'extrémité, le 7e avce 2 dents aiguës; les seg' ments ventruux largement arrondis a leur sommet.-Ottawa (Guignard).

Très jolie petite espèce; $q$ encore inconnue.

\section{Gen. Andronique. Andromicus, Cress.}

Tête transverse, aussi large que le thorax. Antennes a scape plus grêle à la base, le pavillon inégal, articles 2 d 5 dilatés, 6 brusquement rétréci, les suivants diminuant graduellement jusqu'au sommet qui se termine par une pointe fine. Palpes labiaux de 4 articles, les 2 premiers articles allongés, les 2 derniers petits et insérés sur le côté frès du sommet du $2 \mathrm{e}$; palpes maxillaires de 4 articles. Ailes à 2 cellules cubitales, la 1ère récurrente s'unissant à la 1ère nervule transverse, la 2e reçue par la $2 \mathrm{e}$ cubitale près de son sommet. Abdomen allongé, sublinéaire, légèrement rétréci vers la base; dans les $\sigma^{7}$ recourbé au sommet.

Une seule espèce rencontrée.

Andronique cylindrique. Andronicus cylindricus, Cress._Proc. Ent. Soc. I'hil. II, 384.

ర-Long. 37 pce. Nuir ; la tête finement ponctuée avoc pubescence blanchâtro sur la fucc. Antenues noires, terminées on 
pointe fine. Thornx finement ponctue, quelque peu brillant, couvert d'une pubescence hlanchâtre longue et épar'se; le métathorax encore plus finement ponctué avec une ligne longitudinule enfoncée. Ailes subhyalines, les nervures brunes. Pattes a pubesvence pâle courte ; les cuisses et les jambes courtes, fusiformes, les jambes intermédiaires surtout très conrtes ; tarses uussi longs que la cuisse et la jambe réunies, ongles bifides. Abdomen cylindrique, a pubescence courte ei rare, un peu plus abondante a la base ot d l'extrémité, l'extrémitó courbée en dessous, les marges des segments comprimées, le segment basilaire convexe et arrondi en avant; le segment basilaire ventral marginé au sommet par. une carèno semi-circulaire et portant sur son disque un petit tubercule hifide; sur les segmenls 3 et 4 il y a deux tubercules obliques, un de chaque côté, dernier segment en forme de pinice, frangé de longs poils jaunes-Ottawa, CapRouge.

Insecte bien remarquable par la conformation de ses antennes.

Après le genre ANDronicus, ajoutez le suivant.

24. Gen. Alcidamer, Alcidamea, Cress.

Tête transverse, aussi large que le thorax. Antennes de la moitié de la longueur du thorax, à scape robuste et assez long, plus grêle à la base, pavillon comprimé, submoniliforme, à peu près d'égale longueur que le scape, légèrement atténué à l'extrémité, à article terminal courbé en forme d'épine. Palpes labiaux et maxillaires de 4 articles. Ailes supérieures avec la $2 \theta$ cubitale recevant les 2 nervures récurrentes. Abdomen subovale, convexe en dessus, légèrement courbé dans les ó, avec le 2e segment ventral plus ou moins appendiculé.

Une seule espèce rencontrée.

Alcidamée à-front-poiiu. Alcidamea pilosifrons, Cress. -Proc. Ent. Soc. Phil. II, 385.

$\sigma^{\pi}$ Long. .50 pce. Tête noire, finement ponctuée, couverte d'une pubescence jaune-pâle, très longue sur la face. Antennes à scape noir, lo pavillon roux-testacé en dessous, noirâtre en dessus. Thorzx convexe, densément et finement ponctué, noir, bril- 
lant, d pubescence blanchatre a:sez longue. Ecaillettes brillantes, noirâtres. Ailes hyalines, a nervures noires. Pattos noires, brillantes, a' poils pâles épar'w, les épines tibiules testacées, articlo terminal des tarses ferrugineux, les ongles bifides. Abdomen subovale, noir, brillant, finement ponctué, convexe en dessus, un peu aplati en dossous, son sommet pointu et reeriurbé en dessous; chaquo sogment porte un e frange apicalo blancho, le $6 e$ porte en arrière de chaque côté une dent aiguë, le terminal étroit, pointu, caréné en dessus ; en dessous, le second segment ventral porte sur son disque une projection obtuse, transver'se, le segment terminal est on forme de pince.

M. Cressón n'ayant point vu la femelle, nous la décrivons ci-dessous.

\&-Face presque nue, n'ayant de poils qu'anx côtés. Anténnes sans appendice à l'extrémité, le pi'emier article allongé, maì d peine plus gros que los autres. Abdomen allongé, cylindrique, chaque segment avec une large bande lisse a la base, le reste fortement ponctué, les sutures enfoncées avec lignes argentées alıx côtés, en dessous chaquo segment portant une longue frange de poils densès et blanchâtres représentánt comme une biosse interrompue transversalemeni. Le reste sombable aux ठొ.Ottuwa (Harrington .

Gen. Epwolus, Latr. p. 718.

Aux 2 espèces décrites, ajoutez la suivante.

3. Đpéole à-écusson-roux Epeolus scutellaris, Say.

-Am. Ent. 1. 240.

ㅇ-Long. .35 pce. Noir foncé, densément ponctué; la face arec une tache de pubescence blanche entourant la base des an. tennes, colles-ci brun-foncé avec les 3 articles basilaires, de même que les madibules, plus ou moins roux. Thurax marginé d'une ligne de pubescence blanche. Les tuberlules, les écaillettes, l'écusson avec sés den'ts latérales dilatées, roux. Ailes hyalinès aveo le sommet largement obscurci. Pattes rousses, les hanchcs noires. Addomen noir, le premier segment aree 2 bandes cendrées s'unissant sur les côtés, les 3 suivants avec une semblable bande au sommet, le 5 e avec une tache de chaque côté. et sa plaque terminale argenté, brillante.-CapRouge. 
Espèce bien distincte par son écusson roux plus forte. ment dilaté que d'ordinaire; ses pattes entièrement rousses la séparent aussi du mercabus.

Gen. Nomada, Latr. p. 720.

Aux 5 espèces décrites, ajoutez les 3 qui suivent.

1(14) Ecusson mutique;

2(3) Abdomen sans taches do jauno..... 1. Am zricana, 721.

3(2) Abdomen avec taches jaunes;

4(7) 2 e segment avec une bande juune continue ou brièvement interrompue au milieu, mais non composée de 2 taches en pointe;

5 (6) Chaperon jaune, scupe jaune en dessous. 4. luteola, 723.

6(5) Chaperon jaune seulement an bord antérieur, scape noir ou roussâtre en dessous............. 6. bella.

7 (4) 2 e segment avec taches jaunes sur les côtés s'allongeant en pointe vers le miliou ;

8(11) Tête et thor'ax, noir ;

9 (10) ler segment avoc bando jaune, ćcusson roux.

10(9) ler segment noir, sans tâches; écusson ........ 7. vicina. Ecusson noir.................... 8. proxima.

11(8) Tête et thorax, roux;

12(13) Abdomen avec une seule tache jaune sur les côtés du $2 \theta$ segment.................. 2. bisignata, 722 .

13(12) Abdomen avec taches de jaune sur tous les segments, excepté le premier ........ 3. maculata, 722.

14(1) Ecusson avec une épine de chaque côté. 5. punctata, 723.

6. Nomade jolie, Nomada bella, Cress.

-Proc. Ent. Soc. Phil. II, 287.

б-Long. .30 pce. Tête et thorax, noir, la première finement et densément ponctnée avec poils blancs coirts; le bord antérieur du chạperon, le labre, les mandibules excepté à l'extrémité, les orbites au dessous des ycux, jaune-blanchâtre. Antennes noires, leur pavillon roux en dessous. Thorax avec poils blanes courts, finement ponctué, les écaillettes ferruginouses, l'écusson indistinctement bilobé. Ailes hyalines, légèrement obscurcies au sommet. Les pattes avec poils blanchâtres, les hanches, les tro$40-$ Mui, 1828. 
chanter's et les cuisses exceptó au sommot, noirâtres ; les jambes et los tarses ferrugineux, les premieres tointes do sur en dohors. Abdomen firiemont ponctue, noiratro svec la marge apjeale des segments forrugineuso; lo 1 or segment noir d la baso, forruginellx au sommet uvec une trche jaune un milieu plus ou moins échancrée en avant, les segments $2,3,4$ et 5 avec une bande jaune a la base plus ou moins atténuée au millieu, celle du 20 beaucoup pius large, le segment terminal d'un ferrugineux noiratre et légerement bifide, dessous ferruginoux noirâtre, quelquefois avec taches juunâtres sur lo 3 e segment ot les suivants. CapRouge.

Se distingue surtout de la luteola, par sa coloration en général plus foncée, et son chaperon qui n'est jaune qu'à son bord antérieur.

7. Nomade voisine. Nomada vicina, Cress.

-Proc. Ent. Soc. Phil. II, 292.

Q-Long. .35 pce. Noire, densément ponctuée, les orbitcs obsoletcment ferrugineux, le labre avoc les mandibules d'un roux .brunâtro. Antennes noires, forrugineuses en dessous, excepté au sommet. Thorax noir, densément ponetué; les tuborcules, les écaillettes, uno tacho sur le bas des flancs avec l'écusson, qui est bilobé, d'un roux brunâtre; le mótathorax frangé de poils blancs sur les côtés. Ailes hyalines, légèrement obscurcies au sommet et portant une lunule clairo en avant de l'extrémité, lo stigma roux pâle. Pattes ferrugineuses-brunâtres, les hanches avoc les cuisses en dessous, noir. Abdomen finement ponctué, brillant, noir; le lor segment avec une étroite bande jaune interrompue au milieu, le 20 avec une grande tache jaune à la base, de chaque côté, s'allongeant en pointe vers le milieu et légèrement échancrée en avant sur les côtés, le $3 e$ avec une semblable tache, is beaucoup plus petito et n'atteignant pas le milieu, les 2 suivants avec une bande continue, échancrée de chaque côté, celle du 50 beaucoup plus large, l'anus brunâtre ; dessous brunâtre avec nne tache pâle de chaque côté des segments 2,3 et 4.-CapRouge.

Son absence de jaune dans la face et les marques de son abdomon la distinguent surtout de la précédente. 
es jambes in dohors. picale des , ferrugiou moins ine bande lle du 20 r'ugineux itre, queluivants, -

en généson bord

les orbites d'un roux excepté au rcules, les on, qui est oils blancs u sommet lo stigma es avec les é, brillant, terrompue de chaque tent échantache, is 2 suivants celle du 5 e re avec nne pRouge.

ues de son.

\section{Nomade proche. Nomada proximc, Cress.}

- Proo. Ent. Soo. Phil. II, 2!)4.

$\delta^{x}$-long. 38 pce. Noire, la tête ot lo thorax aveo puboscence blanchâtre dense; le bord antérieure du chaperon, les orbites au dessous des yeux, le labre, les mandibules excepté d l'extrémité, jaune. Antennes noires, roussâtres en dessous et d l'extrémité. Les tuberculés avec les écaillos alaires, ferrugineux. Ailes hyalines, légèrement obscurcies d l'extrémité. Pattes noires, les jambes aveo l'extrémité des cuisses ot les tarses, rouxbrunâtre. Abdomen uoir, a premier segment long et rétréci graduellement vers la base, sans taches; le $2 \theta$ kegment aveo :ne grande tache jaune de chaque côté, en pointe en dedans, le $3 e$ aveo une étroite bande de nême couleur, inégale da la base, les 40 et 5e avoo une semblable bande, plus large et plus courte sur le 5e et marginée de ferrugineux; l'anus testucé marginé de nnirâtre. Dessous arec une tache jaune sur les segments 2, 3, 4 et 5.CapRouge.

Se distingue surtout de la vicina, par son écusson noir, son 1er segment abdominal sans taches etc.

Gen. Sphecodes, Latr. p. 724.

A l'espèce décrite, ajoutez la suivante:

2. Sphéoode a-mandibules-rousses. Sphecodes mandibularis. Cress.-Trans. Am. Ent. Soc. IV, 250.

$\sigma^{7}+$ o-Long. .21 pce. Noire aveo l'abdomen roux. La face avec poils blanchâtres sur les côtés, le chaporon luisant, ponctué; les mundibules entièrement rousses (quelquofois brunes au sommet), les antennes roussâtres a l'extrémité. Thorax d ponctuations profondes, le métathorax fortement rugueux, comme alvéolé et subcuréné au sommet. Ailos hyulines-jaunâtres, iridescontes, les nervures et le stigma jaunât.es, los écaillettes testacées. Pattes brunroussâtre avec poils gris. Abdomon convexe, ovale, roux, noir a l'extrémité, les segments terminaux avec quelques poils blancs. -Ottawa (Harrington).

Après le gen. Caclioxys, p. 724, ajoutez le suivant. 
Gen. Stere. Stelis, Panz.

Tête transverse, Antennes filiformes dans les 2 sexes. Palpes labiaux de 4 articles, les maxillaires do 2, petits. Teux glabres. Ailes supérienres avec 2 cellules cubitales, la radiale aussi longue que les 2 cubitales réunies, aiguë au sommet; la 2e cubitale recevant les 2 nervures récuirentes. Abdomen sans brosse, ni lenté ni lobó dans les $\sigma^{x}$; pelotte des tarses petite dans les + , grande dans les $\sigma^{2}$.

Une seule espèce rencontrée.

Stèle fédérale. Stelis faderalis, Smith.

-Brit. Mus. Cat. II, 275.

\%-long. .25 pee. Noire, la face couverto d'uno pubescenco grisâtro. Antennos roussâtres à l'extrémité. Tête ot thorax fortement ponctués. Ailes hyalines-brunâtres, étant légèroment obscurcies à l'extrémité. Pattes noires aveo l'articlo terminal des tarses ferrugineux. Abdomen ovale, brillant, finement ponctue, le segment basilaire portant de chaque côté une. tache jaune pâle en forme de poil, les 4 suivants avec une bancie étroite au milieu légèroment interrompue sur le dos, le be sans tacho, a bord arrondi, ontier.

$\sigma^{x}-$ Avec la face plus donsémont pubescente, les cinq sogments busilaires de l'abdomen avec une fascie sinuée inférieurement de chaque côté; le segment apical arrondi- - Ottawa (Guignard).

Gen. Ceratina, Latr. pp. 717 et 812.

Des 3 espèces décrites, retranchez la 1ère, bidentata, Prov. qui appartient aux ANTHophora, et à laquelle nous assignons, comme espèce nouvelle, le nom spécifique de nudata, Irov.

Anthophora nudata, Prov.

Ceratina bidentata, Prov. p. 718.

Diffère surtout de la subglobulosa, Prov. par son ubdomen à peu près nu et sa pubescence plus courte et moins dense. 


\section{.VI उHJUAJ9 AI 30 JOUIDJJ}

no pubes. ot thor'ax ggerement minal des t ponctué, jauno pâle au miliou a bord arcinq soginférieur'e- Ottawa

ata, Prov. assignons, , Prov.

son ubdoet moins

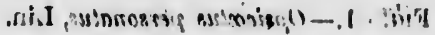

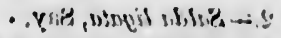

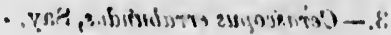

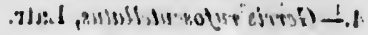

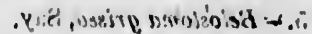

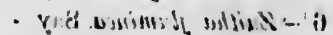

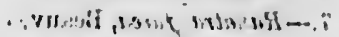

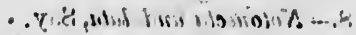

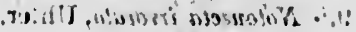

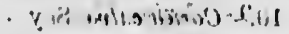

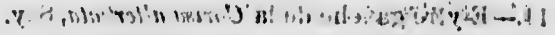

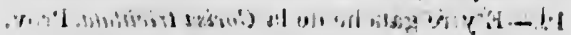

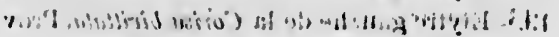<smiles>[Y5][18F]</smiles> 


\section{LEGENDE DE LA PLANCHE IV.}

Fia. 1.-Opsicaitus personatus, Lin.

2.- Salda ligata, Say.

3.-Cerascopus errabundus, Say.

4.- Cetrie rufoscutellatus; Latr.

5.- Belóstoma grisea, Bay.

6.-Zaitha fuminea. Suy.

7.-Railcster fasea, Benuv.

8.- Notonela undulata, Say.

1. - Notonecta irrorata, Uhter.

11.- - Corisa calva. Say.

11.-Elytre ganche de la Corisa alternata, S:iy.

1..-Eiytre gauche de la Corisa trivittata, Prov.

1i.- Elytre gauche de la Corisa biviltutu, Prov. 


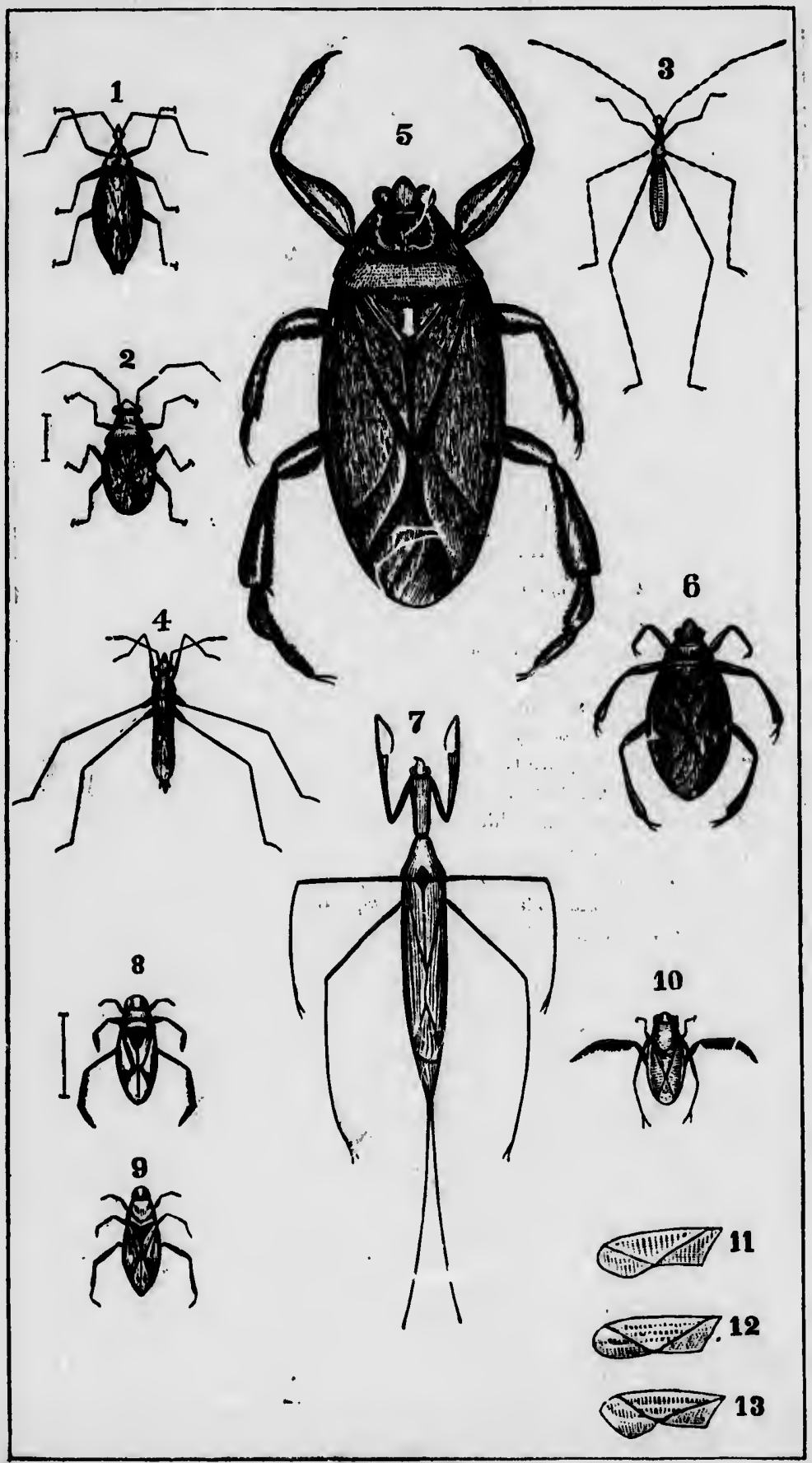

AUEGEC ENLI. CO. 


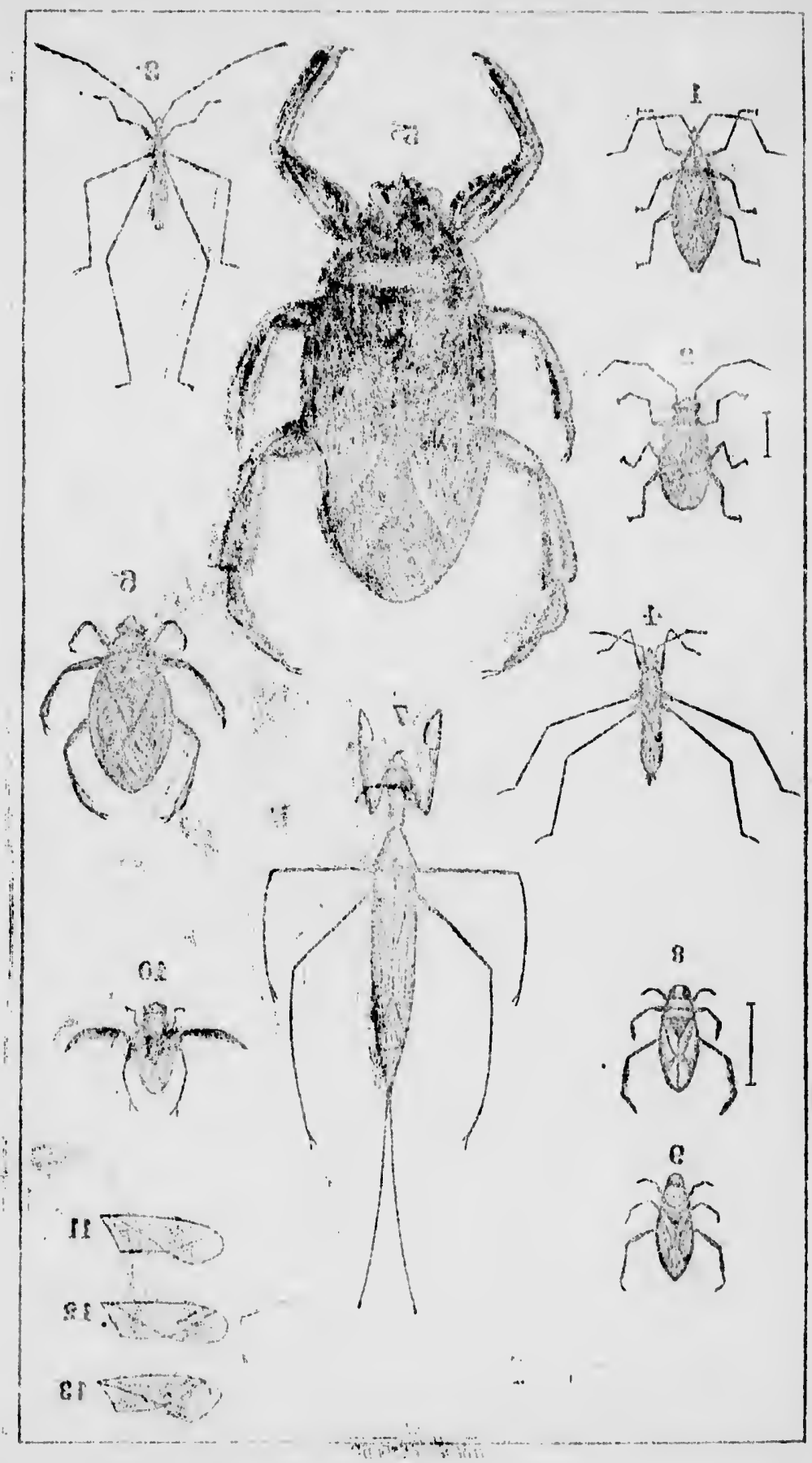

les yeu cubitale arrondi pen prè domen $\mathrm{Ce}$ Andrèn par ses en géné Nc $\sigma^{\top}-$
bescenc
peron $n$
fléchi, b
court,
plus lon
mite, le mite, le tarses te tous les poils sur tant un - $\quad$ ㅇ.

Au 1(13) 2(12) 


\section{Gen. Nomזs. Nomia, Latr.}

Tête courte avec la face légèrement plus étroite en haut, les yeux allongés. Thorax court et robuste. Ailes à 3 cellules cubitales, la radiale un peu plus courte que la 1ère discoïdale, arrondie au bout qui ne touche pas lia côte, la 2e récurrente à pen près droite. Pattes dans le $\sigma^{7}$ renf́lées et contournées. Abdomen ovale-elliptique.

Ce genre a été omis dans la clef de la page 295 ; voisin des Andrènes et des Halictes, il se distingue des unes et des autres par ses pattes arquées et renflées et par sa forme plus robuste en général. Une seule espèce rencontrée.

Nomie compacte. Nomia compacta, n. sp.

$\delta$-Long. .30 pce. Noire, la tête et le thorax avec une pu-• bescence blanchâtre courte, la face allongée, presque nue, le chaperon noir foncé, fortement tronqué en avant et légèrement réfléchi, brillant. Anteınes noires, roussâtries a l'extrémité. Thorax court, compacte, fin-me.st ponctué, les flances avec poils blancs plus longs et plus apparents. Áiles hyalines, cobscurcies a l'extrémité, les nervures brunes. Pattes noires, brillantes, les cuisses et les jambes renflées, arquées, avec poils blancs peu denses, les tarses testacés-roussâtres. Abdomen court, convexe, presque nu, tous les segments avec une bande apicale testacée, firungéo do poils sur les terminaux et sur les côtés des basilaires, le $7 \theta$ portant un petit appendice noir en forme de grouttière.-CapRouge.

o Encore inconnue.

Fam. XXII. APIDES. Apida, p. $72 \%$.

Gen. Bombus, Fabr. p. 733.

Aux 4 espèces décrites, ajoutez les 8 qui suivent.

1(13) Abdomen jaune et noir, sans bandes de roux;

2(12) Thorax jaune avec une bande ou seulement une tache noire entre les ailes; 
3(6) Le segment basilair'e seul jaune;

4(5) Touti l'abdomen noir excepté le 1er segmisnt.

5. Virginicus.

5(4) 1er segment jaune, 2e roussâtre-brun, le reste noir..... 6. affinis.

6(9) Segments 1 et 2 jaines;

7 ( 8 ) Tuille plus forte, plus allongée, $\sigma^{x}$ avec poils jaunes sur la face.

7. vagans.

8(7) Taille plus petite, plus compacte; $\sigma^{7}$ a face noire ............................. 1. consimilis, p. 734.

9 (6) Les 4 segments basilaires jaunes;

10 11) Thorax noir sur les côtés.

2. fervidus, 735 .

11(10) Thorax jaune sur les côtés 8. borealis.

12(2) Thorax avec une bande jaune en avant seulement, ler segment noir, 2 et 3 jaunes . 3. terricola, 735.

13(1) Abdomen avee bandes de roux;

14(17) Segments 1 et 4 avec jaunes;

15(16) Segment 4 entièrement jaune, 2 et 3 roux.

4. ternarius, 735 .

16(15) Segment 4 noir à la base, jaune au sommet, 2 et 3 roux

9. lacustris.

17(14) Segmeuis 1 et 2 jaunes;

18(19) Tous les segments roux à partir du 3e.... 10. praticola. 19(20) Segment 3 noir, 4 roux ....................... 11. frigidus. 20(19) Segments 3 et 4 roux, le reste jaune sur les eôtés et roussâtre an milieu avec l'anus noir 12. rufocinctus.

5. Bourdon de Virginie. Bombus Virginicus, Fabr. -Proc. Ent. Soc. Phil. II, 87.

q-Long. 1 pee. Tête noire avec poils jaunes plus ou moins abondants sur le vertex. Thorax jaune sur le dessus et les côtes, souvent avec une tache noire sur le dos. Ailes hyalines, légèrement enfumées, quelquefois violacées. Pattes noires, taries bruns avec le premier article roux endessous. Abdomen avec lo 1er sogment jaune, le reste noir ; dessous noir.-Ottawa. petite.

8-Mêne coloration que dans la $q$ mais de taille plus 
8-Long. 60-.70 , $\cup 0$. Face avec poils jaunes au vertex ${ }^{\circ}$ et su dessous des antennes. Yeux très gros et proéminents. Thorax d'un jaune roussâtre. Les euisses aves longs poils jaunâtres endessous. Abdomen avec le ler segment et la partie antérieure du $2 \theta$ au milieu jaune, le reste noir.

Non encore rencontré à Québec.

6. Bourdon allié. Bombus affinis, Cress.

-Proc. Ent. Soc. Phil. II, 103.

우 $\delta$-Long. .60 pce. Noir et jaune; la face au dessous des antennes, le vertex, tout le thorax, avec poils jaunes; le thorax porte une tache noire au miliou. Ailes fusco-hyalines. Pattes noires, les cuisses avec poils jaunes en dessous, le 1er article des tarses postérjeur's d'un jaune doré en dedans sous une certaine lumière. Abdomen avec le 10 regenent jaune, le $2 \theta$ brun-roussâtre dans sa moitié antérieure, le reste noir. Le roussâtre du 2 e segment s'avance plus ou moins sur le promier au milieu.

-Ottawa (Guignard).

La couleur du 2o segment abdominal de cette espèce la distingue facilement de ses voisines.

7. Bourdon vagabond. Bombus vagans, Smith.

-Brit. Mus. Cat. II,399. -Proc. Ent. Soc. Phil. II,91.

q-Long. .55 pce. Tête noire, plus on moins jaune sur le vertex. 'Thorax jaune en dessus et sur les côtés, souvent avec une tache noire sur le disque. Ailes hyalines-enfumées. Pattes noires, lo premir article des tar'ses postérieur's roux-brillant en dessous. Abdomen avec les 2 segmonts basilaires jaunes, le reste noir"; dessous noir.-CapRouge.

\&-Long. .45 pree. Même coloration que dans la $९$.

$\sigma^{7}$-I.ong. .47 pce. Tête avec une touffe de poils jaunes $x$ dessous des antennes. Les cuisses munies de poils jaunâtres en dessons. Segment apical de l'abdomert souvent avec poils jaunes entremôlés aux noirs. Dossous avoc poils jaunâtres.

Très rapproché du consimilis par sa coloration, mais s'en distingue surtont par sa plus forte taille et sa brosse tarsale rouxclair et non brune. 
8. Bourdon boréal. Bombus borealis, Kirb.

-Faun. Bor. Am. IV, 272.-Proc. Ent. Soc. Phil. III, 52.

२-Long. .55 pce. Tête noire avec poils jaunes sur le vertex et an milieu de la face au dessous des untennes. Thorax jaune en dessus, les côtés, avoc une large bande transva"se entre les ailes, noir. Ailes légèrement obscures, plus foncées près de la côte. Pattes noires, les tarses pâles en dchors, roussâtres en dessous. Abdomen avec les 4 segments basilaires jaunes, les 2 apicaux noirs; dessous noir.

q-Même coloration que dans la $q$.

$0^{3}$-Semblable à la o mais avèc l'abdomen plus allonge, les 4 premiers segments jaunes et les 3 apicaux noirs d la base et jaunes au sommet. Long. .65 pce.-Ottawa, CapRouge.

Nous avons reçu d'Ottawa 2 petites ouvrières que nous rapportons avec hésitation à cette espèce, car elles en diffèrent quelque peu. La face est entièrement noire et les côtés $d u$ thorax jaune. pâle. Long. .40 pce.

9. Bourdon des-lacs. Bombus lacustris, Cress.

-Proc. Ent. Soc. Phil. II, 103.

ㅇ-Long. .75 pce. Noir avec poils!jaunes sur la face et le vertex. Thorax avec le devant et les côtés à poils jaunes entremêlés de noirs, le milieu noir et l'écusson jaune. Ailes subhyaines, la marge apicale plus obscure. Pattes noires, la base des cuisses jaunâtre, les tarses brunâtres avec la brosse tarsale d'un roux brillant. Abdomen avec le 1er segment et lo bord upical du 4e, juune, 2 et 3 roux, les terminaux noirs; le dessous noir avec poils jaunes entremêlés aux noirs.

8-Avec la frange apicale dn te segment moins apparente; taille plus petite.

$\delta^{7}$ - Semblable a la ㅇ, mais avec moins de poils noirs entremêlés aux jaunes sur la face et le devant du thorax.-Ottawa (Guignard).

Non encore rencontré dans les environs de Québec. La frange jaune de son $4 \mathrm{e}$ segment abdominal le fait facilement distinguer du ternarius. 
10. Bourdon piatiosle. Bombus praticola, Kirby. Proc. Ent. Soc, Phil. 11,106.

. $\sigma^{\top}$-Long. .70 pee. 'Tête noire avec poils jaunes ontremêlés aux noir's au dessous des antennes et sur le vertex. Thorax jaune avee une grande tache noire entre les ailes; colles-ci légèremen? obseurcies. Pattes noires, les euisses arec quelques poils jnunes en dessous. Abdomen avee les segments 1 et 2 jaunes, tout le reste roux exeepté l'anus qui est noir, les segments 4 et 5 portent aussi du jaune sur leur's côtés; dessous avec poils jaunes.

8-Long. . 40 pce. Face entidrement noire; le roux s'étend sur le sommet du 20 segment et l'anus noir est presque sans poils roussâtres; la brosse tibiale brun-roussâtre. - Ottawa (Guignard).

Reçu un $\delta$ et une $\$$ de M. Guignard, aucune $\$$ encore rencontrée.

11. Bourdon froid Bombus firgidus, Smith. - Brit. Mus. Cat. 11,399.

\&-l long: .70 pce. Tête noire avec poils jaunes sur le vertex. Thorax jauno avec une bande noire entre les ailes; celles-ci hyalines, légèrement obseurcies. Pattes noires, les cuisses avec quelques poils jaunes; brosse tibiale rousse. Abdomen avec les 2 segmeus basilaires jaunes, lo 3 e noir, et le reste roux ou jauneroussâtre. Dessous noir avec quelques poils jaunes.

६-Long. .45 pce. Même coloration que dans la $q$.

$\sigma^{3}$-Même coloration, excepté que la tête et les pattes portent des poils jaunes.-Ottawa (Guignard).

Reçu 2 \& de cette espèce d'Ottawa, aucune + ni $\sigma^{\top}$ encore rencoutré.

12. Bourdon à-ceinture-rousse. Bombus rufocinctus, Cress.-Proc. Eint. Soc. Phil. II, 106.

f-Long. 62 pee. Tête noire avec une touffe de poils jaunes au dessous des antennes et une autre sur le vertex. Thorax jaune avee une bande noire plus ou moins distincte entre les ailes, les eôtés et le dessous aussi avee poils jaunes. Ailes subhyalines, un peu plus foncées vers la eôte. Pattes noires, les euisses avec poils jaunes en dessous, la brosse tarsale brun-roussâtre. 4:-Juin 1888

noirs entreax.-Ottawa

Québec. La it facilement 
Abdomen avec les segments 3 et 4 roux, tous les autres juunos, la pubescenco jauno au milion des deux premiers segments et a l'anus très pen dense, laissnnt paraitre le nuir des tégumonts. Lo dessous à poils jannes peu denses.

8-Long. 49 pce. Même coloration que dans la $q$ d l'oxception de la face gui est toute noire.-Ottawa (Guignard), CapRouge. ration.

Aucun $\sigma^{7}$ rencontre. Espece bien distincte par sa colo-

\section{EXTRA LIMINA}

Bourdon à-ceir

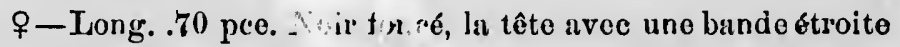
transversale jaune sur le vertex. $\delta_{1, j}$ !horax avec une large bande jauno en avant. Ailes fortement enfumées. Pattes noiros. Abdomen à segments 1 et 3 noir's, 2 jaune, le reste roux-jaurâtre,

- Úalifornie (Coquillett).

Nous n'avons trouvé aucune description répondant à cette o qu'on nous a envoyée de Californie.

$\delta$ et 8 non encore connus.

Gen. Apathus, Newm. p. 736.

Aux quatre espèces dicrites, ajoutez les 2 qui suivent:

\section{FEMELLES}

Abdomen noir a la base;

Segment 3 soulement arce jaune sur les côtés.................... 1. laboriosus, 736 .

Segments 3, 4 et 5 avec jaune sur les côtés... 5 . insularis.

Segment 4, entièrement, bord postérieur de 3

et côtés de 5, juune.............. 2. Ashtoni, 736.

Femelles des autres espèces non encor'c connues.

\section{MALES.}

Segments : 1 jaune, le reste noir........... 5. insularis.

$1,2,3$ juunes ; ahdomen rétréci à l'extrémité .................. 4. citrinus, 737 
en jununos, nents ot a gents. Lo

of a l'oxard), Cap-

sa colo-

ctus, n. sp. nde étroite urge binde ires. Abdotiatto,

ant à cette

suivent:

riosus, 736. insularis. shtoni, 736.

5. insularis. itrinus, 737
1, 2, 3 jannos ; abdomen arrondi ì l'extrémité ;

Thorax a bando noire entre los ailes distincte, face noire.......... 1. laboriosus, 736. Thorux entidrement jauno; fuce jaune, sogments 5 et 6 a poils juunes entremêlés aux noirs...............6. dorsalis

Tous les segmonts jaunes, les 3 dorniers noir's a la base.................. 3. elatus, 737.

Les femelles de citrinus, clorsulis et elatus, non encore connues.

5. Apathe insulaire. Apatlus insularis, Smith.

- Bombus interruptus, Greene-Ann. Lyc. Nat. Hist. N. Y. VIr, 11.

Apathus insularis, Sm.-Journal of Entom. I, 155.

q-Long. 80 pee. Tête noire avec poils juunos sur lo vertex, quelquefois aussi au dessons des antennes. Thorax jaune en dessus et sur les côtés, noir entre les ailes; cellos-ci bruneshyalines. Pattes noires; tarses brun-roussâtre. Abdonien d'iın noir brillant avec les côtés des segments 3,4 et 5 jaunes. $\Gamma_{\text {ssous }}$ noir.

Var. Lo jaune des côtés du 4e segment s'avance quelquefois jusqu'au milien.

$0^{x}-$ Long. 60 pee. Abdomen avec les segments 2 et 3 (ou sa partie antérieure) et le milieu des 3 segments apicaux, noir, le reste jaune. Cette coloration varie parfois en plus ou moins de jaune.-CapRouge.

La \& est très rapprochée de l'Ashtoni, mais elle s'en distingue par sa plus forte taille et son écusson toujours jaune, tandis qu'il est plus ou moins brun dans cette dernière.

6. Apathe dorsal. Apathus dorsalis, n. sp.

\&-Long. 50 pce Tête noire avec une touffe de poils jaunes sirr la face ot une autre sur le vertex entremêlés de poils noir's. Thorax entièrement couvert de poils jaunes, sans bande noiro entre les ailes, celles-ci subhyalines, a nervuros brunos. Paltes noires, a poils noirs entremêlés de jaune; le premier articlo des 
tarses jaune rougentre on dedans. Abdomen avec les segments 1,2 et 3 converts de poils jaunes, non tris dunses, 4 et 5 a poils noir's entremêlés de jaune, lo terminal avec quelques poils blanchâtres ; dessous a poils jaune-pâle. - Ottawa (Guignard).

Rapproché du citrinus, Sm., mais s'en distinguant par son thorax sans tache de noir, sa forme plus trapue, l'extrémité de son abdomen avec poils blancs etc. Vu plusieurs spécimens, bien constant dans sa coloration. o encore inconnue.

\section{EXTRA LIMINA}

Gen. MÉlipone, Melipona, Latr.

Ces insectes comme mellifères appartiennent à la tribu dés Apiarides. Ils se distinguent surtout des véritables abeilles par Jeurs yeux lisses et le manojue d'aiguillon. Comme les abeilles, leurs jambes postérieures sont conformées en corbeillo pour la récolte du pollen, et le premier article de leurs tarses est aussi dilaté et aplati. Leur's ailes portent une longue cellule radiale, 2 cubitnles séparés l'une de l'autre par une nervure incomplète, et 2 discoïdales, la 3e n'étant pas fermée extérieurement.

Une espèce rencontrée que nous croyons nouvelle.

Mélipone de-Trinidad. Melịpona Trinicladensis, n. sp.

\&-Long. .30 pee. Noir foncé, las antenues quolquo pou roussatres on dessous, surtout a l'extrémité et sur lo scape. Les mandibules roussâtr's's sur leur marge extérieure. Fuce très finement ponetuée, nue, portant seulement une courte pubescence noire sur le vertex; lo chuperon poli, brillant. Ailes noires, plus claires au sommet. Thorax poli, brillant, à poils noirs courts et peu abondants, Pattes noires avec poils noirs, les tarses avec les articles terminaux roussâtres, leur pubescence en dedans du $1 \mathrm{er}$ article aussi roussâtre. Abdomen court, noir, non caré́ú en dussous, poli, brillant, avec poils noirs seulement à l'extrémité.

- Port-d'Espagne, Arima, dans l'île de Trinidad.

C'est sur des fleurs de bananier que nous avons pris les premiers de ces insectes, à Port d'Espagne; nous en avons 
gments

is poils

ils blan-

par son

émité de

écimens,

tribu des

s abeilles

omme les

corbeillo

urs tarses

tue cellule

ervure in-

extérieure-

ssis, n. sp. helque peu scapo. Les e très fineoubescence oires, plus courts et ses avec les ans du $10 \mathrm{r}^{\circ}$ śné on desémité.

as pris les en avons

trouvé ensuite deux nids considérables dans des trous de boulins laissés vides à l'église d'Arima. If. l'ubbó Daudier, curó du lieu, nous dit que plusieurs fois déja il avait détruit ces nids, et que toujours elles les reconstruisaient pour y loger leur miel. Comme il nous donnait l'assurauce que ces abeilles ou guêpes, comme on les appelle lit, ne piquaient pas, nous en brisâmes un nid, et aussitôt nous fûmes littéralement couvert des noirs insectes, dont nous avions peine à nous protéger les yeux, $l_{a}$ bouche et les oreilles, mais sans toutefois nous fairo sentir aucun aiguillon.

La calotte extérieure du nid nous parut do terre noire, aglutinée avec un liquide qui la durcissait en séchant. Les rayons étaient composés d'une cire aussi noirître, et ne portaient d'alvéoles que d'un eôté. Nous prîmes un grand nombre de ces insectes, mais c'étaient toutes des ouvrières; nous ne pûmes distinguer aucun mâle ni femelle.

On suit partout que ces insectes produisent di miel, mais on n'a pas l'habitude de l'exploiter là, comme on le fait à la Guyane et au Brézil.

Nous avons vu ensuite un semblable nid, très voluminenx, sur l'un des contre-forts de la cathédrale de Port-d'Espagne, et à plusieurs endroits nous en avons aussi remarqué d'autres attachés à des arbres dans la forêt. 


\section{SUPPLEMENT}

\section{Avx \\ ADDITIONS AUX HYMÉNOPTÈRES}

DE LA PROVINCE DE QUEBEC.

Commencée en 1885, cette revue de nos Hyménoptł̇es n'a pu se prolonger durant un si long espac z de temps, sans que plusieurs espéces nouvelles ne soient venues s'ajouter aux anciennes. Nous dounons ci-dessous la description de celles qui, rencontrées trop tard, n'ont pu prendre place à leur rang en suivant la classification.

1-Tenthrédinides, Faune II p. 170, Anditions p. 5. Gen. Acondulechra, Say, Faune p. 738.

Acordulecera saginata, Prov. ㅇ p. 739 (1).

Ci suit la description du $\sigma^{\nearrow}$.

$0^{7}-$ Noir; la bouche, les joucs, le scape des antennes en dessous, les épaules jusqu'a l'insertion des ailes, les écuillettes, toutes les pattes y compris les hat.ches, blanc verdâtre. Ailes avec lo stigma brun bordé d'une ligno noire, d'poine obscurcies au milieu. Abuomen sans aucuno tacho do blane d la base.-CapRouge.

Gen. Euura, Newm. p. 183.

A l'espèce décrite, ajoutez la suivante.

2. Euura noire. Euura nigra, n. sp.

+ -Long. .20 pce. Noire sans aucune tache, les mandibules brunâtres. A'rtennes brun-fonce. Thorax poli, brillant. Ailes hyalines, à ne "es brunes, le stigma pâle à la base. Pattes

(1) Le renvoi simple à une page se rapportera toujours au vol. II de la Faune, et les lettres A.DD. indiqueront les Additions. 
testncé-brunatre, les hunches ot la baso des cuisses, noir, l'extrémité des jambes postérieures aveo les tarkon, plus ou moins brunatres. Abdomen allongé, noir sans ancune tucho.-CapRouge.

Bien distincte de toutes les autres espéces décrites Iar sa coloration.

\section{Gen. EmpHYTus, Leach. p. 191.}

De ce genre ont été distraits les 2 qui suivent.

Antennes courtes, presque en massue, lo 30 article lo plus long; cellulo lancéoléo pétioléo....... Fenuras. Antennes longues, filifor'mes, grêles, artieles 3 ot 4 prosquo égaux; cellulo lancéoléo avoc une nervure transverse oblique;

Ailes inférioures sans cellules médianes........ Esrmytos. Ailes inférioures aveo une cellule médiano... Harprpnokus.

Gen. Fenuss. Benusa, Leach.

Corps court et trapu. Ailes avec 2 cellules radiales et 3 cubitales presque égales, la 1ère et la 2e chacune avec une norvure récurrente; cellule lancéolée pétiolée; ailes inférieures sans cellules discoïdales. Antennes de 9 articles. Tête large, transverse. Pattes simples.

Ces insectes se distinguent surtout des Emphytus par leur corps plus ramassé et leur cellule lancéolée qui est pétiolée.

-Une seule espèce rencontrée.

Fénuse courte, Fenusa curta, Nort.-Proc. Ent. Soc Phil. 1,199.

\%-long. .14 peo. Noire, polio, bililante; les antennes \& l'extrémité ot les mandibules brunâtres, do même que les écaillettes. Ailes fortemont enfumées, plus elaires à l'extrémité. Pattes d'un jauno bíu âtro, los hunchos et los cuissos, oxcepté d l'extıémité, noiles. Abjomen avce lo sommet des segments dé. primé, sans aucuno tache.-CapRougo.

Capturé $\sigma^{x}$ tt sur des rosiers. au vol. II de la illant. Ailes base. Pattes 
Genre. Lмphytus, Leach, p. 191.

6. Emphyte à-stigma-noir. Emphytus nigristigma n. sp.

O -Long. .25 pee. Noir ; le labre avec le bord du chaperon, les écailles alaires et lo collier, blanchâtres. Antennes fortes, les articles 3 et 4 à pen près d'égale longueur. Ailes hyalines, les nervures noires, le costa et le stigma noir's. Pattes blanches, les cuisses cxcepté aux 2 cxtrémités, la moitié apicale des jambes postérieures avec leur's tarses, ot l'extrémité de tous les autres tarses, noir; les hanches blanches, noires a la base. Abdomen robuste, noir, les étuis cie la taridre roux a la base, les filets du dernier segments très allongés, apparents.-CapRouge.

Voisin du malacus, mais s'en distinguant par sa plus forte taille, son stigma noir; son costa aussi noir, ses hanches h] auches etc.

Gen. Harpiphore. Harpiphorus, Hartig.

Cinq espèces.

Harpiphorus varianus, Nort. $=E m p h y t u s$, Nort. p. 1.94.

“ versicolor, Nort. $=$ Emphytus versicolor, Nort. p. 194.

“ tarsatus, Say,=Emphytus, tarsatus, p. 194.

" semico:nis, Say, = Emphytus semicornis, p. 195.

" maculatus, Nort. = Emplıytus maculatus, Nort. p. 195.

Gen. Nematus, Jurine, pp. 183 et 740 ; ADD. p. 6.

Aux 17 espèces décrites, ajoutez les 2 qui suivent.

18, Némate jaune. Nematrs chloreus, Nort.-Trans. Am. Ent. Soc. I, 221.

o--Long. .30 pee, Jaune verdâtre; corps court et trapu. Antennes noices, articic 3 plus court que 4 ; pâle, a sutures pro- 
fondes; labre orunâtro, les écailles alaires avec les angles antériours, blunntsittres. La moitié postérioure de l'écusson noiro avec une tacho de la même conleur" s'stendant plus ou moins sur les plaques basilaires et le dos de l'abdomen, valves de la tariero junne-verdâtre. Ailes hyalines, les nervures brunes, lo stigma verdâtre, la 2 e cellule cubitalo avec 2 angrles en destous. Pattes de la coulenr du corps avec l'extrémité des jumbes et uno partie des tarses brunâtres.--Chicoutimi (Huart).

Superbe espèce, bien distincte par sa coloration.

19. Némate décoré. Nematus decoratus, n. sp.

$0^{\pi}$-Long. 21 pce Noir; la face au dessous des antennes, les joues, les orbites antérieurs et postéricur's, une grande plaque sur les côtés du prothotax, los écailles alaires avec les pattes, Wlane ou jaumo pâle. Ailes hyalines, le stigma jauıâtre, pâlo à la hase. I Les cuissess postérieures en dessus, aroc l'extrémité de leur's jumbes et leurs turses, noir. Abdomen allongé, poli, brillant, los segments déprimés à leur sommet - Floride (Ashmead).

o Inconnue. Espèce bien remarqualle par les plaques blanches de son prothorax.

Gen. Sklandria, Leach., pp. 199 et 172. ADD. p. 7.

Le genre Selandria se subdivise aujourd'hıi en 8 genres différents, qu'on peut, comme suit, distinguer les uns des autres.

1(6) Cellulo lancéulée pétiolée;

2(3) Ailes infériemres sans cellule tiscoïdalos. Blennocanpa. 3(2) Ailes inférieures avec une cellule discoïdale;

4(5) Antennes filiformes, courtes, non poilues, a articles 3 plus long que 4 ................. Monopuadnus.

5(4) Antennes sétacées, longues, poilues, d article 3 plus court que 4................ Pirysiatocera.

6(7) Cellule lancéolée contractéo au milieu; ailes inférieures d 2 cellules discoïdales.... Horlooampa.

7(11) Cellulo lancéoléc avec une nervure truusvorso oblique;

8(9) Ailos inférieures sans cellule discoïdale.. Calroa.

9(10) Ailos inférieures avoc 1 cellule discoïdale... Monostegra. 43-Juillet, 1888. 
10( 9 ) Ailes inférieures avec 2 cellules discoïdales... Errocampa.

11(7) Cellule lanccolée ouverte à l'épaule, sans nervuro transivel'se; ailos inferieures avec 2 cellules discoïdules

Selandria.

Gen. Buennocampa, Hartig.

Deux espèces.

Thorax roux. Blennocampa pygmæa, Say,-Am. Ent. I, 23.

Selandria vitis, Hurr.-Faune, p. 200.

Thorax noir. Blennocampa paupera, Prov.

Selandria paupera, Prov. p. 742.

Gen. Monophadnus, Hartig.

Quatre espèces.

Thorax roux. 1. Monophadnus bardus, Say.

Allantus bardus, Say-Am. Ent. I. 218.

Selandria bairda, Say-Faune, p. 200.

Selandria media, Nort-Trans. Am. Ent. Soc.

Thorax noir ; I, 250 ; F. p. 200 ,

Dos de l'abdomen roux au milieu. 2. Monophadnus rubi, Harr._Selandria rubi, Harr. Proc. l'hil. VIII, 221; F. 201 .

Abdomen tout noir ;

Ecailles alaires blanches. 3. Monophadnus medius, Nort.

Selandria nedia, Nort.-Proc. Phil. III, 9; F. 201.

Ecailles alaires noires. 4. Monophadnus tiliz, Nort.

Selandria tilia, Nort.--Proc. Bost. VIII, 221; F. 201.

Geu. Phymatocera, Dahlb.

Une seule espèce.

Fhymatocera fumipennis, Nort.

Selanaria fumipennis, Nort-Trans. I, 252 ; F. 201. 
Gen. Hoplocampa, Hartig.

Deux espèces.

Couleur, iaune. 1. Hoplocampa haloion, Nort.

Selandria halcion, Nort.-Trans. I, 25.

Selandria flavicornis, Prov.-F. 201.

Couleur noire. 2. Hoplocampa Canadensis, Prov.

Selandria Canadensis, Prov. ADD. 7.

Gen. Caliroa, Costa.

Unie seule espèce.

Caliroa obsoleta, Nort.

Selandria obsoleta, Nort-Trans. I, 254; F. 202.

Gen. Monostegin, Costa.

Deux espèces :

Ecailles alaires et collier, blanc. 1. Monostegia ignota, Nort. Selandria ignota, Nort. - Trans. I, 257; F. 262.

Ecailles alaires et collier, noir. 2. Monostegia rosæ, Harr.

Selandria rose, Harr.-Trans. I, 256 ; F. 202.

Gen. Eriogampa, Hartig.

Deux espèces dont une nouveile.

1. Exiocampa marginata, Prov.

Selandria marginata, Prov.-ALD. p. 8.

2. Eriocampe superbe. Eriocampa superba, n. sp.

Q - Long. .30 pee, Vaciéo de jaune et do noil', le thorax on partie noir ut l'abdomen entierement, jaune. Tête noire avac lo chaperon, le labre, les mandibules, les joues, orbites dilatés sur le vertex, blanc, un tubercule jaune entre los antennes an milieu de la ficce. Antennes pûles en dessous, articles 3,4 ot 5 a peu près égaux. Thorax noir aveo les bords du prothorax, les 
Écailles alaires, une tache sur les flancs, l'écusson et le métathe. rax on partie, jauı pâle. Ailes hyalines, les nervures et le stigma, brun. Pattes jaunes, l'extrémité des jambes postérieures avee leurs taries, plus ou moins obicures. Abdomen rohnste, janne, sans autre tache qúo les valves de la tariere qui sont noires. -CapRouge.

Cette jolie espèce se distingue à première vue par sa coloration.

Gen. Macrophya, Dahlb. p. 203.

Aux 17 espèces décrites, ajoutez la suivante.

18. Macrophye à-cornes-épaisses. Mucrophya crassicornis, n. sp.

万人-Longr. 28 pce. Noire, le ehaperon, lo labre, les mandibules excepté a l'extrémité, les bơrds supérieur's du prothorax, les écaillettes, une large bande horizontale sur les flancs, les pattes excepté le sommot des enisses postérienres aver lemr's jambes et leurs talses, blanc. Antennes fortes, shiderement noires, festonnées en dessous. Ailes hyalines, les nurvures noires, la cellulo lancéolée avec une petite nervaro transverso droite. Toutes les hanches sans aucune tache. Abdomen noir", sans aucune tache.-Chicoutimi.

Voisine de l'albomaculata, Nort., mais avec ies hanches blanches etc.

Gen. Taxonus, Meg. pp. 213 et $743:$ And. p. 9.

A.ux 8 espèces décrites, ajoutez la suivante,

Extra limina.

Taxon de-la-Floride. Taxonus Floridanus, n. sp.

万-Long. .38 per. Noir, fortement ruguenx excepté sur l'abdomen; le bord du chaperon, lo labre, le seape des antennes, lr: bord du prothorax avec une grando tacho au dessous, les ecailles slai!cs, junne ronssâtre. Chaperon tronqué, labre arrondi en itrant. Antennes contes, atteignant à peine l'insortion des ailus, épaisses, festonnéus on dessuins. Ailes passablement obs- 
curcics, cellule lancéolée avec une nervure transverse ublique, lo stigma pâlo, les inféricures sans cellules discoïdales. Pattes jaunes, toutes les hanches arec les cuisses postérievres excepté au sommet, noir, les trochantere, les jambes excepté au sommet, blanc on jauno pâle; les hanches posterienres avec lours cuisses, finement ponctués-rugueuses. Abdomen poli; brillant, noir avec le 1 er segrnent et les plaques basilaires, roux.-Jacksonville (Ashmead).

우 Inconnue. Les anteinnes de sette espèce la rendent tout-à-fait remarquable.

Gen. Tenthredo, Lin. pp. 219 et 745 ; Add. p. 12.

Le genre Linnéen a été divisé en deux comme suit : Articlo 3 des antennes beaucoup plur long que 4... Tenthiedo. Articles 3 ef 4 des antonnes à peu près égatux ...................... Tenthrledolsis, Custa.

Gen. Tenthredopsis, Costa.

Cinq espèces.

Abdomen tout noil; ailes enfumées......... 1. atroviolacea. Abdomen plus ou moins roux;

Thorax noil, sans tache................. 2. delta.

Tholax goir avec taches jaunes ou lousses;

Tête noire au dessus des antennes......... 3 confusa.

Tête en grande partie blanc-verdâtre......4. semilutea. Abdomon jaune, linéolé de brun........... 5. 14-punctata.

1. 'Tenthredopsis atroviolacea, Nort.

Allantus atroviolaceus, Nort.-Trans. II, 233 ; Faune 226.j

2. Tenthredopsis delta, Prov.

Pachyprotasis delta, Prov.-Fiune 210.

3. Tenthredopsis confusa, Nort.

Tenthredo confiusa, Nort.-Trans. II, 241 ; Faune 747.

4. Tenthredopsis semi-jaune. Tenthredopsis semilutea, Nort. 
Tenthredo semilutea, Nort. Trans. Am. Ent. Soc. II, 240.

q-Long. .24 pce. Jaune en majeure partio. Têto blancverdâtre avec une gl'unde tacho noiro sur le ver'tex descondant entro los antennos, bouche blanche, le dernier article des palpes br'un. Antennes grêles, jaunes, los 2 articles basiluiles avec une ligne en dessus sur los autres, noir. Thorax noir, les écaillettes, les bor'is du protharax, une tache sur chaqne lobe latéral dı mésothorax, les flancs ot la poitrine, jauno; une tacho irrégulièro sur les flanes et les plaques basilaires, noir. Les pattes ot l'abdomen jaune-miel, les hanches ot la base des cuissos, blanc; los cuisses postérieures en dessus noirâtres; éperon intérieur des jambes antérioures obtus, bifide. Ailes hyalines, lo costa avec la moitiè apicale du stigma, jiuno; nerrure transvor'so divisant les radiales courbo et reçue au iniliou de la 30 cubitalo; ailes inférieures saus cellulo médiano.

$\sigma^{\pi}$-Avec les antennes jaune-roussâtro portant une tache noire sur los 2 articles basilaires en dessus. Segment apical do l'abdomen, noir.-CapRouge.

5. Tenthredopsis 14-punctata, Nort.

Tenthredo 14-punctata, Nort.-Trans. II, 241 ; F. 747.

\section{Gen. Monoctenus, Dahlb.}

Ce genre distrait des LophIRus s'en distingue par sa cellule lancéolée qui est contractée au milieu et non avec ner. vure transverse.

Une seule espèce.

Monoctenus fulvus, Nort.

Lophirus fulvus, Nort.-Tians. IV, 86 ; AdD. 20.

\section{Tar. II. UROCERIDES.}

Gen. CkPrus, Latr. (Phyllaceus, Newm.) p. 233.

Anz 3 espèces décrites, ajoutez la suivante : 
QUE

. II, 240.

Tête blanc$x$ descendant e des palpes ires avec uno es écaillettes, atéral dı méto irrégulièro thes et l'abdoisses, blanc; ron intérieur nos, le costa insvorse divi3e cubitalo;

nt une tache ient apical de

F. 747 .

ngue par sa on avec ner.

33.

\section{Céphus interrompu. Cephus interruptus, n. sp.}

o-Long. 38 pee. Noir, les mandibules, excepté al l'extrémité, les palpes, les écailles alaires avec lo bord du prothorax, blanc. Mandibules furtes, avec 2 grandes dents et nne autre plus petite dans l'eehancruro. Antennes filiformes, noires. Prothorax inédiocrement allongé en coll, son bord postérieur blanchâtre. L'écusson et le post-éeusson chacun avec une ligne transversale blanche; lo métathorax avec une tache membraneuse blanche a son sommet. Ailes hyalines, iridescentes, les nervures noires, lo costa blanchatre, le stigma noir, la lère cellulo radialo petite, en carré oblique, sa nerruro antéricure intorrompuo vers lo miliou. Pattes jaune miel, les banchos aitérieures, les trochanters avec un anneau a la base de toutes les jambes, blanc, les jambes antérieures avec un seul éperon, les postérioures avoc 4, en portunt 2 latéraux en outre des ter! 1inaux, 1 r.s jambes postérioures, a part leur anneau blanc de la base, noires de mêrne que teurs tarses. Abdomon allongé, légèrement comprimé, les segments 1 et 2 roux, le reste noir, poli, brillant; tariere forte, voluc, sortante. Les palpes maxillaires ont les 2 derniers articles insérés sur lo côté du précédent.

$0^{7}$-Semblablo a la o a l'exception de l'abdomen qui est entierement noir sur lo dos, les 2 premiers segments étunt rou $x$ senlement en dessons. - CapRouge.

lien distinct surtout par sa première cellule radiale, dont la nervure antérieure est interrompue.

Les Céphus se rangent dans la famille des Urocérides plutôt que celle des Tenthrédinideș.

Fam. III.-EVANIIDES, p. 244.

Aux 4 genres décrits, ajoutez le suivant :

Abdomen inséré a la partie supériouro du métathorax ;

Jimbes postérieures renflés.............. 1. Fenus.

Jambes postéricures simples ;

Hanches postérieures prolongées à l'uxtrémité $\ldots \ldots \ldots \ldots \ldots \ldots \ldots$ 4. Pammegischia. 
Abdomen trids petit ot très longuement pédiculé, comprimé en forme de hachette... 5. Evania.

Abdomen ordinarie, médiocremont comprimé 2. Aulacus. Aludomen inséré a la partio inférieure du métathorax. 3. Pelrornes.

Après le geure Fonnus, ajoutez le suivant.

5. Gen. Evanie. Evania, Fabr.

Tête courte, à antennes insérées vers le hant des yeux qui sont oblongs et éloignés des mandibules. Antennes filiformes, ì scape allongé. Mésothorax petit, déprimé; métathorax déclive postérieurement. Ailes avec une seule nervure récurrente. Abdomen attaché sur le dos du métathorax par un pétiole aussi long que le reste des segments, qui forment un corps en forme de hachette comprimée, triangulaire; tarière non sortante. Pattes postérieures très longues.

Une seule espèce.

Evanie appendigastre. Evania appendigaster, Linn.

Sphex appendigaster, Lin.-Syst. Nat. I, 943.

ㅇ-Long. .25 pce. Noire dans toutes ses purties, avec une courte puboscence grise en certains endroits. La tête avec lo prothorax et lo mésothorax lisses, le reste rugruoux, alvéolé. Pattes postérieures plus longues que la tête et le thorax pris ensemble; abdomen très petit.-Ottawa.

Fam. IV. ICHNEUMONIDES, p. 247.

Gen. Ichneumon, Lin., pp. 257 et 752, AdD. 29.

Aux 89 espèces décrites, ajoutez les 2 qui suivent :

90. Ichneumon du Saguenay. Ichneumon Saguenayensis, sp. nov. 
. Evania.

Aulacus.

Peleinus.

es yeux qui filiformes, d rax déclive rrente. Abétiole aussi ps en forme n sortante.

aster, Linn.

s, avoc une tête nvou lo ux, alvéo!s. 'ax pris on-

7.

29.

ent :

Saguenay-
$0^{7}-$ Tong. 63 pee. Noir varié do janne et de ronx. La face su-desions des antennok jnano; los orbites postérieur's, lo scapo on doesous, une tincho de chạ jue côté sur los lobes latéraux du mésothorax, une sutre sur los flunes de la même partie, une plus grande convrant presque tout le métathorax, roux. L'écusson, les écaillet tes, jaune, une ligne sur les bords latéraux du prothorax juune en arrière et rousse en avant. L'écusson convoxe ; l'aréole contrale du métathorar en car'ré transversal. Ailes jaunâtres, les nervures brunos, le stigma jaune. Pattes. $y$ compris les hanches, d'un roux jaunâtıe, les jambes postérieures légèremont obscurcies au sommet. Abdomen fort, allongé, chaque segment noir a la bave, roux an milieu ot jaune au sominet, les segments torminaux entièrement roux jaunátres, lo pédicule dilaté au sommet, ponctuórugneux.

Superbe espèce, voisinè du creperus, Cress., mais s'en distinguant surtout par sa plus forte taille, ses hanches rousses et les taches rousses de sou thorux. Capunrée à Chicoutimi. (Huart).

91. Ichneumon à-2-taches. Ichneumon bimaculatus, n. sp.

$8^{7}$-Long. .28 pee. Noir avoe l'abdomen roux, la faeo an dessous des antannes, lo labre, los mandibules, los orbites interrompus sur lo vertex, lo scape en dossous, une petite ligno sous les éenilles alaires, les bords latéraux du prothorax, uno petite ligno sur la partie infériouro de celui-ci, l'écusson et le post.écusson, avec les + hanches antérieur'es, jaune pâlo. Antennes fortes, grenues, roussâtres en dessous. Métathorax ponctué-rugueux avoe uno tréole en demi cerulo an centre, sa face postérieure avec une tache de chaque côté rousse a la base et jaune au sommet. Ailes hyalines, lo stigma brun-foncé, les écailles alnires noires. Pattes rousses, les postérieures avec la moitió apicale des cuisises, des jambes, et les tar'ses, noir. Abdomen roux, lo premier serment noir excepté au sommot, les sutures enfoncées, les gastrocelles distincts.-Ottawa (Harrington).

Tr's distinct par sa coloration. 
358

ADDIIONS A LA FAUNE HYMENOPTEROLOGIQUE

Gen. Phalogents, Wesm. pp. 307 et 769 ; Aud. p. 39.

Des différents genres qu'on a distraits du genre Phorogenes, nous avons rencontré des représentants des trois qui suivent : Mandibules bidentées, la dent inférieuro très courtu. Herpessiomus. Mandibules à 2 dents égales ou sub-égules ;

20 Segment abdominal saus dépression en-dessus;

Mandibules o échancrées inférieu:ernent, leur pavillon $\sigma^{7}$ filiforme................. Colpognatus.

Mandibules $q$ non échancréess inférieurement ; post-écusson sans dépression; pavillon $o^{7}$ grêle à la base.................... Cenntiterus.

2e Segment abdominal avec dépressions plus ou moins distinctes a la base

Pheoglenes.

Gen. Herpestomus, Wesm.

Une seule espèce rencontrée.

Herpestomus pyriformis, Prov. $=$ Phoogenes pyriformis, Prov.-Faune p. 309.

Gen. Colpognathus, Wesm.

Une seule espèce rencontrée.

Colpognathus helvus, Cress. $=$ Phoeogenes helvus, Cress. Trans. I. 312 ; F. 308.

Gen. Centeterus, Wesm.

Une seule espèce rencontrée.

Centeterus tuberculifrons, Prov.=Phoogenes tuberculifrons, Prov.-F. 308.

'Gen. Phaogenes, Wesm. pp. 307 et 769; Add. 39.

Aux 18 espèces décrites, ajoutez les 3 qui suivent.

19. Phéogène coupé. Phagenes sectus, $n$. sp.

$\sigma^{7}$-Long. .22 pce. Noir, le chaperon, les mandibules, le scape en dessons, les écailles alaires, les 4 hanches antéricures avec leurs trochanters, blanc. Thorax court, robuste, finement 
p. 39.

haogenes, uivent :

RPES'IOMUS.

LPOANATUS.

AENTLTERUS.

Phimoglines.

nes pyrifor-

elvus, Cress.

nes tubercu-

ADD. 39.

livent.

- sp.

nandibules, le es antéricures uste, finement ponctuc. Ailes hyalines, lo stigma jaune. Pattes roux-cluil, les postéricures avec les hunches, le sornmet des jumbes ot les tarses, noir plus ou moins foncé. Abdomen linénire, poli, brillunt, tous los sogments; excepté le premier, marginés d'vrie ligne juuno uu sommet, lo dornier roussatre.-Vancouver (Tuylor).

20. Phæogenes fungor. Nort $=$ Cryptus fungor, Nort. p. 337.

21. Phrgenes Huarti, Prov. = Posocentrus Huarti, Prov. p. 409.

Gen. Stillpus, Grav. pp. 310 et 772 ; Add. p. 44.

Aux 4 espèces décrites, ajoutez la suivante :

Stilpne manquant. Stilpnus deficiens, n. sp.

우 - Long. 18 pco. Noir, le labre, les mandibules, le scape en dessous, lus écrilles alaires avec les pattes, jaune-roussâtre. Aintenues ì articles courts, d'égale grosseur dans toute leur longucur. Tête conrte et large. Métathorax a lignes soulovées distinetes, formant une petite aréole sur le dos. Ailes hyulines, le stigma gr'and, noir, la cellule radiale subtriangulaire, l'aréolo incomplète, sess nelvures extérieures manquant. Pattes d'un junne-roussâtr'e salo, les tar'ses postériemrs brunatres. Abdomen allongé, poli, brillant, noir, quelquefois le $2 \theta$ segment uvee les suivants ronssâtres, épaissi à l'extrémité, les derniers segments vontraux fondus pour lu réception de la tarièro; celle-ci aussi longue que l'abdomen. Ottawa (Harrington).

Gen. Phygadeuon, Grav. pp. 311 et 772 ; ADd. 44.

$P$ ygadeuon fusiformis, Prov. ci-dessus p. 51.

Nous avons décrit cet insecte soris le nom spécifique d'annulatus, Nat. VII, 179, mais ce nom avait déjà été employó par M. Cresson.

Aux 61 espèces décrites, ajoutez les 2 stivantes.

62. Fhygadeuon annelé. Phygadeuon annulatus, Cress.-Proc. Phil. III, 308.

우 - Long. .25 pce. Noir, brillant. Antennes assez grêles, avec un annean blanc au milien. Thorax finement ponctué, brillant, le métathorax à lignes sonlevées peu distinctes, légèrement excavé en arrière, ses angles latéraux saillants, submucronés. 


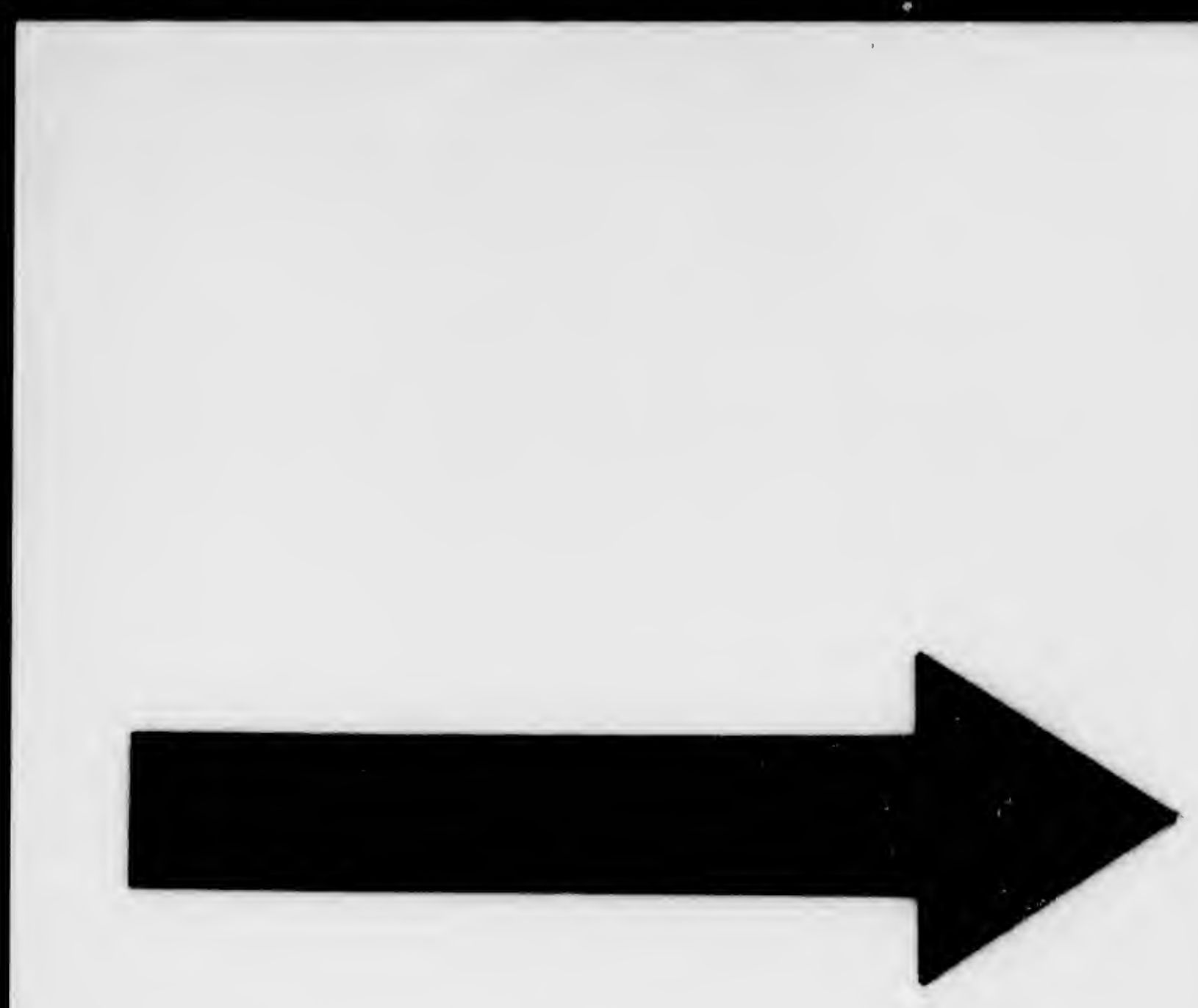




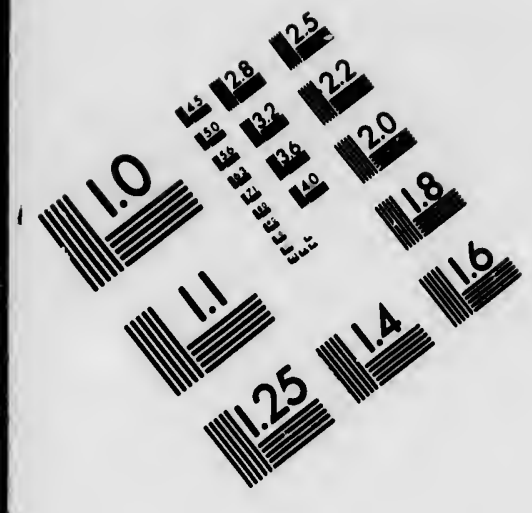

IMAGE EVALUATION

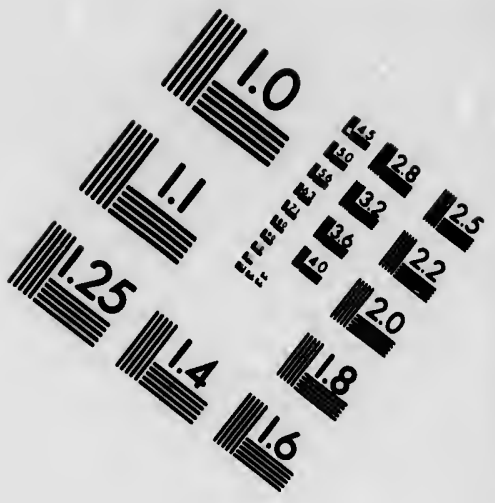

TEST TARGET (MT-3)
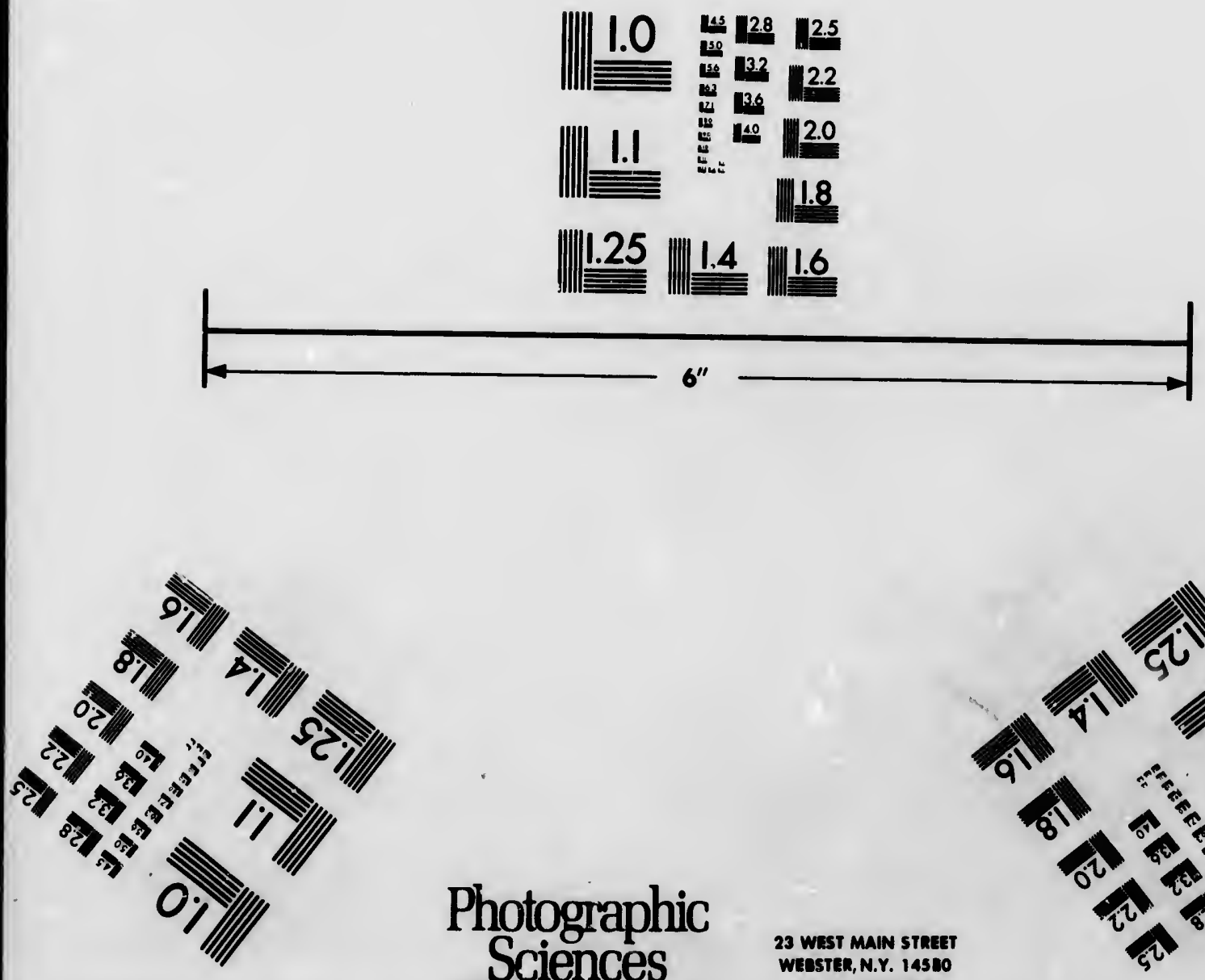

Photographic Sciences Corporation

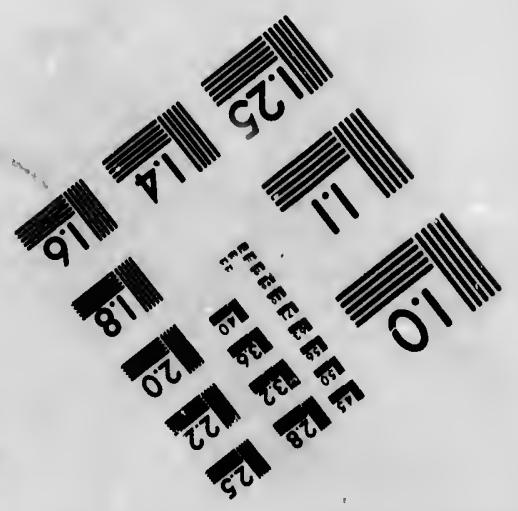




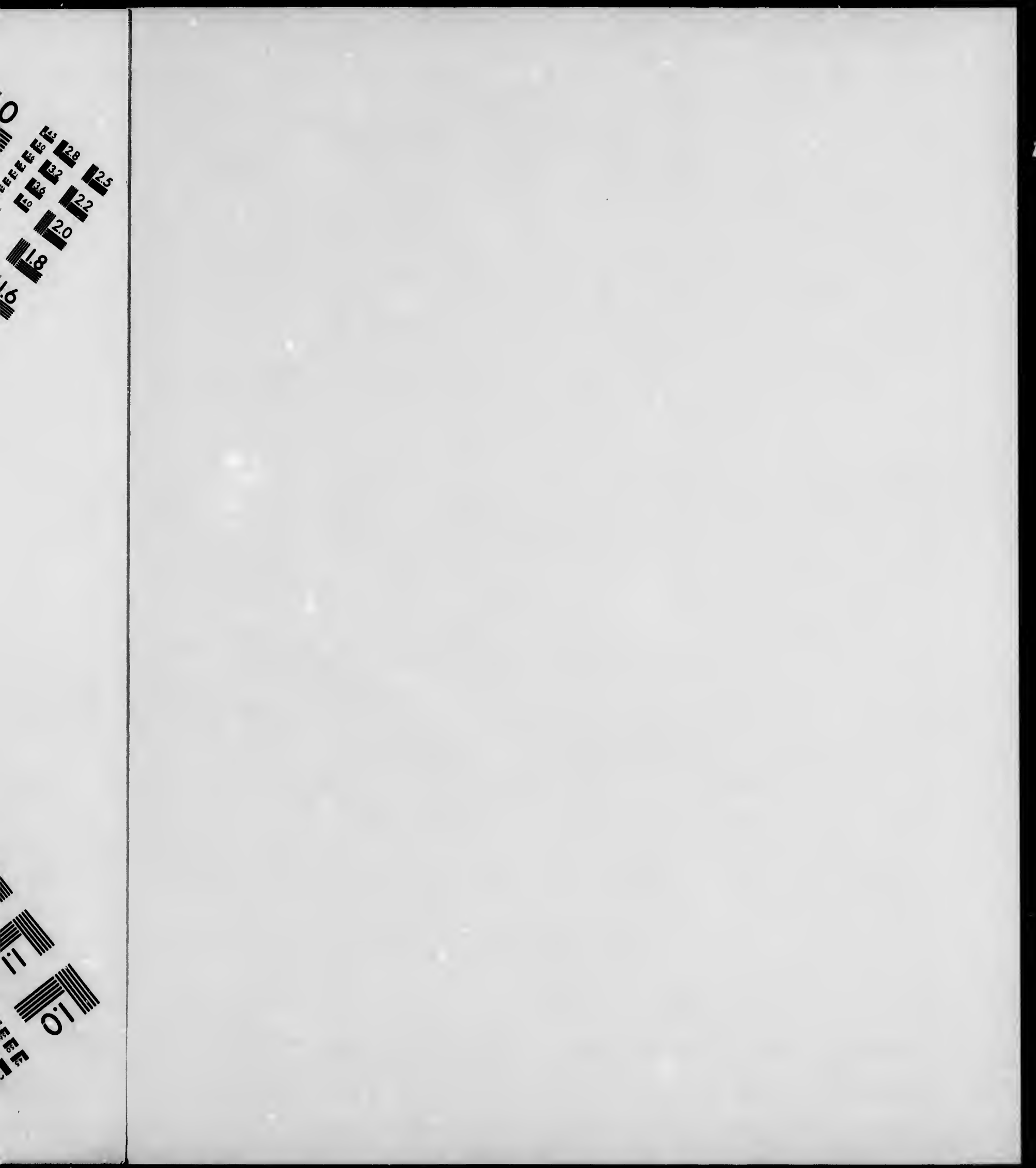


Ailes subhyalines, teintes lo brun pâle, les écaillettes jaunatres. Pattes rousses, y compris les hanches, les postérieures avec les cuisses plus ou moins et l'extrémité des jumber, brun plus ou moins foncé. Abdomon subovale, déprimé, aussi long que la tête et le thorax réunis, le pédicule fort, élargi au sommot, les segments basilaires roux, les terminaux noirs, le dernier plus ou moins taché de blane au sommet; tarière de la moitié de l'abdo. men environ.-Sorel

Voisin du truncatus, Prov., mais s'en dissinguant surtout par ses hanches rousses, son métathorax sans mucrons etc.

63. Phygadeuon à-ouisses-courtes. Phygadeuon curticrus, n. sp.

9-Long. 31 pee. Noir avec l'abdomen roux; les mandibules, les antennes excepté a l'extrémité, les écailles alaires avec les palpes, roux. Antennes a articles courts, fortement enroulees, jo scape avee la moitié inférieure du pavillon, roux, le reste noir: Thorax finement ponctué, non excavé postérieurement, à lignes soulevies formant une aréole allongée verticalement sur le dos. Ailes subhyalines, le stigrna jaune. Les 4 pattes antérieures y compris leurs hanches ronx-clair, les cuisses treds courtes et renflées; les pattes postérieures noires avec les jambes excepté un petit anneau au sommet, et les tarses, roux. Abdomen en ovale allongé, convexe, les 3 premiers segmonts roux, lo reste noir, tarière à peine sortante.-Chicoutimi (Huart).

Sa forte taille et sa coloration la font aisément distinguer des espèces voisines.

Gen. Cryptus, Fab. pp. 328 et 783 ; AdD. 61.

Cryptus fungor, Nort. p. $337=$ Phøogenes fungor, Nort.-Trans. Phil. VI, 204.

Cryptus scutellatus, Prov. ADD. p. $69=$ Cryptus ornatus, Prov. Par un lapsus calami, le nom spécifique ornatus, qui se trouve dans la clef p. 63 , a été remplacé par celui de scutellatus dans le texte, il faut le rétablir, puis ajouter les 3 espèces qui suivent : 
56. Crypte hanches-noires. Cryptus nigricoxus, n. sp.

$8^{7}$-Long. 25 peo. Noir fonces sur tout le corps, y compris les hanches et les écailles alaires; métathorax court, fortement ponctue, a ligncs soulevees distinctes. Ailes hyalines, a nervures noires, le stigma brunfoncé, aréole grande, presque on carrě. Pattes rousses, toutes les hanches, avec l'extrémitê des cuisses, les jambes et les tarses des postérieures, noir. Abdomen a pédicule long et grêle, en ovale allongé a partir du 20 segmont, les segments 2 et 3 obscurément marginés do roux au sommet.-CapRnuge.

Petite espece bien distincte de toutes ses roisines.

on cur-

mandires avec nroulées, iste noir. a lignes il lo dos. rieures y burtes et sexcepté lomen en lo reste istinguer

57. Crypte cornes-6paisses. Cryptus spissicornis, n. sp.

q - Tlong. 25 pee. Noir foncé arec les pattes et l'abdomen en partie, roux. Antennes fortes, enimulces, noires arec un anneau blanc au milieu, les articles basilaires du pavillon plus ou moins roux. Thorax finement ponctué, le métathorax sans lignes soulevées bien distinctes. Ailes hyalines, les nergures brunes, l'aréole pentagonale. Pattes, y compris las hanchos, d'un beau roux, les postérien aves l'extrémité des cuisses, des jambes ot les tarses, brunâtres. Abdomen fusiforme, noir foncé arec une bande rougo courrant le le segment en entier et partio du ler et du 23 ; tariero aussi longue que l'abdomen. - SteGertrude,

Espeve bien distincte de toutee ses voisines par sa coloration.

58. Crypte de-Fletcher. Cryptus Fletcheri, n. sp.

\%-Lung. 50 pce. D'un boa reux foncé; l'extrémits des mandibules, leur marge inférieare, uno petito ligne sur.lo charperon de chrqque côté, le tier's spical des snternes, une petito tache ar milieu do !a face aurdessous do lour insertion, les sutures du thomx, les environs de l'écasson, une ligne à la base des segmonts abdominaux 2 et 3 , noir. I roux un peu plus clair. Tre métathorax densément et finement ponctue, avec une potite carène transversalo à sor sommet. Ailes bruwes, lo stigma noir au sommet ot roux-jaunatie d la base, celto

ornatus, atus, qui de scutel3 espèces 
partio plus claire terminant une tache transversale fale sur le limbe de l'aile. Pattes concolores. Tarière noire, plus longue que le corps. La bande noile de la base du 20 segment abdomillal interrompue au milieu.-Vancouver.

Nous dédions avec plaisir ce bel insecte à M. James Fletcher, d'Ottawa, qui nous l'a transmis, l'ayant reçu lui-mềme du Rév. G. Taylor, de Victoria, Vancouver.

Gen. Mesostenus, Grav. pp. 344 et 785 ; AdD. p. 76.

Mesostenus skriceus, Prov. = Mesoleptus sericeus, Prov. p. 245. Puis, ajoutez l'espèce suivante :

Mésostène face-blanche. Mesostenus a?bifacies, n. sp.

9-Long. .29 pce. Noir avec l'abdomen roux; toute la faco an dessous des antennes, le labre, les mandibulon, les palpos, le scape en dessous, les écuilles alaires, une tache en avant et une autre au dessous, une tache sur les lobes latéraux du mésothorax, une autre plus petite de chaque côté du lobe médian, les '4 hanches antérieures avec les trochunters, blanc. Antenues brunes, blanchâtres en desous, le thorax poli, brillant, le métathorax d̀ lignes soulevées distinctes. Ailes hyalines, le stigma brun; grand, aréole en parallélogramme oblique, subpédicnlẹe. Pattes rousses, les postúrieures avec les jambes pâles d la base et birunes a l'extrémité de même y ue leurs tarses. Abilonen subpédicule, roux avec le premier segment et la moitis basilaire du 2e, noir, le premicr rétréci à la base avec un petit sillon n'atteignant pas le sommet; tariè e a peine visible.-Ottawa (Harrington).

Gen. Pezbuachus, Grav. p. 347 ; Add. 7 ..

Aux 2 espèces décrites, ajoutez la suivante :

3. Pézomaque noir. Pezomachus niger, n. sp.

- -Long. 12 pce. Noir, la fuce. les antennes avec les pattes, d'un roussâtre sule. Thor'ux sans sucune tache, à nouds à peu près d'śgalo longueur. Antennes noires d l'extrémité. Pattes d'un jaunatro sule pius ou moins obscur, les harches avec los cuisses 
noir plus ou moins foncé, les jumbes postérieures avec l'extrếmité et un petit anneau au-dessous de la base, noir. Abdomen bridvement pédiculé, sans aucune tache, turière du tier's de sa longueur. environ. - Los Angeles (Coquillett).

Bien distinct par son absence de taches au thorax et à l'abdomen.

Gen. Hztaropet.Ma, Wesm. p. 355.

A l'espèce décrite, ajoutez la suivante :

Hétéropєlme longs-pieds. Heteropelma longipes, n. sp.

$\sigma^{7}-$ Long. .85 pee. Noir varié de roux. La face au' dessous des antennes, les mandibules avec le scape en dessous, jaune-pâle, le reste de la tête, excepté une grande tuche noire sur le vertex, jaune roussâtre. Antennes assez courtes, minces à l'extrémité, jaune-range, le scape noir en dessus. Thorax roux, les sutureś, le bord inférieur du prothorax, une tache sur les lobes latéraux du mésothorax, une autre sur lo lobe médian on avant de l'écusson, le sommet du métathorax, noil'; l'écusson et les écailless alaires, jaunev Métathorax à rugosités transverses. Ailes subhyalines, jaunatros à la base et brunâtros à l'extrémité, le stignna jaune, les nervures brunes. Pattes jaune-orange, les 4 antérieures plus claires, l'extrémité des hanches, des cuisses et des jumbes postérieures, noire. "Abdomen allongé; grêle, lońguement pédiculé, jaune-roussât:e, le $2 \mathrm{e}$ segment avec une tache noire sur lo dos, les derniers brunâtı 9s.-Californio (Coquillett).

Nous devons à la bicnveillance de M. D. W. Coquillet, de Los Angeles, Californie, de posséder un lot d'Hyménoptères parmi lesquels se trouvait catte espèce nouvelle avec quelques autres que nous décrivous ci-dessons.

Gen. Cremastus, Grav. pp. 375 et 788.

Aux 5 espèces décrites, ajoutez la suivante:

6. Crémaste noirâtre. Cremastus piceus, Cress. -Trans. Am. Ent. Soc. $I V, 176$.

q-Lo:g. 22 pee. D'un noir do poix brillant; les mandibules avec le chaperon jumne-miel de même que les orbites; les 
6railles alaires avec la base des ailes blanchatres. Métuthorax d lignes soulevées bien distinctes. Ailes hyalines, les nervures et le stigma, jnune-pale. Pattes juuno-miel, teintes de ferrnginenx, les hanches postérieur'es noires, leurs jambes ot leur's tarses plus ou moins obscures. Abdomen noiratre, poli, plus pâle a b'extrémité; le ventre avec bandes páles; la tarièro presque aussi longuo que l'abdomen... Canp Rouge.

Espèse bien distincte par sa coloration.

Gen. Porizon, Fallen p. 377 ; ADD. 91.

Aux 4 espéces décrites, ajoutez les 2 qui suiven.

5. Porizon pieds-blanes. Porizon albipes; n. sp.

१-Long. .21 pce. Noir avec les pattes blanches ow jaunepâle; les mandibules, le scapo en desious avec les écrilles alaies, blanc. Antennes assez longuen, noires. Métuthornx bearcoup plas long que baut, fnement ponctué. Lia face a pubescence blanche au bus vue de cóté. Ailes hyalines, sans aréde, lo stigma petit, lancédé, byn, la ise cellule diseoïdale médiocroment rétrécie a la base, nevvure furmant la grande eollufe pontéricurement assez longuc. Pattes jaune-psle, les hanchus pontérieures, la base et l'ixtrémité do leurs jambes arce leur's tarsen, noir. Abdomen a pédiculo médivere, Kgrèremont plus harge nu sommet, les segments terminaux comprimés of élargis de minière a présenter un profil en forme do coin, tronqué al l'extrémité, la tarière à peine sortante-CapRouge.

Bien distincte des autres espèces par son absence de roux à l'abdomer.

6. Porizon de Calitisnie. Porizon Califonmieum, n. sp.

శ-Long. 20 pec. Noir, avec les pattes d'vn jaunfitre salo plus on moins obscure. Ia face au dessous des antennes, le chaperon, le labre, les mandibules, les orbites antérienrs ot postérieurs à peine interrompus sur le rertex, avec le scape en dessous, blanc; la face porto de chaque côtc une ligne noire, se ressorrant dans un point enfoncé audessiss du chaperon. Thorux finement ponctué et avec tno légè 'e pubuscence grisưtre; ;e métalborax a lignes soulerées pea stillantes. Ailes hyalines, a nor- 
vures manquant completement dans la moitié postérieur.j, la 30 discoïdale fortoment doétrécio i la bisse, lo stigma brun, pâle a la base, les écailles alaires avec la buso des noivures, blanc. Toutes les hunches noires, jaunes au sommet. Abdomen uussi long quo lo corps, noir, légèrement puboscont, comprimé a l'oxtrémité.Los Angoles, Californio (Coquillott).

\section{o Encore inconnve.}

Insecte bien remarquable par la nervation de ses ailes. Parasite d'une Tinéĩde.

Gen. Mrsochorus, Grav. pp. 380 et 790.

Aux 9 espèces décrites, ajoutez la suivante.

10. Mésochore tronque. Mesochorus truncatus, n. sp.

o-Long. .21 pce. Noir arec une bande rousse d l'abdomen; les matndibules, excepté a l'oxtrémitê, le scapo on dessous, les écailles alaires, les 4 hanches antéri'sures avec leurs trochauters. blanc. Têto plus large que lo thorax, les mandibules larges. Antennes longuos, brunâtres. Thor'ux finoment ponctứ. Ailes hyalines, le stigma grand, triangulairo, brun-roussâtree, aréolo assez petite, subrhomboîdale, brièvement pédieulée. Pattes jaune miel, les hauches postérieures, excepté au sommot, avec l'oxtrémité des jambes ot les tarses, noir ou orun-foncé. Abromen pédiculé, le $1 \mathrm{er}$ segment élargi au sommet, l'eusemble de forme ovale, déprimé, les segmonts 3 et 4 roux, le reste noir, les segments termiraux comprimés, tronqué a l'oxtrémité avoc la tarid̀re jaune, un peu plus courte que la troncature du dernier segment. -Vancouver (Taylor).

Bien remarquable par son abdomen tronqué à l'extrémité.

\section{Gen. Charops, Holmg.}

Un écusson plat, presque carré, point d'aréole aux ailes antérieures, des yeux profondément échancrés, tels sont les principaux caractères qui séparent ce genre des Campoplex.

Charops à-ailes-obscures. Charops fuscipennis, n. sp. f-Long. 38 pee. Noir avec les pattes ot l'abdomen roux. 
Les mandibulos, lescape des anteunes en dossous avec les écailles alaires, roux. Fuce finement poictuée. Antennes assez courter, fortes, atténnées a l'extrémite. Thoinix court ot robuste, los du nésothorax avec bandes ponctuées a l'ondroit des sillons par'ıp.j. daux ; métathorux lange, resserré a la buse, rugueux, uveo uno ligne soulevée de chuque côté du milieu formant une aréole ouverte postérieurement, ses côtés portant une piotubérarıco obtuse. Ailes obscures-violacées, le stigma rounsâtro infériourement, point d'aréole, la 3 e discoïdale rétrécie al la base. Pattes roussos, les postérieures fort allongées, leurs hanches noires. Abdomen roux, pétiolé, le pédiculo noir à la base, ćlargi su sommet, les segments ter'minaux comprimés-tranchants, la dernier tronqué postérieur'e. ment, tarière pas plus longue que la lurgeur du dernier segment, ses valves épaissies a l'extjémité. - Los Angeles.

Obtenu par M. Coquillett de la larve du Melitcea Chalcedon. Ses tarses pectinés uvec ses stomates' métathoraciques ovales et son absence d'aréole uux ailes, distinguent surtout ces insectes des Exetastes.

Gen. Banchus, Fabr. p. 3S7; ADD. 121.

Aux 9 espèces décrites, ajoutez la suivante.

10. Banche polychrome. Banchus polychromus, n. sp.

q-Long. .40 pce. Varié de noir, de jaine, et de roux. La face excepté une strie longitucinule noire uu milien, avec un point de chaque côtś du chaperon, les mandibules, les orbites. les joues, lo scapo des antennes on dessons, jaune brillunt, le reste de la têto noir. Antennes longues, poires en dessus, rousses en dessous. Thorax noir, uno grande tache en crochet de chaque côté du mésothorax, les écuilles alaires, une ligno au dessous, une grande tacho sur les fluncs, une semblable tache sur les flancs du métathorax, avec la faco postérieure de celuj-ci, l'écusson et le post écusson, jaune; une grande tache de chaque . cóté sur le ís entre les ailes, avec les bords de la tache jauno du métathorax, roux. Ailes hyalines, légòlement enfuméos, lo stigma jaune. Pattes jaunes, les postérieures quelque peu : sussâtree, la base des hanches, lo dessous ot l'extrémitó des posté- 
rioures aveo le sommet de lour's jambes, noir. Abdomen médio. oremont conprimú, les segmonts 1,2 et 5 noirs id la biswo, roux onsuito ot jaunes dans lo reste, los auties nogments roux a la buse et juunes duns lo reste, le dessous varió aussi des trois coulour's. Vancouver (Taylor).

Espèce bien distincte par sa coloration.

Gen. Exentenus, Hartig ; p. 796.

M. Cresson dans son Synopsis of Fumilies and Genera of Hymenopteru, fait disparattre le genre Exenterus pour confondre ces insectes avec les Citeniscus ; il nous semble cependant que les Exentères, du moins quant aux, 2 espèces q 1 nous possédons, se séparent bien distinctemont des Cténisques, ils sont plus rugueux, leur abdomen est plus renflé et pliss recourbé en dessous à l'extrémité, l'écusson est plus grand etc.

Gen. Posocentrus, Prov. p. 408.

M. Cresson range ces insectes parmi les Phosogenes; ils portent en effet le principal caractère de ce genre, les stigmates mótathoraciques circulaires ; ils ont aussi l'aréole des ailes pentagonale. Au lieu donc de:

Posocentrus Huarti, Prov., il faudra lire :

Phøogezes Huurti, Prov. F. p. 408.

Gen. Truphon, Grav. p. 410 ; AdD. p. 100.

Aux 14 espèces décrites, ajoutez la suivante :

15. Tryphon a-poitrine-rousse. Tryphon rufopectus, n. sp.

$\sigma^{7}$-Long. 25 pce. Noir; le chaperon, les uandibules, les palpes, les écailles alaires, une petite ligne er avant, une autre au dessous, l'écusson, une pcti to ligne sur le post-écusson, tous les trochanter's avec les 4 tar'ses antérieurs et une ligne au sommet do tous les segments ubdominaux, blane; les 4 pattos antśrieures avec la poitrino et les flanc's du mésothorax, d'uv beau roux clair. Antennes noires, roussâtries en dessous, le scape noir. 
Métathorax à lignes soulevées distinotes. Ailes hyalines, sans aréole, le stigma brun foncé. Pattes postérieures noires, lenr's hanches plus on moins roussatres a la base, leurs cuisses rouswatres on deduns, lours jambes avee un tout petit anneau blanc d la baso, leurs tarses entièrement noirs. Abdomen sessile, asser allongé, déprimé, tous less seginents marginés de blanc au sommot, le ler avec 2 petites cardnes atteignant presque le sommet.Ste-Gertrade.

Les flancs de son métathorax noirs avec la coloration de ses pattes postérieures empêchent de le confondre avec le Me80leius submarginatus, Cress.

Gen. Mrsoleius, Holm. p. 415 et 796.

Aux 8 espèces décrites, ajoutez la suivante.

9. Mésolol de-Chicoutimi. Mesoleius Chicoutimiensis, n. sp.

o-Long. 37 pce. Noir aroc les pattes d'un beau jaunemiel ; le chaperon, les mandibulos, les 6uussons, aussi d'un ,jnunemiel. Antennes entièrement noires. Ecailles aluires jaune pâle; métathorax finemont ponctué arec un petit sillon au milieu. Ailes hyalines avec les nervures noires, le stigma noir a la pointo et jaune-pâlo à ĺa baso. Aréole petite, trianguluire oblique, pédiculee. Les pattes y compris les hanches, jaune-miel, les jambes postérieures avoc lours tar'ses et l'extrémité des cuisses, noir. Abdomen ponctué à la base et lisse d l'extrémité, le promier' segmont avec 2 petitus carènes n'utteignant pas lo sommet, los segrments terminaux avec une petite marge blanche peu distincte au sommet.-Chicontimi ( Huart).

Voisin du submarginatus, mais à jambes postérieures cntièrement noires et ses flancs sans aucune tache.

Gen. Bassus, Fabr. pp. 427 et 798 ; ADD. 111.

Aux 21 espèces décrites, ajoutกz la suivante.

22. Basse aciculé. Bassus aciculatus, n. sp.

9-long. . 18 pce. Noir, poli, brillant; la face, los mandibules, les palpes, lo scapo on dessous, les écailies alaires, tune

pet

har

bru

dist

ner

d $\mathrm{pr}$

bast

som

los

$\cos 2$

face

mon

soul

les $n$ jaun

Abdc poli, (Ha)

segm

n. $\mathrm{sp}$.

on ca les éc Mésot 
potite troche en avant, une petite ligne au-dessous, toutes les lianches aveo lours trochanter's, jauno pâlo. Antennes longues, bruncy. Ecusson noir, proéminent; métathor'ax a lignes soulevées distinctes. Ailes hyalines-jaunatres, sans ar'ole, le stigma et les nervures jaunatres. Pattos jaune-roussatre, les jam bes postélicures a peine obscurcies a l'extrémite. Abdomen linćairo, noir a la buso ot d l'extrémité, les segments 3,4 , avec la buse de 5 et lo sommet de 2, roux, 1 ot 2 finement aciculés, le reste poli, brillant; los gastrocellos jaunes,-Ste Gertrudo.

Espèce bien remarquable par la structure de son abdomen.

Gen. Orthocentrus, Grav. pp. $434 \& 800$.

Aux 6 espèces décrites, ajoutez la suivante:

7. Orthosentre hanches-noires. Orthocentrus nigricoxus, n. sp.

ㅇ-Long. .12 pce. Noir; poli, brillant; le renflement de la face au dessous des antennes obscurément roussâtre supéricurement. Antannes fortes, courtes, poilues. Métathornx a lignes soulevées peu distinctes. Ailes hyalines, legerement enfumces, les nervures jaunâtres, l'aréole peitite, pentagonalo. Pattes d'un jaunâtre sale, les hanches noiros, les cuisses plus ou moins noires. Abdomen sessile, le premier segrinent a peine rugueux, le reste poli, brillant; tarière sortanto; ventre juunâtre-brun.-Oltawa (Halrington).

Se distingne du carinatus par la structure de son premier seginent abdominal.

Gen. Euxorides, Cress. Add. 115.

A l'espèce décrite, ajoutez la suivante.

Euxoride de-Vancouver. Euxorides Vancouveriensis, n. sp.

\&-long. .60 pce. Noir avec les pattos jaune-miel. Tête en carré, sans aucune tache. Les bords inférieur's du prothorax, les ccailles ulaires avec une petito ligne en avant, jauno-pâle. Mésotbo:ux à partio médiano soulovéo et projotéc en avant. Mé- 
tuthor'nx ullongé, finenont rugueux, uvec un potit sillon longitudisul un miliou. Aslos hyalines uvoc une aróole triangulniro subpédiculéo, les norvirion ot lo ntigma birun. Puttes juuno-miol, los jambos antérioures plus palos, los hanches postérioures allongéos, leur's cuisses noirâtres on dessun, lour's tarbes noirs. Abdomon allongé, trés finomont ponctué, los segmonts plus ou moins distinctumont murginés d'uno lignno pâlo au sommot, lo 1or médiocroment rétréci d la buse, suns cnidues sur son disque, lo dornicr brievomont lancéolé ; tarière anssi longue que l'abdomen.-Vuncouver (Tuylor).

Espece voisine de l'americanus, Cress, mais plus robuste, à jambes postérieures noires, etc.

\section{Fam. V.-BRACONIDES p. 491 ; ADD. p. 121}

La publicntion du Synopsis of the families and yenera des Hyménoptères, par M. Cresson, résumant lez travaux les plus récents des auteurs européens sur cet ordre si iınportant, uous oblige a de nombreux changements dans la distribution et la distinction des genres des Braconides. Nous croyons devoir, pour faciliter davantage l'étude de ces derniers, donner de nouvelles clefs pcur la distinction des geures de chaque sous-famille.

\section{Sous-fam des CYCLOSTOMIDES p. 495.}

Cinq genres dans cette sous-famille.

1(4) Occiput non marginé ou no l'étant qu'ọbsoletoment sur les cùtés;

2(3) Abdomen avec nombreuses impressions transversalos, larges et uréneléos .............. 1. Iphiaulax.

3(2) Abdomen suns impressions transverses cré. nelées ou uvec une sculement. ........... 2. Braonn.

4(1) Occiput margine, distinct du vortex;

5(6) Abdomen pédiculé ............................ 3. Spatrizus.

6(5) Abdomen sessile ou subsessile; ailes antérieures à 3 cubitules;

les
men
Tuill
Tull
temo
noir
mont
de e
obliq
milie
autre
met,
apres
forte,
Amér
502. 
ngitudisubpódiajambes es, leur's allongé, etemont to rétréci zont lan(Tuylor). robuste,

d genera travaux re si imins la disis. Nous 3 derniers, geures de

phiaulax.

2. Bracon.

Spatiluds.

7(8) Têto cubique, non rétrécio en urriè"o los yeux; cellule médiuno des ailes antérien'es plus courte que la sous-módiane; hanchess postérieures anguleuses en avunt, nbdomen o obovale, convexe, $\delta$ plus étroit, allongó, dóprimé ..................................... 4. Donyctes.

8(i) Têto ț'unsvor'so, plus ou moins rétrécio en atrridre des youx, ubdomon rugueux, exceptó a l'extrémité, tarière courto ou cachée........ 5. Rnoass,

Gen. Iphaulax. Iphiaulax, Först.

Ce genre ne diffère des Bracons que par son abdomen dont les sutures sont enfoucées, larges, crénelées, rendant les segments convexes transversalement.

Deux espèces rencontrées.

Taillo plus forte, tariere plus longuo que l'abdomen ......................................... 1. Americanus. Tulle plus petite; tariere plus courte que l'abdomen ........................................... 2. decoratus.

1. Iphiaulax d'amérique. Iphiaulax arnericanus, n. sp.

9-Long. .30 pee. Noir aveo l'ubdomen roux; les ailos furtement enfumées; la bouche, les antennes, lo thoras, les pattes, noir sans aucune tache. Abdomen entièrenent roux, lo lor sogr. ment avoe un sillon transversal vor's le milieu ot un autre de chaque côté près du sommet, lo 20 avec une impression oblique de chaque côté, une petite plaque soulovée ot lisse au milieu et suivio d'annulations plus ou moins nombreuses, et une nutre petitu in prossion coupant obliquement les angles du sommet, los autres segmonts polis, lisses, convexer, avec les sutures après les segments 2,3 ot 4 profondes, larges ot crénolées; taridre forte, noire, rigide, plus longue quo l'abdomen.-Ste-Gertrude.

C'est le premier représentant de ce genre mentionné en Amérique.

2. Iphiaulax ornatus, Prov. $=$ Bracon ornutus, Prov. p. 502. 
Gen. Bracon, Fab. pp 497 et 803 ; Add. 121.

Des 19 espèces décrites, retranchez la 9e, B. ornatus, Prov. qui appartientanx Iphiaulax, et ajoutez les 4 qui suivent.

19. Bracon pieds-jaunes. Bracon auripes, nov. sp.

p-Long. .18 peo. Noir; poli, brillant, avec la bouche, lo scape des antennes, les écailles alaires, les sutures laterales du thorax, les pattes, le ventre et l'extrémité de l'abdomen, jauue d'or. Antennes longues, grêles, brunes. Mésonotuın a lubes dis. tincts, roussâtro à la baso. Métathorax poli, brillarit. Ailes hyalines, les nervures brunes-janâtres, la 20 eubitaie longue et à peu près d'êrale longueur, les deux discoïdales d'égale longueur' à la base. Les huı.ches jaunes comine le reste des pattes. Abdomeu en ovule, les 2 premiers segments rugueux, lo 20 avec uno petite plaque triangulaire polie au milieu de sa base, les 2 dorniers jaunes, tarière noire, volue, de la longueur de l'abdomen Ottawa (Harrington).

Voisin de l'oequalis mais s'en distinguant par sa forme et sa coloration.

20, Bracon rouge-sang. Bracon sanguineus, $n$. sp.

+ -Long. .45 pce. Poli, brillant, d'un beau rouge-sanguin, les antenues, les pattes, une tache sur l'occiput, une tache de chaque côté sur le dos du métathorax se joignant à une autre sur les flancs, une strie de chaque côté de la poitrine avec les ailes, noir. La face au dossous des antennes plus ou moins obscure. Métathoras poli, brillant, sans sillon ni carènes. Ailes brunfoncé, avec une tache hyaline on arrière de la lère discoïuale et une strie dans la lèro cubitale. Abdomen en ovale allongé, poli, brillant, le premier segment avec une fossette de chaque côté du $m$ 'lieu, le 20 avec uno fossette oblique sur sun disque, sans protubérance a son milieu, la suture entre les segments 2 et 3 bifulguéo de chaque côté. Tarière plus longue que l'abdomen.-Los Angreles (Coquillett).

Superbe espèce bien reconnaissable par sa coloration.

21. Braoon d'Angeles. Brucon Angelesius. n. sp. q-Long. .14 pce. Jaune-micl, lo dossus do la tête, les an- 
tennes uno tache a la poitrine, le disque du métathorax plas on moins, avec la tarière, noir. Ailes hyalines, sans taches elaires ni foncées, le stigma épais, brun-jaunâtre. Lres tarses plus ou moins obscur's. Abuomen allongé, le 1er sę̧ment avec un sillon de chaque eôté, taché de biun au milieu, lo ze avee une petite protubérance au milieu de sa base, les terminaux ceinturós do noir au sonımet. Turière forte, aussi longue que l'abdomen.Los Angules (Coquillett).

Voisin du xanthostigma, Cress., mais s'en distinguant par son stigma brun, son abdomen allongé et poli etc.

22. Bracon poli. Bracon politus, n. sp.

ð’Long. .12 pce. Noir, poli, brillant; la bottche, les mandibules, les pattes avec la base de l'abdomen, jaune-miel. Tête subglobuleuse; antennes longues, noires. Métathorax non lugueux. Ailos hyalines, à nervures brunes, la 20 cubitale d'égale largeur diıns toute sa longueur, son extrémité basilaire en coin ; stigina brun-jaunâtre. Pattes y compris les hanches d'un jauno sale. Abdomen allongé, linéaire, poli, brillant, jaune à la base, le 1er segment noir en dessus, le 20 jaune avec une espece do carère au milieu. - Los Augeles (joquillett).

Petite espèce bien distincte par sa coloration.

Gen. Rhogas, Esenb. p. 504.

Aux 6 espèces décrites, ajoutez les 2 qui suivent.

1(6) Thorax entièrement noir ;

2( 3 ) Abdomen noir a la base.

7. rugosulus, $n .8 p$.

3(2) Abdomen roux-jaunâtro d̀ la base;

4' 5 ) Jambes postérieures noires aves un anneun pâle.............................. 1. terminalis, p. 505.

5 (4) Jambes postérieures rousses, sans anueau jâle

2. abdominalis, p. 505.

6(1) Thorax juune ou roux, quelquefois taché de noir ;

7, 8 ) Antennes blanches a l'extrémité... 3. Quebecensis, p. 506.

8(7) Antennes non tel'minées de t’lanc;

9(12) Abdomen noir a la base ;

10 (11) 1 or segment noir, les autres noirs sur les côtés ............................ 5. canadensis, p. 507.

11(10) 1er segment noir, les médians entièrement l'ollx 6. intermedius, p. 507.

s. n. sp.

tête, les an- 
12(9) Abdomon roux on jaune i la base;

13(14) 'Iête, sommot des cuisses et des hanches postérieur'ss, noir.

8. parasiticus.

14(13) Tête ronsse, cuisses et jambes postérieuros concolores

4. Sti-Hyacinthi, p. 506.

i. Rhogas rugosule. Rhogas rugosulus, n. sp.

-Long. .21 pce. Noir avec l'abdomen roux. Ailes légèrement enfumées, le stigma brun-jaunâtre; le métathorax rugıoux par des stries transversalos. Pattes brun-foncé. Abdomen acicule sur les deux premiers segments, le busilaire noir, le reste roux jaunâtre, le dessus plan, renflé en dessous, l'extrémité plus pâle. - CapRouge.

Espèce bien distincte par sa forme et sa coloration.

8. Rhogas parasite. Rhogas parasiticus, Nort.

-Trans. Am. Ent. Soc. II. 327.

Aleiodes parasiticus, Nort.

ㅇ-Long. .25 pco. Jaune miel, la tête, le métathorax et l'extrémité de l'abdomen, noir. Antennes grêles, presque aussi longues que le corps, jaunes avec l'extrémité brunâtıe. Thorax jaune-miel, les fianes et le métathorax noir's. Ailes légèrement obscurcios, le stigma bıun, de même que les neivures. Pattes de la couleur du corps, l'extrémité des cuisses et des jambes postéricures avec celle de tous les tarses, noire. Abdomen avec l'oxtrémité noire a partir du milieu du 30 segment, toute la partie jaune finement aciculée, avec uno carèro distincte au milieu.Otlawa. (Guignard).

Espèce bien distincte par la coloration de ses pattes. Parasite du Lophyrus sabietis, Leach.

Gen. Doryctes, Haliday - Syngaster, Brullé p. 508, ADd. 122.

Toutes les espèces de Syngaster appartiennent aux Doryctes.

Des 6 espèces décrites, retranchez la 6 e S. rugosus, Prov. qui appartient an geure CAPITonius, et ajoutez celle ci-dessous. 
1. Doryotes cingulatus, Prov.=Syngaster cingulatus, Prov. p. 508.

siticus.

p. 506.

3 légèrerugueux nen acile reste iité plus

hornx et que aussi Thorax gèrement Pattes do pes postéavec l'exla partie miliou.es. ParaADD. 122. t aux Dosus, Prov. -dessous.

2. Doryotes bøticatus, Prov. = Syngaster baticaius, Prov. p. 509.

3. Doryctes fartus, Prov.=Syngaster fartus, Prov. 509.

4. Doryctes macilentus, Prov.=Syngaster macilentus, Prov. 509.

5. Doryctes atripes, Prov.=Syngaster atripes, Prov., ADD. 122.

\section{Doryotes pieds-pâles. Doryctes pallipes, n. p.}

q-Long. .18 pee. Noir ou brun foncé, brillant, la face au-dessous des antennes, tout le dessous, tant du thorax quo de l'ubdomen, jaune pâle, les pattes y compris les banches, bianc. Antennes plus longues que corps, brunaties, plas claires à la base. Tête subglobuleuse, transver'sale; métathorax finement rugueux. Ailes hyalines, le stigma brun-jaunâtro. L'extrémité des jambes et des tarses postéricurs plus ou moins obscurece. Abdomen déprimé, poli, brillant, lo premior segment finement aciculé, noir, le reste brunâtre; tarière épaissie à l'extrémité, plus longue que l'abdomen.-Cap-Rouge.

Sa coloration suffit pour le distinguer de toutes les autres espèces.

Sous fam. des POLYMORPHES, p. 495, 511.

1(14) Abdomen pétiolé;

27 ) Ailes antér'ieures à 3 cellules cubitales;

3 (6) Abdomen inséré a la purtio inférieuro du métathorax;

4(5) Antennes sétacées, grêles .... .................... Meteorưs.

5(4) Antennes \& coudées, plus épaisses à l'extrémité ..................................... Eugtalocerus.

6(3) Abdomen inséré à la partio supérioure du métathorax. Capitonius.

$7(2)$ Ailes antérioures avec 2 cubitales;

8,11) 1ìre cubitale séparée de la 1ère discoïdalo; 
9(10) Cellule radiale sublancóolée, finissant a peu près a mi-distance ontre le stigma ot le bout de l'aile, plus grande que le stigma, sa ner. vure inférieure droite ver's l'extrémité; 2 cellules cubitales distinctes; métnthorax tron. qué, tarière sortante

Dinocamptus.

10(9) Cellule radialo semi-cordiforme, finissant plus près du stigma que du bout de l'aile, plus petite que le stigma, sa nervure inférioure courbée dans tout son parcours; quelquefois point de cellules cubitales ; tarière cachée.... EupHorts.

11( 8 ) lère cubitale confluent avec la 1ère discoïdale;

12(13) Radiale lancéolée, atteignant presque le sommet de l'aile.

Mtcrootonds.

13(12) Radiale semi-cordiforme, finissant a peu près a mi-listance entre le stigma et le bout de l'ailc, ou plus pres du stigma

Pertlitus.

14(1) Abdomen sessile ou subsessile;

15(26) Ailes antérieures a 3 cubitales; radiale allon. gée;

16(19) Cuisses postérieures renflécs ; tête en carré ; vertex excavé, l'ocelle médian áuns l'excation;

17(18) Cuisses postéricures armées d'une dent.......... Helcon.

18(17) Cuisses postérieures inermes:................. Grunoscerits.

19.16) Cuisses postérieures simples; tete transverse, vertex noir ou a peine excavé;

20(23) Abdomen linéaire, plus long que le thorax;

21(22) Abdomen inséré au dessus des hanchès postérieures...................................... Macrocentrus.

22(21) Abdomen inséré entro les hanches postérieures.... ZELE.

23(:20) Abdomen ovale, pas plus long que lo thorax; occiput non marginé, cellule anale des ailes antérieures sans nervuie transverse;

24(25) Seconde piurtio du radius non ou à peine plus longue quo la première, en conséquence seconde cubitale très étroite; 2 e segment abdo. minal nou impressionné

HedYLUS. 
25(2t) Sećonde partio du radius beaucoup plus longue que la première, en conséquen:o 20 cubitalo assez large, sutures des segments 2 et 3 peu distinctes. Oprus.

26 15) Ailes antérieures avec 2 cubitulo.s.

CAMPTUS,

27,30) Cellule anule des ailos antérieures fermće au sommet;

28(29) Abdomen allongé, ses côtés paralleles, laissant voir 8 segments on-dessus, le ler beaucoup plus long que large ......................... EuBadizon.

OPHORES.

LOCTONUS.

ERILITUS.

HeLcon. INOSCELIS.

OOENTRUA. ZELE.

29(28) Abdomen court, ses côtés arrondis, laissant voir au plus 3 ou 4 segments en dessus, les autres étant rétı'actés, le ler non ou d peine plus long que sa largeur au sommet...... ..... Caryprus.

30(27) Cellule anale des ailes antérioures ouverte au sommet; le radius droit, sa 1ère partio longue, distincte; tarière droite... ................. Buadous.

Gen. Metionus, Hal.=Perilitus, Nees, p. 511 ; AdD 125.

Les 8 espèces décrites appartiennent toutes au genre Meteonus.

1. Meteorus dimidiatus, Cress. = Perilitus dimidiatus, Cress. p. 512.

2. Meteorus vulgaris, Cress.=Perilitus vulgaris, Cress. p. 512 .

3. Meteorus communis, Cress.=Perilitus communis, Cress. p. 512.

4. Meteorus humilis, Cress, = Perilitus humilis, Cress. p. 513 .

E. Meteorus graoilis, Prov.=Perilitus gracilis, Prov. Aid. 125.

6. Meteorus robustus, Prov. $=$ Perilitis robustus, Prov. ADD. 125.

7. Meteorus politus, Prov.=Perilitus politus, Prov. ADD. 126. 
8. Meteorus inoompletus, Prov.=Perilitus incompletus, Prov. Add. 126.

Gen. Eustalocegus, Forst. Rhopalophorus Halid. p. 515 ; ADD. 128.

1. Fustalocerus taurioorzis, Prov. = Rhopalophorue tauricornis, Prov. p. Eils.

2. Eustalocerus petiolatus, $\mathrm{Prov}_{,}=$Rhopalophomus petiolatus, Prov. ADD. 128.

3. Eustalocerus longicornis, Prov. = Rhopalophorus longicornis, Prov. ADD. 129.

4. Eustalocerus fasciatus, Prov.=Rhopalophorus fasciatus, Prov. AdD. 129.

Gen. Capituniug, Brullé, Add. 134.

Bien que l'abdomen soit inséré à la partie supérieure du métathorax, comme dans les Eyaniides, la forme de la tête, l'abdomen déprimś au lieu d'être comprimé comme dans les Aulacus, la coloration et la nervation des ailes comme dans ce dernier genre, nous confirment dans l'opinion que ces insectes appartiennent plutôt aux Braconides qu'aux Evauiides.

A l'espèce décrite, ajoutez la suivante.

2. Capiton rugueux. Capitonius rugosus, Prov.

Syngasier rugosus, Prov. ADD. p. 122.

- Gén. Dinocamptús, Först. (Voir la clef ci-dessus p. 375)

Une seule espèce rencontrée.

Dinocamptue linearis, Prov. = Microctonus linearis, Prov. ADd. p. 127.

Gen. Euphorus, Nees (Voir la clef ci-dessus p. 375).

Deur espèces rencontrées. 
1. Euphorus oephalious, Prov.=Microctonus cephalicue, Prov. ADD. p. 127.

2. Tuphorus punotatus, Prov.=Microctonus puncíatus, Prov. F. 804.

Gen. Microctonus, Wesm. p. 804.

Deux espieces rencontrées.

1. Microctonus vigilax, Prov. = Gamosecus vigilax, Prov. F. p. 514.

2. Microctonus laticeps, Prov. $=$ Gamosecus laticeps, Prov. ADD. 126.

Gen. Perilutus, Nees p. 511.

Deux espèces rencontrées.

Thorax et abdomen, jaune

1. mellinus.

Thorax et abdomen, noir

2. nigritus.

Ire du

1. Perilitus mellinur, Prov.=Gamosecus mellinus, Prov. 514.

2. Pórilite noiraud. Perilitus nigritus, n. sp.

$\sigma^{7}$-Long. .22 pce. Noir avec les pattes jaune-miel. Face finement striée, la bouche avec les écailles alaires jaunâtres. Métathorax scabre, sa face postérieure excavée et striée transversalement dans cette excavation. Ailes hyalines, le stigma grand, birun-jaunâtre, la radiale assez courte, semi-cordiforme. Pattes d'un jaune-sale, les tarses avec les jambes postérieures, plus ou moins obscurs. Abdomen pédiculé, le ler segment aciculé, le reste en ovale, poli, brillant._Ste-Gertrude.

Gen. Helcon, Nees p. 515.

Une seule espèce rencontrée.

Helcon dentipes, Brullé=Helcon albitarsis, Cress. F. 516.

Gen. Gymoscrlus, Först. (Voir la clef ci-dessus p. 375).

Une seule espèce rencontrée. 
Cymnosoelus pedalis, Cress $=$ Helcon pedalis, Cress. F. p. 516.

Geu. Macroceytrus, Curtis, p. 518.

Aux 5 espèces décrites, ajoutez les 2 qui suivent.

6 Macrocentrus pacifious, Prov. = Phylax pacificus, Prov. Can. Ent. XVII, 117.

7. Macrocentre acioulé. Macrocentrus aciculatus, n. sp.

ㅇ-Long. 12 pce. Jaune-miel, avec la têto, l'écusson ot le dos des 3 lobes da meśsothorax plus ou moins noir. Lus antennes brunes, plus foncées à l'extrémité. Ailes hyalines, iridescentes, le stigma pâle, la 20 cubitale assez longue. Pattes et abdomen d'un jaune-sale, le dernior avec le ler segment et partio du $2 e$ finement aciculés. Tarière de la longueul de l'abdomen.-Los Angeles (Cuquillett).

Susceptible de varier dans sa coloration, le noir se montrant plus ou moins abondant.

Gen. Zele, Curtis=Phylax, Wesm. p. 521; AdD. 130.

Il faut substituer le nom de ZkLe à celui de Phylax pour les 5 espèces décrites, et ajouter celle qui suit.

1. Zele palliventris, Prov.=Phylax palliventris, Prov. p. 521.

2. Zele rufipes, Prov.=Phylax rufipes, Prov. 521.

3. Zeie cinctus, Prov.=Phylax cinctus, Prov. p. 522.

4. Zele curtus, Prov.=Phylux curtus, Prov. ADD. p. 130.

5. Zele gracilis, Prov.=Phylax gracilis, Prov. ADD. p. 131.

6. Zélé a-base-noire. Zele basalis, n. sp.

\%-Long. .12 pce. Jaune-miel avec les pattes un peu plus páles. Antennes longuos et grêles, obscur'cies a l'extrémité. Le mésothorax partagé en 3 lobes distincts; le métathorax rugueux. Ailes hyalines, à nervures brunes, lo stigma jauno-pâlo, obscur 
au sommet, la 20 cubitale pentagonale, assez lon ̧̧ue, atténuéo d son extrémité antérieure ou ello regoit la récurrente. Abdomen en ovale, plus long que le thcrax, le ler segment noir, plus étroit que lo 2e, le dos jaune-páe aveo une ligne noirs sur ${ }_{38}$ côtés; turieres furte, di quart de l'abdomen environ. - Los Angelos (Coquillett).

Voisin du melleus, Ciess., mais s'en distinguaint surtout par la forme de sa 2e cellule cubitale et celle de son abdomen. Obtenu de larvos de tinéides et de tortricides.

Gen. Hedylus, Marsh (Voir la elef ci-dessus p, 375).

Ce genre, comme on peut le voir par la clef p.375, a été distrait des Opius. Une seule espèce rencontrée.

Hedylus politus, Prov.=Opius politus, Prov: p. 804.

Gen. OpIU:s, Wesm. pp. 511, 804; AdD. 123.

Des 5 espèces décrites, retranchez la 2e 0 . politus, Prov. qui appartient aux Hedylus, et la 3e, macrocephalus, Prov. qui ast une Alysis, et ajoutez les 4 qui suivent.

$1(2)$ Abdomen entièrement noir ............... 1. niger, n. sp

2(1) Abdomen plus ou moins juune ou roux;

3(11) Thorax noir ;

4(9) Abdomon noir à la baso et à l'extrémitó;

5 (6) Tête rousse ......................... 2. ruficeps, ADd. 124.

6(5) Têto noire;

7(8) Segment abdominal 2 testacé, poli, lisso.

\$21.

p. 522.

D. p. 130.

ov. ADD.

peu plus mité. Lo rugueux. 3. cinctus, ADD. 124.

8 ( 7 ) Segments 2 et 3 testanés, scabres... ........ 4. nanus, n. sp. 9(10) Abdomen à segments 1 et 2 noirs, lo reste jaune roussâtre ........................... 5. mellipes, 511.

10(9) Abdomen à segment 1 noir, le reste brun jaunâtre sale. ............................ 6. brunneiventris.

11(3) Thorux varie de jaune et de noir.... 7. variabilis, n. sp.

1. Opius noir. Opius niger, n. sp.

f-Long. 03 pee. Noir, poli, brillant, aveo les pattes jaunes; les mandibules rousses. Ailes enfumées, le stigma trian- 
gulnire, brnn-jnunatre. Putter jaunos, les hanches posteriouros "voc leurs jum!,ns ot leurs turses, brun pli 1 moins foncé. Abdomen elliptique, ontierement noir; tarjer - sque aussi longue que l'ubdomen.-CapRouge.

\section{Opius nain. Opius nanus, n. sp.}

$\sigma^{7}$ - Long. .09 pee. Nuir aroo les pattes, une tr.che d l'abdomon, In bon'he et ln buse des antennes, surtout on dessons, jaune-miol. Antennes longues et grêles. Thorax poli, brillant, le métuthorax finement rugueux. Ailes hyalines, les nerrures brunes, nou prononcées, le cubitus intelrompu avant d'attoindre lo bord do laailo, le stigma long et étroit, jaunatro. Pnttos juuno-miel, les hanches et les trochanters plus palos. Abdomon court, on ovale, les segments 2 let 3 jaunes, lo promier noir, finement ruguoux, les terminaux noirs, polis, brillants._Los Angeles (Coquillott).

\%- Semblable au $\delta$ avec les antennes noires ou brun.foncé a la base et la tarière d peine sortante, moins da quart de l'abdomen.

Obtenu d'une larve de diptère. Bien reconnaissable par sa petite trille.

6. Opius a-ventre-brun. Opius brunneiventris, Cress. Trans. IV, 178.

$\sigma^{7}$ - Irong. .12 pee. Noir, brillant; le chaperon, les mandibules et le scape on dessous, jnune-roussatro. Antennes anssi longues quo lo corps, brunes; écailles alaires jaunes. Métathorax rugueux. Ailes légèrement enfumées, iridescentes, stigma noirâtro, liurgoment lancéolé. Puttes jauno-miel.' Abdomen déprimé, poli, brillant, d'un brun pâle, lo premier segmont noir, les bords latéraux redressés.-CapRouge.

7. Opius variable. Opius variabilis, n. sp.

ठ-Long. 13 pce. Jaune varié de noir ; têto jaune avec une grande tuche noire sur le vertex. Le scupe des antennes jauuebrunâtre, le restu noir. Thorax jaune, une tacho à la poitrine, une autre sur chaque lobe du mésothorax, lo métathorax on dessus, jaune. Ailes hyalines, a peino enfumées, le stigma triangulaire, jauncebrunâtro. Pattes jaune-pâle. Abdomon nllongé, 
dóprime, jauno avoo uno tache noire on dessus a la baso, et yno sutro vers l'extrémité.-CapRouge.

\section{Gen. Eubadizon, Nees, p. 517.}

Des 4 espéces décrites, retranchoz la 3e oubmucronatus, Prov. qui appartient aux Calyprós, et ajoutez celle qui suit.

Eubadizon de Californio. Eubadizon californicus n. sp.

q-Long. .20 pce. Noir, poli, brillant, aveo los pattes rouxfonct. Antennes fortes, rousses a la base, surtout on dessous, lo scape ot l'oxtrémité, noir. Le mésothorax poli, a lobos distinets, lo métathorax ruguoux. Ailes passablomont onfumées, avec une strie hyaline dans la 1 dere cubitale so joignant ano autre en arrière de la 1ero discoildale, lo stigma étroit, noir, les écailles alaires jaunes. Pattes roux-fonce, lo sommot des jambes postérieures avec leurs tarses, noir. Abdomen allongé, a côtés paralleles, les segments 1 et 2 finement rugueux, lo r'osto poli, brillant, tariero plus longuo que lo corps,-Los Angeles (Coquillett).

Gen. Caly ptus, Hal.=Brachistes, Wesm. AdD. 131.

Deux espèces. Il faut substituer le nom de Calyptus a celui de Brachistes.

1. Calyptus submuoronatus, Prov. $=$ Braclistes $s u b$ mucronatus, Prov. F. 518.

2. Calyptus orassigaster, Prov. $=$ Brachistes crassigaster, Prov. ADD. 132.

Gen. -Blacus, Nees. ADD. p. 132

Aux 2 espèces décrites, ajoutez la suivante.

3. Blaque en-coin. Blacus cuneatus, :n. sp.

9-Long. .12 pce. Noir aveo les pattes jaunes. Antennes filiformes, jaunoe, noires a l'extrémité. Dos du mésothorax a 3 lobes bien distincts, le métathol'ax finement ponctué. Ailos hyalines, le stigma brun, étroit, la radiale très petite, en coin, sa 
Jorvure inforieuro droito, attoignant la coto avant l'oxtrémit6. Puttes juunes, les postérioures aveo l'extrémité dos jambos tachóo do noir. Abdomon noir, los segments 1 ot 2 avoo uno putito tucho juuno do shnque cótố uu sommot, 1 finement ponotué a la base, lo reste poli, brillunt; lo ventro jaune d la baso; taridro do la longuour de l'abdomen,-CupRougo.

Se distingue surtout des 2 autres par les taches jaunes de son abdomen.

\section{3ous-fam. des ARtol}

1(8) Sutures du mésothornx distinctes; cellulo radiale petite, n'attcignant pas le sommet do l'aile;

2(7) Ailes antérienres d 3 cubitales;

3(4) Face prolongée triingulairement en rostro; 1ere cubitale plus ou moins confluento $\mathbf{1 v 0 0}$ la 1 dere discoïdalo AaAtris.

4 (3) Face de forme ordinairc, non prolongéa on rostre;

5(6) 1ère cubitale séparée dé la 1ere discoídale; flanes sans sillon; ailes hyalinos................. EArivus.

6(5) 1ère cubitale plus on moins confluente aveo la Jere discoïdale; flancs aveo un sillon ru. guoux; ailes généralement enfumées.......... Mrcrodus.

7(2) Ailes antérioures aveo 2 cnbitales, dont la 1 je ost sépuréo de la 1di'o discoïdale; flancs aveo un sillon crénelés face non rostriformo.. Oraruas.

8(1) Sutures du mésothorax indistinctes; collule radiale grando, atteiguant to sommet de l'aile;

9(12) Ailes antérienres à 3 cellules cubitales, la soconde plus on moins complete;

10(11) Eperons des jambes postérieures plus do la moitic de la longueur du premior articlo de leurs tarses, articulation suturiformo distincte; 20 cubitsle souvent incornpldto.. Microgastr 
trémités. tachóo putito tué a la ridro do unes de

AaAtiris. ;

Earinus.

IGRODUS.

Drarlus.

DGASTRR.

11(10) Eperons des janmbes postérioures moins do ln moitió de la longuear du premier urticlo do lours tarses; niticulation suturiforme obsolite; 20 cubitalo compldte, putite.... ........ Mronoplitis.

12(9) Ailos antérioures areo 2 cullules cubitales, In 20 confondue aveo ln 80 , lo radius obsoldte ou subobsoldto Apantelege.

Gen. Miorogaster, Latr. p. 727 ; Add. 138.

Des 17 espèces décrites, retranchez: 2. xylinus; 3. congregatus ; 4. carpatus; 6. cinctus ; 7. clavatus ; 13. crassicornis ; 14. femur-nigrum; 15. acaudus ; 16. longicornis; qui toutes appartiennent au genre APANTELEs, et ajoutez les 4 qui suivent:

1(2) Ailos avoo bandos brunes.......... 1. callipterus, p. 327.

2(1) Ailes hyalines ou subhy:llines, sans bundes hrunes;

3(15) Abdomen noir ou aveu soulement les bords du premier segment jaunos;

4(5) Rudius nussi distinct que les autros norvures, thorux \& lignes obliques...................... 9. mellipes.

5 (4) Radius peu distinct, plus ou moins offacé;

6(7) Les jambes postérivures aveo un nnnenu blanchâtre d la buse. ensiger, 529.

7 (6) Los jambes posterieures jaunes ou roussos, sáns anneuu blanchâtro;

8(9) Hanohes noires d la base, rousses au sommet 10. gelechiø.

9 (8) Hanchos entierement roussos ou jaunes;

10(11) 2 e segment abdominal caréné au miliou; hanches postérioures noires........ brevicaudus, ADD. 140.

11(12) 20 segment aveo une impression transversale................................. lateralis, Add. 141.

12(11) 2e segment sans impression transverse ;

13(14) Les 2 premiers segments rugueux. 11. rubricoxus, n. sp. 14(13) Lo 1er segment seul rugueux... 12. crenulatus, n. sp. 15(3) Abdomen plas ou moins roux;

16(17) 20 sogment avec un potit sillon do chaque côté du milieu ........................... auripes, ADD. 141. 
17(16) 2e segment sans sillons longitudinaux ;

18(19) Hunches noires. 4-dentatus, ADD. 140

19(18) Hanches rousses ou jaunes; tête et thorax noirs;

20(21) Scape noir; les 2 premiers segments abdominaux rugueux......................... melligaster, ADD. 143.

21(20) Scape roux en dessous, le ler segment abdominal soul rugueux au milieu.... zonarius, ADD. 140.

9. Microgastre pieds-jaunes. Microgaster rnellipes, Say. Am. Enntomology II, 712.

+-Long. .16 pce. Noir avec les pattes d'un bean jaunemiel; le labre, les mandibuies, le scupe des antennes en c.sssous, les écailles alaires; jaune-roussâtre. Mésothorax avec 2 lignes obliques en dessus. Liles hyalines, le radius avec les autres nervures de l'extrémité bien distincts quoique plus faibles que les nervures discoïdales. Abdomen fusiforme, déprimé, le premier segment rugueux au milieu, ses bords lisses et jaunes, do même que la majoure partie du ventre.-CapRouge.

10. Miorogastre du-Geleohia. Microgaster Gelechice, Riley. Riley's First Annual Report p. 178.

으-Long. .18 pce. Noir avec les pattes jaune-ronssâtre, la bouche avec les écailles alaires, roussâtre. Mésothorax avec 2 lignes enfoncées obliqucs, le m.étathorax rugueux avec une carène longitudinale et une autr'e transverse a la base, lisses. Ailes hyalines, les nervures brunes. Abdomen avec les 2 premiers segments rugueux, lo ventre jaune a la base, cette couleur jaune débordant sur les côtés du $2 \theta$ segment en dessus, à la base ; tarière non sortante.-CapRouge.

11. Microgastre hanohes-rousses. Microgaster rubricoxus, n. sp.

ㅇ-Long. .20 pce. Noir avec les pattes d'un bean roux; les mandibules, le labre, les écailles alaires, les antennes en dessous, brun-roussâtre; le scape noir, Le mésothorax avec 2 iignes enfoncées en dessus, l'écusson poli, lisse, avec une fossette crénelée en avant; lo métathorax scabro aveo une petite carène au milicu. Ailes hyalines, les nervures brunes, la 2 e cellule cubitale petite, sa nervure postéricure brievement interrompuo au miliou. 
Pattes, y compris les hanchos, d'un benu roux, les postérieures avec lo sommot des cuisses, la baso et le sommet dos jambes, et les tarses ontièrement, noir. Abdomen avec les 2 promiors segments scabres, sans lignes longitudinales, le reste poli, brillant; tarière nou eortante. - CapRonge.

Ses tarses postérieurs noirs le distinguent surtout du gelechioe.

12. Microgastro crénelé. Microgaster crenulatus, n. sp.

\&-Long. .17 pce. Noir avec les pattes rousses, lo labre, le scape, les mundibules, les écailles alaires, plus ou moins roussâtres. Le mésothorax avec 2 lignes en ỏncées obliques sur le dos, le métathornx scabre, avec une petite carène longitudinale et uno autre transverse près de la base; les flancs avec une grande plaque lisse portant une dépression crénelée au dessous la suture du métathorax anssi crénélée. Ailes hyalines, la 20 cubitale parfaite. Pattes rousses. Abdomen à premier segment portant un sillon de chaque côté qui se courbe on dedans en arrière pour former un disque au milieu scabre, les côtés jaunes, le reste du dos noir, poli, brillant; taricire à peine sortante.CapRouge.

\section{Gen. Apantelis, Först.}

Ce genre qui a été distrait des Microgaster s'en distingue surtout par la 2 e cellule cubitale des ailes qui est incomplète, manquant de ses nervures extérieures.

Neuf espèces rencontrées.

1(13) Dos de l'abdomen entièrement noir ;

2(3) Cuisses noires, le reste des pattes brunâtre

3(2) Cuisses rousses;

4(11) Toutes les hanches noires;

5(6) Mandibules prolongées en bes; antennes épaisses....................... 2. crassicornis.

6(5) Mandibules ordinaires;

7 ( 8 ) Segmonts 1 et 2 avec uno petite carène.... 3. acaudus.

$8(7)$ Segmonts 1 et 2 sans cartue; ellule cubitale puo au milieu. avec 2 iignes $\theta$ fossette crétite carene au 
9(10) Taridre aussi longue que l'abdomen....... 4. clavatus. 10( 9 ) Tarière a peine sortante.............. 5. carpatus. 11(12) H:ınches postérieures noires, les autres rousses.............................6. xylinus.

12(11) Toutes les hanches rousses.......... 7. congregatus. 13(1) Dos de l'abdomen plus ou moins roux ;

14(15) 2 e segment rugueux.............. 8. longicornis. 15(14) 2 e segment non rugueux, roux de même que lo 30 ........................... 9. cinctus.

1. Apanteles femur-nlgrum, Prov.=Microgaster $f_{e}$ mur-nigrum, Prov. ADD. 142.

2. Apanteles orassicornis, Prov.=Microgaster crassicornis, Prov. ADD. 142.

3. Apanteles acaudus, Prov.=Microgaster acaudus, Prov. ADD. 142.

4. Apanteles olavatus, Prov. = Microgaster clavatus, Prov. Faune 529.

5. A panteles carpatus, Prov. = Microgaster carpatus, Prov. 528.

6. Apanteles xylinus, Say. = Microgaster xylinus, Say. 528.

7. Apanteles congregatus, Say.=Microgaster congregatus, Say, 518.

8. Apanteles longicornis, Prov.=Microgaster longicornis, Prov. ADD. 143,

9. Apanteles oinctus. Prov.=Microgaster cinctus, Prov. 529.

\section{Sous-fam· des CRYPTOGASTRES, p. 530.}

Deux cellules cubitales; ventre concave d'un bout d l'autre, à bords aigus.............. SigalpHus, p. 530. Trois cellnles cubitales, ventre concave, ses côtés ré. fléchis, corps rugueux; 
clavatus. carpatus.

xylinus. gregatus.

agicornis.

cinctus. laster feer crassiacaudus, clavatus, carpatus, xylinus, congreer longitus, Prov. 30. us, p. 530.

- Abdomen a 3 segments distincts en dessus, les côtés non réfléchis en dessous; 1̇̀re eubitale et 1ère discoïdale séparées;

Abdomen sans dents endessous, nervure récurento subobsolète, $2 \mathrm{e}$ cubitale très rétrécio a la base; jambes intermédiaires gibbeuses en dehor's................ Phanerotoma, p. 533.

Abdomen avec 2 dents en dessous dirigées en arrière, la récurrente reque par la lèro cubitale, la 20 cubitale non rétrécie a la base; jambes interınédiaires simples....... ............... SPH 2 ROPYX $=$ Rhitigaster, 534 .

Abdomen non divisé en segments en dessus, ses bords latéraux repliés en dessous;

Yeux poilus; 1ère cubitale confluente arec la 1 dere discoïdale................. Chelonus, $p 530$. Yeux lisses; ler cubitale ot 1ère discoïdale distinctes ..................... Asgogaster, Add. 145.

Gen. SPHжROPYx, Hall.=Rhitigaster, Wesm. pp. 534 et 805; ADD. 146.

Le genre Spheropyx, Hal. ayant la priorité de date sur celui de Rhitigaster, Wesm. doit lui être substitué.

1. Sphæroppx Quebecensis, Prov. = Rhitigaster Quebecensis, Prov. 534.

2. Sphæropyx parvus, Prov. $=$ Rhitigaster parvus, Prov. 805.

3. Sphæropyx ovalis, Prov.=Rhitigaster ovalis, Prov. ADD. 14u.

Sous-fam. des EXODONTES. p. 335 ; ADD. 147

Aux 5 genres décrits, ajoutez les 4 qui suivent. Clef pour la distinction des genres.

1(14) Trois cellules cubitales; rarement apteres ou subaptères ; 
2 ( 7 ) 1 dere nerrure cubitale transvorse aussi longue ou plus longue que la 20 partie du radius;

3 (4) 1 ère cubitale confluente avec la 1ere discoïdale. 1. SYaLdis

4 (3) 1ère cubitalo séparéo do la 1ère discoïdale; 40 articlo des anteunes pas plus long que le 30 ; sillon des flancs du mésolhorax rugueux ou crénelé ;

$5(6)$ Nervure parallèle intersticiale ....... 2. Gratospila.

6(5) Nervuro parillele non intersticiale; stigma court, oblong, recevant lo radius on arriere do son milieu........................ 3. Alysia.

7 (2) 1ero nervaro cubitale transverse plus courte que la seconde partie du radius;

$8(9)$ 1ere cubitalo confluente avec la lère discoïdale ....................... 4. Aphereta.

9 (8) 1èro cubitale séparée de la 1ère discoïdale;

10(11) 4 e article dos antennes plus long que le $3 \mathrm{e}$; cellule sous-médiane des ailes inférieures moins de la moitié de la longueur de la médiane, la radiale atteignant lo sommet de l'aile......................... 5. Рhanocarpa.

11(10) 40 articlo des anternes pas plus long que le 30 ; cellule sous-médiano des ailes inférieures de la moitié de la médiane;

12(13) Stigma nul, pas plus épais que la nervure costale...................... 6. Aspilota.

13(12) Stigma allongé, atténué, mais plus épais que la nervures costale, cunéiforme........ 7. Prosapha.

14/ 1 ) Deux cellules cubitales aux ailes antérieures;

15(16) Segments 1-3 formant une carapace rugueuse (comme dans les Sigalphes), lo resto caché ou très court; post-écusson avec une élévation dentiforme ..................... 8. Enone.

16(15) Segment 3, et généralemont 2, lisse, ne formant pas une carapace, lo r'este non caché ni tres court; post-6́cusson inorme........ 9. Dacnusa. 
Gen. Sxnaldis, Först.=Trinaria, Prov. Add. 149.

Synaldis pilicornis, Prov.=Trinaria pilicornis, Prov. ADD. 149.

2. Gen. Cratospila, Först.=Asynaphes, Prov. Add. 150.

1. Cratospila caudata, Prov.=Asynaphes caudata, Prov. AdD. 150.

2. Cratospila acioulata, Prov. = Asynaphes aciculata, Prov. AdD. 150.

3. Cratospila brevicauda, Prov.=Asynaphes brevicauda, Prov. AdD. 151.

8. Gen. Alysia, p. 535. AdD. p. 147.

Aux 5 espèces décrites, ajoutez les deux qui suivent.

6. Alysie fossulee. Alysia fossulata, n. sp.

o-Long. .18 pce. Noire, avec les pattes roux-sombre; les mandibules avec le scape en dessous, roux obscur. Tête grosse, plus largo que le thorax, a vertex poli, brillant. Thorax poli, brillant, le mésothorax avec une fossulette an milieu avoisinant la fossette striée transversale en avant de l'écusson; métathorax fortement rugueux, sans carènes distinctes. Ailes hyalines, le stigma noir, épaissi. Pattos roux-foncé, sans aucune tache. Abdomen a côtés paralleles, le ler segment aciculé avec une petite carène au milieu, les autres polis, brillants, les terminaux brusquement atténués en une petite pointo; tarière non sortante.Los Angeles (Coquillett).

Espèce bien remarquable par la fossette de son mésothorax.

7. Alysie rougeâtre. Alysia rudibunda, Say-Am. Ent. I, 380.

o $\delta^{7}$-Long. .15 pce. D'un jaune roux, avec la tête et l'extrémité de l'abdomen en dessus, noir. Les mandibules avec une petite taché de chaque côté de la bouche, roussâtres. :Tête très grosse, à vertex excavé. Ailes plus ou moins enfumées, le stigma allongé, recevant le radius au dela de son milieu. Pattes brun- 
rouskâtre, les cuisses postérieures $\sigma^{7}$ avec lours hanches de la coulour du corps. Dos de l'abdomen déprimé avec une tache joire sur les sogmonts terminaux.-Ottawa (Harrington).

Se distingue surtout de la lucens par son thorax roux.

4. Gen. Aphжreta, Först=Trichesia, Prov. 536.

Aphæreta auripes, Prov.=Trichssia auripes, Prov. 537.

5. Gen Phanocarpe. Phoenocarpa, Först.

Tête en carré transversal, plus large que le thorax. Antennes aussi longues que le corps, à 4 e article plus long que le 3e. Ailes à stigma ovale, la cellule radiale très grande, atteignant l'extrémité, la 1ère cubitale séparée de la lère discoïdale; ailes inférieures à cellule sous-médiane moins de la moitié de la raédiane. Pattes ordinaires. Abdomen linéaire; tarière à peine sortante.

Une seule espèce rencontrée.

Phénocarpe tête-rouge. Phonocarpa rubricepes, n. sp.

+ -I long. .18 pce. Variée de noir et de jaune. Tête jauneroussâtre, le vertex avec une tache au dessus des anteunes, noir. Antenues grêles, pubescentes, aussi longues que le corps, pâles d la base, noires dans le reste. Thorax noir avec une bande rousse sur les lobes latéraux du mésothorax; métathorax à lignes soulevées distinctes. Ailes hyalines, lo stigma jaune-bıunâtre. Pattes jauno-pâle. Abdomen allongé, linéaire, jaune, noir à l'extrémité; tarière à peine sortante.-CupRouge.

\section{Gen. Aspilote. Aspilota, Först.}

Tête en carré transversal, aussi large que le thorax. Antennes à article 4 pas plus long que 3 . Ailes à 3 cellules cubitales, la 1ère séparée de la 1ère discoïdale; -ailes inférieures à cellule sous-médiane de la moitié de la médiane; stigma nul, pas plus épais que la nervure costale. Pattes ordinaires. Abdomen brièvement pédiculé, tarière plus courte que l'abdomen.

Une seule espèce rencontrée. 
es de la ne tache ).

oux.

36.

rov. 537.

2x. Anng que le de, atteire discoïns de la linéaire ;

pes, n. sp. ête jaunenes, noir. ps, pâles d de rousse nes soule-. e. Pattes xtrémité;

ax. Anules cubibrieures à gma nul, s. Abdodomen.
Aspilote sans-stigma. Aspilota astigma, n. sp.

o-Inng. .14 pee. Juuni-pâle, la tête et lo thorax plus ou moins tachés de noir. Autennes pâles à la base, noiros dans le resto. Thorax noir on dossus, les fluncs avec le métathorax jaune-brunâtro. Ailes hy:lines, is collule rarliale très grande, atteignant l'extrémité de l'aile, point do stigma, la nervnre costale à poine plus épai-so que les autres; la 2e cubitale très longue ot étroite. Pattes, y compris les hanches, d'un jaune-pâle uniforme. Abdomen bridvoment pédiculé, le dossus, vers l'extrémité, légère. ment laves de brun; tarière du quart de la longueur de l'abdomen ouviron,-CapRouge.

Var. La tête, le thoriıx et l'abdomen presque entièrement noirs.

\section{Gen. Prosa Phв. Prosapha, Först.}

Tête en carré transversal, plus large que le thorax, excavée postérieurement. Antennes filiformes, assez fortes, plus longnes que le corps, leur 40 aricle pas jlus long que le 3 e. Ailes avec une grande cellule radiale atteignant presque l'extrémité, le stigma étroit et allongé, recevant le radius au deld de sa base, la 1ère cubitale séparée de la 1ère discoïdale, la cellule sous-médiane des ailes postérieures de la moitié de la médiane. Pattes ordinaires, assez fortes Ablomen subsessile.

Une seule espèce rencontrée.

\section{Prosaphe hyalino. Prosaphu hyalina, n. sp.}

\&-I mandibulus avec lo scape en dessous; jaune. Thor:ax poli, brillant, noir aans aucane tache. Ailes hyalines, les nervurus brunes. Abdomen subsnssile, on ovale allonge, to 1er segment noir, rugueux; le 20 jaune, lo resto noir, poli, brillant; tarière non sortante.-Ottawa (Guignurd).

8. Gen. Esone. ERnone, Haliday.

'Cête grosse, en carré transversal. Antennes nssez longues, Thorax robuste. Ailes avec une radiale semi-cordiforme, assez 46-Octobl's, 1888. 
large, n'atteignant pas l'extrémité, la 1ère cubitale seule fermée, assez grande, ricevant la récurrente, la 20 commencée seulement, la nervure parallèle non intersticiale; le stigma large et peu allongé. Abdomen déprimé, sessile, plus large à l'extrénité, Je dos en carapace, divisé cependant en 3 segments; tarière d peine sortante.

Une seule espèce rencontrée.

CEnone soyeuse. EEnone sericea, n. sp.

? -long. 12 pce. Noire avec les pattes jaune-miel. Los mandibules jaunes avoc l'extrémité noire. Antennes soyeuses, noires, le scape jaunâtre en dessons; les écailles alaires jaunes. Le mésothorax à 3 sillons bien prononcés, se réunissant avant d'attricione la fossette de la base de l'écusson, les 2 laténux crénelés; le métathorax finement rugueux. Ailes hyalines, le stigma et les nervures brun-foncé. Pattes jaune-miel sans aucune tache, y compris les hanches. Abdomen sans aucune tache, soyeux, seulement 3 segments; tarielre d peine sortante.-Ottawa (Harrington).

Sous-fam. des FTEXILIVENTRES, p. 537 ; ADD. 151.

Des 9 genres mentionnés dans cette sous-famille, retranchez Copei is, Prov., Ropronia, Prov., qui appartiennent aux Proctotrupides, et Arotropus Prov. qui appartient aux Formicides, et ajoutez celui qui suit.

Clef pour la stinction des genres.

1(8) 1ère cellule discoïdale complete;

2(3) Nervures cubitales transverses nulles, par conséquent une seule cellule cubitale......... 1. Praon.

3 (2) Nervures cubitales transverses distinctes";

4(5) Deux cellules cubitales...... 2. Radiolaria, Add. 154.

5(4) Trois cellules cuòitales;

6( 7 ) Nervure parallèle intersticiale.. 3. Ephedrus, Add. 155.

$7(6)$ Nervure parallèle non intersticiale. 4. Scotioneurus, AdD. 156. 
iiel. Los soyeuses, es jaunes. ant avant raux crélo stigma Ine tache, , soyeux, iwa (Har-

ADD. 151. etranchez ix Proctoicides, et

8 (1) 1ère cellule discoîdale incomplete;

9(12) Une nervur cubitale transverse présente;

10(11) Cubitus présent, se joignant a la baso à la 2e discoïdale.............. 5. ApHidius, 537, Adv. 15\%.

11(10) Cubitus absent a la base, les discoïdales 1 et 3 confluentes avec la 1ere cubitale ...................6 Aphidaria, Add. 153.

12 (9) Aucune nervure cabitalo transverse présente; cubitus nul............. 7. Nevropenes, Add. 153.

1. Gen. Praon. Praon, Haliday.

Tête transverse, aussi large que le thorax. Thorax court et robuste. Ailes avec la lère cellule discoïdale complète, la radiale incomplète, le radius étant interrompu avant d'atteindre l'e ‘némité de l'aile. La nervure parallèle non intersticiale. Abdomen à premier segment peu allongé et non très grêle; tarière à peine sortante.

Une seule espèce rencontrée.

Praon simulant. Preton simulans, Prov.

Aphidaria simulans, Prov.-ADD. p. 153.

\section{Gen. Ephedrus, Halid. AdD. 155.}

Retranchez l'espèce incompletus, ADB. 156, qui est la of du Seotioneurus dieres, Prov., ADD. 157; un meilleur spécimen nous a permis de constater que la nervure. parallèle n'est pas intersticiale comme nous avions cru la voir.

5. Gen. Aphidius, Nees, p. 537, ADd. 152.

1. Praon.

Aux 2 espèces décrites, ajoutez la suivante.

Tête noire;

A bdomen jauno a la base, brunâtre plus ou moins

foncé dans le r'este... 1. Oanadensiz, Pror. And. 537.

Abdomon entièrement noir, les pattes juunâtres

................. 2. obscurus, Prov. Add. 152. Tête jaune, le reste jaune varié de noir... 3. nigrovarius, n. sp. 
8. Aphldius varlé-de-noir. Aphidius nigrovariuz, n. $8 \mathrm{p}$.

\&-long. .11 pce. Juune, les untennes, une tache sur lo vertex, uno tache sar chacun des lober du mesothorax, noil: Ailes uvec lo cubitus três distinct enuis interyon pu, do memo que le radius, a peu de distanco do ln nervure transverse qui los unit. Pattos jaunes, los tarsos pastóriours légdrement obsenreis. Abdomen allongé, linéiire, longuement acuminé a l'extrécité, les seginents jaunes a la buse ot plus ou moins obscurs dans lo rosto ; tarière a peine sortante. - Los Angeles (Coquillett).

\section{Gen. Aphidaria, Prov. Add. p. 152.}

Ce genre, confondu dans sa description avec les Praon, doit être déterminé comme suit :

Ailes à lère cellule cubitale confluente avec les discoïdales 1 et 3 , le cubitus n'existant pas à la base; le radius a ses deux premières parties bien distinctes et porte une petite nervure cubitale transverse qui se joint all cubitus qui n'est pas distinct à la base; le stigma grand, triangulaire; la $2 \mathrm{e}$ cubitale quoique petite est seule fermée, et reçoit la nervure parallèle à son angle supérieur, c'est-d-dire que cette nervure est intersticiale.

Une seule erpèce.

Aphidaire a-base-pâle. Aphidaria basilaris, n. sp.

б' o -Long. .11 pee. Noire, polie, brillante, avec le pédicule do l'abdomen jaune-pâle. Antennes acsez longues, filiformes, brun foncé. Los mandibules avec les palpes jaunies. La fossette en avant de l'écusson large ot profonde, le métatborax non r'ugueux. Ailes hyalines, légerement poilues, lo stigına brunjaunâtre, le radius très court, ne dépassant pas la pointe du stigma, mais portant près de la base une nervale intercubitalo avec un commencement de radius de chaque côté a son extrémité. Paltes d'un jaunâtre sale plus ou moins foner. Abdomen linéaire, le pédicule légèrement plus large au sommet, les segments 2 et 3 bruns, le reste noir; tarière a pcine sortante.-Los Angeles (Coquillett). 
Obtenue de la Siphonophora citvifolia et d'autre nphides. Son absence de lère cellule discoïdale et sa nervule transverse la distinguent surtont des Praon.

\section{Fam. VI CYNIPIDES p. 540, AdD. 156.}

\section{Gen. Neurotìre. Neuroterus, Hartig.}

Ailes à radiale ouverte en avant. Sillous parapsidaux nuls ou peu distiuets, ne s'étendant pas sur toute la longeur du mésonotum; le radius atteignnnt le bord de l'aile. Antennes et pattes pubescentes. Aréole oblitérée.

A l'espèce décrite, p. 548, ajoutez la suivante:

\section{Neurotère terminal. Neuroterus terminalis, Hartig.}

\$--Long. .08 pee. Jaune, finemont ponetue. Antennes épaissios et noires al l'extrémité. Thorax sans aucune tacho. Les sillons parapsidaux peu distincts. Ailes hyalines avec les nervures brunâtres. Les jambes postérieures, noir plus ou moins foncé. Abdomen jaune, plus ou moins teint de noir dans sa moitié postérieure; tarière très longue.-Los Angeles (Cioquillett).

Gen. Periclistus, Först, AdD. 163

\section{A l'espèce décrite, ajoutez la suivante:}

\section{Péricliste oblique. Periclistus obliquus, n. sp.}

f-Long. .10 pec. D'un jaune sale avec une tache au métathorax, les jumbes postérieures, surtout a l'extrémité, et l'abdomen on plus ou moins grande partie, noir. La face non strice. Les sillons parapsidaux obliques, so rapprochant en arriere. Ia radialo ouverte on avant, le radius atteignant le bord costal, l'aréole incomplète. Abdomen presque entièrement noir; la tirrière saillante, l'écaille ventrale torminéo en pointe fine.--Los Angeles (Coquillett) 
Gen. Cenoptres, Hart. Add, 164.

A l'espèce décrite, ajoutcz la suivante :

Céroptre àdos-noir. Ceroptres dorsalis, n. sp.

- long. . 18 pee. D'un bean janne.miel, nvec les yeir, une tacho sur le vertex, lo lobe médinn du mésonotum, lo métanotum ot une ligne sur lo dos des premiers sogments de l'nbdo. men, noir. Les mandibules noires il l'extrémité. Les antennes avec les pattes, jaune sans aucuno tuche. La fuce fintoment striée et d'un jaune plus pâle. Ailes hyalines, d norvires brunes, légèrement velues, la radiule formén on avant. Abdomen comprimé, a tarière redressée, dépassennt la lignno du dos. - Los Angeles (Coquillett).

Superbe espèce, bien remarquable par sa forte taille.

$\sigma^{7}$ - Mêmo coloration que duns in o, mais trìs remar'quable par son deuxième segment abdominal qui se dévoloppo en une double écaillo dépussunt l'extrémité de l'ubdomen ot so prolongenut en dessous d'uu moins le double do l'épaisseur des autres segments.

Gen. Eucolla, Westw., p. 551, ADD. 171.

Aux 4 espèces décrites, ajoutez la suivante :

5. Eucoila plus-petite. Eucoila mino?', n. sp.

q-Long. 08 pee. Noire, polio, brillante, los antennos plus épaisses a l'extrémité, lour 3o articlo plus long quo lo 40. Thorax à sillons purapsidnux distincts. Ailes veluos, frungées, à collule radiale triangulaile, close en arant. Pattes hoires, avoc les jambes, les genoux et le sommot des caisses, d'un jauno plus ou moins salo. Abdomen entierement noir. Toute la moitis apicale des ailes sans aucuno nervure.--Los Angeles (Coquillett). taille.

Se distingue surtout des autres espèces par sa plus petite 


\section{Fam. VII. PROCTOTRUPIDES, p. 657. ADD. 173.}

Les travaux récents do M.M. Howard et Förster sur cetto fanille, qui n'avait encore qu'imparfuitument été étudiéo, nous ont forcé à moditier considérablement les divisions que nous en avions données. Plusieurs spécimens nouveaux venant aussi se joindre à ces modifications, nous donnons une nouvelle clef pour la distinction des tribus et des genres.

Lo prineipal earactìre distinctif entre les Proctotrupides et les Cynipides est la forme du prothorax, dans les premieres lo prothorax se rend toujours jusqu'd l'insertion des ailes, tandis que dans les Cynipides il en est toujours plus ou moins éloigné.

Clef pour la distinction des genres.

1(52) Ailes antérionres snns cellules discoïdales fermées;

2(3) Ailes postérieures lobées a lour baso, ot lorsqu'elles munquont les pattes antérieures pro. pres d fouir : DRYINIDIENS, et BETHY. LIENS; prothorax plus long que lo mésothornx, celui-ci snns sillons distincts....... 1. Eprris.

Point d'ailes, vertex profondément impressionné ........................... 2. Gonatopus.

3(2) Ailes postérieures non lobées d la base;

4 (5) Jrmbes untérioures avec 2 éperons: CERA. PHRONTIENS,.............. 3. Megaspilus.

sp.

ennes plus 10. Thor:ax $\therefore$, a cellule avoc les o plns ou moit: apiuillett..

plus petite

5(4) Jambes antérieures avec un seul éperon;

6(7) Mandibules sans dents: PROCTOTRUPIENS, ....................... 4. Proototrupes.

7(6.) Mandibules dentées;

8(18) Abdomen d bords aigus sur les côtés, antennes insérées près de la boucho;

9(12) Ailes antérieures avec l'ulna ot quelquefois aussi le iradius; dans les apteres poiut d'ocelles (1) SCELIONIENS;

(1) Voir pour la distinction de ces nervures la figure de la page 185, les Proctotrupides ayant à peu près la même dispositiou des nervares que les Chalci tides. 
10(11) Massue des antennes articuléc; ulna nulle, humólus atteignant lo stigma........5. BreneUra.

1 (10) Massue des anterinos articulce; humérus atteignant l'ulna, celle-ci courte; ler segment abdominal petit, le 20 plus grind ..... 6. Thiemonus

12(9) Ailes antérieures sans ulna ri cubitus; tous les genres avec des ocelles: PLATYGAS. TERIENS;

13(16) Humérus avec un nœud à l'oxtrémité;

14(15) Tarses de 5 artieles; antennes de 10 articles; ailes sans nervure basilairo ni médiane; les ocelles basilaires plus rapprochés de l'apical que du bord intérieur des yeux...... 7. Isostasius.

15(14) Ocelles basilaires plus rapprochés du bord interne des yeux que de l'ocelle apical; 1er segment abdominal sans colne......... 8. Acerota.

16(17) Humérus sans nœud a l'extrémitś; écusson somi-circulaire, non aplati; tête non cubique; écusson avec une toufie de poils au sommet...................... 9. Trichacis.

17(13) Ecusson sans touffe de poils au somınet, non séparé du mésothorax par un sillon profond ......................... 10. Pi.atigaster.

18(8) Abdomen, non a bords tranchants sur les côtés; antennes insérées à distance do la boucbe ;

19(20) Ailes postérieures petites, presque linéaires, sans trace de nervure médiane: MIMARI$E N S$; tarses de 5 nrticles; abdomen. distinctement pétiolé; antennes $\sigma^{\lambda}$ de $10 ~ \| 1$ ticlos, 9 de 9................ 11. Camptotera.

20(41) Ailes postérieur's sans traco de nervure médi. ane, nou linéaires, assez larges: DIAPRIENS ;

21(22) Ailes échancrées on cœul a l'uxtrémité... 12. Entomaors.

22(21) Ailes entières a l'extrémité;

$23(24)$ Scupo très grand, mésothorax sans sil-

lons. ........................ 10. Platymeschus.

24(23) Scape ordinaire, non très développé; 
$25,26)$ Scape arce un nœud an milieu; face très allongét........................ 13. Galesus.

26(25) Scape sans nœud au milicu: ; face non très allongée;

27(28) Humérus non uni a l'ulna et portant une nervule. stigmatique au sommet....... 14. Aneurynchus.

28(27) Hứérus uni à l'ulnạ;

29 (36) Mâle ;

30(33) Antennes de 13 articles;

31(32) 1er article du funicule, moins de la moitié du second en longuent................ 15.' Paramesius.

32(31) ler article du funiculo aussi long ou plus long que le second; 20 segment abdominal sans fossulettes à la base............. 16. SpILomionus.

33(30) Anternes de 14 articles;

34(35) Ailes sans norvure basilaire........... 17. Diapria.

35(34) Ailes avec une nervure basilaire, le 1er article du funicule plus court que le second.... 18. BAsár.

37(38) Antennes de 12 articles; tête non aplatie; ailes sans nervure basilaire.............. 17. DiapRIA.

33(37) Antennesi de 13 articles;

39(40) Abdomen conique d l'ex ìrémilé........ 15. Paramesius. 40,39) Abdomen tronqué a l'extrémité; ulna pré. sente..................... I6. Spiromicrus.

41(20) Ailes postérieures avec une nervure médiane; les antérieures avec ou sans ne:vure bnsilaire; funicule saus articlo noduleux: BÉLYTINIENS;

42(47) Mâle; yeux poilus;

43(44) Post-écusson avec une forte épine...... J7. Oxyrabis. 44(43) Post-écusson sans épine; collule radiale fermée; 45(46) Pédicule de l'abdomen pas plus long ou d peine plus long que le mbtathorax, le segment terminal courbo.............20 PANtoolis.

46(45) Pédicule de l'abdomen deux fóis ausi long que le métathorax; abdomen s'aplatissans apres. Ie 2e segment; scape plus long que le 1 er article du funicule. ................ 21. Cinetus. 
48'49) Post-écusson avec une forte épine....... 19. Oxylabis. 49(48) Post-écusson inerme;

50(51) Dernier article du funicule doux fois plus long que large.................. 21. Cinetus.

51(50) Articles du funicule raccourcis vers l'extrémité ........................ 20. Pantocls.

52(1) Ailes antérieures avec une nervure basilaire, une cellule radiale fermée et deux cellules discoïdales : HELLORIENS;

53(54) Nervure basilaire interrompue supérieurement ....................... 22. HeLonds,

54(53) Nervure basilaire complete, non interrompue

23. Ropronia.

1. Gen. EPyre. Epyris, Westw.

Mêmes caractères que dans les Bethrlus p. 563, avec cette seule différence que dans les Epyres la cellule radiale est presque complète, et que dans les Béthyles elle est absente.

Deux espèces rencontrées.

Tête et thorax polis, luisants.............. 1. formicoides. Tête et thorax opaques, finement rugueux.... 2. prolongatus.

1. Epyris formicoides, Prov. = Bethylus formiccides Prov. AdD. 179.

2. Fpyris prolongatus, Prov. = Bethylus prolongatus, Prov. p. 563.

Megaspilus lucens, Prov. p. 808=Proctotrupes flavipes, Prov. p. 562.

5. Gen. B€onure. Bæoneura, Först.

Antennes insérées près de la bouche, s'épaississant en massue à l'extrémité. Mésothorax avec un sillon médian et un autre de chaque côté. L'humérus atteignant directement le stigma, non uni à la côte par une ulna.

Une seule espèce. 
Béonure tête-de-belier. Bceoneura arietina, Prov.= Isostasius arietinus, Prov. ADD. 183.

\section{Gen. Telemonus, Hal. Add. 180.}

A l'espèce décrite, ajoutez la suivante :

2. Télémon roux-noir. Telemonus rufoniger, n. sp.

$\delta^{7}$-Long. .10 pce. D'un noir brillant en dessus, le scape des antennes, la poitrine, les pattes avec la base de l'abdomen d'un jaune plus ou moins roux. Ailes avec l'humérus se confondant avec la nervure costale, u'na élargie, ayant l'apparence d'un second stigma; cellule radiale ouverte, la partie antérioure de l'aile plus ou moins obscurcie de roussâtre. Abdomen assez court, claviforme, subsessile.-CapRouge.

7. Gen. Isostasius, Först. ADD. 183.

Isostasius Canadensis, Prov.=Platygaster Canadensis, Prov. ADD. 181.

\section{Gen. Trichace. Trichacis, Först.}

Tête transverse, non cubique. Antennes coudées, à scape allongé, à peine épaissies à l'extrémité. Thorax rétréci en avant, le mésothorax avec sillons très apparents. Ecusson convexe, avec une touffe de poils au sommet. Ailes grandes, humérus sans nœud au sommet. Abdomen subsessile, déprimé en dessus, arrondi à l'extrémité.

Une seule espèce rencontrée.

Triohaoe a-pieds-dorés. Trichacis auripes, n. sp.

o-long. .15 pce. Noire, polie, brillante; le scape avec les pattes d'un beau jaune d'or. Lo funicule des antennes brunfoncé. Ailes sans nervures distinctes, grandes, plus longues que l'abdomen. Le thorax rétréci en avant, lo mésothorax avec deux sillons très apparents; l'écusson convexe, terminé par une touffe de poils grisâtres, séparé du mésothorux par une double fossette lurge et profonde. Les hanches noires, les cuisses pos- 
térieures renflées en massue et plus ou moins obscures. Abdomen subssesile, poli, brillant, déprinıé, arrondi a l'extrémité, lo 2 e segment le plus grand.-CapRouge.

Gen. 10. Platygaster, Latr. Add. 180.

Platygaster azeurus, Prov. = Aneurynchus ancurus, Prov. ADD. 176.

Gen. 11. Gamprotère. Camptotera, Först.

Antennes insérées sur le front, non près de la bouche. Abdomen plus ou moins arrondi sur les côtés. Ailes postétérieures très petites, presque linéaires, sans nervure médiane. Abdomen pétiolé; tarses de 5 articles.

Une senle espece rencontrée. .

Camptotère en-massue. Camptotera clavata, n. sp.

- -Long. .09 pce. Noire, polie, brillante, les antennos et les pattes jaune-orange. Fuce inférieuro; antennes insérées sur un rebord du front, de 10 articles $\delta^{7}$ et $\theta$ articles $\$$. Cuisses plus ou moins renflées; tarses de 5 articles. Abdomen pédicule, le reste formant une massue en pointe d̀ l'extrémité.-Ste Gertrude.

12. Gen. Enтomace. Entomacie, Först.=Coptera, Say, ADD. 181.

Entomacis politus, Say=Coptera polita, Say, ADD. 182. 14. Gen. Anturynchus, Westw. p. 560.

Aneurynohus mellipes, Prov.=Cinetus mellipes, Prov. ADD. 177.

Aneurynohus foreatus, Prov. =Spilomicrus foveatus, Prov. ADd, 176.

15. Gen. Paramise. Paramesius, Westw.

Tête courte, transversale; antennes inşérées sur un rebord au milieu de la face, longues, à premier article du funicule 
Abdosmité, lo

neurus,

bouche. $s$ postéaédiane.

n. sp. nnos et rées sul' sses plus le reste ide.

Say,

DD. 182.

8, Prov.

pveatus,

rebord inicule moins de la moitié du 2 e en lọgaenr. Ailes avec une nervure basilaire, et l'humérus uni à l'ulna, une petite cellule radiale fermée en triangle allongé. Abdomen pédiculé, aigu à l'extrémité.

Une seule espèce rencortrée.

Paramèse à-longues-cornes. Paramesius longicornis, Prov. Spilomicrus longicornis, Prov. p. 561.

19. Gen. Oxylabe. Oxylabis, Först.

Tête transversale, les antennes insérées sur une proéminence an milieu du front. Les yeux poilus. Le $n$ ésothorax à sillons distincts. Ailes avec une nervure basilaire, l'humérus joint à l'ulna, les postêrieures avec une nervure médiane. Abdomen pédiculé, en massue.

Uno seule espèce rencontrée.

Oxylabe Gpineax. Oxylabis spinosus, Prov.

Aneurynchus spinosus, Prov. 560.

20. Gen. Pantocle. Pantoclïs, Först.

Tête tranverse, aussi large que le thorax. Antennes insérěes sur un tubercule au milieu de la face, à articles allongěs. Mésothorax à sillons distincts. Ecusson inerme. Ailes avec une nervure basilaire, l'humérus uni à l'ulna, la cellule radiale allongée, fermée. Abdomen à pédicule gros et peu allongé, le 2e segment aussi long que tout le reste, courbé à l'extrémité. .

Une seule cspèce.

Pantoule inerms. Puntoclis inermis, Prov. Aneurynchus inermis, Prov. ADD. 176.

22. Gen. Helonus, Latr. = Copelus, Prov. 540.

Elelorus paradoxus, Prov. = Copelus paradoxu, Prov. p. 540. 
23. Gen. Ropronia, Prov. Add. I54.

$\mathrm{Vu}$ l'absence de la 2e récurrente, nous avions rangé ce genre dans les Braconides, mais la forme du corps, et la nervation des ailes, bien qu'un peu différente du genre précédent, le classent évidemment dans la tribu des Héloniens des Proctotrupides.

Ropronia pediculata, Prov. ADD. 154.

Fam. VII-CHALCIDIDES, p. 564, ADD. 184.

Gen. Phrila mpus, Latr. p. 571, Add. 199.

Aux 5 espèces décrites, ajoutez la suivante.

6. Périlampe noir. Périł́smpus stygicus, n. sp.

P-Long. .11 pce. Noir, sans reflets métalliques, le thorax fortement ponctué, la face et l'abdomen polis, brillants. . La face lisse, sans ponctuations, le vertex légèrement ponctué. Antennes entièrement noires, le scape noir-blenâtre. Thorax d'un noir sale. Ailes hyalines, avec une tache brune pres du bord costal depuis l'extrémité de l'humérus jusqu'au bouton qui termine le cubitus. Pattes noires avec tous les genoux, l'extrémité des jambes et les tarses des postérieurs, jaunes. Abdomen court, subpédiculé, coudé, triangulaire postérieurement, poli, brillant.Ca Rouge.

Cette espèce se distingue facilement de toutes les autres par ses ailes tachées et son absence de reflets métalliques.

Après le genre Dinotus, ADD. p. 201, insérez le suivant.

Gen. Rhopalique. Rhopalicus, Först.

Tête aussi large ou à peu près que le thorax. Antennes avec des articles annulaires. Prothorax petit, mais arrondi, non tranchant. Ailes avec l'ulna très longue, mais non épaissie, le radius et le cubitus très courts, à peu près d'égale longueur, le dernier avec un point calleux à peine élargi. Pattes ordinaires. Aldomen plat en dessus, conique et terminé en pointe. 
Ce genre se distingue surtout des Métacoles par son ulna qui est longue, mais non épaissie. .Une seule espèce rencontrée.

Rhopalique pieds-pâles. Rhopalicus pallpies, n. sp.

f-Long. .10 pce. D'un brun vert métallique; le scape des antennes, les hanches, les cuisses et les jambes aussi a coulour métalliquo, les tur'ses pâles avec. l'extrémité noire. Thor'ax finement ponctue. Ailes hyulines, l'ulna iongue, non épaissie, le cubitus et le radius ties courts, mais distincts. A bdomen conique, plat en dessus, épaissi en dessous à la base.-CapRouge.

Après le genre Semiotellus, p. 373, ADD. 202, insérez le suivant.

184.

\section{Gen. Cleonyme. Cleonymus, Latr.}

Antennes de 12-13 articles, insérées vers le milieu de la face, avec 2 articles annulaires. Yeux poilus. Sillons parapsidaux distincts. Ailes avec l'ulna longue, non toutefois de la moitié de la longneur totale de l'aile ; le cubitus très court, séparant à peine le point épais de la côte. Jambes postérieures avec deux éperons. Abdomen subsessile ; tarière non sortante.

Ces insectes se distinguent surtout des Sémiotelles par les 13 articles de leurs antennes.

Cléonyme superbe. Cleonymus superbus, n. sp.

q-Lung. .11 pce. D'un beau vert métallique avec les pattes jaunes. La face et le thorax finemont ponctués. Antennos avec le scapo jaune en dessous, portant 2 articles annulaires et s'épaissisant de là en uno longue massue dont le dernier article est formé de 3 anneanx. Ailes hyalines, l'ulna longue avec le cubitus et le radius très courts, le point épais presque contigu à la côte. Puttes d'un beau jaune d'or, la base des hanches plus on moins coloréc. Abdomen plat en dessus, arrondi postérieurement et torniné par une potite pointe.-CapRouge.

\section{Antennes}

is arrondi, In épaissie, longueur, attes ordien pointe. 
Fam X=FORMICIDES, p. 584, ADD. 224.

Après le genre. Tapinoma, Latr. 237, ajoutez le suivant. Gen. Dolichdere. Dolichoderus, Lund.

\&્-Tête ovale. Epistome triangulaire, déprimé en avant, s'avanç..nt légèrement entre les antennes. Arètes froutale à peine distincte. Mandibules assez larges, dentées. Palpes maxillaires de 6 articles, les labiaux de 4. Antennes de 12 articles; le scape de longueur rooyenne, funicule s'épaississant insensiblement vers l'extrémité. Point d'ocelles. Thorax a vec un étranglement entre le mésonotum et le métanotum, celui-ci à face doı sale égale et à face postéricure concave, séparées l'une de l'autre par une arrête vive. Pétiole avec une écaille robuste, fortement inclinée en avant. Abdomen ne s'a vançant pas sur l'écaille.

†-Comme chez l'ouvrière, mais avec des ocelles. Ailes avec deux cellules cubitales. Taille plus grande que chez l'ouvrière.

$\sigma^{7}-$ Comme chez l'ouvrière. Antennes de 13 articles. Pétiole épaissi, sans écaille. Valvules génitales externes arrondies.

Uine seule espèce rencontrée.

Dolichod̀̀re du nord. Dolichoderus borealis, n. sp.

§̧-Long. 15 pce. La tête, le pavillon des antennes avec l'extrémité de l'abdomen, noir, lo reste d'un roussâtre sale. La tête et le corps finement ponctués, les mandibules et le scape des antennes avec les premier's articles du funicule, rouseâtres. Pronotum séparé du mésonutum par un petit sillon, et celui-ci du métanotum par un étrangloment bien prononcé. La face dorsale du métanotum plus fortement porictuée que le reste, ot la face postérieure excarée, concave. Pétiole avec une écaille épaisse ct dirigée en avant, le reste de l'abdomen en ovale triangulaire, poli, brillant, roussâtre d la base et noír dans le reste, le noir de l'extrémité s'uvance sur lo milieu du dos jusqu'an promier segment, sans toutefois déterminer des taches distinctes sur les côtés comme dans le 4 punctatus, Lin.-CapRonge.

Capturé un seul spécimen \& sur le sol ou lac Sergent sans pouvoir rencontrer les autres sexes malgré de longues recherches. 
on avant, coutale d Palpes. as de 12 aissiseant rax avec celui-ci ées l'une robuste, pas sur 3. Ailes hez l'oucles. Péurrondies.

n. sp. nes avec sale. La seape des es. Prolui-ci du e dorsale t la face o épaisse ngulaire, e noir de premier es sur les

Sergent longues
Aux 2 espèces décrites, ajoutez la suivante:

3 Lasius brun. Lasius brunneus, Latr.-André, II, 193.

8-Long. .14 pce. D'un brun jaunâtre, lo jaune plus clair sur les pattes et les antennes. Corps peu luisant, tinement pubescent, sans poils dressés épars sur les jambes et lo scape. Ocelles indistincts ou nuls. Thorax d'un jaune ou rouge brun, la tête ot l'abdomen plus foncés. Sillon fiontal bien.distinct.

o-Long. .26 peo. Tête plus étroite que le thorax, non échancree à son bord postérieur. Thorax plus étroit que l'abdcmen. Scape des autennes ot jambes sans poils dressés épars. Ailes enfumées de brun sur leur première moitié. D'un brun roussâtre, les mandibules, le scape et les pattes d'un jaune rousEâtı'e.

$\sigma^{x}$-long. .20 pco. D'un brun noirâtre. Tête pelı ou d peine échancrée à l'occiput. Abdomen sans gros points enfoncés. Sillon frontal bien distinct. Ailes enfumées de brun comme dans la 9 . Scape et jambes sans poils dressés épars. - CapRouge.

Comme l'alienus cette espèce n'est qu'une variété du niger.

Fam, XI.-MUTILLIDgS p: 603, ADD. 249.

Aux 4 genres mentionnés, ajoutez le suivant.

Gen. Pноторse. Photopsis, Blake.

Cellule radiale pon tronquée au sommet, touchant la côte; une seule cellule oubitale et 2 cellules discoïdales, les nervures au délà n'étant indiquées que par des lignes hyalines; stigma très apparent, épais. Corps poli, glabre, concolor.

Une seule espèce rencontrée.

18-Norembre 1888. 
Photopse du-Canada. Photopsis Canadensis, n. sp.

ठ-Long. .20 pce. Noire, polie, brillante, très glabre de toutes parts. Ocelles distincts mais non soulevés. Sillons parapsiduux du mésonotum distincts. Ailes légèrement obscurcies, avec une seule récurrente reçue peu en arrid̀re du miliou de la 1ère collulo cubitale, on tenant compte des nervures indiquées, la $2 \theta$ cubitalo serait en carré recevant la $2 \theta$ récurrente en avant de son milisu. Pattes d'un beau jaune miel avec toutes los hanches noires. Abdomen sessile, le ler segment plus potit mais faisant suite a la courbe du profil des suivants, la suture entre les segments 1 ot 2 enfoncée et ('rénoléo; épines du segment terminal courtes tronquées, (probablement rompues par accident). Ottawa (Harisngton).

Le premier du genre capturé en Canada, pensons-nous.

Fam. XII._SCOLIADIDES. p. 605, ADD. 253.

Aux 3 genres mentionués, ajoutez le suivant.

Gen. Elis, Elis, Fab.

Ce sont des Scolies mais avec 2 nervures récurrentes aux ailes antirieures et 2 ou 3 cellules cribitales.

1 Elis riche, Elis dives, n. sp.

q-Long. .8o pce. Noire avec pubescence blanche. Tête noire sans aucune tache; antennes courtes; mandibules forte. ment courbées et épaissies. Le prothorax fortement chargé de poils blance, tont le thorax a ponctuations profondes et peu denses, noir sans aucune tache. Ailes obscurcies de brun violet avec 2 cellules cubitales et 2 nervures récurrentos. Pattes de la couleur du corps, avec épines nombreuses et chargées de poils blancs; les 4 hanches postéricures écurtees. Abdomen aveo 4 bandes juunes sur le dos, sur le 1er segment la bando est au sommet et très étroite, sur les segments 2 et 3 elle est jaune orange et couvre presque tout le segment en portant une échancrure au milicu et une autre anx bords latéraux, lo 4e segment n'a qu'une bando étroite au sommet et une petite tache trian- 
n. sp.

Iabie de is parapscurcics, iou de la ndiquées, en avant les han. etit mais 2:e entre ment terident).-

nous.

53.

entes aux

the. Tête les forte. chargé de ss et peu run violet atles de la de poils on aveo 4 do est un est juune ne échansegment he trian- guluire an miliou do chnque côté de la ligne médinno; tous les segments portent a lour nommot uno frange de noils denses et dores, lo segment torminal est on trianglo mrrondi an sommot, fortement ponctué avoc poils dorés courts.-Lus Angeles (Coquillott).

Superbe inseste, bien différent de l'ephippium, Say, par sa plus petite taille et sa coloration.

2 Elis a-4-cointures. Elis 4-cincta, n. sp.

ơ $q$-Long. 75 pco. Noire aveo taches jaunes et poils blancs. Chaperon marginé d'un rebord aveo une ligne do points nu dessus; mandibules roussâtres excepté a l'extrémité, souvont avec une ligne blanche a la base. Antennes plue longues que le thorax ; celui-ci a ponctuations pou denses ot peu profondes, lo prothorax aveo une petite tache blanche a son angle inferieur, l'ecusson et le post-écusson avec uno tache juuno (munquant quelque fois). Ailes légerement obscures, a 2 collules cubitales ot 2 récurrentes. Pattes noires avec poils blancs, les jambes antérieures avoe une ligne blunche en avant. Abromen allongé, assez robuste, avec 4 bandes jaunes au sominet des segments, ces bandes largement échancrées au milieu et sur les côtés, le segment torminal arrondi, avec poils noirs, l'arceuu ventral terminul présentant trois épines droites à son extrémite, dessous des segments 2, 3 et 4 avec une bande jaune au sommet de chaque cóté.

8-Avec une tache jaune de chaque côté du chaperon, la ligne jaune sur l'écusson interrompue au milieu, la bande jaune du segment basilaire couvrant aussi la base du $2 e$ segment.Los Angeles (Coquillett).

Moins robuste que le 4-notata, Fabr. et avec sa pubescence blanche et non noire sur le thorax.

Fam. XY. BEMBECIDES, p. 529.

Au genre mentionné, ajoutez les 3 qui suivent. Cellule sous médiane des ailes postérieures s'étendant au dela de la cellule médiane sur la nervure externo-médiane, labre plus court que le chaperon : STIZIDES (non représentés); 
Cellule sous-médiano plus courto que la médiane sur la nervure extorno-nédinne; jumbes intermedinires avec un seul époron;

Palpes maxillaires courts, généralement cachés ;

Ailes untérieures sans sinus entre la collule radialo ot la 30 cubitale, colle-ci arrondio au som. met ot a poino rétrécio a lis radialo qui est tronquéo all sommet, côté intérieur do la 20 cubitale courbé en deduns............... 1. Besnex,

Ailes antérieures areo un sinus distiuct entro la radialo et la 3 e cubitalo;

Seconde cellule cubitule très rétrécio d la radiale, subtriangulaire; lubre 2 fois anssi long que large, non renflé a la buse; mundibules grêles, iner'mes; mâchoires, pliées, cachées par lo labire................... 2. Microbembex

Seconde cellule cubitale presque cirr'éo, non ou très pou rétrécio à ln radiale; labre renflé a la base, non dou's fois aussi long que large; mandibules ar'mees d'une dent; mâchoires fermées s'ćtendant on arrièr'e du mésothorax.

3. Steniolia.

Palpes maxillaires longs, grêles; ailes antérieures avec un sinus distinct entro la radiale et la 3e cubitale.................... 4. Monedula.

\section{Bembex. Bembex, Fabr.}

Tête courte, transversale, presque aussi large que le thorax ; labre prolongé en avant, plus long que le chaperon; ocelles plus ou moins imparfaits. Palpes maxillaires courts, généralement cachés. Ailes antérieures avec un sinus entre la radiale et la 3e cubitale, qui est arrondie au sommet et à peine rétrécie vers la radiale laquelle est tronquée au sommet; le côté intérieur de la 2 e cubitale courbé en avant.

Une seule espèce rencontrée. 
Bembex fasolée. Bembex fasciata, Fabr.-Am. Ent. II, 751.

Q - Long. .65 pec. Noiro avoc puboscence blanchatre sur la toto ot lo thorix. Lo chaporon, lo libiro, une potite pointo entro l'insertion des untennes, lo scapo de colles.ni on dessons, les orbites antériours larges ot brusquomont interrompus, los post6́riours réduits d uno fino ligno, los tubcreules aveo uno tache d l'unglo antérieur du prothorix, blıne. Thoiax finement ponctue, a pubesconco assez dense. Ailes hynlines, a nervures brunes. Pattos noires, les jambes uveo l'extrémitó des cuisses ot les tarses, blane ou jaune rio. Abdomen aves 5 puires do tuches blanches sur los sogmunts, colles du 50 sogrment roprésentéos par un point, les autres transvorisales ot ondulécs, plus ou moins rapprochéos d la ligno médiane, celles du 101 segment plus écurtées quo los autres et échancries on dossous ; dossous noir, sans tachos. - CapRouge.

$\sigma^{x}-$ Avec une projoction on forme de mucron au milien du $2 \theta$ sogment vontrul ot uno autro au 5o, lo 60 avco uno épine do chaque cóté.

Var. Les fascies de l'abdomen contiguës à la ligne médiane.

2. Gen. Microbembex. Microbembex, Patton.

Ce sont des Bembex, mais généralement de plus petite taille et avec la $2 \theta$ cellule cubitale subtriangulaire, plıs rétrécie vers la radiale, un sinus se voit aussi entre la radiale et la $3 \theta$ cellule cubitale.

Une seule espèce rencontrée.

Microbembex a-une-dent. Microbembex monodonta, Say.-Am. Ent. I, 226.

\%-Long. .40 pce. Noire avec taches jaunes ou blanc-ver dâtre. La face d pubescence argrantée, lo chaperon noir, lo labio rouge-corne aveo une tache blancho d la base de chaque cộté, les antennes et lo vertex sans nucune tache, le dernier a pubesconce blanchâtre clnire. Le collier, les tubercules, le bord infériour du prothorux, uno tache sur les écaillos alaires, uno lligne au dessus do l'insertion des ailes, une tacho triangulaire do char'so cùté 
sur l'écusson, une ligne sur le post-érusson, une ligne sur le bord postéricur du métathorax interrompue au milieu, blane ou jaune pâle. Ailes hyalines, les nervures brunes. Pattes noires, les genoux, les jambes excepté à l'extrémité, jauno, les tareres brun-roussâtre. Abdomen axoe une large bande jaune ou blanchâtre au sommet de chacun des 5 premiers segments, cette bande cochée uu milieu et échancrée on avant de chuque côté, ces échanerures plus fortes en sllant ver's le sommet. Veritre noir, sans aucune tache. Dans le o $\sigma^{\lambda}$ le 20 arceau ventral ave une dent. -Ottawa (Guignard).

Var. Bande sur le segment abdominal basilaire échancrée en carré au milieu, celles des $2 e$ et 3e segment avec une échancrure en carré de chaque côté du milieu, les segments 5 et 6 preque entièrement couverts par la bande.

\section{Gen. Sténiolir. Steniolia, Say.}

Iabre 2 fois aussi long que large, renflé à la base; mandibules avec une dent; mâchoires s'étendant au de là du mésothorax. Ailes avec la $2 \theta$ cubitale en carré, non ou à peine rétrécie sur la radiale.

Insectes bien remarquables par le long bec que forment leurs mâchoires. Lne seule espèce rencontrée.

Sténiolie a-taches-doubles. Steniolia duplicata, n. sp.

q-Long. 60 pce. Noire arece pubeseence blanchâtre et nom. breuses taches jaunes. Le rhaperem, sxcepté 2 petites taches en forme de points ver's la base, lo labre, les orbites antérieur's, les antennes en dessous, une petite tache de chaque côté sur lo vertex avec les orbites postérieurs, janne-pâle. Le rostre jaune a lis base et noir a l'extrémité. Les antennes noires on dessus, ronstâtres l'extrémité en dessous. Lo bord postérieur du prothorax, ses angles' inférieurs, une ligne reufermant les tubercules, les écailles alair's, une ligno nu dessus do l'insertion des ailes, une petite tache de chaque cốté sur le dos du mésothorax, une tache triangulaire de chaque côté sur l'ícussun, une ligne sur le post-écusson, une ligne interrompue an milieu sur le burd postériear du métathorax, les flanes de celui-ci, une 
le bor'd ano ou noires, s tarses a blanis, cetto :ôté, cos $\theta$ noir, nedent.

hancrée 3 échan5 et 6

mandiu mésoà peine forment $a$, n. sp. et nom. wher en ures, les e côté ile. Le intennes to bord renferssus de $\int \operatorname{dos} d u$ "culsosin, milieu ci, une

tache arquée en avant sur les flancs du mésothorax et une autro en arrière, jaune. Pattes jaunes, les hanches et les cuisses tachées de nöir. Abdomen avec tous les segments tachés de jaune, les 2 premiers avec chaeun 2 taches ovales rapprochées ver's le milien, leur's ç̉tés avec uno large bande jaune; cclle du 20 allongée on pointe antérieurement, les autres segments avec une large bande ondulée, interrompue ou non au milieu et échancréo antérieurement et postérieurement de chaque côté du milieu: tous les arceaux ventraux avec aussi une bande jaune, le 20 jaune avec une tache allongée noire au milieu.

$0^{3}-$ Avec le ventre presque entierement jaune, le 2e segment avec une forte épine au milieu.-Los Angeles (Coquillett).

Les taches abdominales sont très variables, un $\sigma^{7}$ manquait des taches gérninées du milieu des segments, une $q$ en manquait au premier et par contre er portait aux 4 suivants etc.

Gen. Monédule Monedula, Latr. p. 620.

A l'espèce décrite, ajoutez les deux suivantes.

2. Monєdule front-noir. Monedula nigrifrons, n. sp.

q-Long. .50 pce. Noire, variée de jaune. Le chaperon, le labre excepté a l'extrémité, les mandibules excepté a l'extrémité, jaune, toute la face noire à pubescence argentée brillante, le vertex avec poils blarics. Antennes noires, le scape à peino taché de jaune en dessous. Une bande au milieu du prothorax, une ligne sur, sa marge postérieure couviant les tubercules et se joignant à une grande tache sur les flancs du mésothorax, les écriilles alaires, une ligne au dessus de l'insertion des ailes, une tache allongée de chaque côté du mésonotum, une graunde tache sur l'écussun de chaque côté, le post-écusson, tout le sommet du métathorax avec une grande tiche sur ses angles pistérieurs, jaune. Ailes hyalines, les nervures brunes. Pattes jaunes; les hanches avec les cuisses excepté a l'extrémité, noires, les tarses antérieurs jaunes mais avec leurs longues épines noires. Abdomen avec une large bande jaune au sommet de tous les segments, cette bande portant une échancrure en carré au miliou antériour du ler segment, et sur les autres uno petite échancrure de chaque côté du milieu, dessous noir aveo une tacho triangu. 
lairo sur chaque segment d son bord latéral.-Los Angeles (Coquillett).

ð๐-Avec l'abdomen presque entieremert jaune sur le dos, les segmenty n'ayant qu'une petite ligne noire d la base, lo 20 arceau ventral avec une forte épine noire recourbée en arrière.

Beaucoup moins large que la fasciata quoique aussi longue.

3. Monédule parée. Monedula parata, n. sp.

$\$$-Long. 60 pce. Noire; le ehaperon, le labre, les mandibules excepté d l'extrémité, le scape des antennes en densous, avec les orbites postérieur's, jaune, le chaperon bordé d'une ligne noire en avant, et le labre avec une strio brunâtre an milieu. Lu prothorux, les tubercules, les écrilles alaires, une ligne en avant et une autre sur les côtés du mésonotum, une tache de chaque côté sur l'écusson, le post-écusson, les angles postérieur's du métathorax qui sont amincis inférieurement et prolongés en forme d'oreilles arrondies, jaune. Ailes légèrement obscurcies, siurtout du côté antérieur. Pattes jaunes, toutes les hanchos avec la base des cuisses et une ligne en arrière, noir. Abdomen avec une bande jaune, large, sur chacun des seginents, sur le premier la bande eat interrompne et áténuée au milieu, sur les suivants ello porte une petite coche au milieu et une lécère ondulation antérieure de chaque côté, le segment terminal cst fortement ponc. tué et porto une tache triangulaire jaune de chaque côté, divirées

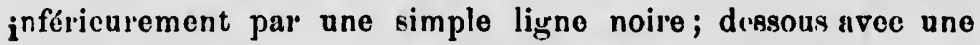
large binde jauhe ondulée sur chaque segment d l'exception du basilaire, chez le terminal la bande jauno est échancree on avant et en arricre, et le segment se termine par une petite queue noire. -Los Angeles (Coquillett).

Espèce bien distincte par sa coloration, le jaune sur le thorax et sur le segment terminal de l'abdomen est beaucoup plus foncé que sur les bandes abdominales. 


\title{
Fam. XVIII-CRABRONIDES p. 639.
}

\author{
Gen. Philanthus, Fabr. p. 641, Add. 278
}

Aux 4 espèces décrites, ajontez celle qui suit :

5. Philanthe poli. Philanthus politus, -Say,Proc.V, 94.

\&-Long. 35 pce. Noir, finement ponctué; le chaporon, les côtés de la fiee, une ligne transversale au dessous de l'insertion des antennes, le scape de celles-ci en dessons, une petite ligne on arrière des yeux, uno ligne sur le sollier interrompuo an miliou, les tubercules, une tache en arridre, une ligne sur le post-écusson, les écuillettes uvec les jumbes, blanc ou junne pâle La tête en des-ous avec puberconce blanche. Le thorax finement yonetué, poli, brillant, l'écusson avers une petite ligne enfoncéo an milieu, le métathorax avec une fosrette à sa base, densément ponctué. Ailes byalines, légèzement obscurcies a l'extrémité, le stigma jaune pâlo. Les hanches, les cuisses avoc le dessous des jambes, noir. Abdomen à ponctuations clair-semées, poli, brillant, lo 1er segment resserre an sommet avec une tache blanche de chaque côté, le $2 \theta$ avec une-ligne transversale au milieu et une tache de chiıque côté, les $3 e, 40$ \& 50 uvee une bunde continue au sommet échancrée de ehaque côté antérienrement, le segment terminul déprimé, arrondi uu sonımet, avec? petites taches indistinctes a la base.-Ottawa (Guignard).

\section{Gen. Cerceiss, Lats. p. 643.}

Aux 3 espèces décrites, ajoutez la suivante.

4. Cercéris à.bandes-6gales. Cerceris axqualis, n. sp.

q- Long. .41 pce. Noire, tachée de jaune; la face les mandibules excepté à l'extrémité, le scape en dessous avec un point en arriere des yeux. Une double tacho sur le prothorax, les écailles alaires avec le post-écusson, jaune, l'espace renfermé du métuthor'ax strié longitudinalement. Ailes passablement enfumécs, jaunâtres à la côte. Pattes jaunes, les hanches, avec la base des 4 cuisses antéricures, l'extrémité dos postéricures avec celle de leurs jambos, noir, les hanches plus ou moins tachées do 
jaune; les tarses brunâtres, noirs a l'extrémité. Abdomon étran glé aux sutures, fortement ponctué, tous les segments avec une bande apicale janne, eette bande largernent échnncrée en avant, lo segment terminal sans tache.-Los Angeles (Coquillett).

Gen. Eucercéris. Eucerceris, Cress.

Ces insectes se distinguent des Cerceris, Cress. par les caractères suivants: Ailes avec la $3 e$ cellule cubitale grande, en carré, à peine rétrécie à la radiale et la dépassant un peu sans laisser de sinus entre les deux; 2e cellule cubitale triangul $:$ re, quelquefois pétiolée dans la $\%$; la radiale obtusément tronquíe au sommet. Abdomen à premier segment rétréci comme dans les Cerceris, la nervation des ailes antérieures souvent dissemblable dans les deux sexes.

Eucercéris remarquable. Eucerceris insigro i^ n. sp.

\& Long. 41 pce. Noire arec taches jaunes; le chaperon, les mandibules excepté à l'extrémité, une bande de chaque côté de Ia face remontant au dessus de linsertion des antennes, une ligne entre celles-ci, une tache en dessous sur leurs 3 ou 4 articles basilaires, les orbites postérieurs, jaune pâle. Le collier, les tubercules, la poitrine avec une tache sur les fluncs; les écailles alaires, une ligne sur l'écusson interrompue au milien, une autre sur le post-écusson, 2 petites taches obliques sur le métathorax, avec une grande tache aux côtés de celui-ci, jaune; le dos dú thorax à ponctuations grosses et assez denses, la base du méta. thorax brillante et aciculée transversalement. Pattes jaunes, les hanches avec les cuisses postérieures, noir. Ailes obscurcies près pu bord antérieur, la partie près de la côte jaunâtre. Abdomen étranglé aux sutures, fortement ponctué, les segments 2, 3 , $4 \& 5$ avec une impression transverse au milieu, tous les segments avec une grande bande jaune, ne laissant de noir qu'aux suturea, les segments 2 a 5 avec une ligne transversale noire au milieu divisant la bande sur le dos mais non sur les côtés, le $6 \theta$ segment avec sa bande entidre, et le terminal noir avec 2 petites taches jaunes a la buse.-Los Angeles (Coquillett).

Bien remarquable par les lignes noires divisant ses bandes jaunes sur l'abdomen. 
in étran vec une $n$ avant, ti).

par les ande, en ell sans guls re, ronquíé ne dans dissem-

* n. sp. oron, les cóté de ne ligne articles lier, les écailles pe autro thorax, dos du a méta. nes, les curcies Abdots 2,3 , gments utures, milieu gyment taches bandes

Gen. Crabro, Fabr. p. 652.

Aux 15 espèces décrites, ajontez la suivante.

16 Crabron noir. Crabro niger, n. sp.

\$-Long. .26 pce. Noir dans toutes ses parties, sans aneune tache. poli, brillant. Le chaperon argenté sur fond noir; le front très brillant. Tête transverwale, non rétrécio en arrière des yeux. Thorax finement ponetué, le métathorax fortement rugueux, à stries irrégulières d la base. Ailes hyalines, les nervures brunes, le stigma noir. Ecailles alaires d'un noir de poix. Pattes sans aucune tache. Abdomen subpédiculé, poli, brillant, lisse, sa projection apicule canaliculée. Ottawa (Guignard.)

On r'a encore jamais que nous sachions annoncé de Crabro sazs pucune tache.

\section{Fam. XIX. - EUMENIDES, p. 670.}

Gen. Odynerus, Latr. p. 71

Aux 10 espèces décrites, ajoutez les 2 suivantes.

11. Odynère de Catskill. Odynerus Catskillensis, Sauss.

o - Long. 32 pee. Noir avec taches jaunes, do forme assez allongée. Quatre petites taches jaunes sur lo chaperon, 2 rappro-

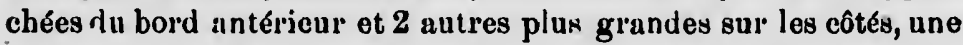
tache a la base des mandibules, une autre entre les antennce, une ligne sur le scape en déssous avec un point on arrière des yuux, jaune; la tête ot lo thorax fortement ponctués. $L_{3}$ bord antérieur du prothorax, une tache au desssous des alles, une uutre sur les écaillettes, deux sur l'écusson, et lo post-écusson, jıunes ; métr thor'ux tronqué, finement strié dans la troncatur's, médioerement rebordé. Ailes enfumécy-jazunâtres, sultout à l'extrémité. Pattes noires, les jan bes et les tarses d'un jaune roussâtre, les jumbes avec une tache noiro en arriere. Abdomon a premier seyment plus étroit que le second, son bord antérieur séparé par ane petite carène, densément ponctué, les autres très finement ponctués les serments 1.5 marginés de jaune au soinmot, sans taches détachées. 
đ-Même coloration, mais avec plus de jaune, le chaperon et les mandibules jaunes, los cuisses on partio jaunes \&c.-CapRouge.

12. Odynère des Antilles. Odynerus Antillarum, n. sp.

$\$$-Long. .31 pee. Noir avec taches jaunes, fortoment ponctué. Le chuperon poli, brillant, arrondi en avant, uno bande circulaire le bordant sur les côtés excepté a la bave, une tacho frontale, les orbites artérieu's jusque dans l'échancrure des yeux, une bande transversale sur le vertex, avec les orbites postéricurs, jaune; les mandibules rouskâtres à l'extrémité; les antennes noires. sans aucune tache. Thorax on carré, trapu, a ponctuations fortes, le prothorax, uno bando sur les flanes, 2 lignes longitudinales sur' le mésonotum réunics en avant de l'écusson par une autre transversale, l'écusson avec une petite ligne on avant de chaque côté, le post-écusson, jaunes. Métathorax tronqué en arrière du post-écus:on, ses bords latéraux formunt une pointe aux côtés. Ailes subhyalines, isgèrement enfuméesjanuâtres près de la côte. Pattes noires, sans aucine tache. Abdomen conique, lo ler segment subsessile, court, sa partio postérieure en forme d'écaille qui s'applique sur la base du $2 e$, celui-ci très grand, beaucoup plus large que le premior, finement ponctué, portant une large bande jaune à son milieu et une autre au sommet, l'une et l'autre avec une petite échancrure en avant de chaque côté; tous les autres, y comprisis le premier, aveo la marge apicale jaune.-Trinidad.

La forme singulière de son premier segment abdominal, distingue cette espèce de toutes les autres.

$$
\text { Gen. Monobia, Sauss. }
$$

Ce sont des Odynerus, mais avec les palpes maxillaires de 5 articles au lieu de 6 et les labiaux de trois articles.

Une seule espèce que nous croyons nouvelle.

Monobie bicolore. Monobia bicolor, n. sp. 
\$-Long. 38 rec. Noire avec l'abdomen rouge. Tête noire sans ancune tache, fortement ponctuée ot avec pubescence grisâtre de même que le thorax. Chaperon po!i, brillant, marqué de points allongés, sa partie médiano prolongée en avant et tronquée; mandibules allongées, droites, dentées en dedans. Pro thorax brusquement tronqué en avant, ne présentant qu'un simple rebo:d au milieu, ce rebord portant un point rouge pou distinct de chaque côté du milieu; mésothorux très long, a ponctuations grosses et peu denses; écusson déprimé, fortement ponctué; métathorax sans dents. Pattes rouges avec les hanches ot la base des cuisses, noir. Abdomen sessile, son premier segment plus étroil que le $2 \theta$ mais non étranglé a la suture, rouge, avec une petite bande transverse noire a ln base des segments 2 et 3, l'extrémité noire.-Anaheim (Coquillett).

Gen. Eumenes, Latr. p. 628.

A l'espèce décrite, ajoutez les 4 suivantes.

2. Euménès crucifère. Eumenes crucifera, n. sp.

९-Long. .40 pce. Noire variée do juune. Thor'áx court. Le chaporon, une ligne entre les antenner une ligne au scape en dessons, jaune. Chaperon plus long que large, bidenté en avant. Le bord du prothorax, les écailles alaires, 2 taches sur l'écusson, une ligrue sur le post-écusson avec un gros point de chaque côté du métathorax, janne. Le thorax et la tête avec poils blanchâtrs. Ailes hyulines, légèrement enfumées-jaunâtres près de la côte, le stigma orange. Pattes noires, les jambes ot les tarsos avee l'extrémité des cuisses, jaune. Abdomen a pédicule élargi posté. rieurement eanalicule en dessus, noir avec une tache jaune, isolée de chaque côté et une bande de ln même couleur au sommet; le reste de l'abdomen jaune, le 20 segment très grand, subglobuleux, jaune avec une croix noire sur le dos. - Los Angeles (Coquillett).

3. Euménès imponctué, Eumenes impunctus, n. sp.

q-Long. .50 pce. Noir, lisse, sans ponctuations, montrant seulement en certains ondroits une pubesconce soyeuse blanchâtre. Chaperon allongé, ponctué ver's l'extrémité, avec un 
petit canal on dessus mais no so terminant pas par 2 dents. Mandibules ponctuées, avor: une petito ligne blanche d la base. Tête sans auca $\theta$ tarho. Lo prothorax avec sa margo postérieuro blanche, le post-écuesen ausi avee une ligne blanche. Thorax plus long que lau'ge. Eiruilles aluires testacées. Ailes enfuméos, noiıâtres au sommet an bord antérieur, la 20 cellule cubitale petite. Patter noires, nnyeuses, sans aucune tache. Abdomen d'un bruı olivâtree, le pétiole campanulé au sommet aveo un point enfoncé sur le dos, la murge arec un rebord blanchátre, le reste de l'abdomen fusiforme, de coulour' uniforme aveo seulement la marge apicale des segments plus pâle.-Trinidad.

Voisin du sericeus, Sauss. mais en différant par son chaperon qui n'est ni bicaréné, ni bidenté, et son absence de poils fauves.

4 Euménès à-ceintures. Eumenes cinctus, n. sp.

q-Long. .44 pce. Noir avec taches jaunes, sans ponctuations distincter. Le chaperon arrondi en avant aveo une petite pointe au milien, noir avec une bande jaune en forme de fer a cheval, lo ceinturant excepté à la base. Bande jaune couvrant le bord postérieur du prothorax, subinterrompue au milieu, 2 taches sur l'écusson, le post-écusson, avee une grande tache de chaque côté du métathorax, jaune; écuilles ulaires noires, flancs avec aussi une petite tache jaune. Ailes subhyalines, obscurcies a la côte. Pattes noires, les tarses antérieurs brun-rouseâtre. Abdomen à pétiole campanulé, son summet ceinturé de jaune aveo uII point enfoncé au miliuu, les segmonts 2,3 et 4 ausisi marginés de juline, au moins sur los côtés.-Trinidad.

Dans toutes les espèces décrites par Saussure, nous n'avons pu en trouver alıcune répondant à notre insecte ni par la forme, ni par la coloration.

\section{Euménès poitrine-jaune. Eumenes flavopectus,} n. sp.

q-Long. 38 pce. D'un jauné miel plus au moins lavé de brunâtre, presque dépourvu de pubescence. Tête jaune avec le $\nabla$ rtex brun, le chaperon triangulaire on avant, avoc une pointe (nen bifide) au milieu. Autennes brunes avec le scape entidre- 
2 dents.

la base. sstérienro

Thorax enfumées, cubitalo

Abdomen un point o, le reste lement la

son cha3 de poils

n. sp.

ponctuane petite do fer a couvrant milieu, 2 tache de \&, flancs oscurcies oussâtie. une areo naryinés n'avons a forme,

opectus, lavé de avec lo pointo entiere- ment et les articles terminaux en dessous, jaune. Prothorax aveo sa marge postérieure blanc.jaunâtre, le ménonotum brun aveo une double tache jaune en avant de l'écusson, tout le reste jaunemiel, la poitrine plus claire. Ailes fortement enfumeses, surtout près de la cóte, la $2 \theta$ cellule cubitale très petite. Patter jaunes, les postérieures plus ou moins brunes. Abdomen jaune d la base et s'obscurcissant graduellement jusqu'au noir en allant a l'oxtremité, le pétiole un peu plus large au sommet mais non campanulé, avec un point enfoncé près du sommet et sa marge pâle; le 2 e segment jaunâtre da la base et d marge apicale blanche.Trinidad.

Espèce bien distincte par sa coloration que nous avons trouvée peu variable dans un grand nombre d'individus.

\section{Fam. XX.-VESPIDES p. 685.}

A l'espèce décrite, ajoutez la suivante.

\section{Poliste a'Anaheim. Polistes Anaheimensis, n. sp.}

\$-Long. .70 pce. Noir avec taches jaunes. Le chaperon, les mandibules, les orbites antéricur's, uno bando anguleuso audessus des antennes, les joues, les orbites postériours, jaunes. Antennes d'un beau jauno miel, sans aucune tache. Thorax noir, les bords antériour et postérieur du prothorax, les écailles alaires, une tache sur les flances, une ligne au-dessous des ailes postérieures, les bords de l'écusson, le post-Écusson, avec 2 lignes longitudinales sur le métathorax, junnes. Ailes enfumées jaunâtres, les nervures brunes. Pattes jaunes, les hanches, les denx tiers des cuisses avec une tache en dedans a l'extrémité des jambes postérieures, noires. Abdomen jaune soufre, tous les segments avec une bande noire à la base, cette bande sul les $2 \theta$ et $3 \theta$ prolongée en pointe triangulaire au milieu, le segment basilaire est noir avec lo sommet jaune et une tache latérale jaune contiguë à la bande apićale.-Anaheim, Culif. (Coquillett).

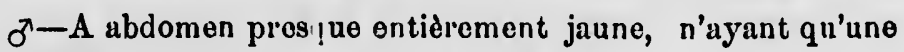
étroite ligne noire à la baso des segments. 
Fam. XXI - ANDRtNIDES, p. $68 i$.

Gen. Macropis, Panz. ADD. p. 320.

A l'espéce décrite, ajoutez la suivante.

2. Macrope a-longue-lanjur. Macropis longilingua, n. sp.

o - Lnig. .28 pce. Noire, la tâte et lo thorax aveo une pu. bescence grisâtre dense. La ficco noire, sans aucune tuche, lo chuperoul avec poils blanes longs muis ne carhunt pas les téguments. Ailes légèrement enfuméen, la -e rubitulo rétrécre şur la rndialo, les écuillettes brun roussâtro. Paltes brun ronswâtre, avec poils bluncs, les cuisses particulicrement les postérieures, renflées. Abulomon on ovalo allongé, poli, brillint, tous les segrments avec unu bande apicalo enfoncée, testacée, les telminaux ponctués plus distinctoment et converts do poils noir's; dessous brun-rouseâtre. CâlRougro.

Bien distincte de la précé lente ; q encorı inconuue.

Gen. Megachile, Latr. p. 709.

Aux 13 espèces décrites, ajoutez la suivante.

14. Mégachile de Vancouver. Megachile Vancouveriensis, n. sp.

$\sigma^{7}$-Long. .40 pce. Noire, finement ponctuéc, d pubescence grise la couvrant de toutes partr, cette pubescence blanche, derise et longue sur le chaperon. Tête plus large que le thorax, celui-ci d téguments a peine visibles. Ailes hyulines, d nervures brunes. Pattes noires avec poils blançs, bunches antérieup. inermes; leur cuisses fortement dilatées, main sans palette écailleuse, jaunes en dedans et frangées de poils blanes, lours jumbes courter el renflées, le premio article des tarses dilaté, janne aroce une ligne noire en dessins et une longur fiange blanche, le reste du tarse jaunc, les + tar'es postérieurs noirs. Abdomen convexe, couvert de poils blancs, plus longs à la base et entremêlés do poils noirs sur les segments 3 et 4 , lo segment basilaire forte- 
ment coneave en apant, l'epiçal échanorés au miliou do manidro d former vne dent de ohaque côté.-Vancouvel' ('i'aylor').

Ses hanches inermes, ses ouisses dilatées et surtout sa pubescence, la distinguent facilement de toutes les espèces voisines. Très rapprochée de la femorata, Smith, mais ayant les mandi. bules, ponctuées tandis que dans colle-ci elle sont striées au bord interne et lisses dans le reste.

Gen. Hrriadeq. Spin. p. 716, Add. 323.

une pu. tache, lo es téguie șur la la ousisâtie, élicures, les sersrminaux dessous

le.

rancou-

pesconce bluncho, thorax ervures erieur. te éc'ailjumbes ire uvec reste du onvexe, hêlés do o forte-
A l'espèce décrite, ajoutez les 2 qui suivent.

2. Fíriade a-brosse-planohe, Heriades alboscopatum, מ. sp.

f-Long. .22 poe. Noire, densément ponctuée, a pubescenoe blanche. Tete épaisse en arrière des yẹux; antennes courtes. Métathorax ponotu6-rugueux. Ailes légèrement obscurcies, plus fortornent a l'extrémité, nerrunes noiros. Pattes noil'es, a pubescence blanche; la brosse abdominale aussi blanche. Abdomen convexe, densément ponctú, d sutures enfoncées, les segments 1-4 marginess do blano au sommet.-CapRouge.

Bien distincte de la carinatum par sa forme moins allongée, et ses ceintures blanches.

\section{H6riads ploine. Heriades plenum, n. sp.}

ơ-Long. .15 pee. Noire, densément ponctuse, a pubescence blanche; l'occiput plein, non coneave en arrière. Le métathorax rugueux. Ailes hyalines, a peine obscurcies a l'extrémité. Pattes de la conleur du corps, pou pubescentes. Abdomen robuste, densément ponctué, a sutures enfoncées, les seginents 1, 2 et 3 avec un point blanc au milieu de chaque côte.-Ottawa (Guignard).

Sa petite taille et sẹs points blancs sur les côtés la font facilement distinguer. 
Gen. Eprolus, Latr. p. 718 ; ADD. 332.

Aux 3 espèces décrites, ajoutez la suivante.

4. Epéole pilosule. Epeolus pilosulus, n. sp.

of-Long. 30 pee. Noir aveo poils blunehâtres pen denses, la face d'un noir foncé, brillunte, presque nue, lo labre a pubescenco argentéo. Anteunes aveo lo scape noir et le pavillon ferrugineux, surtout on dossous. Thorax densément ponctué, sans aucune tache, le ménothorax avec un potit sillon an miliea, l'écusson bilobé avec une petito dent rousso pen apparente de chaque côté, étant entouréo de poils blanchâtres. Ailes enfumées arec une grande lunule hyaline nu dela des collules. Pattes d'un noir brillant, avec poils blances courts, presque nuen, les cuisses et les jaunbes renflées. Abdomen court, compacto, pubescent a l'extrémité seulement, suas bandes de pubesconco, la marge apicale des segments nuo et plus au moins testacéo.-CapRougro.

Espèce bien distincte de toutes les autres par sa pilositó et son manque de pubescence.

Gan. Nomada, Latr. p. 720 ; Add. 333.

Aux 8 espèces décrites, ajoutez les 2 qui suivent.

9. Nomade pieds-jaunes. Nomada flavipes, n. sp.

q-Long. .40 pce. Noiro variée do jaune. La tête et lo thor'ux densément ponetués. La fuce au clossons des antennes, le labre, les mandibules, le seape en dessous, les orbites postérieur's, jaune; antennes ferruginousos, brunât'es d l'extrénité. Thor'ax finemont chagriné, le collier, les tuboroules, les écaillettes, une grande tucho sur les flances, 2 taches sur l'écusson, le post-6́cusson, une tache sur les angles du métathorax, jauno. Ailes enfumées avec une grande lunule hyaline au dela des cellules. Pattes jaunes, les hanches noires, tachées de juune, les 4 cuisses antérioures plus ou moins ferrugineuses en ivant ot noires on arrière, les postérieures aussi noires en arrièro. Abdomen allongé, grlabre, tons les segments avec une large bande jaune au sommet, cette bande échancrée au milieu en avant sur les segments 1-4 et dilatée sur les côtés, dessous avec 3 larges bandes et 3 taches à l'oxtrémité, jauuse. - Los Angoles (Coquillett).

face

a pu

nule

avec

slin

en 0

a pe

sous

de la

avec

les

ferro

brun

le br

$\mathrm{F} 8$

ticles 
Var. Les segments terminaux ferrugineux avec bande jaune, le 20 segment avec la bande beaucoup plus large que les autres et échancréo anguleusement en avant.

10. Nomade rouge. Nomada rubra, n. sp.

8-Long. 32 pee. D'un beau rouge clail dnns toutes ses parties, avec pubosconce blanche courte, plus apparente sur la face ot le métathorax. Mandibules noires d l'extrémité; le labre a pubescence argentée dense. La tête et le thorax ponctués-granuleux. Les écailles alaires testacées. Ailes légèrement enfuméos aveo lo sommet plus foncé et précédé d'une bande arquée hy. uline; lo stigma jaune. Pattes de la couleur du corps. Abdomen on ovale aveo poils blance a l'anus, la marge apicale dos segments a peine plus claire.-Los Angeles (Coquillett).

Espece bien remarquable par son manque total de taches.

Fam. des APIDES, p. T27.

Gen. MelipoNA, Latr. Ap̣. 344.

A l'espèce décrite, ajoutez la suivante.

2. Molipone pauvre. Melipona paupsra, n. sp.

8-Long. .20 pce. Noire, le pavillon des antennes en dessous a la base, aveo la base des mandibules brun-roussâtre. Poils de la face, du thorax et do l'abdomen, noir's ou bruns. L'écusson avee une touffe de poils noirs. Ailes hyalines, sans aucune tache, les nervures testacées. Pattes noires, les jambes postérieures ferrugineuses. Abdomen court, coudé, presque triangulaire, d'un brun foncé, les eegments plus pâles a la base.-Trinidad.

Bien différente de la précédente, par sa plus petite taille et le brun de son abdomen.

Fam des TrNTHRteINIDES p. 170, ADD. et 346. Gen. Sphacophule. Sphasophilus,n. gen.

(De Sphakos herbe et philos ami).

Tête courte, de la largeur du thorax. Antennes de trois articles, le $3 e$ le plus long, mais non en massue dans les comme 
chez les Hylotomes. Lobe médian du nésothorax plus long que large et non séparé de l'écusson par une fossette. Ailes antérieures avec une cellule radiale longue, non appendiculée, trois cellules cubitales, la 1ère et la $2 \mathrm{e}$ chacune avec une nervure récurrente, cellule lancéolée longuement pédiculée ; ailes postẹrienres avec 2 cellules discoïdales. Stigma grand, subovale. Pattes avec les jambes portant 2 éperons an sornmet, mais sans épines latérales. Abdomen court, large, à bords tranchants.

Ces insectes ont toute l'apparence des Acordulécères, mnis s'en séparent par leurs antennes de 3 articles; ils se confondraient a vec lf $s$ Thémos, mais les cubitales 1 et 2 reçoivent chacune une nervure récurrente.

\section{Sphacophile de Craw. Sphacophilus Crawii, n. sp.}

o-Long. .20 pee. Noir, sans aucune tache. Antennes courtes, mais a 30 article trois fois plus long que 1 et 2 réunis, ce 3e article filiforme et légèrement atténué a l'extrémité. Eeailles alaires noires. Thorax finement ponctué. Ailes hyalines, les nervur'os brunes, le stigma 'grand, brun-jaunâtre., Pattes noires avec !as jambes d'un blane. sale, les postérieures noires à l'extrémité. Abdomen court et large, de couleur uniforme, mais ondulé entre les segments, tarière noire.-Los Angeles.

Nous dédions cette espèce à $M$. Alexander Craw, de Los Angeles, Californie, grand amateur d'entomologie qui en fait la capturt.

Fam. des ICHNEUMONIDES, p. 249, ADJ. 29 et 356.

Gen. Ichneumon, Lin. p. 242 et 752 ; AdD. 20.

Aux 89 espèces décrites, ajontez la suivante.

90. Ichneunion a-ailes-courtes. Ichreumon brivipennis, Cress.-Proc. TiI, 174.

o-Long. .45 pee. D'un beau roux ferrugineux; sntennes rousses a la baso, plus elaires et quelquefois jaunes an milieu et brunes a l'extrémitó. Thorax finoment ponctué, avec les sutures 
noires, les arètes du métathorax peu prononcées. Ailes enfirmées-jaunâtres, le stigma jaune. Pattes de la couleur du corps, les hanches en dessous avec la puitrine et un petit anneau en dessous à l'uxtrémité des cuisses postérieures, noir. Abdomen robuste, fusiforme, avce une étroite bando noire a li base des segments 1 et 2.-Cap Rouge.

Gen. Bassus, Fabr.pp. 427 et 798 ; Add. 111.

Aux 21. espèces décrites, ajoutez les deux qui suivent.

22. Basse auricule. Bassus auriculatus n. sp.

q-Long. 20 pce. Noir avec l'abdomen roux. La face, la base des antennes en dessous, āiac les 4 hanches antérieures, blanc ou jaune pâle. Les écsilles alaires avec une petite ligne en dessous, jaunes. Facé à peine soulevée pour l'iusertion des antennes. Métathorax à lignes soụlevées distinctes. Ailes hyalines, sans aréole, le stigma aune avec vue tache blanche à la base. Pattes jaune-miel, les hancheo postérieures variées do jaune etale blanc, l'extrémité de leur's jambes et de leurs tarses, brunâtre. A.bdomen assez fort, plus épais à l'extrémité, noir à la base et à l'extrémité, d'un beau roux duns le reste, le premier sergment avec la moitié busilaire du $2 e$ aciculés, le reste poli, brillant.-CapRouge.

Espèce bien distincte par les aciculations de la base de son abdomen.

23. Basse pieds-jaunes. Bassus mellipes, n. sp.

-Long. 15 pce. Noir, poli, brillant, sans taches, avec les pattes y compriv les hanches d'un beau jaune-miel. Antennes assez robustes, brunâtres, le scupe en dessous jaune de même que les écrilles alaires. Ménosotum sans sillons parapsidaux; métathor'ax avec un petit sillon au milieu formé yar 2 petites cardènes. Ailes hyalines, sans aréole, les nervures brunes, le stigma juunâtre. Les tar'ses postérieur's bruns à l'extrémité. Ábdomen allonge, cylindrique, le premier segment aciculé, le 20 segrment ponctue, lo reste poli, brillant.-Ste-Gertrude.

Var. Quelquefois le 3e segment abdominal brun-jaunâtré. 
Gen. Meniscus, Schiödte, pp. 481 et 802.

Aux 4 espèces décrites, ajoutez la suivante:

5. Ménisque d'Ashmead. Meniscus Ashmeadii, n. sp.

ᄋ-Long. 38 pree. Noir foncé brillant, avec les pattes rousses. Antennee grêles, à articles allongés. Thorax finement ponctué, le métathorax a lignes soulevées peu saillantes. Ecailles alaires rousses. Ailes légèrement obscures, le stigma noir avec une tache pâle d la base. Pattes d'un beau roux brillant y compris les hanches, les jambes postérieures noires avec un asneau blanc près de la base, leurs tarses aussi noirs avec le premier article brunâtre. Abdomen fort, finement et densément ponctué, les segments 1,2 et 3 avec une ligne rousse au sommet, tarses de la moitié de l'abdomen environ-Floride. (Ashmead).

Nous dédions avec plaisir cette espèce à M. Ashmead, zélé hyménoptérologiste, qui nous l'a transmise de Jacksonville, Flor.

Gen. Phytodietus, Grav. p. 483.

Aux 4 espèces décrites, ajoutez les 3 qui suivent.

5. Phytodiète superbe. Phytodietus superbus, n. sp.

7-Long. 60 pce. Superbe insecte poli, brillant dans toutes ses parties, roux foncé avec la tête et partie du thorax, noir. Le chaperon, la face au dessous des antennes avec des lignes orbitales non interrompues sur le vertex, les joues et un large anneau aux antennes, blanc.Thorax noir dans dans sa moitié antérieure et roux dans le reste; les bords latéraux supérieur's et inferriours du prothorax, les écailles alaires, 2 taches au dossous des ailes, avec une autre plus allongée sur les flancs, 2 lignes sur le dos du mésonotum, l'écusson avec les arêtes qui lui font suite en avant, et le post-écusson, blanc. Métathorax poli, brillant, avec un mucron aux angles postérieur's. Ailes subhyalines, d nervures noires, stigma très étroit, noir, aréole subtriangulaire, la pointe étant aussi en carré. Pattes rousses avec les jambes et les tarses jaures, les hanches antérieures noires a la base avec une tache blanche daus ce noir, la poitrine porte aussi au dessus de ces hauches une tacho bl.unche. Abdumen robuste, coudé au 
premier segmont, rótréci postérieurement; tarière forte, un peu plus courte que l'abdomen.-Trinidad.

\section{Phytodiète élégant. Phytodietus elegans, n. sp.}

ㅇ-Long. .50 pce. Rouge avec la tête et l'abdomen noirs, poli, brillant. Le chaperon avec la face au-dessous des antennes ot un large anneau i colles-ci, blanc. Antennes longues, noires g.vec un anneau blanc. Thoirax sans aucune tache, le métathorax avec une épine mousse aux angles. Ailes subhyalines, d' nervures noires, aréole en carré mais un pou plus étroite en avant. Pattes de la couleur du corps avec les tarses noirs d l'extrémité. Abdomen noir, allongé, à pédicule grêlo et allongé, roux excepté au sommet, tous les segments marginés de blane au sommet, tariere plus courte que l'abdomen.-Trinidad.

7. Phytodiète "orné. Phytodietus ornatus, n. sp.

ㅇ-Long. -25 pce. Differe peu en coloration du superbus, mais de taillo beaucoup plus petite et avec les divergences qui suivent : la face noire, blanche seulement sur les côtés ; scapo des antennes noir, mais la bare du pavillon blanchattre en dessous, anneau blanc au milieu imparfait. Les hanches antérieures blanches, les tarses bruns, blanchâtres au milieu. Abdomen a pédicule long et grêle; tarière courte, moins du quart de l'ab. domen.-Trinidad.

Fam. des BRACONIDES, p. 491, AdD. 121.

Gen. Bracon, p. 497, ADd. 121.

Aux 18 espèces décrites, ajoutez les 2 suivantes.

19. Bracon pieds-poilus. Bracon pilosipes, n. sp.

Q-Long. 28 pce. Noir avec l'abdomen rouge. Antennes longues, grêles. Ailes fortement enfumées avec une petite tache hyaline dans les celles discoïdales 2 et 3 . Pattes noires, revêtues do poils courts ot denses. Abdomen poli, brillant, rouge, noirâtre a l'extrénité, le premier segment coudé a son milieu et sa partio médiane formant une pointe au milieu mais sans sillons sur les côtés, de forme conique d partir de co coude.-Trinidad. 
Bien distinct de tous les autres par ses pattes pólues.

20. Bracon strie. Bracon striatus, n. sp.

$\sigma^{x}$ - Long. .20 pce. Noir aveo la tếte et l'abdomen rouges. L'extrémité des mandibules, nne tache sür le veŕtex et lo ler segment abdominal, noir. Antennes noires. Thoorax poli, beillant. Ailes passablement obscures. Pattes noires. Ábdomen avec les segments 2 ot 3 fortement striés a la base, le 20 avec un sillon courbé de chaque côté, leurs sommets polis, brillants Vancouver.

Fam. des CYNIPIDES, p. 540, ADD. 156 et 397.

Notre revue de cette famille était déja imprimée, lorsque nous avons reçu le travail de $M$. Áshmeäd publiè dans !es Transactions of the An. Ent. Society, vol. XIV, p. 125 et suivantes.

Comme il se trouve plusieurs genres nouveaux qu'il a formés, nous donnons ci-dessous la clef des Cryptogastres, par lequelle il distingue ces nouveaux genres des anciens. Cette clef comprend tous les genres mentionaés par lui, nous mettons en lettres noires ceux dont nous avons rencostré des représentants.

\section{CRYPTOGASTRES.}

1(4) Abdomen court, globnleux ou semiglobuleux, 2e segment lo plus long; ecusson ariondi, contexe: ALLOTRIIDES;

2 (3) Ecusson arrondi, convexo, lisse, séparé da mésothorax par un sillon; thorax sans sillons parapsidanx. Antenties of 13 articles, ơ 14 articles ......................................... Atlobria.

3(2) Ecuisson rugurenx. nơn sépar da mesonotum par un silton; sillons prirapsiducux sabpapalleles, antennes filiforme's ABartriss.

4(1) Abdomen en ovale allonge, comprime, 1 sommot plus ou moins pointu; 3e segment abdo:

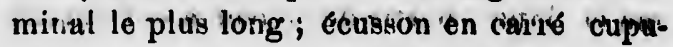
liforme ou épineux : EUCOILIDES ; 
5(18) Ecusson en cupule; abdomen obliquement tronqué au sommet;

6(17) Mésothorax poli, sans sillons ;

7(13) Ailes ciliées;

8(9) Antennes o a 13 articles, les 3 derniers ren-

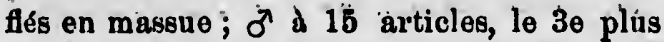
court que le $4 \theta$; cellule radiale ferméc..... Kleidotoma.

9 (8) Cellule radiale ouverte: ailes échancrées au sommet............................... Coptereucorla.

10(11) Antennes o avec les 6 articles terminaux élä̈gis, ơ avec le 30 article lo plus long... Hexarlasta.

11(12) Antennes o afec les 8 articles terminaux élargis; ò à̃ec le 3e rétréci a la base, le dernior allongé.................... D.microstrophis.

12(11) Anténnes ò de 15 articles, lo 30 plus court que le $4 \mathrm{e}$, les suivants 4 fois aussi longs que larges

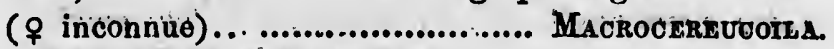

13(16) Ailes nò ciliés, pubescentes;

14(15) Métaplcuires non poilues, 2 e segmentt abdơmiliál ateo un annean poila; antennes io s'epaississant graduellement; on avoc l'article 3 un pou plus cotrt qué 4 ou à peu près égal, les suitivat 2 fois plus longs que lairges.. ...... Inucoila.

15(14) Métápleures poilues, antennes on avoc l'aiticle 3 plus long que 4 , les suivants 4 fois plus longs qùe larges..................... GLautrospidiA.

gment IDES ;

Chria.

GIFIPB.

16(13) Ailes entierement dépourvies de pubescence; 2e segment abdominal sans anneau poilu. Coñhonaspis.

17( 6 ) Mésothorax poli avec deux sillons parapsidaux; antennes of a 13 articles, on a 15, filiformes, le 30 aussi long que le 40 et for. tement courbé et échancré.................... Intucoiliciea.

18(5.) Eucusson non on cupule, canalicule, ariondi, épineux, lugueux, eto. : FIGITIDES;

19(22) Ecusson lisse, poli, bifovéolé ;

20(21) Ecusson avec une petite projection sur son disque au bord postérieur, mésothorax lisse, poli, d 2 sillons; antennes of moniliformes, gìaduellement 'épaissiès.

Thyreocera. 
21(20) Ecusson sans projection sur son disque; mésothorax d 2 sillons convergents postérieurement; antennes $\delta$ \& 14 articles, le $3 e$ bien plus long que le 4e, le terminal le plus long. Oraraspis.

22(19) Ecusson rugueux, de forme variée;

23,26) Ecusson arrondi au sominet ou aigu, mais non terminé par une longue épine; pédicule de l'abdomen court, strié; mésothorax a 2 sillons, antennes o moniliformes, épuisses, d 14 articles, $\sigma^{7}$ filiformos, a 14 articles ;

24(25)Yeux poilus; article 3 des antennes $\sigma^{7}$ bien plus long que 4

\section{Figites.}

25(24) Yeux non poilus; article 3 des antennes $\sigma^{\top}$ pas plus long que $4 \ldots . . . . . . . . . . . . . . . . . . . . .$. Figitodes.

26(29) Ecusson se terminant par une longue épine, bifovéolé ;

27(28) Mésothorax lisse, a 2 sillons; ailes non pubescentes, la radiale ferméo; écusion rugueux, avec un caual s'étendant jusqu'a l'épine, article 3 des antennes $\delta$ plus long que 4 ...... Solenaspis.

28;27) Mésothorax scabre, à plusieur's carenes; la radiale ouverte, les youx bordés d'une carene antérieurement; antennes $\%$ et $\sigma^{\prime}$ filiformes. Aspicera.

29(26) Ecusson non terminé par une longue épine ;

30(31.) Ecusson allongé, tronqué, canaliculé dans toute sa longueur ; mésothorax scabre, opaque, avec 2 sillons et une carène médiane; antennes filiformes dans les 2 sexes..................... Onychis.

31(32) Ecusson conique, non fovéolé, mésothorax scable, brillant, a 2 sillons, son bord postérieur droit, avec un petit rebord; antennes o d 14 articles non interrompus, abdomen longuement pédiculé, son extrémité arrundic Acothyreus.

32(33) Eccusson subconique, bifovéolé, mésothorax poli, a 2 sillons, son bord postérieur r'ebordé; abdomen longuement pédiculé, pointu à l'extrémité; antennes filiformes dans les 2 sexes. Anacharis. 
33(34) Ecusson tronqu's, Glevé postérieurement, bifovéolé, mésothorax uniformément ponotué, a 2 sillons; métapleures opaques; nervures des ailes bien développées, formañt une cel. lule radiale, une cubitale et une aréole; abdomen médiocrement pédiculé, en massue, légèremont pubescent $d$ la base; antennes filiformes dans les 2 sexes, le 5e article $\sigma^{\pi}$ fortement échancré......... Amblynotus.

34(19) Ecusson ordinaire, bifovéolé;

35(36) Mésothorax, poli, a 2 sillons ; métapleures polies, ailes avec une radiale, une cubitale et une aréole; abdomen cultriforme ou très comprimé, antennes courtes, filiformes dans les 2 sexes, l'article $3 \sigma^{\prime}$ non échancré...... Sarothrus.

36(35) Mésothor'ax subopaque, légèrement pubescent, a 2 sillons peu distinots; métapleures poilues; abdomen comprimé; antonnes courtes, filiformes dans les 2 sexes, l'urticle 3 on fortement échanuré ................................ Mruanips.

37(34) Ecusson unifovéolé ; antennes o de 13 articles, epaisses, l'article terminal très grand. Lonchidia.

Gen. Kleidoroma, West. p. 552.

M. Ashmead, dans une revue de cette famille, publiée dans les Transactions of Am. Ent. Soc. vol. XIV, p. 150, donne pour caractères aux Kléidotomes' $d$ 'avoir les ailes frangées, et les antennes $\&$ de 13 articles avec les 3 terminaux grossis en massue, et les antennes $\sigma^{\top}$ de 15 articles; le mésothorax en outre n'a pas de sillons parapsidaux distincts. D'après ces carzctères, les deux insectes que nous avons décrits sous ce nom, appartiennent aux Eucoila, et le suivant est un véritable Kleidotoma.

Kléidotome d'Amérique. Kleidotoma Americana, Ash. -Trans. XIV, 152.

\%-Long. .10 pee. Noire, très polie; tête areo quelques ponctuations. Antennes de 13 articles, rousses, légèrement pu- 
bescentes, le 1er article aussi long que 2 et 3 réunis, 4 d 10 très courts et très petits, les 3 termınaux fortoment épaissis. Thorax poli, sans sillons, les angles extérieurs du prothorax rougeatres; l'écusson avec une petite cupule au sommot et une piofonde fossette a la base. Pattes d'un jaunâtre pâle brunâtre. Abdomen noir, brillant, en ovale allongé, légèrement comprinué et faiblement acuminé. Ailes hyalines, ciliées, pubescentes, la cellule radiale petite, triangulaire, fermée; point d'autres cellulos.CupRonge.

Gen. Dimicrostro: efi, Ashm. Add. 173.

A l'espéce décrite, aj $\theta_{2}$ suivante.

2. Dimicrostrophe cornes kuires. Dimicrostrophis nigricornis, n. sp.

i-Leng. .08 pce. Noir, poli, brillant. Les antennes noires, pi:vescentes, l'article basilaire épais, allongé et courbé en deh.urs, le 20 globuleux, le $3 e$ deux fois aussi long que le $2 e$, les 8 terminaux épaissis. Mésothorax sans sillons; cupule de l'écusson bien distincte. Ailes pubescentes, ciliceses, hyalines, los nervures jaunes, la cellule radiale a demi close, la nervure costale s'effagant postérieurement. Puttes d'un roux brunâtre, les cuisses renflées et noires au mílieu. Abdomen comprimé, pointu 1) l'extremité.-Ottawa (Guignard).

Gen. Eucorlidea, Ashm.

Ce genre se distingue des Eucoila par son mésonotum qui porte deux sillons qui se réunissent à envirr a les deux tiers de sa longueur et forme delà jusqu'à la base de l'écusson une petite carène. La cupule de l'écusson est grande, élevée, et séparée du mésonotum par une ligne arquée. L'anneau de la base du l'abdomen est dépourvu de pubescence; pour le reste comme dans les Eucoila. Une seule espère.

Fucoïlidée du Canada. Eucoilidea Canadensis, Ashm. -Trans. XIV, 154.

9-Long. .09 pce. Noire, polie. Antennes rousser, plps 
longues que le corps. Pattes d'un roux fonce. Ailes hyalines, pubesuentes, los nervures jauries.-CupRouge.

Gen. ThyrEocerre. Thyreocera, Ashm.

Ce genre semble servir de passage entre les Eucoila et les Figites, son écnesson est lisse aveo une petite projection en arrière et 2 fovéoles à la base. Une seule espèce connue.

Thyréocère à-éousson-lisse. Thyreocera loeviscutum, Prov. Figites laviscutum, Prov. ADd. p. 170.

Thyreocera nigrifemora, Ashm.

D'après la loi de priorité, le nom spécifique imposé par nous doit prévaloir sur celui de M. Ashmąad, le nôtre ayant été publié en janvier 1887, et celui de M. Ashmead en septembro de la même année.

Gen. Aspicera, Ashm.

Caractères tels que donnés dans la clef. Une seule espèce. Aspicera 5-lineata, Say. Diplolepis 5-lineatus, Say,Am. Ent. II, 716. Figites 5-lineatus, Say, Faune p. 556.

Gen. ONYchia, Haliday:

Voir la clef pour les caractères de ce genre.

Onychia Provancheri, Ashm. Callaspidia Provancheri, Ashm. ADD. 167.

Gen. Figrtes, Lat. p. 555, Add. 169.

Trois espèces dans notro Faune.

1. Figites armatus, Say. F. p. 556.

Onychia armata, Say, (Prov.)-Ad. 171.

2. Figites inermis, Prov. Onychia inermis, Prov.Ad. 171.

3. Figites impatiens. Say.-Ad. 171.

Gen. Acothyre. Acothyreus, Ashm.

L'abdomen longuement pédiculé, non comprimé, arrondi au sommet, l'écusson non fovéolé, suffisent pour distinguer ces insectes des genres voisins. Voir la clef. 
Acothyre plods-jaunes. Acothyreus mellipes, n. sp.

\$-Long. 12 pce. Noir aveo les antennes, y compris le ler article, et les pattes, y compris les hunches, d'un beau jaune miel. Les antennes sont à peu près de la longueur du corps, a articley d peine étranglés aux articulations. Le mésothorax poli, aveo 2 sillons; l'écusson conique, rugueux, non foréole. Abdomen non comprimé, longuement pédicule, obtus au sommet. CapRouge.

Se distingue surtout de l'osceola, Ashm. par ses hanches rousses, l'article basilaire de ses antennes non noir, etc.

Fam. des Chalcides, p. Faune p. 569.

Gen. Olygostenus. Walk. Ad. 195.

A l'espèce décrite, ajoutez la suivante.

2. Oligostenus stigma, Fabr. $=$ Monodontomorus viridaneus, Prov. F. 569.

Gen. Decatoma, Spin. p. 568, Ad. 193.

Decatoma basilaris, Prov. F. 569=Isosoma hordel, Harr.

Gen. Euнутома, Illig. p. 568, Ad. 192.

Eurytome grante. Eurytoma gigantea. Walsh. Am. Ent. 390. Eurytoma conica. Prov. Ad. 193.

Gen. Cryptus, p. 328, Ad.

Cryptus oalipterus, Say.=Cryptus Fletcheri, Ad. 361. 


\title{
TABLE ALPHABETIQUE
}

\author{
DES NOMS D'AUTEURS ET DES OUVRAGES
}

Ou se trouvent decrites les especes d'hymenopteres mentionnes dans notre Faune et ses Additions.

Aar. Aaron, S. F.-Chrysidida, Trans. Am. Ent. Boc. XII. 209.

1d. Idd.-Additions et corrections a ia Faune hyménoptérologique de la Pro. vince de Québec (18గ9).

Am. Ent.-American Entoinologist, Vols. 1. 2, 3 (1868-\%0.)

Am. Nat. - American Naturalist (18tifet suiv.).

Andre, Ed.-Spéeies des Hyménoptéres (d'Europe, 1879 et sulv.)

Amn. Lye. Nat. Hist. N. Y.-Annals of the Lyceum of Natural History (1823-7 )

Aun. Nat. Hist.-Annals of Natural History, Londres, 5 vols (I3:3e-10).

Aun. Mag. Nat. Hist. - The Annals and Magazine of Naturul History, Londres (1841).

Ann. Sel. Nat.-Annales des Sciences Nat. Paris 18:21.

Ann. Soc. Eut. Fr.-Anuales de la Société Entonologique de France, Paris, 1Ni3:.

Ash. Ashm. Ashmead, W. H.-Trans. Am. Ent. Soc. ; Canadian Naturalist \&c.

Atk. Atkinson, G. F.-Am, Naturalist XXI, ;70 (1887).

Bass. Bassett, H. F.-Cynipidæ, Am. Nat ; Proc. Ent. Soc. Phil. ; Transactions, \&c,

Beauv. P. de.-Palissot de Beauvais. Insectes d'Afrique et d'Amérique, 1805.

Beth. Bethune, c. J. S. - Rep. Ent. Soc. Ont (1-80-ti).

Blake. C. A.-Mutillidæ, 'Trans. Ain. Ent. Soc. III, IV, VII et XIII.

Bost. Jour,-Boston Juurnal of Nat. History (i vols. 18:34-63).

Bowl. Bowles, G. J.-Can. Ent. III, XI.

Brullc Hym.-Hist. naturelle des'ins. vol, IV (1846.)

Buck. Buckley, S. B. - Formicidæ,, Proc Ent. Soc. Phil. I ; Proc. Acad. Nat. Sci. Yhil.

Bull, Ac. Brux.-Bulletin de l'académie royale des fciences de Bruxelles, 1832.

Bull, Ent. W. S. Wept. Agr.-Bulletın of the Division of Enitomology UnitedStates Depurtment of Agriculture, Nos. 1-15 (1883-87). 
Bull, U. s. Ent. Com.-Budletin of tho United States Entomological Comaito alon, Nor. 1.7 (Washington 1877-81).

Ball. E. 8. Cee. Burv. - Bulletin of the United States Goological Survey, rol. V. (Washlugton 1879).

Burq. Burque, F. X. -Nat. Can. XI (1879).

Burm. Burmelater, $\mathbf{H}_{1}$ - Dans dinerents ouvrages.

Can. Ent. - The Canudian Entomologlst, London, Ont. (1869 ot suiv.).

coms Comatoek, J. R.-Rep. Ent. U. 8. Dopt. Agrlo. (187y).

Coq. Coquillot, w. W. -111 , Hep. $(1-81-8 \%)$.

Conta, A.-Fauna di regno di Napoll, 18is.".

Coup. Couper, W.-Proo. Ent. Soc. Phll. 1 ; Can. Ent. I, 11.

Cox, J. D.-Am. Nat. XII (1878).

Cress, Cresson, E. T.-Proc. Ent. Soc. Phil. 1-VI ; Traps. Am. Ent. Soc, 1-XIV, Can. Ent. I, IV ; Proc. Bust. Soc. Nat. Hist. XII ; Proc. Acad. Scl. Phil. 1878.

Curtls, J. -Britist Entomology, London (182:3-40),

Dahlb. Dahlbom, 1. 0.-Conspectus Tenthredinidum \&c.

Dalm. Dalman, J, W.-A nalecta Eintomologion, Stockholm (1823).

De Geer, C. - Mémoires pour ervir \& l'hlstoiro des insectes, Btackholm, (1858-78).

Drury, D.-Divers $1870-82$.

Edw. Edwards, Henry.-Prno. Cala. Acad. Sci. V ; 4 m. Nat, VII.

Ent. Am.-Entomologica Americana, Brooklin I et suiv.

Dat. Mag.-The Entomological Maguxine (Londt es I8333-18.)

Ent. Month, Mas, - Entomologist Munthly Magazine (Londres 1834 et suir.)

Fabr, Fabriclux, J. C. - Entolnologit systensatica, Copenbague (1:92-94),

Fleteher, Jamen.-Rep. Ent. Soc. Out. (1884).

Forb, Forber, A. A.-III. Ilep. (18s3-84).

Ford, A.-Etudes Myrmícologiquen, Bulletin de la Société Vaudoise des Sciences Naturelles XVI, XX (18i9-8i).

Frenoh, 9, H.-Can. Ent. XII (1<甘u), XIV (1-8\%); Prairie Farmer (18\%1),

Full. Fuller, A, 8.-4m. Ent. III (1880).

Fall. Fallop, C. F,-Mopographin Teuthredinidum Suecim, London (18:29),

Fitch, Asa.-Reports (1-y) on Noxious and Beneficial Insects of the state of New-York, (1E\&j-65).

Forel A. - Divirses pullications.

Först. F\&̈ruter, 1. - Hymenopterologische Studien, Formicariæ, Chalcịdidø, Pructotrupidii, Aix in Chapelle.

Foure. Fourerol, A. F.-Diverses publications.

Gent. Gentry, T. G. - Cnn. Ent. VI (1874).

Germ.-Gerınur's Zeịtsc :t für die Entomologie (1E39-44).

Green, J. W.-Ann. Ly, . ¿. Hist. N. Y. VII (1860).

Grib, Gribodo, G.-Ann. Mius. Genov. VI (1874).

Gutr. Cuérin-Menneville, F. H.-Kev. Zool, (1833) Mag. do Zopl. (1831-4ళ).

Culg. Culgnard, J. A.-Can. Ent. XVIII (1886). 
Grav. Graventorat, J. C. L. - Irhucumologia Euro mon, Breslau (I\&!!).

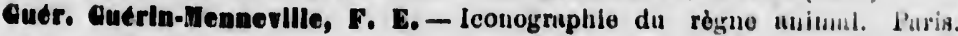
$(18 \times 2-14)$.

Bar. Hagea, H,-Can Ent. $X$ (1,78).

Hald. Haldeman, 8. B.-Proc. Acad. Nat Scl. Phll. II (1814) III (1816i) IV (1819) VI ( $185: 3)$.

Bal. Hallday, A, B.-Hymenoptem Britunnice, London ( $18: 19)$.

Bar. Harrington, W. A. Cun. Ent. XII (18-0) XIV (18+:) ; R R. Lit, Five.

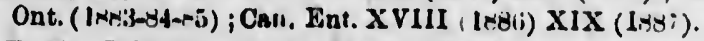

Giarrin, T. W.-.Injurioun Insects, Buston (Idd:-fi:?).

Hartlg. T. - Dle Fumillen der Bluttweexpen und Holzwespen \&c. Bullin (1-:it)

Holmg. Dolmgren, A. E. - Ins, ctu Hyinouoptern, Stocklaolu (IEiis).

c. 1-XIV, cad. Sci.

tockholm,

et suiv.)

$4-94)$,

doise des

(1881),

$(18: 9)$. te state of

alcildidm,

$831-48)$.

- iliig. IIIIger, J. C. W. - Fauna Etruwca, Hilmstedt (Irũ).

How. Howard, L. O. - Rep. Eut. U. \&. Depurt. Agriu. (18i9-80); Cit1. Liıt.

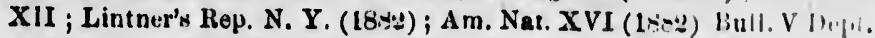

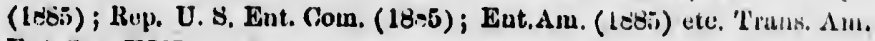
Ent. Soc. XIII (IS;B).

Enart, V. A,-Nut. Can. XI (I8R!)).

Hubb. Hubbard, H, G. -Am, Ent. III (1R>0-85).

Hump. Humphreya, J. T. - Am. Ent. I (I8s(1)).

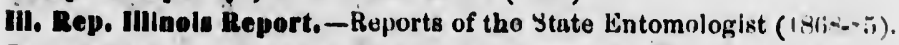

Jar. Jarlac, Lo - Nouvelle Mo hodu de chasser Jes Hyménoptecres et les lifi)tères, Genève et Paris ( $1 \times 07$ ).

Rirb. IIrby, W. F,-Journ. Linn Soc. Lond, XVII (1883).

Elag, F. -Divérses public itluns alleinundes $(180 ;-10)$.

Rohi, F. F.-Verch z ol. bot. Ges. (1:-44).

La Mun, La Manson, T. W.--Proc. Nebr. Assoc. Adv. Sci. (18ii).

Latr. Latrelilic, P. A,-D.ver's ouvrnges, (180i-2:!)).

Leach, Zool, Gise, -The Zoologilcal Mlscellnny, (|x|4-Ii).

Lo Bar. Le Barron, G.-Am. Nat I (186ji) VIII (18\%t).

Lin. Llnne, C. -Fauun Suecicn (1761).

Lint. Lintner, J. A.-Am. Nut. V (1871) Psyche IV (1883).

Wayr, G.-Diffërentes publicatious Allemandes ( $1 \times 6:-5 \tau)$.

MeC. Mecook, H. C. -Trans. Am. Ent. Soc. V (1876); Am. Nat. XII (IKi૪); Proc. Acul. Nat. ScI. Phil. (18:7) \&c.

Mio. Rep.-Reports of the State Entomologist of Missouri.

Morr. Morris, G. $\mathrm{K}_{0}-$ AIn. Nat. XIV, XV (18E(1)-81)).

Nat. Can.-Le Naluraliste Cinadien (1868 et suiv.)

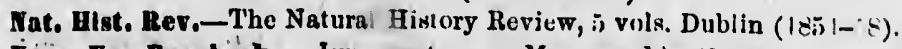

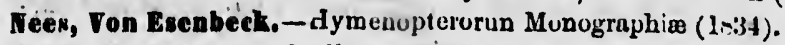

Newm. Newman, E, - In Entomologist.

I. Am. Ent. - North American Entomologist, Buffalo (18ז9-40).

Nort. Norton, Edward.-Bust Journ. Nat. Hist. ; Proc. Bosı. Soc. Natt. Hist. ; Proc. Ent Soc. Phil.; 'Trans. Am. Eut. Soc. (It60-i!)).

Nyl. Nylander, W.-Monographin Formicarum (1846). 
Osb. Osborn, H,-Can. Ent. XVI (1884).

Oliv, Oilvier, A. G. - Divers ouvrages.

O. Sack. Osten Sacken, R.-Divers ouvrages.

Paek. Packard, A. s. Jr. -- Proc. Bost. Soc. Nat. Hist. ; Proc. Essex Inst. ; Proc. Ent. Soc. Phil.; Pract. Ent. ; Am. Nat. ; Bull. U. S. Ent. Com.; Rep. Ent. U. S Dept. Agric. (186?-83).

Panz. PanzeI, G. W. F.-Faunæ Insectorun Germaniæ Initia (1792-1\&10.)

Patt. Patton, W. H.-Can. Ent. ; Bull. U. S. Geo. Surv, ; Am. ; Nat. Proc. Bost. Soc. Nat. Hist. ; Ent. Month. Mag.; Am. Ent. (1879-80).

Proc. - Proceedings of the American Society of Philadelphia, 6 vols. (1861-67).

Proe. Ent. Soe. Phil.-Proceedings of the Am. Entomological Soc. of Philadelphia, 6 vols. (186i1-1iz).

Proe. Acad. Nat. Sel. Phll. - Proceedings of the Academy of Natural Sciences of Philadelphia (1ช+1 et suiv.).

Proe. Bont. Soc, Nat. Blst - Proceedings of the Boston Society of Natural History (1841 et suiv.),

Proc. Cala. Acad. Scl.-Proceedings of the California Academy of Siciences (1isis 4 et suiv.).

Proc. Dav. Acad. Nat. Scl.-Proceedings of the Davenport Academy of Natural Sciences (Davenport, lowa, 1867 et suiv. '.

Proe. Ent. Sec. A. N. S.-Proceedings of the Entomological Section of the Academy of Natural Sciences (Philadelphia, 1879 et suiv.).

Proe. Essex Inst.-Proceedings, of the Essex Institute (Salem, Mass' 184 s et seg.).

Proc. U. S. Nat. Mus.-Proc. of the United State National Museum (Washington, D. C. 1 is 8 et suiv.).

Pror. Provancher, L.-Le Naturaliste Canadien, 18 vols. (Cap Rouge 1869 et sniv.); Fuune Entomologique du Canada, vol. 11, 1883; Can. Ent. XVII (1885); Additions d̀ la Faune Hyménoptérologique du Canada (1889).

Put. Putnam, F. W.:-Pror. J'ssex Inst, IV (1863).

Quay, J. $-\Lambda m$. Ent. 111 (1880).

Ratz. Ratzburg, J. T. C.-Die Ichneumonen der Forstinsecten, etc (1844-52)

Reed, E. B. - Rep. Ent. Soc. Ont. ; Can. Ent. 111 (1871).

Reinh. Relnhard, H.-Divers.

Rep. Ent. Soc. Ont.-Reports of the Entomological Society of Ontario (Toronto $18 i 1$ et suiv.).

Bep. Ent. U. S. Dept. Agrle.-Reports of the Entomologist of the United States Department of Agrieulture, Washington (1878-86).

Rep. v. S. Ent. Com.-Reports of the United States Eutomological Commirsion, Washington (187z-85).

Rop. Whe .r. Expl, - Report of Wheeler geological Exploration, Washington (18;5).

Rev, Mag. Zool, -Revue et Magazin de Zoologie (Paris 1849 et suiv.)

BII. Blley, C. V.-Divers ! h.pports, Washington $(1 \leq 60)$ etc.

Roger, J.-Berl. Ent, Zeiis. (18:9-ï3). 
issex Inst. ;

Ent. Com.;

92-1410.)

; Nat. Proc. 30).

(1861-67). ioc. of Phila-

ural Sciences

of Natural

of Sciences

Academy of

ction of the

alem, Mass'

hal Museum

Cap Rouge 1883; Can. blogique du

c (1844-52)

of Ontario

the United

gical Com-

Washington

(v.)

Banbern, F. A.-Reports of Massachusetts of Agriculture (186:3).

Saund. Sannders, W.-Can Ent. ; Rep. Ent Soc. Ont. (1869-i5).

Saus. Sausgnres, H. de-Rev. Mag. Zool. (185i-58).

Say, Thomas, - Say's American Entomoiogy 2 vols. (1869).

Seh. Sehwary, W. D.-Am. Nat. XV (1881).

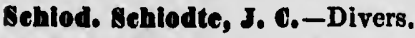

Scop. Seopoll; J. 4.-Divers, Leipzig, (1768-7\%).

Sm. Smith, D. A.-Trans. Ent. Soc. London (1874).

Shuek. Shuckard, W. C,-Divers.

Bmith, F.-British Museum Cotalogue (1879).

Spli. Splnola, II.-Insecta Liguriæ (180tj-08).

St-Farg. St-Fargeau, Lopelletler de-Hyménoptères (1836-46).

Tayl. Taylor, G. W.-Can. Ent. XVI, XVII (1884-85).

Town, Townsend, B. R.-Am. Ent. 11 (1870).

Tr., Trans., Trans. Am, Dnt. Boc,- Transactions of the Entomological Society (Philadel phia 1867 et suiv.)

Trans. Lnn. Noe. Lond.-Transactions of the Linnæan Bociety of London (1791 et suiv.)

Trans. St-Louls Aead. - Transactions of St-Lonis Academy of Sciences (18ī6 et suiv.)

Treat, Wary.-Am. Nat. XIII ; Am. Ent. 111 (1880).

Walk. Walker, F.-Can. Ent. IV, V (187/2-73).

Walsh, B. D.-Proc. Ent. Soc. Phil. ; Am. Ent. ; Can. Eist. (1864-73).

Feed, C. W.-Bull, Ill. St. Labr. Nat. Hist. 111 (1887).

Wenm. Wesmarl, O.-Braconides de Belgique.

Westw. Westwood, J. O.-Diverser Revues allemaudes et anglaises (18:39-81).

WIIl Wullams, Jos,-Rep. Ent. Soc. Ont. (1876). 


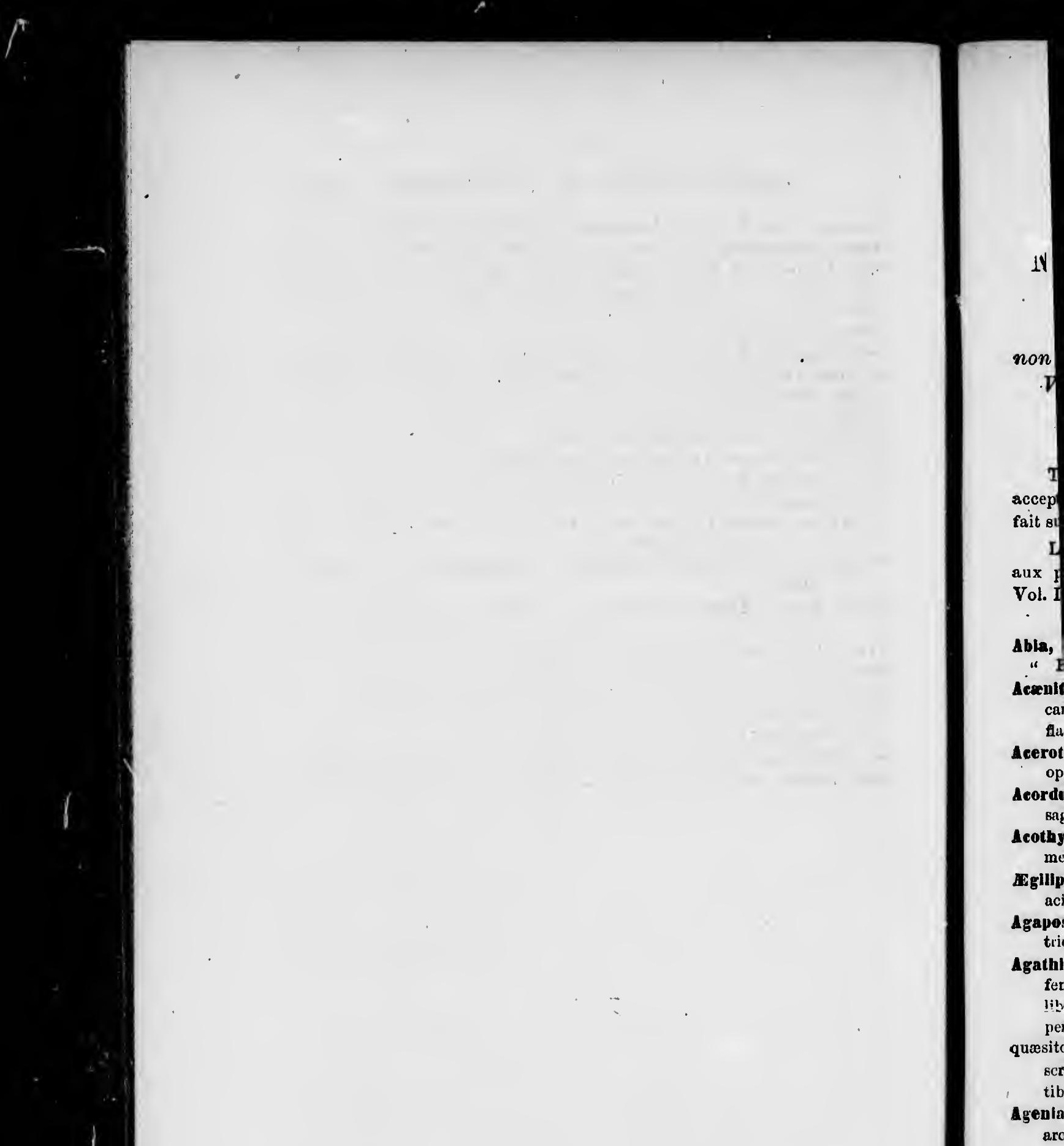




\section{TABLE ALPHABETIQUE}

DES

\section{NOMS DE GENRES ET D'ESPECES}

\section{MENTIONNÉS}

non seulement dans le présent volume, mais encore dans le

Vol. II de la Petite Faune Entomologique du Canada, comprenant les Hymenopteres.

Tous les noms en italiques sont ou des noms pris dans une fausse acception, ou des synonymes que des descriptions mieux caractérisées ont fait supprimer.

Le chiffire indicatif de la page, précédé des deux lettres Ad., renvoie aux pages du présent volume, dans le cas contraire, c'est la page du Vol. II de la Faune qui est indiquée.

Abla, Leach, 177.

“ Kennicotti, Nort. 177.

Acrenites, Grav. 441. canadensis, Prov. 442. flivipes, Prov. 441.

Acerota, Först. Ad. 183. opaca, Prov. Ad. 184.

Aeordulecera, Say, 738; $\Delta$ d. 346. saginatil, Prov. 739.

Acothyreus, Ashm. Ad. 437. mellipes, Prov. Ad. 437.

AEglllps, Hal, 554. acicu (atus, Prov, 554.

Agapostemon, Guér. j03. tricolor, Lepell. 703.

Agathls, Latr. 5i2 ; Ad. 137. femorator, Prov. 524. liberator, Bosc, 523. perforator, Prov. 523.

quæsitor, Prov. 5:3. scrutator, Prov. Ad. 13\%. tibiator, Prov. כ224.

Agenta, Cress. 6:5i, Ad. 262. architectus, Say, 6:7.
Agenla, atrata, Prov. Ad. 263.

calcarata, Cress. Ad. 263.

mellipes, Say, 626 .

perfecta, Prov. 627.

petiolate, Cress. 627.

pulchripennis, Cress. 63t.

rufigastra, Prov. Ad. 263.

Alcldamea, Cress. Ad. 331. pilosifrons. Cress. Ad. 331.

Aleiodes $=$ Rhogas. abdominalis, Cress $=$ Rhogas abdom canadensin, Cress. = Ihhogus canad. intermedius, Cress. = Rhogas interm. parasiticus, Nort. $=$ Rhogas parasit. terminalis, Cress. $=$ Ehogas terminalis

Allantus, Panz 210, Ad. 8. anuularis, Nort. :11.

atroviolaceus, Nort. $=$ Tenthredropsis. atroviolaceus.

bardus, Say $=$ Monoph ${ }^{-d n u s ~ b a r d u s ~}$ basiluris, Say (Tenthredo), 211.

cogitans, Prov $=$ Teut $\quad \ldots$ cositaus. dubius, Harris, 21:.

robustus, Prov. $\mathrm{Ad} .8$. 
Allantus rubricus, Prov. Ad. 9. rubrocinctus, Noit,:=Strongylogaster rufocinctus.

Allotria, Westw. A.d. lib6. avenæ, l'itch, Ad. 166. tritici, Fitch, Ad. 166.

Alomya, $=$ Orthocerus. $=$ fungor, North. $=$ Phæogenes fungor. pulchra, Prov. = Phygadeuon pubescens.

Algs sla, Latr. 535, 865 ; Ad. 147, 391. astigma, Prov. 805. caudata, Prov.=Cratospila caudata. completa, Prev. Ad. 147. fossulata, Prov. Ad. 391. lucens, Prov. 535. nigriceps, Prov. 536. rubriceps, Prov. 806. rudibunda, Sr.y, Ad. 391.

Alyson, Latr. 633; ; Ad. 269. conicus, Pruv, Ad. 271. Guignardi, Prov. Ad. 271. melleus, Say, Ad. 270. oppositus, Say, 636 . triangulifer, Prov. Ad. 272.

Ambiynotus = Geroptres. petioticola, 0 . Sack. $=$ Ceroptres petiolicola.

Amblyopene, Erichs. Ad, 239. binodosa, Prov. (Arotropus) Ad.240.

Amblyteles, Wesm. 292, 766, Ad. 34. Belnngeri, Cress. 29\%. bifasciatus, Prov. ¿97. borealif, Prov. 767. detritus, Brullé (Ichneumon) \$99. electus, Cress. (Ichneumon) 299. excultus, Cress. :!:14. expunclus, Cress. (Ichneumon) 766. improvisus, Cress. (Ichneumon) 295 indistinctus, Prov. 300.

inetus, Cress. (Ichneumon) 207 Marucephalus, Prov. Ad. 34. Milrinatus, Prov. $76 \%$. 2lontauus, Cress. (Ichneumon) 766. ITortoni, Cress. (Ichneumon) 768. uubivagus, Cresa. 301.
Amblyteles ormenus, Cress. ( $I c h$ neumon) $: 296$.

perluctuosus, Prov. 295.

Quebecensis, Prov. 299.

robustus, Cr. 8.. (Ichneumon) 299.

rufizonatus, Cress.(Ichneumon) 298 .

semicæruleus, Cress. (Ichneumon) 300.

Stadaconensis, Prov. 296. subrufus, Cress. (Ichneumon) 301. superbus, Prov. Ad. 35. suturalis, Say (Ichneumon) 301. tetricus, Prov. 294. ultus, Cress. (Ichneumon) 296.

$\triangle$ mmophlla, Kirb. 613 ; Ad. 255. communis, Cress=Pelopæus communis.

conditur, Smith, 616.

gracilis, St-Farg. 615.

gryphus, Smith, 615.

luctuosa, Smith $=$ Chalybion luctuosum.

Ampulex = Rhinopsis.

- canaliculata,Say=Rhinopsis canalic.

Inacharls, Dahlb. Ad. 16\%. Marginata, Prov. Ad. 163. pediculata, Prov. Ad. I69. subcompressa, Pv.(Eucoila) Ad. 168.

Indrena, Fabr. 693 ; Ad. 304. aliena, Smith, Ad. 310. algida, Fabr. 396. bicolor, Fubr. (i)1. clypeata, Smith, Ad. 310. convext, d'rop. Ad. 311. desponsa, with, Ad. 309. distans, Prov. Ad. 307. fimbriąta, Smith, Ad. 307. fragilis, Switb, Ad. :09. frigida, Smith, 695 . fulvipennis, Smith, Ad. 3 I3. hilaris, Smith, 694. hirticeps, Smith, 6:5. hirticincta, Prov. Ad. 308. integra, Smith, 697. laticeps, Prov. Ad. 307. lineata, Prov. Ad. 309. macilenta, Prov. Ad. 313. 
(tmon) $29 \%$ leumion) $\bullet 98$. Ichneumon)

6. (mon) 301.

301.

n) 296.

d. 255. poous com-

Iybion luca

psis canalic. 3. 63. I69. ila) Ad. 168. 304.

Andrens. miserubilis, Cress. Ad. Aprnteles, curpatus, Say, (Microgasier) sil.

nivalis, Smith; 694.

nubecula, Smith, Ad. 312.

perplexa, Smith, 696 .

placida, Smith, 696.

simplex, Smith, 697 .

simulatu, Prov. Ad. 313.

vicina, Smith, 645 .

Andricus, Hart. 544; Ad. 163. palustris, O. Sack. Ad. 163.

Andronicus, Cress. Ad 330. cylindricus, Cress. Ad. 330.

Ineurynchus, Weríw. 560; Ad. 176, 404.

aneurus, Prov.-Platygaster aneurus. foveatus, Prov. (Spilomicrus) Ad. 404.

Ad. :88.

clavatus.Prov.(Hicrogaster) Ad.338.

cougr 'hatus, Suy, (Microgasier) Ad. 3 ro.

crassicornis, Prov.(Microgaster) Ad. 388.

femur-nigrum, Prov. (Microgaster) 388.

longicornis, Prov. (Microgaster) Ad. $38 \mathrm{z}$.

Apathus, Newm. 736 ; Ad. 342.

Ashtoni, Cress, 736.

citrinus, Smith, 737.

dorsalis, Prov. Ad. 343.

elatus, Fabr. 737.

insularis, Smith, Ad, 343.

laboriosus, Fabr, 736.

inermis, Prov.=Pantoclis inermis. Aphareta, Först. Ad. 392.

mellipes, Prov. (Cinetus) Ad. 401.

spinosus, Prov $=0 \times \mathrm{xylabis}$ spinusus.

auripes, Prov. (Trichesia) Ad. 392.

Anomalon, Jur. 355 ; Ad. 78.

Ambiguus, Nort. = Exochilum nigrum.

anale, Say, $35 \%$.

chlamidatum, Prov. Ad. 82.

exile, Prov. 358.

filiforme, Prov. Ad. 83.

hyaline, Nort. 337.

- Paterale, Brullé, Ad. 81.

nigripennis, Prov. $=$ Exochilum mundum.

nigritum, Nort. Ad. 80 .

nigro-rufum, Nort. Ad. 81 .

nigrum, Prov.=Exochilum nigrum.

prismutıcum, Nort. 358.

relictum, Fabr. 357.

rufulum, Prov. Ad. 80.

semirufum, Nort.Ad. 79.

unicolor, Prov. Ad. 82.

Inthophora, Latr. 689.

bomboides, Kirb. 691.

nudata, Prov. (Ceratina) 718.

subglobulosa, Prov. Ad. :97.

terminalis, Cress. 691.

Apanteles, Först. Ad. 387. acaudns,Prov. (Microgaster) Ad.388.

phidarla, Yrov. Ad. 15:, 396.

basilaris, Prov. Ad, 396.

simulans, Prov.=Praon simulans.

Aphidius, Esenb. 537 ; Ad. 152, 395.

canadensis, Prov. 538 .

nigroviuius, Prov. Ad. 396.

obscurus, Prov. Ad. 152.

Aphlanthops, Putt. Ad. 9;8. frigidu,- Smith (Philanthus)Ad. 273.

Apis, Linn. $7: 8$.

mellifura, Lin. 732.

Aplomerus, Prov. Ad. 119.

tibialis, Prov: (Platysoma) Ad. 120.

Arenetra, Holng. 481 .

nigritá, Walsh, 802.

Quebecensis, Prov. = Lampronota tcgularis.

rufipes, Cress. 481.

Irotes, Griv. 482.

amænus, Cress. 448.

, formosus, Cress. 442.

superbus, Prov.=vicinus.

vicinus, Cress. 443.

Arotropus, Prov.=Ambigopone. binodosus, Prov. = Amblyopone birodosa. 


\section{TARLE ALPHABETIQUE DES NOMS, DE GENRES ET D'ESPLCFA}

Ascogaster, Wesm. Ad. 145. rufipre. Prov. Ad. 146.

Asplcera, Ashm, Ad. 4;37. i-liuenta, Sny, Ad. 437 .

Aspllola, Först. Ad. 392. astierm'l, Prov. Ad. 303.

Antata, Intr. (i.31. unicn!or, Say, fi31.

Asynaphes, Prov.=Cratospila. aciculata, Prov, = Cratospila aci- Bassus, Falır. 427, 798; Ad. 111, 368, culata.

brevicauda, Prov.=-Cratospila brevicauda.

candatd, Prov. $=$ Cratospila caudata.

Atractodes, Grav. 379.

antumnalis, Prov. 789.

Cloutieri, Prov.=Linoceras Cloutieri.

fusiformis, Prov.=Cremastus fusiformis.

mellipes, Prov. = Cremastus mellipes.

nigricoxus, Prov. 790.

nitens, Prov. 790.

Augochlora, Smith 705, Ad. 317.

obliqua, Prov. Ad, 318.

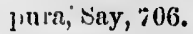

ricliata, Say. 705.

striata, Prov. Ad, 317.

Atscodes, $=$ Capitonius. rubriceps, Prov. = Capitonius rubriceps.

Aulacus, Jur, 247.

lilobatis, Prov, 247.

rutut rsus, Cress, 248, 751.

stimanturus, Cress. 247.

Anlax, Hartier. 550.

silvestris, O. Sack. „55l.

Baxแmsะ, Först. Ad, 40ะ. urietina, Prov. (1sostasius) Ad. 403.

Bancisas. Fabr. 35\%, Ad. 121, 366.

boreulis, Cress. :350.

cistudensis, Cress. :390.

candatus, Prov. Ad. 121.

forrugineus, Prov. 390.

flavescens, Cress, 390.

Banchus fluvovariegatus, Prov .388.

fornidabilis, Prov. 308.

inermis, Prov. 189.

pallescens, Prov. 391.

Baryceros, = Miesoleptus.

rhopalocerus, Prov. $=$ Mesoleptus rhopalcicerus.

Basalys, Westw, 559. ruficornis, Prov, 560. 429.

agilis, Cress. 430.

albicarnis Prov.=orbitalis.

amænus, Prov.=orbitalis.

areolatus,Prov.=Lampronota punctulata.

auriculatus, Prov. Ad. 4\%9.

Belangeri, Prov, 430.

Bouleti, Prov. = Erronemus pedalis.

cingulatus, Prov, 7:78.

costalis, Prov. 432.

cylindricus, Prov, Ad. 111.

dorsalis, Prov. Ad. 112.

elongatus, Prov.=Ichneumonoidt's.

frontalis, Cress, 42y.

fuscitarsus, Prov. 430.

humeralis, Prov. 4\%9.

ichneumonoides, Prov, 432.

limitaris, Say = Earinns limitaris.

longicotnis, Prov. 799.

mellipes, Prov. Ad. 429.

orbitalis, Cress, $4 \geq 9$

pallipennis, Prov 431.

pectoralis, Prov. 4:31.

pulchripes, Prov: 428.

kagınntur, Prov. 43:.

scapulatus, Prov. 798.

scutellaris, Cress, Ad, 11:.

tibialis, Cress, 4:8.

Bembex, Fubr. Ad. 41\%. fasciata, Fnbr. Ad 413.

Bethylue, Latr. 5ti3; Ad. 179. formicoides, Prov, $=$ Epyris formicuides. 
Bethylus prolongatus, Prov. = Epyris prolongatus.

Blacus, Esenb. Ad 13\%, 383 . cunentus, Prov. Ad. 383. defi'ctuosus, Prov..Ad. 13:3. longicıudus, Prov. Ad. 133.

Blennoesamya, Hart. Ad. 349. inhubilis, Hurris, (Selanuria) Ad 26. palipera, Prov (Selunaria) 74:. pygmæu, Say,( Tenthredo) $: 300$.

Blepharipus, St-Furg. 6 ti6 ; Ad, 294. uter, Cruss. (Crabra) $617 \%$. maculiṕennis, Fabr. 667. nigricornis, Prov. Ad, 294. minimux, Puck. 667.

Bombus, Fubr. 7333 ; Ad. 337. affinis, Cress. Ad. 3:34). borealis, Kırb Ad. 340. consimilis, Cress, 734 . fervidın, Fubr. 7:35, interruptus, Guén. = Apathus insuluris.

frigidus, Smith, Ad. 341. lacilstris, Creks Ad. 340. nigrocinctus, Prov Ad. 34\%. terumrius, Say, 735\%. terricola, Kirb. 7:3:. vagank, Simith, Ad. 3:39. virginlcus, Fubr. Ad. 338.

Irachlstes, W'sm. Ad. 13!. crassigaster. Pruv.=Ca!yptus crassigaster.

submucronatus, Prov. $=$ Calyptus submucronatus.

Bracon, Fabr. 497 ; Ad. 12ì, :372, 431. nciculatus, Cress. 500. æqunlis, Prov Ad. 502.

Angelesins, Prov. Ad. 3\%2.

apicntus, Prov. 504. nuripes, Prov. Ad. 372. dissitus, Oress. 500 . inquisitor, Prov. 499. Jevis, Prov. 448. langicuudus, Prov. 50:. lutus, Prov. 503. nanus, Prov. 504.
Bracen nigripes, Prov. Ad. 121.

nigropectus, Prov. 503.

nitidus, Prov. \&03.

obliquin, Prov, 501. ornatus, Pruv.=I Ilisulax ornatus. pilosipes, Prov, Ad. 431. politus, Prov. Ad. 373. pyguimus, Prov. 504. rufovirienatus, Prov. 503. situgnimeus, Prov. Ad. 3i2. striatus, Prov. Ad. 4:3l, 500. ventralis, Cress, 501.

Callroa, Costa, Ad. 349. obsoleta, Nort. (Selandria) :0\%.

Callaspldia, Dahlb. Ad. 167. Propancheri, Ashm =Onychis Prok.

Callimone, $\mathrm{S}_{\mid}, \mathrm{ir} .670$; Ad. 170.

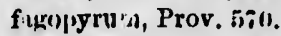
flavic sa, O. Sisck. Ad. 197. longricauda, Prov. ros. tubicola, O. Sikck. Ad. 197.

Calliopsts, Smith, Ad. 319. andrenoides, Smith, 1,124. interıuptis, Prov. Ad. :320. 4-lineata, Prov. Ad. 319.

Callirhlt's, Först.=Andrleus.

Calyptus, Hal. Ad. 38:3. crussigaster, Prov. (Brachistes) Ad. 38:3.

submucronatus, Prov. (Brachistes) Ad. 38:3.

Campoplex, Grav. 361, :86 ; Ad. 83. alius, Nort. 364. argente11, Nort. Ad, 83. cnrinatus, Prov. 365. diversus, Nort. :36:3.

favipennis, Prov. $=$ Opheletes glaucopterus.

Jaticiuctus, Cress. 362.

lucens, Prov.= Mesoleptus lucens. luctuosus, Prov. 36.. marginatus, Prov.=Limneria marg. minor, Prov. 364.

niger, Prov.=Limneria genuiua. nigripes, Prov.=laticinctus. politus, Prov. =-Exolytus politus. scalaris, Prov, Ad. 84. 


\section{TABLE ALPHABETIQUE DES NOMS DI GENRES ET D'ESPLOES}

Camp, seinirufus, Prov. 786, Ad. 84. Cerop, bipunctata, Say, An. :65. unicolor, L'rov. $=$ Mesuleptus uni- frnter'a, Smith, 6:8. formis.

vicinus, Prov. 364.

vitticollis, Harr. 36 (it.

Camponotus, Mayi; Ad. 227. longipes, Smith, 810 . superba, Prov. 810.

hurculeauus, Lin, (Formica) Ad. 231.

ceropires, Hurt. Ad. 164, 398. dorsalis, Prop. Ad. 3!98. petiolicola, 0. Sack. Ad. 164.

lignlperdus, Latr. (Formica) Ad.231. marginatus, Latr. (Fornica) Ad. 2:31.

Chalcis, Fabr. Ad. 190.

microgaster, Say = Smicra micro. gastra.

ovata, Say, 190.

Pensylvanicus, D.G.(Formica Ad. Chalybion, Dahlb. Ad. 256. $\because 31$. cæruleum, Lin.(Pelopæus) Ad. 257. luctuosum, Smith, (Ammophila) Ad. 257.

Camptotera, Först. Ad. 404. cluvatu, Prov. Ad, 404 .

Capitonius, Brullé, Ad. 134, 378. rubriceus, Prov. Ad. 135.

Charitopas, Först. Ad. 202. facialis, Prov. Ad. 203. rugosus, Prov. (Syngaster) Ad. 378. Charops, Holmg. Ad. 365.

Catocentrus, $W$ ulsh $=$ Polyblastus. fusuipennis, Prov. Ad. 365. dilatatus, Prov.=Pulyb astus dila- Chelonus, Jur. 5,0 ; Ad. 144. tatus.

Cemonus, Jur. 64i). inoınutus, Say, (Pemphredon) 645.

Centeterug, Wesm. Ad. 3ix. tuberculifrons, Prov. (Phsogenes) 308.

Cephns, Latr. Ad. 354. bicinclus, Prov. (Phylloecus) 233. bimaculatus, Nort. (Phyllocus) 234. Integer, Nort. (Phyllocus) 234. interruptus, Prov. Ad. 33isj.

Ceratina, Latr. $71 \%, 31 \%$; Ad. 336. bidentata, Prov. - Anthophora nudata.

dupln, Say, 812.

Tejonensis, (Yress. 8L2.

Ceratosoma, Cress. 383. rufa, Prov. (Exetastes) 794.

Cercerls, Latr. 643 ; Ad. 417. æqualis, Prov. Ad. 417. clypeatu, Dablb. 644. deserta, Siry, 64:. imitutor, Cress. $=$ deserta. nigrescens, Sinith, 64:3.

Ceropales, Latr. $6 \% 8,810$; Ad. 264 . argentitrons, Prov. Ad. 145. basiciuctus, Prov. 531. casinatus, Prov. 633. fissus, Prov. 5.2. insularis, Cress. 531. iridessens, Cress: 532. nanus, Prov. 533. rufiscapus, Prov. Ad. 144. sericeus, Say, 532.

Chelynia, l'rov. Ad. 321. labiata, Prov. Ad. 322.

Chlloneurus, Westw. Ad. 203. maculatipenuis, Prov. Ad. 203.

Chorinaus, Holıng. 433. carinatus, Cress. 433. pulchripes, Prov. 800.

Chrysis, Fabr. 579 ; Ad. 214. amcethistina, $\mathrm{Fabr} .=$ Stilbum amcethistinum. aurichalcen, Prov. 579, Ad. 215. bclla, Cress. =cærulaus. carinatus, Say = parvula. cærulaus, Lepell. 579, Ad. 217. halictula, Grib. = hilaris. hilaris, Dahlb, Ad, 215. 
Chryals nitidula, Fabr. Ad, 217. nitidula, Brullé=cærulani. Nortoni, Aar. Ad. 217. parrula, Fabr. Ad. 216. perpulclira, Cress. Ad. 216. strialella, Nort. = verticalis. tridens, Lepell. = parvula. verticalis, Patt, Ad. 215. virens, Cress. = parvula.

Chrysocharla, Walsh. Ad. 209. viridis, J'rov. Ad. 209.

Clmbex, Oliv. 175. amerioana, Leaoh, 176. Dahlbomii, Guér. 176. decemmaculi, D'Urb. 176 . femorata, Kirb. 176. ulmi, Peck. 176.

Clnctus, Jurine, Ad. 177. mellipes, Prov.=Aueurynohas mellipes. nasutus, Prov.Ad. 178.

cladlus, Illig. 180. isomira, Harr. 181.

Cleonymas, Lair. Ad. 407. aupcrbus. Prov. Ad. 407.

Clepten, Latr. 583. americana, Prov.=Provancheri. Provanoheri, Aar. Ad. 223. speciosa, Aar. Ad. 223.

Milstopyga, Arr r. 467. Canndensis, Prov. 407. truncato, Prov. 801.

coceophagus, Westw. Ad. 205. brunueus, Prov. Ad. 205. compressicoruis, Prov. Ad. 206. pallipes, Prov. Ad. 206.

Calloxys, Latr. 724. mæsta, Cress· 725. rufitarsus, Smith, 725. tristis, Cress. (Prov.=mosta).

coleocentrus, Grav 440 ; Ad. 113. mellipes, Prov. Ad. I13. Pettitii, Cress. 440. Quebecensis, Prov.=Pettitii. rufus, Yrov. 141.
Colletes, Latr. Ad. 803. hyalina, Prov. Ad. 303.

Colpognathus, Wesm. Ad. 858. helvus, Cress. (Phocogenei) 308.

Copelus, Prov. = Eelorus. paradoxus, Prov. $=$ Helorus paradoxus.

Copldosoma, Rntzb. All. 204. pallipes, Prov. Ad. 20 b. vagum, How. Ad. 204.

Coptera, Say. Ad. 181. polita, Sny = Entomoscelis polita.

Grabro, Fab. 052 ; Ad. 283. aciculatus, Prov. 661. advena, Smith =I'hyreopus advenus. arcuatus, Say =chrysargyrus. ater, Cress=Blepharipus ater. atrifrous, Cress, Ad. 289. bellus, Cress. Ad. 288. chrysargyrus, St-Fary. Ad. 287. cubiceps, Pack. 661. denticulatus, Pack. 662. effossus, Pack. 660. interruptus, St-Farg. 654. moutanus, Cress. Ad. 289. niger, Prov. Ad. 418. uigrifrous, Cress. 657 . obscurus, Smith. 659. pauper, Pack. 659. productloollis, Pack. Ad. 288. 4-maculaı us, Prov. 654. rufifemur, Pack. 657. 6-muculatus, Say, 655. singularis, Pack. 658. atirpicola, Pack. 655. tenuiglossus, $\mathrm{Pack}=$ Thyreopus tenu. iglossus.

trifasciatus, Say, 656. villosifrous, Puck. 656.

Crasus, Lench, 739. latitarsus, Nort. 740.

Cratosplla, För-t. Ad. 391 . aciculata, Prov. (Asynaphes) Ad. 391. 
Cratosplla breviounda, Prov. (Asynaphes). Ad. 391.

caudata, Prov. (Asynaphos) Ad. 913.

Cremantogaster, Grav, 375. Ad. 243. scutellaris, Oliv. Ad. 244.

Cremastuv, Grav. 375,788 ; Ad. 363. angularis, Prov.=Porizon angulare. fusiformis, Prov. 376. melliprs, Prov. 377. sectus, Prov. 376. Royi, Prov. 788.

Cryptus, Fabr, 329, 783 ; Ad. 61, 360, 438.

affahilis, Prov. 341.

alacris, Cress.=Phygadeuon alacris.

alacris, Cress. (Prov.)=affabilis.

albitarsi:,, Cress, (Prov.) = canadensis.

albonotatus, Prov. Ad. 75.

amblytelarius, Prov. Ad. 70. americnnus, Cress. 333.

aunulatus, Prov. 339.

apicatus, Prov. 336.'

otricollaris, Wnlsh, 341.

Belangeri, Prov. $=$ nuncius.

Blakei, (Plygadenon) Cress. 313.

bevicinctus, Prov. Ad. 67.

calipterus, Say, Ad. 438 .

brevicornis, Prov. = Phygadouon impressus.

Canadensis, Prov. 337.

caudatus, Prov,=Phygadeuon caudatus.

certus, Prov.=Phygadeuon fungor.

cinctus, Prov. 336.

circuncinctus, Prov, 331.

collaris, Prov. Ad. 71.

contiguus, Cress, 333.

dubius, l'rov. Ad. 71.

eburı. ifrous Prov. 332.

elougatus, Prov. 784.

erythropygus, lerov. Ad. 69.

exilis, Prov, 332.

extrematis, Cress, 340.
Cryptas jlavipectus, Prov. =Iohneub mon scltulus.

Fletcheri, Prov. = oalipterus.

fungor, Nort. = Phwogenes fungor. gracilits, Prov Ad. 74.

ignotus, Prov. Ad. 73.

imitator, Prov. 330.

incognitus, Prov, Ad. 70.

insignis, Prov. =Blakei.

7atus, Prov.=Phygadeuon occideutalis.

limatus, Cress. 334.

linenris, Pror. Ad. 72.

longicaudus, Prov. Ad. 68.

luctunsus, Cruss. Ad. 71.

melli.oxus, Prov. Ad. 75.

mellipes, Prov. Ad. 68.

moutivagus, Prov. 338.

mundus, Prov. 336.

vigricoruis, Prov. 338.

Lotatus, Prov. 340.

nuucius, Say, 340.

occidentalis, Prov. = Pnygadeuon occidentalis.

oruatus, Prov. Ad. 69.

osculatus, Prov. 331.

pentagonalis, Prov. Ad. 66.

perditus, Prov. Ad. 73.

persimilis, Cress. 335.

proximus, Cress. 330.

pubesceus, Prov, Aci. 72.

pumilus, Cress. (Prov.)=Phygadeuon pubescens.

Quebeccnsis, Prov. = velox.

reotur, Prov. Ad. 75.

robustus, Cress, 783.

ruficornis, Prov.=Phýgadeuon nitidulus.

rufoaluulatus, Prov. 335.

rufus, Prov, 342.

scutcllatus, Prov.=olnatus.

segregalus, Prov. Ad, 73.

sericeif. ons, Prov. 331, 783.

signatus, Prov! = Pliygadeuon sigu. similis, Cr. (l'rov.) =moutivagus. 
Cryptus sordidna, Prov. Ad. 67. sorioulatus, Prov. 784. spissicornit, Prov. Ad. 68. trisnnulatus, Prov. Ad, 74. varius, Prov.zatricollaris. velox, Cress. 330.

Cteniscun, Hal. 420. Ad. 109. apicatus, Prov. 421. olypeatus, Cress. 422. concolor, Cress. (Prov.) $=$ Mesoleptus concolor. consors, Cress. 422. crassipes, Prov. Ad. 109. flavicoxæ, Cress. Ad. 109. mediatus, Cress. 421. orbitalis, Cress. Ad. 110. rufus, Prot, 423.

Ctenopelma, Holmg. 406. sanguinea, Prov. 406.

Cyllocerla, Schiodte, 418. Lemoinei, Prov. 468. occidentalis, Cress. 468.

Cynips, Lin. 546. aciculata, 0 . Sack. 547. crassitelus, Prov. 548. gibbosa, Prov. 547. quercus-fusiformis, O. Saok. 806.

Cyrtocentrus, Prov. 793. Quebecensis, Prov. 794.

Dacnusa, Hal. Ad. 148. crassitela, Prov. Ad. 148. spatulata, Prov. Ad. 119.

Deeatoma, Spin. 568, Ad. 193, 438. basilaris, Prov.=Isosoma hordei. hyalipennis, Walsh, Ad. 193. varians, Walsh, Ad. 194.

Dlaprla, Latr. Ad. 175. apicalis, Say (Psilus) Ad. 175.

Dlastrophus, Hart. 549, 807. Ad. 161. nebulosus, 0 . Sack. 550. piceus, Pror. Ad. 161. 5-costatus, Prov. 807.

sigu. vagus.
Dinenra, Dahlb, 741. smericana, Prov. 741 luteipes, Cress. 712.

Dinocamptus, Förat. Ad, 378. linearis. Prov. (Microctonus) Ad. 378.

Dinotus, Först. Ad. 201. acutus, Prov. Ad. 201.

Diplolepis, Say =Figiter. arnatus, Say=Figites armatus. pedatus, Say $=$ Eucoila prdata. 5.lineatus, Say $=$ Aspicera 6-lineata. stigmatus, Say = Eucoila stigmata.

Dolerus, Leach, 187, Ad. 7. abdominalis, Nort. 197, Trans. I, 237.

slbifrons, Nort. Ad. 7,Trans. I, 237. apricus, Say, 197, Traus. I, 236. aprilis, Nort. 197, Trans. I, 236. arvensis, Say, 196, Trans. 1, 235. bicolor, Beauv. (Tenthredo) 198, Trans. 1, 239. collaris, Ssy, 197, Trans. I, 238. sericeus, Say, 187, Trans. I, 235. similis, Nort. 198, Trans. I, 238. unicolor, Beanv. (Tenthredo) 196, Trans. I, 23 I.

Dollehoderus, Lund. Ad. 408. borealis, Prov. Ad. 408.

Doryetes, Hal. Ad. 374. angulatus, Prov. (Syngaster) Ad. 375.

stripes, Prov. (Syngaster) Ad. 375. bæticatus, Prov. (Syngaster) Ad. 375.

fartus, Prov. (Syngaster) Ad. 375. macilentus, Prov. (Syngaster) Ad. 375 .

pallipes, Lrov. Ad. 375.

Earinus, Wesm. 526. limitaris, Say, 526.

Echthrus, Grav. 485, 803 ; Ad. 118. abdominalis, Cress. 487. canadensis, Prov. 486. 


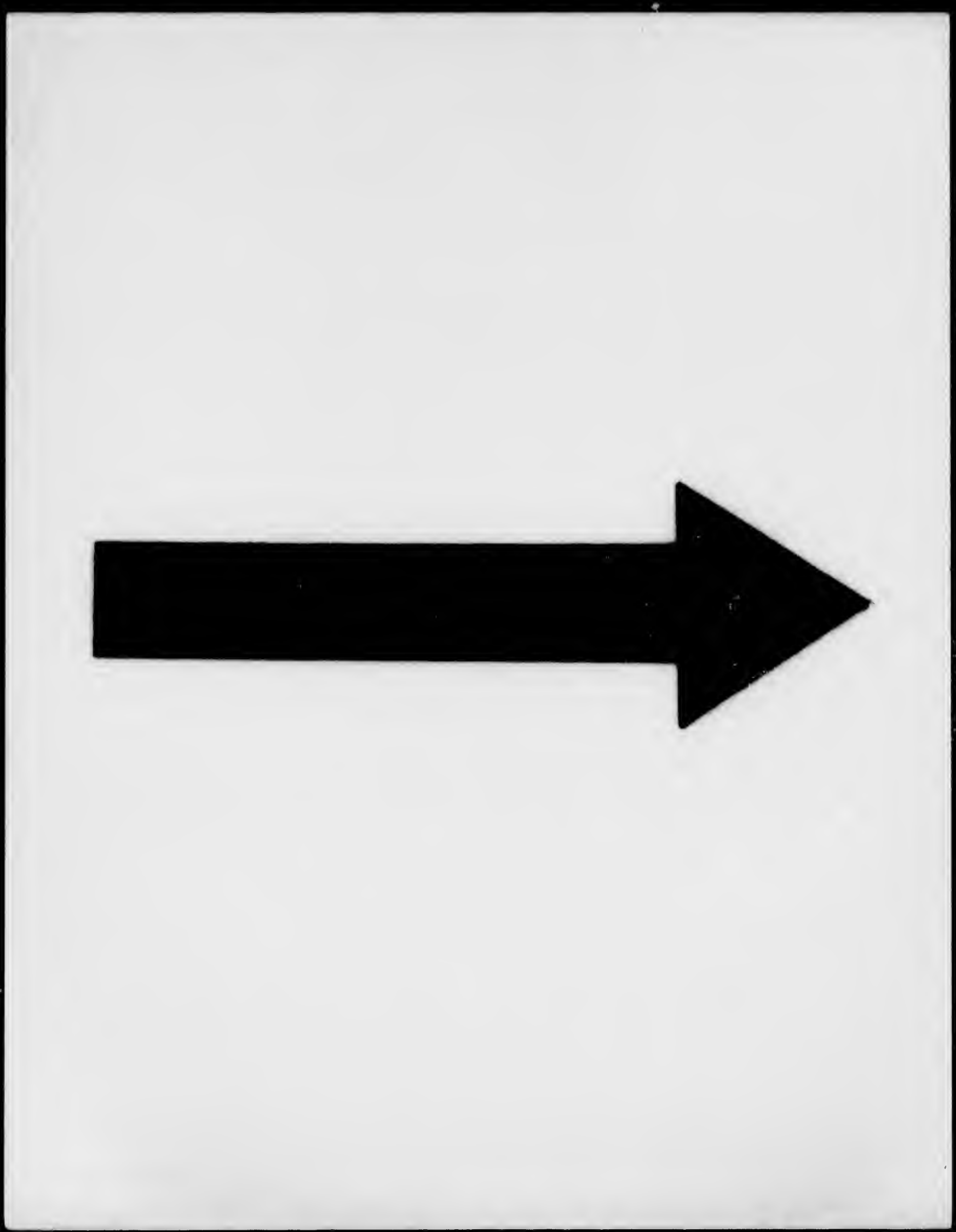




\section{IMAGE EVALUATION TEST TARGET (MT-3)}
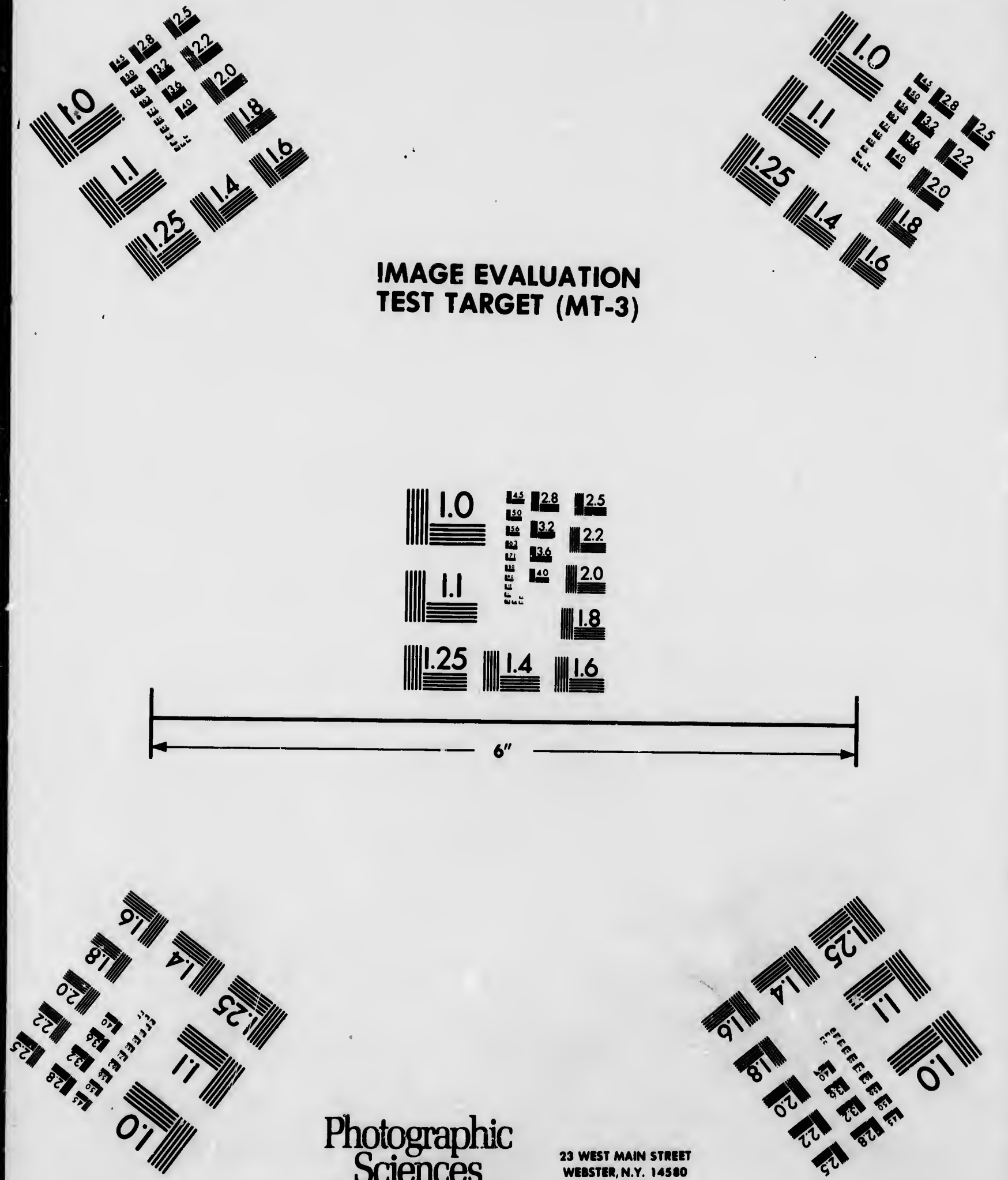

Photographic Sciences Corporation

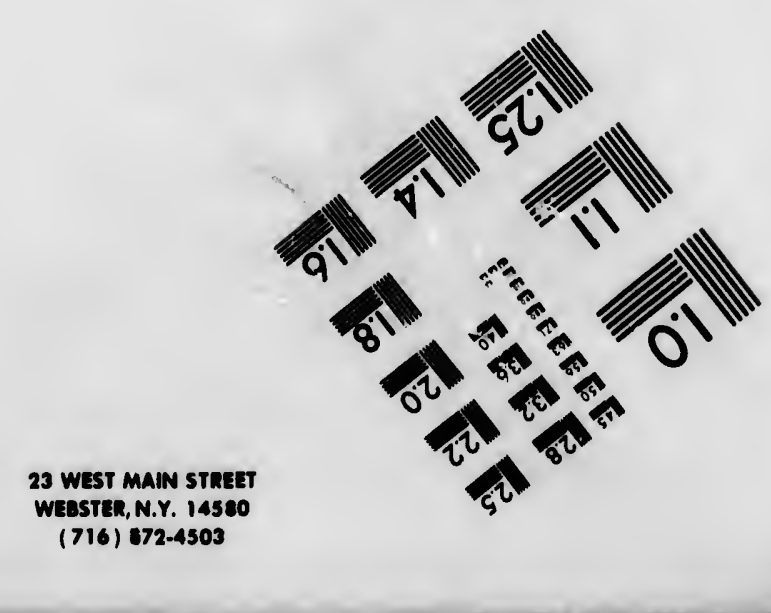




\section{TABLE ALPHABETIQUE DZS NOMS DE GRNRES ET D'ESPEOES}

Eehthrus eau zatus, Prov.=Hemiteles canaatus.

lactuosus, Prov. 486. mellipes, Prov. $=$ Mesoleius mellipes. niger, Cress. 485.

nigrioomis, Prov. 486, 803.

pediculatus, Prov. 487.

Provanoheri, Brodie, Ad. 118.

Eelytus, Holmg. 408.

pleuralis, Prov. 108.

robustus, Pror. 795.

Clampas, Spir. 581 ; Ad. 220.

corruscans, Nort. $=0$ malus corruscans. dæneus.

Cressoni, Aar. Ad. 220.

cyanescens, Prov. $=$ Omalus læviventris.

loeviventris, Nort.=Omalus læevi. ventris.

marginatus, $\mathrm{Prov},=0 \mathrm{mal} n \mathrm{~s}$ iridea cene.

purpnrascens Prov.=Omalus sinuosuse

sinuosum, Nort. $=0$ malus sinuosus. Ephlaltes; Grav. 150 ; Ad: 114.

speculum, Say, Ad. 221,

spinosus, Prov. $=$ Notosus viridse. nens.

viridicyaneus, Nort. $=$ Notozns viridæneus.

viridis, Prov.=Notosus marginatus.

Ella, Fabr. Ad. 410.

dives, Prov. Ad. 410.

4-cincta, Prov. Ad. 111.

Eephytur, Leach 191, Ad. 25,347.

cortu, Har 108,

canadensis, Kirb. 192, Brit. Mus:

I, 204.

cinctipes, Nort. 193, Trans. 1, 220.

Hullensig, Prov. Ad. 25.

iuornatus, Say (Dolerus) 192, Exiocampa, Hart. Ad, 348.

Trans. I, 227.
Bmplytar maculatus, Nort, $=$ Harpiphorus maculatus.

mellipes, Harr. 193, Trans. I, 228.

pallipes, Prov.=canadensia.

semicornis, Say = Harpiphorus semicornis.

stramineus, Cress. Ad. 25, Trans. VII. 52.

tarsatus, Say = Harpiphorus tas. satus.

varianus, Nort. $=$ Harpiphorus varianus.

versicolor, Nort. $=$ Harpiphorus versicolor.

polita, Say (Coptera) Ad. 104.

Dpeolus, Latr, 718 ; Ad. 332, 426.

douatus, Harr. 719.

mercatus, Fubr. 719.

pi osulus, Prov. Ad. 426.

scutellaris, Say, Ad. 332.

Ephedrus, Hal. Ad. 155, 395.

completus, Prov. Ad. 156.

incompletus, Prov.=Scotioneurus dives.

albipes, Cress, 452.

gigas, Walsh; 451.

irritatol, Fabr. 453.

occidentalis, Cress. 461.

pygmæuв, Walsh, 452.

tuberculatus, Fourc. (Ichneumon) 453.

variatipes, Prov. Ad. 114.

Epirhyasa, Cress. 449 ; Ad. 116.

olavata, Prov. Ad. 116.

Crevieri, Prov. 149.

pjorts, Westw. Ad. 102.

formicoides, Prov. (Bethylus))]Ad, 402.

prolongatus, Prov. (Bethylus); 1 d. 202.

marginate, Prov.(Selandria) Ad.8. 
Eriocampa superba, Prov. Ad. 351.

Erronemus, Holmg. 423 ; Ad. 110.

Bedardi, Prov. 424.

crnssus, Cress. 424.

dimidiatua, Cress. Ad. 111.

marginatue, Pror. 797.

pedalis, Cress. 423.

triatis, Prov. Ad. 110.

Eubadizon, Faenb. 517 ; Ad. 383. americanus, Cress. 517.

califurnicus, Prov. 883.

gracilis, Prov. 518.

pleuralia, Prov 517.

submucronatus, Prov, = Calyptus submueronatus.

Eucera, Latr, 692. nuda, Prov.=Macropis ciliata.

Eacereerls, Cress. Ad. 418. inaignis, Prov. Ad. 418.

Euceros, Grav. 624. burrus, Cress. 426. canadensis, Cress. 425.

Couperii, Cress. 426. medialis, Cress. 427

Quebecensis, Prov. = Pol! blastus Quebecensi8.

Eueharis, Latr. 670. gibbosa, Prov. 571.

Eucolla, Westw. 551 ; Ad. 171, 388. impatiens, Say, Ad. 172. mellipes, Say, Ad. 172. minor, Prov. Ad. 398. pedata, Say. Ad. 172. stigmats, Say, Ad. 172. subcompressa, Prov. = Anacharis aubcompressa.

Eueollidea, Assm. Ad. 36. cnnadensis, Ashm. Ad. 436.

Ealophus, Geoffroi, 576, Ad. 208. ramosus, Prov. 576. tricladus, Prov. Ad. 208.

Eumeues, Latr. 678, Ad. 421. cincta, Prov. Ad. 422. crucifura, Yrov. Ad. 421.
Rumenes flaropeotus, Prov. Ad. 422. fraterna, Say, 678. impuncta, Prov. Ad. 121.

Euphorus, Nees, Ad. 378. cephalicus, Prov. (Microctonus) Ad. 379.

punotatu8, Prov. (Microctonus) Ad. 379.

Eaplectrus, Westw. Ad. 206. lucens, Prov. Ad. 207. mellipes, Prov. Ad. 207. viridæneus, Prov. Ad. 207.

Rarytoma, Illig. 568 ; Ad. 192, 438. conica, Prov.=gigantea. diastrophi, Walsh, Ad. 192. gigantea, Prov. Ad. 438. studiosa, Say, 568.

Eustalocerus, Först, Ad. 378. fasciatus, Prov. (Rhopalophorus) Ad. 378.

Jougicornis, Prov. (Rhopalophorus) Ad. 378.

petiolatus, Prov. (Rhopalophorus) tauricornis, Prov. (Rhopalophorus) Ad. 378.

Duura, Newm. 183, Ad. 346. nigra, Prov. Ad. 346. orbitalis, Nort. 183, Trans. I, 179.

Fuxorldes, Cress. Ad. 115 ; Ad. 369. americanus, Cress. Ad. 116. Vanconverieusia, Prov. Ad. 869.

Erania, Fabr. Ad. 356. appendigaster, Lin. Ad. 356.

Exetastes, Grav. 883, 794 ; Ad. 92. affinis, Cress, 385. albitarsia, Prov. 385. brevipennis, Prov. = Mesostenus promptus.

clavatus, Prov. 386.

fasoipennis, Cress..Ad. 82.

matricus, Prov. 385.

nigcr, Cress. (Prov.) $=$ Arenetr. rufipes.

rufofemoratus, Prov. 384. 


\section{TABLE ALPHABETTUE DES NOMS DE GENRES LT D'ESPHCES}

Exotantes riifus, Prov. $=$ Ceratosoma rufa.

suaveoleus, Walsh, 384.

Exenterus, Fart. 796 ; Ad. 104, 867. canadensis, Prov. 796.

Hullensis, Prov. Ad. 104.

Erochlnum, Wesn. 353 ; Ad. 78.

fuscipenne, Nort. 355.

mundum, Say, 354.

nigrum, Prov. (Anomalon) Ad. 78.

Exochus, Grav. 436 ; Ad. 113.

albifrons, Walsh, 438.

annulicrus, Walsh (Prov.)=albifrons.

fulvipes, Oress. 437.

lævis, Cress. 437.

propinquus, Cress. (Prov.) $=$ Odon-

tomerus canadensis.

pygmæus, Cress. 437.

rufomaculatns, Prov. Ad. 113.

semirufus, Cress. 438.

Exolytus, Holmg. 380 .

politus, Prov. 380, 790.

Eryston, Schiödte, 406 ; Ad. 99. olavatus, Cress. 407, Trans. 1I, 113. marginatum, Prov. Ad. 99. variatum, Prov. 407.

Fenusta, Leach, Ad. 347. curta, Nort. Ad. 347, Trans. I, 225.

Figites, Latr. 555; Ad. 169, 437. armatü, Say, (Diplolepis) 556, Ad. 37.

impatiens, Say, Ad. 437.

inermis, Prov. Ad. 437.

locviscutum, Prov.=Thyreocera læ. viscutum.

mellipes, Say, $=$ Encoila mellipes.

5-lineatus, Say, (Diplolepis) Aspicera 5-lineata.

Fonus, Fabr. 245.

incertus, Cress. 246, Pros. III, 113. tarsata:ius, Cress. 246, Proo. III, 133.

Formlea, Lin. 596, Ad. 231.

flava, Fubr. 601.
Formilen fusca, St-Farg. 590, Ad. 234.

hereuleana, Lin, $=$ Camponotus herculean us.

ligniperda, Latr. = Campoinotus herculeanus.

marginata, Latr. = Camponotus marginatus.

mellea, Prov.=Lasius finvas.

pallitursis, Prov. 598, Ad. 235.

Pensylvanica, NeG.=Camponotus Pensylv́anicus.

rufa. Lin. 600, Ad. 234.

rutibhrbis, Fabr. Ad. 235.

sanguiuea, Latr. Ad- 233.

Galesus, Curt. 559.

Queb censis, Prov. 550.

Camosecus, Prov. 513 ; Ad. 126.

laticeps, $P_{1}$ ov.=Microctouus laticeps,

mellinus, Prov.=Perilitus melli-

vigilax, Prov.=Microctouns vigilax.

Glypta, Grav. 169 ; Ad. 117.

borealis, Cie s. 471.

californiça, Prov. Ad. 117.

canadenais, Cress. 471.

erratioa, Cress 470.

macra, Cress. 472.

ruficornis, Prov.=macra.

rufofasciata, Cress. 471.

rugulosa, Prov. 801.

tuberculifrons, Walsh, 470,

Anathocera, Piov.= Megachlle.

cephaida, Prov.=Megachile pngnata.

Gonatopus, Klug. Ad. 178.

decipiens, Prov. Ad. 179.

Corytes, Latr. 636, Ad. 272.

annatus, Prov. Ad. 272.

atricornis, Pack.=Hoplisus atricornis.

ephippiatus, Pack $=$ Hoplisus $\vdash$ phippiatus.

eximius, Prov. Ad. 274. 
Corytes laticinctus, Prov. Ad. 274. phaleratus, Say, $=$ Hoplisus phaleratus. ruficornis, Prov. Ad. 273.

Gymnoseelus, Först. Ad. 379. pedillis, Cress. (Helcon) Ad 380.

Halietus, Latr, 697 ; Ad. 314. albitarsus, Cress. 701. cinctipes, Prov. Ad. 316. confusus, Swith, 702. coustrictus, Prov. 702, Ad. 316. corianeus, Smith, 698. crebertimus, Cress. Ad. 317. discus, Sunith, 700. disparilis, Cress. Ad. 317. distinctus, Prov. 700. Lævissimus, Smith, 701. ligatus, Say, 699. ontariensis, Prov.=Ceratiua dupls. pi.osus, Suith, 701. scubrosus, Prov. 700. 6-cinotus; Prov. 700.

Haltichelia, Spin. Ad. 1,1 . viridis, Prov. Ad, 182.

Hedyehrum, Latr. 680 . s nuosum, Say $=0$ inalus sinuosus. speculum, Say = Elampus specnlum. ventrale, Say $=$ Holopyga ventralis. violacoum, Lepell.= Holopyga ventralis.

Hedylu, Marsh. Ad. 381. politus, Prov. (Opius) Ad. 381.

Helcon, kisenb. 515, Ad. 379. albitarsis, Cress. $=$ dentipes. dentipes, Binllé, 516. Hem's is: depressus, Prov. 328. gigss, Prov. 69. humeralis, Prov. 327. longicomis, Prov. 783. maudibularis, Prov. 324. mucronatus, Prov. Ad. 58. nigricans, Prov. 782.

orbicularis, Prov. =Stilpnus Americanus.

ovalis, Prov. 325. pallipenuis, Prov. 782. parvus, Prov. 324. ruticoxus, Prov. 325. scabrosus, Prov. 324. semirufus, Prov. 326. sessilis, Prov. 327. subspinosus, Prov. 326. tener, Prov, 326. utilis, Prov. =depressus.

Herlades, Latr. 716 ; Ad. 323, 425. alboscopatum, Prov. Ad. 125. cartiatum, Cress. 117. maculatum, Prov. Ad. 323. plenum, Prov. Ad. 425.

Herpestomus, Wesm. Ad. 358. pyriformis, Prov. (Phoeogenes) 309. pedalis, Cress.=Gymnoscelus peda. Hoplismenus, Grav, 291, Ad. 34. lis.

Helorus, Latr. Ad. 105. paradoxus, Prov.(Copelus) Ad. 405. aciculatue, Ad. 60. caudatus, Prov. 324. crassus, Prov. 783. debilis, Prov. Ad. 59. declivus, Prov. dd. 60. inpar, Prov. 292. morulus, Say (Ichnerumon) 291. scutellatus, Prov. 291. stygicus, Prov. Ad. 34.

Boplisus, St-Fa'g. id. 275. atricoruis, Pack.(Gorytes) Ad. 276. ephippiatus, Pack. (Gorytes) Ad. 276.

phaleratus, Say (Gorytes) 276.

flavicorne, Brullé, 355.

Holcopelte, Först. Ad. 210.

Holopyga, Dahlb. Ad. 222. compacta. . Cress. $=$ ventralis. ventralis, Say, Ad. 222(Hedychrum violaceum).

51-F6rrier 1880. 
Hoplocampa, Hart. Ad. 348. cauadeusis, Prov. (Selandria) Ad. 7. haleiov, Nort. (Selandria) Ad. 35.

Hylotoma, Latr. 179.

calcanea, Say, 180.

clavicornis, Fabr. (Tenthredo) 179.

dulcinris, Say, 180.

soapularis, Klug, 180.

Ibol a, Lati. 553 ; Ad. 165.

ensiger, Nort. 554.

maculipennis, Hald. Ad. 165.

Ichneumon, Lin. 249, A. 29, 356, 228.

absconditus, Prov. Ad. 81.

acerbus, Cress. 267.

adjunctus, Prov. Ad. 29.

aqualis, Prov.=Amblyteles nubi. Fagus.

ajer, Cress.=malacus.

albomarginatns, Cress. 265,

ambigurus, $\sigma^{\top}$ Cress.=graudis.

annulatus, Prov. 288.

aunulipes, Cress. 765.

approximans, Prov. Ad. 32.

atcrrimus, Prov. Ad. 30.

bifasciatus, I'rov.=Amblyteles bifasciatus.

bimaculatus, Prov. Ad. 357.

bimembris, Prov. 269.

Blake $i$, Cress.=Cryptus Blakei.

breviciuctor, Say, 270.

brevipennis, Cress. Ad. 428.

bronteus, Cress. 273.

cæruleus, Cress. 268.

calcaratus, Prov. = Hoplismenus morulus.

caliginosus, Cress. 760.

canacensis, Cress. 287.

calidatus, Prov. 283.

centrator, Say, 267.

cervulus, P:ov. 282.

cincticornis, Cress. 266.

cinctipes, Prov. $=$ navus.

cinctitarsis, Prov. 273.

citatus, Prov, 269.
Iehneumon citrinus, Prov. Ad. 81.

Clapini, Prov. =milvus.

ojnes, Cress. 276.

comptus, Say, 279.

consimilis, Cress. $=$ Amblyteles nu. bivagus.

corvinus, Cress, 761.

creperus, Cress. 280.

decoratus, Prov. 282.

deviuctor, Suy, 286.

duplicatus, Say, 288.

electus, Cress. = Amblyteles electus

erythropygus, Prov. = Platylabus ery tliropsgus.

excultus, Cress.=Amblyteles excultus.

extrematatis, Cress. 270.

feralis, Cress. 275.

fivitimus, Cress. 281.

flavicornis, Cress. =centrator.

flavizonatus, Cress. 278.

fortis, Prov.=centrator 우.

funestus, Cress. 287.

galeuus, Cress. 206.

grandis, Brullé, 284.

hasilans, Prov.=lunestus.

helvipes, Cress. 275.

humilis, Prov. 283.

improvisus, Cress. $=$ Aublyteles improvisus.

incertus, Cress: $=$ rufiventris.

incoustans, Cress. 763.

indistinctus, Prov. $=$ Amblyteles indistinctus.

inflatus, Prov.=Phygadeuon inf. insoleus, Cress. 286.

instabilis, Cress. 284.

jucuudus, Brullé, 280.

lachrymaine, Prov. 282.

lætus, Brullé, 277.

lincolatus, Prov. $=$ Platylabus li. neolatus,

lividulus, Prov. 286.

lobatus, Prov.=duplicatus. 
Iehnenmen malscus, \$ay, $2,66$.

Morianapolitanensis, Prov. $=\mathrm{Am}$ -

blyteles. rufizonatus.

mellicoxus, Prav. = pnerilis.

mellipes, Cress. Anblyteles luctua.

milvus, Cress. 281.

mimicus, Cress, 277.

montivagus, Cress. $=$ devipotor.

mucronatus, Prov. 290.

munificus, Cress. 762.

nauus, Cress. 765.

navus, Say, 268.

nigripes, Prov. 764.

nigruvariegatus, Prav. 283.

- nitidus, Prov. $=$ Amblyteles electus.

nobilis, Cress.=munificus.

Ontariensis, Prov. Ad. 30.

ormenus, Cress. = Ambiyteles oxm.

otiosus, Say, 273.

paradoxus, Prov.761.

paratus, \$\$\$, 280.

pepticus, Cress. 761.

pilosulus, Prov. 271.

placidus, Prov. 285.

pomilius, Prev. 27.8.

pravus, Cress. 271.

propinquus, Cress. =Amblytelonsaturalis.

teles

proximus, Prove 290.

puerilis, Cress. 274.

pullatus, Cręss. = suboyaneus.

4-punctatus, Prov. Ad. 83

Quebecensis, Prov. = Amblyteles Quebeceasis.

regnatrix of Cress. yrandis.

robustus, Cress. = Ambljteles , robustus.

rubicundus, Cress. 765.

rufiventris, Brullé, 285.

rufizonatus, Cress. = Amblyteles rufizonatus.

IAhnopumen scutellatus, Prov. = Ho. plismeuns scutellatus. semicoccineus, Cress.=rutiventris. seminiger, Cress. 289.

signatipes, Prov.=atygicue. similaris, Prov. 274.

coror, Cross. 66.

Stadaconensis, Pror. $=$ Ambly teles Stadaconensis.

stygicus, Rrov., 27.0.

suadus, Creass. 761.

subdolus, Cress. 279.

anboysneus, Creac, 269.

sublatus, Crese. 272.

syphax, Cress.=Amblytoles detritus.

cenebrosus, Cress.=Amblyteles luctus.

tibialis, Brallé =devinctor.

trizonatus, Prov. 276.

welus, Cress. = Amblyteles ultus

unifasciatorius, Sey, 272.

, patus, Prov. 7.63.

vagans, Prov. 271.

Tapcouverienais, Prov. Ad. a8, varipes, Prov.-cinctitaraio.

Trelpx, Gress. 287.

versabilis, Cross. 762.

resangs, Prov. 27.8.

viainus, Cress. Ad. 32.

vịola, Cresse. 265.

volens, Cress. (Jrehnus) 289.

W-slbum, Cress. (Irehnuw) 288.

Iphianiax, Föpst. Ad. 371.

americanus, Prov. Ad. 871.

ornatus, Prov. (Bracon) 5,02.

Ischloceras, Prov. 609.

regosa, Prov, = Myrmase nuioolor of rugosa, Prov. = Methoca atygia ot.

Inehnus, Grav, = Phrgadenes \&c.: impresses, Prov. $=$ Phygadenon im. pressus.

lentus, Prov. $=$ Cryptus limatus. parvus, Prov. = Hęmiteles parrpu. 
Ischnus plucidac, Prov,$=$ Herpestomus rectus

pyrifurmis, Prov. $=$ Herpestomus pyriformi s.

ruficurnis, Prov.=Pliygadenon ruficornis.

seut llatus, Prov, $=$ PIntylabus scut. variegatus, Prov. $=$ Ichneunson $\mathrm{W}$. a buin

Isosoma, Walsh, Ad. 104.

hordei, Harr. Ad, 194, 498.

tritici, Riley, Ad. 194.

Isostasius. Först. Ad. 183.

arictinus, Prov. $=$ Bæonura arietima.

cnmalensis, Prov. (I iatygaster) Ad. 403.

Joppa, Bı ullé. Nat. VI, 336.

Canadensis, Prov.=Ichneụmon inso!eus.

Kieidotoma, Westw. 552 ; Ad. 435. americana, Ashm. Ad. 435.

cupulifcra, Prov.= Lucoila impatiens.

maculipennis, Prov.=Encoila stigma.

minima, Proi.=Eucoila mellipes.

Labldia, Prov. Ad. 21.

Columbiana, Prov, $=$ optmus.

opimus, Cress. (Allantus) Ad. 21.

Lampronota, Curt. 473; Ad. 117.

agrilis, Cress. 480.

albifacies, Prov.=pleuralis.

americaua, Cress. 479.

brunnen, Cress. 479.

exilis, Cresss. 480.

frigidia, Cress. 478.

Inumeralis, Prov. 479, 802.

ins ta, Cress. 475.

jocosa, Cress. 475, 801 .

Iævigata, Cress: Ad. 117.

macra, Cress. (Prov.) = Bassus humeralis.

marginatr, Prov. 476.
Lampronota nigricornis, Prov. 477, nigripes, Prov. Ad. 118. [Ad. 117. parva, Cress. 476.

pleuralis, Cress. 476.

puuctulate, Cress. 475.

rubrica, Cress. 480.

rufipes, Prov, 477.

scuteliaris, Cress. (Prov.)=punctu. Jata.

tegularis, Cress. 478.

Larra, Latr. 633 ; Ad. 266. arcuata, Swith, $\Lambda d .267$. lævifrons, Smith, Ad. 267. minor, Prov. 267.

Quebecensis, Prov.=abdominalis. terminata. smith, 633.

Lasius, Fabr. Ad. 2:5, 409. alienus,' Först. Ad, 236. biuuneus, Latr. Ad. 409. flavus, Fabr. Ad. 238.

Leptohates $=$ Phygadeuon. canadinsis, Frov. $=$ Phygadeuon signatus.

Leptothorax, Mnyr, Ad. 244, canndensis, Prov. Ad. 245.

Leucop: is, Fabr. 56i. affinis Say, 567. fraterna, Say $=$ affinis.

Limneria, Holmg. 365, 783 ; Ad. 85. annulipes, Cress. $=$ fugitiva. argentea, Prov. 369. basilaris, Prov. 371, 786. betevicauda, Prov. Ad. 88. clnvata, Prov. 371, Ad. 89. compreta, P ov. Ad. 89. crassicornis, Pro\%. Ad. 88. dentata, Prov. 373. distincta, Prov. 787. dubitata, Cress. 787. excavata, Prov. =valida. flavipes, l'rov. 371. flavirista, Cress. 372. fugitiva, Suy (Banchus) 367. fusiformis. Prov, 371. 


\section{TABLE ALPHABETIQUE DES NOMS DE GENRES ET D'ESPĖCES 461}

LImnerla genuina; Say, 368.

Guiguardi, Prov. Ad. 87. hyalinn, Prov. 369. infumatu, Prov. 370. marginata, Prov. 370. nigricoxn, Prov. 786. pallipes, Prov. 372. parvn, Prov. 368. pilosula, Prov. Ad. 89. plene, Frov. 367. ruficornis, Prov.= dentata. ruficoxa, Prov. 372. rutipes, Prov, 368. serieen, Prov. 37.1. sessilis, Prov. 370. valida, Cress. 367.

Llnoecras, Tassh. 343. Cloutieri, Prov. 343.

Lonehldia, Thumps. Ad. 170. hirta, Prov. Ad. 170.

Lophirus, Latr. Ad. 18. Ablotii, Leach, Ad. 19, Trans. II, 324.

abietis, Harr. Ad. 19, Trans. II, 325.

fuivus, Nort. $=$ Monoc enus fulvus.

Lyda, Fabr. 228, 749, Ad. 16.

Burquei, Prov. 230.

Canadensis, Nort. 230.

Chicoutiniensis, Huart, 749.

discolor, Cress. 749, Trans. VIII, 26.

excavata, Nort. 230.

Harringtonii, Prov. Ad. 17. inconspicua, Nort. 232, Trans. II, 341.

luteicornis, Nort. 232, Trans. II, 339.

luteomaculata, Cress. 749, Trans. VIII. 28.

maculativentris, Nort. 229, Truns. Il, 333.

ocrerta, Say, Ad. 18, Traus. II, 333. ochroceri, Noit. Ad. 16, Truus.. 1I, 332.
Lyda pallimacula, Nort. 231, Tirus. II, 337.

perplexa, Cress. Ad. 17, Trans. Vill, 31.

Provaucheri, Huart, 7 E0.

Qnebecensis; Prov. 231.

Lyroda, Say, 632. sub ta, Prov. 632. triloba, Suy, (Lyrops) 632.

Maerocentrus, Curt. 518, Adl. 380. aciculatus, Prov, Ad, 380. delicatus, Cress. 620. longicornis, Prov. 619. mell 198, Prov, 519. pectoralis, I'rov. 520. uniformis, Cress. 520.

Macrocera Sny =Illiksodes. obliqua, Say=Meliswodes obli rustica, Sny $=$ Melissodes rustic:.

Macrophya, Dahlb. 203 ; A.l. 3 i2. albomaculata, Nort. 206, 'l'raus. I, 272.

contariuinta, Prov. 207.

crassicornis, Prov. Ad.

epinota, Say, 204, (Allantus)Traus. I, 268.

eurythoma, Nort. 208, Traus. I, 278.

exterll:, Say (Allantus) 208, Trans. $1,271$.

flavicoxa, Nort.: (Alluntus) 204, Trans, I, 269.

incertn, Norc.(Allantus) 205, Tirans. I, 269.

intermedia, Nort. (Allantus) 209, I, 278.

lineata, Nort. 204, Truns. I, 268. nigra, Nort. (Allantrus) 207, 'Trins. I, 273.

pannosa, Say, (Allantus) 200, Trans. I, 270.

proximata, Nort. 206, Trans. I, 270. pulchella, Klug, ('Tenthrcdo) 842, Trans. I, 266.

tibiator, Nort. 206, Traus. I, 271. 
Eiching thisllibs; Nort. (Allan.

(นง) 207, Srane. 1, 274. variir,? " Nedisusn 208; Trans. 1. bid 201......,

Encrople; :

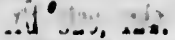
cilinte, l'att. Ad. 320. longillingue, Prov. Ad. 424 :

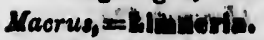
donlatue; Prov:= Limineris dentati.

Dozeditiv; Latr. 709 ; 1d. 828, 424. acuta, Smith, = litimanus: brevis, Say, 713. centunculatis, St-Parg. 714. founotate; Smith, 712. frigida, Smith, 711. grancils; Crevin. 713. hiernits; Prov. Ad. 823. latimatins, Bay, 710. tiveroch, Crés.=puiguáti. niélanophese; smith, $71 \%$. meudicu, Cress. 716. oblongi , Prov. 714. optiva, Cruaci, 716. phigutiti, Say; 712. ucrobioulata, Smith; 711. dimplecé. Prôt. Hinérnis. Vancouveriensis, Prov. 124.

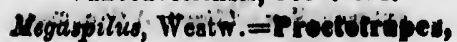
lucens, Prov. $=$ Proctotrupes flavipes.

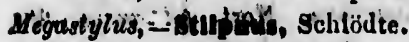
politus, Prot. .=Stilpuúa immericanus. moffyid, Lätit. Ad. 844, 427. paupera, Prov. Ad. 427. Trinidadeusis, Prov. Ad. 344.

Lellnnoten, Latr. 691 ; Ad. 298. deutivévtris, Sinith, Ad. 299. despónises Smith, 692.

fentonata, Prov. Ad. 800. lata; Prov. Ad. 302.

nigricornis, Prov. Ad. 302. nigtripes, Sinith, Ad. sod. obliquà, Bâ, (Maírocerä) Ad: 299.

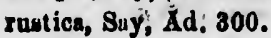

Dellenectivi innilib, Snith, Ad. s01:

nenleant, Solibdte, 481,802 ; 1 d. 480. Auhmeadii, Prot'. Ad. 180 '. Crevieri, Plöv.=sintelluris. elegann; Cross. 182. marginatus Pror. 802. scutellusis, Crew". 482. superbuy, Prót. 482.

Denoethornif, Grar. 880, 790 ; Ad. 365. aroolatus, Prov. 793. atriventris, Creav, 881, 791. canadonsis; Pror.=Eohthrus cans. deusis.

Aavipea, Prov. 882. bumeralis, Pror. 792. jucundus, Prov. 792. Jutoipes, Cress, 792. luctuosus; Prov.=Echthrus luctuosùs.

pleuralis; Pror. 381. politus, Prop. 791. fufúluś, Prór. 381. truncatus, Prov. Ad. $\mathbf{3 6 5}$.

thecredid; Holmg. 416, 796 ; Ad. 105. 868.

intiulictus, Prov. 106. anténndtus, Prov. 118. cauadenait; Prot. 117. fissus. Prov, 415. inflatus, Pror. Ad. 107. juividus Prot 787. mellipes, Prov, 116. niger, Prór. 796. submarginatus, Cress. 116. turdus, Prov. 117. telarius, Prov. Ad. 106, Fitolottut, Grav. 394, 704 ; Ad. 83. angustus, Prov. Ad. 96. dibopileuralli, Prov. 397. annulatipes, Prov. Ad. 96. hunuatus, Prov. 307. annulipes, Cress,=Limneris fugitirk.

buirbatute; Prov. Ad. 98. 
Mesoleptun oanaliouintus, Prov, 103. Zesoloptus unicolor, Cress. 102.

ooncolor, Crens, 103.

deecns, Cress. (Prov.) $=$ Eolytus

uniformis, Prov. 205.

pieuralis.

depressus, Prov. 309.

discolor, Cress. 102.

oreotus, Prov, 404.

fuscintuge, Prov. Ad. 90.

filiformin Prov. Ad. 98.

flavicorais, Prov. 401.

Aavirictus, Cress, = Limuerin favir.

fucalus, Cress. (Prov.)=leotus.

honestus, Cress. 400.

inceptull, Cress. 399.

incompletus Prov. = Cremastus fussformis.

interrujtis, Prov. 398.

Jetus, Prov. 404.

largus, Prov. Ad. 98.

Inurentianus, Prop, 101.

longipes, Prov.=Moyeui.

lncenn, Prov. 101

maenlatus, Prov, $=$ Exyston olavatus.

Ad. 105.

major, Cress, (Prov.) $=$ Limneris genuiup.

micanis, Prov. $=$ Therailochus micalls.

muliebris, Cress. 400.

nigricornis, Prov. Ad. 99.

oxylus, Cruss.(Prov.) = Limneria clavata.

perditus, Prov. Ad. 97.

peregriụus, Cress. 794.

rhopalocerus, Prov. 105.

ruti] es, I rov. 399.

rufomixtus, Prov. Ad. 97.

rufulus, Prov. 402.

Sti-Hyacinthi, Prov.=inceptus.

seminiger, Prov. 403.

variabilis, l'rov. =muliploris.

Mesontenux, Grav. 341, 7ะ5; $\mathrm{Ad}, 76$, 362.

alhifuoies, Prov. Ad. 362.

apicalis, Prov, =Iohneumon finitl. mus.

armatus, Prov. Ad. 70.

collinus, Prov.=Cryptus eburueifrons.

flavipes, Prov. 785.

joconus, Prov. 346.

latigaster, Prov. Ali. 77.

longicornis, Prov. = Mesoleptus Mojeni.

nigricornis, Prov,=Echthrus $\mathrm{ui}$ gricornis.

nitidus, Prov. $=$ Phygadeuou nitidulus.

nobilis, Prov. 785.

pallipes, Prov.=MLesoleptus triau. gularis,

pluricinctus, Prov. Ad. 70.

promp̧tus, Cress, 386.

ruficornis, Prov.=Phygadeuon nitidulus.

rufus, Prov.=Cryptus rufiss.

sagex, Prov, 345.

Saint-Cyri, Prov.=Eehthrus ab. dominalis.

sericeus, Prov. = Mesoleptu» sericeus.

tarsatus, Piov.=Cryptus amesicanus.

thoracicus, Crers. 346.

Iensa, Leach, Ad. 6. hyalinn, Nort. Ad. 6.

IEtacolus, Först. Ad. 200. conicus, Prov. Ad. 200. aericeus, Prov. (Mesostenus) 345, Meteorus, Hal. Ad. 375. 395.

tibiator, Cress.=Limneria fugitivs communis, Cress. (Perilitus) Ad. 377.

triangularis, Cress. 398.

dimidiatue, Cress.(Perilitus)A 1.377. 


\section{TABLI ALPHABETJQTE DES NOMS DE GENIES ET D'ESPtCES}

Eeteerno grneillin, Pror. (Porilitus) Ad. 877.

humilit, Cress. (Perilitus)Ad. 877. incompictus, Prov. (Perilitus) Ad. 8, 8.

politue, J'iov. (Perilitus) Ad. 378, robustus, Prov. (Perititus) Ad. 377. vulgarle, Cress. (Perilitus) Ad. 877.

Eetheen, Lntr. 604 ; Ad. 258.

blcolor, Say, 605.

stygis, Say, Ad. 253.

netoplas, Panz. 172.

Hageni, Crews. 478.

Wlerobembex, Patt. Ad, 118. monodontr, Say, Ad. 113.

alerectonus, Wesm, 804, Ad. 127, 379. cephalicus, Prov.-Euphorus ce. phalicus.

laticupe, Prov.(Gamosecus) Ad. 379. linearis, Prov. = Dinocamptus $1 \mathrm{i}$. nearis.

punctatus, Prov.=Euphorus puno. tatus.

vigilax, Prov. (Gamosecus) Ad.379.

Illerodus, Esenb. 624; Ad. 137.

aglis, Cress, 626.

anuulipes, Cress, 525.

bicolor, Prov. 526.

dispar, Prov. Ad. 138.

Inticinctus, Cress. 525.

nigricoxus, Prov. Ad. 138.

Quebecensis, Prov. 525.

Illeroganter, Lntr. 527 ; Ad. 138, 385. acaudus, Prov. $=$ Aponteles acaudus.

aurijes, Prov. Ad. 141.

brevicaudus, Prov. Ad. 140.

callipterus, $\mathrm{Say}, 527$.

carpatus. Say = Apanteles carpatus.

cinctus, Prov.=A panteles cinctus.

clavatus, Prov. $=$ Apanteles clava.

tus.

congregatu's, Say = Apanteles con- Mou

gregatus, mleroganter orassicornis, Prov.= Apnuteles crnss cornils. crenulatue, Prov. Ad. 387. - vilger, Say, 529, 805.

femur-nigi um, Prov. $=$ Apanteles fenur-nigrum.

femur.rubrum, Prov. = A pauteles fenur-rubrum.

golechiø, Kiley, Ad, 386.

lateralis, Prov. Ad. 141.

longicornis, Prov.=A panteles longicornis.

melliguster, Prov. Ad. 143.

mellipes, Say, Ad. 386.

4-clentatus, Prov. 1d. 140. rubricoxis, Prov. Ad. 386.

xylinus, Say $=$ A panteles $x y l i n u s$. zonarius, Sny, Al. 140.

igrioornis, Prov. 200

IItmena, Schuuk. 647 ; Ad. 279. argeuti frons, Cress. 648. cingulata, Pack. Ad. 281. deuticuinta, Puck. 648. paupera, Paok. 647. proxinua, Cress. Aii. 280. unicinctn, Cress. Ad. 280.

iilotrople, Thomps. Ad. 207. nebulosa, Prov. Ad. 208.

Wonedula, Latr. 629 ; Ad. 115. nigr.frons, Prov. Ad. 415. parata, Prov. Ad. 416. ventralis, Say, 629.

nonobla, Sauss. Ad. 420. bicolor, I'rov. Ad. 420.

Jonoctenus, Dahlb. Ad. 354. fulvus, Nort. (Lophirnes) Ad. 354.

Bonodontomerins, Walk. 669. viridoneus, Prov. $=$ Oligostenus stigms.

Monomorlum, Mayr. Ad. 248. Pharaonis, Lin.(Myrmica) Ad. 249.

oupphadnue, Hart. Ad 349. bardus, Sey (Selandria) 200. 
Donophadnus medius, Nort. (Selan. uria) 201.

rubi, Hnrr. (Solandria) 201.

tiltio, Nort. (Selandria) 201.

nonostenia. Costa, Ad. 849. Ignotn, Nort. (Sclandria) 202. 108\%, Harr. (Selandria) 202.

Iutilin, J,in. Ad. 249. canadensty, Prov. Ad. 250.

IJ Jrmiea, Latr. 601, Ad. $2+6$. incompleta, Prov.=levinodis. løvinodin, Nyl. Ad. 247.

molesta, Sny-Monomorium Pharaonis.

ruginorlis, Nyl. Ad. 217.

IIyrmosa, Latr. Ad. 252.

unicolor, Sar, Ad. 252.

Nematopodius, = Cryptur.

Canadensis, Frov. Cryptus Canadensis.

coxatus, Prov. = Cryptus americanus.

Tematus, Jur. 183, 740 ; Ad. 5, 22, 348.

bivittatus, Nort. 188, Trans. 1, 210. chloreus, Nort. Ad. 348, Trnus. I, 221.

concolor, Nort. Ad. 22, Traus. I, 186.

corniger, Nort. 186, Trnns. I, 189. decoratus, Prov. Ad. 349.

Erichsonii, Hart. Ad. 5.

erythrogaster, Nort. Ad. 23 , Trans. I, 205.

extensicorn 297.

fulvicrus, Prov, 740.

inquilinus, Wulsh, 180, 'Trans. I,

213.

Lahradori $19 \mathrm{C}$.

latifnsciatus, Cress. Ad. 24, Trans. VIII, 7.

luteolus, Nort.187, Trans. I, 200.
Nematun luteotergum, Nort. 740, T'rnus. 1, 206.

malncus, Nort. 185, Trans. I, 196. mendicus, Nort, 181, Trany. I, 220. militaris, C1ess. Ad, 23, I'rans. VIII, 7.

mowetn, Nort. 186, Trnnะ. I, 198. proximatus, Nort. 187, Trans. I, $20 \%$.

ribesii, Scop. 188. Trans, I, 208.

s. pomum, Nort. 741, Trnus. I, 216.

Saskutchewan, Nort. 187, Trans. I, 200.

similaris, Nort. Ad. 24.

sundus, Cress, Ad. 24.

subalbatus, Nort. 186, Trans. I, 100.

ven'ricosus, $\mathrm{Klng}=$ ribesii.

Ienroterun, Hart. Ad. 397.

terminalis, Hart, Ad. 397.

Ievropenes, Prov. Ad. 153. ovalis, Prov. Ad. 153.

Fomada, Latr. 720 ; Ad. 333, 426. Alaericnn, Kiıb. 721. belin, Cress. Ad. 333. bisignata, Say, 722. flnvipes, Prov. Ad. 426. luteoln, St-Farg. 723. maculata, Cress. 722. proximn, Cress. Ad. 335. punotatn, Fahr. 723. rubra, Prov. Ad. 427. vicinn, Cress. Ad. 334 .

nia, Latr. Ad. 837. compncta, Piov. Ad. 337.

Jototrachis, Massh. (Trachynotus) 853.

Canacieusis, Prov. 353.

249. marginntus, Patt. (Elimpus) Ad. 222 nitidus, Aar. Ad. 222.

viridicyanens, Nort. (Llampus) Ad. 2:\%, 


\section{TABLE ALPHABtTIQOE DES NOMS DE GENRES ET D'ESPECES}

Iywen Latr. 635 ; Ad. 268. leterale, Say, 635. nigripes, Prov. Ad. 269. rustiour, Cress. Ad. 260.

Odontomerus, Grav. 489. bicolor, Cress. 490. canadensis, Yrov. 190. mellipts, Say, 490 Am. Ent. II, 697.

Ophion rugosus, Brullé=macrujum Oplan, Wesm. 511, 804 ; Ad. 123, 381. brunneivontris, Cress. Ac. 32. ciuctus, Prov. Ail. 124. macrocephalus, Prov. $=$ Alysia rudibuuda.

mellipes, Prov. Ad. 123. neuus, Trov. Ad. 382. niger, Prov. Adl 381. pallipes, Pror.=mellipi a, Ad. 123. politus, Prov. $=$ Hedylus politus. ruficej's, Pror. Ad. 124. variabilia, Prov. Ad. 382. campestris, Sisuss, 676. Cauadeusis, Sauss. 673. Catskillensis, Sauss. Ad. 119. capra, Sauss. 674. debilis, Sruss. 673. leucomelas, Suuss. 677. Pensylvanicus, Sauss. 6i77. Walshianus, Sauss. 672.

Cnone, Haliù. Ad. 393. serices, Prov. Ad. 394,

Oligostenan, Walk. Ad. 195, 438. bimacula us, Prov. Ad. 196. stiginn, Fabr. Ad. 438.

Omalun, Jur. Ad. 218. corruscans, Nort.(Elampus)Ad.219. Oryssus, Fabr. 237, Ad 26. iridescens, Nort. (Elampus)Ad.219. læviventris, Cress.(Elampus)Ad.219. sinuosus, Suy (Elampus) Ad. 210.

Onyehla, Dalu. Ad. 171. armata, Say $=$ Figites armatus. incrmis, Prov. $=$ Figites annulatus. Provaucheri, Ashm. Ad, 437. b-lineata, Say $=$ Figites 5-liueatus.

Opheleter, Holing. 359. glaucopterus, Lin. 358.

Ophlon, Fabr. 350.

biforeolatus, Brullé, 351.

bilineatus, Say, 351 . cecropia, Harr. = macrurum. macrurum, Lin. 350. nigrovariue, Pror. 351. purgatus, Sny, 351.

Orgylan, Hal. Ad. 133. detectur, Prov. Ad. 134.

Ormyrus, Westw. Ad. 198. bruuneipes, Prov. Ad. 198.

Orthocentrua, Grav. 434, 60 ; Ad. 369.

abdominalis, Prov. 435. albofaciatus, Prov. 800. Cauadersis, Prov. 135. carinatus, Prov. 436. .Jucens, Prov, 435. pilifrous, Prov. 434. pleuralis, Prov. = Eclytus pleuralis. affinis, Harr. Ad. 28. hacmorrhoidalis, Harr.=terminalis.

occideuta: Cress. Ad. 27.

Sayi, Westw. Ad. 27, terminalis, Newn. 237.

Osmla, Latr. 706, 811 ; Ad. 324. albiventris, Cress. Ad. 327. - atriventris, Cress. 812. brevis, Cress. Ad. 326. bucconis, Say, 708. exigua, Cress. Ad 329. faceta, Cress. Ad. 326. frigida, Smith, 811. lutitarsis, Cress. Ad. 327. liguaria, Sny, 707. liguicola, Prov. 708. 
rurum.

123,381 .

. 32.

ysis ru.

Ad. 123. olitus.

8.

00 ; Ad.

pleuralis.

termina-
Orthla oblongü, Prov. (Kegachile) Ad. Paphagun, Walk. 572. 326. parva, Cress, 812. proxima, Cress. Ad. 329. simillims; Smith, 708. spol ata; Prov. Ad. 327. taisats; Prov. Ad. 328. vicina, Cress. Ad. 329.

oxybelus, Latr. 652.

Brodiei, Prov. 811. 4-notatus, Say, 652.

Oxylabls, Först. Ad. 105. spinosus, Pror. (Aneurynches) Ad. Pelopieat; Lat. 612 ; Ad. 256. 405.

Pachypretasls, Hart. 200. deltci, Prov. =Tenthredopsis delta. omega, Nort. 209, Trans. I, 280.

Pammegisehla, Prov. 751. Burquei, Provi. 752.

Paniseuk, Schreb. 360. albotargatus, Prov. 861. albovariegatus, Prov. 360. appendiculatus, Prov.=geminatus. . cunaliculalus, Prov.=Mesoleptus caualiculatus.

geminatus, Say, 360.

interrupitus, Prov.=Mesoleptus interruptus.

Quebecensis, Prov.=Exetastes suaveolens.

rufulus, Prov.= Mesorhorus rufulus. seininiger, Prov.=Mesoleptus sominiger.

Pantoells, Först. Ad. 405. inerunis, Prov. (Aneurynchus) Ad. 405.

Panurgus, Latr. 704 ; Ad. 321. astivalis, Prov. $=$ C .lliopsis msti. valis.

8-maculatus, Soy $=$ Perdita \&-maculata.

vernal s, Prov,=Calliopsis andre. noides. rugosus, Prov. 572.

Paramenilas, Westw. Ad, 404. long cornis, Prov. (Spilomicrus) 1.. 405.

Pasalcens, Schuoh. 651. mandibularis, Cress. (Pemphredon) $65 \mathrm{l}$.

Peleelnuw, Latr. 248. polycerator, Drur.=polyturator. polyturator, Drur. $=($ Ichneumion $)$ 218. argentipilis, Próv. Ad. 256. coruleus, Lin, =Chalybion cerul. cementarius, Drur. 612. communis, Cress. (Ammophila) Ad. 256. lunatus, Fabr, =cementarius.

Peinyluredon, Latr. 616. concolor, Say; 646.

inornatus, $\mathrm{Say}=$ Comonus Inorna. tus.

mandibularia, Cress.=Passalcecus mandibularis.

Perlelietus, Ad, 168, 397. obliquus, Prov. Ad, 397. semipiceus, Harr. Ad. 163.

Perilumpus, Latr. 671 ; Ad. 189, 406. aciculatus, Prov. Ad, 199. byalinus, Say, 672. lævis, Yrov. Ad, 199. platygaster, Say, 572. stygicus, Prov. Ad. 406. triaugulariw, Suy, 671.

Perilltus, Esenl. 511, Ad. 125. communis, Cress.=Meteorus commuuis.

dimidiatus, Creis, $=$ Meteorus dimidiatus.

gracilis, Prov.=Meteorus gracilis. humilis, Cress.=Mrteorns humilis incompletus, Prov, = Meteorus iircouplotue. 
Perilltus mellinus, Prov. (Gamosecus) Ad. 379.

nigritus, Prov. Ad. 379.

politus, Prov.=Mettorus robustus. vulgaris, Cress. $=$ Meteorus vulg.

Perithous, Holmg. 454. pleuralis, Cress. 454.

Pezomaehus, Grav. 347 ; Ad. 77, 362. Canadensis, Cress. 347. niger, P'rov. Ad. 362. Quebecensis. Prov.=Canadensis. sulcatus, Prov. Ad. 77.

Phrogenes, Wesm. 307, 769 ; Ad. 39. aunula ipes, Prov. Ad. 43. aterrimus, Prov. 769. crassitelus, Prov. Ad. 41. Falardeaui, Prov. Ad. 771. fungor, Nort. (Cryptus) 337. Gaspesianus, Prov. 770. hebrus, Cress. 307, Trans. I, 316: holvus, Cress = Colpognathus helvus.

Huarti, Prov. (Posocentrus) 409. indistinctus, Prov. Ad. 43. mellinus, Prov. 3 (18. nigricoruis, Prov. 770. orbus, Prov. 771. pinguis, Prov. Ad. 43. pyriformis, Prov. = He:pestomus pyriformis. quadriceps, Cress. 771. recticaudus, Prov. Ad. 42. recticoruis, Prov. Ad. 42. tuberculifer, Prov. 770. tuberculifrons, Prov.=Centetes us tuberculifrous.

Phenocarpa, Först. Ad 392. rubriceps, Prov. Ad. 392.

Phanerotoma, Wesm. 533. fascinta, Prov. 534.

Phasgonophora, W'stw. Ad. 180. elegans, Prov. Ad. 181.

Philanthus, Fabr. 641 ; Ad. $278,417$. bilınatus, Cress. 643.
Phllanthus frigidus, Snith = Aphilauthops frigidus

Harringtouii, P'rov, Ad. 278. politus, Say; Ad. 417. solivagus, Say, 641.

Photopsis, Blake, Ad. 400.

Canadensis, Prov. Ad. 410.

Phygadeuon, Gr.v. 311, 772 ; Ad. 44, 359 .

abdomintlis, Prov. 319.

acaudus, Prov. 780.

aciculatus, Prov. 778.

alacris, Crcss. $=$ Cryptos alacris.

albicoxus, Prov. 318.

alternans, Prov. 780.

annulatus, Prov. $=$ fus fo mis.

apicatus, Prov. $=$ Iohneumon velox ater; Prov.=lihneumon heivipes. atteuuatus, Prov. 781.

autumunlis, Prov. 779.

Blakei, Cress.=Cryptus Blakei. brevicaudus, Prov. Ad. 54. capitalis, Prov. All. 57. cuudatus, Prov. 319.

cephalicus, Prov. 777.

constrictus, Prov. 779.

cornutus, Prov. 77\%.

crassipes, Prov. 3:00.

curticrus, Prov. Ad. 360.

dubius, Prov.=pubescens.

electus, Prov. i).

fasciatus, Prov. Ad. 55.

fraterculus, Prov. Ad 55.

fusiformis, Prov. Ad. 51.

Geddesii, Prov. Ad. $n 4$.

gracilicornis, Prov. Ad, 56.

Guignardi, Prov. Ad. 50.

hilaris Prov. =Colpognatus helvus. intpressits, Prov.=Platylabus thoracicus.

inflatus, Prov. 321.

inhabilis, Prov. 31ī.

insignis, Prov. $=$ Phæogenes h'bbrus. jucosus, Prnv. Ad. 53.

Lavoiei, Prov. 756. 
Phygadeaon Lechevallierl, Prov. 77t. Phygadeuon 3-anuulatus, l'rov 7i..

lungicornis, l'rov. Ad. j\%.

lucens, Prov. 318.

maculatus, Prov. 314.

mujor, Cress. 320.

marginatus, Prov. Ad. 56.

muturus, Prov. 314.

mellinue, Prov.=Phæogenes mellinus.

Mignuulti, Prov. 777.

mucronatus, Prov. 319.

niger, Prov.=lchneumon extrematatis.

nigriceps, Prov. Ad. 52.

nitidulus, Prov. 317.

orbitalis, l'rov, $\mathbf{7 7 6 .}$

occidentalis, Pruv. 316.

ornatus. Prov. $=$ Platylabus ornatus.

ovalis, Prov. 317.

pallicoxus, Prov. 321.

parulielus, Piov. 777.

planus, Prov. $3 \%$ :

proximus, Prov.=Ichneumon proximus.

pubescens, Prov. 318.

4-carinatus, Prov.=Platylabus 4carinatus.

rectus, Prov. 315.

robustus, Prov. 322.

rotundiceps, Prov. 320.

rubricus, Prov. 780.

rubrocinctus, Prov, 315.

ruticornis, Prov. 321.

rufipes, Prov.=Platylabus lineolatus.

rufulus, Prov.=Mesuleptus rufulus.

gegnis, Prov. :317.

signatns, Prov.=Platylabus signatus.

similaris, Prov. Ad. 57.

subfuscus, Cress. 316.

subspinosus, Prov. 7\%9. .

tegularis, Prov. =alacris.

terminalis, Prov. =Ichneumon caudatus.

terminatus, Prov. 780. truncutus, l'rov. Ad. s.i.

vulgaris, Cress. (Prov.) = ovillis.

Phylax, Wesm. 5:I ; Adl. 1:0.

cinctue, Prov. $=Z$ Zie cinctus.

curtus, Prov. = Zeie curtus.

gracicis, Prov =Zule gracilis.

niger, Piov. Ad. 1:31.

pacificus, Prov. $=$ Microcintrus

pacificus.

pallivent, is, Prov. $=$ Zele palliventris.

rufipes, Prov.=Zele rufipes.

Phylløecus, Newm. 2333.

bicinctus, Prov.= Uephus bicinclus. bimaculatus, Nort. $=$ Cefhus bimac. integer, Nort. =Cephus integer.

Phymatocera, Dahlb. Ad. 350.

furuipunnı, Nort. (Selandria flavicornis) : Ul.

Phytodietus, Grav. 483 ; Ad 4.5\%.

distinctus, Cress. 484.

eleguns, Prov. Ad. 431.

gracils, Prov.=Plectiscus gracilis.

oruatus, Yrov. Ad. 4331.

pulcherrimus, Prov. = Meniscus pulcherrinus.

superbus, Prov. Ad. 430.

vulgaris, Cress. 484.

zonatus, Prov. 48:3.

Plinpla, Fabr. 454 ; Ad. 116.

æqualis, Prov. 4 jo.

al boricta, Cress. 460.

anuulicornis, Walsh, 458.

annulipes, Brullè, $45 \%$.

conquisitor, Say, 463.

hirtic.tudu, Prov. Ad. 116.

indagutrix, Walsh, 460.

inquisitor, Say, 461.

novit I, Cress. 460.

Ontario, Cress. 458.

pedalis, Cress. 456.

picticornis, Cress. 459.

pterelas, Say, 46\%.

rufopectus, C. s8s. 461.

rufovariata, Cress. 463.

4-cingulnta, Prov. $45 y$.

ebrus. 
Pimpla scriptifrons, Walsh, $46 \%$. tenuicornis, Cress. 457.

Plzon, Spin, Ad, 26i.5. lovis, Smith, Ad. 266.

Platyganter, Latr. Ad. 180, 404. aneurus, Prov. (Aneurynchus) .Ad. 40 '.

Canadensis, Prov, $=$ Isostasius Canadensis.

Platylabrs, Wesm. 304, 769, Ad. 35. aciculatus, Prov. Ad. 37. cincticornis, Prov, Ad- 38. crnssicornis, Prov. Ad. 37. lineolatus, Prov. 306. magnificus, Prov. Ad. 36. mitraiis, Prov. Ad. 3i. ornatus, Prov. 305.

4-carinatus, Prov. 306. Rubricapensis, Prov. 768. ruficornis, Prov. Ad. 38. scutellatus, Prov. 304. signatus, Prov. .305. thoracicus, Cress. 306.

Piatymisehus, Westw. Ad. 182. torquatus, Prov. Ad. 182.

Platysoma, Prov. = Aplomerus. tibralis, Prov.=Aplomerus tibialis Ad. $1: 2$.

Plectisenn, Grav. 382. gracilis, Prov. 382. niger,Prov. 793. pleuralis, Prov.=Mesochorus pleuralis.

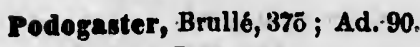
radiatus, Prov. 37̄5. sulcatus, Prov. Ad. 90.

Polistes, Latr. 685 ; Ad. 423. auripes, Sanss. Ad. 423. pallipes, Lepell. 686.

Polybiantus, Holmg. 4 I8 ; Ad. 107. annulicornis, Prov. Ad. 108. aunulipes, Cress. 419. decoratus, Prov. Ad 107. dilatatus, Prov: 419. Gaspesianus, Prov. (Tryphon) Ad. 107.
Polyblantus inornatus, Prov. Ad. 108. Quebecensis, Prov. 4:20. subcrassus, Cress. 420.

Polgsphineta, Grav. 463. acuta, Prov. 465.

Bruneti, Prov. 466. Burgessil, Prov. 464. cingulata, Prov. 466. limata, Cress. 466. pleus alis, Praq. = Bassus pulchripes. Rubricapensis, PrQv. 465. rufopectus, Prov, =limata. Texana, Cress. (Prov.) =vicina. vicina, Prov. $46 \dot{0}$.

Pomplius, Fabr. 617, 809 ; Ad. 259. æthiops, Cress. 618. angustatus, Cress. 621. apicalis, Prov. 621. argenteus, Cress. 809. biguttatus, Fabr. $62 \%$. castaneus, Prov, =argẹteus. Coquillettl, Prov. Ad. 26 l. cylipdricus, Cress 6282. fuscipennis, Say =Priocnemis alienatus.

griseus, Prov. 619.

hyacinthinus, Cress. 620. luctrosus, Cress. 61 . marginatus, Bay, 623. maurus, Cress، 6 i21. parvus, Cress. $\Delta d$, 261. Phlladelphicus, Cress. 5-notatus, 8ay = biguttatns. scelestus; Cress, 619. tenebrosus, Cress, 622. VirgInicus, Cress. 620.

Ponera, Latr. Ad. 241. contracta, Latr. Ad. 241.

Porlzon, Fallen, 377 ; Ad. 91, 364. angulare; Prov. 378. boreale, Prov. 378. elongatum; Pror: Ad. 91. rugosum, Prov. 378.

Porecentras, Prov. 408 ; Ad. 367. Huarti, Prov.=Phæogenes Huarti. Praon, Hal, Ad: 395. 
TABLE ALPHABETIQUE DES NOMS DE GENRES ET D'ESPECES 471

Praon simuians, Prov.(Aphidaria)Ad. Rhodites hicolor, Harr. Ad. 160. 395.

Prioenemils, Cress. (624.

alienatus, Smith, 6:5.

conicus, Say, $6: 4$.

germanus, Say, 625.

Priononyx, Dahlb. Ad. 258.

Canadensis, Prov. Ad. 258.

Priatiphora, Latr. 1\$1, Ad. 22. roræ, Lin. 549.

lehripes. identidem, Nort. 182, Trans, I, 77. idiota, Nort.=identidem. grossulariæ, Walsh, 18\%, Trans. I, 77. Sycophanta, Waish. Ad. 22. tibialis, Nort. 18:, Trans. I, 76.

Proctotrapes, Latr. 561. abruptus, Sny, 5 Ki2.

flavipes, Prov. (Megaspilus lucens) 562. rufigaster, Prov. 561.

Prosapha, Först. Ad. 393. hyallna, Prov. Ad. 393.

Prosopls, Fabr. :26. affinis, Smith, 727. basalis, Smith, $72 \%$.

Pron, Latr. 649. leucopus, Say, 649. niger, Pnck. 649.

$P$ silus, = Dlapria. apicalis, Say=Diapria apicalis.

Pteromalus, 8wed. 575. acutus, Prov. 576.

nigricornis, Prov.= Micromelus nigricornis. picridis, Prov. 575.

Thogak, Esunb. 504 ; Ad. 373. abdominalis, Cress. 505 . Canadensis, Cress. 507. intermedius, Cress. 507. parasiticus, Nort. Ad. 374. Quebecensis, Prov. 506. rugosulus, Prov. Ad. 374. Stl-Hyacinthi, Prov. 506.

Bhopaliens, Fürst. Ad. 406. pallipes, Prov. Ad. Ad. 40\%.

Rhopalophorum, Hai. 515 ; Ad. 128. fasciatus; Prov. $=$ Eustalocerus fasciatus.

longicornis, Prov. $=$ Eustalocerus longicornis.

petiolatus, Prov.=Eusialocerus petiolatus.

tauricornis, Prov. $=$ Eustalocerus tauricornis.

Bhopalum, Kirb. 668. pedicellatum, Pack 668. rufigaster, Pack. 669.

Bhysea, Grav, 447. Canadensis, Cress. 449. Crevieri, Prov $=$ E pirhyssa Crefleri. clavata, Prov. =Epirhyssa clavata. persuasoria, Lin. 447.

Ropronia, Prov. Ad. 154, 406. pediculata, Prov. Ad. 154, 406.

Boptrocerus, Ratz. Ad.201. rectus, Prov. Ad, 202.

Pyracmon, Holmg. 373, 787 ; Ad. 90. Sapyga, Latr. 610. annulatum, Prov. $\mathbf{3}$ 4. incompletum, Prov. Ad. 90. macrocephalum, Prov. 374. rúfum, Prov. 787.

Radiolaria, Prov. Ad. 154. clavata, Prov. Ad. 155.

Rhinopsis, Westw. Ad. 259. canaliculata, Say (Ampulex) Ad. 259. maculata, Prov. 610.

Behlzoneurus, Latr. 178. Bericeus, Nort. 178, Trans. I, 55.

Selapterix, Steph. 198. punctum, Frov. 198.

Seolla, Latr. 606. unicincta, Prov.=Sphærophthalma unicincta.

Ehitigastër, Wesm. 534 ; Ad. 146. ovalis, Prov.=Sphæropix ovalis. parvus, Prov.=Sphæropix parvus.

Seotloneurus, Prov. Ad. 156. dives, Prov. Ad. 157. stenostigma, l'rov. Ad. 157.

Bhöaltes, Hurt. 548 ; Ad. 160.

Selandria, Leach, 1149; 742, Ad. 7, 26. 
Belsndria barda, Say (Allantus) $=$ Monophadnus bardus.

Canailensis, Prov, $=$ Hoplocampa Canadensis.

dubia, Cress. $=$ Monophadnus bardus.

favicornis, Prov.=Hoplocampa halcion.

flavipes, Nort. 202, Trans. I, 258.

fumipennis, Nort. $=$ Phymatocera fumipennis.

ialcion, Nort. =-Hoplocampa halcion.

ignota, Nort:=Monostegia ignota. inhabilis, Harr.=Blennocampa inhabjlis.

Sphacophlius Crrwii, Prov. Ad. 428.

Sphwrophthalma, B ake: Ad. 251. argentipilis, Prov. Ad. 2ōl. unicincta, Prov. Ad. 2is:.

Spheroplx, Hal. Ad 3i9. ovalis, Prov. Ad. $38 \%$. parvis, Prov. Adl. 389. Quebecensis, Prov. Ad. 389.

Sphecodes, Latr. 7:44; Ad, 33ii. dichron, Smith, 724. mandibularis, Cress. Ad. 335.

Sphex, Lin. Ad. 257. appendiguster, Lin =Evania appcn. digaster.

ichncumonen, Lin. Ad. 257.

marginata, Prov.=Eriocampa marg. media, Prov $=$ Monophadnus medius.

obsoleta. . Nort. $=$ Caiiror obsoleta. llomicrus, Westw. $\mathbf{5 6 0}$.

foveatus, Prov =Aneurynchus foveatus.

longicornis, Prov.=Paramesius longicornis.

paupera, Prov.=Blennocampa paup. Stells, Panz. Ad. 336.

rosis. Harr.= Monostegia rosæ.

${ } u b i$, Harr.=Monophadnu 3 rubi.

tilize, Nort. $=$ Monophadnus tilim.

vitis, Harr.=Blennocampa vitis.

Semlotellus, Westw. 573 ; Ad. 20:2. chalcidiphagus, Walsh, Ad. 20\%. cupræus, Prov. 574. fasciatus, Prov. 573. fuscipes, Prov. 574. melanicrus, Prov. 573. minimus, Prov. 574. oblongus, Prov. 5 ĩ 4. suborbicularis, Prov. 575.

Sigalphus, Latr. 530 ; Ad. 143. Canadensis, Prov. 530. foederalis, Smith, Ad. 333 .

Stenlolia, Suy, Ad. 414. duplicuta, Prov. Ad. 414.

Stigmus, Jur. (iso. fraternus, Say, 650.

Stílbum, Spin. Ad. $21: 3$. amethystiuum, Fabr. Ad. 213. calceus, Sy)in.=amethystinum. splendidum Brullé=amethystinum.

Stllpnus, Gruv. 310, :†i ; Ad. 44, 359 . Americanus, Cress. 311. appendiculatus, Prov. Ad. 44. Canadensis, Prov. 311. deticiens, Prov. Ad. 359. lævis, Prov. 77\%. soriceus, Say $=$ Chelonus sericeus. trisectus, Prov. Ad. 143.

Smic' a, Spin. Ad. 109. Canadensis, Cress. Ad. 189. microgaster, Say " (Chalcis)Ad. 189.

Strongylogaster, Dahlb. 215, 743, Ad. 10.

abnormis, Prov. Ad. 10. albosectus, Prov.= =oecilostoma albosecta.

Bpalangia, Latr. Ad. 200 . ænea, Prov. Ad. 200.

Spathius, Esenb. 510. Lafiummci, Prov, 510.

Sphacophilus, Prov. Ad. 427. annullosus, Nort. 219, Trans II, 221. apicalis, Say (Allantus) 217, Trans. II, 216 .

ef: cerus, Say (Allantus)217, Trans. II, 217 . 


\section{TABLE ALPHABETIQUE DES NOMS DE GENRES ET D'ESPẸCHS 473}

v. Ad. 428. dd. $2: 51$. 501.

\section{i.}

389. 3:35.

d. 335.

ania appen-

257.

Irynchus foamesius lon-

336.

14.

At. 213.

ystinum.

lethystinum.

Ad. 44, 359.

1.

Ad. 44.

69.

215, 743,

0.

!ostoma

rans II, 221.

) 21\%,Trans.

)217, Trans.
Atrongyloganterimpressus, Prov, 219. Taxonus multicolor, Nort. (S/ronlongulus, Nort. 21E, Truns. TI, 220. Inctuosus, Prov. Ad. 12.

pallicoxus, Prov. Ad. 11. pailldlcornis, Nort. 744, Trans. II, 216.

pinguis, Nort. (Allantus) 218 , Trans. II, 218.

politus, Prov. 743.

proximus, Prov, Ad. 12. rubrocinetus, Nort. = rufoclnctus, rufocinctus, Nort. 744, Trans. II, $21 \%$.

soriculatus, Prov. 745.

tacitus, Say (Allantus) 218, Trans. II, 219.

terminalis, Sny (Tenthredo) $\bullet 17$, Trans. 11, 21:5

Synalrema, Hurt. Ad 15. amuricans. Prov. Ad. 15. Pacifica. Prov. Ad. 15.

Byenldis, Först. Ad. 391. pilicornis, Prov. (Trinaria) Ad. 391.

Syeergun, Har., 807 ; Ad. 165. lignicola, 0. Sack. Ad. 16.5. rhoditiformis. Whalsh=lignicola.

Bgugaster, Brullè, 50x; Ad. 12:2. atripes, Prov.=Doryctes atripes. beticatus, Prov.=10ryctes bøticatus.

cingulatu, Prov.=Doryctes cingulatus.

fartus, Prov.=Doryctes fartus. macilentus, Prov. $=$ Doryctes macilentus.

rugosis, Prov.=Capitonius rugosus.

Afntomanple, Först. Ad. 196. splendens, Prov. Ad. $1 \$ 6$.

Tapinoma, Latr. Ad. 237 ; Ad. 408. borcale, Roger, Ad. $23 \%$.

Taxonun, Meg. 213, 743, Ad. 9, 352. albidopictus, Nort. 215, Trans. II, 213.

amicus, Nort. 215, Trans. II, 213. dubitatus, Nort. 215, Trans. II, 212. Eloridanus, Prov. Ad. 352. gylogast(r) 21.4, Tiu:s 11, : i.2.

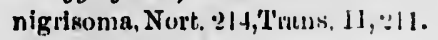
purens, Prov. Ad. 9.

robustus, l'rov. $74: 3$.

unicinctus, Nort. :14, Trins. II, 211.

Telemonus, Hal. Ad. 180, 40:3. rufoniger, Prov. Ad. 403. styglcus, Prov. Ad $1=0$.

Tenthredo, Lench, 219, 7.45; Ad. 12. angulifura, Nort.(Allantzis) :.:::, 'l'r. I1, 2.29 .

atrocmeruleq, Prov. Ad. 1:3, :3;3.

atroviolacea, Hur.-T(uthiciopsis atroviolacen.

basilaris, Prov. =signata.

cinctitibiis, Nort. 74\&, Tran $\div$. II, 239.

cingulata, Prov. =verticalis.

decorata, Prov. 2:26;.

confusa, Nort. $=$ Tenthredo $/$ sis confusa.

erythroneura, Prov Ad. 1:3.

pximia, Nort. 2:4, Truus. II. :2:1.

graudis, Nort.(Allantus) : : 1, Tauns. II, $22 \%$.

jocosa, Prov. 747.

lineata, Prov. 224.

lobata, Nort. (Allantus) i 4․, Truns. II, $2: 29$.

mellicoxa, Prov =rufopectus,

mellina, Harr.(Allantus) $2: 21$, Trans. II, 227.

montana, Prov. Ad. 1:2.

mutune, Nort. 2:27, Trnns. II, 23i.

nigricostata, Prov, Ad. 14.

pallicoxa, Hrov, 2:27.

14-punctata. Nort. = Tenthredo 1 sis 14-punctats.

rufipes, Sily, :2i25 Trans. If, ::37. rufopectus, Nort. (Allantus) :2.5, Trans. 1I, :34.

semirubrn, Nort. 74», Traus. II, :::86. signata, Nort. (Allentus) $2: 27$, Trans. II, 2332.

52-Mare, 1868. 


\section{TABLF AIPHARETIQUE DES NOMS DE GENRES ET D'ESPECES}

Tenthredo terminalis, Prov. Ad. 14. Tiphla, Latr. 607;.Ad. 273. vari us, Nort. :2:6, T ans. 1I, «:35. ventritis, Shiy (Allentus) Ad. l:3. verticuli ; suy, $\cdot 9 \cdot 2,2$, Trans. II,

Teuthredopsis, Custu, Ad. : $55: 3$. ittoriolis ent. Nort. (Allantus) 296,

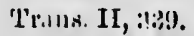
confusi, Nort. ( Tenthredo) i47 ;

Trumin. II, $\div 41$. deit: Prov. (Peichyprotasis) 210. 1.1-punctuta, Nort. (Tenthredo) 7.17, 'Trans. I1, $: 21$. semiluten, Norr. (Tenthredo) Ad.

Tetrastichus, H:Ll, Ad. 210. trivikatus, Prov. Ad. 211 .

Thalessa, Ifolmg. 444. acratit, Filbr. 415. .miator, Fabr. 446. nititia, Cress. 44i). Nortuni, Cre'ss, +45 .

Thercolax, Wistw. roj. Canudensis, Prov. e.09.

Theroula, Grav. Ad. 114. melumocephala, Brullé, Ad. 114.

Thersilochus, Holmg. 379, 789 , Ad. 91. erraivundns, Prov. Ad. 92. maturus, Prov, Ad. J2. nicuns, Prov. Prov. 379. pallipes, Prov. 789.

Thyreocera, Ashm. Ad. 437. læviscutum, Prov. (figites)Ad. 437. nigrifemora, Ashm. =læviscutum.

Thyreodon, Brullé, 3ì2. morio, Fabr. $35 \%$.

Thyreopus, St-Farg. 662 ; Ad. 290. udvenus, Smith (Crabro) Ad. 291. argus, Harr. 29:?. elongatus, Prov. Ad. 293. lntipes, Smith, $66 \mathbf{0 5}$. monticola, Pack. 663. pegasus, Harr. 6605. rugosopunctatus, Prov. $B 64$. sinuitus, $P$ ov. 664. tenuiglossus, Pack. (Crabrol Ad. inornntn, siny, (i)ly. mluor, Prav. Ad. 2is4. tnrda, Say, Ad. : transvo" $x \cdot \sigma^{\top}$ Suy =inomntr.

Tra:hynotus, Grav.=Notohrachys. Cuna ensis, Prov. = Notobrachis.

Tremex , Jur. 241. coiombn, Lin. 242.

Triballa, Walsh. Ad. 161. botutoruin, Walrh, Ad. 162.

Trichaels, Försi, Ad. 40:3. auripes, Prov, Ad. 403.

Trichaslus, Prov. Ad. 20:\%. clavitus, Priv. Ad. :09.

Trichesia, !rov.=-Aphoreta. auripes, Prov = Aphereta auripes.

Trichlosoma, Lench, Iä6, Ad, 20. 'Inylori, Prov, Acl. : 20 . triauginlun, Kirb. 177.

Trinarla, Prov. Ad. 149. pilicornis, Pro $7 .=$ Synaldis pilic.

Trógus, Grav. 30\%. Brullei, Cress. 303. Cnnadenșis, Prov. 3 3.3. Copei, Cress. 768. exesorius, Brullé, ,3C3. fulvipes, Cregs. 3 ti? obsidianator, Prov. =fulvipes. Provancheri, Burq. = Amblyteies expunctus.

Tropistes = Arotes. elegans, $\mathrm{Prav} .=$ A rotes a nouns.

Tryphon, Grav. 410; Ad, 100, 367 . affinis, Cress. (Prov.) $=$ Cteniscus clypeatus.

americanus, Cress, Ad 10?. annuilatus, Prov.=Mesoleptus ann. Canádensis, $P$ iov. $=$ Mesoleius Can. canaliculatus, Prov. $=$ Mesolejus submarginatus.

carinatus, Prov. =-Chorinæus carin. Clapini, Prov. 41:. citpeatus, Prov. $4 \mathrm{i} \%$ communis, Creas. 413. 2y\%. 
Tryphon crassus, Oress.=Erronemus

Dionnei, Prov, 414. [crassus. dorsalis Prov, 411.

Dufresnei, Prov. 411.

excavntus, Prov. 41:?.

fractus, Prov. 101.

frontalis, Cr.3ss. (Prov.)=Cteniscus cunsors.

Gaspesianus, Prov. $=$ Polyblastus Gispesinnus.

Hervieuxii, Prov. 412.

humeralis, Pruv. = Bassus hum.

Urecerus flivicornis, Fabr. (Sirex) 239,

Trans. II, 362.

Veupa, Réanm. 681.

consobrina, Sauss. 683.

dinbolica, Sauss, 684.

germinnica, Fabr. $6 \div 3$.

maculuta, Fabr. 682.

media, Oliv. (884.

rufa, Lin. (i85.

Wentwoodla, Brulle, 391.

fumipennis, Prov. 342.

Laurentianus, Prov. = Mesoleius Laurentianus.

Xlela, Dahlb. 234. minor, Nort. 234, Trans. II, 349.

Xylonomun, Grav. $48 ర$; Ad. 119.

Moyeni, Prov. = Mesoleptus Moyeni. pedalis, Cress.=Erronemus ped. pediculatus, Prov. Ad. 10\%. rufigaster, Prov. Ad. 104.

rufucinctus, Cress. Ad. 103. sanguineus, $P_{10} .=$ Ctonopelma sanguinea.

seminiger, Cress. 413.

scutellatus, Prov. =Dufresnei. albopictus, Crese. 489. caliclus, Prov. Ad, 119.

frigidus, Cress. 489.

humeralis, Say (Anomalon) 4 ㅇ.

Lavallensis, Prov.=humeralls. stigmnpterus, Say (Acænites) 488.

ldis pilic.

suberassus, Prov. = Polyblastus subc. XIphldria, Latr. 242, 750, Ad. 28.

submarginatus, Cress $=$ Mesoleius

subunnrginutus.

tarlus, Prov, $=$ Mesoleius tardus.

tuber ulifer, Prov. Ad. 103.

Trypexilon, Latr. 669' ; Ad, is3.

cluvituuu, Say, 670.

strialuin. Prov. Ad, 283.

Urocerus, Geoffi: :38.

albicurnis, Fabr. (Sirex) 240 ,

Trans. II, 360.

caudatus, Cress. 24I, Truns. II, 363. cyaneus, Fubr. (Sirex) :41, I'rans. II, $3 \dot{*} 7$.

Xiphidion, Prov. :\$3.

Canadense, Prov. $=$ Xiphidria Provaucheri..

albicornis, Harr. :443, 'I'rans. II, 352. attenuuta, Nort. Ad. 28.

Canadensis, Prov. 24:3.

Provancheri, Cress.(Xiphidion) 244.

Iorides, litruv. 4:0. bor'alis, Cress. 450.

Zele, Curtis, 521. basalis, Prov. Ad. 380.

cinctus, Prov. (Phylax) Ad. 380. curtus, Prov. (Phylax) Ad. 380. gracilis, Prov. (Phylax) Ad. 380. palliventris, Prov.(Phylax)Ad. 3=0. rufipes, Prov. )Phylax) Ad. 380.

Jeptus ann. solejus Can. $=$ Mesoleius inæus carin. 


\section{ERIRATA.}

Page $37^{\circ}$, ligne 6e din bes, an lien de : aculatus lises : aciculatus.

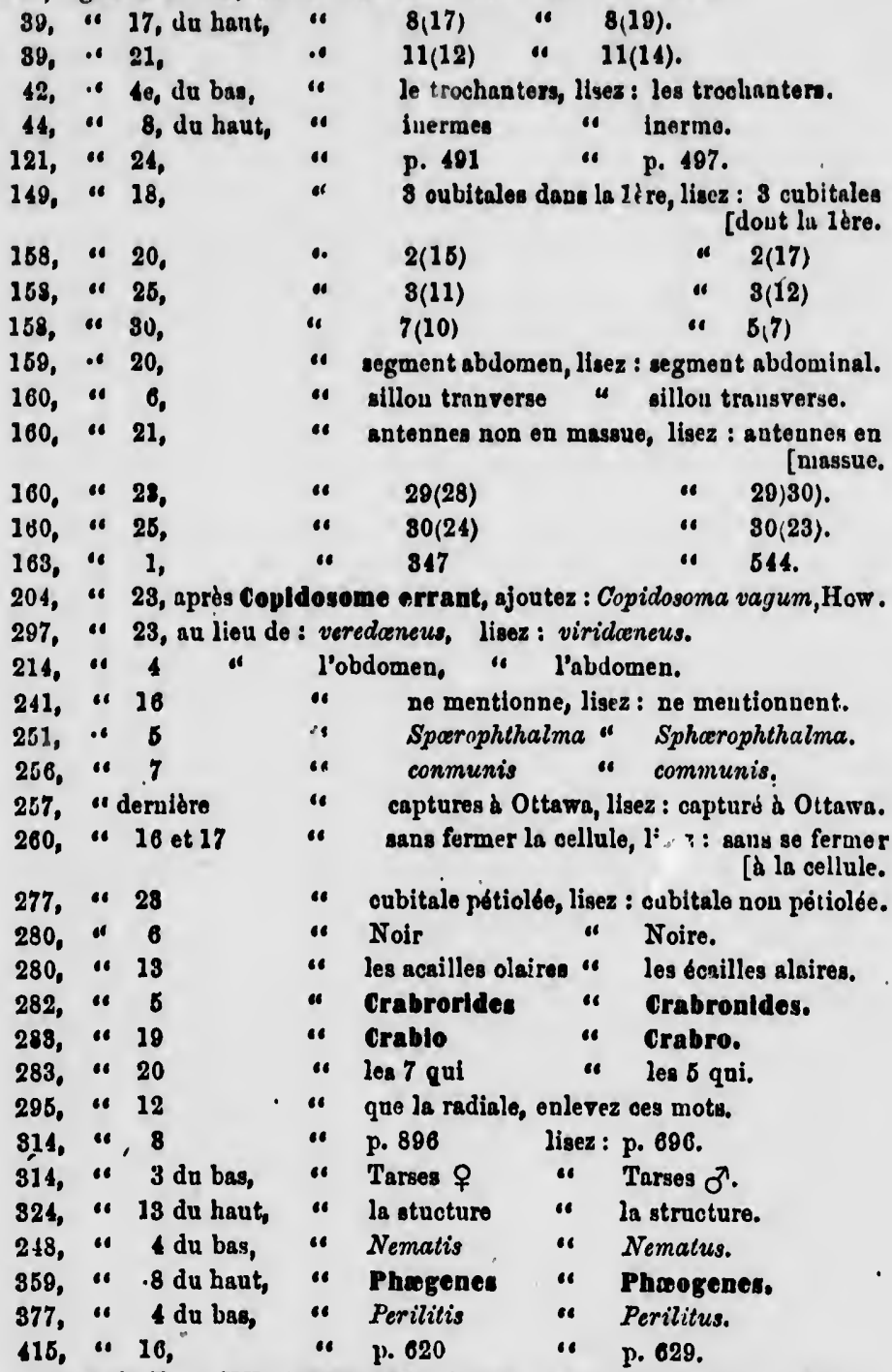

423, après FAX. XX-VESPIDES, ajoutez: Gen. Pourstes, Latr. 685.

.Au lien de Polistes Anaheimensis, lisez: Poliktes anripes, Sauss.

403, 20 colonne, ligne 30, au lieu de Doryeten, lisez : Doryetes. 


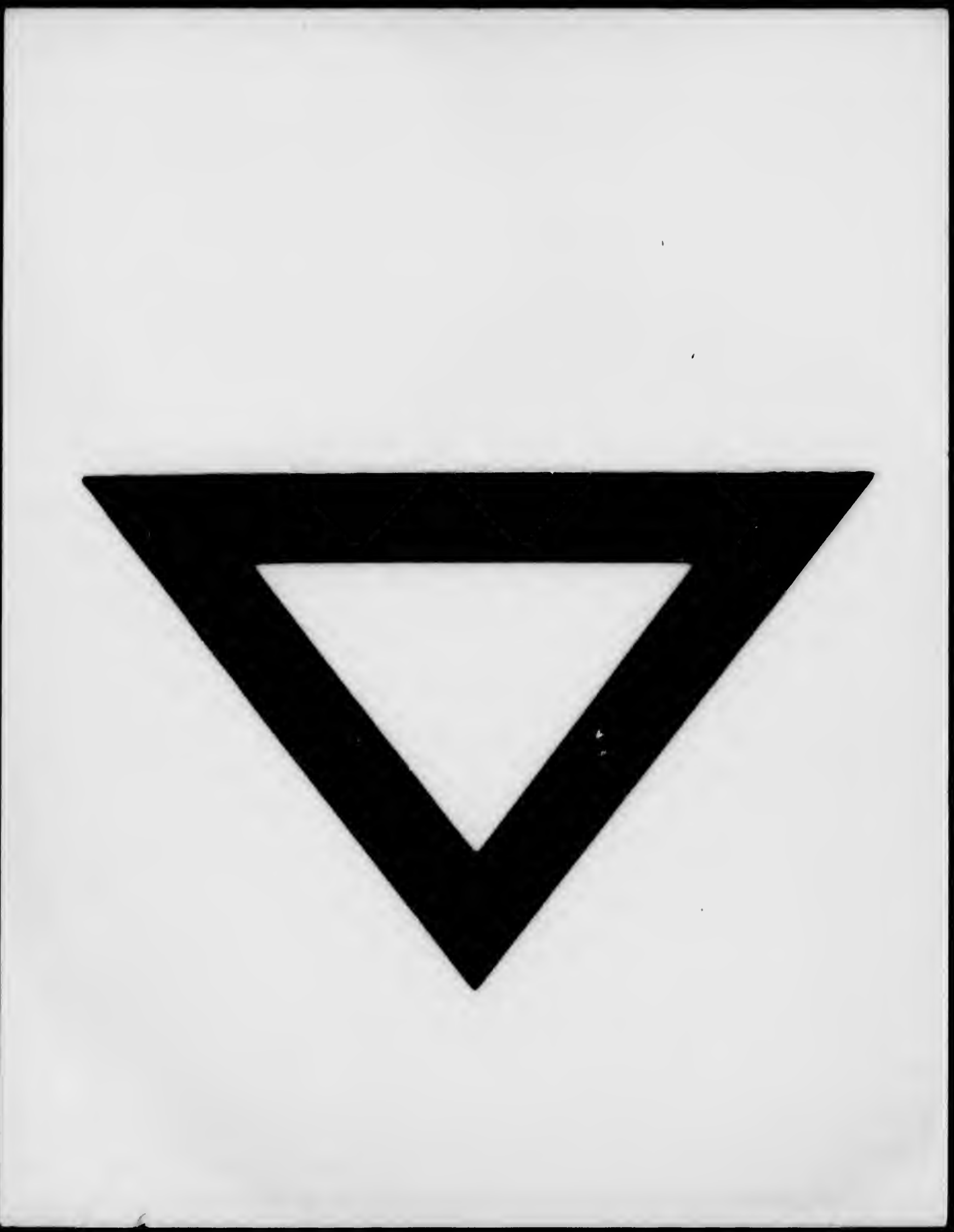

